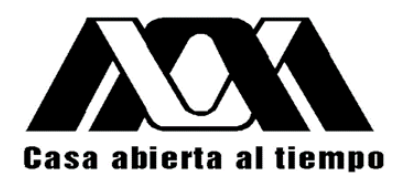

UNIVERSIDAD AUTÓNOMA METROPOLITANA (UAM)- UNIDAD IZTAPALAPA

\title{
EVALUACIÓN DE LA EFICACIA DEL MANEJO DE LOS RESIDUOS SÓLIDOS URBANOS EN LA CDMX, BAJO UN ENFOQUE DE GESTIÓN INTEGRAL, PARA EL PERIODO 2014-2015
}

\author{
Tesis que presenta \\ I.Q. Araceli Cisneros Castro \\ Para obtener el título de: \\ Maestra en Ciencias (Energía y Medio Ambiente)
}

Asesor: $\quad$ Dra. Fabiola S. Sosa Rodríguez

Jurado calificador:

Presidente: $\quad$ M. en I. Guillermo Encarnación Aguilar

Secretario: $\quad$ M en B.E. Enrique Mendieta Márquez

Vocal: $\quad$ M en C. Cristal Berenice Ayala Hernández

México, CDMX, julio de 2017 


\section{Resumen}

Los tomadores de decisiones de la CDMX, que tienen a su cargo el manejo de residuos sólidos urbanos RSU, deben contar con herramientas que les permitan determinar la eficacia de su desempeño en el manejo de los mismos, bajo un enfoque de Gestión Integral de Residuos Sólidos Urbanos GIRS, y así tomar las decisiones más apropiadas para el mejoramiento de su servicio, pero ya desde un punto estratégico y específico que les permita mejorar las debilidades y mantener las fortalezas. El objetivo de esta investigación consistió en evaluar la eficacia en el manejo de los residuos sólidos urbanos en la CDMX desde su generación hasta su disposición final para el periodo 2014-2015, determinando en qué medida cumplen con los objetivos propuestos por el modelo de gestión integral, así como con base en aquellos objetivos planteados en el marco normativo y de planeación de la CDMX. Se generaron indicadores que evalúan el desempeño en el manejo de los RSU en todas sus fases. La Metodología consistió en generar una base de datos conformada por diversos indicadores, para cada una de las fases del manejo de los residuos y para cada una de las demarcaciones territoriales de la CDMX; éstos a su vez fueron insumo para el programa de Análisis de Componentes Principales SPSS que finalmente generó el modelo que ayudaría a obtener el Indicador de desempeño del manejo de los RSU en la CDMX y en cada una de sus demarcaciones territoriales. Estos indicadores, dejaron en evidencia las debilidades del manejo de los RSU, que básicamente se encuentran en la mala administración de presupuesto público, la debilidad del marco normativo, y la falta de instrumentos económicos, para incentivar la reducción en la generación de los residuos. 


\section{Contenido}

1. Evolución de los residuos sólidos y su situación actual en México y el mundo........................... 1

1.1 Residuos y residuos sólidos urbanos RSU ......................................................................... 3

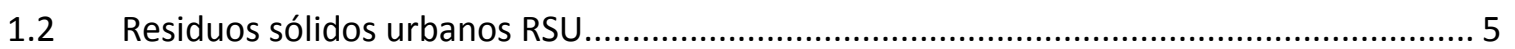

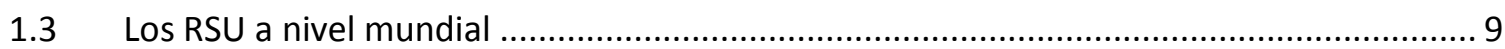

1.4 Residuos Sólidos Urbanos en México................................................................................ 14

$1.5 \quad$ El manejo de los residuos sólidos en México .................................................................. 21

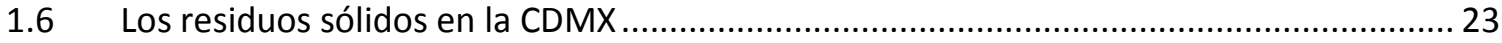

2. Gestión Integral de Residuos Sólidos Urbanos GIRS ............................................................. 26

2.1 Definición y conceptos de Gestión Integral de Residuos Sólidos Urbanos (GIRS) ............ 26

2.2 Manejo de los residuos sólidos urbanos y sus fases ..................................................... 30

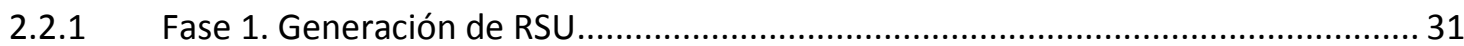

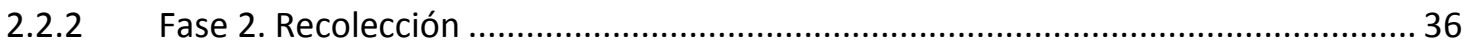

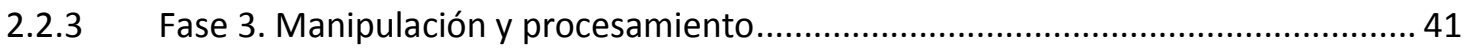

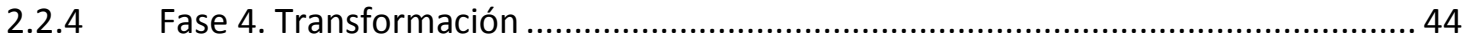

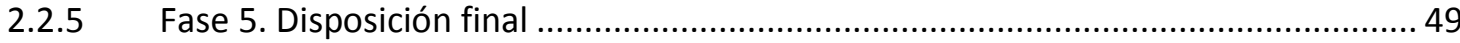

2.3 Manejo de los RSU en países desarrollados y en vías de desarrollo; cuatro casos de

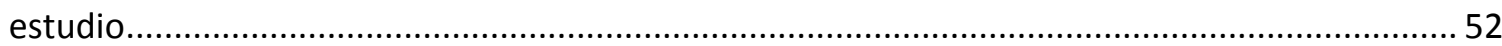

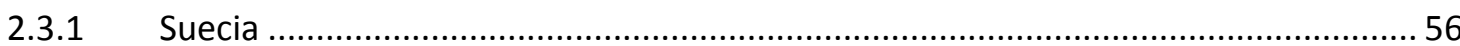

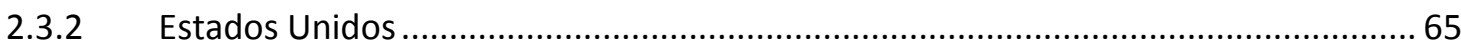

2.3.3 India

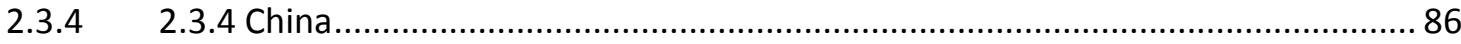

2.4 Lecciones aprendidas de los cuatro casos para un buen manejo de RSU.........................94

3. Marco normativo y de planeación y las fases del manejo de los RSU en la CDMX................ 101

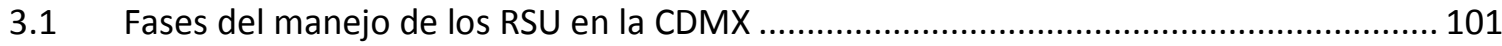

3.1.1 Fase 1: Generación de RSU en la CDMX ........................................................... 102

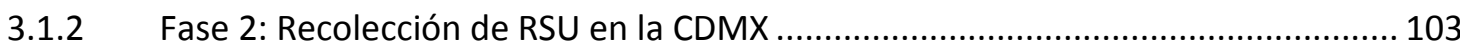

3.1.3 Fase 3: Manipulación-procesamiento en la CDMX............................................. 107

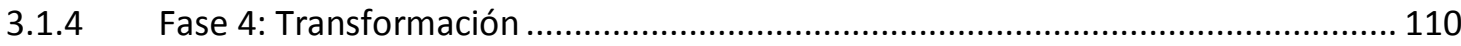

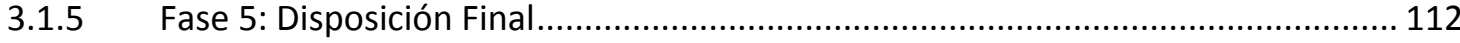

3.2 Composición y propiedades de los RSU en la CDMX ................................................. 115

3.3 Marco jurídico normativo de México, respecto a el manejo de RSU.............................. 117 
3.3.1 Constitución Política De Los Estados Unidos Mexicanos ........................................ 118

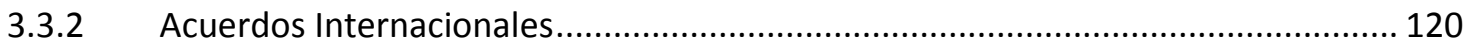

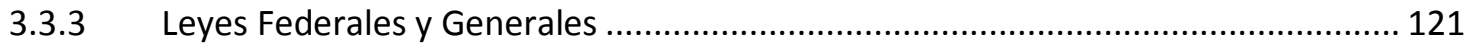

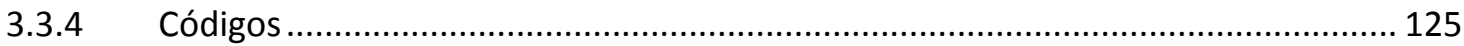

3.3.5 Reglamentos y Programas Federales y Locales.................................................. 126

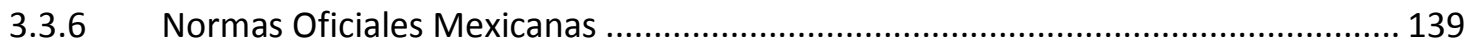

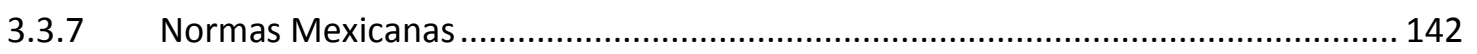

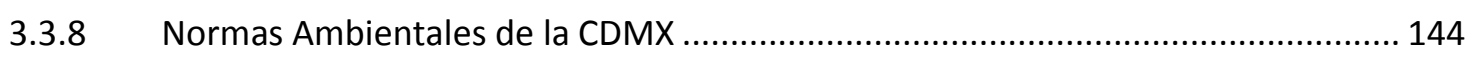

4. Modelo de evaluación de la eficacia del manejo de RSU.................................................. 149

4.1 Componentes para medir la eficacia en el manejo de los RSU ..................................... 149

4.1.1 La GIRS, el marco normativo y de planeación de la CDMX ......................................... 149

4.2 Indicadores de desempeño para la evaluación de la eficacia en el manejo de los RSU. 152

4.2.1 Características básicas de un indicador y sus tipos ..................................................... 154

4.2.2 Proceso para la construcción de un indicador .............................................................. 157

4.3 Modelo de análisis de componentes principales para evaluar la eficacia en el manejo de

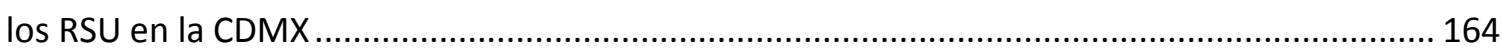

4.3.1 Planteamiento del modelo de Análisis de Componentes Principales (ACP) .................. 164

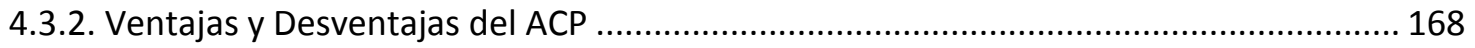

4.3.3 Análisis de datos con el Statistical Package for Social Sciences (SPSS) ......................... 170

4.4 Metodología para la evaluación de la eficacia en el manejo de RSU en la CDMX ........... 170

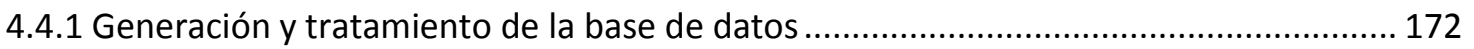

4.4.2 Procedimiento para la estimación del modelo de Evaluación ....................................... 180

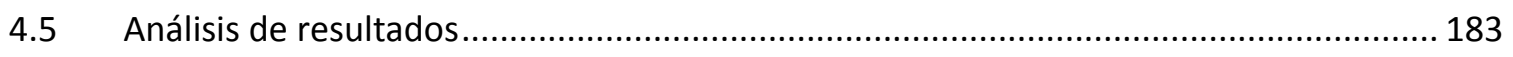

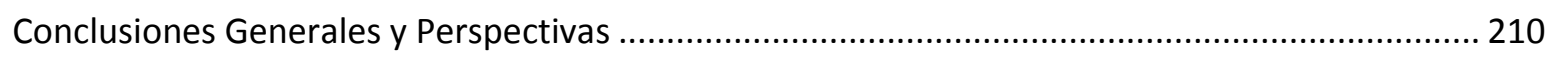




\section{INTRODUCCIÓN}

La industrialización y el desarrollo económico, consecuencia del actual modelo económico capitalista, que fomenta el consumo sostenido no sólo ha favorecido una acelerada urbanización y concentración económica y demográfica en las grandes ciudades sino también la generación y disposición de millones de toneladas de residuos sólidos urbanos, los cuales sobrepasan las capacidades instaladas para su adecuada disposición final. Esta problemática demanda que el sector académico plantee alternativas y estrategias para dar solución a uno de los problemas ambientales más relevantes que enfrentan las ciudades en la actualidad como lo es la disposición sustentable de los residuos sólidos generados, lo cual requiere guiar a los tomadores de decisiones del país con el conocimiento necesario para realizar una gestión más eficaz y sustentable de dichos residuos. Este reto no sólo afecta a las ciudades mexicanas sino también a las ciudades de diversos países desarrollados y en vías de desarrollo en el mundo, siendo de particular interés para esta investigación el manejo de los residuos sólidos urbanos en la Ciudad de México, entidad que junto con su zona conurbada constituye la cuarta ciudad más grande del mundo (ONU, 2014).

En general, los países que mayor éxito han tenido en el manejo de sus residuos han desarrollado un sistema de gestión integral de residuos sólidos urbanos (GIRS) orientado a fomentar la sustentabilidad ambiental. La gestión integral es una selección y aplicación de técnicas, tecnologías y programas de gestión idóneos, además de un marco jurídico-normativo para lograr metas y objetivos específicos de manejo de residuos sólidos, donde se gestiona su reducción, reutilización, reciclado, transformación y vertido final (LGEPGIR, 2014). También considera, la administración de elementos funcionales como su generación, manipulación, recolección, separación, procesamiento y transformación, transferencia, transporte, vertido y recuperación de suelo post-clausura del vertedero de disposición final (Tchobanouglus et al., 1994; Cortinas Nava, 2004; Colomer et al., 2007; LGEPGIR, 2014). Esta investigación precisa hacer una aclaración de suma importancia: la diferencia entre gestión y manejo. La gestión como anteriormente se mencionó, implica actividades administrativas, normativas, jurídicas, de implementación de programas y de acciones financieras, así como de investigación y educación. Por otro lado, el manejo de residuos es el conjunto de actividades relacionadas con la vida del residuo, desde la cuna hasta la tumba que, por lo general, conlleva cinco fases o etapas: (1) generación, (2) recolección, (3) manipulación y procesamiento, (4) transformación y (5) disposición final (Karak et al., 2012). Precisar esta diferencia es necesario para clarificar los objetivos de este trabajo, dado que lo que se pretende evaluar es el manejo de residuos sólidos urbanos en la CDMX con base en un enfoque de gestión integral, pero no la gestión integral en sí misma, la cual comprendería analizar otros componentes y sus interrelaciones en el ámbito jurídico, social, económico, político, ambiental y cultural. Como resultado de las restricciones de tiempo y dada la complejidad de realizar este tipo de análisis, lo cual requeriría la colaboración directa con otras disciplinas, esta investigación sólo se enfocará en la parte esencial de la gestión integral de residuos sólidos en la CDMX, la cual se refiere al manejo de los residuos y a cada una de sus fases durante el periodo 2014-2015.

Bajo este contexto, es pertinenete preguntarse ¿en qué medida el manejo de residuos sólidos urbanos en la CDMX, desde su generación hasta su disposición final, ha sido eficaz para cumplir los objetivos propuestos por el modelo de gestión integral?, así como aquellos objetivos planteados en el marco normativo y de planeación para esta entidad enfocados en las fases del manejo de los RSU. Se piensa 
que el manejo de los RSU en la CDMX no es eficaz, porque está centrado en la fase de recolección y disposición final, sin prestar atención a la adecuada separación que permita un procesamiento eficiente de los residuos para su valoración y aprovechamiento en otras fases productivas, para la generación de energía y la producción de composta

El objetivo general de esta investigación consiste en evaluar la eficacia del manejo de los residuos sólidos en el DF desde su generación hasta su disposición final, determinando en qué medida cumplen con los objetivos propuestos por el modelo de gestión integral, así como con base en aquellos objetivos planteados en el marco normativo y de planeación de la CDMX para el manejo de los residuos sólidos en sus fases de generación, recolección, manipulación-procesamiento, transformación y disposición final. Mientras que los objetivos particulares son los siguientes:

a. Analizar la problemática de la GIRS a nivel internacional, comparando la gestión entre países desarrollados y en vías de desarrollo, identificando sus prácticas, lecciones aprendidas y principales obstáculos

b. Analizar la problemática de los RSU a nivel nacional, y en particular en el DF, con la finalidad de conocer con mayor profundidad el manejo de los RSU desde su generación hasta su disposición final, teniendo en cuenta su origen y tipo de residuo

c. Hacer una revisión del estado del arte sobre las características que debe tener una GIRS, poniendo énfasis en los objetivos que deberían cumplirse en las diferentes fases que constituyen su manejo

d. Evaluar la eficacia del manejo de los residuos sólidos en la CDMX utilizando como herramienta la generación de indicadores y un modelo de componentes principales; esta evaluación se hará desde su generación hasta su disposición final, identificando qué tanto se ha avanzado para realizar una GIRS.

e. Identificar en el marco legal y en los programas de manejo de residuos sólidos en el DF los objetivos-metas en términos de su manejo desde su generación hasta su disposición final, con el fin de apoyar la evaluación de su eficacia

f. Identificar los principales obstáculos para alcanzar un manejo que promueva la gestión integral; esto con el fin de hacer recomendaciones de política pública.

Evidentemente, una mala gestión de los RSU trae impactos negativos en varios aspectos en un, municipio, estado, ciudad y por consecuencia en una nación. Los impactos negativos más severos son en la salud y el medio ambiente local y mundial. Existe una parte de los RSU que genera gases de efecto invernadero promoviendo el calentamiento global y cambio climático, y acarreando problemas de contaminación de aire, suelo y agua y estos su vez generan focos de infección trayendo consecuencias negativas a la salud ya que los lixiviados de los residuos sólidos urbanos pueden permear a los mantos acuíferos o llegar al sistema de agua potable llevando enfermedades infecciosas estomacales y de la piel a los pobladores o simplemente por la presencia de fauna nociva que genera la acumulación de RSU. Lamentablemente, los escasos recursos económicos y la falta de visión de los tomadores de decisiones en países en vías de desarrollo, no les permite ver que a largo plazo una buena gestión de RSU resulta económicamente más factible que remediar problemas derivados de una mala gestión de este tipo de residuos. Es aquí donde se fundamenta la relevancia de esta investigación, ya que urgen políticas públicas orientadas a estrategias que fomenten la reducción, la reutilización y el reciclaje de los desechos sólidos urbanos, es decir que promuevan el manejo sustentable de los RSU de la CDMX. 


\section{Capítulo I}

\section{Evolución de los residuos sólidos y su situación actual en México y el mundo}

El hombre genera residuos como mero resultado de sus actividades, por ende, el aumento en la generación de residuos está directamente relacionado con el aumento de la población y la modernización de la sociedad. Pensemos en el Paleolítico, hace casi dos y medio millones de años, el hombre era nómada, cazaba recolectaba, pescaba y consumía frutos de los árboles que iba encontrando a su paso; en este sentido, se podría pensar que los residuos que pudo haber generado en esta época eran sólo huesos y pieles de animales que ya no ocupaba, así como piedras y palos que tallaba. Construía chozas para protegerse de la intemperie y tener un lugar en donde descansar y cuando emigraba dejaba esos residuos. Conforme el hombre fue evolucionando llegando a ser sedentario, formando poblados con cada vez más habitantes y en donde las actividades realizadas comprendían la agricultura y ganadería, los residuos generados fueron cambiando en cantidad y composición (Colomer et al., 2007).

Las primeras sociedades consumían alimentos de fácil descomposición y producían bienes duraderos basados en materias naturales como la madera, el barro, el cuero y las fibras textiles naturales, por lo que los residuos se seguían generando (Colomer et al., 2007). En ese entonces, los residuos producidos eran fácilmente asimilables por el medio ambiente, pero la evolución que experimenta la humanidad hace que se inicie la extracción y transformación de elementos naturales más difíciles de asimilar por los ecosistemas como, por ejemplo, los metales, cuya producción y tratamiento requieren procesos más complejos, además de requerir mayor energía para ser eliminados. Las culturas más evolucionadas surgieron a partir de la aparición de la metalurgia, la alfarería, y las incipientes producciones de productos químicos. Fue en este momento, cuando las sociedades urbanas comenzaron a tener dificultades para eliminar los residuos que producen, sobre todo donde las concentraciones urbanas son más importantes. Por ejemplo, existen referencias de los graves problemas que tenía la ciudad de Roma como resultado de la enorme generación de residuos sólidos, destinando una colina como un inmenso vertedero para su disposición final (Bono y Tómas, 2007). Al parecer, las grandes civilizaciones del mundo antiguo buscaron maneras de deshacerse de los residuos que generaban, enterrando su basura y aguas residuales. Debido a esta creciente necesidad, se introdujo por primera vez el alcantarillado en la Europa mediterránea por los griegos y los romanos (Calvo, 1997), aunque el resto de los poblados tomó más tiempo para que pudieran construir sus sistemas de alcantarillado. Al principio de la Edad Media, alrededor del siglo XIV, las ciudades habían ya crecido de manera considerable, enfrentando importantes carencias de servicios de saneamiento por lo que los pobladores se veían en la necesidad de disponer sus residuos a la calle; situación que ocasionó fuertes problemas a la salud como la epidemia de la peste que dio muerte a casi la mitad de la población europea de esta época (Hontoria et al. 2000). Los impactos negativos de una mala gestión de los residuos ponen en evidencia los riesgos que podrían enfrentar tanto las ciudades como las zonas rurales tanto para garantizar la salud de la población como el propio 
funcionamiento de las mismas. Además de la peste, otra epidemia que también diezmó la población europea durante los siglos XIV, XV, XVI, y XVII fue la peste bubónica, lo que originó que se decretara retirar los RSU de las calles (ABORGASE-EDIFESA, 2001). Para el siglo XIX, la gestión de los residuos seguía siendo precaria, limitándose a la retirada de los residuos urbanos de las calles de las ciudades y a su transporte fuera de estos centros urbanos, con lo que se dio una solución parcial a este problema, ya que los esfuerzos de las autoridades del siglo XIX se concentraron en el abastecimiento de agua potable en condiciones adecuadas de salubridad y en la depuración de las aguas residuales, cuya inadecuada disposición representaba un foco de enfermedades como la fiebre amarilla, el cólera y la tifo; enfermedades consideradas típicamente urbanas (Colomer et al. , 2007). Hasta este momento, los impactos más fuertes se habían dado sólo en la salud de la población, pero con la llegada de la Revolución Industrial, un par de siglos después, los impactos no sólo afectaban a la población sino también al ambiente.

La Revolución Industrial del siglo XIX dio lugar a un gran incremento de la generación de residuos, siendo su gestión insuficiente, a la par de presentarse una explotación irracional de los recursos naturales, degradación ambiental, deforestación sin control, reducción de la biodiversidad, y contaminación atmosférica (Carreras, 1992). En este período de progreso, con la utilización en gran escala de energía no renovable y la intensificación de la industria extractiva, aunado a un incremento acelerado de la población, fue determinante para que los residuos generados y su disposición se identificarán un problema ambiental relevante. A este hecho, también se suma el cambio de la composición pues los residuos urbanos resultado de la alimentación, pierden importancia en comparación con nuevos residuos que se empezaron a generar para facilitar su comercialización como el vidrio, papel, cartón y plásticos.

La explosión demográfica empeoró la situación de la mala gestión de RSU, ya que incrementó la problemática producida por los residuos, al estar directamente relacionada con el aumento en la generación de RSU a lo largo del siglo XX. Bajo este contexto, se comenzó a reflexionar sobre técnicas más innovadoras para reciclar los diversos residuos sólidos generados por las ciudades tanto de tipo orgánico como inorgánico; prácticas que hoy en día son comunes para realizar el reciclaje de materia orgánica y la recuperación de residuos (Colomer et al., 2007).

Los problemas para la eliminación de los residuos urbanos se agravan fundamentalmente al ir creciendo los núcleos de población y no disponer de sistemas para la recolección ni lugares adecuados para su disposición y almacenamiento. Las ciudades siguen creciendo y la implementación de medidas sustentables para la disposición de los residuos sólidos generados y su reutilización son cada vez más necesarios para garantizar la salud de la población y reducir el deterioro ambiental.

En México, en la época prehispánica, bajo el gobierno de Moctezuma, Tenochtitlán contaba con un sistema de recolección de residuos sólidos eficiente y sus habitantes disponían en sitios definidos sus residuos (Deffis, 1994). Fue a partir de la llegada de los españoles, que manejar los residuos de forma arbitraria se volvió una práctica común. En el año 1787, las calles de México eran intransitables por la falta de limpieza, ya que no se contaba con el servicio de recogida de basura, depositándose éstos en la vía pública, y como una consecuencia de esto el Virrey Revillagigedo hizo las primeras reglamentaciones municipales para limpiar las calles y recoger la basura de ellas con el uso de unos cuantos carritos tirados por mulas. Para 1884, el servicio de limpia ya contaba con 83 carros, 143 mulas y 43 pipas que regaban las calles (Deffis, 1994), lo cual era ineficiente debido al tamaño de la ciudad; esta situación favoreció a que se gestionaran los primeros reglamentos que imponían multas a las personas que arrojaban basura de manera arbitraría, reglamento que hasta la fecha no se ha hecho cumplir. Fue hasta 1940, cuando se comienza a hablar de la relevancia de reciclar y reutilizar los 
residuos sólidos como una estrategia tanto para reducir los costos de producción del sistema económico como para reducir los impactos ambientales resultado de la extracción de estos recursos

y su disposición; otros temas relevantes que entraron a la agenda pública para su reflexión fueron los problemas ambientales resultado de la contaminación de suelo, agua y aire, así como la gran necesidad de alejar de las urbes los tiraderos de basura por sus impactos directos sobre la salud de la población y la degradación ambiental. En México fue hasta la década de los noventa, cuando los problemas ambientales se incorporaron en la agenda de gobierno, normándose por medio de la Ley General de Equilibrio Ecológico que en su Artículo $7^{\circ}$ párrafo VI enuncia que corresponde a los Estados la regulación de los sistemas de recolección, transporte, almacenamiento, manejo, tratamiento y disposición final de los residuos sólidos e industriales que no estén considerados como peligrosos (LGEEPA, 1996).

En la actualidad, uno de los temas más preocupantes es el deterioro ambiental y se hacen grandes esfuerzos por que la población tome conciencia de que su calidad de vida y salud dependen de manera relevante de la manera en que se disponen los residuos sólidos y el volumen que se está generando, reutilizando, reciclando y transformando en energía u otros insumos que se reutilicen en otros sectores productivos. Esta situación debe ser considerada con mayor énfasis y prioridad en ciudades como la Ciudad de México y su zona conurbada, ya que es considerada como la cuarta megaciudad más grande del mundo con una población cercana a los 20 millones de personas. Este tipo de asentamientos urbanos se estima que pueden generar hasta 10,000 millones de toneladas de RSU cada año (PNUMA e ISWA, 2015). La elevada generación de RSU en las megaciudades pone en evidencia los retos que tendrán que enfrentar para poder disponer de manera sustentable este volumen de RSU, cuyo inadecuado manejo se ha convertido en un problema de salud pública, además de incurrirse en elevados costos de oportunidad al no reutilizar estos residuos en diversas actividades económicas.

Uno de los principales problemas que han existido en la Ciudad de México y en otras megaciudades de países en vías de desarrollo, es la incapacidad que tiene la ciudadanía para percibir la basura como un recurso y no como algo inservible, que no se quiere ver. Este problema parece agravarse para el 2030, ya que se espera un incremento del doble en la generación de RSU por parte de las metrópolis. Este aumento está impulsado principalmente por el crecimiento demográfico y urbano, así como por un repunte en el consumo de bienes y servicios por parte de la población (PNUMA e ISWA, 2015). Estos datos son alarmantes para nuestra sociedad y las autoridades, dado que existen graves problemas en la gestión de los RSU en las ciudades mexicanas, identificándose zonas en donde no cuentan con los servicios básicos de recolección de desechos, en particular aquellas que se encuentran en la periferia. Adicionalmente, la capacidad de los tiraderos a cielo abierto en donde se disponen los RSU recolectado está sobrepasada, requiriéndose identificar nuevos sitios en donde estos residuos sean colocados. Finalmente, la cuestión cultural y de educación ambiental en estos rubros es prácticamente nula, existiendo un desconocimiento social de esta problemática, así como una clara falta de compromiso para promover una adecuada gestión que emané desde la ciudadanía hasta las autoridades responsables.

\subsection{Residuos y residuos sólidos urbanos RSU}

Un residuo según la Real Academia Española es parte o porción que queda o que sobra de un todo o aquello que resulta de la descomposición o destrucción de algo y quizá de una manera más general se podría decir que un residuo es el material que queda como inservible después de haber realizado 
un trabajo, una operación o alguna actividad (Real Academia Española). Sin embargo, ahondando en esta definición de residuo y tomando en cuenta factores ambientales, económicos y sociales es pertinente reflexionar si un residuo es inservible. En este sentido, los residuos son considerados como co-productos de las actividades humanas que carecen de valor. Sin embargo, un residuo contiene en la mayoría de su composición los mismos materiales que contienen los productos usables de los que provienen, ¿por qué carecería de valor? Esta definición tiene un trasfondo importante de la manera en que se comprende la importancia y el valor de los residuos sólidos en muchas de las sociedades modernas. En este contexto, en las ciudades del tercer mundo como la Ciudad de México, existe un claro énfasis en mantener los residuos como algo inservible y despreciable, algo de lo que nos queremos deshacer sin importar la forma, simplemente desaparecerlo de nuestra vista; y es precisamente aquí, donde germina el grave problema de gestión de residuos que actualmente tenemos. Incluso los empleos que tienen que ver con la recolección de residuos son percibidos como por la población como empleos denigrantes. Esta pobre visión es la que en parte ha contribuido a que no se realice una GIRS, ya que, al no asignarles valor a los residuos generados, se dejan de aprovechar. Esta es una característica que se presenta frecuentemente en los países en vías de desarrollo, y se explica en parte por la falta de educación ambiental. En este sentido, es importante revalorizar los residuos con el fin de que su gestión sea más sustentable.

Bajo este contexto, la manera de manejar más adecuadamente los residuos es devolverles su valor e incorporarlos a los procesos productivos (White et al., 1992). Al mismo tiempo, se reducirían los problemas asociados a la contaminación y la búsqueda de espacios en donde ubicar sitios para su disposición. La falta de valor en muchos de los casos de los residuos que pueden ser reutilizados se explica en que los residuos están mezclados con otros residuos, algunas veces desconocidos que limitan su posterior aprovechamiento, es decir no están clasificados. Por lo tanto, cuando los residuos son separados y clasificados, su valor se incrementa, cuando esto ocurre los residuos pueden reutilizarse o venderse nuevamente.

Considerando las críticas mencionadas sobre la manera en que se han conceptualizado los residuos, éstos podrían definirse como co-productos de las actividades humanas que necesitan ser clasificados y procesados para incrementar su valor económico, además de ser integrados de nuevo a los procesos productivos favoreciendo su reúso y transformación.

Es imprescindible reflexionar la manera en que se ha conceptualizado los residuos sólidos y su gestión, con el fin de favorecer una gestión integral de los mismos, en particular en los países en vías de desarrollo.

En México, no sólo se debe cambiar esta visión de los residuos como objetos sin valor, sino que también se debe generar consciencia en todos los sectores de la población: desde las grandes industrias que generan residuos peligrosos e industriales, hasta la más pequeña de las viviendas que genera RSU, siendo fundamental reducir el volumen generado, y posteriormente, favorecer el reciclaje y reúso; sistema conocido como la regla de las 3-R (Reduce-Reúsa-Recicla). El primer paso, que es el más importante para poder llevar a cabo esta filosofía comienza por clasificar a los residuos, una vez clasificados podemos llevarla a cabo; en general que se refiere en primera instancia a "reducir" que a grandes rasgos implica hacer un cambio en la manera de consumir, comprando sólo lo necesario para evitar desperdiciar. Como segunda R se refiere a "reusar o reutilizar" lo que implica darle otros usos a las cosas que generalmente terminan en la basura y finalmente el "reciclar" que implica utilizar algún objeto que ya no se pudo reusar para incorporarlo a otro proceso de manera que se convierta en materia prima para la elaboración de otros productos. 
Aunque los residuos pueden ser clasificados en diversas categorías, es de particular interés para esta investigación su clasificación con base en estado físico

ya sea sólido, líquido y gaseoso. Este trabajo se enfoca específicamente en los residuos sólidos. Cabe destacar que, en este caso, la palabra sólido es imprecisa pues en una parte de los contaminantes líquidos y gaseosos existen sólidos suspendidos en estos medios como por ejemplo en el caso de la decantación de efluentes líquidos (Deffis, 1994).

Los residuos sólidos pueden clasificarse de acuerdo con su origen, el material que los conforma, su nivel de seguridad, sus propiedades físicas. Con respecto a su origen, los residuos sólidos pueden ser de tipo doméstico, industrial o agrícola (Hoornweg y Bhada, 2012). Con base en el tipo de material, los residuos sólidos se dividen en vidrio cartón, plástico, metal, textil y orgánico, (Hoornweg y Bhada, 2012). Por su nivel de seguridad, éstos se dividen en residuos peligrosos o no peligrosos, dónde los residuos peligrosos son definidos por la Ley General de Equilibrio Ecológico (LGEEPA) como aquel material o producto en estado sólido, semisólido, líquido o gas que posean alguna característica de corrosividad, reactividad, explosividad, toxicidad, inflamabilidad, o que contengan agentes infecciosos que les confieran peligrosidad, así como envases, recipientes, embalajes y suelos que hayan sido contaminados, por lo que previo a su disposición final se requiere de algún tratamiento (SEMARNAT, 2007). Los no peligrosos, son aquellos que no presentan las características de peligrosos como son los RSU, que comprenden todos los residuos que provienen de actividades realizadas en los núcleos de concentración poblacional, en donde se genera productos resultado de las actividades domésticas, comerciales y de servicios, así como los procedentes de la limpieza de calles, parques y jardines (Lemus, 2014). Por sus propiedades físicas, los residuos sólidos se clasifican en orgánicos que son los biodegradables, es decir, se descomponen naturalmente y tienen la característica de poder desintegrarse o degradarse rápidamente, transformándose en otro tipo de materia orgánica más simple como los restos de comida, frutas y verduras, sus cáscaras, carne y huevos. En el caso de los inorgánicos, comprenden aquellos residuos que por sus características químicas sufren una descomposición natural muy lenta; muchos de ellos son de origen natural pero no son biodegradables, por ejemplo, los envases de plástico. Los residuos sólidos inorgánicos generalmente se reciclan por medio de métodos artificiales y mecánicos, como las latas, vidrio, plástico y gomas (Navarro, 1995; Colomer et al., 2007).

\subsection{Residuos sólidos urbanos RSU}

Son de primordial interés para esta investigación los residuos sólidos urbanos, también conocidos como residuos municipales, los cuales constituyen residuos provenientes de los hogares, comercios pequeños y medianos, edificios públicos, instituciones, pequeñas empresas, residuos de jardinería y áreas verdes, así como aquellos que provienen de contenedores, y la limpieza de las calles. Una clasificación muy útil es la que hace el Banco Mundial (2012), ya que ésta se basa en el tipo de material de donde son originados, facilitando el identificar su procedencia. Sin embargo, ésta no es la única clasificación que se le da a este tipo de residuos. Con base en su origen los RSU se clasifican en orgánico, papel, plástico, vidrio, metal y otros (p.e., textil, cuero y residuos electrónicos, entre otros).

Tabla 1.1. Clasificación de los Residuos Sólidos Urbanos por su origen 


\begin{tabular}{|c|l|}
\hline $\begin{array}{c}\text { Clasificación } \\
\text { Orgánico }\end{array}$ & \multicolumn{1}{c|}{ Tipo de Residuo } \\
\hline Papel & $\begin{array}{l}\text { Residuos de comida, jardinería (hojas, ramas, arbustos), madera } \\
\text { guías telefónicas, papel picado, vasos, de papel bolsas, cajas, papel de regalo, }\end{array}$ \\
\hline Plástico & Botellas, envases, recipientes, bolsas, tapas, copas \\
\hline Vidrio & Botellas, vasos rotos, bombillas, cristales de colores \\
\hline Metal & $\begin{array}{l}\text { Latas, papel de aluminio, latas, latas de aerosol no peligrosos, } \\
\text { electrodomésticos (línea blanca), barandillas, bicicletas }\end{array}$ \\
\hline Otros & $\begin{array}{l}\text { Textil, cuero, caucho, multi-laminados, residuos electrónicos, } \\
\text { electrodomésticos, cenizas, y otros materiales inertes }\end{array}$ \\
\hline
\end{tabular}

Fuente: Hoornweg y Bhada, 2012.

En la tabla 1.1, se describe de manera puntual la clasificación de los RSU s partir del origen que tienen; esta clasificación no incluye los desperdicios de construcción y demolición, y tampoco los residuos y tratamiento de las redes de alcantarillado municipal (Hoornweg y Bhada, 2012).

Es muy importante hacer mención, que la importancia de los RSU sobre otro tipo de residuos generados radica principalmente en el volumen que se genera de estos en las grandes urbes, siendo una un tema prioritario a resolver por parte de los gobiernos locales, además de una preocupación a nivel mundial el reducir el volumen final de estos que se dispone. El acelerado crecimiento de la generación de RSU en el mundo en parte se explica por dos factores principalmente: el aumento de la población urbana y la forma de consumo de dicha población. En el caso particular del CDMX, el tema de los RSU es uno de los principales retos de la administración de Mancera, Jefe de gobierno de dicha ciudad, el cual asegura estar consciente de que cada habitante de la Ciudad de México produce un promedio diario de un kilogramo de residuos, lo que resulta en miles de toneladas diarias que necesitan cierto espacio para ser depositadas, a ese volumen habría que sumar residuos generados por los millones de personas que viajan diariamente a la CDMX para trabajar, estudiar o esparcirse (Teorema Ambiental, 2015). Por otro lado, es importante reconocer que la necesaria implementación de nuevas tecnologías, diseños, métodos y programas para la adecuada gestión de RSU requiere mucho más que un periodo de seis años que es lo que dura la administración de cada Jefe de Gobierno de la Ciudad de México, requiriéndose de un trabajo constante por parte de las autoridades y los ciudadanos en general. El gobierno federal trata de dar aparente solución a los problemas que trae consigo las grandes ciudades concesionando los servicios públicos de recolección y disposición final; sin embargo, esta tarea suele no ser cumplida correctamente por parte de las empresas privadas o públicas encargadas de la prestación de este servicio ante la falta de vigilancia por parte de las autoridades responsables y la falta de continuidad en considerar el gestionar de manera integral los RSU como una prioridad de los gobiernos en turno. El concesionar y privatizar los servicios públicos como una estrategia para resolver el problema de la gestión de los RSU no constituye una solución real, si no se analiza la manera en que dicha gestión sea más eficiente, integral y sustentable. En este sentido, uno de los objetivos de esta investigación es apoyar a los tomadores de decisiones responsables de la gestión RSU en la ciudad, a conocer con mayor detalle el manejo que se hace de los residuos desde su generación a su disposición final, con el fin de que puedan identificar las acciones que podrían implementar para mejorar cada una de las etapas que comprenden el proceso de manejo, y con ello, fortalecer la GIRS. 
Para la Organización Panamericana de Salud (OPS), los RSU son los residuos generados en las ciudades que incluyen los desechos domésticos y de comercios, así como los originados en las pequeñas industrias e instituciones (incluyendo clínicas y hospitales) (OPS, 2012). En algunas partes de México, por ejemplo, muchos de los residuos generados en clínicas y hospitales son considerados como peligrosos o infecciosos; sin embargo, es importante resaltar que este tipo de lugares generan tres tipos de residuos: urbanos, de manejo especial y peligrosos, es decir, no todo lo que genera es residuo peligroso. Complementando esta definición, el Panel Internacional sobre el Cambio Climático (IPCC) propone que precisa los RSU son los residuos de alimentos, jardín, y parques, así como los residuos como papel, cartón, madera, textiles, pañales desechables, caucho y cuero, plástico, residuos de metal, vidrio (cerámica y porcelana); asimismo, incluye en esta definición la ceniza, suciedad, polvo, tierra y residuos electrónicos (Bonger et al., 2012). La Tabla 1.2 sistematiza las diversas definiciones sobre los RSU.

Tabla 1.2. Definición de residuos sólidos urbanos

\begin{tabular}{|c|c|c|}
\hline AUTOR & DEFINICIÓN & $\begin{array}{c}\text { ASPECTOS } \\
\text { RELEVANTES }\end{array}$ \\
\hline $\begin{array}{l}\text { Artículo 50, } \\
\text { fracción XXXIII } \\
\text { de la LGPGIR }\end{array}$ & $\begin{array}{l}\text { Son los generados en las casas habitación, que } \\
\text { resultan de la eliminación de los materiales que } \\
\text { utilizan en sus actividades domésticas, de los } \\
\text { productos que consumen y de sus envases, } \\
\text { embalajes y empaques; los residuos que provienen } \\
\text { de cualquier otra actividad dentro de } \\
\text { establecimientos o en la vía pública que genere } \\
\text { residuos con características domiciliarias y los } \\
\text { resultantes de la limpieza de las vías y lugares } \\
\text { públicos. }\end{array}$ & $\begin{array}{l}\text { No incluye desechos de } \\
\text { cínicas u hospitales } \\
\text { como lo incluye la } \\
\text { Organización } \\
\text { Panamericana de Salud }\end{array}$ \\
\hline (Esquer, 2009) & $\begin{array}{l}\text { Conjunto de materiales residuales sólidos o } \\
\text { mezclados con pequeñas cantidades de agua que } \\
\text { por el estado de división o deterioro se consideran } \\
\text { inservibles o sin valor para la sociedad. }\end{array}$ & $\begin{array}{l}\text { Esta definición no } \\
\text { especifica los tipos de } \\
\text { residuos, pero } \\
\text { menciona algo muy } \\
\text { importante: los RSU } \\
\text { pudieran venir } \\
\text { mezclados con líquidos }\end{array}$ \\
\hline $\begin{array}{l}\text { (Gaggeo \& } \\
\text { Ordoñez, 2002) }\end{array}$ & $\begin{array}{l}\text { Desechos generados en la comunidad urbana, } \\
\text { provenientes de los procesos de consumo y } \\
\text { desarrollo de las actividades humanas, y que } \\
\text { normalmente son sólidos a temperatura ambiente. } \\
\text { Además de los producidos por los usos } \\
\text { residenciales, comerciales e institucionales, y por } \\
\text { el aseo del espacio público, los RSU incluyen los } \\
\text { residuos originados en las industrias y } \\
\text { establecimientos de salud, siempre que no tengan } \\
\text { características tóxicas ni peligrosas. }\end{array}$ & $\begin{array}{l}\text { Aunque no precisa } \\
\text { cuales son los } \\
\text { establecimientos de } \\
\text { salud, podemos intuir } \\
\text { que se refiere a clínicas } \\
\text { y hospitales, pero } \\
\text { aclara que siempre que } \\
\text { no contengan } \\
\text { características tóxicas } \\
\text { ni peligrosas. }\end{array}$ \\
\hline
\end{tabular}




\begin{tabular}{|l|l|l|}
\hline (Bertolino et al, & $\begin{array}{l}\text { Son residuos sólidos urbanos (RSU) los generados } \\
\text { por distintas actividades en los núcleos urbanos, } \\
\text { incluyendo tanto los de carácter doméstico como } \\
\text { los provenientes de cualquier otra actividad. }\end{array}$ & $\begin{array}{l}\text { Cualquier otra } \\
\text { actividad, puede } \\
\text { referirse a lugares que } \\
\text { presta servicios }\end{array}$ \\
\hline (Mazzeo, 2012) & $\begin{array}{l}\text { Los generados en los domicilios particulares, } \\
\text { comercios, oficinas y servicios, así como todos } \\
\text { aquellos que no tengan la calificación de peligrosos } \\
\text { y que por su naturaleza o composición puedan } \\
\text { asimilarse a los producidos en los anteriores } \\
\text { lugares o actividades. }\end{array}$ & $\begin{array}{l}\text { No menciona } \\
\text { industrias. }\end{array}$ \\
\hline
\end{tabular}

Es fundamental tener claro que es un RSU, ya que de ahí partimos para tener una buena clasificación, es decir, podemos confundir fácilmente un residuo de manejo especial con un RSU lo cual puede ser un problema o contratiempo en la GIRS. Las definiciones de la Tabla1.2 ayudan a tener un panorama un poco más claro teniendo como base las definiciones de los organismos internacionales y lo que marca la normativa en México. Podemos decir entonces juntando todas estas definiciones que los residuos sólidos urbanos comprenden todos los residuos sólidos o incluso semisólidos que se generan en casas, oficinas, escuelas, mercados, comercios, instituciones públicas y privadas como clínicas, hospitales e industrias (que no requieren manejo especial, ni son biológico-infecciosas ni son tóxicas tampoco); también los residuos generados de la limpieza de jardines, parques, y vías públicas. Esta definición, engloba todas la mencionadas en la Tabla 1.2, con el fin de ampliar la perspectiva y entender mejor el concepto de RSU, lo cual es necesario para esta investigación.

Los residuos sólidos urbanos se han convertido en un severo problema para las ciudades del mundo, en particular para las ciudades de los países en desarrollo y, por ende, representan un importante reto para la gestión. El incremento en la generación de RSU se explica en el caso de los países de primer mundo por el incremento incontrolado del consumo de bienes y servicios aunado con el aumento de la población; y en el caso de las ciudades de países en vías de desarrollo, a estos dos problemas mencionados se suma la ignorancia, la falta de educación ambiental y desvalorización de los RSU. El problema principal en la gestión de los desechos en ciudades de los países en desarrollo (incluida la Ciudad de México), son las limitaciones en términos administrativos, operativos, en recursos humanos, tecnológicos, que obstaculiza el desarrollo de un sistema más eficiente y eficaz, dentro de un marco formal e incluyente, y que derive en mayores beneficios para la sociedad en general y el medio ambiente. El aprovechamiento de los residuos y la generación de nuevas fuentes energéticas, y con una disminución de su efecto contaminante al aire, suelo y agua, es una necesidad predominante para la Ciudad de México (Schwanse et al., 2013). Bajo este contexto, esta investigación pretende contribuir a un mejor conocimiento sobre el proceso del manejo de los RSU en la Ciudad de México; proceso que constituye una parte fundamental de la Gestión Integrada de los Residuos Sólidos Urbanos (GIRS). Cómo anteriormente se ha mencionado, el problema de los RSU es un problema global, es decir que prevalece en la gran mayoría de las ciudades del mundo.

Para el 2030, por ejemplo, se espera que haya 41 megaciudades, cuando actualmente hay 28, es decir se incrementaría en un $146 \%$ el número de ciudades de más de 10 millones de personas (Tapia, 2014); situación que repercutirá en un incremento importante en la generación de los RSU. Esto sin duda obliga a reflexionar sobre la GIRS con mayor seriedad como una alternativa para tratar resolver este gran reto, siendo una oportunidad para los países en vías de desarrollo no sólo por su potencial para 
generar fuentes de energía alternativa y materias primas para los procesos productivos, sino también para reducir los impactos a la salud y ambientales resultados de su inadecuada gestión.

En América Latina, ciudades como Sao Pablo, Ciudad de México, Rio de Janeiro y Buenos Aires, todas con más de 10 millones de habitantes, se les sumarán Lima, Perú y Bogotá. La capital peruana pasará de tener 9.7 millones de habitantes a 12.2 millones; mientras que Colombia pasará de 9.7 millones de habitantes a 12.2 millones. La Ciudad de México será la única urbe en el top 10 de las megaciudades del mundo, siendo la generación de RSU uno de los principales retos que tendrá que enfrentar (Tapia, 2014). Actualmente, los problemas de GIRS repercuten en varios aspectos incluyendo la salud, economía y el medio ambiente; a pesar de contar con planes de manejo, programas para promover el reciclaje y reúso de los RSU y un marco jurídico para la regulación de la gestión de los RSU, las mejoras con respecto a una gestión más integral, eficiente y sustentables no han sido las esperadas, lo cual justifica la necesidad de reflexionar de manera crítica sobre el manejo que se está haciendo de los RSU en la capital del país. Evidentemente, la GIRS para el 2030, será uno de los principales problemas que enfrentará México y sus ciudades, lo cual pone en evidencia la urgencia de mejorarla.

\subsection{Los RSU a nivel mundial}

Las ciudades a lo largo de las últimas cinco décadas han acelerado su crecimiento, siendo uno de los principales fenómenos urbanos en el mundo. Las ciudades son motores del desarrollo, albergando millones de personas y actividades económicas que demandan una gran cantidad de servicios urbanos, incluyendo la recolección, tratamiento y disposición de los RSU generados. En las ciudades del mundo se genera aproximadamente un 60\% del Producto Interno Bruto (PIB) total mundial, siendo estos centros en donde se presenta un $80 \%$ del crecimiento económico (BM, 2015). Si bien las ciudades en la actualidad constituyen el principal motor para el crecimiento económico, sería importante reflexionar si en un futuro continuarán aportando "beneficios" o más bien representarán grandes costos para el planeta, al demandar enormes volúmenes de materias primas, alimentos y energía; además de generar enormes cantidades de desechos que se traducen en residuos sólidos, emisiones contaminantes y aguas residuales.

Hacer frente a los retos de estas grandes aglomeraciones urbanas no sólo requerirá de la implementación de planes, programas y leyes, sino que se requiere crear conciencia en la sociedad, dado que los gobiernos locales junto con sus pobladores son los encargados de accionar para lograr verdaderos cambios, debido a que son ellos quienes mejor conocen el entorno en donde viven.

Como se mencionó anteriormente, a la par del crecimiento de las ciudades se ha incrementado la generación de residuos sólidos urbanos (RSU), resultado del aumento poblacional y los cambios de patrones consumo modernos. Por ejemplo, en el año 2002, existían alrededor de 2.9 billones de residentes urbanos en el mundo que generaban al día un promedio de $0.64 \mathrm{~kg}$ de RSU per cápita, por ende, en el mundo se generaban 0.68 billones de toneladas de RSU por año. Para el año 2012, los residentes urbanos en el mundo aumentaron a 3 billones, generándose en promedio $1.2 \mathrm{~kg}$ de RSU por persona al día; situación que implica que el volumen total de toneladas de RSU al año prácticamente se duplicó a 1.3 billones de toneladas (Banco Mundial, 2012) (Gráfica 1.1). Se estima que para el 2025, los residentes urbanos alcanzarán una cifra de 4.3 billones de personas, las cuales generarán $1.42 \mathrm{~kg}$ de RSU al día per cápita, proyectándose que el total de RSU generados alcanzará una cifra de 
2.2 de billones de toneladas de RSU al año (Gráfica 1.1). Dadas estas cifras, es alarmante el volumen de RSU que se generará y los impactos ambientales, sociales y económicos que tendría esta problemática; destacan las repercusiones a la salud humana (desde enfermedades respiratorias hasta infecciosas) aunado a la generación de gases de efecto invernadero (GEI) que contribuyen al cambio climático, y a la contaminación del aire, agua y suelo. Es importante mencionar, que la psicología social afirma que la contaminación tanto física como química afecta a las personas psicológicamente, en especial a las personas mayores y niños (Evans, 2003). Además de los efectos fisiológicos que pueden desencadenar como los antes mencionados a causa de los RSU, los efectos psicológicos no son pocos; se destaca la depresión, el insomnio, dificultad de juicio y tristeza.

En la Gráfica 1.1 inciso a, se describe la evolución de la generación de RSU, mientras que en el inciso b se presenta una proyección del crecimiento de la población. El crecimiento de la generación de los RSU ha presentado un crecimiento más acelerado en donde se muestra una pendiente más inclinada para la generación de RSU que implica una mayor tasa de crecimiento de los RSU generados en el mundo en comparación con el crecimiento demográfico; en este sentido, la población mundial está generando cada vez más residuos sólidos de manera per cápita.

\section{Gráfica 1.1 Generación de residuos sólidos urbanos en el mundo y población}

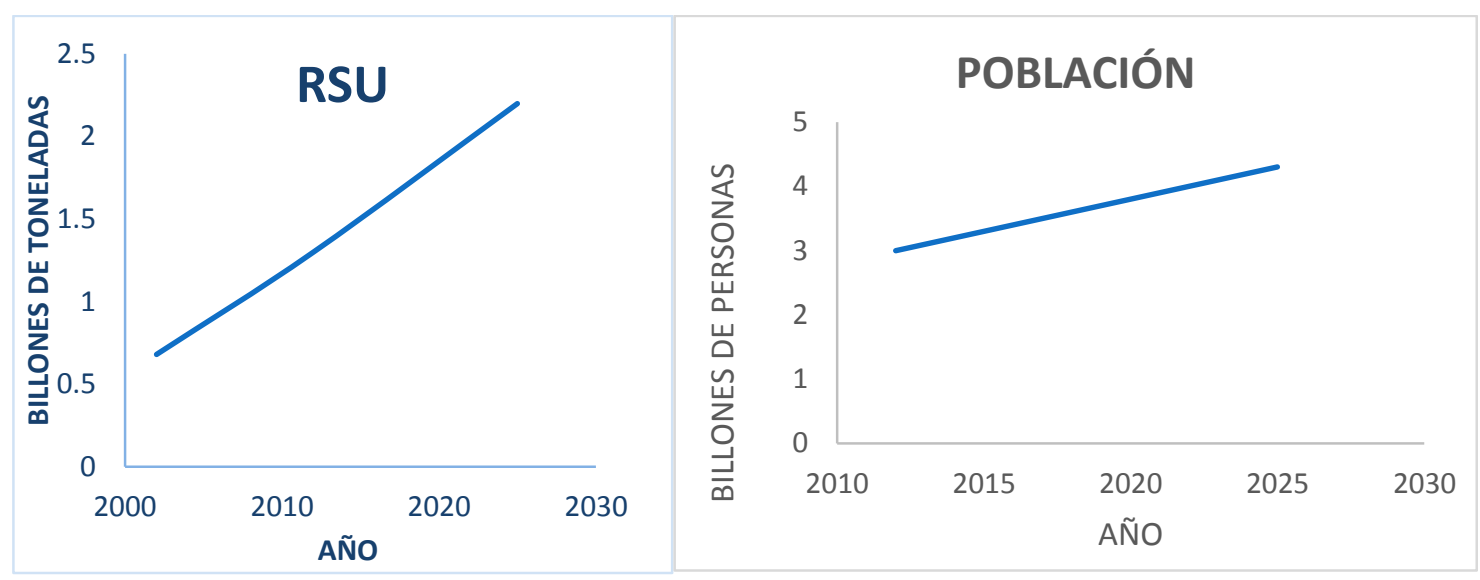

Fuente: Elaboración propia con base en Hoornweg y Bhada (2012).

Se puede concluir que la generación de RSU está directamente relacionada con el número de habitantes, aunque existen otros factores que influyen en el volumen generado. Sin duda, el desarrollo económico, los estilos de vida y los patrones de consumo, son factores que incrementan el consumo de bienes y servicios de los pobladores principalmente en las zonas urbanas; esto se refleja inmediatamente en la generación de desperdicios de comida, empaques y embalajes de diversos tipos de materiales como cartón, papel, plásticos, así como residuos provenientes de dispositivos electrónicos. Ante esta situación, es pertinente reflexionar si los patrones de consumo actuales en las ciudades del mundo son sustentables y qué tan sustentable es el manejo de estos residuos, reduciendo el volumen general que se dispone y promoviendo el reciclaje y reutilización de los mismos. Los impactos ambientales del consumo son desde hace tiempo una preocupación en los países desarrollados, en donde se observan los mayores índices de gasto energético, consumo de materias primas por habitante y cantidad de desechos per cápita. 
En un análisis que hizo el Banco Mundial en el 2012 por regiones, se estimó que casi la mitad de los RSU generados en el mundo ( $44 \%$ del total), son producidos por la mayoría de los países que conforman la Organización para la Cooperación y el Desarrollo Económicos (OCDE), dicha organización agrupa a los 34 países más desarrollados del mundo, entre los cuales destacan Estados Unidos, Inglaterra, Japón, Dinamarca, Países Bajos y Noruega. En segundo lugar, se encuentra la región del este de Asia y la región del Pacífico con una generación de RSU a nivel mundial de 21\%; esta región comprende 19 países entre los que destacan China, Indonesia, Malasia, Singapur y Tailandia. Los siguientes productores de RSU en el mundo son los países de América Latina, los cuales producen $12 \%$ del total de los RSU en el mundo; entre estos países se encuentra México, ocupando el décimo lugar de producción de RSU a nivel mundial (SEMARNAT, 2012; Banco Mundial, 2012) (Tabla 1.3).

Tabla 1.3 Clasificación de los países por región para la generación de los RSU

\begin{tabular}{|c|c|c|c|}
\hline $\begin{array}{l}\text { Organización para la } \\
\text { Cooperación y } \\
\text { Desarrollo Económicos } \\
\text { (OCDE) }\end{array}$ & América Latina & $\begin{array}{l}\text { Región Pacífico y } \\
\text { Este de Asia }\end{array}$ & Resto del mundo \\
\hline Andorra & Antigua y Barbuda & Brunei & \multirow{23}{*}{$\begin{array}{l}\text { El Resto del mundo } \\
\text { que no se menciona } \\
\text { en las tres regiones } \\
\text { anteriores }\end{array}$} \\
\hline Australia & Argentina & Camboya & \\
\hline Austria & Las Bahamas & China & \\
\hline Bélgica & Barbados & Fiji & \\
\hline Canadá & Belice & Hong Kong & \\
\hline República Checa & Bolivia & Indonesia & \\
\hline Dinamarca & Brasil & RDP Lao & \\
\hline Finlandia & Chile & Malasia & \\
\hline Francia & Colombia & Islas Marshall & \\
\hline Alemania & Costa Rica & Mongolia & \\
\hline Grecia & Cuba & Myanmar & \\
\hline Hungría & República Dominicana & Filipinas & \\
\hline Irlanda & Ecuador & Singapur & \\
\hline Islandia & El Salvador & Islas Salomón & \\
\hline Italia & Granada & Tailandia & \\
\hline Japón & Guatemala & Tonga & \\
\hline Corea del Sur & Guayana & Vanuatu & \\
\hline Luxemburgo & Haití & Vietnam (19) & \\
\hline Mónaco & Honduras & & \\
\hline Países Bajos & Jamaica & & \\
\hline Nueva Zelanda & México & & \\
\hline Noruega & Nicaragua & & \\
\hline Portugal & Panamá & & \\
\hline
\end{tabular}




\begin{tabular}{|l|l|l|}
\hline República Eslovaca & Paraguay & \\
\hline España & Perú & \\
\hline Suecia & San Cristóbal y Nevi & \\
\hline Suiza & Santa Lucia & \\
\hline Inglaterra & San Vicente y las granadinas & \\
\hline Estados Unidos & Surinam & \\
\hline$(\mathbf{2 9})$ & Trinidad y Tobago & \\
\hline & Uruguay & \\
\hline & Venezuela (32) & \\
\hline
\end{tabular}

Fuente: Banco Mundial, 2012.

Considerando las cifras anteriores, tres regiones (los países de la OCDE, América Latina y la región Pacífico y este de Asia) que constituyen aproximadamente un $40 \%$ del total de los países del mundo, se produce casi la totalidad de los RSU generados a nivel mundial (77\%); esta situación pone en evidencia la urgente necesidad de promover la colaboración entre estos países para favorecer no sólo una menor generación de RSU sino hacer más eficiente su reciclaje y reúso a partir de la implementación y desarrollo de tecnología y modernización de los procesos productivos (Gráfica 1.2).

\section{Gráfica 1.2 Generación de Residuos Sólidos urbanos a nivel mundial}

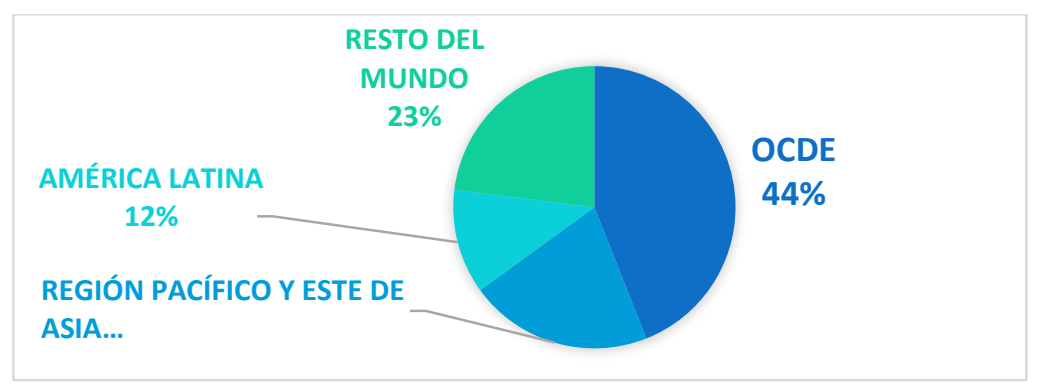

Fuente: Elaboración propia con datos del Banco Mundial, 2012.

La generación de RSU está relacionada directamente con el número de habitantes, los ingresos per cápita de los habitantes y sus patrones de consumo de bienes y servicios. Sin embargo, es importante mencionar que la gestión de los RSU difiere entre las diferentes regiones, destacándose algunos países por su capacidad para integrar en los procesos productivos y reutilizar los residuos sólidos generados, realizando una disposición mínima de los mismos. Las ciudades del primer mundo en países como Japón, Suecia, Suiza, Australia y Alemania han mostrado ser eficientes y sustentables en el manejo de los RSU, realizando una adecuada gestión de los mismos. Por ejemplo, en el caso de Alemania se hace un aprovechamiento más eficiente de los residuos orgánicos, los cuales no sólo se utilizan para la generación de energías limpias, sino además se obtienen un beneficio económico resultado de la comercialización de co-producto como lodos fertilizantes (ECB Envairo, 2008).

El aprovechar los residuos orgánicos y generar biogás para utilizarlo como una fuente de energía limpia, térmica o eléctrica, es un proceso que ya se ha hecho en otras partes del mundo desde hace varias décadas. Alemania, es un país completamente desarrollado y son pioneros en Europa en este tipo de proyectos a gran escala; asimismo, son poseedores de una de las más importantes plantas de reciclaje de materia orgánica. El dueño de la planta es AEP Putbus Gmbh, la cual se ubica en la Isla 
Rûgen, Alemania; esta planta tiene una capacidad de tratar 100,000 toneladas/anuales de desechos agrícolas y desperdicios orgánicos, el tiempo de construcción de la misma fue de 8 meses y opera desde el año 1997. Este proyecto surgió como resultado de la implementación de adecuadas políticas públicas, ya que a mitad de los años 90 las leyes ambientales estrictas comenzaron a tener un mayor impacto en toda Europa. En Alemania, la comunidad agrícola de la Isla Rûgen se enfrentó a un enorme reto ambiental, ya que dicha comunidad agrícola sólo había vivido del turismo veraniego por muchos años. Al paso del tiempo la isla se convirtió en un popular destino turístico trayendo algunos problemas especialmente ambientales (ECB Envairo, 2008). El control de olores y la protección del agua fueron os de los más grandes retos por enfrentar; la solución implementada por ECB Envairo fue recolectar los residuos de ganado, residuos orgánicos de los hoteles, restaurantes, hospitales no peligrosos, escuelas y desechos municipales, los cuales fueron mezclados, tratados y reciclados al $100 \%$ en un proceso que produce energía eléctrica y térmica, y un residuo en forma de lodo inodoro y rico en nutrientes que se emplea como fertilizante. La energía térmica derivada del proceso es vendida y utilizada para la calefacción de hospitales escuelas y casas aledañas y la energía eléctrica es retroalimentada al sistema siendo una fuente de ingresos para la cooperativa de pequeños a medianos campesinos involucrados en proyecto de la isla Rûgen; por otro lado, el tratamiento para los residuos industriales y municipales garantiza de una manera eficaz el tratamiento de desperdicios y una estabilidad económica y social por un largo tiempo. En el caso de las ciudades de los países en vías de desarrollo, como en el caso de la Ciudad de México, se hacen grandes esfuerzos por enseñar y concientizar a la población acerca de la importancia de clasificar los residuos, por lo que ni siquiera se ha logrado que la población aprenda a clasificarlos correctamente, esto también basado en datos proporcionados por el Inventario de RSU de la CDMX, 2013, donde se presentan gráficas de eficiencia en separación, motivo por el cual se limita el uso potencial de los RSU que pudieran reciclarse e incorporarse en los procesos productivos. De allí la importancia de implementar políticas públicas orientadas no sólo a efectuar una GIRS desde un enfoque técnico sino también a la par, trabajar con la creación de una cultura para la separación, reciclaje y reúso de los RSU favoreciendo su revalorización.

En el caso de los países en desarrollo, ubicados en dos de las regiones que más generan RSU en el mundo cómo la región del este de Asia, del Pacífico y América Latina. Otro de los países que está realizando importantes avances para una gestión más eficiente y sustentable de los residuos sólidos generados es China, siendo uno del país que más inversión ha estado realizada en los últimos años para mejorarla (Hoornweg y Bhada, 2012). Aunque China es de los países más contaminantes del mundo, es de los que más recicla e incluso está exportando alrededor del $70 \%$ de sus plásticos reciclados (Schejtman \& Cellucci, 2014). Asimismo, China ha estado implementado diversos programas y estrategias para una adecuada GIRS por medio de reformas para el control de la contaminación por las aguas residuales favoreciendo un mayor tratamiento del volumen generado, además realizar importantes obras de infraestructura para el manejo de los residuos sólidos que promuevan la separación y recolección de los mismos (Hoornweg y Bhada; 2012).

En el caso de México, se hacen intentos por favorecer el reciclaje y reúso de los RSU, pero estos no han logrado tener los resultados esperados ya que sólo se recicla un 9.63\% generado, disponiéndose 78.54\% tanto en rellenos sanitarios como en tiraderos a cielo abierto (LGEPGIR, 2012). Evidentemente, los esfuerzos realizados no han sido suficientes dado que menos de un $10 \%$ del total de los RSU se está aprovechando en otros procesos productivos. En la siguiente sección se reflexionará sobre esta problemática en México. 


\subsection{Residuos Sólidos Urbanos en México}

Debido a la industrialización que el país presentó durante la segunda mitad del siglo pasado se incrementó la demanda de materias primas y con ello el consumo de los habitantes, lo cual repercutió a su vez en un aumento de generación de RSU (SEMARNAT, 2007); sin embargo, es importante hacer mención de que muchos de los datos que se encuentran registrados básicamente se han estimado ya que no se pueden medir directamente. Por ejemplo, para el 2011 según estimaciones de SEDESOL, se generaban alrededor de 41 millones de toneladas al año, lo que equivale a 112.5 mil toneladas diariamente, es decir, México entre el año 2003 y 2011, presentó un incrementó en aproximadamente un $25 \%$ en el número de toneladas de RSU generados por año. (SEMARNAT, 2012) (Gráfica 1.3). Esto nos confirma que México sigue la tendencia mundial en el incremento de la generación de RSU, lo cual se explica por la urbanización acelerada en las ciudades del país, las cuales han pasado de ser ciudades pequeñas a ciudades medianas y grandes, tal es el caso de Monterrey, Guadalajara, Puebla, Juárez. Tijuana, León, Nezahualcóyotl, Ecatepec, etc. Otro factor que explica el incremento en la generación de RSU en el país está relacionada con los patrones de consumo poco sustentables que impone el actual modelo económico. En otras palabras, podríamos decir que el desarrollo de un país, en la actualidad, se encuentra medido por la producción que éste presenta, lo que conlleva a un consumo sostenido que implica una mayor generación de RSU. Sin embargo, resulta difícil pensar que sólo se debe al modelo económico en el que actualmente estamos inmersos, también se debe a los patrones de consumo que la sociedad mexicana ha desarrollado, transformado e incrementado en las últimas décadas (Merino, 2012). En estas últimas décadas la sociedad mexicana ya no consume sólo lo necesario, sino consume también lo que no necesita e incluso lo que ni siquiera tiene para pagar. Esto, como consecuencia directa recae en un incremento de RSU.

Como se puede verificar en la Gráfica 1.3, el incremento en la generación de RSU en México está estrechamente relacionado con el incremento en el PIB, por ende, conforme se ha incrementado la riqueza generada en el país, también lo ha hecho la generación de RSU, al incrementarse de la misma forma el consumo final privado de los mexicanos. En este sentido, el incremento en la riqueza de los mexicanos traerá consigo un repunto en la generación de los RSU. Esta situación pone en evidencia que si bien una de las prioridades de la política económica y social en México orientada al combate de la pobreza se espera que ésta traiga consigo importantes repercusiones en el ámbito ambiental, las cuales tienen que reducirse y prevenirse con una adecuada gestión de los RSU. 
Gráfica 1.3 Generación de RSU, PIB y Gasto del consumo final privado

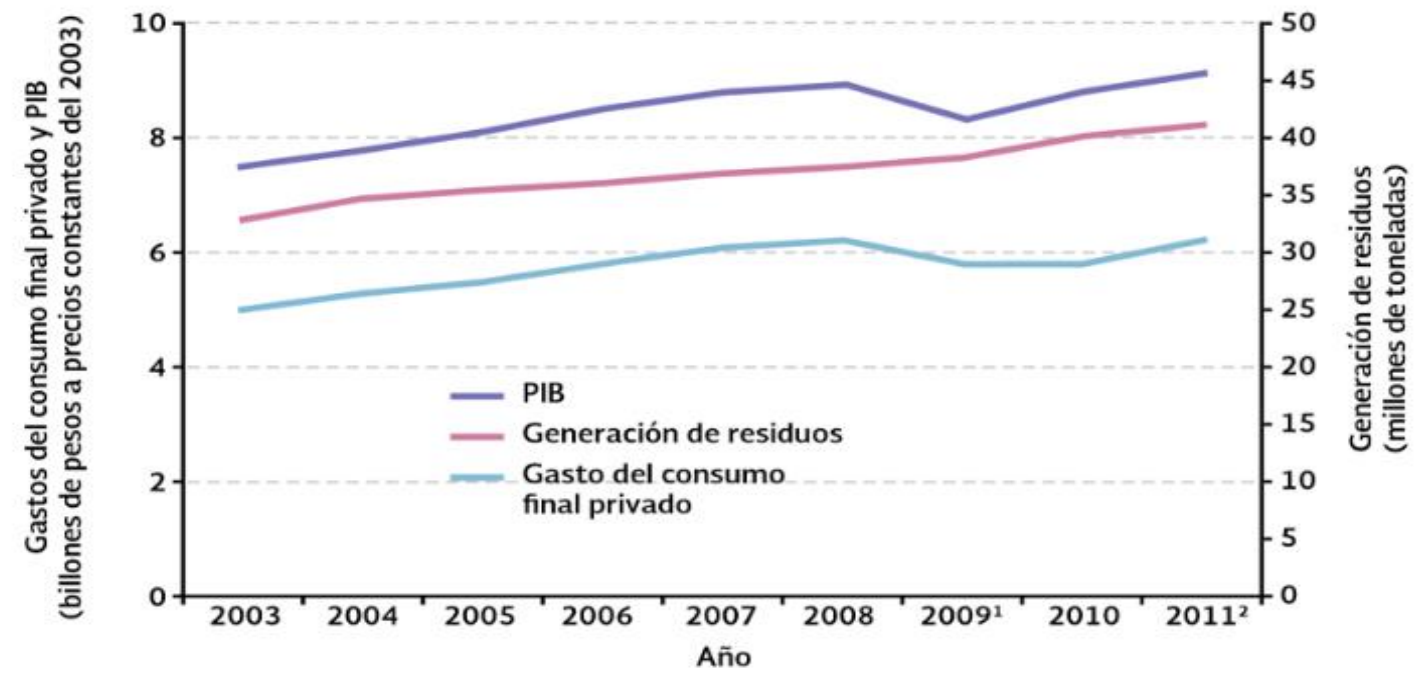

Fuente: SEMARNAT, 2012.

Existen varios factores que influyen en los elevados patrones de consumo de bienes y servicios en las ciudades como la publicidad, el acceso a créditos y la facilidad con la que se pueden adquirir diversos bienes y servicios, así como la falta de educación para evitar consumos innecesarios y dispendiosos y la falta de cultura para reducir la huella ecológica como sociedad. Sin embargo, reducir el consumo implicaría ir en contra del modelo económico actual, en cuyo se requeriría modificar las actuales políticas públicas para reducir aquellos incentivos orientados a un consumo creciente de ciertos bienes y servicios (Callejo, 1994; Torey, 1996; Lipovetsky, 2007). Cabe destacar, que las prácticas para promover o desincentivar el consumo varían dependiendo de la cultura predominante en cada país.

Sin duda alguna, una GIRS va mucho más allá de recolectar residuos y clasificarlos; es más una cuestión de atacar la enfermedad y no los síntomas, por lo que se requiere implementar políticas públicas que apoyen estrategias como Reduce-Reutiliza-Recicla (3Rs). Esta estrategia de las 3Rs fue expuesta durante la Cumbre del G8 en junio de 2004 por el Primer Ministro de Japón Koizumi Junichiro, quien propuso transformar a la sociedad en una orientada hacia el reciclaje (Cumbre del G8, 1997).

En México, así como en muchas otras partes del mundo, es difícil encontrar información precisa y sistematizada con respecto al tema de RSU. Las cifras sobre la generación de los RSU a nivel nacional que se han reportado en los últimos años presentan limitaciones importantes, básicamente porque no se trata de mediciones directas sino de estimaciones sobre la generación de dichos residuos por sectores de población (Jiménez, 2015). Estas cifras son calculadas por la Secretaría de Desarrollo Social (SEDESOL) conforme a lo establecido en la norma NMX-AA-61-1985, la cual precisa el procedimiento a seguir para determinar la generación de residuos sólidos municipales a partir de un muestreo estadístico aleatorio. Según esta norma, los residuos sólidos municipales se subdividen en domésticos (que son los generados en casas habitación) y en no domésticos (generados fuera de las casas habitación); después del procedimiento requerido por la norma se llegó a la conclusión de que se generaron 41 millones de toneladas de residuos en México, lo que equivale a cerca de 112 mil toneladas de RSU generados diariamente (SEMARNAT, 2012). La mayor parte de los RSU (52.4\% 
del total) son residuos de comida, jardines y materiales orgánicos; el papel, cartón y diferentes productos de papel constituyen $13.8 \%$; los plásticos $10.9 \%$; el vidrio $5.9 \%$; el aluminio $1.7 \%$; los metales ferrosos $1.1 \%$; otros metales no ferrosos $0.06 \%$, y el $12.1 \%$ restante comprende otro tipo de residuos como aparatos electrónicos, textiles, cuero y caucho (Figura 1.1). En la Figura 1 se detallan la participación porcentual de la composición de los RSU generadas en México (SEDESOL, 2011).

\section{Figura 1.1 Composición de RSU para México en el año 2011}

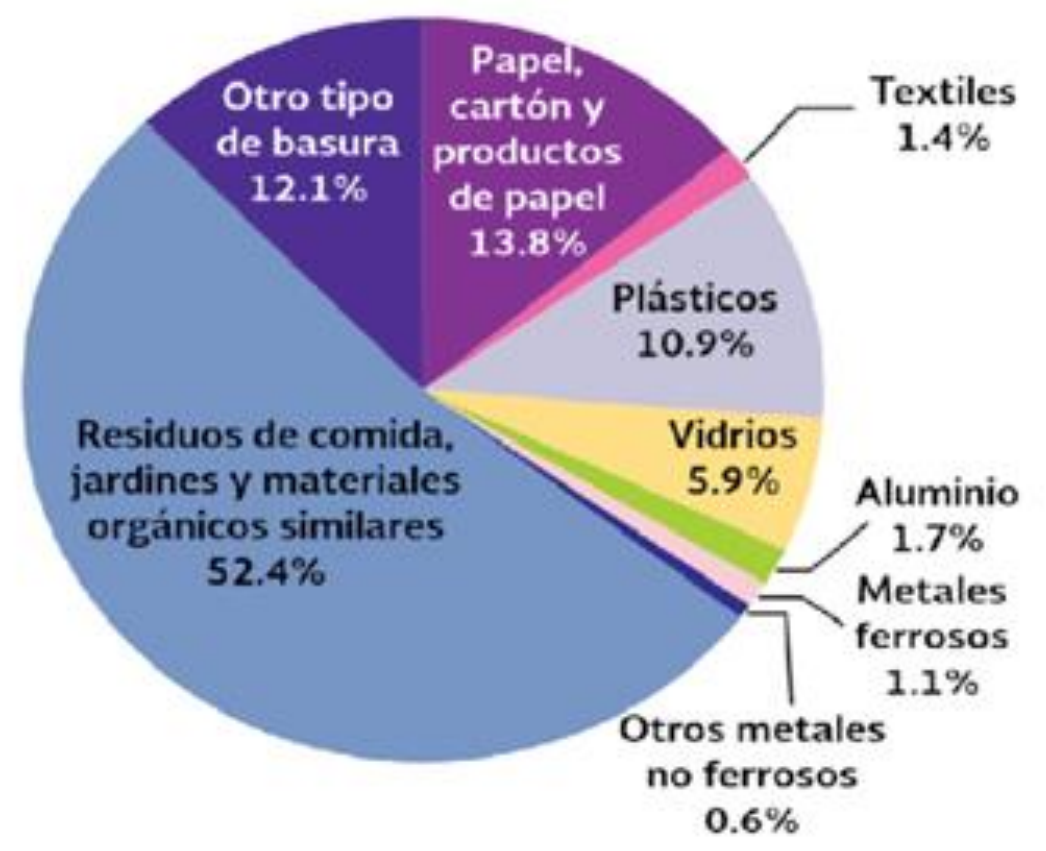

Fuente: SEDESOL, 2011.

Los RSU generados en México están conformada principalmente por material orgánico, que podría ser aprovechado con algún tipo de tecnología para la generación de biogás. Es decir, la composición de los residuos sólidos urbanos, es un parámetro de gran importancia que permite determinar su manejo y valorización. Los residuos orgánicos en promedio se generan entre el 27.86 y 43.29\%, los residuos susceptibles de aprovechamiento varían entre 33.23 y $44.49 \%$, los residuos restantes corresponden entre un 16.13 y 30.18\%. Así que la mayoría de los RSU que se están generando son aprovechables incluso para generar algún tipo de energía verde, como lo es el gas natural o biogás que se genera a partir de la descomposición anaerobia de la materia orgánica. Actualmente la gestión de los residuos sólidos urbanos está orientada a considera dos enfoques generales, el pre y post consumo (SEMARNAT, 2012).

En el diagnóstico básico año base 2012 se propone un diagrama de flujo de los RSU (Figura 1.2) el cual muestra que en nuestro país existe un bajo porcentaje de reciclaje de residuos del $9.63 \%$, el mayor porcentaje de los residuos generados (78.54\%) son dispuestos en rellenos sanitarios y sitios controlados, existiendo todavía un porcentaje considerable del $15.93 \%$ de residuos que son dispuestos en tiraderos a cielo abierto, aumentado los impactos al medio ambiente. 
Figura 1.2 Diagrama nacional de RSU en México de acuerdo al Diagnóstico Básico 2012.

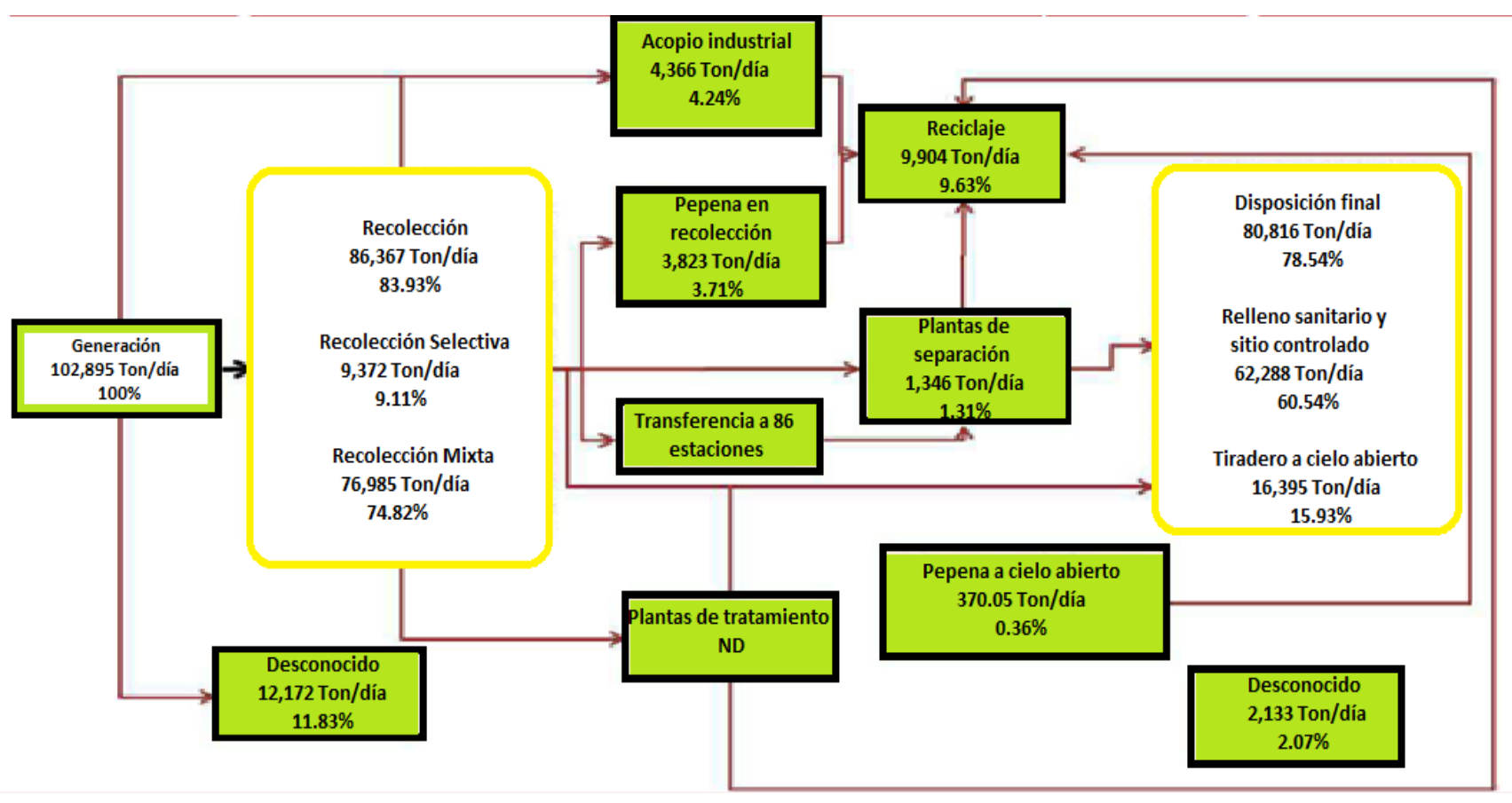

Fuente: Diagnóstico Básico, 2012.

Aunado a esto, como se mencionó anteriormente, la mayoría de los desechos que no se reciclan son $100 \%$ aprovechables, lo que incluso podría repercutir de manera positiva en la economía, ya que si se ocuparan estos residuos pa generar algún tipo de energía podría haber un ahorro en consumo de energía deribada del petroleo.

Dado que los factores que influyen en la generación de RSU son el incremento de la población urbana y los patrones de consumo que reflejan las actividades económicas, es importante destacar que la generación y el manejo que se hace de dichos residuos varía en las diferentes entidades. Es de particular interés para esta investigación, analizar el manejo de los RSU en la Ciudad de México, dado que es una de las entidades que genera la mayor cantidad de RSU a nivel nacional debido al número de habitantes, las actividad económica predominantes y los patrones de consumo de sus habitantes. En la Figura 1.3, se analiza la generación de RSU por entidad teniendo en cuenta su actividad económica y el tamaño de su población. Como se evidencia en ésta figura, las entidades con una mayor concentración poblacional y de actividades ecónomicas son las que un mayor volumen de RSU. De esta manera podemos observar de una manera más clara el patron que existe entre la generación de RSU, el número de habitantes y los hábitos de consumo en entidad. Podemos ver que las entidades que se encuentran con mayor población y son entidades económicamente activas, son las que mayor RSU generan a nivel nacional. 
Figura 1.3. Generación de RSU por entidad.

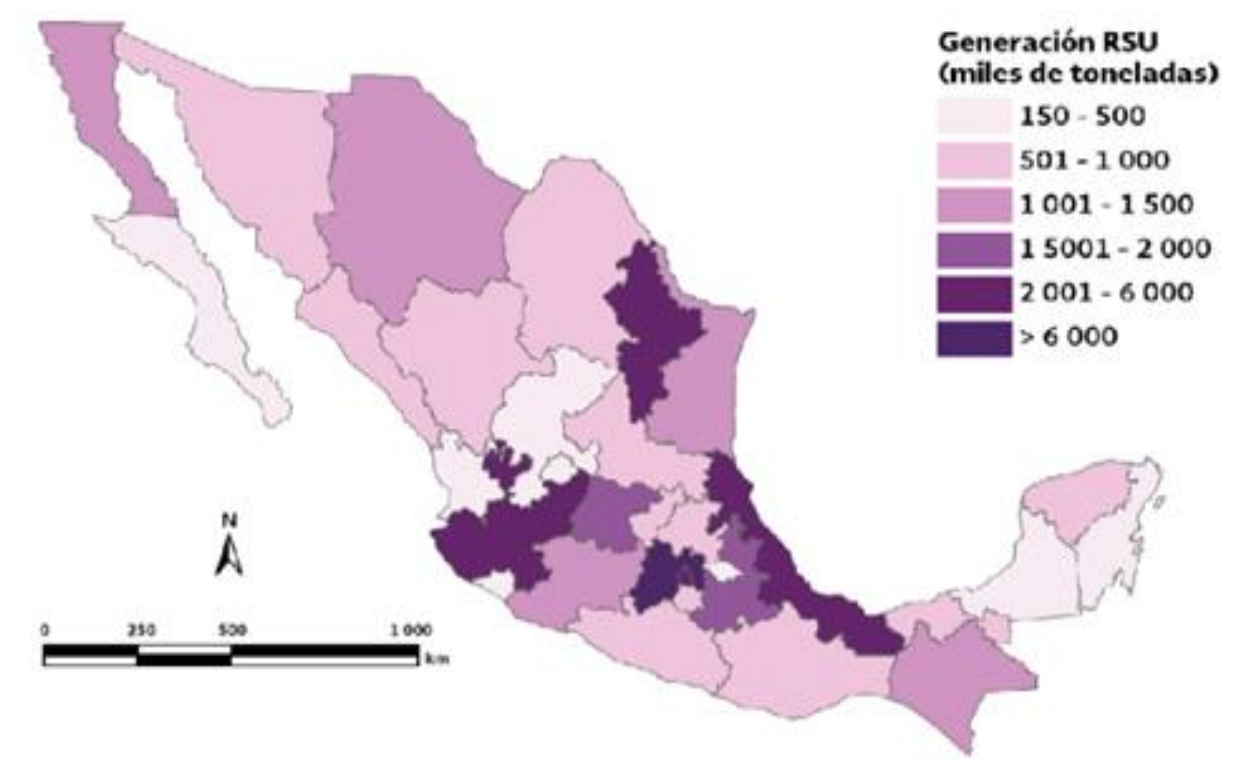

Fuente: SEMARNAT, 2012

Para el año 2011, en menos de 1\% del territorio nacional se generaron alrededor de 6 mil toneladas diarias de RSU, siendo un gran reto para las autoridades de esta entidad gestionar adecuadamente estos residuos. Si se analiza la contribución relativa de las entidades al PIB, puede deducirse que existe una relación lineal positiva con su participación en la generación nacional de RSU (Figura $1.4)$.

En la Figura 1.4, podemos observar que los estados que estan por encima de la línea estan produciendo más RSU en comparación con su contribución al PIB nacional, tal es el caso de el Estado de México y Jalisco . En el caso de Nuevo León y la CDMX, estos contribuyen más a la generación del PIB en comparación con su generación de RSU.

Figura 1.4. Contribución al PIB y la generación de RSU por entidad federativa para el año 2011

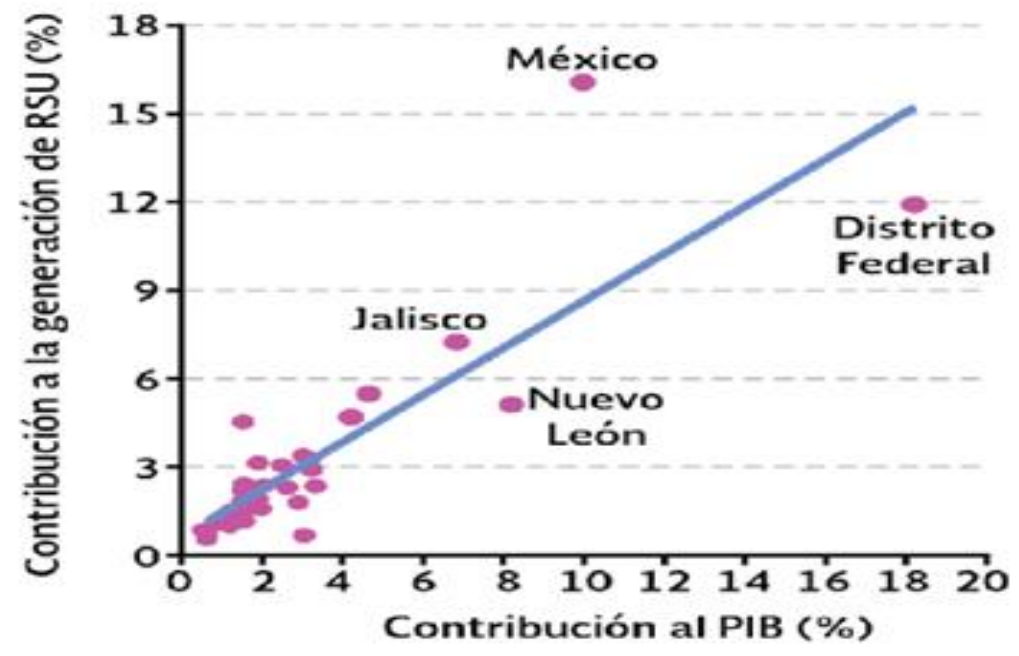


Fuentes: INEGI, 2013.

Tomando en cuenta lo anterior y poniendo en contexto a México en un panorama mundial, podemos darnos cuenta que la situación no es muy alentadora, ya que la economía mexicana, no es precisamente la más activa entre los países de la OCDE, lo que implica que probablemente estamos desarrollando una mala GIRS, para lo cual esta investigación pretende encontrar las fortalezas y debilidades en la etapas del manejo de RSU para poder ser una herramienta de apoyo a los tomadores de decisiones y asi poder mejorar dicho manejo. La grafica 1.4, muestra la postura que México tiene ante los paises de la OCDE.

A pesar de ser un país en desarrollo, Méxicio está casi al promedio de la generación per capita de RSU por día. El gran problema es que el manejo de los residuos sólidos no parece ser tan eficiente ya que son muy escasos los lugares de México en donde se aprovechen este tipo de residuos, al nivel que se hace en los países desarrollados.

Es importante considerar que los datos emitidos por esta gráfica son del año 2012, En información reciente, se puedrá ver más adelante que China ha triplicado su generación de RSU por habitante por día, a un valor de alrededor del $4 \mathrm{Kg} / \mathrm{hab} /$ día. Estos datos son alarmantes ya que estamso hablando de uno de los países más pobledos del mundo. México, por el contrario, ha mantenido la generación de sus RSU por habitante a una catidad menor al kilo y medio por habitante por día, sin embargo se debe considerar que su población ha aumentado, lo que ha traido como consecuencia el aumento de RSU de manera neta. 
Gráfica1.4 Generación de RSU per cápita en países de la OCDE, 2010

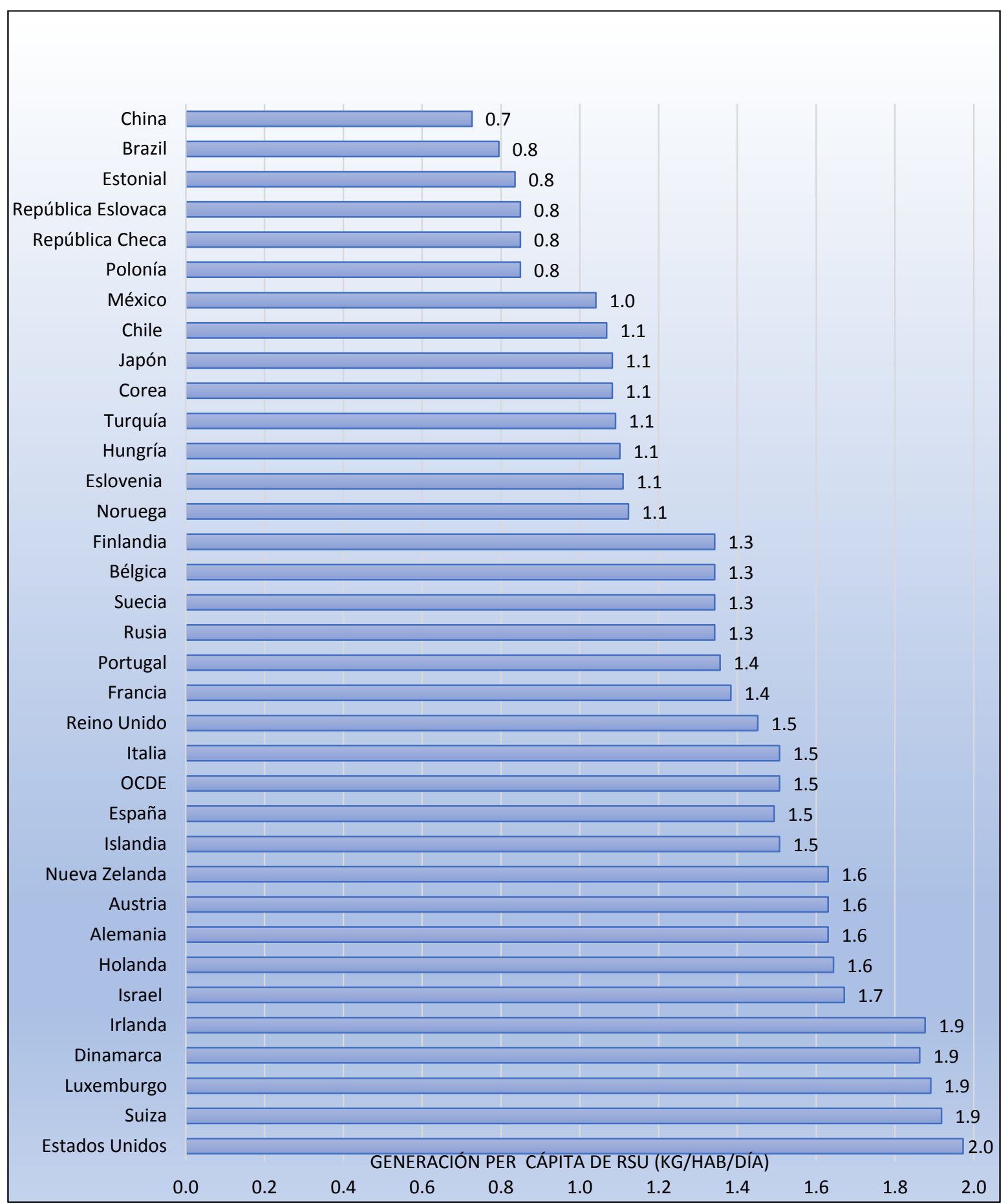

Fuente: Elaboración propia con datos de SEMARNAT, 2012 


\subsection{El manejo de los residuos sólidos en México}

Como se ha mencionado anteriormente en esta investigación está enfocada a evaluar la eficacia del manejo de los residuos sólidos en la CDMX, pero es importante tener una noción clara de lo que se realiza de manera general a lo largo del país. Es bien sabido que el manejo de los RSU en todas las naciones ha sido, es, y será un desafío interminable, especialmente en las zonas urbanizadas de las naciones. El Manejo de RSU en todas sus etapas constituye un reto para cualquier país y se encuentra entre las cinco principales problemáticas que los gobiernos locales enfrentan. (ONU-HÁBITAT, 2010), pero a pesar de ello este tema parece quedarse en el olvido para muchos gobiernos locales, aunque esto implique el consumo de una importante porción de su presupuesto.

Como se mencionó anteriormente, en esta investigación se ha considerado que el manejo de RSU se lleva a cabo a través de cinco fases. El proceso de manejo comienza con la generación de los RSU, los cuales, a su vez involucran el resto de las fases: recolección, manipulación, procesamiento y transformación, y disposición final. En México el $92.87 \%$ de los municipios que ofrecen estos servicios, sólo el $6.02 \%$ ofrece algún tipo de tratamiento o transformación para los RSU (Jiménez, 2015), razón por la cual el manejo de RSU en México no parece ser integral. Sin embargo, se ha observado que esta es una característica no sólo de México sino de muchas naciones en vías de desarrollo debido a las características propias de los residuos y la poca infraestructura disponible para llevar a cabo un manejo de RSU integral, como lo son plantas de tratamiento, reciclaje, composta o plantas que generen energía a partir de los RSU (Jiménez, 2015).

En general el porcentaje de cobertura de recolección es un indicador que es alto en promedio para las zonas urbanas alto, para México este porcentaje se ubicó en el año 2010 en un 83.85\% y para el 2012 se colocó en un $93.41 \%$ ya que se relacionó directamente con los RSU generados (INEGI, 2010: Jiménez, 2015). Al parecer este porcentaje varía según la zona geográfica (ONU-HÁBITAT, 2010). Estados como Colima, Quintana Roo, Aguascalientes, Chihuahua, Nayarit, CDMX, muestran una cobertura de recolección del 100\%, lo contrario que pasa en Baja California Sur, Guerrero, Puebla mantienen un porcentaje de cobertura de recolección de sólo un 50\%. La parte Noreste también reporta buena cobertura (94.47\%) gracias a la cooperación de los estados fronterizos a través de la Comisión de Cooperación Ecológica Fronteriza y del Banco de Desarrollo de América, ya que han otorgado importantes financiamientos destinados a incrementar la infraestructura y aunado a esto la iniciativa privada también juega un papel importante. (Jiménez, 2015: Couto y Hernández, 2012).

Otra parte, lo que se refiere a manipulación, procesamiento y transformación de los residuos, México, como muchos países en el mundo, no ha podido superar la visión de recolectar, trasferir o trasportar y disponer. Es decir, en lo que se refiere a estas dos etapas casi pasan desapercibidas por los gobiernos locales y por la población en general. En México, del total de RSU recolectados el $89.15 \%$ se recolecta sin separar y sólo el 10.85\% únicamente se recolecta separado (INEGI, 2012). Pero lo más grave quizá es que el poco reciclaje que se da en México, se da desde el sector informal lo que se llama comúnmente en el territorio nacional como pepena. Esta informalidad hace imposible conocer datos exactos de lo que realmente se recicla y la composición de lo que se recicla, pero ha habido estimaciones hace algunos años. 


\section{Gráfica 1.4. Materiales recolectados}

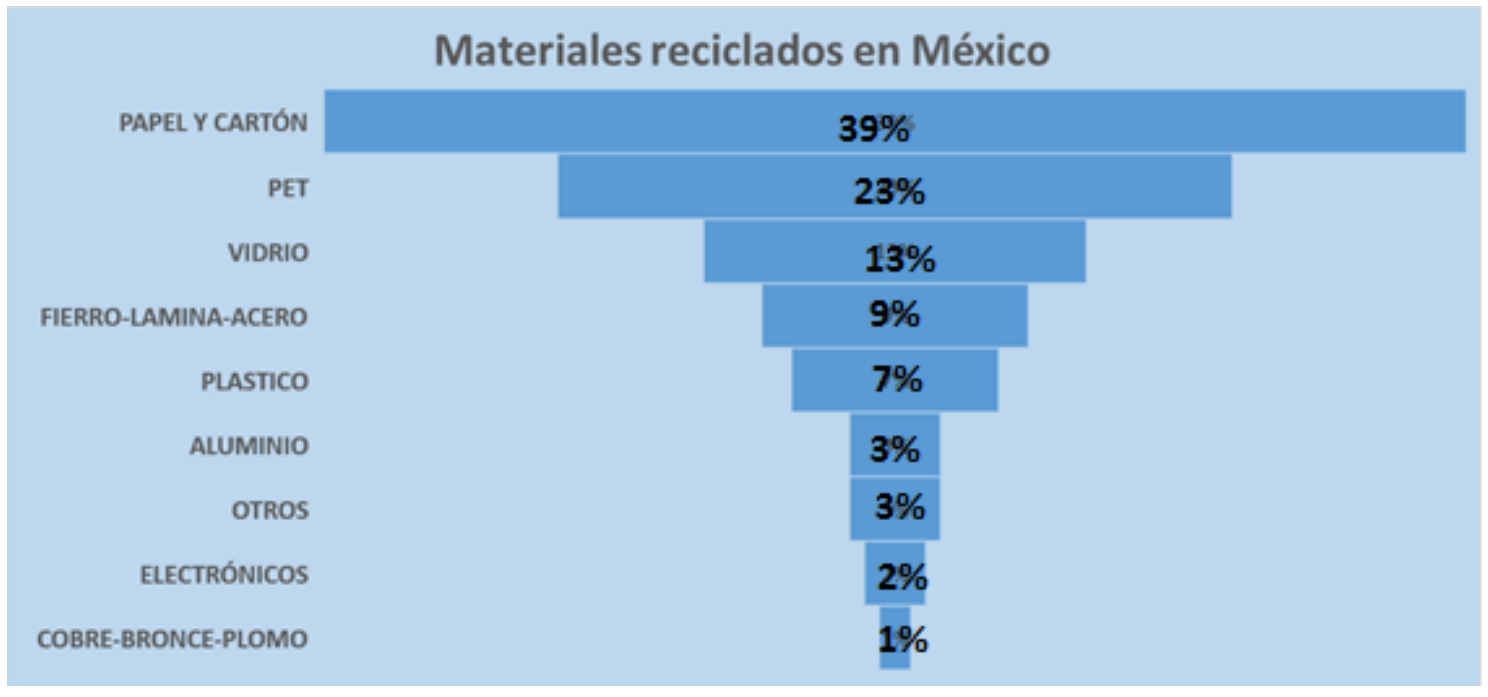

Fuente: elaboración propia con datos del INEGI, 2010

Como se puede ver en la Gráfica 1.4, el material que se considera valorizable y es recuperado en mayor cantidad es el papel y cartón con un 39\% del total de los materiales recuperados, la cantidad de cartón y papel es abundante debido a las grandes cantidades de productos que se consumen y tienen embalaje los cuales desechamos sin ningún problema. En cuanto al cobre, bronce y plomo, tanto la disponibilidad como la recuperación es mínima, esto puede deberse también al costo de los metales ya que como es elevado se tiende a conservar por más tiempo todo este tipo de materiales.

En lo que a disposición final se refiere, en México el 77\% de los municipios cuentan con sitios para la disposición final de sus RSU generados, de estos el 13\% son rellenos y el $87 \%$ restante corresponde a tiraderos a cielo abierto (INEGI, 2012: Jiménez, 2015). Por otro lado, la cantidad del total de residuos recolectados, sólo el $65 \%$ fue a parar a un sitio de disposición final un $22 \%$ se depositó en tiraderos a cielo abierto, mientras que un $8 \%$ se dispone en rellenos de tierra controlados, y el restante $5 \%$ es lo que se recicla (Jiménez, 2015). Es importante resaltar que se encontraron discrepancias entre los datos emitidos por un documento y otro, en este caso los datos emitidos por INEGI, tienen algunas diferencias con los datos emitidos por el Diagnóstico Básico de RSU, 2012.

Uno de los objetivos del manejo integral de RSU es llevar la menor cantidad posible de RSU generados a sitios de disposición final y aprovechar en la manera de lo posible y mientras siga siendo viable la mayor cantidad los residuos generados. Es decir, si se generan 12,000 toneladas de residuos al día (como es el caso de la CDMX), entonces tratar de aprovechar el 100\% de estas toneladas, evitando que lleguen en su totalidad a sitios de disposición final, además de que el aprovechamiento de estos residuos debe ser viables, económica, social y ambientalmente. En la realidad y como las propias cifras lo demuestran, esto no se esto no llevando a cabo en ninguna de sus formas.

Es muy importante atender la raíz de los problemas, en vez de sólo tratar de dar solución a las problemáticas que se generan de un problema de manejo integral de RSU, es por eso que debemos poner especial atención a las entidades que más generan RSU, entre estas entidades se encuentra la Ciudad de México. Por este motivo el siguiente apartado se enfoca en la generación de RSU a nivel de la Ciudad de México. 


\subsection{Los residuos sólidos en la CDMX}

De acuerdo con lo que se ha manejado en esta investigación, la Ciudad de México, con una superficie de $1,485 \mathrm{~km}^{2}$, donde residen alrededor de 8.8 millones de habitantes en 16 demarcaciones territoriales, como en cualquier ciudad del mundo, el desarrollo económico de la sociedad, las actividades industriales, la actividades comerciales y de servicios, además del crecimiento poblacional ha implicado un aumento en la generación de RSU, en el caso particular de la CDMX se generan cerca de 12,893 toneladas diarias de residuos sólidos urbanos producidos por 8,851,080 habitantes de población fija, así como por la población flotante que proviene de la Zona Metropolitana del Valle de México que ingresa diariamente a la ciudad. La generación promedio por habitante es de 1.31 kilogramos por día presentando una variación de 0.89 y 2.48 entre delegaciones. Estamos hablando de que en las demarcaciones de Cuauhtémoc donde cada habitante genera un estimado de 2.49 kilogramos al día, seguida de Miguel Hidalgo y Venustiano Carranza con 2.16 y 1.98 kilogramos de residuos generados diariamente. (Inventario de RSU, 2014). Se sabe que hay factores que están directamente relacionados con estos números, los cuales son: el crecimiento y desarrollo de servicios, comercios e industria, nivel de urbanización, aumento en los niveles de consumo en esas demarcaciones. Aunado a esto, las delegaciones con mayor generación total de RSU son: Iztapalapa con 2,256 toneladas, Gustavo A. Madero con 1,702 toneladas y Cuauhtémoc con 1,320 toneladas al día. La generación de RSU de estas tres demarcaciones representan $41.18 \%$ de la generación total de esta entidad, lo cual se atribuye a la población y las actividades económicas que es estas localidades se realizan, como anteriormente se mencionó (Figura 1.5).

Figura 1.5. Generación de RSU y número de habitantes en cada delegación.

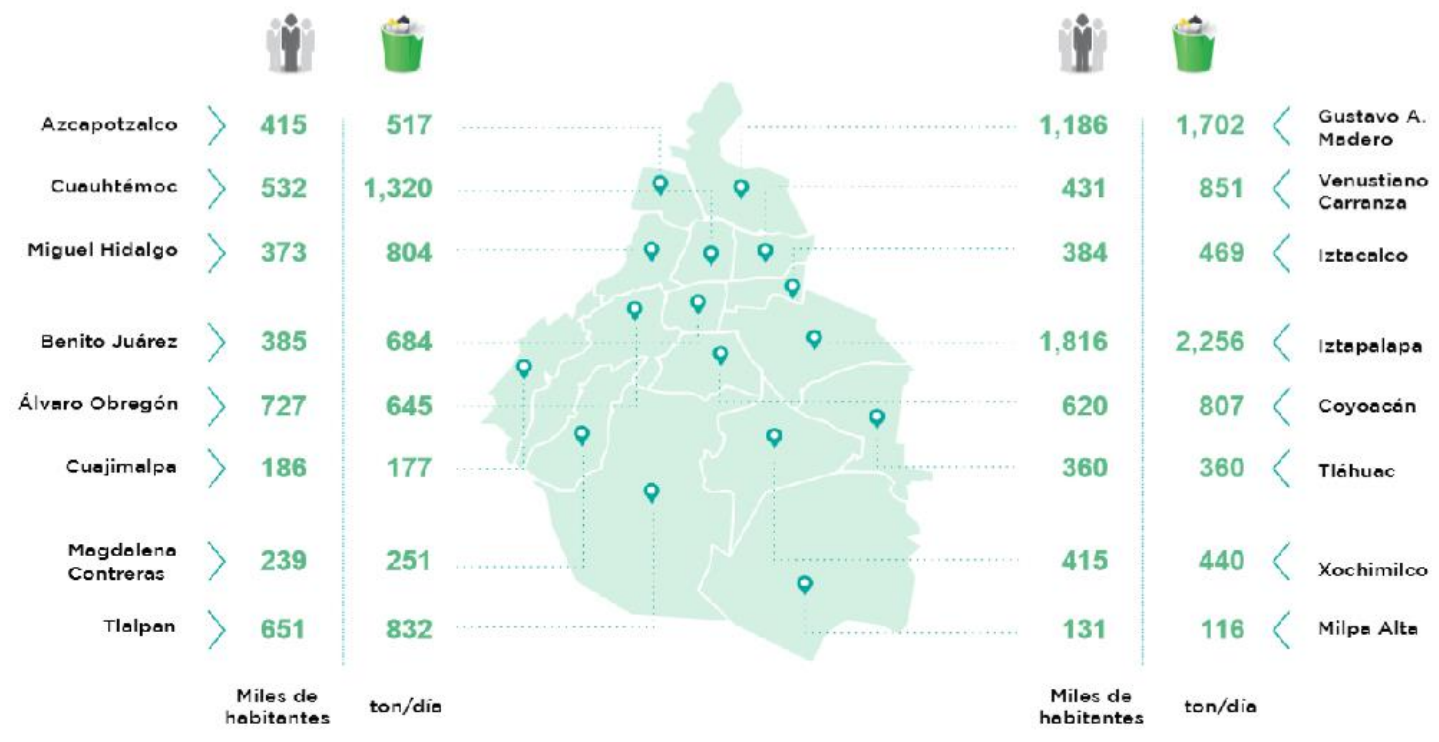

Fuente. Inventario de RSU, 2013

En el caso particular de la delegación Miguel Hidalgo y Cuauhtémoc, existe una discrepancia entre el patrón que las demás demarcaciones plantean. Es decir, el número de habitantes no es tan alto como para generar la cantidad de RSU que produce. La Figura 1.6 muestra la generación de RSU por 
habitante en cada entidad, lo que nos da pauta a suponer o reflexionar que también los patrones de consumo influyen de manera directa en el aumento de generación de RSU tal como es el caso de la delegación Miguel Hidalgo y Cuauhtémoc.

Figura 1.6. Generación de RSU en kg por habitante.

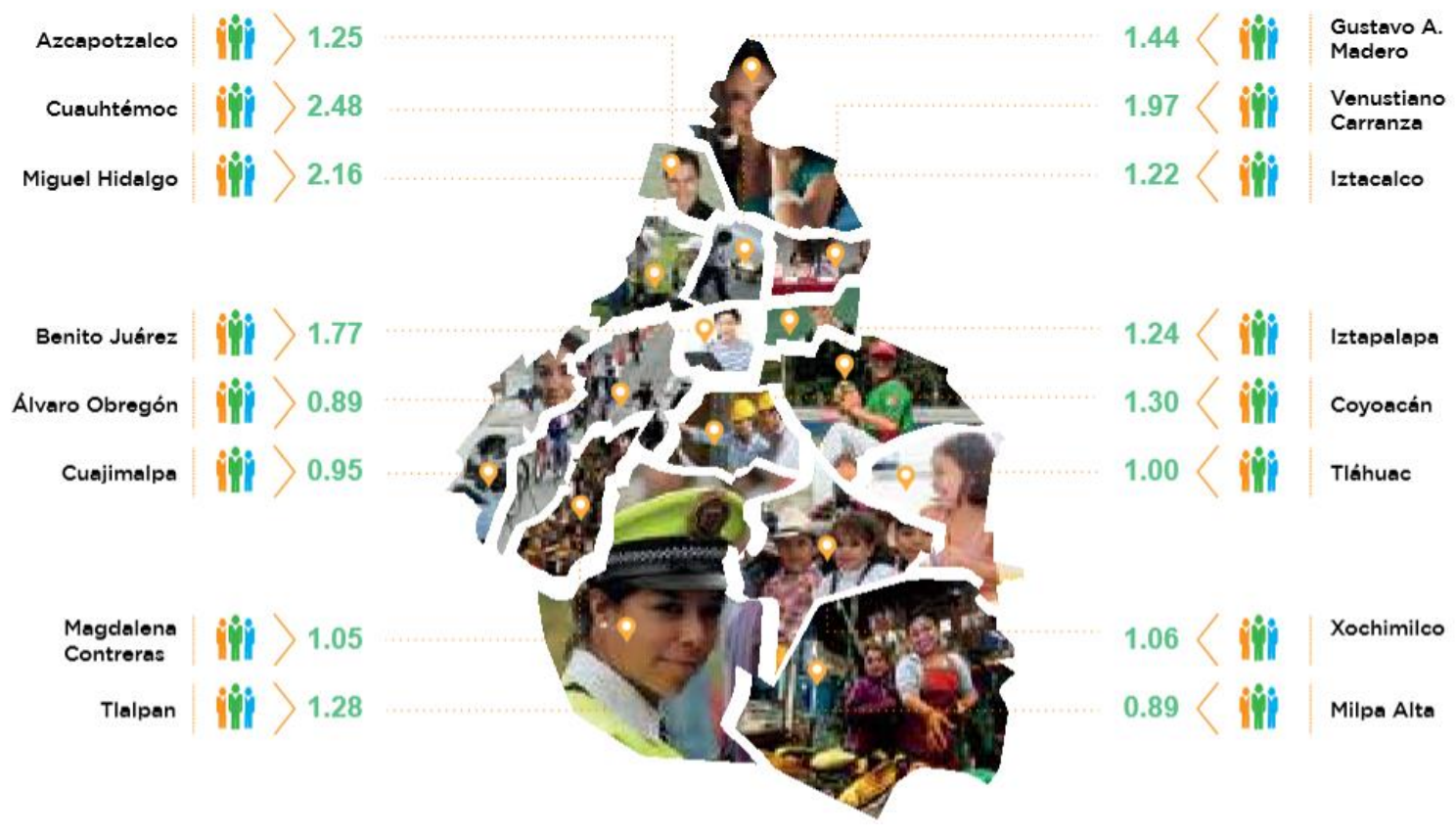

De estos residuos generados es muy importante conocer la fuente de la que provienen, ya que piedra angular para el desarrollo de estrategias que ayuden a minimizar y controlar este incremento. La Figura 1.7 muestra la fuente de la que provienen la mayor parte de los RSU generados en la CDMX provienen de los domicilios, lo que una vez más pone en evidencia los patrones de consumo de los capitalinos.

Figura 1.7. Generación de RSU por fuente. 


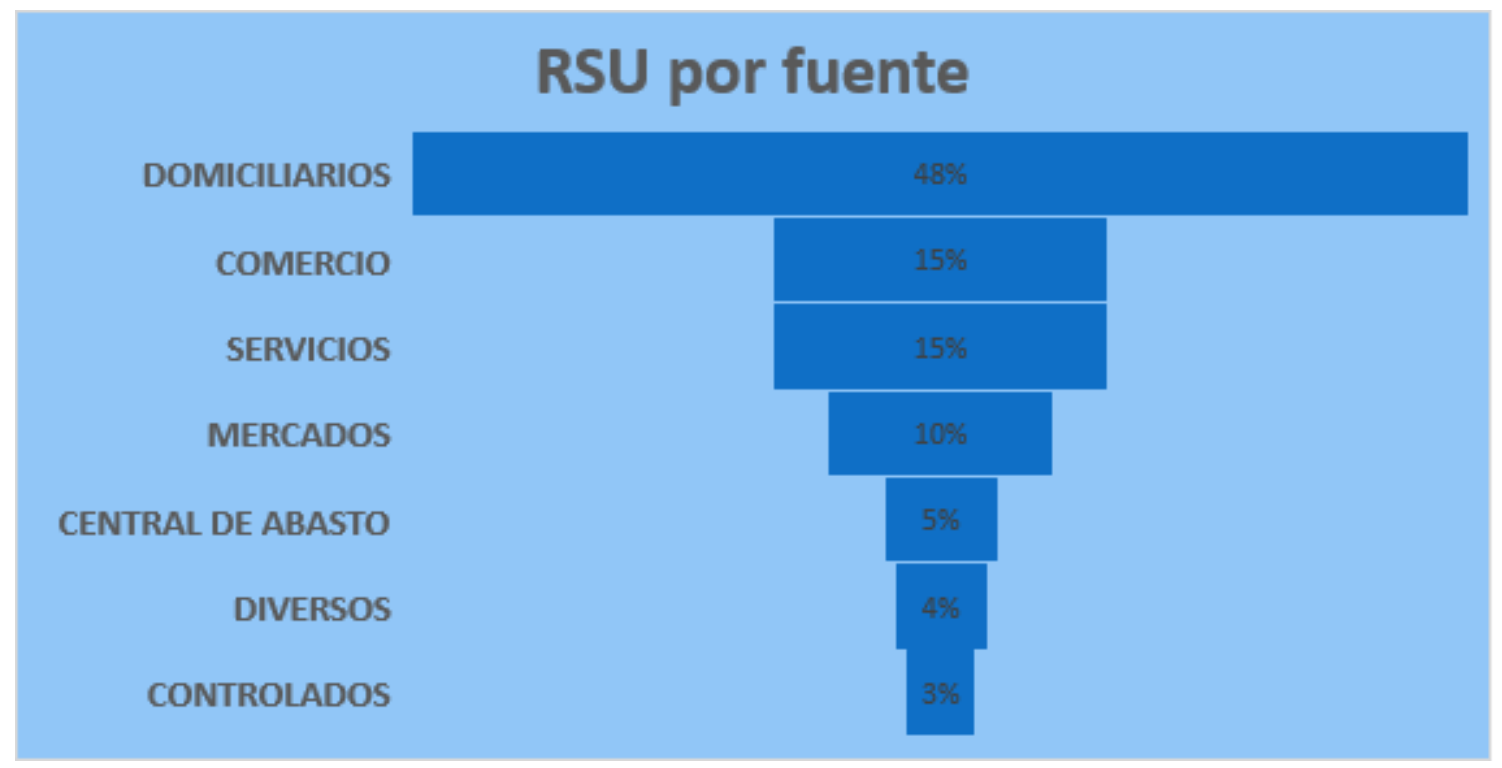

Fuente. Elaboración propia con datos del Inventario de RSU, 2014

Dentro de los parámetros que deben considerarse para lograr un manejo integral de residuos sólidos se encuentran la estrategia de separación de los mismos en varias clasificaciones, de la misma manera es muy importante conocer las fuentes generadoras de dichos residuos ya que esto dará pauta priorizar o saber que es lo más urgente de atender. Cómo lo muestra la Figura 1.7, del total de residuos sólidos generados en la ciudad de México se estima que $48 \%$ corresponde a residuos domiciliarios, seguido de $15 \%$ que generan comercios y servicios de manera independiente, $22 \%$ de los residuos restantes son generados por mercados, Central de Abasto, diversos y controlados, estos dos últimos corresponden a residuos provenientes de reclusorios, hospitales y en general de manejo especial.

El gobierno de la CDMX ha emprendido una fuerte campañas para tratar de reducir el consumo en los capitalinos, pero parce que los esfuerzos no han sido suficientes, por eso es necesario implementar nuevas políticas públicas que ayuden a dar solución al problema de raíz. Es importante aprender estrategias no solo de la literatura, sino también reconocer los países que hacen una excelente GIRS y aprender de ellos. Para ello la siguiente sección nos ayudará a hacer un análisis de lo que se hace en países con un gran éxito con la GIRS. 


\section{Capítulo II}

\section{Gestión Integral de Residuos Sólidos Urbanos GIRS}

La gestión consiste en realizar una serie de actividades con tendencias administrativas con la finalidad de alcanzar una meta o un propósito en particular (Real Academia Española). Esta definición es relativamente sencilla de entender, pero ¿qué pasa cuando adicionamos el término integral? La Gestión Integral es un conjunto de actividades y mecanismos que se relacionan entre sí y que están enfocadas a un tema en particular. En este apartado se analiza a detalle lo que es la Gestión Integral de los Residuos Sólidos Urbanos (GIRS), con el fin de poder conocer cómo ha sido conceptualizada a lo largo del tiempo y por diversos autores de diferentes partes del mundo. Tener claro el concepto de GIRS, es de vital importancia para esta investigación, ya que así se puede visualizar fácilmente la diferencia entre gestión integral de residuos sólidos urbanos y manejo de residuos sólidos urbanos. Con esta información y teniendo claridad en la diferencia entre ambos conceptos se podrán analizar posteriormente casos de éxito y fracaso de algunos países a lo largo del globo, con la finalidad de identificar lecciones aprendidas para lograr una mejora en el manejo de residuos sólidos urbanos bajo el enfoque de GIRS que se puedan implementar en la Ciudad de México.

\subsection{Definición y conceptos de Gestión Integral de Residuos Sólidos Urbanos (GIRS)}

Tchobanouglus et al. (1994) define la GIRS como la selección y aplicación de técnicas, tecnologías y programas de gestión idóneos para lograr metas y objetivos específicos de manejo de residuos, donde se gestiona su reducción, reutilización, reciclado, transformación y vertido; también considera la administración de elementos funcionales como su generación, manipulación, recolección, separación, procesamiento y transformación, transferencia, transporte, vertido y recuperación de suelo post-clausura del vertedero. Complementando esta definición, GTZ-COMIA (2003) incorpora otros elementos relevantes de la GIRS como acciones normativas, operativas y financieras que una administración municipal basadas en criterios sanitarios ambientales y económicos para recolectar tratar recolectar y depositar los residuos sólidos de una ciudad. En el caso de México, el marco jurídico normativo también considera como parte de la gestión la realización de monitoreos, supervisión y evaluación, para el manejo de residuos, desde su generación hasta la disposición final, a fin de lograr beneficios ambientales (Ley General para la Prevención y Gestión Integral de los Residuos, 2014). Otras definiciones hacen énfasis en la sustentabilidad, definiéndose GIRS como un sistema orientado al mercado flexible y capaz de manejar todos los tipos de residuos sólidos, comprende una serie de acciones que, en su conjunto, establecen un sistema ad hoc para cada localidad, donde el objetivo es la maximización del aprovechamiento de los recursos y la prevención y reducción de los impactos adversos al ambiente que pudieran derivar de un mal manejo. Todo esto considerando que las acciones a utilizar sean técnica y económicamente viables, ambientalmente sustentables y socialmente aceptables, es decir bajo un esquema de sustentabilidad. Lo anterior, con el fin de lograr un manejo sustentable de los residuos, por medio de la reducción de gases efecto 
invernadero, disminución de tasas de residuos que llegan a rellenos sanitarios y maximización del aprovechamiento de los recursos (Cortinas Nava, 2004).

Bajo este contexto, en esta investigación en particular se plantea la siguiente definición: GIRS es el conjunto de atributos orientados a la aplicación de técnicas, o tecnologías en pro de un manejo integral de los residuos y que además de técnicas, tecnologías, educación e investigación, también conlleva actividades administrativas como acciones normativas y jurídicas, financieras, de programas y de planeación, así como de supervisión, evaluación y monitoreo. Todos estos atributos se han de basar y modificar respecto a las fases que implican el manejo integral de los residuos. El manejo de los residuos en sus diferentes etapas que van desde la generación, recolección, manipulación, procesamiento y transformación de los residuos hasta su disposición final. Por esta razón el manejo de los residuos sólidos debe ser considerado cómo el componente medular de la GIRS, y de donde los demás atributos se irán adaptando y modificando (Figura 2.1). En la Figura 2.1 se detalla la definición de GIRS, desde la perspectiva de esta investigación.

Figura 2.1. Definición de GIRS

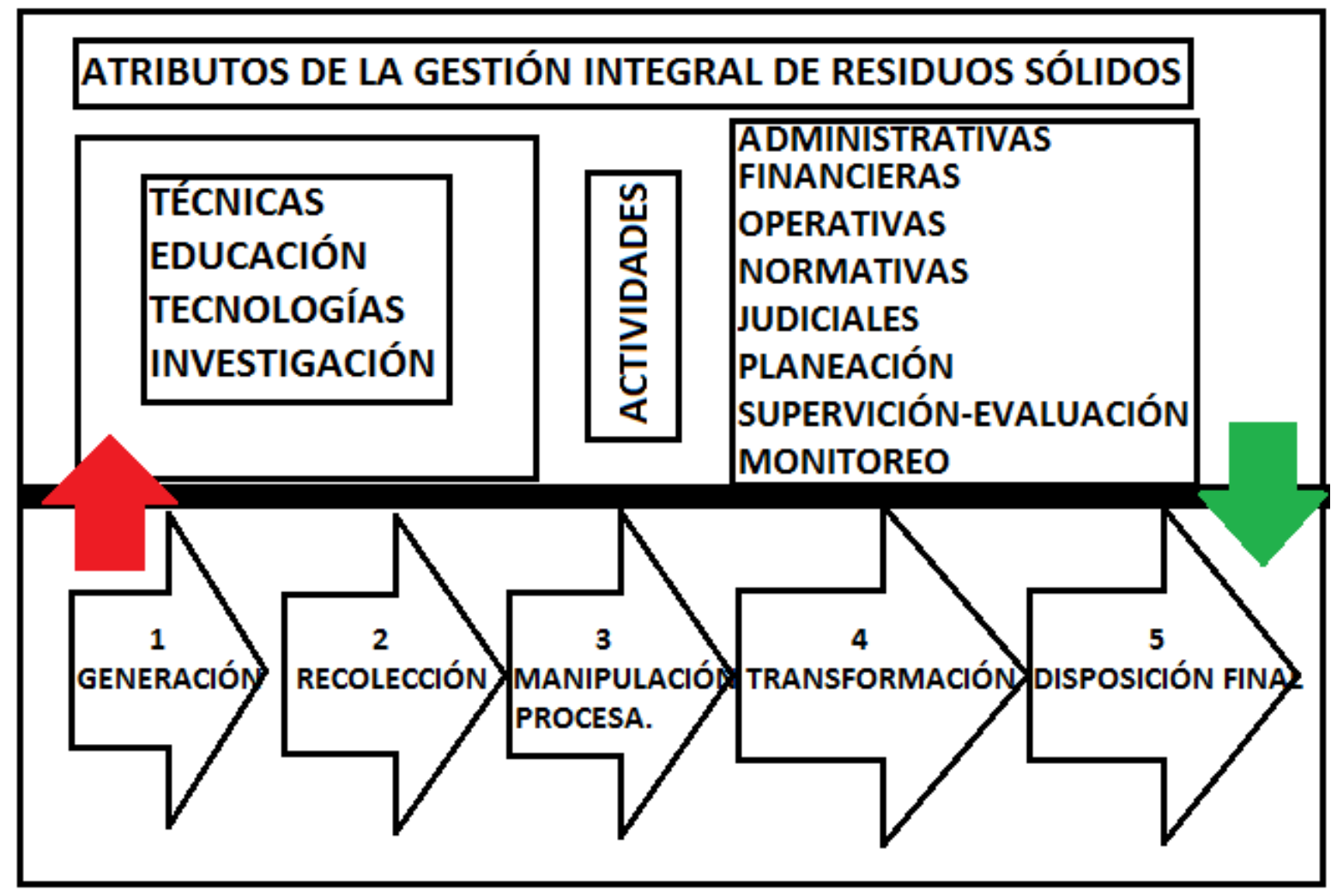

Fuente: Elaboración propia con base en: Tchobanouglus et al. (1994); GTZ-COMIA (2003); Ley General para la Prevención y Gestión Integral de los Residuos (2014); Cortinas Nava., C, (2004)

Es importante hacer un énfasis, en que las fases que se consideran en la definición particular que se generó en esta investigación, son consideradas también por la Ley General para la Prevención y Gestión Integral de los Residuos, sólo que bajo distintos nombres. Es de importancia aclarar este 
punto, ya que esta investigación está dirigida especialmente a los tomadores de decisiones, motivo por el cual vale la pena hacer una equivalencia entre los distintos nombres que se la da a las fases, ya que los tomadores de decisiones se encuentran más familiarizados con los conceptos que la Ley marca en México. Para ello es importante definir el manejo integral según la Ley: El Manejo Integral son las actividades de reducción en la fuente, separación, reutilización, reciclaje, co-procesamiento, tratamiento biológico, químico, físico o térmico, acopio, almacenamiento, transporte y disposición final de residuos, individualmente realizadas o combinadas de manera apropiada, para adaptarse a las condiciones y necesidades de cada lugar, cumpliendo objetivos de valorización, eficiencia sanitaria, ambiental, tecnológica, económica y social (LGPGIR, 2014).

A partir de esta definición que la Ley estipula, se identificaron las fases y se buscaron las equivalentes con las fases del manejo de los residuos que se generaron en esta investigación, donde:

- Reducción en la fuente $=$ Generación

- Acopio, almacenamiento, transporte= Recolección

- Separación, reutilización, reciclaje, co-procesamiento= Manipulación y/o Procesamiento

- Tratamiento biológico, químico, físico o térmico = Transformación

- Disposición final de residuos= Disposición Final

A manera de analizar sistemáticamente la definición en la Tabla 2.1 a partir de las diversas definiciones de GIRS se identifican los atributos y características que definen diversos autores como centrales en estos conceptos como resultado de una revisión del estado del arte de la manera en se conceptualiza la GIRS. En las diversas definiciones identificadas la investigación y educación no fueron incluidas como parte de los atributos o características de la GIRS, lo cual representa una importante limitación, dado que ambas constituyen herramientas fundamentales para el desarrollo de una adecuada GIRS. Por otro lado, las definiciones de GIRS consideran el manejo de los RSU en todas sus etapas, dando así por hecho que la parte fundamental de la GIRS está en el buen manejo de los residuos. 
Tabla 2.1. Sistematización de la definición de GIRS

\begin{tabular}{|c|c|c|c|c|}
\hline $\mathrm{P}_{\text {Atributos }}^{\text {Autores }}$ & $\begin{array}{l}\text { Tchobanouglus } \\
\text { et al. (1994) }\end{array}$ & $\begin{array}{l}\text { GTZ- } \\
\text { COMIA } \\
(2003) \\
\end{array}$ & $\begin{array}{l}\text { LGPGIR } \\
2014\end{array}$ & $\begin{array}{l}\text { (Cortinas } \\
\text { 2004) }\end{array}$ \\
\hline \multicolumn{5}{|l|}{$\begin{array}{l}\text { Técnicas } \\
\text { y tecnologías }\end{array}$} \\
\hline \multicolumn{5}{|l|}{ Reuso } \\
\hline \multicolumn{5}{|l|}{ Reciclado } \\
\hline \multicolumn{5}{|l|}{ Reutilización } \\
\hline \multicolumn{5}{|l|}{ Generación } \\
\hline \multicolumn{5}{|l|}{ Recolección } \\
\hline \multicolumn{5}{|l|}{ Manipulación } \\
\hline \multicolumn{5}{|l|}{ Transformación } \\
\hline \multicolumn{5}{|l|}{ Vertido final } \\
\hline \multicolumn{5}{|l|}{ Transferencia } \\
\hline \multicolumn{5}{|l|}{ Transporte } \\
\hline \multicolumn{5}{|l|}{ Vertederos } \\
\hline \multicolumn{5}{|l|}{$\begin{array}{l}\text { Recuperación de } \\
\text { Suelos de vertederos }\end{array}$} \\
\hline \multicolumn{5}{|l|}{ Acciones normativas } \\
\hline \multicolumn{5}{|l|}{ Acciones operativas } \\
\hline \multicolumn{5}{|l|}{$\begin{array}{l}\text { Acciones } \\
\text { Financieras }\end{array}$} \\
\hline \multicolumn{5}{|l|}{ Criterios sanitarios } \\
\hline \multicolumn{5}{|l|}{ Criterios ambientales } \\
\hline \multicolumn{5}{|l|}{ Criterios económicos } \\
\hline \multicolumn{5}{|l|}{ Criterios sociales } \\
\hline \multicolumn{5}{|l|}{ Localidad y región } \\
\hline \multicolumn{5}{|l|}{ Supervisión } \\
\hline \multicolumn{5}{|l|}{ Evaluación } \\
\hline \multicolumn{5}{|l|}{ Monitoreo } \\
\hline \multicolumn{5}{|l|}{$\begin{array}{l}\text { Disminución de gases efecto } \\
\text { invernadero }\end{array}$} \\
\hline \multicolumn{5}{|l|}{ Sostenibilidad ambiental } \\
\hline \multicolumn{5}{|l|}{ Programas de manejo } \\
\hline \multicolumn{5}{|l|}{ Investigación } \\
\hline Educación & & & & \\
\hline
\end{tabular}

Fuente: Elaboración propia con base en Tchobanouglus et al. (1994); GTZ-COMIA (2003); Ley general para la prevención y gestión integral de los residuos (2014), y Cortinas Nava (2004).

Es muy importante poner en contexto y recalcar nuevamente la importancia de la diferencia entre el manejo y la gestión ya que ambas cosas pudieran confundirse. Como lo vemos en la Tabla 2.1, la gestión tiene una gran cantidad de atributos que deben ser considerados para llamarse gestión integral, esto a su vez, complicaría una evaluación general de la GIRS. Sin embargo, todas las definiciones encontradas conllevan el manejo de los residuos, es decir la generación, la recolección, la manipulación y/o procesamiento, la transformación y la disposición final. Estas cinco fases son consideradas, por esta investigación, la medula espinal de la GIRS y son estas mismas fases las que se desean evaluar en un área y periodo determinado, que en este caso es la CDMX durante el periodo 2014-2015. Se hará la evaluación del manejo de los residuos, ya que, sabiendo las debilidades de 
dicho manejo, se podrían modificar ciertas actividades que promuevan la mejora de la gestión en sí, estas actividades van desde las que contempla la Figura 2.1 por su lado derecho hasta las actividades que contempla la misma figura, pero por el lado izquierdo, pero todas en relación con el majo de RSU. Realizar la evaluación del manejo, facilitará a los tomadores de decisiones el saber en qué parte se debe poner más atención, al mismo tiempo saber las fortalezas con las que se cuentan.

El manejo debe ser comprendido y estudiado en cada una de sus fases, por lo que el siguiente apartado clarifica la definición del manejo y explica todas y cada una de las fases que éste conlleva.

\subsection{Manejo de los residuos sólidos urbanos y sus fases}

En esta sección, se describe qué es el manejo de RSU, sus fases, y en qué consiste cada una de ellas. La Figura 2.1 describe el parte central de la GIRS, la cual se basa en el manejo de los residuos. Este manejo es el conjunto de actividades relacionadas con la vida del residuo, desde la cuna hasta la tumba (Jiménez, 2015). Generalmente, el manejo de RSU es un proceso de cinco fases que van en el siguiente orden: (1) generación, (2) recolección, (3) manipulación y procesamiento, (4) transformación, y (5) disposición final. Todas y cada una de estas partes, deben cumplir con los objetivos fijados en la normatividad y programas de manejo, ya que de que se cumplan dichos objetivos dependerá la eficacia de una verdadera GIRS. Es importante reconocer, que mientras haya un manejo completo de los RSU, podrán ser valorizados dichos residuos, ya que de ello dependen ciertas actividades técnicas como la cuantificación y la caracterización de los RSU generados en ciertas regiones (Karak et al., 2012). En este sentido, conocer ambos datos (cantidad y composición) son herramientas fundamentales para desarrollar e implementar tecnologías adecuadas para un manejo eficaz de los mismos. Con esta información se puede, además, formular una visión para el manejo de los RSU que considere los factores propios de cada zona de trabajo, para asegurar la sustentabilidad de la gestión integral y garantizar el alcance de los beneficios esperados. Después, se debe establecer e implementar un programa de manejo para lograr objetivos propuestos por un enfoque de GIRS. Para la realización adecuada de esta actividad, es preciso conocer los elementos que la condicionan, lo cual nos permitirá darles un mejor destino; la clasificación de los RSU según su naturaleza y origen, las características que se derivan de sus propiedades, su composición, así como las etapas del ciclo de vida de estos. Las fases del manejo de RSU se muestran en la Figura 2.2 para una mejor visualización y se explican a continuación en el orden que aparece en la misma figura; esto es de vital importancia ya que así podremos entender cada fase y se podrán identificar objetivos en cada una de éstas, en relación con el marco jurídico en una sección posterior. 
Figura 2.2. Fases del manejo de RSU

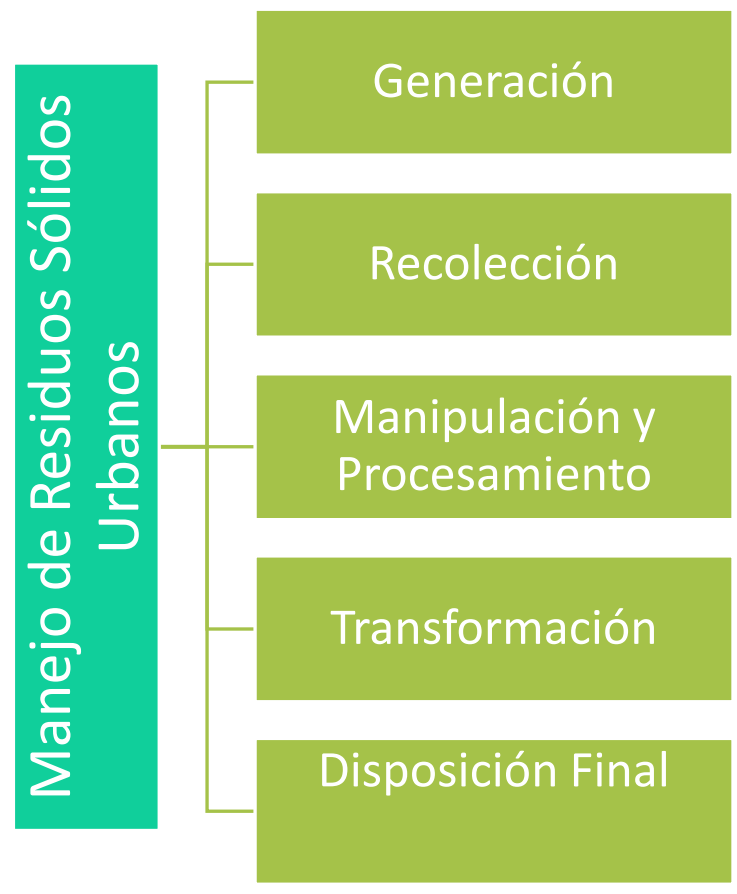

Fuente: Elaboración propia

\subsubsection{Fase 1. Generación de RSU}

La generación de residuos es una consecuencia directa de cualquier tipo de actividad desarrollada por el hombre; hoy en día nos encontramos en una sociedad de consumo que genera gran cantidad y variedad de residuos procedentes de una amplia gama de actividades. En los hogares, oficinas, mercados, industrias, hospitales y otro tipo de establecimientos, se producen una gran diversidad de residuos que es preciso recolectar, tratar y eliminar adecuadamente. Es muy importante esta etapa para el análisis, evaluación y mejora de la GIRS, ya que es aquí donde se deben generar datos que estén disponibles a todo público con la finalidad de usarlos como herramienta para el desarrollo de tecnologías, leyes, normas e instrumentos económicos para su manejo, de una manera general para su estudio. De acuerdo con la SEDESOL (2010), los residuos sólidos se pueden clasificar de acuerdo a su fuente de origen en:

- Domiciliarios

- Comerciales

- De sitios públicos

- Institucionales

- Hospitalarios

- Industriales

A su vez existe otra clasificación de acuerdo al manejo que debe darse a cada uno en:

- $\mathrm{RSU}$

- Residuos de manejo especial RME 
Los RSU comprenden aquellos generados en casas-habitación, comercios, mercados, instituciones, vías públicas, parques y jardines. Los residuos especiales son los generados en procesos industriales, servicios, hospitalarios y de laboratorios, actividades agrícolas y actividades de construcción y demolición, los cuales por sus características físicas, químicas y biológicas deben ser manejados, tratados y dispuestos utilizando métodos adecuados para evitar riesgos a la salud y a la ecología (SEDESOL, 2010). Es muy importante, tener claro que cada residuo generado, dependiendo de sus características y de su composición, deberá ser tratado. En México, como en muchos otros países de América Latina, los estudios realizados se enfocan en el análisis de la generación de RSU domésticos, al igual que los que se generan en comercios y mercados. En realidad, es difícil encontrar información o estudios que estudien la generación de residuos sólidos a nivel industrial (Gaggero y Ordóñez, 2010).

Existen diversos métodos para calcular o estimar la generación de RSU en México, el índice de generación per cápita se obtiene con base en la generación promedio de residuos sólidos por habitante, medido en $\mathrm{kg} / \mathrm{hab} / \mathrm{día}$, a partir de la información obtenida de un muestreo aleatorio en campo y en cada uno de los sectores socioeconómicos de la población (SEDESOL, 2010). Básicamente, el procedimiento se divide en dos partes; la primera consiste en el muestreo aleatorio en campo para posteriormente realizar la evaluación de los resultados que consiste en un análisis estadístico de los datos obtenidos en el muestreo, con el fin de verificar la confiabilidad del muestreo efectuado. El trabajo de campo o muestreo consiste en la toma diaria de muestras de los residuos generados en las casas-habitación seleccionadas, durante un periodo de siete días. El procedimiento para efectuar el estudio de la generación de residuos se encuentra descrito a detalle en la Norma NMX-AA-61-1985: Generación (Figura 2.3).

\section{Figura 2.3 Estimación de la generación de RSU}

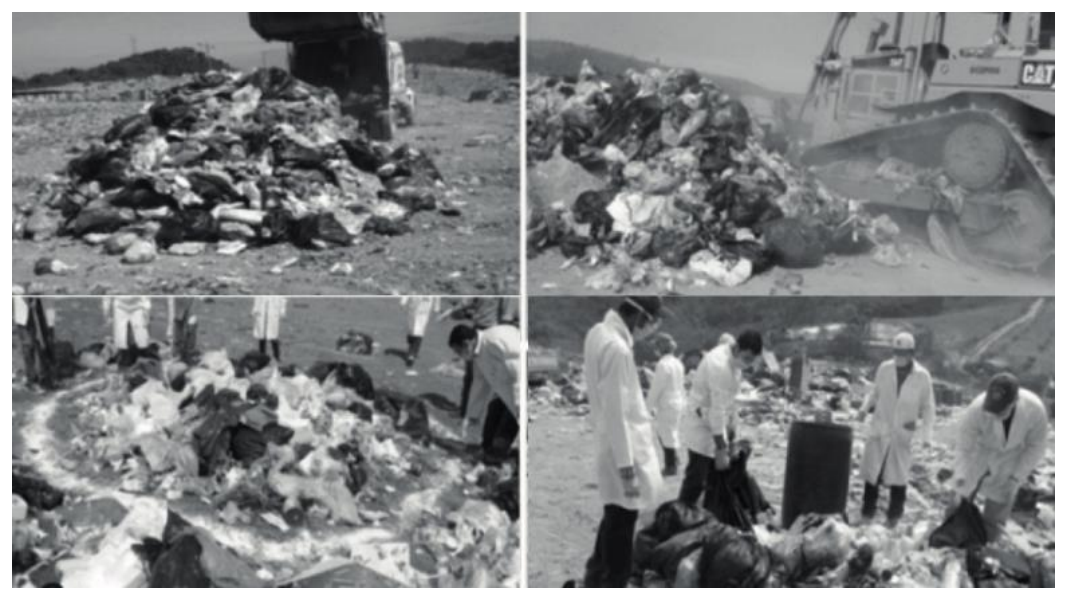

Fuente: Google Imágenes

El valor obtenido de los residuos sólidos generados se divide entre el número de habitantes de las casas habitación, para de este modo obtener un valor de producción per cápita de residuos en $\mathrm{kg} / \mathrm{hab} / \mathrm{d}$ áa, correspondientes al día en que fueron generados. Con los valores diarios se obtiene el promedio de la generación de residuos per cápita para cada una de las casas habitación incluidas en la premuestra. De acuerdo a lo anterior se obtiene una serie de " $n$ " valores promedio de generación de residuos per cápita, uno para cada casa habitación incluida en la premuestra. Con esta información se procede a realizar el análisis estadístico de los valores obtenidos para definir lo siguiente: 
- Rechazar o aceptar valores que resultan muy bajos o muy altos con respecto al total

- el tamaño de la premuestra

- la confiabilidad del muestreo

Es pertinente mencionar, que el manejo de RSU es parte fundamental y objeto de estudio para el desarrollo de una GIRS, que como se ha venido mencionando a lo largo de esta investigación, es un asunto de importancia nacional e internacional, en el ámbito ambiental y de salud. Es por eso que, así como es importante conocer la cantidad de RSU que se están generando, es de vital importancia conocer la composición de dichos residuos, y es sólo en esta fase, la fase de generación, donde es posible conocer una composición más precisa de los residuos generados. La generación de los residuos no es constante con respecto al tiempo y de la misma forma, la calidad de dichos residuos también va cambiando a lo largo del tiempo, tanto en calidad como en su composición físicoquímica y esto debido a los avances tecnológicos y desarrollo industrial que se va dando en cada zona de estudio. Por ejemplo, hace cincuenta años, no se generaba la misma cantidad de embalajes o empaques que se genera ahora y eso hace un cambio en la composición de los residuos generados. Por esa razón es importante conocer la generación y la composición de RSU, ya que es la única manera de enfrentar adecuadamente su manejo.

El conocimiento de "qué se produce" y "cómo se produce" permite no sólo conocer el desarrollo de las sociedades, sino también describir la relación existente entre el hombre y su entorno; sólo entendiendo esta relación, podríamos desarrollar grandes posibilidades para llevar acaba acciones que permitan el reúso y reciclaje de los residuos, mediante la selección y clasificación de los subproductos (SEDESOL, 2011). En general, conocer estos datos sobre la generación y composición, son el parteaguas para la aplicación de tecnologías adecuadas en su manejo; esto conlleva también a poder valorizar los residuos y dejar de conceptualizarlos como inservibles. A partir de estos datos, también se toman medidas para la separación de los subproductos que los residuos trae consigo y de esta actividad también depende la operación de pequeñas empresas dedicadas al reciclaje y transformación de nuevos productos. Como, por ejemplo, en el caso de los residuos alimenticios, a través de sencillos tratamientos se puede transformar en composta (fertilizante orgánico) o en alimento para animales, pero sólo será un fertilizante adecuado si se conoce la composición de lo que se está procesando. Las acciones por realizar en la etapa de generación de residuos sólidos difieren en cuanto a la fuente generadora. En nuestro país, son pocas las ciudades que se han preocupado por cuantificar los residuos sólidos domésticos y no domésticos que se generan, para con ello planear y programar las inversiones en el corto, mediano y largo plazo que permitan desarrollar un manejo adecuado de los residuos. De hecho, los estudios para determinar la generación de residuos están enfocados principalmente a los residuos domésticos, ya que las fuentes generadoras no domésticas presentan un vacío en cuanto a su clasificación y a los procedimientos aplicables para obtener parámetros o índices representativos. Por lo tanto, es necesario incrementar los estudios sobre generación de residuos sólidos, principalmente de las fuentes no domésticas, esto es, de comercios e industrias para enfrentar con mayor seguridad su manejo (SEDESOL, 2010). Conocer la composición de los residuos sólidos es importante ya que con ello se puede determinar la factibilidad de proyectos para la clasificación de subproductos, para su venta en centros de acopio, empresas recicladoras o industrias de tratamiento de RSU.

Cualquier material que adquiere la calidad de residuo pasa a formar parte de un proceso de operaciones secuenciales que conforman un sistema de manejo. Una vez que se generan los residuos pasa cierto tiempo antes de que sea recolectada, mientras esto sucede los residuos tienen que estar almacenados. El almacenamiento se entiende como la acción de retener temporalmente los residuos 
generados en se entregan al servicio de recolección y se procesan para su aprovechamiento (Mazzeo,2012). Debido a que los residuos que se generan no se pueden eliminar de inmediato, se requiere de un tiempo, un depósito y un lugar adecuados para mantenerlos mientras se espera que sean evacuados o retirados. Esta operación es responsabilidad exclusiva del generador del residuo por ello, es necesario que exista una reglamentación con respecto al objeto que tenga almacenado, para que esta tarea de haga de manera adecuada. El almacenamiento apropiado de los residuos tiene una influencia positiva en el manejo de los mismos y en el aseo urbano. Por el contrario, el almacenamiento inadecuado tiene varios efectos negativos en el servicio de recolección, debido principalmente a lo siguiente:

- Uso de recipientes de capacidad inadecuada (muy grandes o muy pequeños)

- Material de los recipientes inadecuado

- No se separan los componentes (residuos orgánicos e inorgánicos)

Lo anterior, propicia que aumente el tiempo de recolección, además de que puede ocasionar lesiones al personal del servicio de recolección y afectar la salud de la población al proliferar fauna nociva como insectos y roedores. En nuestra sociedad, el uso de recipientes inadecuados representa uno de los principales problemas en la forma de almacenar los residuos mientras éstos son recolectados. Por ejemplo, el uso de recipientes de gran capacidad, como los tambos de más de 200 litros, ocasionan problemas debido al gran peso el recipiente puede alcanzar una vez llenado, además de que se complica la descarga y como se mencionó anteriormente en muchas ocasiones las personas que trabajan dando el servicio de recolección pueden salir lastimadas. Otro tipo de recipientes, como las cajas de cartón y las bolsas de papel, resultan problemáticos debido a que los residuos que normalmente se desechan contienen una alta cantidad de residuos orgánicos, lo que origina que estos recipientes se humedezcan y se desbaraten con el manejo, esparciéndose los residuos; también son fácilmente accesibles para la fauna nociva, propiciando su proliferación. El uso de la bolsa de plástico también presenta algunos inconvenientes, ya que son perforadas fácilmente por materiales punzocortantes y además retardan la descomposición de los residuos contenidos en ellas una vez que son depositados en los rellenos sanitarios (SEDESOL, 2011). No todo el almacenamiento se da en la casa, en los sitios públicos se utilizan los recipientes conocidos como papeleras. Estos recipientes se colocan en calles, parques y otros sitios públicos, y se destinan a recibir aquellos residuos que son generados por el público asistente a esos lugares. Los residuos generalmente acumulados son restos alimenticios, envolturas, colillas de cigarros, envases, embalajes y envolturas. Por lo común, las papeleras son de construcción metálica, aunque el tamaño de estos recipientes no está completamente definido. La determinación exacta de la capacidad o tamaño de estos recipientes se efectúa por el método de "prueba y error" hasta encontrar el tamaño adecuado (aunque no es la única técnica para muchas zonas donde ya se ha estudiado y determinado con exactitud la capacidad de los contenedores). Esto es, se coloca un recipiente de capacidad conocida en el que se captarán los residuos generados por los transeúntes o visitantes de los sitios públicos. De este modo, y de acuerdo con la frecuencia de recolección, se observará si su capacidad es suficiente para almacenar los residuos generados. En caso de que el volumen del recipiente sea insuficiente, se colocará un recipiente de mayor capacidad, repitiéndose la operación hasta encontrar el recipiente adecuado (SEDESOL, 2011). Por lo regular, en los días en que hay una mayor afluencia de personas a esos lugares lo que se hace es reforzar las áreas de almacenamiento, ya sea colocando más recipientes o aumentando la frecuencia de recolección, esto en un caso ideal pero aún en la actualidad encontramos sitios públicos con deficientes instalaciones para el almacenamiento de sus residuos. 
También hay sitios donde se genera una gran cantidad de residuos y son conocidos como sitios o centros de gran generación, en los cuales diariamente se genera una gran cantidad de residuos sólidos, y deben ser almacenados en forma segura e higiénica mientras se recolectan. Estos centros por lo regular son grandes tiendas de autoservicio, terminales de transporte, mercados, industrias, o instituciones públicas y privadas. En estos lugares se realiza almacenamiento interno y externo. Para el almacenamiento externo se pueden utilizar contenedores de distinta capacidad como son los de 1.5 $\mathrm{m}^{3}$ o de gran capacidad como los contenedores de $8 \mathrm{~m}^{3}$ o más, para cuyo manejo se utilizan los vehículos especiales (SEDESOL, 2010).

Existen diversos tipos de recipiente para almacenar los RSU generados, es muy importante esta etapa que se da entre la generación y la recolección; sin embargo, es una actividad a la que no se le da suficiente importancia, ni las autoridades ni el público en general. Dependiendo de la fuente de generación existen varios tipos de recipientes, los cuales varían en cuanto a su capacidad de almacenamiento y material de construcción. En general, existen los siguientes tipos de recipientes para almacenar (SEDESOL, 2011):

- Recipientes para casas-habitación

- Recipientes para multifamiliares

- Recipientes para sitios públicos

- Recipientes para centros de gran generación

- Recipientes para almacenamiento industrial

- Recipientes para almacenamiento en hospitales

Por otro lado, es muy importante mencionar que la zona en donde se de este almacenamiento también es un factor de importancia y deben cumplir con ciertas características que permitan un almacenamiento adecuado de los residuos y faciliten las labores de recolección, tales como (Deffis, 1994):

- El lugar deberá estar cubierto para evitar que factores ambientales como lluvia o sol los descompongan a una velocidad mayor.

- Los recipientes deberán de estar por lo menos $20 \mathrm{~cm}$ por encima del suelo, para evitar que los lixiviados se filtren en el suelo.

- El lugar deberá ser inaccesible a animales domésticos y a personas ajenas al lugar ya que podían esparcirlos y no facilitar su recolección.

- Antes de la entrega de los residuos al servicio de recolección se deberán barrer los residuos dispersos e incorporarlos a los recipientes de almacenamiento.

- No deberá haber cosas en desorden o materiales que no estén destinados para entregarse al servicio de recolección.

- El lugar se deberá de lavar por lo menos una vez a la semana, con agua caliente y detergente, con la finalidad de eliminar bacterias y malos olores ocasionados por los residuos que puedan adherirse al piso del lugar.

Una vez que se generan los residuos, se almacenan un determinado tiempo en el lugar donde se generaron para ser dispuestos al servicio de recolección. La recolección es la siguiente fase del manejo de RSU que se considera en esta investigación. La etapa de la recolección de los RSU está muy ligada a la salud pública. La ausencia de esta actividad y su vinculación con la proliferación de enfermedades 
infecciosas en el siglo XIX fue el factor detonante para atribuir a los gobiernos locales la responsabilidad de ofrecer dicho servicio (ONU-Hábitat, 2014).

\subsubsection{Fase 2. Recolección}

La etapa de recolección es la parte medular de un sistema de aseo urbano y también la más costosa. Tiene como objetivo principal evitar problemas de salud pública y daños al medio ambiente ya que, de no llevarse a cabo esta etapa, los sitios de generación estarían en condiciones deplorables acarreando problemas de distinta índole al ambiente, y por consecuencia a la salud pública. Por esta razón, es de gran importancia esta etapa en el manejo de RSU para posteriormente transportarlos al sitio de tratamiento o disposición final en forma eficiente y al menor costo. Esta etapa es la que emplea un número considerable de recursos económicos (SEDESOL, 2011) se requiere de una gran infraestructura, especialmente en los países en vías de desarrollo (Hoornweg y Bhada, 2012) ya que se necesita de gran cantidad de vehículos de todo tipo y tamaño, además de una flotilla considerable de trabajadores que se dediquen a recorrer las calles de manera continua; aunado a esto el mantenimiento y el combustible que los vehículos necesitan diariamente, implican unan gran cantidad de recursos destinados sólo a esta parte del manejo (Figura 2.4). Para esto es importante diseñar rutas eficientes de recolección y con el fin de diseñar un sistema adecuado de recolección, los municipios deben contar con ciertos parámetros técnicos y demográficos como procedencia y volumen de los residuos sólidos, tipo de almacenamiento, frecuencia de recolección, método de recolección y tripulación, y tipo de vehículos recolectores. Una de las decisiones primordiales a tomarse para el diseño de un sistema de recolección dentro del manejo de RSU es definir el método que se empleará para recolectar dichos residuos; entre los más comunes se tienen son: las "de parada fija", "de acera" y "de contenedores". Esta es una decisión importante porque incide en las otras variables de recolección, incluyendo el tipo de recipiente para el almacenamiento, tamaño de la cuadrilla y en la selección de los vehículos recolectores (Manual Técnico Sobre Generación, Recolección y Transferencia De Residuos Sólidos Municipales, 2011). Otro punto de decisión es la frecuencia de recolección; ambos factores, el método y la frecuencia deben considerarse en cuanto a su impacto en los costos de recolección. Dado que el costo de la recolección constituye entre 70 y $85 \%$ del costo total del manejo de los residuos sólidos y, a su vez, el costo de mano de obra representa del 60 al $75 \%$ del costo de la recolección (SEDESOL, 2010; 2011). El incremento en la productividad del personal de recolección puede reducir significativamente los costos globales, dado que en esta fase del manejo de RSU los trabajadores encargados de llevar a cabo la recolección bien pueden evitar que se recolecten ciertos materiales tales como neumáticos, residuos de jardinería, muebles y animales muertos debido a que este tipo de residuos no son aceptados en el vehículo recolector. Los residuos peligrosos deben ser definitivamente excluidos de la recolección regular por los peligros que entraña su recolección y disposición, tanto para los trabajadores como para el público en general, ya que muchos de estos materiales son muy persistentes en el ambiente y llegan a través de cadenas tróficas al ser humano. 
Figura 2.4. Recolección de RSU

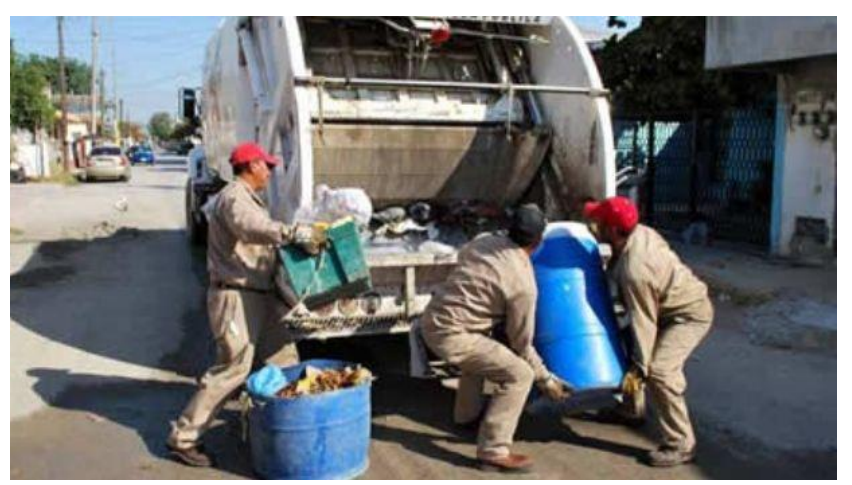

Fuente: Google Imágenes

Los diferentes métodos de recolección son descritos por el Manual Técnico sobre Generación, Recolección y Transferencia de Residuos Sólidos Municipales (2011) de la siguiente manera:

a. Método de parada fija o de esquina. Como su nombre lo indica, este método consiste en recoger los residuos en las esquinas de las calles, previamente con la ayuda de una campana se anuncia la llegada del camión y los usuarios acuden a entregar sus residuos a las esquinas. Este método parece ser de los más comunes que hay en la mayoría de los municipios y también suele ser de los más económicos. Sin embargo, en lugares donde no fluye mucho la información sobre el adecuado manejo de RSU, cuando no hay alguien en los domicilios que acuda a las esquinas con sus residuos o la saque, esta se acumula de manera abrumante y después se arroja de manera clandestina.

b. Método de acera. En este método, los trabajadores al mismo tiempo que van recorriendo su ruta asignada para la recolección de los residuos, los van recolectando. Estos sólo serán recolectados si los residentes de los hogares colocan los residuos en la cera frente a su casa. Para este método es necesario tener un horario de recolecta y una frecuencia, ambos deben ser acatados por los trabajadores que recolectan. De esta manera los residentes son informados de dichos horarios para que saquen sus residuos en tiempo y forma. Respetando los horarios se evitan varios incidentes como, por ejemplo, que las bolsas de los residuos sean rotas por las mascotas de los residentes o por otro tipo de animales, y los residuos sean derramados en las calles. Esto suele pasar cuando los residuos son sacados con mucha anticipación y fuera de los horarios establecidos. Es por eso que se les sugiere a los residentes instalar un tipo de soporte o canasta metálica fuera de sus viviendas y fuera del alcance de los animales para que en ella se deposite los residuos que posteriormente será recogida por los trabajadores que recolectan. Por lo general, el equipo o cuadrilla de recolección consta de tres personas, un chofer que conduce el camión recolector y dos trabajadores, también conocidos como peones, los cuales se encargan de ir recolectando los residuos y depositándolos en el camión recolector. La razón de que haya dos trabajadores es porque cada uno va recolectando los residuos de cada una de las ceras. Por otra parte, el chofer del camión también tiene que cumplir con ciertas obligaciones cómo los horarios de recolección, las rutas destinadas, y con el adecuado mecanismo de compresión de residuos que realiza el camión al ir recorriendo la ruta que se le designó. 
c. Método de Contenedores. Este tipo de recolección requiere de vehículos especiales y que los contenedores de residuos se encuentren en la posición correcta para que los vehículos recolectores los puedan manipular sin problema. Sin embargo, este método es el más convencional e ideal para los centros de gran generación, como los que se han mencionado con anterioridad (hospitales, mercados, plazas y centros comerciales), ya que es necesario que la recolección sea con frecuencia, porque de lo contrario se estarían almacenando grandes cantidades de residuos en distintos lugares de la ciudad, lo cual podría traer focos de infección y plagas nocivas para el ser humano (Figura 2.5).

\section{Figura 2.5. Contenedores de RSU}

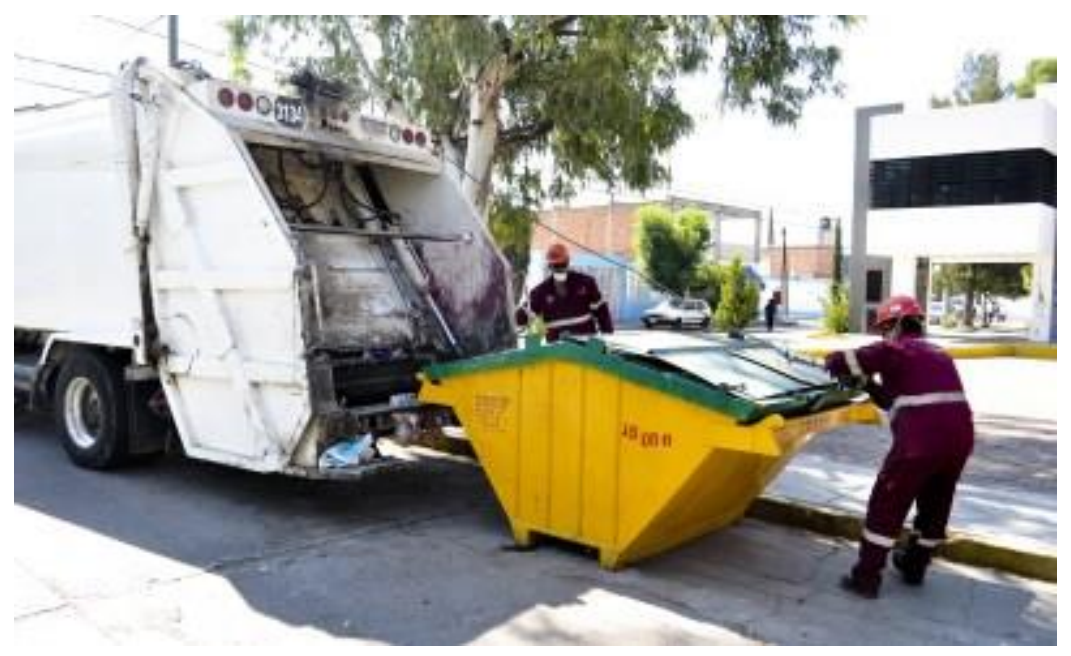

Fuente: Google Imágenes

Dentro de esta fase como anteriormente se ha mencionado se encuentran establecidas las rutas de recolección y se reconoce como un punto importante del sistema de recolección de residuos sólidos municipales. La ruta de recolección no es más que el recorrido específico que los vehículos recolectores de residuos deben de cumplir a lo largo del día en una zona establecida específicamente (SEDESOL, 2010). Se le asigna a cada camión una ruta a seguir, con la finalidad de cubrir la mayor cantidad de territorio posible y que se recolecten los residuos generados por los ciudadanos de la mejor manera posible. En México, el método que se ha venido empleando para el diseño de ruta ha sido con base en la experiencia de los jefes de limpia y a base de ensayo y error, como un conocimiento que se ha trasferido de generación en generación, aunque cabe destacar que existen métodos basados en algoritmos que rara vez se utilizan, ya que los jefes de limpia imponen sus métodos. También, los choferes opinan sobre ciertas modificaciones a las rutas de recolección cuando es necesario. Desafortunadamente, la mayoría de las rutas de recolección diseñadas de la manera mencionada tienen dificultades de operación y funcionamiento, además de un mal diseño de rutas de recolección trae como consecuencia graves daños al sistema de recolección, por ejemplo: deficiente operación y funcionamiento del equipo, desperdicio de personal, reducción de las coberturas del servicio de limpia, y la proliferación de tiraderos clandestinos a cielo abierto en diferentes puntos de la ciudad. Para tomar una decisión de cambiar alguna ruta de recolección, debe justificarse claramente las razones por las cuales se quiere hacer, tanto al público en general como a las autoridades pertinentes, ya que este tipo de decisiones podría incurrir en el aumento del costo de recolección y aunque la mayoría de estos gastos están subsidiados por el estado, los ciudadanos con sus impuestos también contribuyen al pago de los mismos. Si bien, por lo general, estas rutas están diseñadas con 
base en la experiencia de personas que se han dedicado a este tipo de actividades, existen reglas básicas para generar un diseño de ruta. Estas reglas están descritas en el Manual Técnico sobre Generación, Recolección y Transferencia de Residuos Sólidos Municipales (2011), las cuales versan de la siguiente manera:

- El diseño de rutas trata de aumentar la distancia productiva en relación a la distancia total.

- Los recorridos no deben fragmentarse ni traslaparse. Cada uno debe consistir en tramos que queden dentro de la misma área de la ciudad o localidad en cuestión.

- El inicio de una ruta debe estar cerca de la cochera donde se guarda el vehículo recolector y el final del recorrido cerca del lugar de disposición final de residuos sólidos.

- En lugares con pendientes fuertes o desniveles altos, debe procurarse hacer el recorrido de la parte alta a la parte baja. Si se presentan cuencas que hay que bajar y luego subir, hay que procurar atenderlas al comienzo del viaje, cuando el vehículo recolector va con poca carga.

- Tratar de recolectar simultáneamente ambos lados de la calle. Sin embargo, ello no es recomendable en avenidas muy anchas o con mucho tránsito.

- Se debe respetar el sentido de circulación y la prohibición de ciertos virajes.

- Evitar los giros a la izquierda y las vueltas en U, porque hacen perder tiempo, son peligrosos y obstaculizan el tránsito.

- Las calles con mucho tránsito no deben recorrerse en horas pico.

- Cuando hay estacionamientos de vehículos, hay que procurar efectuar la recolección en los momentos que la calle está más despejada.

- En las calles muy cortas o sin salida, es preferible que los vehículos recolectores no entren en ellas, sino que esperen en la esquina y que el personal vaya a buscar los residuos, o en su caso el público lo deposite en la esquina más cercana a la ruta de recolección. Esto ahorra tiempo.

- Cuando la recolección se hace simultáneamente a ambos lados de la calle, deben hacerse recorridos largos y rectos, con pocas vueltas.

- Cuando la recolección se hace primero por un lado de la calle y después por el otro, generalmente es mejor tener recorridos con muchas vueltas a la derecha alrededor de manzanas.

- Es preciso reconocer muy bien las características propias de la ciudad para que las rutas de los camiones recolectores no causen gran cantidad de problemas.

Existen dos tipos de rutas posibles de diseñar: la macroruta y la microruta. Se denomina macrorutas a la división de la ciudad en sectores operativos, a la determinación del número de camiones necesarios en cada una y a la asignación de un área del sector en cada vehículo recolector. Básicamente el macroruteo consiste en dos etapas: un proyecto de gabinete y ajuste de campo. En el primero, se hace el cálculo teórico de las necesidades y áreas asignadas a cada vehículo; y en el segundo, se afinan los contornos de las mismas para balancearlos y nivelar las cargas de trabajo entre los diferentes equipos de trabajo o cuadrillas (SEDESOL, 2010). En forma general, se puede decir que el diseño de las macrorutas se puede llevar a cabo mediante la sectorización, que consiste en dividir la ciudad en sectores operativos, de manera que cada uno tenga los vehículos de recolección necesarios o requeridos, oficinas y cocheras, buscando que sea una sección administrativa autónoma con servicios de mantenimiento preventivo y limpieza, criterios para definir los sectores, además de unidades de recolección (por ejemplo, cerros, cañadas, ríos, calles, avenidas y vías férreas). Asimismo, las macrorutas pueden definirse con base en la zonificación del sector, que consiste en que cada sector se divida en zonas que serán cubiertas por un vehículo recolector durante la semana. 
Para realizar esto, se debe contar con la siguiente documentación para cada colonia o barrio dentro del sector: (1) planos que contengan urbanización, áreas pavimentadas, topografías y tipos de disposición y/o tratamientos, y zonas de habitación unifamiliar con respectivos datos de nivel socioeconómico, (2) número de casas, vialidades y habitantes por vivienda, (3) localización de puntos de gran generación de residuos sólidos (p.e., mercados, supermercados, centros comerciales, cines, hospitales y restaurantes), (4) generación unitaria de residuos sólidos de los elementos anteriores, (5) método de recolección a utilizar, y (6) frecuencia de recolección (SEDESOL, 2011).

Por otro lado, se denomina microruteo, al recorrido específico que deben realizar diariamente los vehículos recolectores de residuos sólidos en los sectores de la ciudad donde han sido asignados. El diseño de microrutas debe hacerse con base en una serie de factores variables de acuerdo con la zona en estudio, por lo que se requiere de un plano que contenga: (1) trazo urbano, topografía, ancho y tipo de calles y tipos de disposición final, (2) método de recolección, (3) equipo de recolección, (4) densidad de población y (5) cantidad de generación de residuos sólidos. En general, se puede decir que los métodos determinísticos son los más recomendables para el diseño de microrutas, ya que en ellos se pueden involucrar todos los parámetros que inciden en el diseño de las rutas de recolección de residuos sólidos. Además, con este tipo de métodos si se obtienen rutas óptimas de recolección de residuos sólidos (SEDESOL; 2010).

Otra actividad que se encuentra dentro de la fase de recolección es el barrido, ya que esta es una actividad considerada como una recolección manual o mecánica de residuos sólidos depositados en la vía pública. El tipo de residuos en la vía pública es muy diverso, ya que puede variar de acuerdo al clima, al número de peatones y al uso del suelo, entre otros (SEDESOL, 2011). Entre los principales componentes se encuentran el polvo, estiércol, colillas de cigarros, envolturas y envases de plástico, cartón, vidrio y animales muertos. El polvo se origina tanto por eventos naturales como por la actividad humana; dependiendo del número de peatones que circulan en la vía pública, de las condiciones socioeconómicas y del grado de educación ambiental se van acumulando en las calles y lugares de esparcimiento los materiales anteriormente mencionados. La razón más importante por la que debe de efectuarse la limpieza en las calles es por la conservación de la salud humana (ONUHABITAT, 2010). Las excretas y los desperdicios orgánicos como se sabe tiene efectos negativos en la salud del ser humano, especialmente porque se genera fauna nociva, los cuales son transmisores de diversas enfermedades. El polvo afecta los ojos, garganta, vías respiratorias y ocasiona también molestias de tipo alérgico. Otro tipo de residuos, como el vidrio pueden producir lesiones a los peatones. Por otra parte, la acumulación de residuos puede obstruir el alcantarillado-drenaje del agua pluvial, ocasionando inundaciones en algunos sectores de la ciudad, y esto es sólo el comienzo de otra serie de problemas más. Además de los factores ya mencionados, otro factor muy importante y que pocas veces se les da prioridad, son los impactos visuales negativos que implican las calles sucias; es decir, la estética ambiental de una ciudad es parte fundamental del desarrollo psicológico de los habitantes (Torey, 1994). Las vías de circulación peatonal y de vehículos, mercados, ferias, lugares de esparcimiento, parques, playas y ocasionalmente estadios, coliseos y la rivera de los ríos, son los lugares en donde debe de efectuarse el barrido. La limpieza en las vías de circulación vehicular y de peatones debe de efectuarse a todo lo largo de las cunetas y de un ancho de alrededor de un metro. Finalmente, el sector comercial de una ciudad debe de ser barrido en su totalidad y las veces que debe de barrerse dependerá de la cantidad de residuos que sea necesario retirar; algunas veces no es suficiente una limpieza diaria, sino que, es necesario que se realice en varias ocasiones durante el día. 


\subsubsection{Fase 3. Manipulación y procesamiento}

La manipulación y procesamiento se refiere a todo lo que implique transportar, clasificar y procesar los RSU generados; el transporte de los mismos puede realizarse de manera directa o por medio de centros de transferencia; para que un municipio adopte cualquiera de los dos sistemas de transporte directo o indirecto, deberá realizar un análisis de los costos y beneficios con base en: (1) la generación de residuos producidos en los distintos sitios o fuentes, (2) la frecuencia, (3) los métodos de recolección, (4) el personal necesario, y (5) las condiciones medio ambientales y sociales de cada ciudad (SEDESOL, 2011).

Se sabe que, en México, solamente 16 ciudades medias han realizado estudios relativos a la selección del transporte adecuado, incluyendo las que han elaborado estudios de factibilidad. En lo que se refiere al tipo, cantidad y calidad de los vehículos empleados por el servicio de limpia pública, se tiene (SEDESOL, 2010):

- Que el transporte más usado es el de camión de volteo y otro tipo de vehículos, los cuales no son los más indicados desde el punto de vista económico y sanitario.

- Los vehículos compactadores a pesar de reunir mejores ventajas para el transporte ocupan un segundo término.

- Con respecto a los vehículos descompuestos, se estima en casi el $20 \%$ del total, se tiene que el $37 \%$ de las ciudades carecen de presupuesto específico para el mantenimiento, lo que significa que los municipios de dichas ciudades no cuentan con taller apropiado, refacciones especiales y equipo necesario.

- De los vehículos restantes en servicio, un alto porcentaje se tiene de malas a regulares condiciones, lo que refleja también que se carece de un mantenimiento preventivo y correctivo.

- Es importante entonces recalcar que no es sólo la compra suficiente de vehículos lo que requiere el sistema para el transporte de los residuos, sino que también se deben impulsar acciones como organizar y equipar los talleres de mantenimiento, minimizando con esto los costos y prolongando la vida útil de los vehículos para realizar una cobertura más eficiente. Aunado a lo anterior, en lo referente al aspecto de eficiencia del servicio, se debe considerar dentro de la planeación, la posibilidad de instalar centros de transferencia en sitios estratégicos para que los vehículos recolectores de residuos puedan ampliar su cobertura al reducir las distancias al sitio de disposición final o de tratamiento. Actualmente solo 16 ciudades medias del país cuentan con centros de transferencia, los cuales operan como tales o a través de remolques o tráileres; en dos más existe el proyecto de construcción y en otra están por concluirse los trabajos de instalación.

Los residuos, después de ser recolectados se llevan a zonas o estaciones de transferencia, esta actividad implica la manipulación e incluso el procesamiento (Figura 2.6), ya sea para prepararlas para un sitio de transformación o para llevarlas a un sitio de disposición final. Se aplica el término estación de transferencia a las instalaciones en donde se hace el traslado de residuos de un vehículo recolector a otro vehículo con mucha mayor capacidad de carga. Este segundo vehículo, o transporte suplementario es el que transporta los residuos hasta su destino final (SEDESOL, 2010). En general, estas estaciones son una plataforma elevada dotada de una rampa de acceso o a un edificio sofisticado y de grandes dimensiones. El traslado de los residuos se puede hacer por gravedad o con equipos mecánicos especiales. Los vehículos recolectores que utilizan las estaciones de transferencia son, 
generalmente, camiones compactadores, camiones abiertos tipo volquete, camiones porta contenedores y para el transporte suplementario se emplean, regularmente, y camiones de gran capacidad tipo tráiler, además de ser necesario se pueden utilizar otros medios de transporte como el ferroviario o el acuático. El objetivo básico de las estaciones de transferencia es incrementar la eficiencia global del servicio de recolección a través de la economía en el sistema de transporte y en la disminución del tiempo de mano de obra empleada en la recolección. Otro objetivo de las estaciones de transferencia es usarlas cuando la distancia del transporte de residuos desde la zona de recolección hasta los sitios de disposición final es muy larga, por lo tanto, se recomienda el empleo de medios de transporte más adecuados para cubrir largos recorridos (Inventario de RSU, 2006).

\section{Figura 2.6. Manipulación de los RSU}

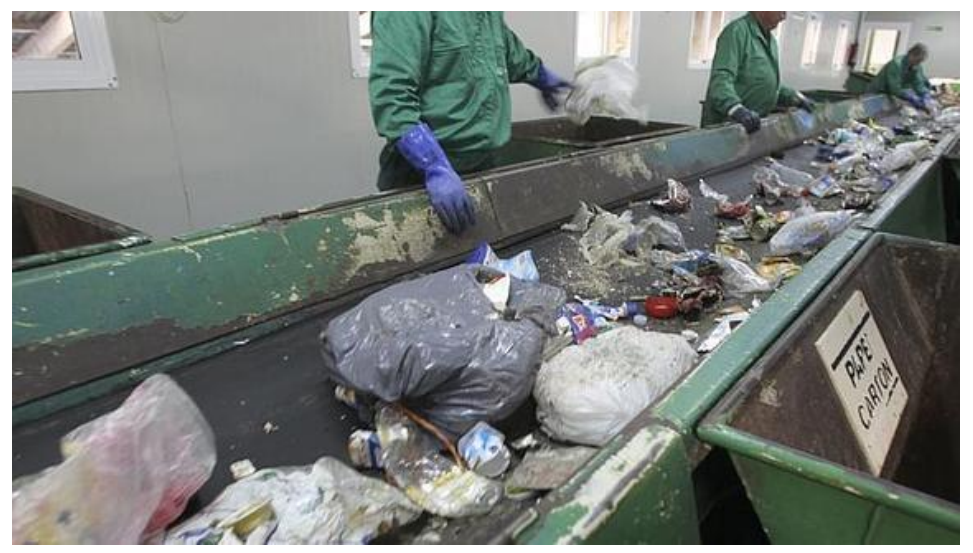

Fuente: Google Imágenes

Las características propias de los sitios destinados para una estación de transferencia son: (1) la distancia de amortiguamiento a zonas de colindancia, (2) la dirección e incidencia de vientos, (3) accesos a las instalaciones y accesos viales al sitio destinado para un relleno sanitario, (4) además de la superficie amplia disponible. Es muy importante reconocer la importancia de las zonas de transferencia, ya que ayudan a minimizar los costos y la energía, y permite la recuperación de residuos que pueden ser valorizados, ya que incluso en algunas zonas de transferencia, en su mismo emplazamiento, existe un centro de reciclaje.

Existen varios tipos de estaciones de transferencia en las cuales utilizan diferentes medios de transporte suplementario. Hay fundamentalmente dos tipos de estaciones de transferencia en cuanto a la operación de descarga: la directa y la indirecta. La directa emplea la gravedad para el traslado de los residuos de los camiones recolectores a los vehículos de transferencia; mientras que la indirecta utiliza locales de almacenamiento, además de equipos mecanizados para mover los residuos y alimentar los vehículos de transferencia (SEDESOL, 2010). Asimismo, existen estaciones de carga directa e indirecta, en las de carga directa el contenido de los camiones recolectores se descarga directamente en vehículo de transferencia, pero tienen una seria desventaja que es la imposibilidad de almacenar los residuos, lo que exige que siempre haya un vehículo de transferencia en condiciones de recibir los residuos sólidos de los camiones recolectores. En las de carga indirecta, los residuos se descargan indirectamente en los vehículos de transferencia y tienen locales para almacenamiento de residuos que pueden ser hoyos o patios. Los hoyos pueden tener el sistema de fondo móvil con correas transportadoras que llevan los residuos a una altura que permita cargar los vehículos de transferencia; además, usan puentes-grúas para remover los residuos del foso y cargar los vehículos de transferencia (SEDESOL, 2011) 
En cuanto al procesamiento de los recursos, éste depende básicamente de las características de los RSU y del vehículo de transferencia, dependiendo de esto los residuos pueden ser procesados o no. Los residuos sin procesamiento son los que no sufre ningún procesamiento, salvo la compactación recibida y, por lo tanto, es transferida en su estado original. Las instalaciones sin compactación son muy utilizadas en razón de la simplicidad de su construcción, operación, bajo costo inicial de las construcciones y de los vehículos de transferencia. En la mayoría de las ciudades latinoamericanas se presenta esta condición después de que los residuos han sido compactados en los equipos de compactación (ONU Hábitat, 2010).

Los RSU que si son procesados en estaciones de transferencia tiene generalmente dos objetivos: el más común es aumentar la densidad de residuos y así utilizar con más eficiencia la capacidad de transporte de los vehículos de transferencia; el segundo objetivo, cada vez más atractivo para nuestra condición, es aprovechar la operación de traslado para hacer la selección de residuos y así aprovechar los materiales reciclables. Los métodos de procesamiento más utilizados son los de compactación, la trituración y la selección de materiales. La compactación se realiza por medio de compactadores o por equipos montados en el vehículo de transferencia. En el primer caso, los residuos son colocados en el vehículo por la parte posterior de su caja, esta caja esta acoplada a la prensa compactadora por medio de garras mecánicas. En el inicio de la operación la prensa tan sólo coloca los residuos en el interior de la caja, logrando la compactación justo al final de la operación de carga. Cuando la compactación es efectuada por equipos instalados en el propio vehículo de transferencia, los residuos se colocan por una abertura en la parte superior de la caja y la compactación se realiza por medio de la placa de eyección de los residuos que, en esta operación, compacta los residuos contra la puerta trasera que permanece cerrada. Por otro lado, la trituración también se efectúa con el objetivo de reducir el volumen de los residuos y así facilitar su transporte. La operación de trituración se hace por medio de molinos especiales para basura. Hay molinos de diferentes modelos y capacidad de acuerdo al fabricante. La ventaja de este tipo de procedimientos, además de la reducción del volumen, es que los residuos triturados tienen características menos agresivas y su disposición en rellenos es más fácil. El costo de la trituración es alto, con relación a los costos de inversión y el mantenimiento, especialmente por el frecuente reemplazo de los martillos del molino. En el caso del empaquetamiento, éste consiste en compactar los residuos en bloques colocándoles cintas para mantenerlos empalmados, y tienen como principal ventaja la utilización de vehículos con carrocería de tipo plataforma (Figura 2.7). Para la selección de materiales, ésta consiste en la remoción de materiales de los residuos que pueden ser aprovechados, transportándose a los rellenos sanitarios o a los sitios de disposición final, la fracción no aprovechable, o sea los rechazos del proceso. Con la selección de materiales se logra la disminución de la cantidad de residuos a ser transportados y, además se obtienen ingresos a partir de la venta de los materiales seleccionados, esto es vidrio, metal, papeles y plásticos. Las construcciones o edificios que están destinadas a ser centros de transferencia van desde una plataforma elevada en un terreno a cielo abierto, hasta sofisticados y costosos edificios, como en muchos países de primer mundo, aquí los camiones recolectores descargan su contenido en la carrocería del vehículo de transporte suplementario que está colocado a un nivel más bajo (SEDESOL, 2011). Después del procesamiento o manipulación, que anteriormente se describió, sigue la etapa de transformación. En esta etapa los residuos ya manipulados o tratados y que son

valorizados, pueden ser vendidos como materia prima o insumos para algún otro proceso que implica una transformación fisicoquímica; a continuación, se detalla la fase de la transformación.

Figura 2.7. Compactadora de RSU 


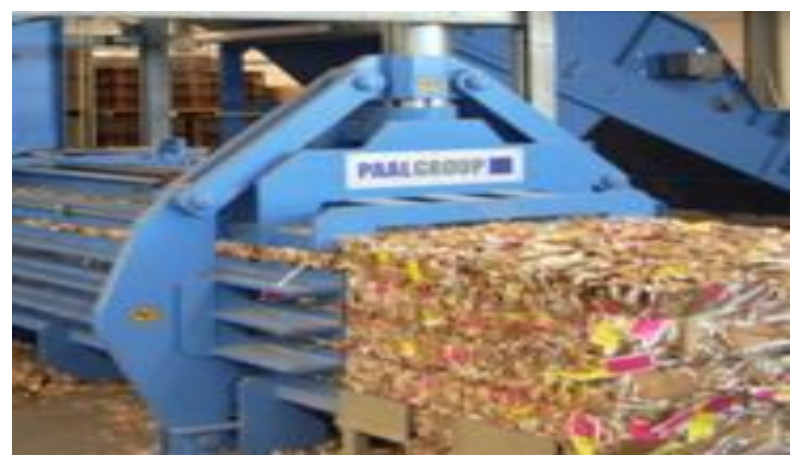

Fuente: Google Imágenes

\subsubsection{Fase 4. Transformación}

Se entiende por transformación o tratamiento de residuos las distintas operaciones o métodos para deshacerse de los RSU que son valorizados después de ser manipulados o procesados. Los métodos de tratamiento pueden ir desde algo muy sencillo, como un vertido controlado, hasta algo bastante complejo que requiere de sofisticadas instalaciones como la producción de biogás o la pirolisis (Dffis, 1994).

A continuación, se describen los métodos más comunes:

\section{a. Vertido controlado}

En este tipo de tratamiento resulta fundamental la elección de un terreno desde el punto de vista hidrogeológico, con capacidad suficiente y buenas comunicaciones. Los vertederos controlados pueden ser de varios tipos según el tratamiento a que se sometan los residuos. Por ejemplo, los de baja densidad son aquellos en los que los residuos se someten a una compactación ligera obteniendo una densidad media de $600 \mathrm{Kg} / \mathrm{m} 3$ y los residuos vertidos diariamente se cubren. En el caso de los de media densidad, los residuos son compactados hasta una densidad media de $750 \mathrm{Kg} / \mathrm{m}^{3}$, realizándose la cobertura con una mayor periodicidad. Finalmente, en los de alta densidad, los residuos son tratados con maquinaria pesada que los tritura y compacta llegándose a obtener densidades medias de 1100 $\mathrm{Kg} / \mathrm{m}^{3}$, este tipo de vertederos no se necesita cubrir (SEDESOL, 2011). La elección de uno u otro tipo influyen varios factores, aunque muchas veces se somete al volumen de residuos generados: así los de alta densidad se utilizan en pequeños vertederos de menos de130 T/día, los de media para vertederos que reciben entre 130 y 300 T/día y los de baja para más de 300 T/día (SEDESOL, 2010).

\section{b. Incineración}

Durante años, se ha considerado la incineración como la única solución realmente eficaz para la eliminación de RSU. Sin embargo, hay que considerar que la incineración transforma un residuo sólido en uno gaseoso. La incineración es un proceso de combustión controlada que transforma los RSU en materiales inertes (cenizas) y gases. En este proceso se efectúa una reducción del peso en un $70 \%$ y del volumen de entre 80 y $90 \%$ (Deffis, 1994). Aunque existen instaladas plantas incineradoras sin aprovechamiento energético, hoy en día las instalaciones suelen acoplar la combustión de los RSU con la generación de energía. Los factores que determinan o condicionan la implantación de un sistema de incineración son: (1) el volumen de residuos a incinerar, (2) el poder calorífico de residuos 
(PCI), (3) los costes de inversión, y (4) los gastos de explotación. En general, se considera un volumen mínimo para la rentabilidad del proceso de $100 \mathrm{Tm} /$ día de residuos con un poder calorífico mínimo de $1000 \mathrm{Kcal} / \mathrm{kg}$ (Deffis, 1994).

\section{c. Producción de composta}

El compostaje es un proceso de descomposición biológica de la materia orgánica contenida en los RSU que tiene como objeto su transformación en un producto orgánico utilizable para la mejora de suelos en agricultura (Figura 2.8). El compost no es un abono sino un acondicionador del terreno, aunque en la práctica suele sustituir a abonos orgánicos (estiércol), debido a su calidad superior. Esta práctica viene principalmente de valorizar los RSU que provienen de la poda, residuos de comida, y de jardines. En términos generales, el compostaje se puede definir como una biotécnica donde es posible ejercer un control sobre los procesos de biodegradación de la materia orgánica; entendiéndose por biodegradación una consecuencia de la actividad de los microorganismos que crecen y se reproducen en los materiales orgánicos en descomposición. La consecuencia final de estas actividades vitales es la transformación de los materiales orgánicos originales en otras formas químicas. Los productos finales de esta degradación dependerán de los tipos de metabolismo y de los grupos fisiológicos que hayan intervenido; por ello, los controles que se puedan ejercer estarán enfocados a favorecer el predominio de determinados metabolismos y en consecuencia a determinados grupos fisiológicos (Cisneros, 2008).

\section{Figura 2.8. Composta proveniente de RSU orgánicos}

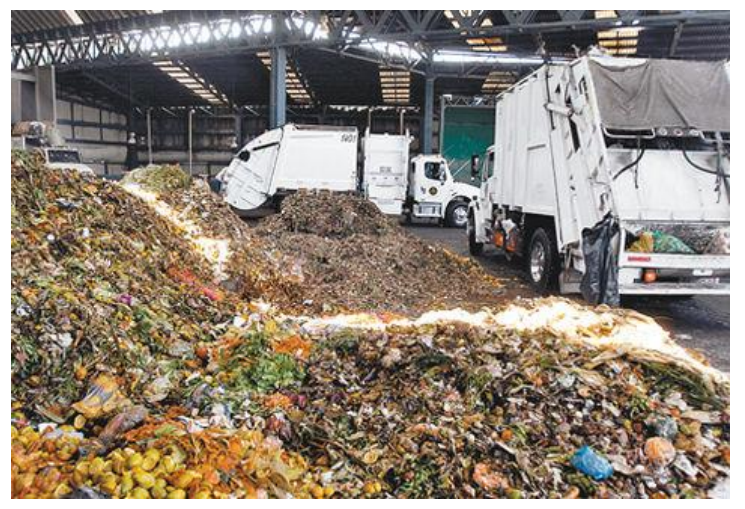

Fuente: Google imágenes

El compostaje es un proceso biológico, que ocurre en condiciones aeróbicas (presencia de oxígeno). Con la adecuada humedad y temperatura, se asegura una transformación higiénica de los restos orgánicos en un material homogéneo y asimilable por las plantas. Es posible interpretar el compostaje como el sumatorio de procesos metabólicos complejos realizados por parte de diferentes microorganismos en presencia de oxígeno. El compostaje consta de las siguientes fases (Cisneros, 2008):

(1) Fase Mesófila: comienza el proceso de compostaje a temperatura ambiente y en pocos días (e incluso en horas), la temperatura aumenta hasta $\operatorname{los} 45^{\circ} \mathrm{C}$. Este aumento de temperatura es debido a la actividad microbiana, ya que en esta fase los microorganismos utilizan las fuentes sencillas de carbono y nitrógeno generando calor. La descomposición de compuestos solubles, como azúcares, produce ácidos orgánicos y, por tanto, el $\mathrm{pH}$ puede bajar (hasta cerca de 4.0 o 4.5). Esta fase dura pocos días (entre dos y ocho días). 
(2) Fase Termófila o de Higienización. Cuando el material alcanza temperaturas mayores que los $45^{\circ} \mathrm{C}$, los microorganismos que se desarrollan a temperaturas medias (microorganismos mesófilos) son reemplazados por aquellos que crecen a mayores temperaturas, en su mayoría bacterias (bacterias termófilas), que actúan facilitando la degradación de fuentes más complejas de carbono, como la celulosa y la lignina. Estos microorganismos actúan transformando el nitrógeno en amoníaco por lo que el $\mathrm{pH}$ del medio sube. En especial, a partir de los $60^{\circ} \mathrm{C}$ aparecen las bacterias que producen esporas y actinobacterias, que son las encargadas de descomponer las ceras, hemicelulosas y otros compuestos de carbono complejos. Esta fase puede durar desde unos días hasta meses, según el material de partida, las condiciones climáticas y del lugar, y otros factores. Esta fase también recibe el nombre de fase de higienización, ya que el calor generado destruye bacterias y contaminantes de origen fecal como Eschericha coli y Salmonella spp..

(3) Fase de Enfriamiento o Mesófila II. Agotadas las fuentes de carbono y, en especial el nitrógeno en el material en compostaje, la temperatura desciende nuevamente hasta los $40-45^{\circ} \mathrm{C}$. Durante esta fase, continúa la degradación de polímeros como la celulosa, y aparecen algunos hongos visibles a simple vista. Al bajar de $40{ }^{\circ} \mathrm{C}$, los organismos mesófilos reinician su actividad y el pH del medio desciende levemente, aunque en general el $\mathrm{pH}$ se mantiene ligeramente alcalino. Esta fase de enfriamiento requiere de varias semanas y puede confundirse con la fase de maduración.

(4) Fase de Maduración. Es un período que demora meses a temperatura ambiente, durante los cuales se producen reacciones secundarias de condensación y polimerización de compuestos carbonados para la formación de ácidos húmicos y fúlvicos. Esta es la forma que en general se produce un compostaje y con la adecuada humedad y temperatura, se asegura una transformación higiénica de los restos orgánicos en un material homogéneo y asimilable por las plantas.

\section{d. Pirólisis de RSU}

La pirólisis se define como un proceso termoquímico mediante el cual, el material orgánico de los subproductos sólidos se descompone por la acción del calor en una atmósfera deficiente de oxígeno y se transforma en una mezcla líquida de hidrocarburos, gases combustibles, residuos secos de carbón y agua. Los gases combustibles pueden servir para accionar motores diésel para producir electricidad o para mover vehículos. El proceso de pirólisis exige un aporte térmico que puede provenir de la combustión de la alimentación o de los productos de pirogenación (Marshall, 2013). Los sistemas pirolíticos que se han desarrollado se agrupan en dos categorías: pirólisis convencional y pirólisis a altas temperaturas. La pirolisis convencional puede efectuarse a baja temperatura o a temperatura media, los de temperatura baja implican una temperatura máxima de hasta $550^{\circ} \mathrm{C}$, este tipo de pirosis generalmente se emplea para la generación de aceites y alquitranes; en tanto que los procesos de temperatura media van desde $\operatorname{los} 550^{\circ} \mathrm{C}$ a $800^{\circ} \mathrm{C}$, y esta temperatura es ideal para la producción de metano e hidrocarburos más pesados. Por otro lado, la pirolisis a alta temperatura se efectúa a temperaturas superiores a $\operatorname{los} 800^{\circ} \mathrm{C}$, con lo cual se logra la producción de gas con bajo poder calorífico (Masera et al., 2005); ésta última pirolisis denominada pirolisis súbita (Fast), que opera en tiempos cortos y a altas temperaturas $\left(800^{\circ} \mathrm{C}-1.000^{\circ} \mathrm{C}\right)$, permite obtener una pequeña parte de material sólido (10\%) y convierte un $60 \%$ en gas rico en hidrógeno y monóxido de carbono. Esto hace que la pirólisis súbita pueda competir con los métodos de gasificación convencionales. Los equipos utilizados en la pirólisis son similares a los empleados en la gasificación, pero sin aporte de oxígeno o aire (Marshall, 2013). En la Figura 2.9, podemos ver el proceso general de la pirólisis a partir de biomasa generada de RSU, previamente seleccionados en fase de manipulación y procesamiento. 
Figura 2.9. Esquema del proceso de pirolisis de biomasa generada a partir de RSU

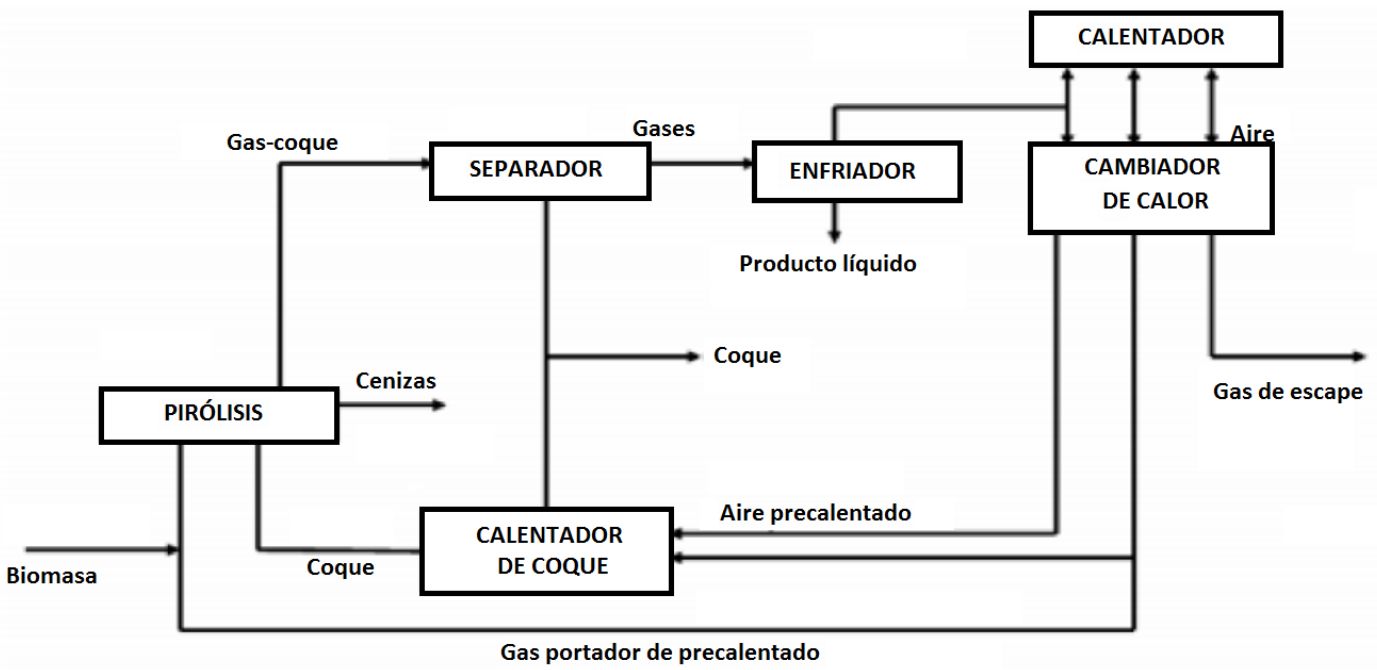

Fuente: Marshall, 2013.

El proceso de pirólisis se puede llevar a cabo de una forma lenta o de una manera más rápida, obteniéndose productos diferentes como se muestra en la Figura 2.10. Actualmente, el proceso de pirólisis rápida es de gran importancia práctica, es un proceso con una alta velocidad de transferencia de calor a la alimentación y un corto tiempo de residencia del vapor caliente en la zona de reacción. Este proceso ha alcanzado un importante éxito comercial en la producción de sustancias químicas y está siendo activamente desarrollada para la producción de combustibles líquidos. Por su parte, en la pirólisis lenta se produce gas pobre que puede utilizarse directamente o bien este proceso puede servir de base para la síntesis de un alcohol o metanol, que podría sustituir las gasolinas para la alimentación de los motores de explosión (Marshall, 2013).

Figura 2.10. Diferencia entre pirólisis lenta y rápida.

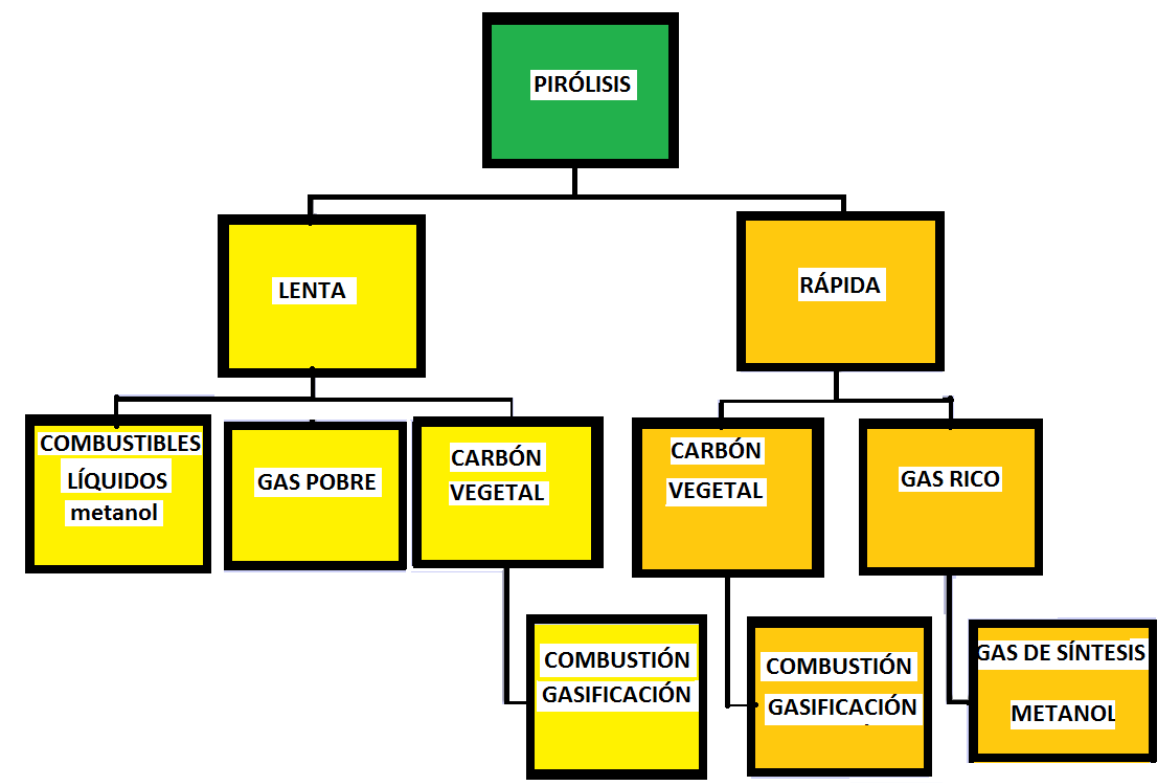


Fuente: Marshall, 2013.

Los resultados de la pirólisis dependen de condiciones de operación y algunos de los parámetros más importantes son la velocidad de calentamiento y el tipo de reactor. Éste último tiene gran importancia en la distribución de productos, por la distinta transferencia de calor. La elección de tipo de reactor está en función del tamaño de partícula, ya que para partículas grandes la velocidad de transmisión de calor disminuye, y a elevadas velocidades se favorece la aparición de líquidos condensables en zonas del pirolizador con menor temperatura y de gases en los puntos calientes. Por otro lado, el rendimiento en carbón vegetal aumenta a velocidades de calentamiento bajas y tamaños de partícula grandes, en detrimento de productos volátiles, gases y líquidos. El tiempo de residencia del gas y de las partículas también es un factor importante en este proceso. En cuanto a la temperatura, cuando es elevada favorece la producción de gas por craqueo y gasificación del residuo carbonoso con el vapor de agua, el monóxido de carbono y el hidrógeno; gases producidos in situ (Marshall,2013).

En general, los productos que se obtienen de este proceso se pueden clasificar en tres grandes grupos:

- Residuos sólidos carbonosos

- Líquidos hidrocarbonados

- Gases compuestos por hidrógeno, óxidos de carbono e hidrocarburos

El grupo de sólidos carbonosos se puede utilizar como combustible sólido para la fabricación de briquetas o como precursor para preparar carbones activados. Los líquidos están constituidos por una fracción acuosa y otra es tipo alquitrán que puede ser usada como combustible líquido adicionándola a gasolinas o como recurso de productos químicos de interés industrial. Los gases constituyen un gas de poder calorífico medio/bajo que puede utilizarse para calentar el reactor de pirólisis o generar energía eléctrica mediante combustión en motores, y si constituyen un gas de poder calorífico alto se emplean tanto en motores como en turbinas de gas (Gaggeo y Ordóñez, 2012).

El carbón vegetal como combustible sólido presenta la ventaja, frente a la alimentación (biomasa) que le dio origen, de tener un poder calorífico mayor. Sin embargo, la pirólisis significa una pérdida importante de la energía contenida en la biomasa utilizada como materia prima. Su uso se justifica cuando el proceso industrial en el cual se emplea lo requiere como condición imprescindible, como por ejemplo en la siderurgia, o cuando debe distribuirse o transportarse (Masera et al., 2005; Marshall, 2013).

\section{e. Producción de biogás (Metalogénesis)}

Los RSU que tienen una composición específica de desechos orgánicos de origen vegetal y/o animal (estiércol bobino, porcino o avícola) se pueden transformar por acción microbiana en una mezcla de gases denominada biogás. El biogás se compone de metano y otros compuestos como dióxido de carbono, amoníaco, nitrógeno y sulfuro de hidrógeno (Mandujano, 1998). En este proceso, conocido como digestión anaerobia o biodigestión intervienen cuatro grupos de microorganismos diferentes:

- El primero consiste en una mezcla de bacterias llamadas hidrolíticas o formadoras de ácidos, las cuales hidrolizan las moléculas complejas de la materia orgánica para formar ácidos grasos de cadena corta y alcohol.

- El segundo grupo es el de las bacterias acetogénicas que producen acetato e hidrógeno.

- Al tercer grupo se le denomina bacterias homoacetogénicas, ya que convierten un amplio espectro de compuestos orgánicos en ácido acético. 
- Las bacterias metanogénicas constituyen el último eslabón de la cadena de microorganismos encargados de digerir la materia orgánica y devolver al medio los elementos básicos para reiniciar el ciclo, ya que estas bacterias tienen la capacidad de convertir el ácido acético en metano y dióxido de carbono (Weiss et al., 2009; Hilbert, 1998; Antoni et al., 2007).

La operación estable de los biodigestores requiere que todos los grupos bacterianos anteriormente descritos estén en equilibrio. Cualquier cambio en las condiciones ambientales puede afectarlo, resultando en una producción desproporcionada de compuestos intermedios que inhiben la formación de metano (Mandujano, 1998).

El biogás, como fuente de energía renovable, ha despertado un gran interés en los últimos años, siendo tal vez una de las tecnologías de más fácil implementación, sobre todo en sectores rurales. Su potencial desarrollo, no solo considerando la producción de biogás, sino que como ayuda a la obtención de biofertilizante y tratamiento de problemas sanitarios en algunos casos, hacen que comience a haber mayor implementación y difusión en sectores con abundantes RSU de tipo orgánico (FAO, 2011). Desde una perspectiva de los países desarrollados y en desarrollo, la biotecnología anaeróbica contribuye a cumplir tres necesidades básicas: a) mejorar las condiciones sanitarias mediante el control de la contaminación; b) generación de energías renovables para actividades domésticas; y c) suministrar materiales estabilizados (bioabono) como un biofertilizante para los cultivos. Por lo tanto, la biotecnología anaeróbica juega un importante papel en el control de la contaminación y para la obtención de valiosos recursos: energía y productos con valor agregado (Hilbert, 1998; Cisneros, 2008)

\subsubsection{Fase 5. Disposición final}

La disposición final de los residuos sólidos ha sido practicada por varios siglos. En realidad, hace 2000 años los griegos enterraban sus residuos sólidos sin compactar. En 1930, en la ciudad de Nueva York y Fresno, California, iniciaron la compactación de los residuos con equipo pesado y cubriéndolos, así el término de "Relleno Sanitario" fue inventado (SEDESOL, 2009).

Hasta la década de 1960, la disposición final de los residuos no tenía control alguno, su eliminación se llevaba a cabo en tiraderos a cielo abierto, mediante incineración o la evaporación de los compuestos volátiles, o los desechos eran vertidos al agua tanto sobre cuerpos superficiales como a las aguas subterráneas o el océano (ONU-Hábitat, 2010). Dicha situación afectó de manera importante al ambiente.

En América Latina, los residuos generados por un 54\% de la población urbana son depositados en un relleno sanitario, los desechos de un $18 \%$ de los ciudadanos terminan en un vertedero controlado, los tiraderos a cielo abierto reciben los residuos del 25\% de la población (ONU-Hábitat, 2012). Estas cifras reflejan el importante déficit de infraestructura y falta de control en la disposición final de los RSU.

En México, de la cantidad de RSU que es enviada a disposición final: $60.54 \%$ es dispuesta en rellenos sanitarios y sitios controlados, $15.93 \%$ en tiraderos a cielo abierto y el $2.07 \%$ restante se desconoce dónde se deposita (Diagnóstico Básico para la GIRS, 2012). 
Un relleno sanitario, es tradicionalmente definido como un método de ingeniería para la disposición final de los residuos sólidos en el suelo, de tal manera que proteja el ambiente, mediante el extendido de los residuos en capas delgadas, compactándolas al menor volumen posible y cubriéndolas con tierra al término de cada día de trabajo (Manual Técnico para la Operación de Rellenos Sanitarios, 2000). El relleno sanitario es la instalación física usada para la disposición final de los residuos sólidos municipales sobre la superficie del suelo (Figura 2.11). En la actualidad, este complejo se usa para la disposición de los residuos sólidos municipales, diseñada y operada para minimizar los impactos a la salud pública y al ambiente. Sin embargo, en el manejo integral de RSU existe prioridad en todas sus fases en cuanto a su desarrollo, pero esta prioridad, solo es contemplada generalmente por los países desarrollados y con gran visión del manejo de RSU. Entre estos países se encuentra Estados Unidos, dónde la Agencia de Protección del Ambiente de dicho país EPA, por sus siglas en inglés (Environmental Protection Agency) recomienda dar prioridad a los siguientes elementos en el orden que se muestra: en primer lugar, reducción en la fuente, después reciclaje, transformación o tratamiento y, por último, su disposición en relleno sanitario (SEDESOL, 2009). Con esto es muy importante resaltar que, debemos poner énfasis en las primeras fases y tratar de llevar la menor cantidad posible de RSU generados a sitios de disposición final; caso contrario a lo que sucede en México.

\section{Figura 2.11. Relleno sanitario.}

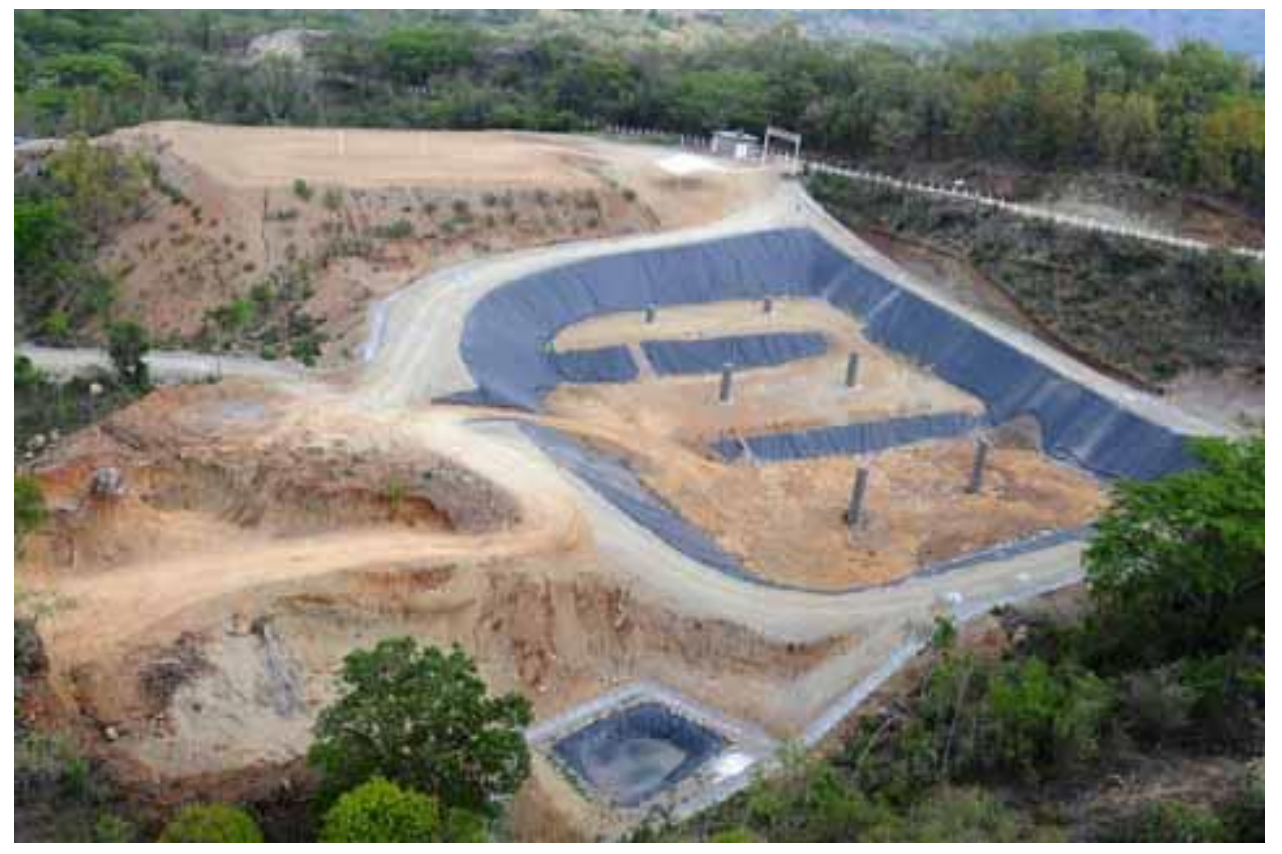

Fuente: Google imágenes

El relleno sanitario presenta ventajas y desventajas, como cualquier tecnología que se desarrolle (Manual Técnico para la Operación de Rellenos Sanitarios, año). Entre las ventajas destacan:

- Es la alternativa más económica, pero no hay que olvidar que es necesario asignar recursos financieros y técnicos suficientes para la planeación, diseño, construcción y operación.

- No requiere de operaciones adicionales, tal como el caso de la incineración o el composteo, los cuales requieren un sitio y de operaciones adicionales para la disposición de los productos finales. 
- Se recuperan terrenos antes considerados como improductivos o marginales, transformándolos en áreas útiles para la creación de parques, zonas recreativas y esparcimiento o simplemente áreas verdes.

- Es un método flexible, ya que en caso de incrementar la cantidad de residuos por disponer se requiere únicamente de muy poco equipo y personal.

- El gas metano generado por la descomposición de la fracción orgánica contenida en los residuos sólidos, puede ser atractivo para su aprovechamiento como fuente de energía no convencional, dependiendo de las características del sitio.

Entre las desventajas de este método se encuentran:

- No es un método muy aceptado por la población, debido a la falta de conocimientos respecto al relleno sanitario y a la mala aplicación de recursos con los que las autoridades realizan su construcción.

- Se requiere de una supervisión permanente para evitar fallas a futuro.

- Cuando no existen terrenos cercanos a las fuentes de generación de residuos sólidos debido al crecimiento urbano, el costo de transporte se verá fuertemente afectado.

- En países en vías de desarrollo fácilmente puede convertirse de relleno sanitario a tiradero a cielo abierto.

- Puede presentarse eventualmente la contaminación de aguas subterráneas y superficiales cercanas.

- Generación de olores desagradables y gases efecto invernadero, si no se toman las debidas medidas de control y de seguridad.

- Los asentamientos diferenciales que sufren los rellenos sanitarios con respecto al tiempo, impide que estos sean utilizados una vez que se han concluido las operaciones.

Es así como se describen cada una de las fases del manejo de RSU en esta investigación. Es importante mencionar que las descripciones en los procesos de transformación pueden ser distintas y más diversas, pero esto depende básicamente del nivel de ingreso del lugar del que se hable y además de las tecnologías con que cada lugar cuenta. Por ejemplo, en el caso de México, aún no se cuenta con tecnología ni presupuesto para poder hacer una transformación adecuada al tipo de RSU generados. Se realizan estudios en diversos tipos de transformación, como lo es la generación de composta y la de biogás a través de diferentes tipos de material orgánico, pero aún no se logrado concretar algún proyecto a nivel local y mucho menos a nivel nacional. México, al igual que muchos otros países en vías de desarrollo invierten la mayor parte de su presupuesto en la recolección y la disposición final (Hoornweg y Bhada, 2012), dejando en el abandono el resto de las fases.

El caso de países en vías de desarrollo, la fase de manipulación o procesamiento, como lo es el reciclaje, se ha convertido más en una forma de sobrevivir, que en un paso hacia la sustentabilidad ambiental. Según el Banco Mundial (2014) al menos 60 millones de personas laboran en este tipo de trabajo, y en los últimos 15 años se ha incrementado la presencia de mujeres y niños en esta labor. Los trabajadores que están en estas actividades son generalmente los más marginales y desprotegidos de todos los estratos laborales (Medina, 2008). El caso de México no es diferente, ya que cerca de 200 mil empresas se dedican a la recolección y reciclaje de residuos sólidos; sin embargo, sólo 2 mil 700 de ellas operan de manera formal de acuerdo con el Instituto Nacional de Recicladores AC (Inare, 2016). El sector estima que al menos 2 millones de familias dependen de esta actividad, en México, desde pepenadores, compradores de metales, plásticos y aluminio hasta transportistas. Sin embargo, la primera parte de la cadena opera en la informalidad por lo que se busca su incorporación a la 
economía formal (Hernández, 2015). En el país sólo 11\% de los residuos generados se recicla y la industria importa cerca de 100 mil millones de pesos anuales, esto a partir de estimaciones del (Inare, 2016). Por lo que es de vital importancia formalizar este tipo de negocios que bien pudieran ayudar a las mejoras en la GIRS del país.

Para esto es muy importante entender y aprender lo que otros países han logrado con sus residuos ya sean éxitos o fracasos, para esto se analizará primero desde una clasificación básica en países en vías de desarrollo y países desarrollados. Esto con la finalidad de poder visualizar desde una perspectiva más profunda lo que ocurre alrededor del globo con los RSU.

\subsection{Manejo de los RSU en países desarrollados y en vías de desarrollo; cuatro casos de estudio}

En el mundo, y en particular la población urbana, ha mantenido un aumento en su generación de RSU, por lo que la generación de RSU tanto para países desarrollados como en vías de desarrollo se ha incrementado de manera constante (Hoornweg y Bhada, 2012). Esto principalmente tiene que ver, como anteriormente se ha mencionado, con el desarrollo económico y el aumento de la población de cada país, sin dejar a un lado los patrones de consumo que cada localidad manifiesta. Por otro lado, el rápido agotamiento de los sitios destinados a la disposición final ocasionó cambios en las estrategias para el manejo de residuos, específicamente orientados a implementar procesos ambientales que acompañen a las tecnologías para tratar residuos.

En los anteriores capítulos de esta investigación, se ha visto que países desarrollados generan una mayor cantidad de RSU. Sin embargo, una visión muy particular de estos países ha logrado que los RSU lejos de ser un desperdicio y un problema, se conviertan en un negocio bastante redituable. Por ejemplo, en países del primer mundo como Suecia, se genera el 55\% del total de energía que consume a partir de los RSU. Es decir, reciclan y transforman el 99\% de sus RSU generados. Lo que lleva al país a sólo disponer un increíble 1\% del total de sus RSU (Hoornweg y Bhada, 2012; SEMARNAT, 2012; Katja, 2013). Por otro lado, es de vital importancia que entendamos que un mal manejo de RSU afecta al mundo entero y no sólo a quien los gestiona mal. El Banco mundial en su publicación What a Waste (1999), estima el volumen generado de los residuos y su composición para diferentes continentes del mundo incluidos Asia, América Latina y Europa. Sin embargo, diez años después estas estimaciones parecían estar cumpliéndose para la mayoría de las regiones urbanas del mundo, por lo tanto, el Banco Mundial consideró de gran importancia actualizar estos datos pero ya de una manera global y generó otro documento What a Waste, en el año 2012 ya con ayuda de otras organizaciones cómo la OCDE y la Organización Panamericana de la Salud de América Latina, por lo que nuevas cifras se estimaron en este documento y se contemplaron la mayoría de los países del mundo.

Los gobiernos locales, son quienes generalmente tienen a su cargo el enorme reto de gestionar y manejar los RSU de la manera más óptima posible, de forma ambientalmente sustentable, socialmente aceptable, y económicamente factible. El manejo de RSU generalmente requiere de una parte importante del presupuesto del gobierno local. Sin embargo, la realización de esta actividad genera una importante fuente de empleo para los mismos pobladores, ya sea de una manera formal o informal, ya que corresponde a entre un $1 \%$ y un 5\% del empleo urbano total (Hoornweg y Bhada, 2012). Manejar los RSU de una localidad requiere de un gran conocimiento técnico, científico, 
financiero, social y ambiental, lo cual habitualmente no se encuentra en los países en vías de desarrollo. Aunado a esto, se observa una gran diferencia entre la participación ciudadana en los países del primer mundo y la participación ciudadana casi nula en los países en vías de desarrollo. Es por eso que debe aclararse que el buen manejo de RSU no sólo es un desafío para los gobiernos locales, sino también debe serlo para las comunidades, porque gran parte de este adecuado manejo depende de la colaboración y la conciencia de los ciudadanos.

Uno de los principales objetivos de este capítulo es estudiar a profundidad el manejo de residuos sólidos urbanos en los países desarrollados que han tenido gran éxito en esta cuestión, así como en países en vías de desarrollo que han trabajado arduamente para generar un cambio; esto con la finalidad de generar lecciones aprendidas a partir del éxito o fracaso de los casos particulares que se abordarán en esta parte. Para el desarrollo de este capítulo se estudiará el caso particular de Suecia, Estados Unidos, China e India.

Se han seleccionado estos países con base en los números que reflejan su éxito en el manejo de sus RSU como lo es el caso de Suecia y Estados Unidos, es decir la cantidad de RSU que genera con respecto a los que lleva a disposición final o los que recicla o transforma en energía con respecto a los que genera. El caso de la India y China se vuelve importante para esta investigación pues son países con situaciones sociales, culturales y económicas similares a las de nuestro país, por lo que es importante observar de qué manera están dando solución al problema de la mala gestión de los residuos.

En general, podemos observar que los países tienen ciertas tendencias para el manejo de sus RSU y esto depende totalmente de sus ingresos y desarrollo económico. En la Tabla 2.2 se explica la diferencia entre el manejo de RSU en países desarrollados y aquellos en vías de desarrollo (Hoornweg y Bhada, 2012). Estas diferencias básicamente constan en la cantidad que invierten, de sus presupuestos y como las invierten, y el procedimiento que realizan en cada fase del manejo de RSU.

La reducción, la reutilización, el reciclaje y la valorización de los residuos urbanos constituyen medios eficaces y de alto impacto para reducir problemas ambientales como, por ejemplo, las emisiones de gases de efecto invernadero. Sin embargo, algo muy particular en los países de primer mundo es que no ven los RSU sólo como un problema ambiental, sino hacen de éste un negocio redituable además de ayudar al medio ambiente y procurar la salud humana (Tabla 2.2).

\section{Tabla 2.2. Comparación del manejo de RSU en países en vías de desarrollo y países} desarrollados

\begin{tabular}{|c|c|c|}
\hline $\begin{array}{l}\text { Actividades } \\
\text { del Manejo }\end{array}$ & Ingresos Bajos & Ingresos Altos \\
\hline $\begin{array}{l}\text { Reducción } \\
\text { de la } \\
\text { generación }\end{array}$ & $\begin{array}{l}\text { No hay programas adecuadamente } \\
\text { organizados, también la tasa de reciclaje, así } \\
\text { como la generación per cápita de RSU son } \\
\text { comunes. }\end{array}$ & $\begin{array}{l}\text { Programas educativos altamente organizados, los } \\
\text { cuales hacen hincapié en la regla de las 3R's } \\
\text { (reduce, reutiliza y recicla). Mayor responsabilidad } \\
\text { de los productores y con gran enfoque en el diseño } \\
\text { de los productos. }\end{array}$ \\
\hline Recolección & $\begin{array}{l}\text { Esporádica e ineficiente. El servicio está } \\
\text { limitado a áreas de alta visibilidad, lugares } \\
\text { residenciales o empresariales, donde el } \\
\text { usuario está dispuesto a pagar, Alta cantidad } \\
\text { de inertes y orgánicos se recolectan juntos; en }\end{array}$ & $\begin{array}{l}\text { El índice de recolección es mayor al } 90 \% \text { con } \\
\text { camiones y vehículos altamente mecanizados. } \\
\text { Abundantes zonas de transferencia. El volumen de } \\
\text { los residuos son un componente clave para el } \\
\text { diseño del sistema, al igual que la edad de los } \\
\text { trabajadores en esta etapa del manejo. }\end{array}$ \\
\hline
\end{tabular}




\begin{tabular}{|c|c|c|}
\hline & $\begin{array}{l}\text { general se recolecta máximo un } 50 \% \text { del total } \\
\text { de los RS generados. }\end{array}$ & \\
\hline Reciclado & $\begin{array}{l}\text { Aunque el porcentaje de reciclados tiende a } \\
\text { ser alto, en ambos sectores, local e } \\
\text { internacional, este se desenvuelve en el sector } \\
\text { informal. Este mercado no está regulado y se } \\
\text { compone de varios intermediarios por lo que } \\
\text { sus precios fluctúan de manera abrupta. }\end{array}$ & $\begin{array}{l}\text { Los servicios de reciclaje son de alta tecnología y } \\
\text { regulados, al igual que los servicios de recolección } \\
\text { de material reciclable y su clasificación; además el } \\
\text { mercado incrementará a largo plazo. Las tasas de } \\
\text { reciclaje son superiores a los países en vías de } \\
\text { desarrollo, aunque el reciclaje de latas sigue } \\
\text { estando en el mercado informal. }\end{array}$ \\
\hline Composteo & $\begin{array}{l}\text { Rara vez existe compromiso de realizar } \\
\text { buenas compostas, aunque la composición de } \\
\text { RSU en estos países es altamente orgánica. } \\
\text { La sensibilización para este tipo de } \\
\text { estrategias es ausente. }\end{array}$ & $\begin{array}{l}\text { Cada vez más popular, tanto a gran escala como en } \\
\text { el patio trasero de los hogares, aunque el flujo de } \\
\text { residuos composteables es mucho menor que en los } \\
\text { países en vías de desarrollo. }\end{array}$ \\
\hline Incineración & $\begin{array}{l}\text { No es común y generalmente no tiene éxito, } \\
\text { debido a la gran inversión económica, técnica } \\
\text { y científica. Por otro lado, los RSU en estos } \\
\text { países tienen alta humedad y gran contenido } \\
\text { de inertes. }\end{array}$ & $\begin{array}{l}\text { Prevalente en lugares donde hay escases de tierra o } \\
\text { el costo de ésta es muy alto para destinarlo a ser un } \\
\text { tiradero o relleno. La mayoría de los incineradores } \\
\text { son de alta tecnología y están diseñados para la } \\
\text { generación de energía. Los gobiernos se mantienen } \\
\text { regulando las emisiones y el costo es } \\
\text { aproximadamente tres veces más elevado si se } \\
\text { disponen en un relleno sanitario. }\end{array}$ \\
\hline $\begin{array}{l}\text { Rellenos } \\
\text { sanitarios y } \\
\text { tiraderos a } \\
\text { cielo abierto }\end{array}$ & $\begin{array}{l}\text { Comienzan siendo rellenos sanitarios de mala } \\
\text { tecnología y terminan siendo tiraderos a cielo } \\
\text { abierto, además que contaminan cuerpos de } \\
\text { agua y se infiltran contaminantes persistentes } \\
\text { a los mantos acuíferos, dañando así la salud } \\
\text { de los pobladores aledaños. }\end{array}$ & $\begin{array}{l}\text { Rellenos sanitarios de alta tecnología, con una } \\
\text { combinación de revestimientos, detección de fugas, } \\
\text { sistemas de recolección de lixiviados y gas, y } \\
\text { sistemas de tratamiento. A menudo problemático } \\
\text { para abrir nuevos vertederos, debido a las } \\
\text { preocupaciones de los pobladores aledaños; aunque } \\
\text { estos después se vuelvan lugares de recreación } \\
\text { como parques o campos de golf. }\end{array}$ \\
\hline Costos & $\begin{array}{l}\text { Los gobiernos locales gastan en la } \\
\text { recolección entre un } 80 \text { y } 90 \% \text { del total del } \\
\text { presupuesto asignado a la GIRS y una } \\
\text { mínima parte se asigna a la disposición final. }\end{array}$ & $\begin{array}{l}\text { Los costos de recolección consumen un } 10 \% \text { del } \\
\text { presupuesto asignado a la GIRS. La mayor parte } \\
\text { del presupuesto se destina a las instalaciones del } \\
\text { tratamiento de los RSU. La participación ciudadana } \\
\text { reduce los costos e incrementa las opciones } \\
\text { disponibles para reciclar y tratar los RSU. }\end{array}$ \\
\hline
\end{tabular}

Fuente: Banco Mundial, 2012

$\mathrm{Al}$ reciclar materiales desechados (residuos), estos proporcionan a la industria una fuente alternativa de materias primas, lo que se traduce en una menor demanda de materias primas cuya extracción, transporte y procesamiento son una fuente importante de emisiones de gases de efecto invernadero. El reciclaje reduce así las emisiones en casi todas las industrias extractivas (minería, silvicultura, agricultura y extracción de petróleo) (Steiner, 2013). El Cuarto Informe de Evaluación del Panel Intergubernamental sobre el Cambio Climático (IPCC) afirma que "la minimización, el reciclaje y la reutilización de residuos representan medida de mitigación indirecta de las emisiones de gases de efecto invernadero, al favorecer la conservación de las materias primas, una mejor eficiencia energética y de los recursos, y evitar el consumo de combustibles fósiles" (Bogner, et al., 2008). Según el informe del PNUMA sobre residuos y cambio climático, la reducción de residuos es una fuente importante de reducción de emisiones por medio de la mejora del diseño de productos y una producción más limpia, lo cual aumenta la durabilidad y maximiza la facilidad de desmontaje de los productos (para el reciclaje) (UNEP, 2010). También se ahorra más energía (y emisiones asociadas) en el propio proceso de fabricación, ya que los materiales reciclados suelen requerir menos energía para su transformación en productos; esto es patente sobre todo en productos como el aluminio, ya que la energía directa requerida para reciclar es un $88 \%$ menor que la requerida para producir aluminio 
primario. El reciclaje de productos de madera y de papel tiene un doble impacto muy significativo: no sólo reduce la demanda de fibra de madera virgen, reduciendo así las emisiones derivadas de la deforestación, sino que también conserva la capacidad de los bosques de seguir actuando como sumideros de carbono, es decir, eliminando el carbono de la atmósfera (Schlesinger et al., 2006). Como podemos ver esta es la tendencia a seguir por los países de primer mundo, pero que hay del origen del problema, es decir la generación de los RSU.

Los países desarrollados de altos ingresos producen más residuos per cápita, mientras que los países de en vías de desarrollo, de bajos ingresos, por lo general producen menos residuos sólidos per cápita. Es pertinente aclarar que, aunque sean países de alto ingreso o bajo ingreso en general, suele haber excepciones e inconsistencias, por ejemplo, la India y sobre todo China tienen tasas desproporcionadamente altas de generación de RSU per cápita relativa a la situación económica global, ya que el tamaño de su población urbana es abundante; adicionalmente, las situaciones sociales que viven dichos países son muy semejantes a las de México. Por consiguiente, la gestión de los RSU que realizan estos países será analizada en este capítulo.

Otro punto importante que la Tabla 2.2 muestra, es la diferencia de la recolección de los RSU entre países en vías de desarrollo y los desarrollados, con respecto al porcentaje que gastan del total de sus presupuestos destinados a la GIRS. Mientras que en un país desarrollado se está consumiendo como máximo $10 \%$ del presupuesto, un país en vías de desarrollo se está gastando hasta un $90 \%$ de su presupuesto (Hoornweg y Bhada, 2012); esto se refleja en los costos del sistema de manejo de RSU. A partir de esta información, se busca analizar el manejo de RSU de los países que anteriormente se mencionaron: Suecia, Estados Unidos, China e India siendo Suecia el que encabeza la lista de éxito con el manejo de sus RSU debido a la implementación de sus innovadores conceptos que ya tienen varias décadas ejerciendo en esa nación; por otro lado, Estados Unidos está intentando dar el salto a la sustentabilidad, lo cual puede representar una oportunidad de aprendizaje con el país vecino. El caso de la India puede resultar interesante para México, debido al contexto político, social y económico que tiene dicho país y que es un tanto parecido al de México; finalmente China está intentando abordar su atenuado problema intensificando el número de investigaciones con respecto al tema, algo que pudiera aportar conocimiento a la CDMX, especialmente porque son lugares muy poblados. El análisis de los cuatro casos de estudio sigue la estructura de la Figura 2.12. Y explica el diagnóstico elemental de cada uno de los casos de estudio al igual que sus retos y estrategias además de una breve reflexión para cada uno de ellos. Al final de esta sección se hace un análisis comparativo con respecto al diagnóstico básico de cada caso y se sintetiza en una tabla las lecciones relevantes de cada caso de estudio clasificando las lecciones en cuatro puntos básicos:

- Gobierno y políticas públicas

- Financiero

- Participación ciudadana

- Tecnología e investigación 
Figura 2.12. Estructura del análisis de los casos de estudio.

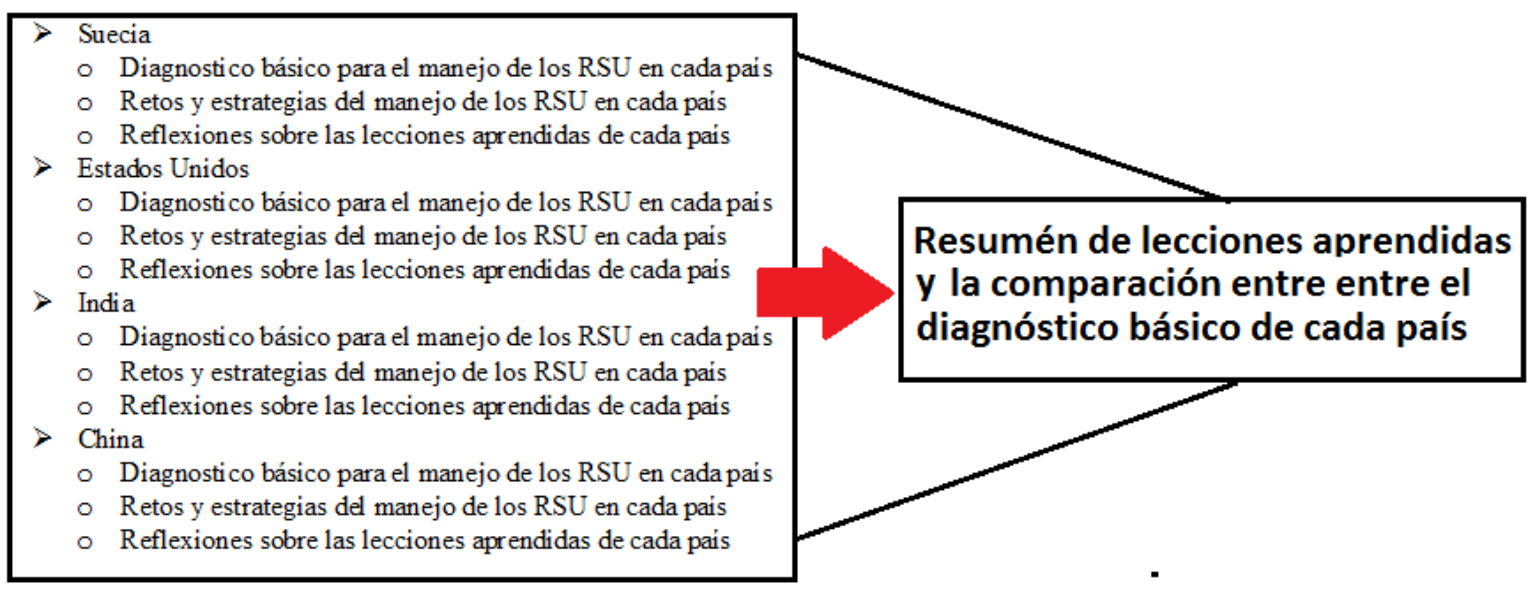

Fuente: Elaboración propia

\subsubsection{Suecia}

\section{Diagnóstico básico de los RSU en Suecia}

Es oficialmente llamado Reino de Suecia (Konungariket Sverige), es un país escandinavo de Europa del Norte que forma parte de la Unión Europea (UE). Limita al norte con Noruega y Finlandia, al este con Finlandia y el golfo de Botnia, al sur con el mar Báltico y al oeste con el mar del Norte y Noruega, tal como lo muestra la Figura 2.13. Tiene fronteras terrestres con Noruega y Finlandia, y está conectado a Dinamarca por el puente de Öresund. Su ciudad más poblada es Estocolmo, la cual también es su capital. Con una extensión de 449964 km², es el quinto país más extenso de Europa. En 2015, contaba con una población

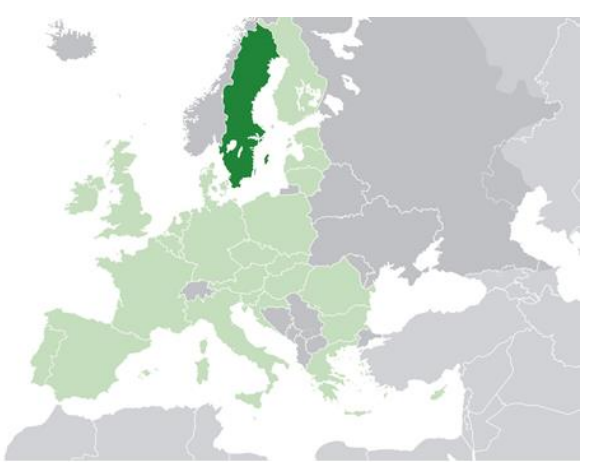

Figura2.13. Mapa de la ubicación de Suecia,

Fuente: Google Imágenes. total de poco más de 9.7 millones de personas. Cerca del $84 \%$ de la población vive en zonas urbanas. Los suecos disfrutan de un alto nivel de vida y con una organización y cultura corporativa que no es jerárquica, y colectivista en comparación con sus homólogos anglosajones (De Geer, et. Al.,2003). En general Suecia destaca ante el mundo por la conservación de la naturaleza, la protección del medio ambiente y la eficiencia energética, por lo cual son siempre son una prioridad en la formulación de políticas públicas que además son muy bien aceptadas por los ciudadanos suecos (Agencia Sueca de Protección Ambiental Naturvårdsverket, 2006).

Hace más de 30 años, Suecia fue la anfitriona de la Conferencia de las Naciones Unidas sobre el Entorno Humano. Aquel evento internacional colocó al medio ambiente en la agenda política mundial y para cierto número de los países, miembros que participaron en dicho evento, se sentaron las bases para que hubiera una mayor comprensión de las amenazas ambientales (Katja, 2013). El Gobierno Sueco realizó políticas ambientales que condujeron a resultados importantes en una serie de áreas, por ejemplo, en la reducción de sustancias peligrosas en los productos y la reducción de los RSU, así 
como en el fomento del reciclaje de materiales y la recuperación de energía a partir de dichos residuos (Opubor, 2004). En la actualidad, el país ha conseguido el reconocimiento internacional por sus estrategias ambientales y sus conocimientos técnicos en áreas como la tecnología ambiental y la gestión de residuos.

El país nórdico ha dado mucho de qué hablar dado a sus avances ambientales y sus encabezados ecológicos en cuanto a su fuerte importación de residuos de países como Noruega, Italia, Inglaterra, entre otros, y que muchos países desarrollados anhelan alcanzar. Sin embargo, detrás de toda esta infraestructura se esconde un arduo trabajo que no se ha gestado en un día, sino llevan trabajando en él desde 1940, con la creación de la primera planta de incineración del país sueco (Salas, 2014). Para el año 2014, el 96\% de los residuos en Suecia eran utilizados en plantas de incineración, las cuales proveen de calefacción a 950.000 hogares, y de electricidad a 250.000. Del total de sus RSU generados, tan sólo un $4 \%$ a $1 \%$ es depositado en los vertederos. El alcance del sistema de incineración es tan grande que la demanda de residuos es mayor que la cantidad producida, por lo cual Suecia ha tenido que importar residuos de sus países vecinos, principalmente de Noruega, con el fin de mantener activo el programa (Greentechnology, 2016). Sin embargo, este tipo de programas no tendría tal éxito, si no hubiera tan fuerte apropiación de la cultura del reciclaje por parte de los habitantes del país (Salas, 2014). La separación en la fuente es fundamental para la incineración, debido a que el $50 \%$ de los residuos incinerados proviene de desechos domésticos, en su mayoría orgánicos, que no pueden incluir metales, plástico, papel periódico, baterías y focos, entre otros, pues podrían afectar negativamente los procesos de incineración. Los sistemas que utiliza Suecia, técnicamente son conocidos como Waste to Energy WTE. La Figura 2.14 muestra el funcionamiento básico de esta tecnología. Estos procesos son el fundamento de más de 32 plantas que Suecia tiene WTE, el sistema WTE trabaja bajo el principio de que tres toneladas de RSU quemada, (a condiciones específicas de humedad) contienen tanta energía como una tonelada de combustible líquido (Salas, 2014; Greentechnology, 2016; Marshall, 2013).

Figura 2.14. Proceso general WTE Desperdicio a Energía (Waste-To-Energy) 


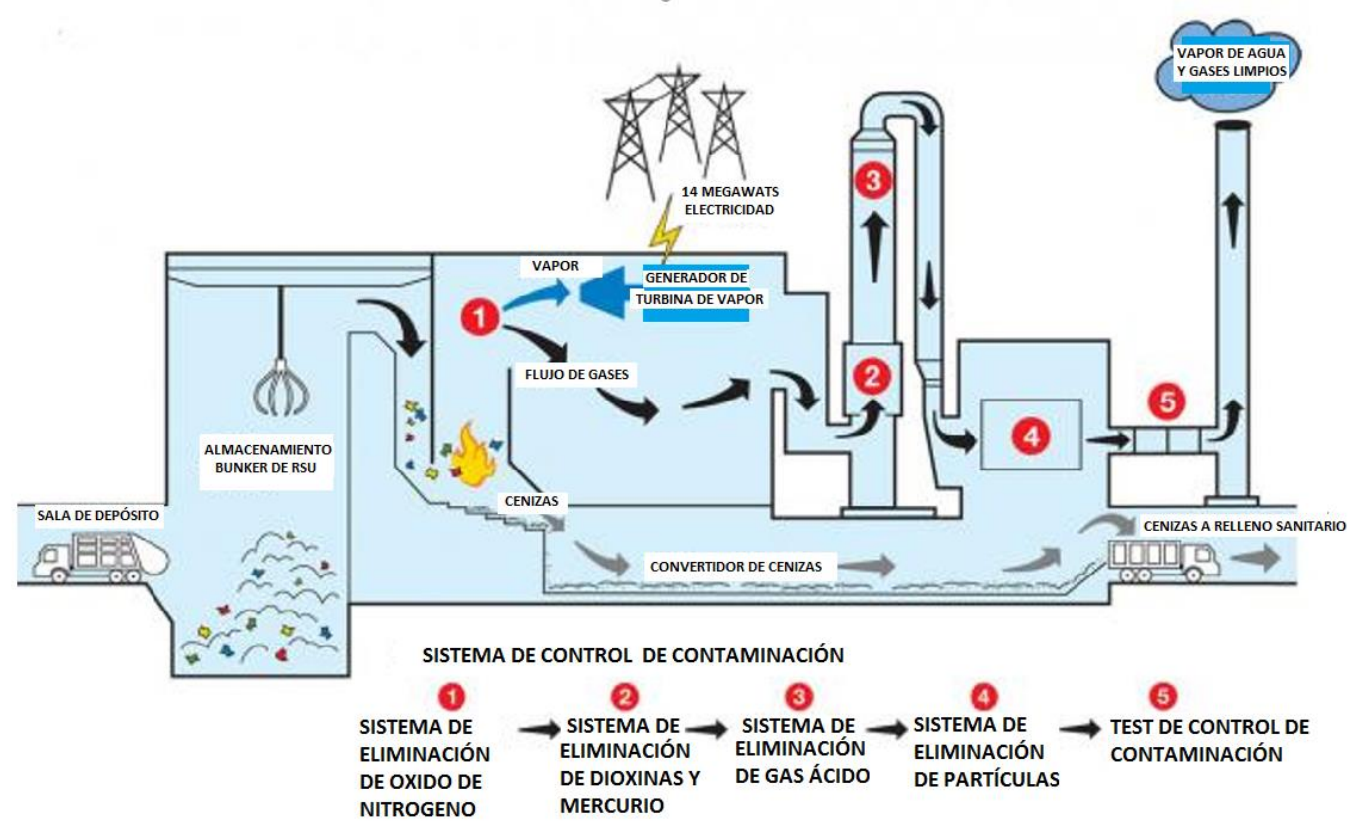

Waste-to-Energy

- 乌o\% De Reducción del volumín dé basura

- |Generación de energia

- control de contaminación

Fuente: www.ecomine.org

Para el 2016, Suecia recicla un 99\% de los RSU, pero esto se logra a partir de la obsesión que los suecos tienen por cuidar la naturaleza, su bien más preciado. Dado estas características del pueblo sueco, por ley debe existir al menos un centro de reciclaje en cada zona residencial y dado su extremadamente organizado sistema Suecia se ha visto en la necesidad de importar al menos el 12\% (800,000 toneladas) de los RSU necesarios para echar andar su programa (Salas, 2015; Greentechnology, 2016). A pesar de que el sistema de incineración de residuos puede ser costoso y variable, desde los 200 hasta los 650 millones de dólares como inversión inicial y dependiendo del tamaño de la planta, resultan interesantes las siguientes cifras, el proceso WTE exporta 0,6 MWh de electricidad por tonelada de residuos incinerados, lo cual se traduce a $380 \mathrm{GWh}$ de electricidad por año y un ingreso aproximado de US\$ 35 millones anuales para la planta más los bonos de carbono que se puedan vender en una planta pequeña, por lo que en general el proceso en general resulta redituable con una línea de recuperación de inversión amortizada aproximada de 15 a 20 años. En gran parte, es por esta razón que los países en vías de desarrollo tienen problemas para implementar este tipo de tecnologías, ya que otro tipo de factores como ambientales o propios del proceso se adaptan a las condiciones de operación. En general, se requiere de una alta inversión en infraestructura, Suecia ha demostrado ir en buen camino para la creación de sistemas limpios de gestión de residuos que pueden ser tomados como ejemplo y adoptados por otros países de Europa y del mundo.

\section{Retos y estrategias para el manejo de RSU en Suecia}

Los planes municipales de los suecos para manejar sus residuos 
En Suecia existe una gran responsabilidad de los gobiernos locales por atender cualquier cuestión que compete al beneficio o perjuicio de sus ciudadanos, por lo que las cuestiones ambientales son prioridad nacional y esto incluye, por supuesto, el manejo de RSU. Además, de las responsabilidades técnicas operativas, se espera que los ayuntamientos tengan planes cohesivos de gestión de residuos. Ese plan contiene información sobre las condiciones locales, referentes a cantidades de residuos y métodos de tratamiento, y resalta también las medidas planeadas por el mismo ayuntamiento para reducir la cantidad y la toxicidad de dichos residuos. Esa información es una herramienta vital a la hora de planificar estrategias a largo plazo para un sistema ambientalmente sano de manejo de residuos. De hecho, hay empresas privadas consultoras suecas que prestan servicios en Suecia y en el extranjero para desarrollar y asistir en la ejecución de planes completos de gestión de residuos, ya que en el país hay grandes conocimientos técnicos, a niveles de política y operativos, en los campos de la tecnología ambiental y de estrategias de gestión de residuos (Katja, 2013).

Aunado a lo anterior, los suecos como ciudadanos parecen ser de primer nivel, ya que suelen estar bastante involucrados e informados en las cuestiones ambientales y en las decisiones que sus gobernantes toman. Un ejemplo de esto, es un caso que se dio en un municipio de Suecia, ya que, para los hogares de un municipio sueco, una idea original sobre planificación medioambiental fue un ejercicio de participación cívica que involucró a toda la comunidad. A los hogares del distrito norte del municipio de Lund, en el sur de Suecia, se les exhortó a que contribuyeran a la planificación ambiental usando "el método del libro de trabajo". Los 4.000 hogares de ese distrito recibieron un libro de trabajo con preguntas cortas sobre distintas áreas ambientales, tales como los residuos, las aguas residuales, la energía y la calefacción, y sobre lo que pensaban los residentes del ambiente en su municipio. Un 50\%, aproximadamente contestaron a las preguntas. Los resultados, recopilados y distribuidos a los 4.000 hogares en otro libro de trabajo, fueron abordados asimismo en reuniones y seminarios que se celebraron después con residentes del distrito. De esta manera se elaboró un plan de acción temporal para la ejecución posterior con las mejores ideas que fueron presentados por los residentes a sus representantes electos del ayuntamiento. Paralelamente, se llevó a cabo un proceso con otro libro de trabajo, pero ahora entre los empleados municipales, en el que estos respondieron también a preguntas sobre diversos temas ambientales en su municipio (Opubor, 2004). En este caso también, las mejores propuestas fueron recopiladas con planes de acción y planes temporales para su realización. Como se puede ver, el ciudadano sueco, también muestra que es necesaria su intervención y que se tome en cuenta en la toma de decisiones de los gobernantes en cuestiones de importancia como lo es el manejo de los residuos.

Como se ha manejado en esta investigación, existen cinco fases o etapas que comprenden el manejo de los RSU, los suecos consideran esas mismas fases para su manejo: generación, recolección, procesamiento o manipulación, transformación y disposición final. Así que, una de las responsabilidades primarias de los ayuntamientos, es la oferta del manejo de residuos, lo que incluye el transporte de los residuos domésticos a las correspondientes áreas de tratamiento para su reciclaje o eliminación, así como la monitorización y aplicación de un sistema de tarifas justas para los usuarios de estos servicios. En términos reales, esto significa que las economías domésticas pagan el coste de la gestión de los residuos en los municipios, ya que son consideradas como productoras y poseedoras de residuos por lo que algunos ayuntamientos han establecido tasas de recolección de residuos escalonadas, a fin de incentivar una clasificación más eficaz de los residuos por parte de los residentes y minimizar la generación de dichos residuos (Salas, 2014). Es decir, cada bolsa de residuos debe tener una etiqueta con el peso y el costo por pagar, la bolsa más pequeña llega a costar hasta un euro tirarla a la basura. Esto puede variar dependiendo de la zona, pero en general paga más el que más genera y menos recicla. Esto en definitiva a transformado la visión que los ciudadanos suecos tienen 
con respecto a los residuos. De esta manera se obliga en cierta forma, por ejemplo, a que los mismos residentes puedan hacerse cargo de parte de sus residuos domésticos, a condición de que se haga de manera responsable y aceptable, como el compostaje. Aunque muchos planes de acción locales centran su atención en el compostaje y la separación de residuos, el reciclaje va también en continuo aumento como método de gestión de residuos. Además, los nuevos usos de materiales reciclados aumentan las posibilidades de la sostenibilidad en todo tipo de industrias. En general Suecia está produciendo $1.61 \mathrm{~kg}$ de RSU per cápita por día lo que da un total de 12,329 toneladas al día. Suecia no solo transforma sus residuos, sino que usa los residuos de países a su alrededor para general alrededor del 55\% de la energía total que consume.

Otro espectacular ejemplo, se desenvuelve en los escenarios del distrito de Liljeholmen, en Estocolmo, donde los suelos de la nueva estación del Metro relucen en tonos azules y verdes, lo que se ha vuelto una prueba más de la participación ciudadana, gracias a que los consumidores suecos cooperaron al reciclar sus botellas de vidrio. El vidrio reciclado y machacado ha sido mezclado con hormigón, de la misma forma que en otras ocasiones se usaron virutas de mármol para dar una dimensión extra de reflejo de la luz a superficies lisas. Las estadísticas recientes muestran que un $89 \%$ de los consumidores suecos reciclan su vidrio (Salas, 2014). Eso significa no sólo la existencia de una cantidad continua de vidrio disponible para usos secundarios, sino que muestra también que la conciencia pública en cuanto a las ventajas del reciclaje es muy alta en ese lugar. En Suecia, la conciencia ambiental comienza en una fase temprana de la vida, puesto que a los niños se les enseña ya en las guarderías los beneficios básicos de la clasificación de los residuos, ya sea para su reciclaje, reutilización o tratamiento (Sullivan, 2015).

Una combinación de tecnología ambiental de punta e iniciativas locales muy innovadoras, están ayudando a los municipios suecos a gestionar y tratar sus residuos sólidos. Los métodos usados para adaptar la política de gestión de residuos a las situaciones locales son varios, desde la monitorización de residuos en grandes sistemas de producción industrial, hasta el examen del impacto que tienen los estilos de vida en el ámbito del reciclaje y la minimización de residuos. Sin embargo, florece el nuevo concepto en el que últimamente se está desenvolviendo el manejo de los RSU como piedra angular para su éxito, este concepto lo denominan "gobernanza híbrida".

\section{Gobernanza híbrida en Suecia}

En Suecia, los tres niveles electos de gobierno, es decir, lo que comprende el Estado es el Riksdag (Parlamento), a nivel nacional; las Diputaciones, a nivel provincial; y los ayuntamientos a nivel local. Cada nivel de gobierno tiene sus respectivas áreas de responsabilidad y sus tareas en cuestiones ambientales. En este contexto, el gobierno sueco muestra gran compromiso a la hora de firmar acuerdos internacionales y no sólo los firma como parte de un protocolo. Los tratados internacionales, tales como la plataforma de las Naciones Unidas para el desarrollo sostenible, Agenda 21, y la legislación nacional sueca constituyen la base de muchas de las políticas ambientalistas aplicadas en dicho lugar. La Agenda 21, por ejemplo, establece que muchos de los mejores métodos para conseguir un desarrollo sostenible en el futuro tendrán que ser desarrollados a nivel local y con la participación ciudadana, así que los 290 municipios de Suecia aplican la Agenda 21 y han ampliado su ámbito del desarrollo sostenible para incluir asimismo los asuntos relacionados con el ambiente (Opubor, 2004). Este escenario es la que se vuelve común, prácticamente en todas las medidas que han venido implementando los suecos a lo largo de su desarrollo y conciencia ambiental. Es por eso que, de esta parte, y como respuesta a una necesidad, se desprende el concepto que los suecos describen como el principal éxito de su gestión ambiental en cuanto a manejo de RSU se refiere y la denominan gobernanza híbrida. 
Es de vital relevancia conocer primero el concepto de gobernanza, el cual se refiere a el "arte o manera de gobernar que se propone como objetivo el logro de un desarrollo económico, social e institucional duradero, promoviendo un sano equilibrio entre el Estado, la sociedad civil y el mercado de la economía" (Brenner \& Vargas del Rio, 2010). El objetivo de la gobernanza está basado básicamente en ejercer poder de manera consensual con negociación de intereses y mitigación de conflictos, donde la relación del Estado con la sociedad es de complementariedad y la forma de toma de decisiones es participativa con base a los resultados de negociaciones colectivas y de acuerdos comunes, complementando las estructuras gubernamentales. Los instrumentos de los que se ayuda la gobernanza son acuerdos ampliamente aceptados que comprometen efectivamente a todos los actores involucrados (Adger et al., 2003; Bulkeley, 2005; Schteingart, 2007; StollKleeman et al; 2006). Asimismo, la gobernanza enfatiza una implicación en la noción normativa y ética "referida tanto al ejercicio de la democracia participativa en la relación entre gobierno y población local o la sociedad civil en general, como a la eficiencia administrativa en la actividad gubernamental para lograr la legitimidad del régimen político" (Schteingart, 2007). Así, teniendo claro el concepto de gobernanza podemos pasar a identificar el significado de gobernanza híbrida.

La segregación de las divisiones tradicionales entre las esferas públicas y privadas, y las nuevas exigencias a la gobernanza crea nuevas oportunidades para el diseño de políticas en cuanto a las prestaciones de servicios, al menos así el gobierno sueco ha manejado esta situación. Así que, en respuesta a esto, en Suecia se han creado instituciones híbridas; en estas instituciones se juega un papel bastante interesante entre los organismos del sector público y privado, con los ciudadanos y las comunidades, todo esto en complejas estructuras institucionales (Sullivan, 2015). En esta creación, se mezclan diversos recursos para ofrecer la mayor posibilidad de lograr objetivos "en común", que de otra manera no serían de alto nivel de eficacia. Estos arreglos híbridos están ahora en prueba en todo el espectro de políticas y su desarrollo no muestra signos de disminuir. De hecho, se plantea que la gobernanza híbrida ya es la norma más que la excepción en las economías capitalistas avanzadas, como empresarios institucionales utilizan su empresa para adaptar las estructuras y para encajar con fines contemporáneos. Para algunos otros, estas formas híbridas son un ejemplo de la capacidad de adaptación a las circunstancias cambiantes de la democracia, pero para otros su desarrollo presenta demócratas con retos difíciles, con sus correspondientes riesgos y consecuencias inesperadas (Callaghan, 2010). Es decir, la gobernanza híbrida implica arreglos estructurales que involucran la interpenetración de las diferentes esferas y actividades del gobierno, empresas, y sociedad civil, sin fines de lucro también incluye organizaciones paraestatales, como las asociaciones público-privadas, de gestión de colaboración y redes de gobierno o de política (Sullivan, 2015). En la siguiente sección, se detallan algunos ejemplos de la gobernanza híbrida aplicada en Suecia para el caso del manejo de los RSU.

La asociación público-privada PPP por sus siglas en inglés (Public Private Partnership) es una de las formas más comunes de gobernanza híbrida, y que, por lo general los gobiernos han hecho mayor uso con la finalidad de obtener mejores resultados en el desarrollo de infraestructuras públicas o prestación de servicios públicos. En la PPP se formaliza acuerdos a largo plazo entre los agentes públicos y privados que pueden hacer uso del financiamiento privado para aprovechar un bien público, y que operan a través de una alguna forma de organización en particular.

La gobernanza híbrida específicamente aplicada a la GIRS, en Scania, municipio sueco.

La gestión de RSU en Suecia sigue una tendencia completamente europea, que básicamente está definida por la subcontratación o externalización, lo que comúnmente se denomina outsourcing, que 
no es más que el proceso en que una compañía identifica que parte de su proceso de negocio podría ser desempeñado de manera más eficiente y/o efectiva por otra corporación, la cual es contratada para desarrollar dichas actividades; esto, libera a la primera organización para enfocarse en la función central de su negocio (Porras, 2012). Este tipo de esquema de negocio ha caracterizado a la reforma de los servicios públicos en las últimas décadas.

Por lo general, las políticas gestionadas para el manejo de residuos, al igual que con las políticas con respecto al cambio climático, se han descrito como un área política de tercera generación (Montin, 2007) que implica la interacción compleja entre varias áreas políticas, así como grupos de interés privado, dónde la interacción y cooperación entre el un número de grupos de interés privado es la base de la gobernanza (Katja, 2013). En una forma más concreta, se puede explicar de la siguiente manera: la primera generación implica la democracia representativa, donde el poder es ejercido por medio de representantes; mientras que la segunda generación, comprende y provee servicios de asistencia pública, otorgados a un amplio sector público. Finalmente, llegan las políticas de tercera generación, que hasta ahorita ha tenido más éxito que las primeras dos, éstas están definidas por la participación de múltiples actores privados atendiendo problemas complejos, los cuales a su vez han generado un patrón de interacción mucho más complejo entre varios actores que incluso se contemplan en las dos primeras generaciones, incluyendo la comunidad y los gobernantes.

Así, estas áreas políticas coexisten en la sociedad contemporánea, como el caso que nos ocupa referente a los RSU. Por ejemplo, la responsabilidad municipal de los residuos sólidos urbanos en los domicilios es un ejemplo de una política diseñada inicialmente durante el apogeo de la prestación de servicios de bienestar o asistencia del sector público (en la recolección de dichos residuos), es decir con la segunda generación; posteriormente en combinación con otros actores empresas privadas que tienen que tienen a su cargo la generación de energía térmica y calorífica a partir de dichos residuos (Katja, 2013).

Los municipios tienden a subcontratar a compañías privadas para una total gestión de residuos o de otra manera gestionan los residuos a través de las compañías municipales, como lo es en el caso del noreste de Scania. La cultura política sueca en general, sigue siendo muy colectiva y basada en el consenso, lo que significa que las decisiones mayoritarias en el ámbito local, no dependen de las campañas individuales de los políticos locales. Mientras que Suecia ha introducido ciertas características de mercado en la administración pública, la idea de la política basada en el interés común es todavía dominante en la política local y la administración pública de dicho lugar (Katja, 2013). Por otro lado, los municipios aún no tienen permitido trabajar fuera de sus dominios geográficos. Aunado a esto, a las empresas de propiedad municipal no se les permite trabajar sobre una base con fines de lucro; por lo tanto, el principal costo de la gestión de residuos y la recolección en sí, queda a cargo de los habitantes. La prestación de este servicio, que tiene un valor sustancial y que no está dentro de un tipo de monopolio municipal, queda y debe ser abierta a licitación de acuerdo a la Ley de Contratación Pública. Esta ley, que entró en vigor desde el año 2007, marca la creciente importancia de la apertura a la competencia como un procedimiento para garantizar la competencia leal y un uso eficiente del dinero de los impuestos (Montin 2007). Muchos municipios han cooperado en la gestión de residuos sólidos domiciliarios a través de sociedades de responsabilidad limitada y propiedad del municipio desde la década de 1970; fecha en que las cantidades de residuos domésticos comenzaron a crecer y a los municipios se les dio la responsabilidad de la gestión de residuos por parte del Estado.

Uno de los más representativos ejemplos en Suecia de gobernanza híbrida en cuestión de GIRS, es el caso de siete municipios con un total de 500.000 habitantes, los cuales poseen conjuntamente la 
compañía regional de manejo de residuos sólidos urbanos: Solid Waste Company of Southwest Scania (SYSAV) Figura 2.15.

\section{Figura 2.15. Compañía de RSU del Suroeste de Scania, Suecia.}
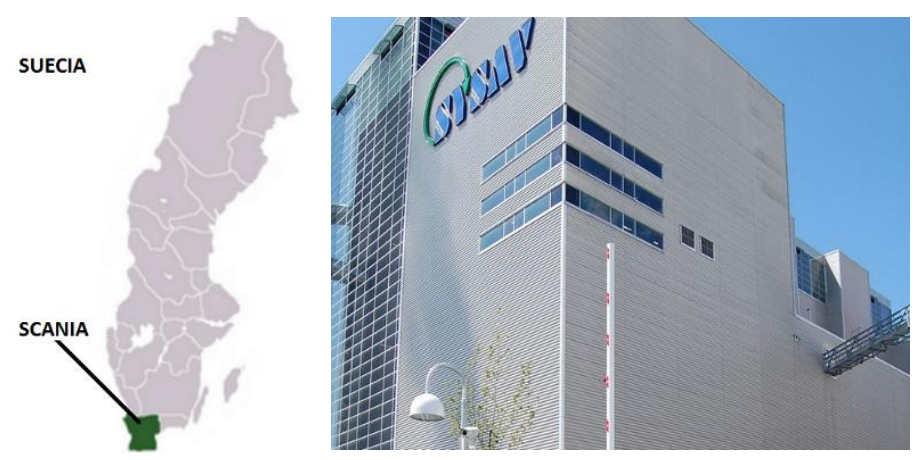

Fuente: Imágenes Google.

Las acciones de esta empresa se distribuyen de acuerdo con el número de habitantes de los diferentes municipios, lo que lleva a la ciudad de Helsingborg, a ser el accionista principal con el $51.56 \%$ de las acciones totales de esta compañía. Los otros municipios son mucho más pequeños que Helsingborg, Bjuvowning con 7.70\%, 6,40\% Bastad, Höganäs 11.48\%, 6.90\% Åstorp, y Ängelholm 15.96\% del total de acciones. Las asambleas municipales nombran a los miembros de la junta directiva de la NSR como máximo órgano que toma las decisiones formales en la compañía; ellos también están representados en el consejo asesor de propietarios (ägarråd). El Consejo Asesor no tiene poder de toma de decisiones formal, pero se genera gran debate entre los propietarios municipales con respecto a la empresa, fuera de las estructuras formales (Katja, 2013; Montin 2007; Salas, 2014). En realidad, es una estructura muy compleja, ya que también se tienen que hacer bastantes consideraciones, pues las casas de esos siete municipios son calentadas a través de la red de calefacción que esta empresa al norte de Scania, provee al de igual forma biocombustible generado en el mismo proceso para los camiones recolectores, lo que tiene un impacto positivo para los pobladores en el costo de sus servicios. Aunado a esto, los pobladores como accionistas, tienen el derecho de exigir documentos de tipo oficial y confidencial, que incluso tienen que ver con las estrategias económicas y de venta, que la empresa desarrollo, con el fin de mantenerse informados de lo que esté pasando con su inversión (Katja, 2013).

Esta empresa es responsable del tratamiento y eliminación final de distintas formas de residuos en la zona más meridional de Suecia (Opubor, 2004). Los residentes y las empresas locales realizan la clasificación inicial, lo que demuestra una comprometida participación ciudadana y una fuerte conciencia ambiental, además de que tienen amplios conocimientos en separación y clasificación de residuos. Por un lado, todos los desechos orgánicos generados en los hogares de estas localidades, son tratados por los mismos residentes de manera responsable a través de compostas, por otro lado los residuos que destinaran a la Compañía SYSAV están completamente separados en bolsas de diferentes colores, ya que separan en plástico claro y de color, vidrio claro y de color, papel, papel periódico, cartón, electrónicos, madera, textiles, cuero, metal, éste último tiene también varias clasificaciones, por ejemplo, no mezclan el aluminio con el fierro, o cobre, sino más bien son separados en diferentes contenedores. En realidad, no hay datos recientes de la composición de los 
RSU en Suecia, sin embargo, este no ha cambiado mucho en los últimos años, por lo que se puede considera que la composición general de dichos residuos oscila en los siguientes porcentajes: papel $44 \%$, vidrio $8 \%$, plástico $7 \%$, metal $2 \%$, orgánico $30 \%$, textil $0 \%$ y otros $9 \%$ (Llopis, 2011); una vez recogidos por SYSAV se integran al proceso WTE para la generación de energía verde. En general, toda la gestión de los residuos tiene como fundamento el ciclo ecológico, ya que los productos residuales son reutilizados con la misma finalidad, reciclados como materia prima para nuevos productos como, energía, lodos o cenizas, estabilizados biológicamente por medio del compostaje, o usados para generar biogás. Es importante tener claro que los residuos pueden ser incinerados y usados como combustible para producir energía eléctrica y térmica, pero para esto se requiere una gran infraestructura y mucho conocimiento técnico y operacional y donde los suecos son líderes mundiales (Opubor, 2004). Los residuos que pueden ser incinerados, representan una opción para reducir los volúmenes generales de desechos. En una planta de incineración de residuos completamente equipada, se pueden incinerar tanto los RSU de origen doméstico, como los residuos industriales orgánicos, tales como las virutas de madera. La energía así producida, como anteriormente se mencionó, se usa de diversas formas, por ejemplo, en la calefacción por distritos o en la generación eléctrica. Para dar viabilidad económica al proceso, las plantas de incineración tienen que contar con cantidades muy grandes de residuos, así como con estándares de emisión más estrictos. La emisión de dioxinas es una de las mayores amenazas ambientales procedentes de la incineración de residuos. En Suecia, donde se incinera casi un $42 \%$ de RSU de origen doméstico, el gobierno se asegura, que todas las plantas de incineración cumplan con los estándares de la Unión Europea (UE) para emisiones de Gases Efecto Invernadero GEI (Salas, 2014; Opubor, 2004). Como muestra podemos observar que Suecia ha sido de los únicos países industrializados que ha logrado una reducción de gases efecto invernadero los cuales contribuyen al cambio climático. Aunado a esto, después de la incineración, es importante conocer lo que se hace con los residuos; además del desecho del horno, quedan cenizas volátiles del equipo de purificación del gas, las cuales generalmente, no están contaminadas y en algunos países, se utiliza en la construcción de carreteras.

\section{Reflexión final sobre Suecia.}

Tomando todo lo anterior en cuenta, se puede observar, que la persistencia de los ciudadanos, gobernantes y empresarios suecos por el cuidado del medio ambiente se debe en gran parte a su visión empresarial. Pues para ellos los RSU no son un desecho inservible, sino más bien son materia prima para la generación de nuevos productos comercializables. Además, es importante destacar, el largo recorrido que los suecos han hecho para lograr tener esta visión, ya que como se mencionó anteriormente desde 1940 el tema ambiental es una prioridad para este país. Sin embargo, no solo tienen bastantes años previniendo la contaminación, sino que más bien han encontrado una fuente de vida en los RSU, ya que han logrado incorporarlos a un ciclo ecológico, que además se vuelve bastante bien remunerado. La sustentabilidad ambiental que los suecos han desarrollado, se debe en gran parte a que han entendido que la naturaleza es la que provee todo lo necesario para vivir, por lo tanto, se volvió prioridad protegerla y cuidarla de todo tipo de abusos que pongan en riesgo su existencia. Además, el claro compromiso de cada uno de los ciudadanos, por fomentar la educación ambiental, incluso desde grados tan básicos como prescolar, son importantes de reflexionar, pues en gran parte los ciudadanos son los que exigen a sus gobiernos la generación de nuevas estrategias para mejorar la eficiencia en el manejo de los RSU en dicho país.

Sin embargo, Suecia no es el único país que muestra tener, a través de sus cifras, grandes avances con respecto al manejo de sus RSU y a su GIRS de manera general. Del otro lado del mundo en Norteamérica, Estados Unidos también hace grandes esfuerzos por manejar sus cifras y llevarlas hacia la sustentabilidad; es por eso que el siguiente caso de estudió se desenvolverá en territorio 
norteamericano y tratando de buscar que es lo mayormente le ha ayudado al más grande generador de RSU en el mundo (Hoornweg y Bhada, 2012).

\subsubsection{Estados Unidos}

\section{Diagnóstico básico de los RSU en Estados Unidos.}

Estados Unidos es el tercer país con mayor superficie del mundo la cual es de 9.826.630 kilómetros cuadrados, es una gran diversidad natural, geológica y cultural. Situado en la zona intermedia de Norteamérica, como lo muestra la Figura 2.16 y limita al sur con México; este país incluye una amplia gama de distintos paisajes, desde las playas tropicales de Florida hasta los picos alpinos de las Montañas Rocosas, pasando por las praderas y los desiertos baldíos del Oeste y los parajes de naturaleza salvaje del Nordeste y Noroeste. Con una población: 296.483.000 hasta el 2014. Estados Unidos es una nación multicultural, hogar de una amplia variedad de grupos étnicos, tradiciones y valores. Aparte Figura 2.16. Mapa de la ubicación de de las ahora pequeñas poblaciones de nativos americanos y Estados Unidos. Fuente: Google Imágenes hawaianos, casi todos los estadounidenses o sus antepasados emigraron durante los últimos cinco siglos (Morrison, 1999). La cultura común para la mayoría de los estadounidenses es una cultura occidental, que en gran parte proviene de las tradiciones de los inmigrantes europeos con influencias de muchas otras fuentes, tales como las tradiciones traídas por los esclavos de África (Adams, 2001; Holloway, 2005; Johonson, 1999). Recientemente, los inmigrantes de Asia y Latinoamérica han añadido más elementos a esta mezcla cultural que ha sido descrita como «un crisol de razas homogeneizados y en una ensaladera heterogénea», en donde los inmigrantes y sus descendientes retienen, comparten y absorben varias características culturales distintivas. Esta razón pudiera influenciar de muchas de muchas formas a la hora de disponer los RSU. Ya que cada cultura tiene su forma de ver los residuos; sin embargo, el gobierno estadounidense lo largo de su historia, ha buscado a través de sus leyes y normas homogenizar cierto tipo de costumbres que pudieran afectar al medio ambiente. Por ejemplo, en algunos países de Latinoamérica se considera que la mejor manera de disponer los residuos finalmente es quemándolos al aire libre, lo cual es penado en EU. Por otro lado, la tendencia consumista que existe en el ciudadano norteamericano, es general. EU es un país desarrollado con una de las economías más fuertes del mundo y como se h ha visto a lo largo de esta investigación el modelo económico capitalista va de la mano con el incremento de la generación de los RSU.

La Agencia de Protección Ambiental (EPA) en Estados Unidos (EU) ha fungido como la máxima autoridad en cuanto al medio ambiente se refiere en dicho país, por lo que ha generado gran número de documentos de todo tipo, tanto de nivel científico, como dirigidos al público en general, con el fin de informar y educar a los habitantes norteamericanos. La Agencia de Protección Ambiental, también ha reunido y presentado datos sobre la generación y eliminación de residuos en los Estados Unidos durante más de 30 años. En general, se hacen este tipo de estimaciones con el fin de utilizar esta información para medir el éxito de la reducción de residuos y programas de reciclaje a lo largo del territorio norteamericano (EPA, 2012). Los números que fácilmente reflejan el éxito del manejo de los residuos básicamente es la generación con respecto a lo que se lleva a la disposición final, ya que 
todo lo que no se deposita, debió ser tratado, valorizado, reutilizado, transformado, etc., por lo que eso números básicamente son clave para conocer el éxito de una nación en el manejo de sus RSU.

En 2006, las cifras de generación de RSU no eran muy alentadoras para Estados Unidos ya que generó alrededor de 250 millones de toneladas de residuos sólidos urbanos, equivalentes a 2.1 kilos de residuos diarios por persona. Con fin comparativo, en 1960 el porcentaje por día de generación de residuos era de 1.2 kilos por persona, lo que significa que la generación de RSU ha incrementado sin control en los últimos años. Sin embargo, para el 2012, la cantidad de RSU per cápita fluctuó hasta en 2.5-3.8 kg en algunas ciudades de este país por New York y Los Ángeles (Hoornweg y Bhada, 2012), lo que equivale a 251 millones de toneladas en el año 2012 (EPA, 2012). Esta situación ha puesto a reflexionar a los tomadores de decisiones de dicho país, con el fin de modificar esas cifras con base en la prevención y la reducción de la generación de los residuos.

En 1980, como lo muestra la figura 2.10, el reciclado y el compostaje ocupaban el $10 \%$ del tratamiento, en tanto que el $90 \%$ de los RSU dispuesto en rellenos sanitarios. Para el 2005, estas cifras cambiaron significativamente y esto también se debió en gran parte a que se comenzó a ver el reciclaje como una fuente de ingresos; así entonces, el 55\% era enviado a rellenos sanitarios, el 32,5\% era recuperado para reciclar o tratar en compostaje y el 12,5\% era incinerado para generar energía. En 2006, con el reciclado y el compostaje, 82 millones de toneladas fueron desviadas de su disposición final (OPDS, 2010). Como podemos ver en la figura 2.17, ha habido un gran avance, ya que ahora se usa un $12.5 \%$ para generar energía limpia y sólo el 55\% se dispone en rellenos sanitarios y hay un $32.5 \%$ que se recicla. Es relevante mencionar que también hubo incineración hacia los años 80, sin embargo, ésta con el paso del tiempo, dejó de cumplir con las actuales normas de generación de dioxinas, es decir el proceso de incineración se ha ido encareciendo debido a que se tienen que respetar las emisiones de contaminantes al aire permitidas, por otro lado, el reciclaje tomó fuerza ya que tiene un efecto positivo en la economía del país. De esta manera se le dio preferencia a invertir en nuevas tecnologías para la mejora del reciclaje y se le dejó de prestar suficiente atención al proceso para convertir desechos en energía limpia. Por otro lado, los materiales que se reciclan se vuelven materia prima para diferentes procesos en el mismo país o se venden a otros países que los utilizan para la fabricación de nuevos productos, como es el caso de China. Este país consume botellas de polietileno (PET) reciclado para la elaboración de otros productos de plástico cómo juguetes o bolsas recicladas del plástico.

\section{Figura 2.17. Manejo de RSU en Estados Unidos}




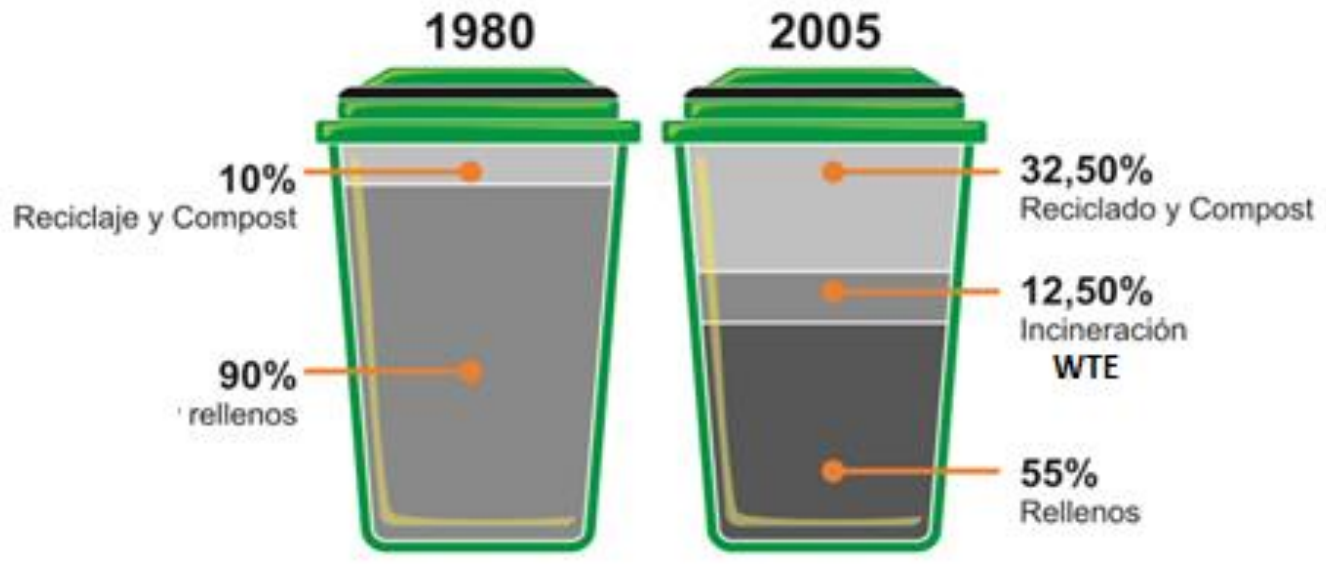

Fuente; EPA, 2012

Los RSU estadounidenses, por lo general tiene cierta composición en común a lo largo del territorio, estos incluyen artículos tales como envases, residuos de alimentos, restos de césped, sofás, computadoras, llantas, y refrigeradores, sin incluir el manejo de los residuos peligrosos industriales o de construcción. En el año 2012, los estadounidenses recuperaron más de 65 millones de toneladas de los RSU a través del reciclaje y más de 21 millones toneladas a través de compostaje. Por medio de la combustión para generación de energía, se recuperaron alrededor de 29 millones de toneladas lo que representó un $12 \%$; esto hace que se eliminen o dispongan finalmente un promedio de $1.32 \mathrm{~kg}$ per cápita de RSU. Aunado a esto, en 2012, la recuperación de la batería de plomo-ácido fue de aproximadamente $96 \%$ (2.8 millones de toneladas); otros materiales que fueron recuperados pueden identificarse en la Figura 2.10, los cuales incluyen baterías, latas, llantas, etc. Finalmente, sobre 135 millones de toneladas de RSU (53.8 por ciento) fueron desechadas en vertederos en 2012 como lo muestra la Figura 2.18, lo que representó un 1.2\% menos que en el 2005. Pareciera poco, pero si se contempla el aumento en la generación y se compara entre ambos años, el avance fue grande, ya que para el 2005 se generaba $2.1 \mathrm{~kg}$ per cápita y para este año, en algunas ciudades llegó hasta $4.2 \mathrm{~kg}$ per cápita, es decir casi lo doble (Hoornweg y Bhada, 2012; EPA, 2012). 
Figura 2.18. Porcentaje de reciclados en productos seleccionados

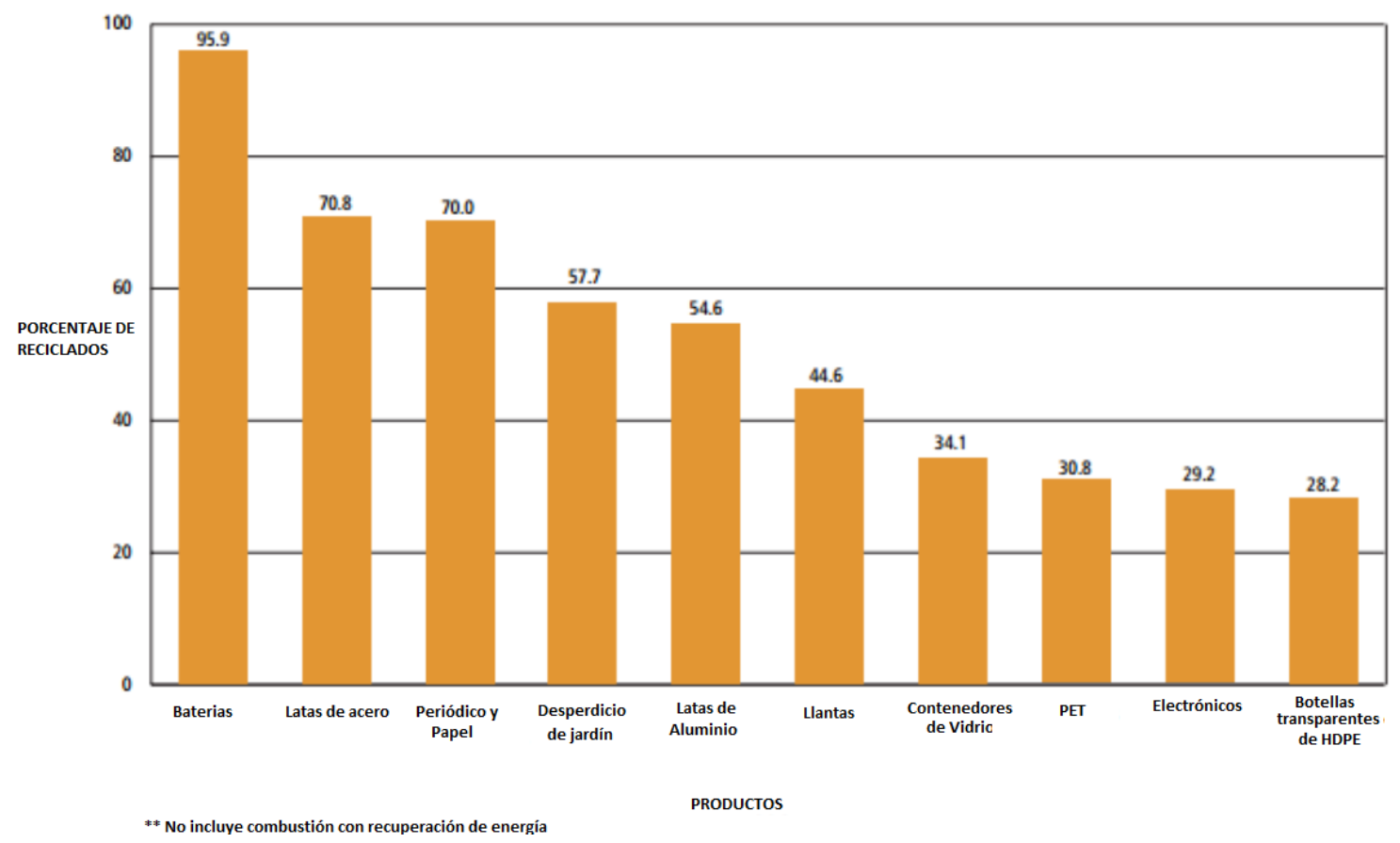

Fuente: EPA, 2012.

Como podemos ver en la Figura 2.18. Se le da gran importancia al reciclaje de las baterías, en general por el gran peligro que estas representan para la contaminación del suelo y mantos acuíferos principalmente. En México las baterías son consideradas como residuos de manejo especial o residuos peligrosos. Por otro lado, el resto de los componentes de la gráfica son considerados como RSU y la mayoría se genera en hogares, así que de esta manera se pude apreciar como el reciclaje tiene gran importancia en la sociedad y el gobierno norteamericano.

Figura 2.19. Manejo de RSU en Estados Unidos

\section{MANEJO DE RSU EN EU PARA EL AÑO 2012}

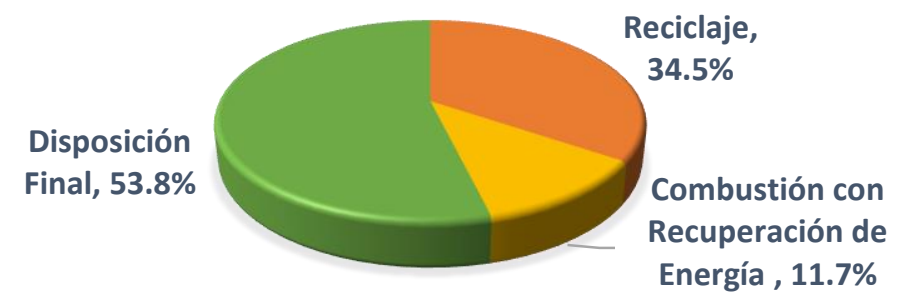

Fuente: EPA, 2012. 
Estos datos realmente se pueden dimensionar cuando los vemos expresados de la siguiente manera: los estadounidenses reciclan casi 87 millones de toneladas de residuos sólidos urbanos; lo cual, se traduce a un beneficio anual en la reducción de más de 168 millones toneladas métricas de dióxido de carbono, comparable a la emisión anual de gases de efecto invernadero de más de 33 millones de vehículos. Dicho de otra forma, el reciclaje de 87 millones de toneladas de RSU ahorró más de 1.1billones de British Thermal Unit BTU de energía, lo que equivale a la misma cantidad de energía consumida por casi 10 millones de hogares estadounidenses en un año. (EPA, 2008; 2012).

Como se puede ver, EU ha estado trabajando arduamente en tratar de minimizar los efectos negativos que los RSU implican al ambiente y como una consecuencia a la salud humana. Una manera de atacar el problema, como anteriormente se ha mencionado, es conocer la composición de los RSU, ya que esta información se vuelve necesaria y una herramienta para saber que procesos o transformaciones se le pudiera hacer a los RSU, que sean factible económica y técnicamente, además de ser aceptados por la sociedad. Motivo por el cual la EPA, ha generado una serie de cifras que tienen que ver directamente con el tipo de material que se encuentran en los RSU de dicho país. Como anteriormente se dijo, la generación total de RSU en 2012 fue de 251 millones de toneladas. La Figura 2.20 muestra el desglose de los RSU generados, por material. Los materiales orgánicos tales como papel y cartón, restos de jardín y residuos de alimentos, continúan siendo el componente más grande de los RSU en los EU: el papel y cartón representan más del $27 \%$ del total de los residuos generados y el otro $28 \%$ proviene de los residuos de comida y jardín. Por otro lado, el plástico comprende aproximadamente $13 \%$ del total de los residuos generados; mientras que los metales constituyen alrededor del 9\%; el caucho, cuero y textiles representan casi un $9 \%$; la madera un $6.3 \%$ del total, y el vidrio $4.6 \%$.

En general, se puede observan en esta gráfica que los materiales reciclables, son de diferentes tipos, pero al igual que en México, la mayor parte de los materiales son de origen orgánico, es decir si tomamos en cuenta el porcentaje de los desechos de comida, de jardín y de madera, todos de origen orgánico, estos se transforman alrededor del 35\%, aunque para México este porcentaje aumenta el $10 \%$, los rangos son similares. Otro porcentaje importante es el de papel y cartón, que por sí solos casi llega al 30\% lo que da un buen margen para la incineración de los RSU y su transformación a energía limpia.

Figura 2.20. Generación total de RSU antes de ser reciclados, en el año 2012. 


\section{GENERACIÓN TOTAL POR MATERIAL DE RSU, 251 MILLONES DE TONELADAS} (ANTES DE SER RECICLADOS).

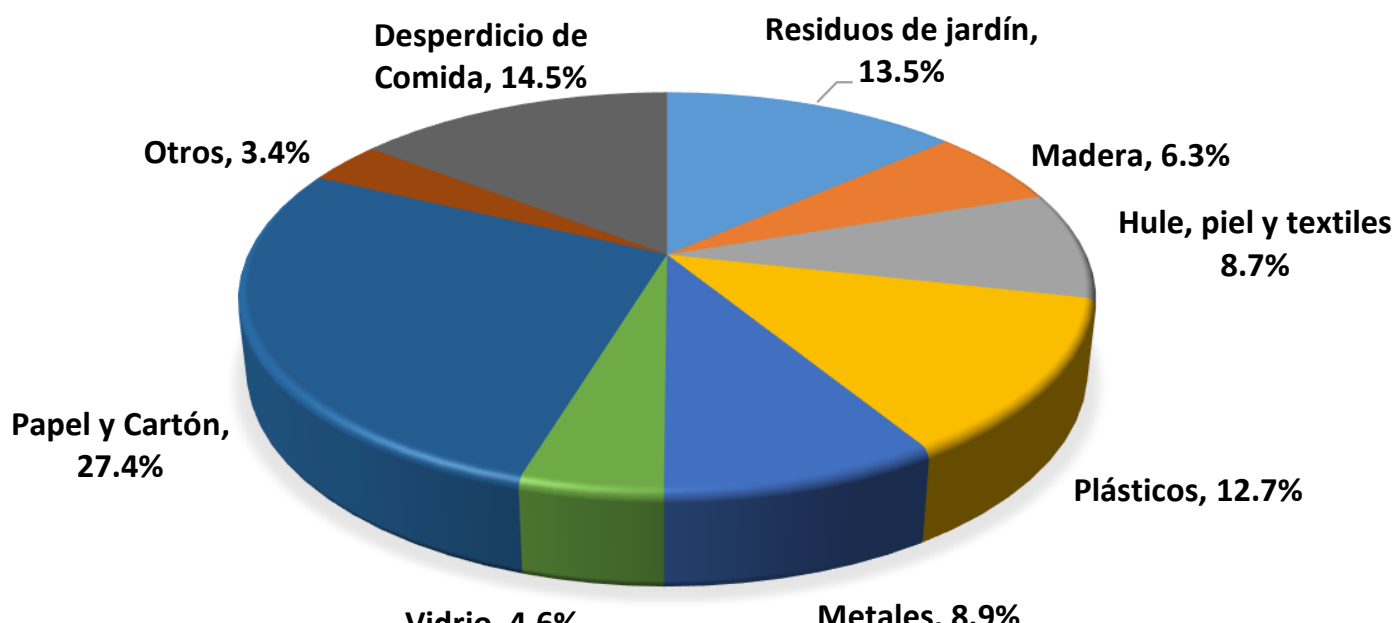

Vidrio, $4.6 \%$

Metales, $\mathbf{8 . 9 \%}$

Fuente: Elaborado con base en EPA, 2012

Sin embargo, a la hora de reciclar surge una absoluta diferencia con los residuos que se van a disposición final, ya que EU ha implementado una serie de programas para fomentar el reciclaje entre sus ciudadanos (por ejemplo, qué programas; en qué consisten; en dónde se aplican (en todos los estados o varían por estado). Este tipo de programas traen un fundamento que más adelante analizaremos. La Figura 2.21 muestra la recuperación total de RSU en 2012, la cual fue de casi 87 millones de toneladas: el papel y cartón fue el residuo que más se recuperó representando $51 \%$ del total de los residuos recuperados, seguido por los residuos de jardín con alrededor del 22\%; destaca que de los residuos de alimentos sólo se recupera el 2\%, lo cual es bajo. En cuanto a los metales, se comprende aproximadamente un $9 \%$; vidrio $4 \%$ y plástico y madera aproximadamente $3 \%$. Es importante reflexionar sobre la gran cantidad de material disponible que EU tendría para hacer WTE, sin embargo, es algo que se está complicando para el gobierno estadounidense, muchas veces también tiene que ver la calidad y grado de humedad que los RSU tienen para llevar a cabo este proceso.

Figura 2.21. RSU recuperados en EU para el año 2012 
TOTAL DE RSU RECUPERADOS, 87 MILLONES DE TONELADAS.

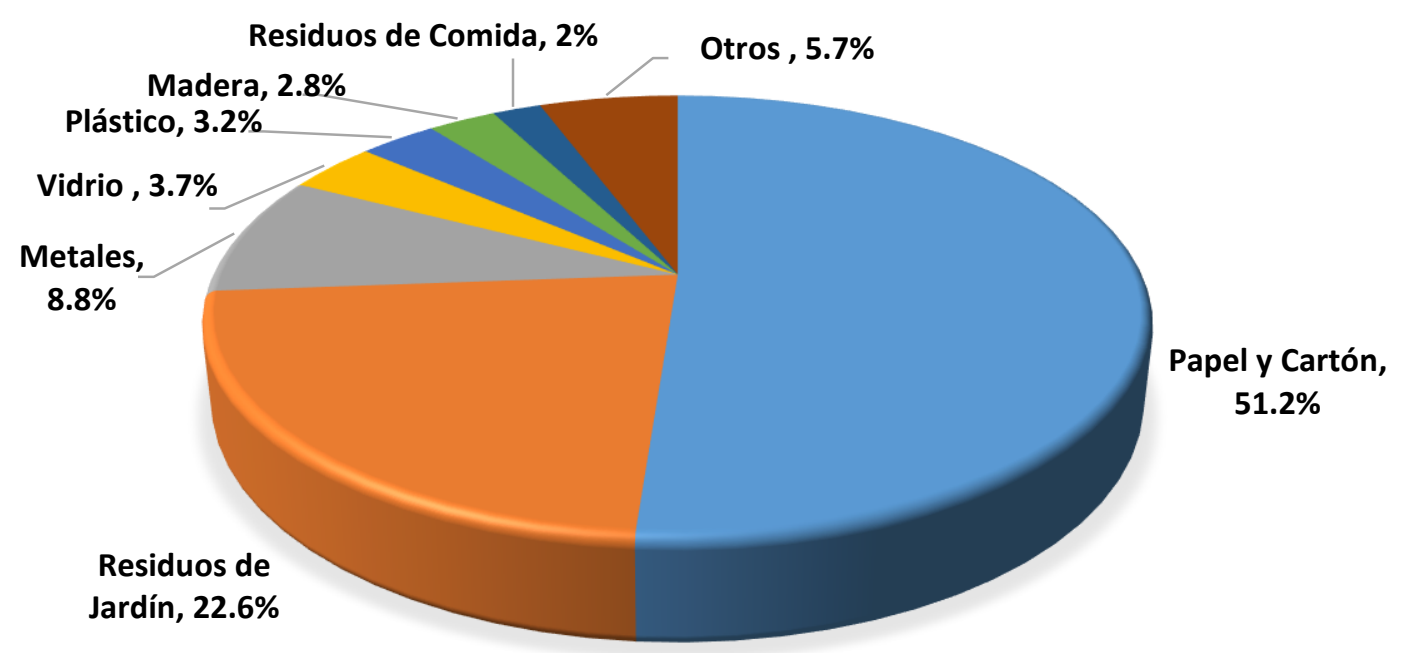

Fuente: Elaboración propia con datos de la EPA, 2012.

Aunque el gran aumento en la recuperación de RSU se dio entre el año 1990 y 2005, las cifras siguen creciendo de manera un poco más lenta, pero esto se debe al aumento también de la generación total de RSU en el país. Esto puede deberse básicamente al aumento del consumo y al aumento de población que ha incrementado notablemente los últimos años. Esto significa que el manejo de los RSU requerirá mayor presupuesto también y por lo tanto la situación con respecto al manejo de los RSU puede volverse tensa o difícil.

\section{Retos y estrategias para el manejo de los RSU en Estados Unidos}

\section{Tendencias en el manejo de RSU en Estados Unidos}

Éste significativo avance se debe en parte a las labores de la EPA, ya que se encuentra continuamente generando información y aplicando programas para integrar en los ciudadanos una cultura total con respecto al cuidado que se debe tener a la naturaleza. Los programas y la gestión ambiental, básicamente está priorizada por dicha agencia. Estas prioridades van de acuerdo a un esquema que la agencia publicó años atrás. Jerarquizar las estrategias de tratamiento de residuos compatibles con el ambiente es el principal método que EU sigue. La minimización en origen (incluidas la separación domiciliaria y la reutilización) es el método preferido, seguido por el reciclado y el compostaje y, finalmente, los rellenos sanitarios y la generación de energía por medio de la combustión. En la Figura 2.22 podemos ver dicha jerarquización propuesta.

En General, aunque la mayoría de cada uno de los estados en Estados Unidos tiene sus propios planes de manejo, todos están basados en la propuesta de la Figura 2.22. La prevención es la prioridad en cada uno de los programas que las grandes ciudades de dicho país tienen. Al igual que en México, el manejo de los RSU es responsabilidad de los gobiernos locales, o lo que cada gobierno pone en marcha sus propios programas. Existen programas muy populares que se aplican en las principales ciudades de los Estados Unidos, cómo:

- Jobs Through Recycling Empleos a través del reciclaje: El objetivo del Programa de Empleos a través del Programa de Reciclaje, JTR por sus siglas en inglés, es construir una 
infraestructura para fomentar las empresas de reciclaje o reutilización que aumenten el uso de materiales reciclables o reutilizables y contribuyan a la creación de empleos y al desarrollo económico. El programa JTR reúne a las comunidades de gran desarrollo económico, esto a través de donaciones, redes e intercambio de información. JTR intenta hacer la experiencia en reciclaje dentro de agencias especializadas en desarrollo económico además de colocar herramientas de desarrollo empresarial - asistencia técnica, financiamiento y mercadotecnia en manos de los profesionales especialistas en reciclaje.

- Pay-As-You-Throw PAYT Pague lo que tira: es un programa donde los hogares pagan por la recolección de basura y por la cantidad de basura recolectada, esto en lugar de una tarifa fija. De esta manera, los hogares ahorran dinero tirando menos basura y aumentan su reciclaje. Por esta razón, la EPA ha desarrollado un kit de herramientas PAYT, tales como hojas de datos, lecciones aprendidas e historias de éxito para ayudar a más comunidades a la implementación de los programas PAYT, ya que este programa solo se encuentra en algunas ciudades de este país y no a lo largo de él.

- WasteWise, Desperdicio inteligente: es un programa voluntario sin fines de lucro, creado para ayudar a las empresas, agencias gubernamentales y organizaciones a ahorrar dinero al reducir su basura. Las organizaciones se unen al programa por un período de tres años y establecen metas en tres áreas: prevención de residuos, recolección de materiales reciclables y la compra o fabricación de productos reciclados. Unirse a WasteWise reduce costos y al mismo tiempo desperdicios de la empresa u organización, una parte importante de este programa, está basado en aprender de los exitosos de otras empresas que ya hayan tomado el programa WasteWise. Unirse al programa no cuesta nada y se otorga reconocimiento público a aquellas empresas que tienen más éxito al alcanzar los objetivos de reducción de residuos.

Esto son tan sólo tres ejemplos de programas exitosos (EPA,2016), y se observa que todos están basados en la jerarquía de la Figura 2.15. Esta jerarquía implica la mayor parte de la atención en la prevención. Una de las cosas a destacar es que los países en vías de desarrollo difícilmente pueden enfocarse en realzar programas destinados únicamente a la prevención, ya que los recursos destinados al manejo de los RSU son pocos y están destinados totalmente a la disposición y la recolección de los mismos (Hoornweg y Bhada, 2012).

Figura 2.22. Jerarquía de Gestión de Residuos 


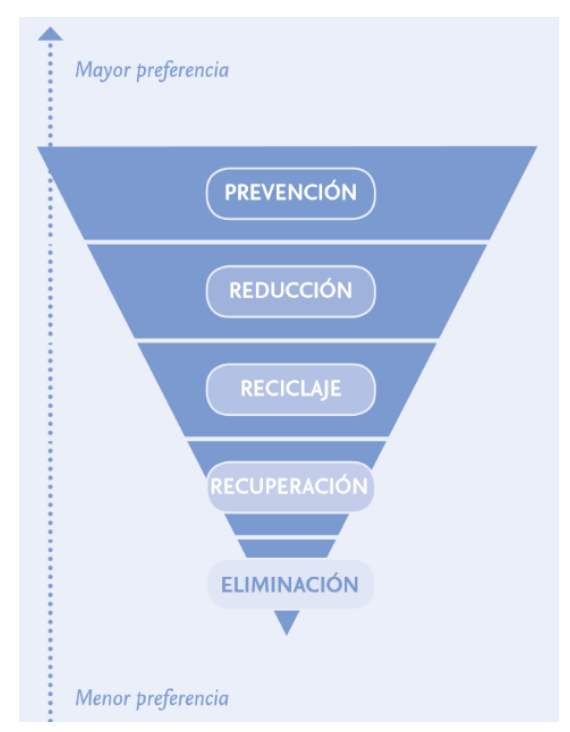

Fuente: (EPA, 2008; UNEP, 2012)

La jerarquía de gestión de residuos indica un orden de preferencia de medidas conducentes a reducir y gestionar los residuos, y suele presentarse de forma esquemática como se ve en la Figura 2.15, este esquema, aunque fue propuesto por la EPA y fue presentado de la misma manera por UNEP en el 2011 (Programa de las Naciones Unidas para el Medio Ambiente, 2013). La jerarquía de residuos se presenta como una pirámide invertida, porque el propósito primordial de la política en Estados Unidos es principalmente, tomar medidas para prevenir que se generen residuos, ya que estos son considerados como el origen del problema. La siguiente medida por orden de prioridad consiste en reducir los residuos (por ejemplo, a través de la reutilización). El reciclaje, incluido el compostaje o la digestión anaeróbica, es la siguiente medida, seguida por las de valorización de materiales y de conversión de residuos en energía. La valorización energética a partir de procesos tales como la combustión y/o pirolisis forma parte también de la recuperación; por último, la cantidad de RSU que se lleve a disposición final, debe ser la mínima en medida de lo posible (UNEP, 2011), ésta, como última medida debe ser la eliminación, ya sea en vertederos o mediante incineración sin valorización energética, debe evitarse en medida de lo posible. Esta medida es el último recurso para los residuos que no se han podido evitar, desviar o recuperar en los pasos anteriores. Por debajo de la incineración sin valorización energética o de los vertederos debidamente diseñados y administrados (EPA, 2008).

\section{Los beneficios que trae para EU el reciclar}

EU, a través de sus programas intenta hacer ver a sus ciudadanos, que el reciclaje o la recuperación de los RSU tienen beneficios ambientales y por consecuencia minimiza los efectos negativos en la salud humana. La recuperación de los RSU tiene beneficios en todo su ciclo de vida, desde ahorrar materia prima, ya sea reutilizándola o siendo el material inicial de alguna industria, evitando así que esta llegue a sitios de disposición final. Sin embargo, se encuentran en un camino complicado, ya que depende mucho de la participación ciudadana, como se ha visto en el caso de Suecia. Por otro lado, la EPA se ha encargado de dar a conocer que los RSU contribuyen a los gases efecto invernadero que a su vez propician el calentamiento global, por lo que se exhorta al ciudadano norteamericano a hacer compostas con sus propios RSU orgánicos generados en casa, lo que los haría hacerse responsables de sus propios RSU. Pero sobre todo repercutiría positivamente en sus bolsillos, ya que se ahorrarían un cobro en el servicio de recolección y generarían un buen acondicionador de suelo, desde luego si 
la composta se realiza con las condiciones adecuadas. Es importante mencionar, que el éxito y fracaso de los programas del manejo de los RSU están basados en la adecuada separación principalmente, y para ello se requiere gran participación ciudadana. La sociedad estadounidense, parece ser participativa e informada a la hora de separar los residuos, en gran parte se debe también a que se usan instrumentos económicos para ello. Es decir, si un ciudadano realiza composta en su jardín trasero de una manera responsable, este recibe apoyo económico y además información, también si no separa sus residuos adecuadamente o genera muchos residuos se le cobran multas. Esto ha logrado de cierta forma concientizar al ciudadano de lo mucho que cuesta, monetariamente, a los gobiernos el manejo de los RSU.

Otro camino que EU se encuentra explorando es el de la recuperación de RSU para generar algún tipo de energía limpia, ya sea térmica o eléctrica. Este camino, es bien sabido, está muy bien recorrido por los europeos y EU no quiere quedarse atrás, así que utiliza alrededor de un $12 \%$ se su total de RSU generados para producir energía verde (EPA, 2012), de la misma manera que se hace en Suecia, con el principio de WTE. El primer incinerador de Estados Unidos fue construido en 1885 en la isla de Gobernadores, en Nueva York y fue hasta mediados del siglo 20 que el incinerador comenzó a funcionar. Posteriormente, no fue sino hasta el año 1960, que se supo de los impactos ambientales de las descargas en el agua y de las emisiones atmosféricas de estos incineradores, entonces con la Ley de Aire Limpio (CAA), que fue promulgada diez años después, la mayoría de los incineradores que no instalaron la tecnología necesaria para cumplir con los requisitos de la CAA, cerraron (EPA, 2013) y de esta manera se estancó su avance tecnológico, ya que los incineradores quedaron sujetos a dicha ley y fueron prohibidos por el tipo y cantidad de emisiones que generaban; así que muy pocas instalaciones que contaban con la tecnología adecuada fueron las que quedaron funcionando. La combustión de RSU creció hasta la década de 1980, con más del 15\% de todos los RSU generados en EU. La mayoría de los incineradores de residuos no peligrosos en este tiempo se usaban para la recuperación de energía y se habían instalado equipos de control de la contaminación. Pero nuevamente se encontraron en disyuntiva para el año de 1990, ya que la generación de mercurio y dioxinas puso en aprietos a muchas instalaciones de este tipo y muchas de ellas no pudieron colocar sistemas más complejos de control de contaminación y cerraron nuevamente. Esto debido a que la EPA interfirió nuevamente y generó nuevas leyes que promulgaron límites permisibles para este tipo de contaminantes (EPA,2014)

Es así como EU, no ha podido superar el bache en cuanto a la tecnología WTE, y uno de los principales obstáculos, sin duda alguna, han sido los tremendos costos que estos implican, ya que el capital inicial necesario para construir una planta de combustión de RSU puede requerir típicamente al menos \$ 100 millones de dólares por adelantado para financiar la construcción; plantas más grandes pueden requerir doble al triple de esa cantidad (EPA, 2013). Además, de que los beneficios económicos de la incineración de RSU pueden tardar varios años para reponer la inversión. Los contratos a largo plazo (generalmente 30 años) a menudo se desarrollan entre la instalación y el municipio para asegurar un flujo de residuos. Por otro lado, las instalaciones de combustión de RSU suelen tener al menos tres fuertes "salidas" de dinero: cuando es necesario pagar a un privado por un aporte de RSU, además también se debe pagar por la eliminación de cenizas y desechos que deja esta industria (EPA, 2014). La cantidad de cenizas generada radica entre los rangos de 15 a $25 \%$ en peso de los RSU procesados y 5-15\% del volumen de los RSU procesados. En general, los residuos de combustión de RSU consisten en dos tipos de material: cenizas volátiles y cenizas de fondo, las cenizas volátiles se refieren a las partículas finas que se desprenden del gas de combustión y son entre un 10 y $20 \%$. El resto de la ceniza de combustión RSU, se denomina cenizas de fondo ( 80 a $90 \%$ en peso). 
Los principales componentes químicos de las cenizas de fondo son sílice (arena y cuarzo), calcio, óxido de hierro y óxido de aluminio. Las cenizas de fondo, por lo general tiene un contenido de humedad de 22 a 62 por ciento en peso seco. La composición química de la ceniza varía dependiendo de la materia prima original de RSU y el proceso de combustión. La ceniza que queda del proceso de combustión de RSU se envía a los vertederos (EPA, 2014). Esta situación no ha podido ser lidiada por los norteamericanos, ya que las cenizas y otras emisiones de la combustión de los RSU siguen siendo un obstáculo para su aceptación y desarrollo tecnológico. Sin embargo, resulta interesante cuestionar el por qué se pueden emplear las cenizas en otros países, como Suecia, donde se venden como materia prima para grandes construcciones como puentes y carreteras.

\section{Reflexión final sobre Estados Unidos.}

Es importante poder reconocer el esfuerzo que se hace por educar a los habitantes de un país en cuestiones que generalmente no se les daba gran importancia, como lo es el cuidado del medio ambiente, especialmente en países, que como se mencionó al inicio de este apartado, son multiculturales. Este es el caso de Estados Unidos que, a pesar de las grandes diferencias entre las ideologías de sus habitantes, en un tema tan en común para todos, se puedan establecer normas y reglas y que estas sean respetadas. EU en general mantiene una gran cantidad de programas funcionando todo el tiempo, los cuales como se vio anteriormente están enfocados a la prevención mediante la educación de los pobladores y reforzadas desde luego, con los incentivos económicos como multas a quien no respeta los límites y recompensas a quien lo hace bien. Es bien sabido que no todo el tiempo el panorama para EU ha sido alentador, sino que se pudo observar a lo largo de este apartado que ha sido un trabajo de varias décadas y que, aunque aún no se logran cifras tan impresionantes como las suecas, se sigue trabajando constantemente. En general, un país de primer mundo con todos los recursos, económicos, técnicos y científicos, continúa teniendo dificultades para manejar sus RSU, pero entonces ¿cuál es panorama que esperan tener los países en vías de desarrollo, como la India? Donde, como cualquier país en vías de desarrollo, carece de infraestructura, así como de recursos económicos, técnicos y científicos y por encima de esto, la mayor parte de la población no tiene ningún tipo de conciencia ambiental.

\subsubsection{India}

\section{Diagnóstico básico de los RSU en la India}

La India, oficialmente República de la India es un país ubicado en el sur de Asia, con más de 1240 millones de habitantes se vuelve el segundo país más poblado, después de China con 1370 millones el cual es el país más poblado del mundo. La india tiene una superficie de 3,3 millones de $\mathrm{km}^{2}$, lo cual lo ubica como el séptimo país más extenso del mundo. Limita con el océano Índico al sur, con el mar Arábigo al oeste y con el golfo de Bengala al este. La India también limita con Pakistán al oeste; al norte con China, Nepal y Bután y al este con Bangladés y Birmania, tal como lo muestra la Figura 2.23. Además, la India se encuentra cerca de las islas de Sri Lanka, Maldivas e Indonesia. Su capital es Nueva Delhi y su ciudad más poblada es Bombay. En 2015, la economía india era la

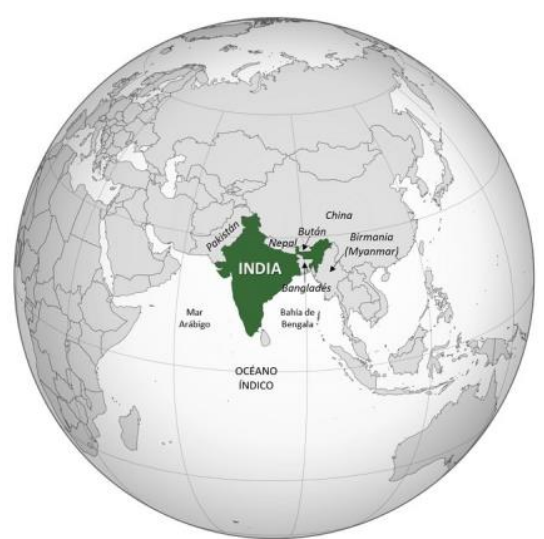

Figura 2.23 Mapa de la ubicación de India Fuente: Google Imágenes. 
séptima más grande del mundo y la tercera en términos de paridad de poder adquisitivo ya que las reformas económicas de 1991 la han transformado en una de las economías de más rápido crecimiento (USDA,2009); sin embargo, todavía sufre de problemas como los altos niveles de pobreza, analfabetismo, pandemias, malnutrición y constantes violaciones de los derechos de las mujeres, por lo que se considera un país en vías de desarrollo según la Comisión especial del gobierno de la India.

Desde una perspectiva de países en desarrollo y con una densa población como lo es India, la Gestión Integral de Residuos Sólidos Urbanos (GIRS) se vuelve un gran reto, no sólo para los gobernantes sino también para los habitantes, debido a las nuevas tendencias de gobernanza que están aplicando países como India. La falta de planes apropiados, restricciones económicas, debilidad institucional, la ausencia de tecnología para reciclar, y desde luego la apatía de los habitantes hacia la GRSU son las componentes más importantes de este codicioso reto. Una efectiva GIRS depende sobre todo de la correlación entre lo que los indios denominan elementos multidisciplinarios o de manejo: generación, almacenamiento, recolección, procesamiento, y disposición final y aspectos estratégicos (participación tecnológica, conciencia social, gobernanza, y recursos financieros) (Gupta y Kumar, 2013).

Diferentes elementos o etapas del manejo de residuos son descuidados o incluso olvidados en la mayoría de los países en vías de desarrollo; es por eso que en esta investigación se ha hecho énfasis en que el manejo de los RSU que es la médula espinal de la GIRS. Aunado a esto, una población creciente que se refleja claramente en el aumento en la generación de RSU y aunque existen diversas tecnologías a lo largo del mundo, especialmente en países desarrollados, para países como India que son países del tercer mundo, estas tecnologías resultan ineficaces. Es decir, la mayoría del tratamiento que se le da a los RSU para generar energía limpia, requiere de una perfecta separación, esto definitivamente no ocurre en países en vías de desarrollo como lo es la India, ya que la mayoría del tiempo un ciudadano común no tiene ni siquiera idea de lo que es un residuo de origen orgánico o inorgánico. Este tipo de problemas complica el proceso, por ejemplo, de pirolisis, ya que al no separar adecuadamente los RSU, a la hora de querer incinerarlos estos pueden estar húmedos y echar a perder el proceso de la pirolisis.

Un elemento en común entre países desarrollados y en vías de desarrollo es la tendencia del incremento en la generación de RSU; incremento que se presenta principalmente en las zonas urbanas. Según Hoornweg y Bhada (2012), se ha reportado que las ciudades del mundo generan en promedio 1.3 billones de toneladas de RSU al año; al mismo tiempo esta investigación enfatiza, en su primer capítulo, sobre la relación que existe en este incremento de la generación con el nivel económico del país. India en particular, ha incrementado su generación en un rango de $1.33 \%$ anualmente, lo que significa que las ciudades indias están generando alrededor de 8 veces más de lo que generaba por los años 50’s (Kaushal et al, 2012; Hoornweg y Bhada, 2012), lo cual agrava más el problema por la pobre infraestructura que éste país presenta para en el manejo de sus RSU en todas sus etapas.

India, conociendo sus limitaciones de infraestructura, apuesta por un modelo que comience por las políticas con bases muy bien fundamentadas en la gobernanza y que comiencen desde la médula espinal de la GIRS. Esta médula espinal está compuesta por las siguientes etapas, como se muestra en la Figura 2.24. 
Figura 2.24. Elementos multidisciplinarios para el manejo de RSU.

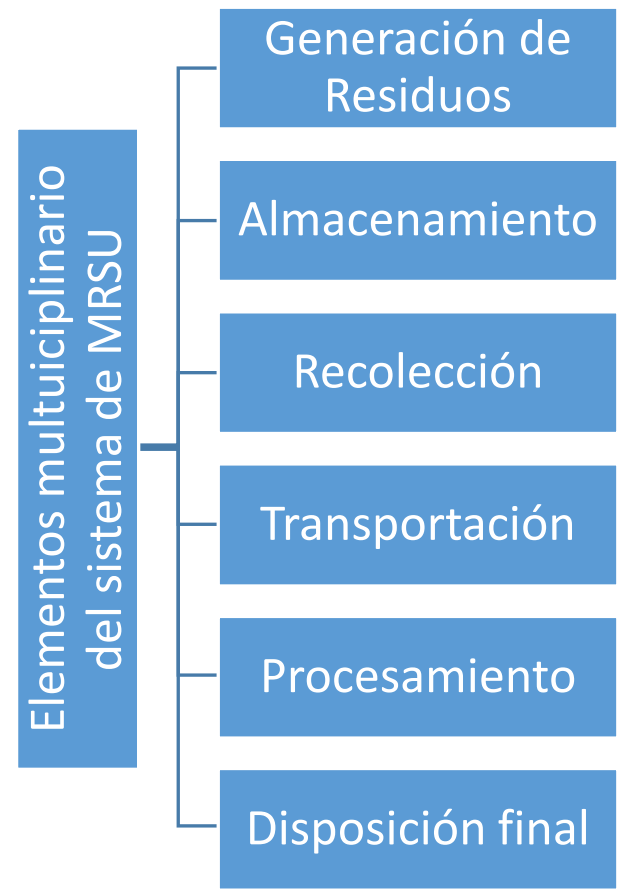

Fuente: Elaborado con base en Kaushal (2012).

En la Figura 2.24 podemos ver que, a diferencia de esta investigación, los elementos multidisciplinarios son seis y no cinco. Sin embargo, en general ellos le llaman elementos multidisciplinarios y no fases de manejo. Incluyen una fase extra que sería almacenamiento, la cual no es considerada por esta investigación ya que, en México, la única vez que se almacena es cuando la tiene en espera de ser recolectada el generador de los residuos, una vez recolectada esta ya no pasa por ningún tipo de almacenamiento, sino más bien se transporta directamente para su aprovechamiento o a sitios de disposición final.

Sin embargo, el objetivo de cada fase o elemento multidisciplinario se encuentra inmerso en cada una de las fases y elementos que se han venido manejando a lo largo de esta investigación. Los números que representan a India, no son por nada alentadores ya que, en dicho país se generó alrededor de 1.27 billones de toneladas al año, de los cuales el $70 \%$ ( 0.89 billones de toneladas) es recolectado y solo el $12.5 \%$ de los RSU es tratado y procesado. La composición básica de estos residuos es una mezcla de papel, plásticos, vidrio, y metales, sustancias tóxicas (pinturas, pesticidas, medicamentos, y baterías usadas), y desechos orgánicos como desechos de comidas, frutas y verduras y comprenden un aproximado del 50\% de la generación total de RSU (CPCB, 2012).

El método más común para el almacenamiento de los residuos, en India, es un bote de basura común. Todo tipo de residuos orgánicos e inorgánicos, incluso el médico-infecciosos, son depositados en botes de basuras comunes desde su origen en domicilios. Es bien sabido, que los RSU que no están bien separados y peor aún, cuando se encuentran mezclados con residuos peligrosos, además de perder su valor, son más difíciles de tratar, ya que hay contaminantes peligrosos muy persistentes y que tienen que tratarse con procesos muy complejos para evitar que sigan contaminando. Un ejemplo de esto, que suele ser muy común, es el de las pilas, ya que estas se depositan en los botes de basura del hogar, a su vez estos residuos generan lixiviados que pueden contaminar con mercurio grandes 
cantidades de agua. El mercurio es uno de los principales componentes de las pilas y deben ser considerados residuos peligrosos y manejarse de manera especial. De ahí que todos los residuos desagregados son transportados a un segundo almacenamiento llamado "Dhalaos" o estaciones de transferencia. Las estaciones de transferencia son utilizadas para almacenar y transferir los residuos que se van a tratar a las plantas de tratamiento y los que se van a llevar a los sitios de disposición final (Gupta \& Misra, 2013). En las prácticas actuales de MRSU el almacenamiento es lo más molesto para la población, por lo tanto, es muy difícil ver depósitos limpios y bien manejados. Usualmente la gente solo llega y lanza la basura a los depósitos sin importar siquiera que la basura caiga en los contenedores; aunado a esto animales extraviados toman los basureros como viviendas y dispersan aún más los residuos. Es por eso, que es de suma importancia en un sistema adecuado de MRSU, seleccionar adecuados contenedores de RSU que no solo reducirían el tiempo de procesamiento de los residuos, sino también se ahorraría tiempo a la hora de clasificarlos y seleccionarlos (Kaushal et al, 2012).

En cuanto a la recolección, parece ser muy ineficiente y por lo general, la mayoría de las prácticas de recolección en la mayoría de las ciudades es a través de un sistema comunitario de recolección, sin embargo, existen otros métodos como colección de residuos casa a casa como. En general, la recolección tiene varias debilidades (Kaushal et al, 2012; Gupta \& Misra, 2013; Kurian et al., 2007):

- Los vehículos de recolección no son diseñados apropiadamente ya que no pueden ser usados en todo tipo de áreas ni lugares.

- Los depósitos de almacenamiento no se encuentran bien distribuidos, en algunos distritos se encuentran varios y unos muy cerca de otros, mientras que, en otros no hay un suficiente número de contenedores además de que se encuentran separados unos de otros, de tal forma que a los barrenderos les es muy complicado cumplir con su función en tiempo y forma.

- Todo el equipo que se usa es equipo convencional, por ejemplo, los instrumentos para limpiar una casa, en vez de ser equipo especial dado que el trabajo de limpia es diferente en magnitud e intensidad.

- La mayoría de los barrenderos no usa ningún equipo de seguridad, como guantes mascarillas, ropa o zapatos especiales mientras recolectan y sortean los residuos, lo cual les hace más complicado desempeñar su trabajo. Aunado a esto, la mayoría de este tipo de trabajadores no tienen educación, motivo por el cual se le hace más complicado entender los impactos a la salud que esto podría traer a sus vidas.

En la India, el transporte de los RSU es llevado a cabo por varios vehículos; el trasporte depende de la ubicación de los residuos, la cantidad de estos y la distancia de los sitios de transferencia a los sitios de disposición final. El trasporte a los puntos de trasferencia es en carretillas, o carretas tiradas por animales, de los contenedores en los sitios de trasferencia a los sitios de disposición final los residuos se transportan en camiones abiertos; esta trasportación es demasiado olorosa y sin higiene, tan es así que es fácil de detectar vehículos de este tipo desde grandes distancias. El trasporte es bastante ineficiente, lo cual implica riesgos ambientales y varios riesgos de salud tanto para los trabajadores como para los pobladores. Esto se debe principalmente a que los municipios no siguen las normas de transporte, lo que nos lleva a reflexionar sobre la necesidad de gobernanza con respecto al sistema de manejo de RSU (Gupta \& Misra, 2013).

Se reconoce completamente en India que el procesamiento de los RSU es esencial, pero este implica costos y tecnologías efectivas, primordiales obstáculos con los que dicho país se enfrenta. Sin embargo, este aspecto ha comenzado a tener relevancia, aunque era un aspecto totalmente olvidado. 
Las tecnologías reportadas a lo largo de la India comprenden la composta y lombri-composta mayormente, y en una muy menor cantidad plantas de biogás (CPCB, 2012). Aunque sólo se trata alrededor del 12\% de los residuos orgánicos (Gupta \& Misra, 2013), este aspecto ha ido progresando en los últimos años. Por otro lado, el tratamiento de residuos peligrosos es de los más complicado de manejar ya que se requiere de un mayor apoyo tecnológico e India, definitivamente carece de ello.

Finalmente, en cuanto a su disposición final, la India como la mayoría de los países en vías en desarrollo, los RSU son depositados en tiraderos a cielo abierto y no controlados, son prácticas comunes que arrastran consigo graves problemas ambientales y de salud. En la india más del 90\% de los RSU en las ciudades y pueblos se tira directamente al suelo, ya sea en tiraderos a cielo abierto o en las calles de la ciudad (CPCB, 2012). En general uno de los retos más grandes que están viviendo los gobiernos municipales en la India, es enseñar a los ciudadanos a identificar los tiraderos. Sin embargo, es confuso para los ciudadanos porque la mayoría de los tiraderos se encuentran limitados de espacio y otros están al límite (Gupta \& Misra, 2013).

\section{Retos y estrategias para el manejo de los RSU en India.}

En general las investigaciones generadas en torno a la India, pregonan que la GIRS se centra en la correlación de diferentes atributos que contemplan dicho sistema. Los que elementos que podemos ver de manera horizontal y que están secuenciados de maneja conjunta en forma de cadena son: generación, clasificación, recolección, tratamiento, procesamiento, y disposición final. Por otro lado, los atributos verticales son los aspectos estratégicos que regulan y proporcionan resistencia al sistema de manejo de los RSU y son: gobernanza, conocimiento, participación ciudadana, tecnología y los recursos financieros. Los atributos tanto verticales como horizontales, deben ser cubiertos por el gobierno, organismos locales, organizaciones no gubernamentales, la comunidad, los trabajadores, etc. (Gupta \& Misra, 2013; Gupta \&Kumar, 2014). Una manera sencilla de ver esto puede ser haciéndose tres preguntas básicas ¿Qué debe hacerse? Que responde a las necesidades y lo componen los atributos horizontales, ¿Cómo debe hacerse? Que los responde los atributos verticales, y ¿Quién debe hacerlo? Que se responde con los elementos que envuelven a ambos atributos tanto horizontales como verticales (ONU Hábitat, 2010). Esto se encuentra explicado en la Figura 2.25.

Figura 2.25. Elementos horizontales y verticales, básicos para lograr un buen manejo de RSU en la India. 


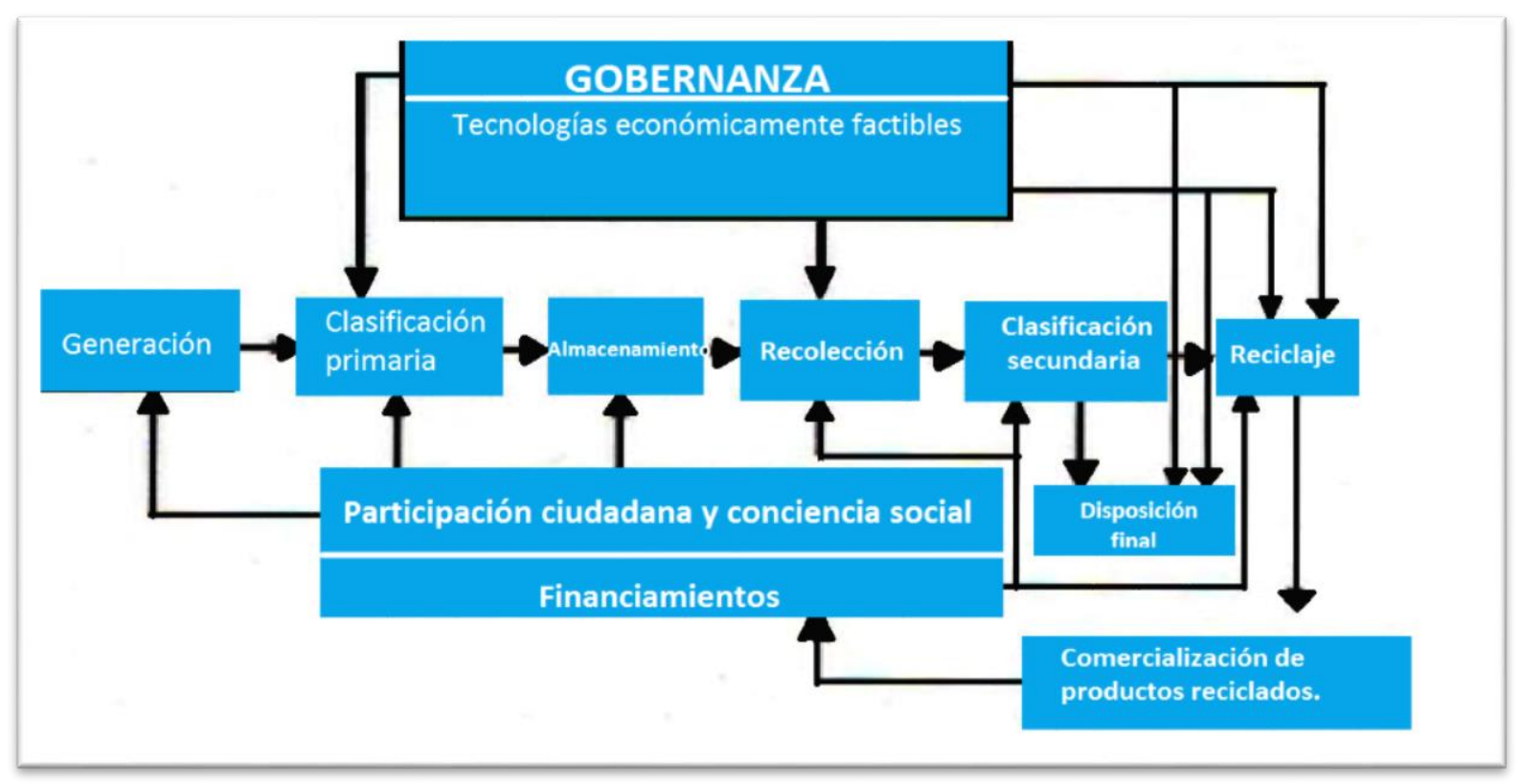

Fuente:Gupta \&Kumar, 2014.

La conciencia social y la participación ciudadana

El papel de la sociedad, para el manejo de RSU es un punto clave e indispensable, ya que teniendo una conciencia ambiental deben cambiar las practicas convencionales para el tratamiento de RSU. La educación de las masas, la motivación para diferentes grupos de la sociedad, y la voluntad de la sociedad en general son aspectos fundamentales en cualquier programa de manejo de RSU (Gupta \& Misra, 2013). Como sabemos uno de los puntos clave para el manejo de los RSU y por consecuencia en la GIRS de un país, comienza por una verdadera sensibilización de su pueblo, ya que éste es la fuente de generación de los RSU y es justo aquí donde la comunidad comienza a jugar su papel. Sin embargo, debemos recordar que no solo minimizar la generación es suficiente, otro problema muy fuerte y en el que la sociedad tiene gran parte la responsabilidad, es la adecuada clasificación. Ya que, aunque se generaran pocos RSU si estos no se manejan adecuadamente, siguen siendo un problema tanto para el ambiente como para los humanos. Si bien es cierto que, si se minimiza la generación de RSU, este a su vez reduce otro tipo de problemas, pero en sí, se debe trabajar en las medidas que se adoptan antes de que cualquier material, sustancia, o producto se convierta en residuo y tenga efectos adversos ambientales y de salud pública. Sin embargo, para los indios puede haber formas sencillas que puedan ayudar a minimizar la generación de RSU las cuales se describen a continuación (Gupta \& Misra, 2013; Gupta \&Kumar, 2014).

- La generación de residuos puede minimizarse mediante la promoción de la utilización de materiales reciclables, biodegradables o lavables. Disminuir la cantidad de necesidad de consumo y reutilización de productos o envases existentes también provocarán un efecto en la generación de RSU

- La eficiencia del sistema de gestión se puede mejorar con la ayuda de la comunidad si se mantiene la clasificación y almacenamiento de residuos adecuado. Los residuos clasificados son fáciles de procesar y requiere menos mano de obra lo reduce el costo. Además, el manejo de estos residuos también no perjudicaría a los trabajadores y recolectores. 
- La comunidad también puede tomar medidas simples como evitar el desperdicio de comida, fruta y considerar que con los residuos de ese tipo se puede hacer el compostaje de residuos de jardinería, desde la comunidad de su hogar.

Alrededor del $20 \%$ de la población en la India se queda por debajo del umbral de la pobreza y hay una falta de conocimiento con respecto a las consecuencias de las prácticas poco saludables de gestión de residuos sólidos. Aquí, el papel de las sociedades de salud, grupos de autoayuda, y ONG es significativo y clave para ejecutar programas de rutina en cada comunidad para crear conciencia (Kurian et al., 2007).

\section{Gobernanza en la India}

En la India la falta de adecuadas planificaciones, las limitaciones financieras, la debilidad institucional, la falta de tecnologías de reciclaje, y la apatía pública hacia cuestiones RSU son los mayores retos para el adecuado manejo de RSU (Kurian et al., 2007). El sistema de gestión de residuos sólidos urbanos, en la India, se divide en varias juntas y ministerios. Estos organismos tienen funciones y responsabilidades específicas tales como la implementación de políticas en cada uno de los atributos horizontales de la Figura 2.18 ya que como se mencionó anteriormente el sistema de manejo de los RSU es importante en la GIRS. Para una mejor estructura institucional, es pertinente señalar a las responsabilidades de cada parte interesada y que debe haber una estricta normativa en caso de incumplimiento. El papel del sector informal, como las ONGs, las empresas de gestión de residuos, y los recicladores debe ser tomado más en serio y facilitarles la infraestructura necesaria. A partir del reciente éxito de la institución Público-Privado (PPP), se pudieran aplicar ciertas lecciones aprendidas. Algunas de las fortalezas y debilidades para los modelos PPP se proporcionan en la Tabla 2.3 .

Tabla2.3. Fortalezas y debilidades de los modelos PPP en la India.

\begin{tabular}{|c|c|c|}
\hline $\mathbf{N}^{\circ}$ & FORTALEZAS & DEBILIDADES \\
\hline 1 & La flexibilidad operativa & Riesgo operacional \\
\hline 2 & No hay bar en salarios & El retraso en las obras de construcción \\
\hline 3 & Efectiva implementación y administración & Costo elevado \\
\hline 4 & Responsabilidades claramente definidas & Operaciones fallidas \\
\hline 5 & No corrupción & Incremento de operaciones \\
\hline 6 & Decisiones rápidas en políticas y procesos & Riesgos de decisiones erróneas \\
\hline 7 & Aumento de eficiencia & $\begin{array}{l}\text { Cambio en la demanda y tipo de } \\
\text { operaciones }\end{array}$ \\
\hline 8 & $\begin{array}{l}\text { Acceso a tecnología y experiencias } \\
\text { avanzadas }\end{array}$ & Incremento de costos de recursos \\
\hline 9 & Acceso a recursos financieros & Riesgo financiero \\
\hline 10 & Mejores equipos y mantenimiento & Carga financiera \\
\hline
\end{tabular}

\section{Problema tecnológico en la India}

La tecnología es uno de los aspectos más importantes del sistema de manejo de RSU, pero en países en vías de desarrollo como la India, es una cuestión muy ignorada. A través del desarrollo tecnológico, una gran cantidad de residuos podría ser utilizado para generar energía, por ejemplo, el método WTE o Plantas de biogás. Las características de los residuos varían de país en país, e incluso se basan en las condiciones climáticas y al mismo tiempo el escenario social y cultural, y la idoneidad de las 
tecnologías necesarias varía también. Las tecnologías que se desarrollen deben contemplar las condiciones locales como hasta incluso detalles simples como disponibilidad de piezas de repuesto para la maquinaria utilizada, la reparación y el mantenimiento, ya que esto debe ser de fácil adquisición y económico (Kurian et al., 2007). Por lo tanto, es esencial para promover trabajos de investigación y desarrollo científico relacionados con el manejo de RSU una caracterización de los residuos y una cuantificación continua. Ministerios y departamentos gubernamentales deben proporcionar fondos para la investigación y desarrollo de tecnologías en todos los aspectos del manejo de RSU.

\section{Financiamiento}

La mayoría de los planes de gestión de residuos están limitados por la falta de recursos financieros. Las autoridades locales están, en su mayoría, faltos de recursos y no son capaces de mantener ni siquiera los puestos básicos de trabajo como recolección de residuos. Los municipios pasan sólo un promedio del $10 \%$ de su presupuesto en RSU porque tienen que gestionar un gran número de actividades. El recurso financiero dedicado a los servicios RSU debe ser proporcional al presupuesto. Las autoridades municipales tienen como requisito dar prioridad al soporte tecnológico en sus presupuestos (Gupta \&Kumar, 2014). Un ejemplo de el arduo trabajo que en la India se intenta hacer para la mejora del manejo de los residuos, es un caso donde los ciudadanos exigieron la devolución del dinero que no se empleó adecuadamente en cierto período de tiempo: el Ministerio de Desarrollo Urbano formulado y remitido a un sistema a la Comisión de Finanzas, pidió la devolución de los fondos por una suma de Rs. 24,455.50 millones para la gestión de RSU en 423 ciudades de Clase pobre. Así, la Comisión de Finanzas ha recomendado en consecuencia la devolución de Rs. 25.000,00 millones durante un período de cinco años, a partir del 1 abril 2005 hasta 31 marzo 2010, para proporcionar el adecuado servicio de recolección, sistema de transporte, plantas de compostaje y vertederos sanitarios para RSU en 423 ciudades de clase pobre y capitales de los estados según el censo realizado en el año 2001 (Gupta \&Kumar, 2014). El Ministerio también ha puesto en marcha dos programas, es decir, Misión Jawaharlal Nehru de Renovación Nacional Urbana (JNNURM) e Infraestructura Urbana, Plan de Desarrollo de la Pequeña y Mediana Ciudad (UIDSSMT), con el fin de proporcionar servicios de infraestructura en todas las zonas urbanas del país, incluyendo los RSU principalmente es un programa orientado a las reformas políticas. Sin embargo, no sólo crear los programas es suficiente, sino se trata de monitorearlos y hacer que se cumplan, por lo que bajo JNNURM desde su creación, 22 proyectos para RSU para 22 ciudades han sido sancionado con un costo total estimado de Rs. 13,902.70 millones por el Ministerio de Desarrollo Urbano por incumplimiento con los objetivos. Algunos de los nuevos proyectos de residuos en energía están bajo la consideración de la asistencia financiera del Ministerio ya que son de fuentes no convencionales de energía verde (Gupta \&Kumar, 2014). Debe haber una lista de comprobación de las obras prioritarias relacionadas con el manejo de los RSM para cada ciudad y especificar los fondos necesarios para su ejecución, es importante destacar que los fondos adquiridos a través de las multas, deben ser empleados en beneficio del mismo programa implementado. El trabajo puede ser designado por las autoridades municipales a las otras partes interesadas también como ONG, empresas privadas y voluntarios. Otras iniciativas también van teniendo fuerza a medida que se están promoviendo en la India, las 3R’s por ejemplo.

\section{Reduce Reutiliza y Recicla $3 R$ 's, en la India}

El concepto de las 3R's, es a menudo muy bien aceptada en la mayoría de las ciudades indias; debido a que la estructura socioeconómica de estas sociedades es tal, que en general, la generación de RSU per cápita es mucho menor que la de las sociedades occidentales, además de que hay actividades que promueven la regla de las $3 \mathrm{R}$ 'S, ya sea a través de una primera estancia con las actividades que 
realizan los pepenadores o en los mercados de segunda mano que son abundantes en ciudades de la India (Kurian, 2014). Estas actividades en general se vuelven complicadas, ya que conlleva diversos problemas de salud a quienes las realizan. Habitualmente, el material que más se recicla es: Periódico, cartón y metales que se recogen de puerta en puerta o de los contenedores de la comunidad. Las personas que se dedican a recolectar la basura gastan alrededor de un 30-50\% de su tiempo en la clasificar los residuos que pudiera venderse, alrededor de 200-500 familias viven en cada uno de los sitios de descarga, y su subsistencia depende de los RSU. Todas estas personas venden a intermediarios que a menudo realizan alguna forma de selección simple y limpieza de los materiales reciclados, esto obviamente de manera informal (Kurian et al., 2007). A su vez estos intermediarios venden a los mayoristas que en general son industrias que generan materia prima para algún proceso. Algunos de los factores clave que en general afectan el potencial de recuperación de los RSU son el mercado para el material separado, su pureza, su cantidad y su ubicación, esta última conlleva costos de almacenamiento y transporte (Kurian, 2014).

En general la opinión pública sobre este tipo de actividades se desaprueba y los ciudadanos se quejan con los funcionarios de que es una amenaza de salud pública. Por otro lado, los funcionarios ven a los pepenadores, y a quienes realizan este tipo de actividades, como una interferencia para el buen manejo de RSU en su fase de recolección principalmente, ya que les es imposible manejar adecuadamente los RSU que tienen un previo dueño, antes de llegar a las zonas de transferencia. Sin embargo, las autoridades locales podrían hacer buen uso de estas personas permitiendo que realicen con eficacia sus actividades (Kurian, 2014). Esto se incluirán en el sistema general de gestión de RSU mediante la contratación de microempresas de recolección y reciclaje de RSU. Dicha facilitación para el desarrollo de los pepenadores como micro empresarios podría ofrecer servicios de recolección de residuos de mejor calidad, en vez de pelear con ellos y quitarles su sustento; lo que sería benéfico para el municipio en varias formas, por otro lado, la interferencia de pepenadores en las instalaciones de procesamiento / disposición de residuos sería nula, lo que mejorará a su vez sus ingresos y las condiciones de trabajo en las que ahora se desempeñarían los pepenadores (Kurian, 2014). Esto a su vez ayudaría a implementar mejores tecnologías que ayudarían a mejorar la calidad de los productos, reducir costos y minimizar riesgos potenciales a la salud. (Kurian, 2014). Una ONG en Madrás, India, llamado EXNORA (Excelente, Novedosas, y Radícales Ideas) está practicando un sistema de gestión de residuos, basado totalmente en la cooperación y la participación de la gente. Emplean pepenadores calificados para llevar a cabo la recolección puerta a puerta de los RSU y el transporte a los contenedores de la comunidad. A parte de que se les paga un salario mensual, también les es permitido aumentar sus ganancias si algo que haya en los residuos les puede servir. Esto es un ejemplo del trabajo en equipo, donde todos ganan.

\section{Temas actuales y perspectivas futuras en la India}

El enfoque contemporáneo del manejo de RSU, ya no tiene el objetivo principal de ser simplemente recolectados y eliminados por razones de salud pública e higiene, ya que esto cada vez están más demostrado que es ineficaz e inadecuado (Singhal y Pandey 2001). Varios intentos se están llevando a cabo para mejorar una el manejo los RSU. El Ministerio de Asuntos Urbanos y Empleo impulsa a la formulación de un documento de estrategia sobre el manejo de RSU y se preparó un manual sobre gestión de residuos sólidos (CPHEEO 2000). Estos documentos ponen de relieve diversos problemas críticos relativas a la gestión de residuos sólidos y han ofrecido varias sugerencias para mejorar las prácticas de gestión.

Algunas recomendaciones son:

- La segregación de los residuos en los hogares se debe estimular y fomentar. 
- Nivel primario de recolección debe garantizarse de cada hogar.

- Las agencias privadas / ONG pueden estar involucrados en la recolección primaria.

- La carga mensual para la recogida puerta a puerta basado en el tipo de ingresos de cada ciudadano puede ser implementada.

- Los vehículos para el transporte de los residuos sólidos desde el punto de transferencia al sitio de disposición final, deben ser de diseño apropiado y adecuado para las características de los residuos.

- Junto con el relleno sanitario, la composta de residuos sólidos municipales debe ser la siguiente opción apropiada.

- La participación privada en el establecimiento de plantas piloto utilizando tecnologías apropiadas para la gestión de residuos sólidos urbanos debe ser estimulada.

La sostenibilidad de los programas de GRSU en ciudades de la India depende de la integración estructural y funcional de la educación y la participación comunitaria, la política y la intervención reguladora, la reducción de residuos, la reutilización y el reciclaje de electrónica y además de los residuos peligrosos del hogar, gestión de tierras para composta, la rehabilitación de sitios de disposición final, residuos para la generación de energía y el financiamiento, el análisis económico y la asociación público-privada (Kurian et al., 2007).

Algunas de las principales medidas necesarias para alcanzar dicha GIRS debe incluir:

- El desarrollo de las ciudades con base en los planes maestros, que incluya la tierra para la gestión de residuos en cada ciudad. Esto requiere una clara conciencia de su necesidad y un fuerte compromiso de los planificadores y los líderes políticos para resistir las presiones de los grupos opositores (pepenadores) para desarrolladores de ganancias a corto plazo.

- Puesta en marcha de las instalaciones de tratamiento y eliminación de residuos comunes o regionales.

- Establecimiento de Tecnología / parques de procesos relacionados con los RSU en el contexto de las condiciones locales.

- Demostración de instalaciones modelo, para ser utilizadas como conductoras y obtener la aceptación de la comunidad para permitir el establecimiento de instalaciones de gestión de residuos sólidos urbanos orgánicos en el patio trasero de los hogares indios

- Asegurar la participación de los estudiantes universitarios en la educación del público sobre RSU.

- Creación de un centro de capacitación de sistema de manejo de residuos a nivel nacional, esto para aumentar la formación profesional y para apoyar la creación de capacidad.

- Recogida selectiva, eliminando residuos de la construcción y demolición, así como residuos inertes o peligrosos procedentes de limpieza del hogar

- Desarrollo y actualización de base de datos sobre generación y características de los residuos 
- Fomentar la separación desde los logares donde se originan los RSU, como los hogares

- El uso de equipo adecuado para la recolección, transporte, procesamiento y el mantenimiento preventivo de dicho equipo.

- Desarrollo y uso de métodos de tratamiento de residuos adecuados, tales como el compostaje, lombri- composta, biogás, etc.

- Fomentar la incineración de residuos urbanos que generan combustible en plantas de cemento donde la infraestructura necesaria ya está en marcha

- Mejorar y formalizar el trabajo de los pepenadores

- La formación profesional y los incentivos para los programas de GIRS

- Generar continuamente indicadores que ayuden a monitorear el trabajo realizado

- Fijación de las tarifas para la recolección de RSU (más paga el que más genera)

- El desarrollo de la gestión de residuos como una profesión

- Promoción de la participación del sector privado para superar las limitaciones impuestas por la falta de fondos y experiencia profesional

Una cuestión fundamental en el manejo de RSU es cómo llevar estas recomendaciones al terreno real, una forma pudiera ser por la transformación gradual de las prácticas de acuerdo con los principios y normas a través de la política oficial y las reformas administrativas científicas (Kurian et al., 2007). Las deficiencias de los sistemas institucionales existentes, tales como personal no capacitado, la falta de incentivos para hacer un buen trabajo, una supervisión inadecuada de los trabajadores y el mantenimiento inadecuado de las instalaciones actúan como barreras (Kumar \& Gaikwad 2004). La preocupación por la eficiencia, para " hacer un impacto " todavía tienden a favorecer la alta tecnología, sin embargo, el cambio parte del ciudadano, ya que es necesario dejar de ver los residuos como residuos y comenzar a verlos como materia prima para algún otro proceso. La tarea de resolver este problema requiere un enfoque integrado que implica no sólo la dirección del gobierno, sino que también exige la participación activa de todos los otros grupos de interés, lo más importante, el público. El papel del gobierno es formular y hacer cumplir las normas y reglamentos relativos a la gestión de residuos con el fin de proteger la salud y la seguridad de las personas y el medio ambiente (Kurian et al., 2007; Kumar \& Gaikwad 2004).

Lo que todas las ciudades y pueblos en vías de desarrollo necesitan, es primero que nada un cambio en la orientación hacia como se perciben los residuos, estudiar de qué manera se reducen las barreras psicológicas que se tiene para ver y valorar un residuo un ciudadano de un país emergente, de cómo invertir la situación para convertirlos en un tema de interés público; en general por los beneficios que el buen manejo pudiera traer. La conciencia pública y las actitudes ante los residuos puede afectar a la buena disposición para llevar los residuos a un contenedor compartido, la disposición a aceptar la proximidad de un contenedor compartido, la voluntad de separar los residuos para ayudar reciclaje, la frecuencia con que se deben recoger los desechos, la cantidad de basura que se genera y las hasta evitar los excrementos de animales que se dejan en la calle, la disposición a pagar por los servicios de gestión de residuos, evitar la oposición a la ubicación de las instalaciones de tratamiento y eliminación de residuos, las cuestiones de género en materia de residuos actividades de reciclaje y recogida, y los grupos sociales a partir del cual los residuos personal de gestión se pueden extraer. 
Las personas pueden participar mediante la generación de menos residuos y proporcionar retroalimentación durante los grandes procesos de toma de decisiones sobre el manejo de RSU.

Otro país que ha emergido como un gran generador de RSU y que ha sorprendido al mundo es China. En el 2004, China superó a los EU como el generador de residuos más grande del mundo. En 2030, China probablemente producirá el doble de residuos sólidos municipales que Estados Unidos (Hoornweg y Bhada, 2012). Dada esta situación, es de vital importancia, para esta investigación, observar las propuestas de dicho país, para enfrentar este gran problema.

\section{Reflexión final sobre la India}

Ha sido importante analizar el caso de la India, especialmente como se ha mencionado anteriormente, por el parecido sociocultural y económico que tiene con México. Una de las lecciones más importantes por aprender de este país, son sus iniciativas realistas, es decir parten de un punto montado en la realidad social, cultural y económica que actualmente existe en la India. Por ejemplo, sus estrategias no apuntan a recolectar el $100 \%$ de los RSU generados, para después transformarlos en energía limpia en su totalidad en tan solo un periodo de gobierno, como lo propone el Programa Institucional de la Secretaría de Obras y Servicios 2013-2018 de la CDMX en su meta sectorial de RSU; sino que más bien, sus iniciativas están directamente enfocadas en la educación y concientización de los ciudadanos con base en la buena gobernanza. Esta educación y concientización está enfocada en dos puntos principales: el de aprender a separar los residuos para ser valorizados y la importancia económica y ambiental que ambos factores implican; y por otro lado el formalizar el trabajo de pepenadores, lo cual en la CDMX también podría ser una solución para los problemas políticos y sociales que se han mencionado con anterioridad y que forman la mayor parte del problema de los RSU que existen en dicha ciudad. Es así como la India, un país que se encuentra en vías de desarrollo, igual que México, aborda sus problemas con los RSU.

\subsection{China}

\section{Diagnóstico básico de los RSU en China}

Oficialmente llamado, República Popular China, situado en Asia Oriental tal como lo muestra la Figura 2.26, y es el país más poblado del mundo, con más de 1300000000 habitantes y la primera potencia económica mundial por PIB, en términos de paridad de poder adquisitivo que dicho país tiene. China es un dividida en veintidós provincias, cinco regiones autónomas, cuatro municipios bajo jurisdicción central. Con una superficie aproximada de 9 $600000 \mathrm{~km}^{2}$, es el tercer país más extenso del globo.

En décadas recientes, China ha sufrido de una severa contaminación y deterioro ambiental (Ma, 2000). Aunque las regulaciones como la Ley de Protección Ambiental de 1979 son muy estrictas, no son bien aplicadas, ya que a

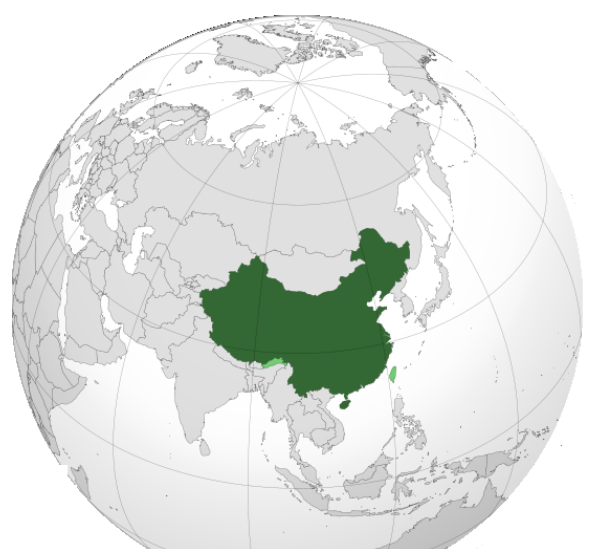

Figura 2.26. Mapa de la ubicación de China. Fuente Google Imágenes

menudo son ignoradas por las comunidades locales y los oficiales de gobierno en favor de un rápido crecimiento económico (BBC, 2012). La contaminación urbana del aire es un problema de salud 
severo en el país; el Banco Mundial estimó que dieciséis de las veinte ciudades más contaminadas del planeta están en China (Bloomberg, 2013) También es el mayor emisor de dióxido de carbono. Tiene asimismo problemas de abastecimiento y contaminación de agua: casi 298 millones de chinos en las zonas rurales no tienen acceso a agua potable, y en $201140 \%$ de los ríos del país estaban contaminados por desechos industriales y agrícolas. Sin embargo, en los últimos años china ha sido de los países que más invierte en investigación para la mejora del medio ambiente (Friedman, 2010).

En una clasificación que el Banco Mundial hizo, por región, determinó que China pertenecía a la región del pacífico y el Este de Asia, donde se generaba un total de 2710 millones de toneladas por año, en toda la región, pero después se refiere a que el productor de más del $70 \%$ de dichos residuos, solo los produce China, lo que representa alrededor de 4.3 per cápita al día en algunas ciudades, contra el resto de la región que comprende alrededor de 0.95 kg per cápita al día (Hoornweg y Bhada, 2012). Podemos ver que China es un caso especial, ya que, aunque es considerado por el Banco Mundial por un país de clase media baja, esto debe a que la riqueza nacional promedio es muy diferente de la riqueza media de sus poblaciones urbanas. Sólo la afluencia de los residentes urbanos es importante en la proyección de las tasas de RSU, por ejemplo, China tienen tasas desproporcionadamente altas de generación de residuos urbanos per cápita relativa a por la situación económica global, ya que tienen las poblaciones rurales realmente pobres y relativamente grandes y éstas tienden a diluir las cifras nacionales (Hoornweg y Bhada, 2012).

En los últimos años, el crecimiento económico de China se ha caracterizado por ser elevado, mostrándose un incremento estable del PIB alrededor de un 8\% como promedio anual desde 1997, con tasas que han superado el $9 \%$ desde 2003. Todo esto ha estado motivado principalmente por su expansión industrial y considerables exportaciones. Entre los productos que China ha desarrollado con fuerza y que han impulsado su crecimiento económico y comercial están los de alta tecnología y demanda en el mercado mundial, como son: semiconductores, automóviles y ordenadores personales. También ha desarrollado otros tipos de productos con una cuota elevada en el mercado internacional, logrando ser el primer fabricante mundial de artículos textiles (entre ellos, prendas de vestir), calzado, productos electrónicos de consumo (teléfonos celulares, reproductores de DVD, televisores, etc.), muebles y juguetes. Además, se han registrado grandes producciones de carbón, cobre, aluminio, acero y cemento, convirtiéndose esta nación asiática en el primer productor mundial en esos renglones. China tiene un peso fundamental en la economía mundial y casi decisivo para el desarrollo de las demás economías, no solo como productor, sino también como consumidor a gran escala, pues representa el 30\% del consumo mundial de carbón, algodón, arroz y acero, y entre un 15 y un $20 \%$ del consumo mundial de cobre, soja, trigo, aluminio y platino (Rodríguez, 2007); pero como se ha mencionado a lo largo de esta investigación, el aumento de la generación de RSU va de la mano con el desarrollo económico, y los patrones de consumo, así que China no puede escapar a ese patrón. Por esta razón China se encuentra enfrentado uno de los retos más grandes de su historia, y este es la contaminación ambiental.

China es uno de los países más contaminados del planeta, pues de las diez ciudades del mundo con más contaminación ambiental, siete pertenecen a este país; más del $70 \%$ del agua de los ríos que están en las ciudades chinas no es asequible para tomar ni pescar, sin contar los millones de personas que presentan problemas para acceder al agua potable debido en gran medida a los lixiviados de los RSU mal gestionados. El aire es otro de los elementos de la naturaleza contaminados en China, ya que contiene altos porcentajes de humo, polvo y existe una gran cantidad de dióxido de sulfuro en la atmósfera y otros gases efecto invernadero como el metano, este último también emitido por RSU mal gestionados. Esta contaminación se debe en gran parte al mal manejo de RSU con el que cuenta el país y es una de las causas principales de enfermedades respiratorias crónicas como bronquitis 
crónica y enfisema pulmonar, las cuales actualmente están provocando el mayor número de muertes en esa nación asiática, superando incluso la tasa de mortalidad de Estados Unidos por el mismo motivo (Rodríguez, 2007; Hoornweg y Bhada, 2010).

- Cada año cerca de 178000 personas en las principales ciudades mueren prematuramente, debido a los elevados niveles de contaminación atmosférica (por encima de los estándares nacionales y mundiales). La contaminación del aire dentro de los hogares, en especial, por la quema de carbón y biomasa para cocinar alimentos y calentar la casa, origina alrededor de 111000 muertes al año.

- Casi 7,4 millones de personas se pierden anualmente por problemas de salud relacionados con la contaminación.

- La lluvia ácida, con altos contenidos de sulfuro por el uso del carbón en las regiones del sur y suroeste de China, tiene el potencial para dañar al $10 \%$ de las áreas cultivables y posiblemente ha reducido la productividad en los cultivos y la foresta en un promedio del $3 \%$.

- Los niños estudiados en Shenyang, Shanghái y otras grandes ciudades presentan niveles de plomo en sangre, en promedio, de un $80 \%$ por encima de los niveles considerados peligrosos para el desarrollo mental.

Entre los diversos problemas ambientales que hoy enfrenta China figuran también los ruidos, la contaminación visual, la degradación del suelo, la erosión y la desertificación (Hoornweg y Bhada, 2010).

\section{Retos y estrategias para el manejo de RSU en China}

Investigación sobre $R S U$, principal herramienta para combatir el problema de los RSU en China Como podemos ver el panorama actual ambienta que vive china no es nada alentador, aunque su desarrollo económico despunte, tal parece que el ambiente no fue por mucho tiempo una de sus prioridades. Sin embargo, el sector académico no puede ser descalificado de la misma manera, ya que en los últimos años China ha tenido un gran número de publicaciones científicas con respecto a los últimos años. Incluso existen documentos donde se analiza el crecimiento y desarrollo de la productividad de la investigación de RSU en China, en términos de la producción de publicaciones como refleja en el Science Citation Index para cierto periodo de tiempo, (1997-2011). Esto deja en evidencia que China trabaja duro para atenuar sus problemas tan fuertes de contaminación.

Un estudio reveló que el resultado de la investigación de RSU en China ha aumentado rápidamente en los últimos 15 años, en contraste con EU como lo muestra la Figura 2.19; autores chinos contribuyeron con 730 publicaciones, de los cuales 708 eran artículos de revistas, 17.3 opiniones material editorial, corrección y 11 resumen de la reunión, de 421 instituciones. Acerca de $13.70 \%$ de las publicaciones fueron aportados por la Academia de Ciencias de China, seguida de la Universidad de Tongji, Shanghái (13.15\%) y la Universidad de Tsinghua, Beijing (11,10\%). Lo que lleva a 20 autores en el área de investigación de los RSU a haber publicado al menos 13 artículos por persona. La cuota anual de publicaciones varió desde 0.27 hasta $20.96 \%$ al año. La participación fue más alta en el año 2009 a 20,96\%. Un análisis de los títulos de las palabras demostró que " disposición final", " incineración " y " gestión " fueron los últimos temas principales de la investigación de residuos sólidos urbanos en China (Yang, et al., 2013). Por esta razón, podemos apreciar el gran interés de los académicos por solucionar el problema del manejo de los RSU; sin embargo, no han sabido cómo 
convencer al empresario chino y los políticos que tienen diversos interese, de que el desarrollo económico no tiene que estar peleado con la protección al ambiente.

En la Figura 2.27. Se observa la evidencia del desempeño que China tiene en la investigación enfocada específicamente en los RSU en comparación con Estados unidos, que como se sabe es uno de los países más realiza intentos para atenuar el problema de los RSU. Claramente se visualiza que China está apostando a que, para tener un avance certero en el manejo de los RSU, debe haber una sólida base cimentada en la investigación, ya que incluso el número de investigaciones es mayor que las investigaciones que realiza EU. Es importante tener conciencia de que para llevar a la práctica real las investigaciones, requiere cierto tiempo, y probablemente se deba a eso que en 1997 las investigaciones que realizaba EU rebasaban por completo a las que hacia China. Sin embargo, se asume que EU ha llevado cierto tiempo investigando y ha comenzado aplicar dichas investigaciones, de tal forma que éstas han logrado cambios importantes en el manejo de sus RSU, como se observó en las lecciones aprendidas de EU.

Figura 2.27. Comparación entre EU y China en cuanto a la generación de investigaciones en el área de la GIRS.

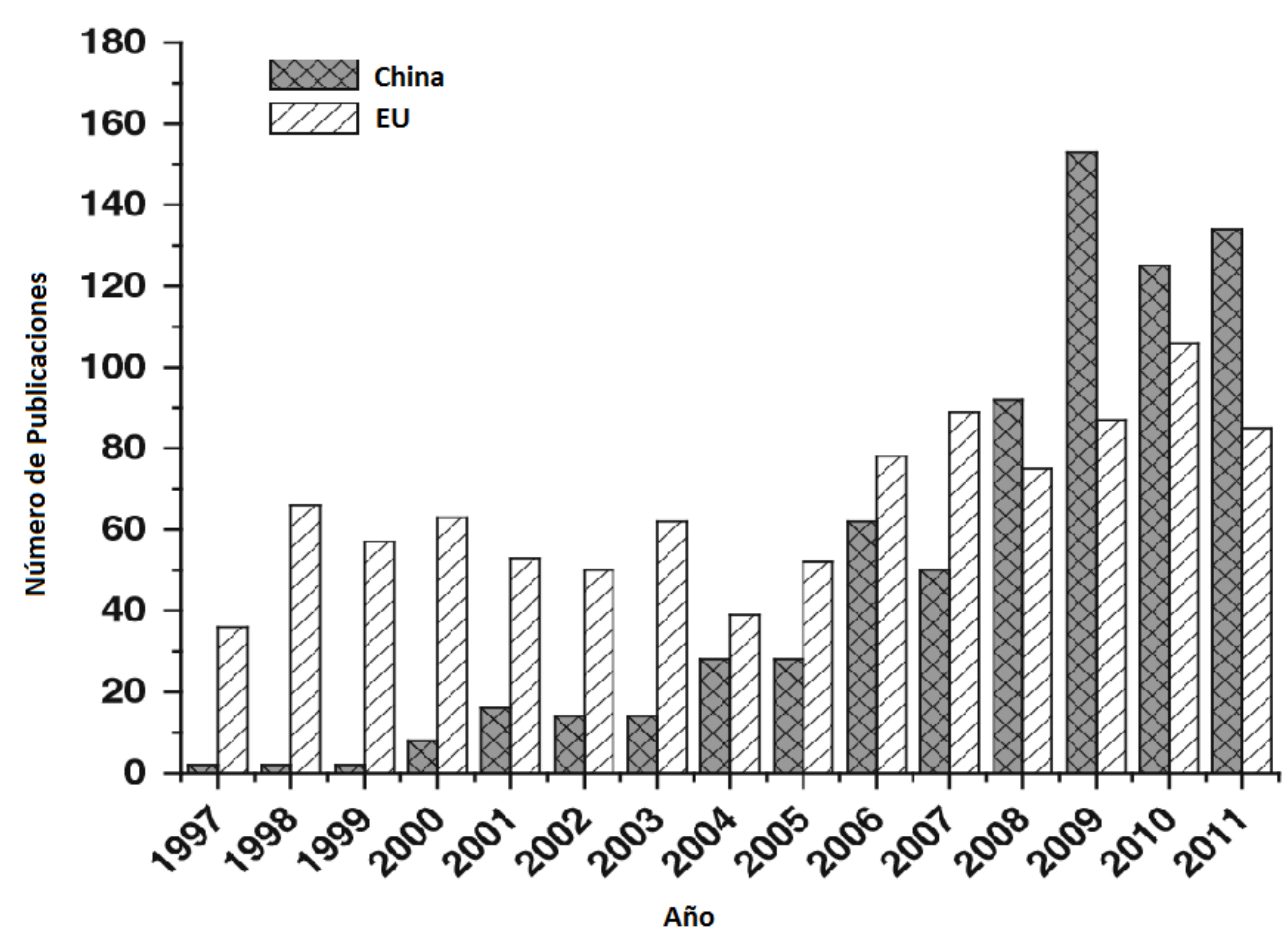

Fuente: Yang, et al., 2013.

Contexto social, político y económico en las áreas urbanas más importantes de China

Existen grandes y prosperas ciudades en China, pero todas por lo general se desarrollan en el mismo escenario; sin embargo, una de las ciudades más importantes para China y para el mundo, por su gran actividad económica es el municipio Dalian. Este municipio se encuentra en el extremo sur de la península de Liaodong, en el noreste de China, la ciudad tiene un área urbana total de 248 kilómetros cuadrados y en 2006 la población urbana de las Dalian fue 1.96 milliones (Dalian Environmental 
Protection Bureau EPB, 2010). Como uno de los mayores centros industriales de China, Dalian ha construido un extenso sistema industrial, en sectores tales como maquinaria, electrónica, textiles, productos químicos, metalurgia, y los productos alimenticios, y es una base industrial increíble para China. Dicho municipio es una de las zonas más prósperas en cuanto a negocios en China, así como un centro de distribución de bienes y materiales en el noreste de dicho país. Es un punto clave de la para que China se mantenga en contacto con el resto del mundo, ya que es la salida al mar más conveniente para todo noreste de dicho país (Wang \& Geng, 2011). Por esta razón, la cantidad cada vez mayor de los RSU se está convirtiendo en un gran reto para el gobierno de la ciudad ya que sus ciudadanos han exigido cada vez una mejor calidad de vida y el lugar disponible para rellenos sanitarios es cada vez más limitada. Por otra parte, Dalian es una de las ciudades modelo nacional del medio ambiente y considera el desarrollo sostenible como una visión clave para su futuro. Por lo que mejorar la imagen ecológica de la ciudad es siempre una misión de su gobierno. Por lo tanto, hay un deseo de los gestores locales de RSU por consolidar su infraestructura de RSU, y un compromiso para hacer esto de una manera ambientalmente sostenible.

Primeramente, en apoyo a una mejora en la GIRS, tanto de los gobiernos centrales como locales lanzaron varias leyes y reglamentos relacionados con los RSU. Por ejemplo, la Ley revisada de la República Popular de China sobre prevención de la contaminación ambiental producida por los residuos sólidos, que se promulgó desde el 1 de abril de 2005. Después El Ministerio de Construcción publicó un reglamento nacional sobre RSU, que fue efectiva desde el 1 de julio de 2007. Sin olvidar que antes de estos, el gobierno de la provincia de Liaoning lanzó una norma provincial de RSU, que fue efectiva desde el 1 de marzo de 2002 en donde básicamente se mencionan las especificaciones en cuanto al manejo de los RSU. Para no quedarse atrás, la ciudad de Dalian también puso en marcha su propia ley, efectiva desde el 1 de julio de 2004. Estas regulaciones proporcionan elementos detallados sobre cómo recolectar, transferir, tratar y disponer los RSU, incluidas las medidas concretas de ejecución y las sanciones, por lo tanto, parece ser que la base judicial es fuerte en dicho país (CSY China Statistical Yearbook, 2008). Esto implica claramente que como en la mayoría de los países del mundo, el manejo de RSU es responsabilidad del gobierno local. Así que cada ciudad, tiene claras las sanciones y trabajan arduamente para informar a sus ciudadanos mediante programas educativos buenas prácticas del manejo de RSU.

China tiene activas a varias agencias del gobierno de las ciudades, participando en el manejo de RSU, incluyendo el EPB, comisiones de la infraestructura, y la comisión de construcción (ya sea mediante agencias o despachos). El EPB local, está a cargo de vigilar la contaminación, únicamente a través de los RSU, de hacer cumplir las regulaciones ambientales relacionadas con el manejo de los RSU, la gestión de residuos sólidos peligrosos y la adecuada separación de los RSU de los residuos peligrosos, además tiene la obligación de divulgar y difundir de los conocimientos relacionados con la reducción de los RSU, la reutilización y el reciclado. Por otro lado, la comisión de infraestructura es el encargado de la parte operativa (recolectar, separar y disponer de los RSU, así como las cuestiones de planificación operativa para la gestión de los RSU) (Wang \& Geng, 2011) ¿Pero si todo parece estar muy planeado, entonces por qué China tiene tantos problemas con el manejo de sus residuos?

El principal problema que parece manifestar China es que rara vez hay coordinación entre los diferentes organismos, los empresarios, los académicos y los ciudadanos, sin lugar a duda algo muy similar a lo que México vive. En China, ninguno de estos organismos está subordinados el uno al otro, como tampoco ninguno de estos desempeña un papel principal en la gestión de los RSU. En consecuencia, los conflictos entre las diferentes agencias siempre existirán. Así como tampoco fluye la información hacia el pueblo y tampoco fluye la información de los académicos hacia los empresarios. 


\section{Datos sobre el manejo de RSU en China}

Como lo es en todas las regiones, las características de los RSU dependen de una gran cantidad de factores, desde los económicos, políticos, sociales, culturales, hasta los climáticos y estilo de vida, etc., así que China no rompe la regla. La composición de los RSU en China es extremadamente heterogénea y la variación se debe a diferencias entre las ciudades: desde el nivel de industrialización y de los ingresos hasta hábitos de consumo, ya que como anteriormente se mencionó la riqueza del país está pésimamente distribuida. En cuanto a los métodos de recolección de RSU también se muestran diferentes entre ciudad. En la mayoría de las comunidades residenciales en Dalian son gestionados por empresas privadas autorizadas. Este tipo de empresas son responsables de la limpieza, jardinería, manejo de residuos, mantenimiento de las instalaciones públicas, sin olvidar que es mediante pago de los residentes de la zona. Ellos pusieron contenedores de residuos en frente de cada edificio de apartamentos (Yang et al. 2014).

Los residentes suelen poner su RSU en bolsas de plástico y depositarlos en los contenedores, sin embargo, casi nunca están separados. Luego, en cada mañana los miembros del personal de la empresa de administración de propiedades eliminan dichos residuos en un pequeño sitio de transferencia de RSU y realiza una simple separación. residuos valiosos, tales como papel, botellas de plástico y metales, en general eso es lo que separan. Esto en cuanto a zonas residenciales, donde ya no es residencial, los ciudadanos depositan sus RSU en contenedores públicos y los trabajadores del gobierno que prestan el servicio, se adueñan de los residuos antes de que llegue a las grandes zonas de transferencia para seleccionar los materiales que puedan vender o recicla y desde luego de manera informal (Wang \& Geng, 2011). Al parecer esto implica grades problemas para las zonas aledañas a los contenedores, pues a la hora de preseleccionar estos RSU, se dejan bolsas rotas y residuos por todo su alrededor. Sin embargo, para combatir este problema se ha creado una comisión gubernamental, a la que se le puede llamar para que vaya a cada hogar a recolectar los RSU reciclables y evitar la venta informal de dichos materiales. En cuanto a escuelas, oficinas gubernamentales, centros comerciales, generalmente contratan servicios privados y tienes sus propias políticas para el manejo de sus RSU generados.

El Grupo de Saneamiento Ambiental ESG establecido 797 estaciones de transferencia dentro del Dalian urbana (EPB, 2010). Todos los RSU recogidos tanto desde los hogares y otras fuentes se entregan a partir de diferentes fuentes para tales estaciones de camiones pesados. Los miembros del personal de Grupo de Saneamiento Ambiental (ESG) realizan una segunda separación de residuos que aún pudieran ser reutilizables y reciclables, así también identifican y separan residuos peligrosos. Los residuos peligrosos, como pilas, tubos fluorescentes y otros productos químicos, se ponen en recipientes sellados, respectivamente, y luego entregados a los sitios autorizados para su posterior tratamiento y eliminación. Si bien no existen tecnologías adecuadas para el tratamiento de las pilas usadas, el ESG simplemente los almacena en un depósito más grande y se envían a confinamiento (Wang \& Geng, 2011).

\section{Barrearas y desafios que China enfrenta}

Aunque china se encuentra trabajando duramente aún le faltan barreras por romper y retos por alcanzar. Tales barreras y desafíos se pueden clasificar en cuatro grupos (Wang \& Geng, 2011):

1) La política y la gestión: aunque la política se está fortaleciendo y actualizando constantemente y se penaliza a las grandes industrias que contaminan, es necesario también incluir multas o recargos a cualquier persona que contamine. Por otro lado, existen grandes problemas y diferencias entre las 
instancias gubernamentales (ESG y EPB), lo cual empeora la situación y reduce la eficacia de ambas instancias.

2) La tecnología y ciencia: Sin duda alguna, partes fundamentales para el desarrollo de una verdadera GIRS, no solo en China, sino en el mundo. Nuevos descubrimientos que ayuden a la mejora y aprovechamiento de los RSU. Apoyo preferencial a todo tipo de proyecto que implique el nuevo concepto de simbiosis urbana, industrial y la tecnología WTE. Sin embargo, las mejores tecnologías del mundo, no sirven de nada si la comunicación entre académicos, empresarios, gobierno y pueblo no trasciende y esto es el caso de China. No existe intercambio de información entre las partes interesadas.

3) Las finanzas. Los retos en esta parte se refieren básicamente a los bajos presupuestos que el gobierno lanza para la GIRS. No sólo es poco, sino que alrededor del $80 \%$ es gastado sólo en la recolección y el restante $20 \%$ en la disposición final.

4) La participación ciudadana. Finalmente, el reto más grande de todos, involucrar al ciudadano y educarlo, aunque la mayoría de lineamientos, que un ciudadano debe seguir, están especificados en el marco legal, no se cumplen. Falta de educación y conciencia ambiental.

\section{Propuesta para las mejoras de un manejo de RSU en China}

La propuesta que en general maneja China, se basa en la creación de una nueva comisión de gestión de residuos sólidos. Esta debe ser creada para abordar la integración de la gestión de los RSU con autorización administrativa para desarrollar, coordinar y ejecutar las funciones pertinentes. La función de esta nueva autoridad debe incluir la recolección y análisis de datos, monitorear la operación cada día y la planificación estratégica para el manejo integral de RSU, fomentar la reducción de fuentes, al igual que una adecuada clasificación, reutilización y reciclaje, además del diseño y la construcción de instalaciones de residuos sólidos urbanos adecuados. Por otra parte, la nueva autoridad debe tener la facultad de establecer las tarifas de residuos sólidos para los diferentes productores de residuos sólidos urbanos de manera que ese dinero puede cubrir sus costos operativos

y de ser utilizado para el desarrollo de nuevos proyectos relacionados con los residuos sólidos, así como la subvención de la observancia de los funcionarios por su lugar de trabajo. Dentro de esta misma comisión deben existir representantes de todas las partes interesada, gobierno, ciudadanos, empresarios y estudiosos del manejo de RSU (Wang \& Geng, 2011).

No se debe olvidar que en el adecuado manejo de RSU, el factor clave es la participación pública, partiendo de la idea de que son la fuente generadora y los que marcan los patrones de consumo. Aunque en un principio pareciera controvertido, el pago de multas a quien no cumple las leyes será necesario. Además de que debe haber un organismo regulador para que se empleen los fondos donde deben ser empleados: en la GIRS. De esta manera se puede lograr una eficiente (implica costos), eficaz (implica cumplir con los objetivos) y equitativa (implica la inclusión de todas las partes interesadas) cumplimiento de la normatividad.

En cuanto a la aplicación de las tecnologías como anteriormente se mencionó, debe existir un claro compromiso de parte de los investigadores por difundir y divulgar sus investigaciones al público en todos los niveles, desde el público en general, el gobierno y los empresarios. De eso debe depende la adecuada aplicación de una tecnología. La Figura 2.28, muestra de manera esquemática las explicaciones de los párrafos anteriores con base en las propuestas realizadas por estudiosos de los RSU en China.

Figura 2.28. Bases para el manejo de RSU en ciudades chinas 


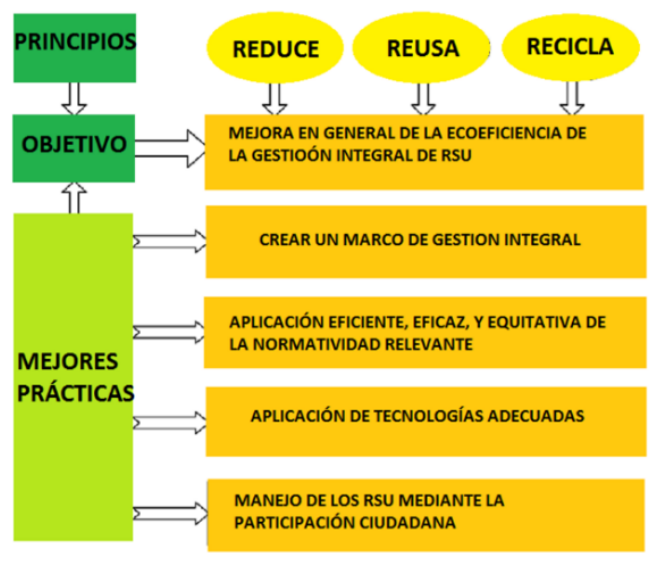

Fuente: Wang \& Geng, 2011.

Enfoque chino en las PPP para cogeneración de energía con el método WTE

Últimamente el sector privado está intentando apostar en proyectos de vertederos y plantas de incineración WTE, ya que son ellos los únicos con el capital suficiente para hacerlo, pero sólo a través de contratos Construcción-Operación-Traspaso (BOT por sus siglas en inglés, build-operate-trasfer) (Chen et al., 2010). El BOT es una nueva estrategia para el desarrollo de infraestructura, que permite la inversión privada directa en proyectos de gran escala, tales como caminos, puentes, puertos y centrales eléctricas. La teoría del BOT consta simplemente en: Construir una compañía privada o consorcio, que acuerda con un gobierno invertir en un proyecto de infraestructura pública, la compañía entonces asegura su propio financiamiento para construir el proyecto; el agente privado después toma posesión temporal del bien, lo mantiene y maneja por un período concesionario convenido, por ejemplo 25 años, y recupera su inversión a través de cargas o de peajes. Finalmente, después del período concesionario la compañía transfiere la propiedad y la operación del recurso al gobierno o a la autoridad correspondiente del Estado, que bien puede ser una empresa del ámbito municipal. Según un informe reciente del Banco Mundial, la inversión privada creciente del sector privado en proyectos de infraestructura ofrece la doble ventaja de disponer de fondos adicionales y de una administración más eficiente. (Hoornweg et al., 2005). Esto resume el sentido del BOT que es permitir al sector privado invertir directamente en proyectos de infraestructura, a la vez que reducir el gasto fiscal y como el sector privado funciona con una lógica comercial de eficiencia, la eficacia también mejorará, por lo tanto, los intereses se conjugan y así marchan las experiencias de alianzas público-privadas en BOT (Requena, 2015).

Aunque, la inversión en infraestructura inadecuada para el manejo de RSU ha sido identificado como un cuello de botella, un informe del Banco Mundial observó una tendencia general de los operadores privados extranjeros tendía a no participar en el manejo de los RSU en los países en vías de desarrollo debido a la complejidad de sus estructuras socio-culturales para el manejo de estos en la fuente de origen (Hoornweg et all., 2005).

Aunque se está tratando de fomentar las PPP en China, los inversionistas privados tienen sus propias consideraciones, las cuales se implican en los siguientes puntos (Chang et al., 2003):

- Los riesgos legales y reglamentarios en China para las actividades del PPP presentan un riesgo para los inversores privados. Por ejemplo, las leyes que rigen las actividades del PPP 
no siempre son coherentes entre sí o las políticas del gobierno pueden ser revisadas con poca consideración sobre el impacto en los socios privados.

- Las Políticas en las tarifas y precios son caóticas debido a la lentitud de la desregulación de las tarifas de los servicios públicos y éstas podrían afectar la rentabilidad del proyecto para el inversor privado.

- La falta de transparencia en el proceso de licitación para la mayoría de los proyectos PPP en China es un obstáculo para los inversionistas.

- Mientras que los proyectos BOT y otros de escala similar en general tienen un horizonte a largo plazo, de hasta unas pocas décadas, las opciones de financiación a largo plazo en los mercados financieros chinos son limitada.

\section{Reflexión final sobre China}

Es importante destacar, que China se ha visto con mucho interés en mejorar el manejo de RSU, especialmente por el número de investigaciones que este está desarrollando en comparación incluso con países que han mostrado avances en su manejo de RSU en los últimos años. Aunque, no se debe perder de vista que la investigación deja de tener relevancia cuando esta no se difunde o se lleva a la práctica. Es por eso que China deja esta reflexión para su análisis. Por otro lado, las iniciativas que están implementado son iniciativas ya probadas, como las PPP por los suecos y las 3R's por los japoneses, estos últimos no forman parte de los casos de éxito de esta investigación, sin embargo, eso no quiere decir que no lo tengan, ya que son un país que al igual que Suecia ha logrado transformar gran parte de sus RSU en valorables mediante la iniciativa de las 3R's antes mencionada.

\subsection{Lecciones aprendidas de los cuatro casos para un buen manejo de RSU}

A lo largo de este recorrido, a través de cuatro países: Suecia, Estados Unidos, India y China, se intentarán rescatar lecciones aprendidas para el manejo de RSU en la urbe más importante de México y siendo la cuarta ciudad más poblada del mundo (ONU, 2010): la CDMX. En primera estancia, se hará un comparativo en cuanto a las cifras que hablan directamente del éxito en el manejo de RSU. Esto es a través de los RSU que generan en total y per cápita contra la cantidad que de estos residuos que se llevan a disposición final.

Figura 2.29 (1 y2). Generación total anual de RSU y Generación de RSU por habitante al día. 
2.29.1

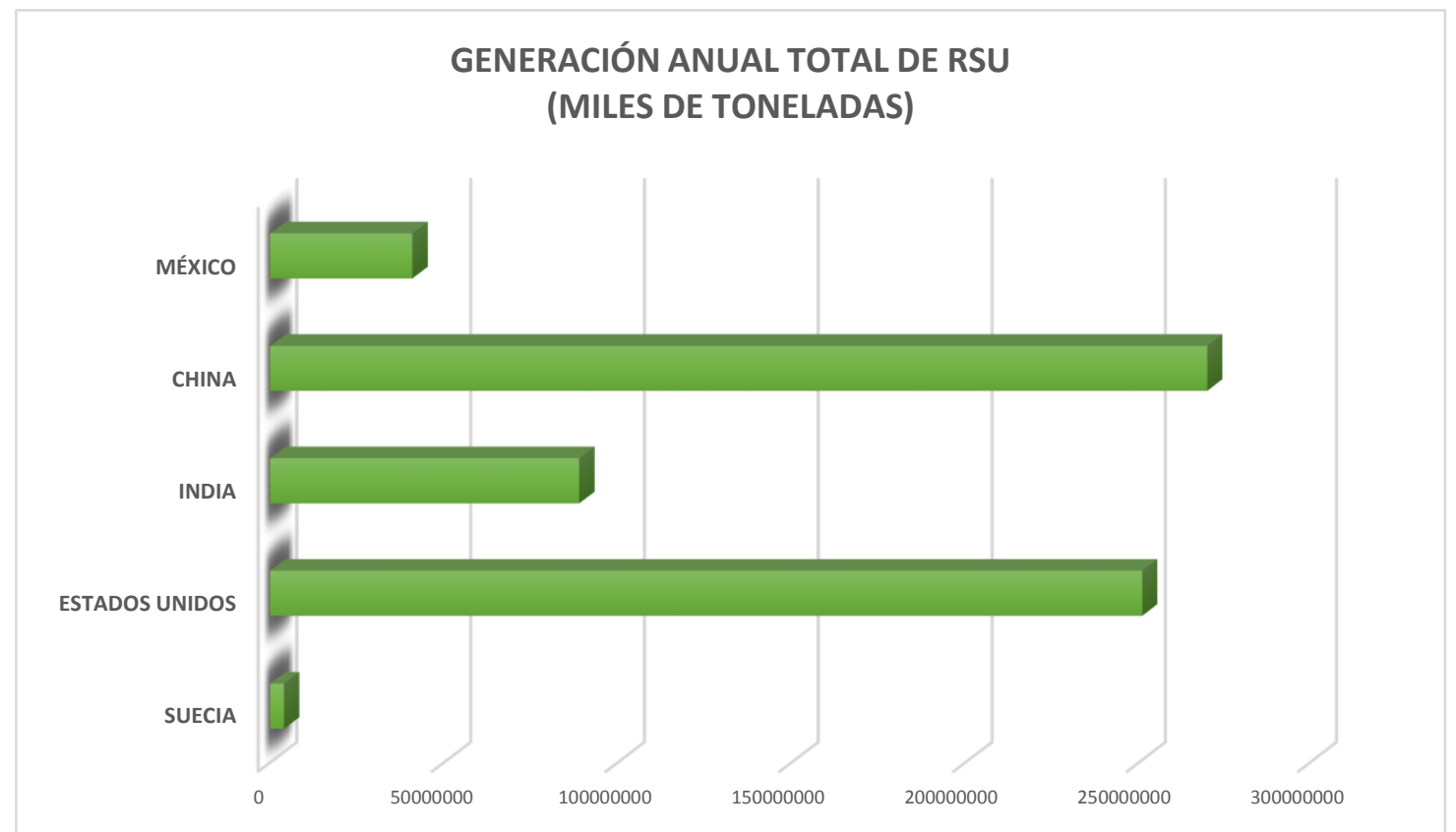

Fuente: Elaboración propia. Comparación de la generación total anual de residuos sólidos de los casos de estudio con respecto a México.

\subsection{2}

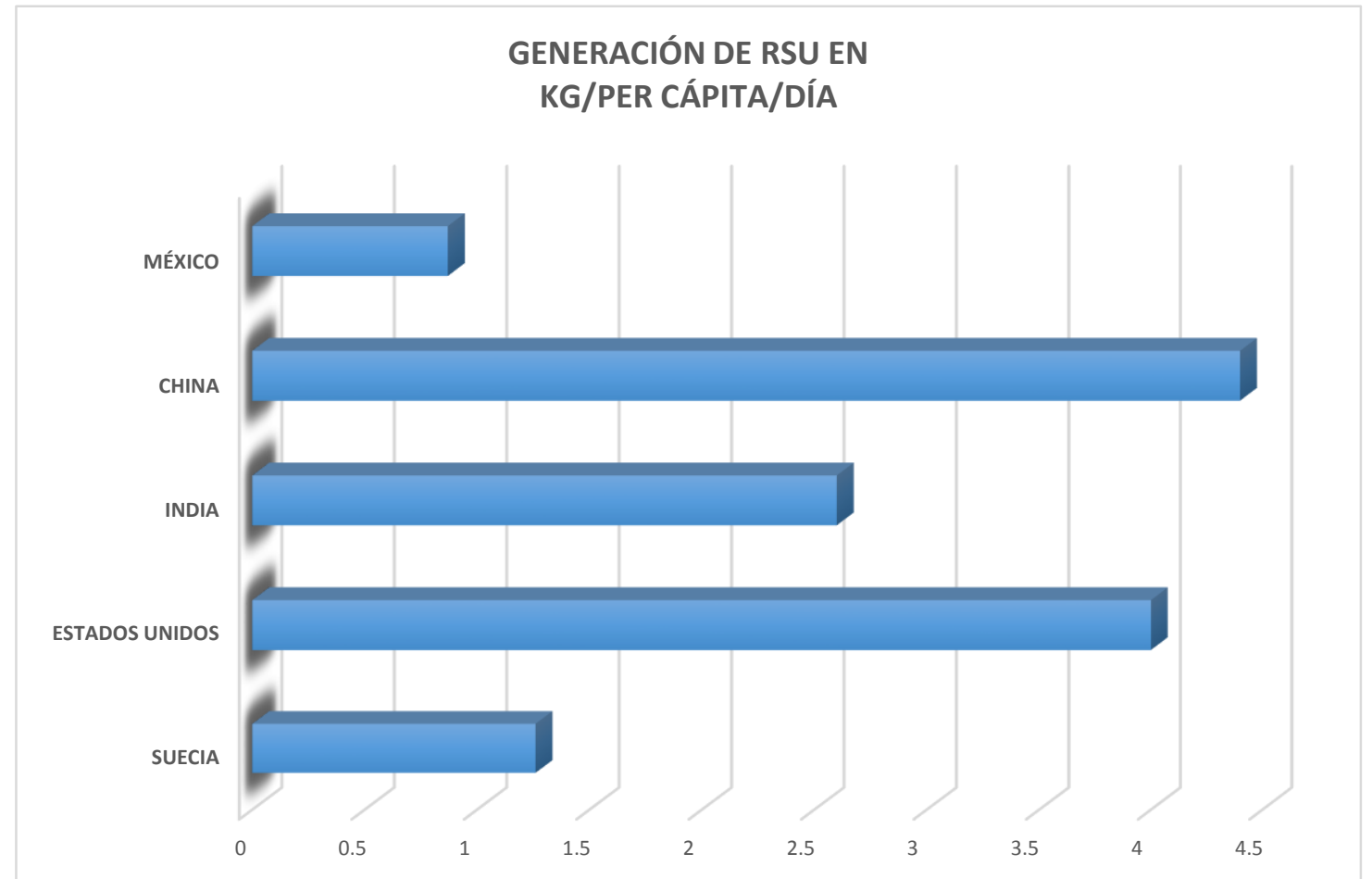

Fuente: Elaboración propia. Comparación de la generación per cápita al día de residuos sólidos de los casos de estudio con respecto a México

En la Figura 2.29.1 podemos ver que actualmlente el país que más RSU está generando es China, esto debido a su gran desarrollo económico, seguido de EU, que fue hasta hace casi cuatro años que China 
quitó a EU del comienzo dela lista de países con la mayor generación de RSU. En tercer lugar econtramos a India, un país en vías de desarrollo al igual que México que le sigue en el cuarto lugar. Finalmente se encuentra Suecia, con la menor generación de RSU al año. Suecia parece ser uno de los países más limpios del mundo, ya que a pesar de un desarrollo económico elevado, este nórdico país sabe muy bien como manejar sus residuos, y no sólo eso, sabe como hacer de ellos un negocio redondo. El la Figura 2.29.2, encontramos la cantidad de RSU que genera en promedio un habitante de cada país en un solo día; así que nuevamente tenemos a los chinos generando alrededor de $4.5 \mathrm{~kg} / \mathrm{hab} /$ día de RSU, seguido de EU, India, Suecia y al final México. Estos resultados son realativos y es un promedio, ya que en la CDMX se están generando hasta $2.4 \mathrm{~kg}$ de RSU al día por persona.

A continuación podemos ver un comparativo del éxito que tiene cada país seleccionado con respecto a la cantidad de RSU que se llevan a sitios de disposición final. Este es un aspecto muy relevante ya que de acuerdo con las definiciones que se vieron en el capítulo anterior de esta investigación, se mencióno que una verdadera GIRS y un buen manejo de RSU intenta llevar la menor cantidad de RSU a sitios de disposición final, debido al poco espacio disponible para ello y además a todos los problemas ambientales y de salud que el mal manejo implica, que también anteriormente ya se ha mencionado. En las Figuras 2.30, se muestran un comparativo de la cantidad de RSU que lleva cada país lleva a disposición final. Suecia con un impresionante 1\%, este país nórdico recicla de cualquier forma el 99\% del total de RSU generados y más impresionante aún, le cobra a sus países vecinos por deshacerce de su basdura, mientras ellos la convierten en energía. Estados Unidos está reciclando casi la mitad y la otra mitad la lleva a sitios de disposición final, no deja de reconocerse el esfuerzó que EU hace, debido a la gran cantidad de RSU que produce, que van de la mano con la cantidad de RSU que China produce. Sin embargo China al igual que México y la India, están llevando a sitios de disposición final casi el $100 \%$ de lo que genera. Lo cual indica que ninguno de estos países está tenieendo éxito en el manejo de sus RSU. Sin embargo fueron seleccionados debido al cumulo de esfuerzos que estos países se encuentran haciendo para mejorar el manejo de RSU, además de que también se seleccionaron debido a las condiciones socioeconómicas y culturales que son muy similares a las condiciones que tiene tienen México en cuanto a RSU se refiere.

Figura 2.30. Comparación del total de RSU generados contra los que se llevan a sitios de diposición final.

\subsection{1) Suecia}

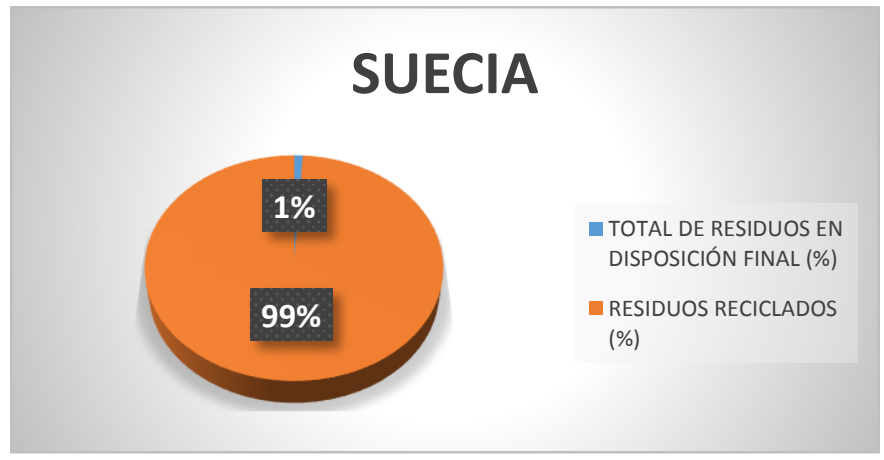

Fuente: Elaboración propia
2.30.2) EU

\section{ESTADOS UNIDOS}

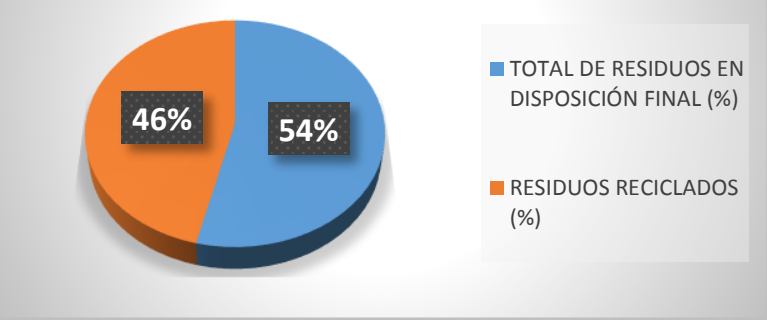

Fuente: Elaboración Propia 


\subsection{3) India}

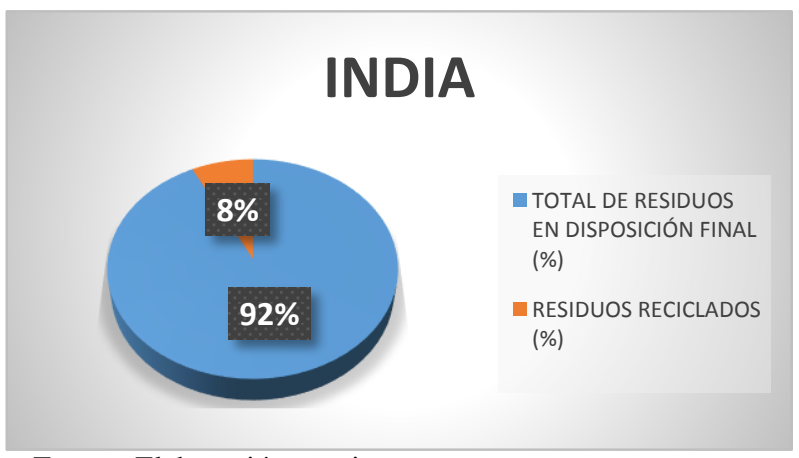

Fuente: Elaboración propia.

\subsection{4) China}

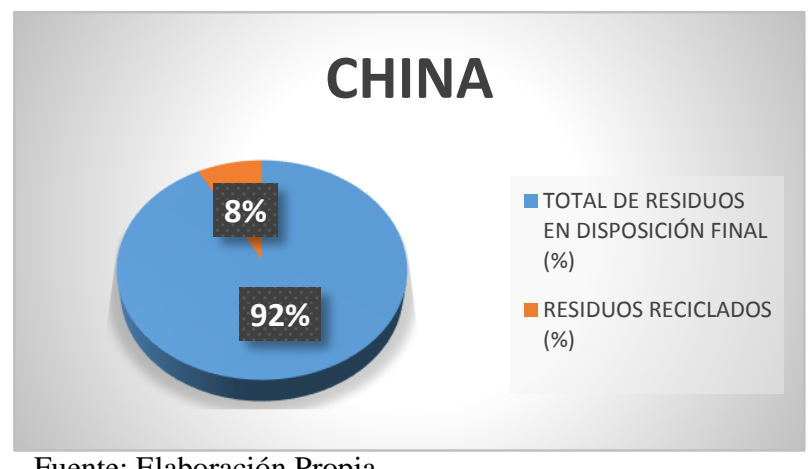

Fuente: Elaboración Propia

\subsection{5) México}

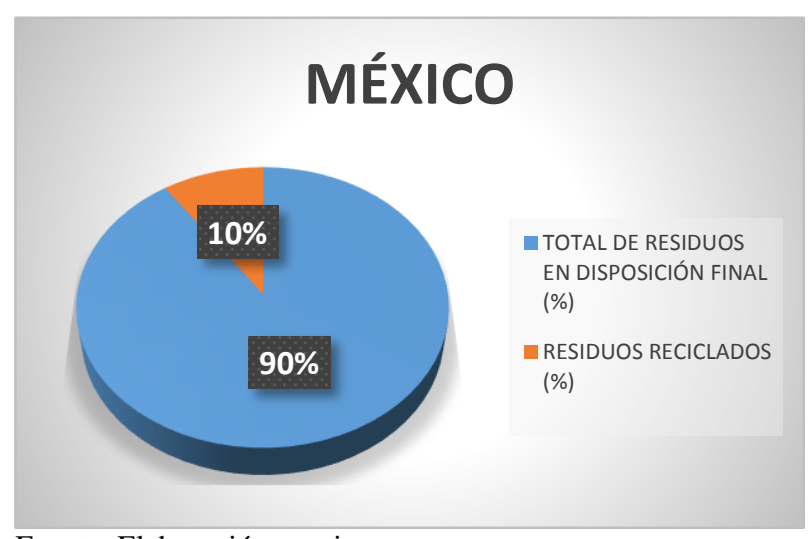

Fuente: Elaboración propia

Después de poder analizar a través de los números, que es lo más objetivo, se puede rescatar lo más importante que cada país aporta al manejo de RSU al mundo con respecto a sus prácticas, pero en este caso especial, lo que pudiera aportar a México. Se encontraron cuatro ejes temáticos, a partir de los cuales se desglosaron las lecciones aprendidas en la Tabla 2.4.

Tabla 2.4. Resumen de lecciones aprendidas

\begin{tabular}{|c|c|c|c|c|}
\hline PAÍS & $\begin{array}{l}\text { GOBIERNO } \\
\text { Y } \\
\text { POLITICAS } \\
\text { PÚBLICAS }\end{array}$ & FINANCIERO & $\begin{array}{c}\text { PARTICIPACIÓN } \\
\text { CIUDADANA }\end{array}$ & $\begin{array}{l}\text { TECNOLOGIA E } \\
\text { INVESTIGACIÓN }\end{array}$ \\
\hline $\begin{array}{c}\text { SUECIA } \\
\text { (País } \\
\text { desarrollado) }\end{array}$ & $\begin{array}{l}\text { 1.Verdadero } \\
\text { compromiso del } \\
\text { gobierno para con } \\
\text { los tratados } \\
\text { internacionales y } \\
\text { para con sus } \\
\text { ciudadanos. } \\
\text { 2. GIRS, prioridad } \\
\text { nacional }\end{array}$ & $\begin{array}{l}\text { 1.Los RSU no son } \\
\text { un problema, son un } \\
\text { negocio. } \\
\text { 2.Subcontratación } \\
\text { de compañías } \\
\text { mediante } \\
\text { licitaciones } \\
\text { transparentes para } \\
\text { proporcionar } \\
\text { infraestructura. }\end{array}$ & $\begin{array}{l}\text { 1.Los suecos suelen } \\
\text { involucrarse en todos y } \\
\text { cada uno de los temas } \\
\text { que afecten al ambiente. } \\
\text { 2.Extremada obsesión } \\
\text { por cuidar la naturaleza. } \\
\text { 3.Conciencia ambiental. } \\
\text { 4.Alta participación } \\
\text { ciudadana en los }\end{array}$ & $\begin{array}{l}\text { 1.Educación ambiental } \\
\text { desde preescolar. } \\
\text { 2.Comunicación y } \\
\text { divulgación de la ciencia } \\
\text { para con el pueblo y el } \\
\text { gobierno. } \\
\text { 3.WTE, es lo más } \\
\text { aplicado. } \\
\text { 4.Biogás. }\end{array}$ \\
\hline
\end{tabular}




\begin{tabular}{|c|c|c|c|c|}
\hline & $\begin{array}{l}\text { 3. Gobernanza } \\
\text { Híbrida: Iniciativa } \\
\text { privada, gobierno } \\
\text { y ciudadanos } \\
\text { forman un solo } \\
\text { equipo. } \\
\text { 4. Políticas de } \\
\text { tercera generación }\end{array}$ & $\begin{array}{l}\text { 3.Apertura a las } \\
\text { estructuras PPP, } \\
\text { donde todos ganan } \\
\text { 4. generan su propia } \\
\text { energía y no } \\
\text { depende tanto del } \\
\text { petróleo. } \\
\text { 5. Generación de } \\
\text { recursos a través de } \\
\text { la consultoría de } \\
\text { GIRS. } \\
\text { 6.Se invierte } \\
\text { constantemente en } \\
\text { la investigación } \\
\text { 7. Pago del servicio } \\
\text { de RSU, } \\
\text { proporcional a la } \\
\text { generación de RSU }\end{array}$ & $\begin{array}{c}\text { programas de } \\
\text { separación, y reciclaje. } \\
\text { 5.Uso y exigencia de la } \\
\text { buena gobernanza }\end{array}$ & $\begin{array}{l}\text { 5.Líderes mundiales en } \\
\text { la GIRS y las } \\
\text { investigaciones que la } \\
\text { fomentan }\end{array}$ \\
\hline $\begin{array}{c}\text { EU } \\
\text { (país } \\
\text { desarrollado) }\end{array}$ & $\begin{array}{c}\text { 1.El que } \\
\text { contamina paga. } \\
\text { 2.Su agencia } \\
\text { ambiental } \\
\text { actualiza su base } \\
\text { de datos } \\
\text { constantemente y } \\
\text { la pone a } \\
\text { disposición del } \\
\text { público. } \\
\text { 3.El marco } \\
\text { jurídico jerarquiza } \\
\text { la GIRS, poniendo } \\
\text { al tope la } \\
\text { prevención }\end{array}$ & $\begin{array}{l}\text { 1.Los presupuestos } \\
\text { por parte del } \\
\text { gobierno son altos y } \\
\text { usan la mayor parte } \\
\text { de este presupuesto } \\
\text { en reciclar y no en } \\
\text { recolectar. } \\
\text { 2. incentivos a los } \\
\text { ciudadanos que se } \\
\text { hacen cargo de } \\
\text { manera responsable } \\
\text { de sus RSU } \\
\text { orgánicos. } \\
\text { 3.Se invierten } \\
\text { fuertes sumas de } \\
\text { dinero en la } \\
\text { investigación }\end{array}$ & $\begin{array}{l}\text { 1.Participación } \\
\text { ciudadana } \\
\text { 2.Ciudadanos } \\
\text { informados }\end{array}$ & $\begin{array}{l}\text { 1.Trabajo arduo por } \\
\text { integrar tecnologías } \\
\text { WTE. } \\
\text { 2.Existen carreras } \\
\text { especializados en GIRS. } \\
\text { 3.continuas } \\
\text { investigaciones sobre el } \\
\text { tema. }\end{array}$ \\
\hline $\begin{array}{c}\text { INDIA } \\
\text { (propuestas } \\
\text { de un país en } \\
\text { vías de } \\
\text { desarrollo) }\end{array}$ & $\begin{array}{l}\text { 1.Fomento de la } \\
\text { buena gobernanza. } \\
\text { Inclusión de todos } \\
\text { 2. No debatir con } \\
\text { los pepenadores, } \\
\text { más bien incluirlos } \\
\text { en los programas. } \\
\text { Intervención de } \\
\text { ONG. } \\
\text { 3.Programas que } \\
\text { apunten a la } \\
\text { sostenibilidad. } \\
\text { 4.Creación de } \\
\text { centros de } \\
\text { capacitación } \\
\text { gubernamentales } \\
\text { 5.LaGIRS debe } \\
\text { convertirse en } \\
\text { prioridad nacional. }\end{array}$ & $\begin{array}{l}\text { 1.Comercialización } \\
\text { de productos } \\
\text { reciclados. } \\
\text { 2.Ubicar } \\
\text { pepenadores } \\
\text { calificados y } \\
\text { hacerlos } \\
\text { microempresarios. } \\
\text { 3.Intervención de } \\
\text { estructuras PPP. } \\
\text { 4.Utilizar el dinero } \\
\text { de las multas para } \\
\text { incentivar al } \\
\text { ciudadano y } \\
\text { fomentar la GIRS }\end{array}$ & $\begin{array}{c}\text { 1.Participación } \\
\text { ciudadana. } \\
\text { 2.Inclusión de todos los } \\
\text { grupos sociales en los } \\
\text { programas ambientales. } \\
\text { 3.Transmitir la } \\
\text { información de } \\
\text { ciudadano a ciudadano } \\
\text { 4. Fomentar la } \\
\text { clasificación de RSU } \\
\text { desde la fuente de } \\
\text { origen. }\end{array}$ & $\begin{array}{l}\text { 1.Tecnologías factibles } \\
\text { económicamente. } \\
\text { 2.Generación de } \\
\text { información asequible } \\
\text { para los ciudadanos } \\
\text { comunes. } \\
\text { 4. Tecnologías que } \\
\text { fomenten la composta, } \\
\text { lombri-composta, y la } \\
\text { generación de biogás. } \\
\text { 5.Demostraciones de } \\
\text { instalaciones modelo } \\
\text { para implementar } \\
\text { tecnologías a todos los } \\
\text { niveles } \\
\text { 6. La GIRS de ser una } \\
\text { carrera universitaria. } \\
\text { 7.Desarrollo y } \\
\text { actualización de base de } \\
\text { datos }\end{array}$ \\
\hline CHINA & $\begin{array}{c}\text { 1.Políticas con } \\
\text { sanciones } \\
\text { económicas como } \\
\text { el que contamina } \\
\text { paga. } \\
\text { 2.Las agencias } \\
\text { ambientales deben }\end{array}$ & $\begin{array}{l}\text { 1.Cobrar por kilo } \\
\text { generado de RSU } \\
\text { 2.incluir estructuras } \\
\text { PPP con BOT. } \\
\text { 2.Invertir en } \\
\text { incentivos e } \\
\text { investigación. }\end{array}$ & $\begin{array}{c}\text { 1. Participación } \\
\text { ciudadana en los } \\
\text { programas ambientales } \\
\text { 2.Fomentar la filosofía } \\
\text { de las } 3 R^{\prime} \text { 's en revistas, } \\
\text { programas de TV, } \\
\text { periódicos, etc. }\end{array}$ & $\begin{array}{l}\text { 1.Gran generación de } \\
\text { información disponible. } \\
\text { Mejorar la comunicación } \\
\text { entre gobierno, } \\
\text { empresario, investigador } \\
\text { y ciudadano. }\end{array}$ \\
\hline
\end{tabular}



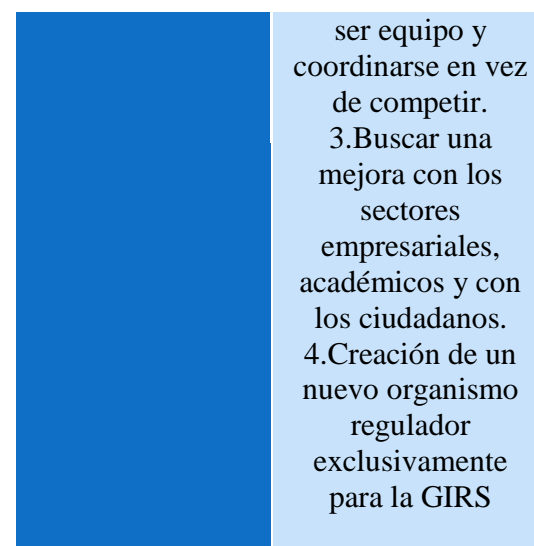

3. informarse y ponerse

al tanto de los temas ambientales. 2.fomentar la Simbiosis

Urbana, industrial y las tecnologías WTE en estructuras PPP o en cementeras que ya tienen gran parte de la infraestructura montada

Fuente: Elaboración propia

En conclusión, se puede decir que existen problemas de RSU a nivel mundial tanto para países desarrollados como para los que están en vías de desarrollo, y aunque algunos países desarrollados puedan contar con los recursos suficientes para mitigar el problema en gran medida, no siempre es prioridad para los mismos. Por otro lado, países en vías de desarrollo intentan echar andar estrategias con limitantes económicos fuertes. Por lo tanto, resulta interesante poder comparar y contrastar el panorama de los RSU a través de estos cuatro casos de estudio, ya que de ellos podemos tomar cosas que puede aplicarse directamente a la CDMX, que incluso pudieran implementarse al resto de ciudades importantes que tiene México.

Es importante también destacar, que los casos de estudio que se seleccionaron, en general alrededor del $70 \%$ de su población es población urbana, como se mencionó anteriormente. Es decir, las estrategias aplicadas en estos países son estrategias, que en general, son tomadas de sus ciudades más importantes y más grandes, por lo que se puede aplicar directamente a ciudades grandes como lo es la CDMX. El caso de México tampoco es diferente en cuanto a la urbanización, ya que, en 1950, poco menos de $43 \%$ de la población en México vivía en localidades urbanas, en 1990 era de $71 \%$ y para 2010, esta cifra aumentó a casi 78\% (INEGI,2012). En cuanto a nivel mundial, por ahora más de la mitad de la población mundial vive en zona urbanas, pero se espera que para el 2050 sea alrededor de tres cuartos de la población mundial sea la que lo haga (ONU, 2014). Esto pone en clara evidencia que la tendencia global, tanto para países desarrollados como en vías de desarrollo es la urbanización, lo que trae como consecuencia lógica el incremento de la generación de los RSU, por lo que es de vital importancia buscar estrategias que puedan aplicarse ya sea de manera general o aplicadas a las condiciones económicas y socioculturales de cada nación en particular, para ayudar a mitigar el gran problema de los RSU. Como, por ejemplo, el caso de India contiene propuestas, en los cuatro ejes temáticos, que en general pudieran ser aplicadas a la CDMX. En el caso de Suecia, resultaría complicado aplicar sus estrategias, especialmente las referentes al cuarto eje, el de investigación y tecnología, ya que dos factores limitarían a México: el factor tiempo, puesto que ellos llevan investigando el tema de manera intensa por varias décadas y por otro lado el factor costo, porque esto les ha implicado grandes cantidades de recursos y en general, este costo resulta inaccesible para cualquier país en vías de desarrollo.

En estos casos de estudio donde se analizaron diferentes estrategias, en cuatro diferentes ejes temáticos, que están expuestos en la Tabla 2.4, tienen como principal objetivo visualizar y aprovechar las experiencias de países exitosos y también experiencias de los intentos que hacen los países en vías de desarrollo por superar el problema. Sin embargo, se debe retomar la idea que en el capítulo uno se mencionó: para poder intentar realizar una mejora en el manejo de RSU en una nación o sus ciudades, 
debe tenerse clara la situación actual de su manejo, ya que esta será determinante para generar estrategias concretas en las fases del manejo que más debilidad presenten.

Para que esto pueda llevarse a cabo, primero que nada, se deben tener bien claros cuales son los objetivos por cumplir en el marco normativo y de planeación de la ciudad o país que se pretenda realizar la evaluación. Es decir, en el siguiente capítulo se podrá observar un análisis en materia del manejo de los RSU en la CDMX, con el objetivo de extraer los objetivos y metas que estos proponen, y así poder identificar si se están cumpliendo o no. 


\section{Capítulo III}

\section{Marco normativo y de planeación y las fases del manejo de los RSU en la CDMX}

\subsection{Fases del manejo de los RSU en la CDMX}

En el capítulo anterior se describieron todas las fases que se consideraron en esta investigación para el manejo de RSU, desde el punto de vista técnico. Además, se hizo un análisis de lo que sucede en países desarrollados comparando sus prácticas de manejo de RSU con los países en vías de desarrollo, como lo es México. Sin embargo, es importante tener conocimiento de lo que el marco normativo y jurídico dicta que debe hacerse en nuestro país, en contraste con lo que realmente ocurre en la gestión, dado que existe una brecha significativa entre el deber ser y el ser; esto debido a diferentes causas de índole político, social, y/o cultural de la Ciudad de México (CDMX) y sus habitantes. Es por eso, que en este capítulo se intenta analizar de manera concisa lo que el marco jurídico establece con respecto a cada una de las fases del manejo de RSU para contrastarlo con lo que realmente ocurre con dicho manejo en la Ciudad, en cada una de las cinco fases que comprenden el manejo de los residuos y se habla de: 1) generación, 2) recolección, 3) manipulación y procesamiento, 4) transformación y 5) disposición final en la CDMX.

Figura 3.1. Manejo de los RSU en la CDMX

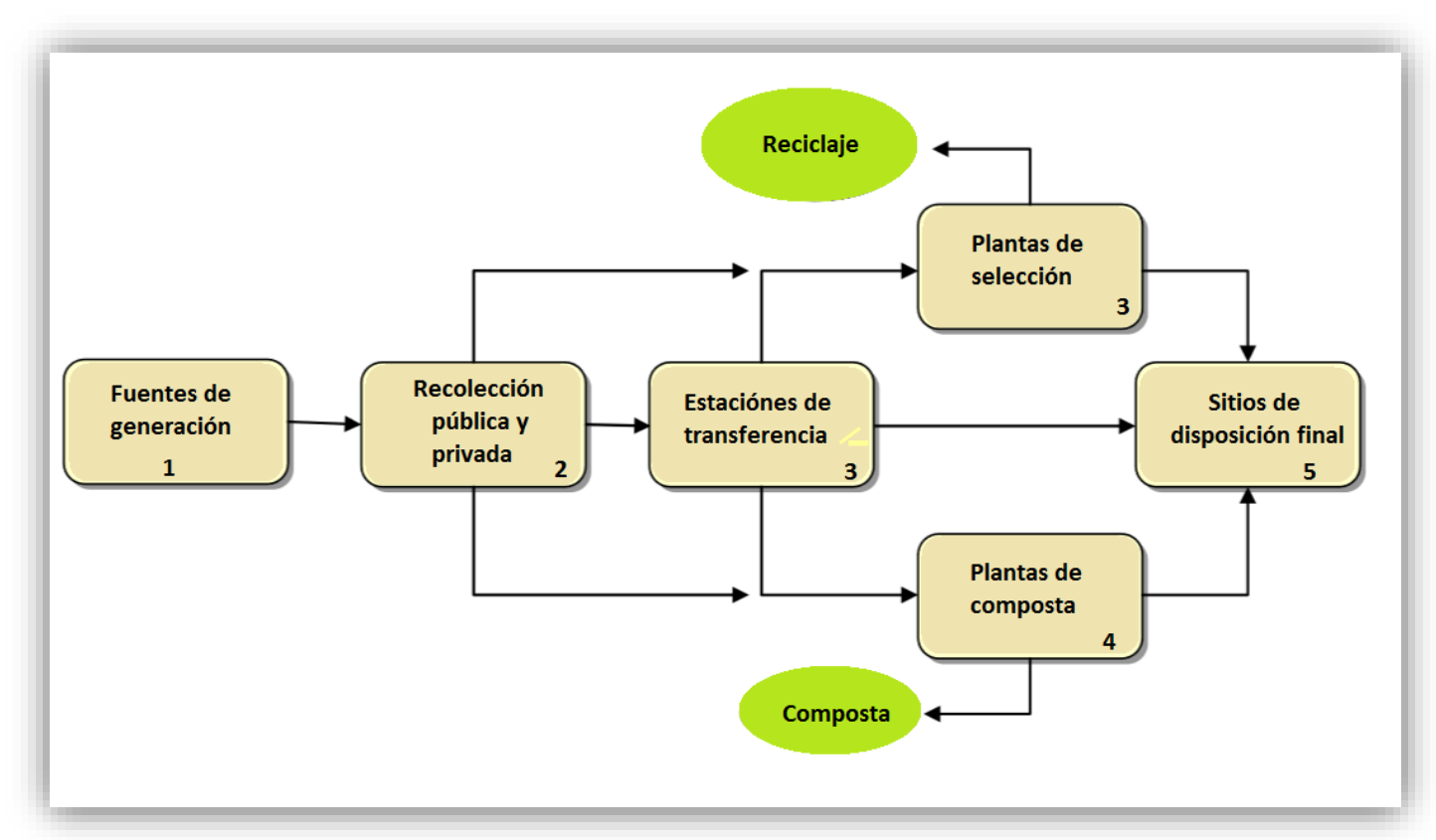

Fuente: Inventario de RSU de la CDMX, 2006. 
Algunos de los documentos más relevantes que se han generado a nivel CDMX, son los inventarios de RSU, los cuales se han realizado año con año desde el 2006. En ellos se llevan los más recientes registros de todo lo que tiene que ver con el manejo de RSU, en todas sus fases: desde la generación hasta la disposición final. Es por eso, que entre los documentos base de donde se extraerá información para este capítulo se encuentran los Inventarios de RSU de la CDMX.

\subsubsection{Fase 1: Generación de RSU en la CDMX}

Uno de los puntos de partida para tener un adecuado manejo de RSU es saber qué cantidad de RSU se ha generado, de dónde provienen y qué composición tiene. Estos datos son primordiales y se vuelven la base del manejo. Es decir, con la cantidad total de RSU generados se puede calcular la capacidad instalada de las plantas de transferencia y se deben planear y diseñar las estrategias para recolectar dichos residuos; con la composición de los RSU se debe establecer el tipo de procesos que se necesitarán para transformar y recuperar el valor de estos residuos. Finalmente, este conjunto de datos ayudará a construir sitios de disposición final adecuados. Sin embargo, a lo largo de esta investigación los primeros obstáculos que se enfrentaron han sido la falta de información y el desconocimiento de los volúmenes generados por cada una de las demarcaciones territoriales, aunque se cuenta con un valor estimado. En este sentido, estos registros se han hecho a partir de diversas estimaciones ya que, por cuestiones esencialmente políticas y sociales, no se han podido calcular de manera exacta la generación de RSU. En primera instancia, porque los residuos una vez recolectados tienen dueño, es decir, éstos no pasan a las estaciones de transferencia que es el lugar donde se pesan por primera vez, tal cual el usuario del servicio de recolección los entrega, sino que primero los conductores de los camiones extraen todo material que les sea útil ya sea para reusar o revender en el mercado informal, como en centros de reciclaje que no se encuentran regulados por ninguna estancia gubernamental. Esta situación no permite que los cálculos que se realizan en los inventarios sean exactos, sino más bien, como se ha mencionado, son basados en estimaciones a partir del peso que se generó en las estaciones de transferencia. Lo anterior es relevante, porque se desconoce con certeza el volumen de residuos que las autoridades de la CDMX pudieran reciclar, lo que pudiera implicar el que no se reciba algún ingreso que apoye el mantenimiento de la infraestructura, los vehículos de recolección, o incluso que apoye parte del financiamiento de nuevas de obras para un aprovechamiento más eficiente de los RSU. Aunado a esto, existen problemas para contar con información desagregada, ya que la información sólo está disponible por demarcación territorial y no hay manera de saber la generación total de RSU por colonia, ya que una ruta de recolección de RSU puede incluir varias colonias que incluso pudieran pertenecer a diferentes demarcaciones territoriales.

En el caso de los datos de generación de RSU, es la secretaría de obras la que los proporciona ya que realizan informes mensuales de la recolección separada que se va haciendo por ruta. Estos reportes a su vez, son enviados a la Secretaría del Medio Ambiente de la CDMX. Los informes mensuales presentan las rutas y establecimientos de recolección que han sido incorporados por las demarcaciones territoriales al programa de recolección separada, los esquemas de recolección, así como las cantidades de residuos orgánicos, inorgánicos y mezclados que se recolectan en cada uno de ellos. Por otro lado, la Secretaría de Obras y Servicios entrega toda la información con respecto a la infraestructura para el manejo de los residuos sólidos generados en la Ciudad. Es así que, con el trabajo de estas instancias gubernamentales, se puede obtener las estimaciones de los datos de generación de RSU de la CDMX (Figura 3.1).

De manera general, se ha calculado que durante el año 2014 los habitantes de la Ciudad generaron aproximadamente 12,893 toneladas por día, lo que equivale a $1.46 \mathrm{Kg} /$ día por habitante. Cabe mencionar que $7.9 \%$ de la población total del país pertenece a la CDMX, ocupando el segundo lugar 
en generación de RSU a nivel nacional, en primer lugar, se encuentra el estado de México, con una generación de cerca de 16,000 toneladas por día y en tercer lugar el estado de Jalisco con una generación de casi 8,000 toneladas por día; teniendo así entre estas tres entidades alrededor del 35\% de la generación total de RSU de todo el país. (Diagnóstico Básico para la Gestión Integral de los Residuos, 2012; Inventario, 2014). Sin embargo, como dato adicional, se tiene que son tres Demarcaciones Territoriales las que se encuentran generado casi la mitad del total de RSU de la CDMX, tal es el caso de: Iztapalapa, Gustavo A. Madero y Cuauhtémoc con 2,274, 1,709 y 1,325 toneladas/día respectivamente.

Otro aspecto relevante a considerar es el tipo de fuente de donde se generaron los RSU. En la CDMX se estima que del total de RSU generados, $48 \%$ corresponde a residuos domiciliarios, seguido con un $15 \%$ que corresponde a los comercios, $15 \%$ de los servicios, $10 \%$ de los mercados, $5 \%$ de la Central de Abasto, la cual se encuentra en la Demarcación de Iztapalapa, 4\% son diversos, y finalmente 3\% son controlados; éstos últimos corresponden a residuos provenientes de reclusorios, hospitales, y en general, de manejo especial.

Básicamente, éstos son los datos de generación con los que se cuentan, pero es transcendental hacer hincapié en la necesidad de generar bases de datos confiables y completas con respecto al manejo de los RSU, especialmente para la generación, y que además se encuentren disponibles, ya que de estos datos depende en gran parte el éxito o fracaso de un adecuado manejo de RSU como anteriormente se explicó.

\subsubsection{Fase 2: Recolección de RSU en la CDMX}

Adicionalmente a los datos de generación de RSU, las demarcaciones territoriales reportan información general sobre la recolección de los residuos. Esta información comprende el número total de colonias, vehículos y rutas de recolección. Por otro lado, la Dirección General de Servicios Urbanos (DGSU) de la Secretaría de Obras y Servicios, integra la información operativa de las 13 estaciones de transferencia, 3 plantas de selección, una planta de composta Bordo Poniente y los sitios de disposición final.

El servicio de recolección de residuos es realizado por las demarcaciones territoriales por medio de diferentes vehículos recolectores y es transportado principalmente a las estaciones de transferencia, y aunque en menor medida, también se transporta parte de los residuos a las plantas de selección. En la Ciudad de México, durante 2014, se generaron diariamente alrededor de 12,893 toneladas de residuos sólidos, que fueron recolectados por medio de un parque vehicular integrado por 2,460 camiones recolectores, con distintas capacidades volumétricas y una plantilla de 3,396 choferes, que atienden 1,868 colonias mediante 1,773 rutas de recolección. Las rutas de recolección, la mayor parte del tiempo, no son planeadas como lo indica el Manual Técnico sobre la generación, recolección y transferencia de residuos sólidos municipales, sino más bien son realizadas de acuerdo a la misma necesidad de los choferes, quienes a través del tiempo o de su experiencia laboral han definido las rutas de recolección que siguen en la actualidad (SEDESOL, 2014). Esto definitivamente es un problema, ya que la eficiencia no es la esperada. Sin embargo, no es posible obligar a los choferes a recorrer rutas específicas, ya que están protegidos por los sindicatos, los cuales no permiten ni aceptan fácilmente nuevas formas para realizar la recolección.

Un punto que también tiene relevancia en la eficiencia de la recolección es el de los vehículos recolectores, ya que éstos son la herramienta principal para la recolección. En la CDMX se cuenta con diferentes tipos de vehículos recolectores que ascienden a 2,460 unidades, entre los cuales destacan de carga trasera con una cantidad de 1,288 , de volteo y doble remolque con una cantidad de 
342 y 281 respectivamente, estos tres tipos son los más importantes dado que representan el $78 \%$ de la flota de vehículos (Figura 3.2).

Figura 3.2. Tipos de vehículos recolectores

\section{Vehículos Recolectores}

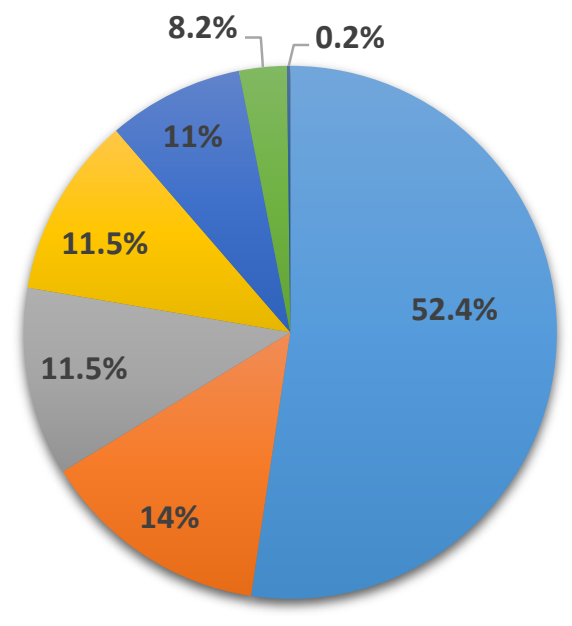

nCarga trasera Volteo Doble compartimiento $\square$ Otros $\square$ Rectangulares $\square$ Tubular $\square$ Frontal

Fuente: Elaboración propia con datos del Inventario, 2014.

Por otro lado, también es importante hacer mención que los vehículos con los que cuenta la CDMX para el servicio de recolección no son nuevos, y esto es otro punto más que merma la eficiencia de recolección; es decir, el hecho de que los vehículos no sean nuevos o estén en perfectas condiciones implica diversos problemas, ya que se descomponen continuamente y al repararse hay menos unidades de las disponibles para hacer el mismo trabajo de recolección. De esta forma, con un total de 1,868 colonias, 1,773 rutas de recolección y un total de 2,460 vehículos recolectores, se ha calculado una eficiencia de 48\% (Demarcaciones Territoriales; Secretaría de Obras y Servicio, 2014). La manera en que este dato se calculó se basó en la información que cada una de las Demarcaciones Territoriales proporcionó a la Secretaría de Obras y Servicios, ésta información tiene que ver con el número de vehículos que se tienen, las condiciones en que estos se encuentran y el número de pobladores a los que se atienden, es decir los datos que se proporcionan tienen que ver con la eficiencia de recolección de RSU, estos tiene que ver directamente con la relación que hay entre realizar la recolección de los residuos en el menor tiempo posible y con el menor uso de recursos posibles, además de lo anterior mencionado. El $51.4 \%$ de eficiencia, en general es un porcentaje bajo y en gran parte esto se debe al grado de separación con que cada demarcación cuenta y otro factor también pudiera ser, como anteriormente se mencionó a la infraestructura para la recolección, como por ejemplo, a la antigüedad de los vehículos con lo que cuenta la CDMX, dado que la mayoría de las unidades son antiguos, (Figura 3.3). En este sentido, casi tres cuartas partes del total de los vehículos recolectores son obsoletos, y a mayor antigüedad del vehículo, éste necesitará mayor mantenimiento, lo que reduce el tiempo disponible para realizar las labores de recolección, además de incrementar los gastos de la recolección. 
Las rutas en general no logran recolectar en su totalidad los RSU de forma separada, la Figura 3.8, nos muestra el porcentaje de eficiencia de recolección separada por demarcación territorial, donde se puede observar que las demarcaciones con menor eficiencia de recolección separada son Benito Juárez, Álvaro Obregón y Azcapotzalco con un 30, 31 y 32\% respectivamente ; mientras que las que muestran tener una mayor eficiencia en su recolección separada son Milpa Alta, Coyoacán y Magdalena Contreras, con un 90, 80 y 75\% respectivamente. Esto sólo es en relación a los residuos orgánicos recolectados, los cuales ascienden a 1,487 toneladas por día de residuos, cifra que representa alrededor del $12 \%$ con respecto al total generado que es de 12,893 toneladas por día. Es importante tener presente que no se recolecta el total de RSU generados, sino sólo un 63\% aproximadamente que ascienden a 8,080 toneladas por día, de esta cantidad sólo se recupera, como anteriormente se mencionó 1,487 toneladas por día en residuos orgánicos y 1,664 toneladas por día de inorgánicos reciclables, 1690 ton/día considerando los de manejo especial, que tienen una composición aproximada descrita en la Tabla 3.1, el resto de los RSU van mezclados e inservibles, por lo tanto se destinan a sitios de disposición final, es decir un total de 4,929, en el 2013 y para el año 2014, 8,099 considerando los residuos de manejo especial toneladas por día. En general, se identifican 6,947 puntos específicos en la CDMX en donde se realiza la recolección de manera separada. Estos puntos de recolección se encuentran distribuidos como lo muestra la Figura 3.4, donde se observa que hay mayores puntos específicos de recolección separada es en escuelas con el $41 \%$, esto también puede deberse a que muchas de ellas tienen sus propias estrategias de manejo de RSU. Por el contrario, en la misma Figura 3.4, podemos observar que uno de los rubros en los que menos puntos de recolección separada hay, es en el de las zonas habitacionales con tan solo un 9\%. Éste punto en específico, representa un problema grande, ya que como anteriormente se ha mencionado, alrededor del $42 \%$ del origen de los RSU es domiciliario. Es importante reflexionar sobre la gran necesidad de recolectar la basura separada y la importancia que esto implica para el aprovechamiento de dichos residuos, ya que sin una recolección separada el aprovechamiento de los mismos se vuelve casi imposible, pues al mezclar los RSU, estos pierden el valor que pudiera dárseles, además de las propiedades físicas ideales como materia prima de otros procesos, tal es el caso del cartón, al mojarse con lixiviados de los RSU orgánicos.

Figura 3.3. Antigüedad de los vehículos recolectores de la CDMX

\section{Antigüedad de vehículos}

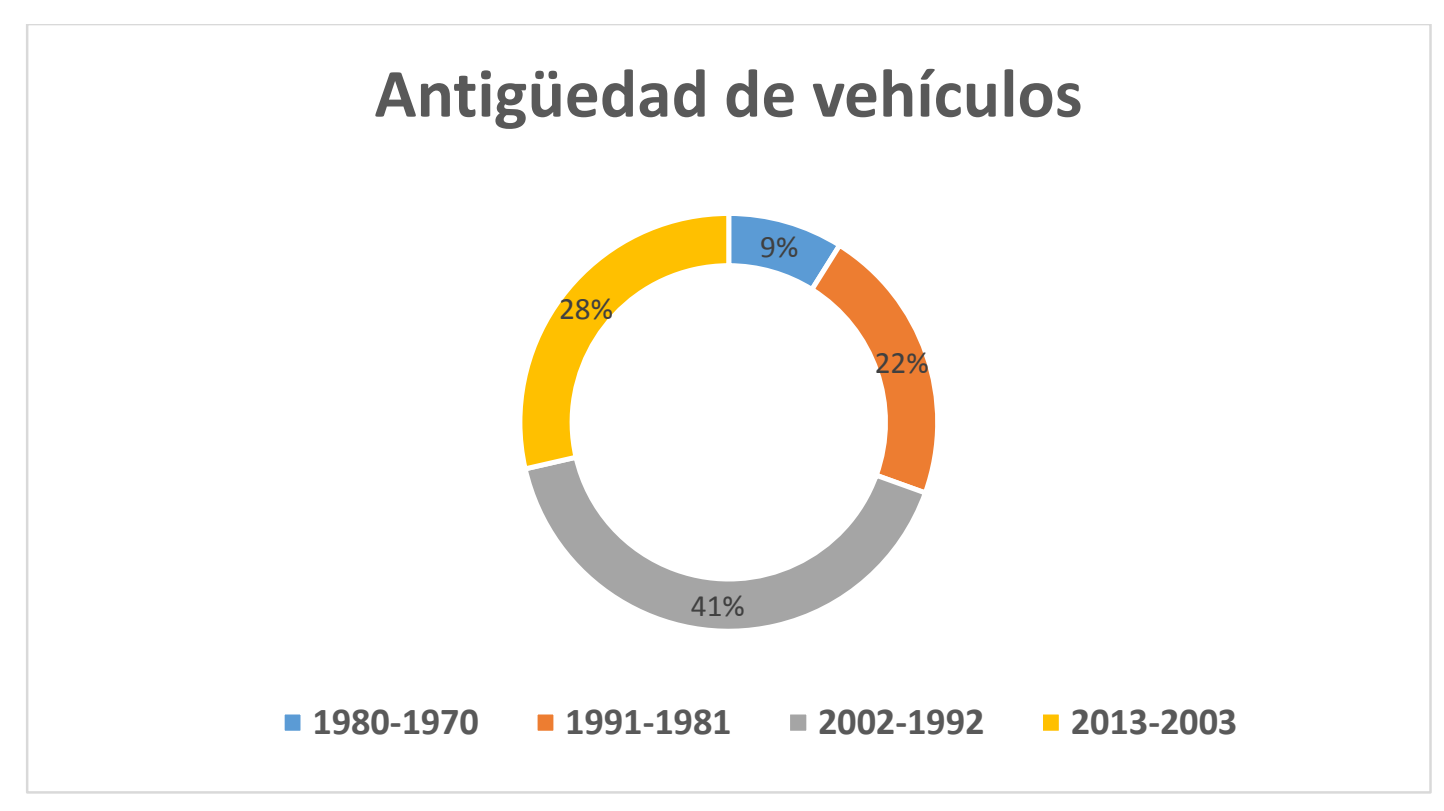

Fuente: Elaboración propia con datos del Inventario, 2014 
Figura 3.4. Puntos específicos de recolección separada en la CDMX

\section{Puntos específicos defters recolección}

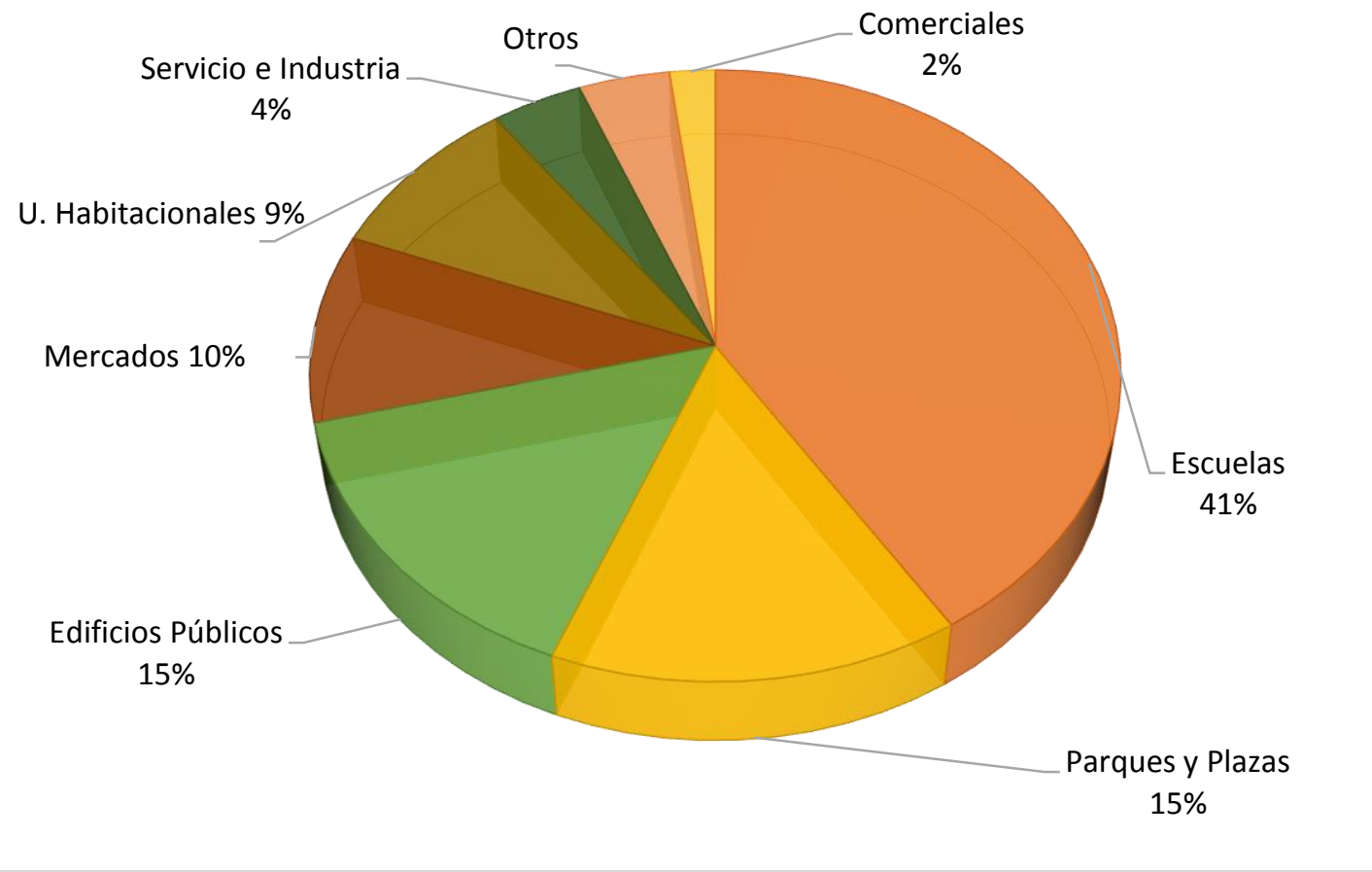

Fuente: Elaboración propia con datos del Inventario 2014.

Tabla 3.1. Composición de los RSU generados en la CDMX.

\begin{tabular}{|c|c|c|c|}
\hline SUBPRODUCTOS & \% DE SUBPRODUCTOS & SUBPRODUCTOS & $\begin{array}{c}\text { \% DE } \\
\text { SUBPRODUCTOS }\end{array}$ \\
\hline 1. Algodón & 0.30 & 21. Papel & \\
\hline 2. Cartón & & Papel Bond & 2.09 \\
\hline Cartón liso & 3.09 & Periódico & 1.68 \\
\hline Cartón corrugado & 2.77 & Revista & 0.62 \\
\hline Otros cartones & 0.50 & Papel higiénico & 6.72 \\
\hline $\begin{array}{l}\text { 3. Envase de cartón } \\
\text { tetrapak }\end{array}$ & 1.51 & $\begin{array}{l}\text { 22. Pañal desechable, } \\
\text { toallas femeninas }\end{array}$ & 2.83 \\
\hline 4. Cuero & 0.33 & 23. Plásticos & \\
\hline 5. Residuo Fino & 2.68 & $\begin{array}{l}1 \text { - PET (Polietilen - } \\
\text { tereftalato) }\end{array}$ & 2.80 \\
\hline 6. Residuo grueso & 1.71 & $\begin{array}{l}2 \text { - HDPE-PEAD } \\
\text { (Polietileno de alta } \\
\text { densidad) }\end{array}$ & 2.92 \\
\hline 7. Fibra dura vegetal & 0.50 & $\begin{array}{l}3 \text { - PVC (Policloruro de } \\
\text { vinilo) }\end{array}$ & 0.15 \\
\hline 8. Fibra sintética & 0.49 & $\begin{array}{l}4 \text { - LDPE-PEBD } \\
\text { (Polietileno de baja } \\
\text { densidad) }\end{array}$ & 5.44 \\
\hline 9. Hueso & 0.70 & 5 - PP (Polipropileno) & 0.92 \\
\hline 10. Hule & & 6 - PS(Poliestireno) & 0.98 \\
\hline
\end{tabular}




\begin{tabular}{|c|c|c|c|}
\hline Llantas de automóvil & 0.48 & 24. Mat. Orgánicos & \\
\hline Llantas de camioneta & 0.06 & Alimenticios & 34.87 \\
\hline Llantas de camión & 0.37 & Residuos de jardinería & 9.18 \\
\hline Otros hules & 0.17 & 25. Trapo & 2.94 \\
\hline 11. Latas & & 26. Vidrio & \\
\hline Lata aluminio & 0.27 & Vidrio Transparente & 1.74 \\
\hline Lata metálica & 1.46 & Vidrio color & 0.74 \\
\hline 12. Losa y cerámica & 0.53 & 27. Tenis & 0.20 \\
\hline 13. Madera & 1.95 & 28. Zapatos & 0.44 \\
\hline $\begin{array}{l}\text { 14. Material } \\
\text { construcción }\end{array}$ & 1.75 & 29. Otros & \\
\hline 15. Material ferroso & 0.37 & Bajo alfombra, Borra & \\
\hline 16. Aluminio & 0.07 & Cera parafina & \\
\hline 17. Bronce & 0.03 & Chácharas & \\
\hline 18. Cobre & 0.02 & Muebles & \\
\hline 19. Pilas eléctricas & 0.07 & Fibra de vidrio & 0.43 \\
\hline $\begin{array}{l}\text { 20. Otros mat. No } \\
\text { ferrosos }\end{array}$ & & Colchón & \\
\hline Acero inoxidable & 0.02 & Electrónicos & 0.11 \\
\hline \multirow[t]{2}{*}{ Suma } & 22.20 & Suma & 77.80 \\
\hline & & TOTAL & 100.00 \\
\hline
\end{tabular}

Fuente: Secretaría de Obras y Servicios, 2016.

Otra forma de recolectar los RSU generados en la CDMX es a partir del barrido de la vía pública de la ciudad. Éste se define como la actividad de recolección manual o mecánica de los residuos sólidos que se han generado, acumulado o esparcido en el área pública; el propósito de esta actividad es dejar las calles de la ciudad libres de todo residuo sólido esparcido o acumulado. Para el 2014, se registraron 6,754 rutas atendidas por 7,304 barredores, distribuidos en 497 cuadrillas, y con la ayuda de 7,835 carritos (IRS, 2014). Por otro lado, el barrido mecánico utilizó equipos que favorecen la disminución de los tiempos de limpieza de las vialidades secundarias, y para llevar a cabo esta tarea se contó con un total de 84 barredoras mecánicas de las cuales $50 \%$ se reportan en malas condiciones; mientras que $48.8 \%$ presentó condiciones regulares y solo $1.2 \%$ estaba en buenas condiciones (Inventario de RSU, 2014). Las condiciones en que se encuentre este equipamiento para realizar la fase de recolección, sin duda alguna entorpece los tiempos de esta actividad. Así que la cantidad de vehículos recolectores disponibles para realizar ese tipo de trabajo es mínima, por que un número importante de los mismos se encuentra en mantenimiento; situación que no permite mantener del todo limpia la ciudad. Una vez que los RSU son recolectados, éstos pasan a una estación de transferencia donde son manipulados y/o procesados de alguna manera, para así poderlos llevar a una cuarta fase de transformación como el reciclaje o el compostaje, o finalmente disponerlos, que es la última fase del manejo de los RSU (Figura 3.1).

\subsubsection{Fase 3: Manipulación-procesamiento en la CDMX.}


Esta fase es una de las fases que representa mayores retos para la CDMX, ya que como anteriormente se mencionó, la mayor parte de la basura que se recolecta no se hace de manera separada. Entonces, el manipularla o procesarla para tratar de llevar la mínima cantidad de RSU a sitios de disposición final, se vuelve una tarea casi imposible. Esta problemática se pone en evidencia en el elevado porcentaje de RSU que se lleva a sitios de disposición final, el cual asciende en la CDMX al 58\% (Inventario, 2014); cifra que es considerablemente superior con relación a otras ciudades de países en desarrollados. Por ejemplo, Suecia, que además de no llevar más que menos del $1 \%$ a sitios de disposición final, incluso importa basura de otros países vecinos para satisfacer sus necesidades de energía. (Agencia Sueca de Protección Ambiental Naturvårdsverket, 2006).

Esta fase del manejo se lleva a cabo en zonas llamadas estaciones transferencia, las cuales se encuentran distribuidas en puntos estratégicos a lo largo de la CDMX. Es necesario la presencia de estas estaciones de transferencia en orden de reducir la emisión de contaminantes generados por todas las unidades que se ocuparían y los recorridos que se harían para trasladar los RSU que no pudieron aprovecharse y que se van a sitios de disposición final.

Las estaciones con las que cuenta la Ciudad de México se ubican en las siguientes delegaciones: Álvaro Obregón, Azcapotzalco, Benito Juárez, Coyoacán, Cuauhtémoc, Gustavo A. Madero, Iztapalapa, Milpa Alta, Tlalpan, Venustiano Carranza, Xochimilco y en la Central de Abasto. El total de residuos sólidos que ingresan a las estaciones de transferencia es de 8,080 toneladas provenientes en su mayoría de las delegaciones, con un aporte de $87 \%$, además ingresa una cantidad menor de la Central de Abasto, la Secretaría de Obras y Servicios y del servicio particular de limpia (pago por derechos), que en su conjunto representan $13 \%$ del total de residuos (Inventario, 2014) (Figura 3.5).

\section{Figura 3.5: Ejemplo de una estación de transferencia en la CDMX}
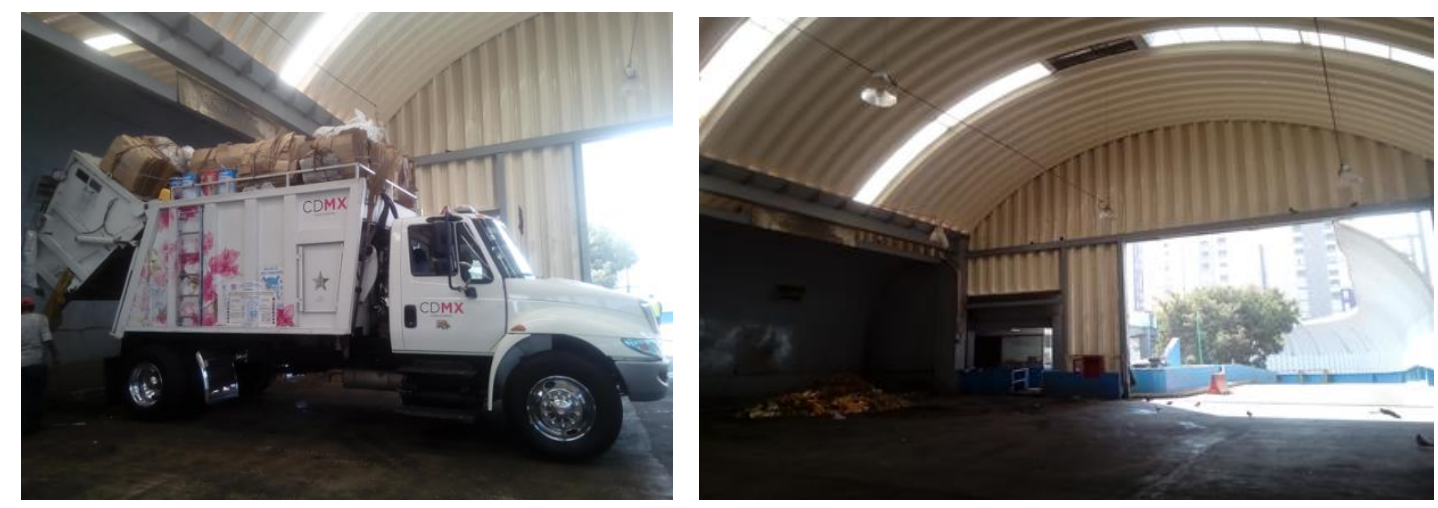

Fuente: Cortesía SEDEMA 
Figura 3.6. Fases del manejo de RSU en la CDMX

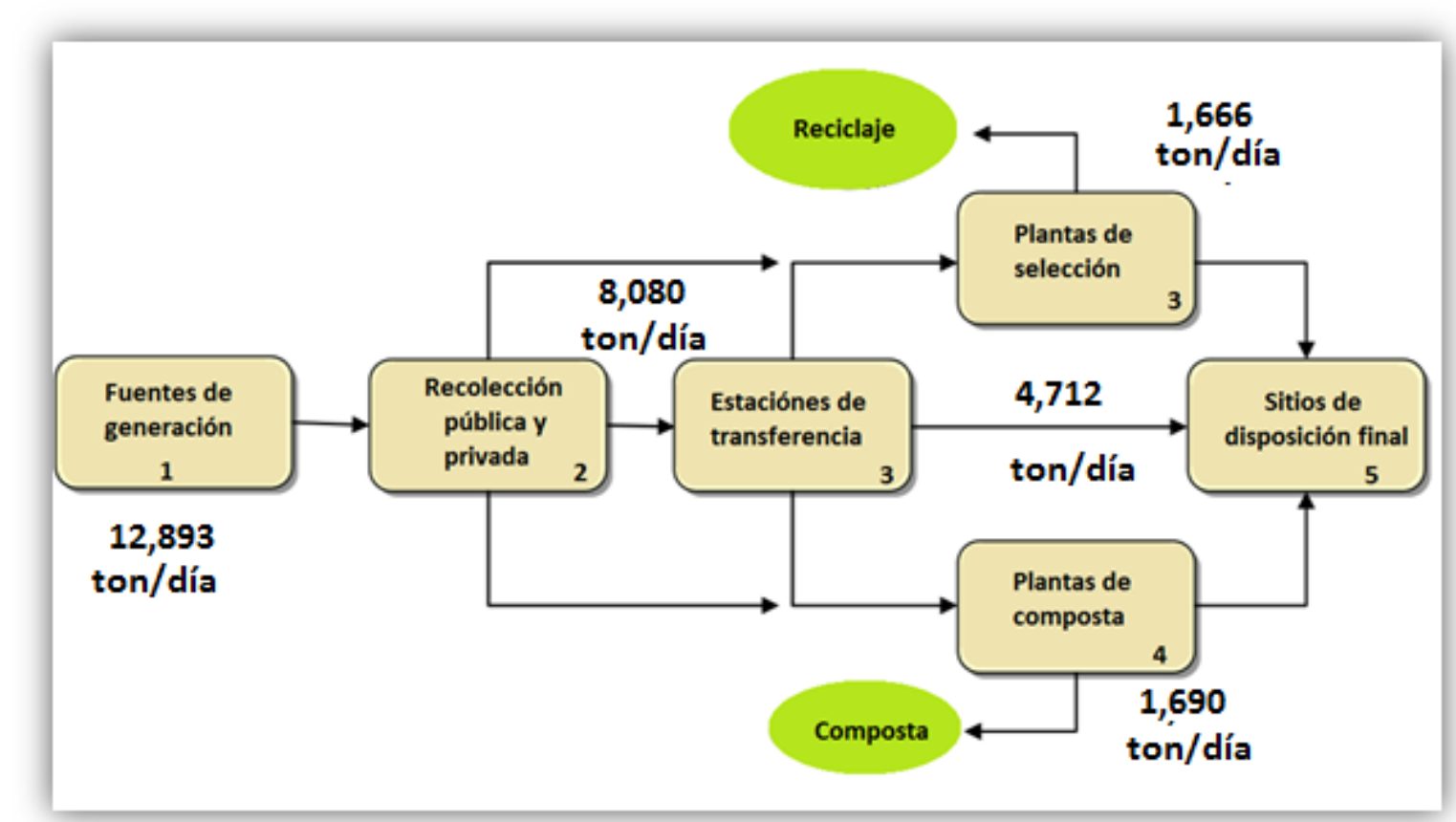

Fuente: Elaboración propia

De las 8,080 toneladas de residuos que egresan diariamente de las estaciones de transferencia, $42 \%$ de residuos son manipulados o procesados de alguna manera y son enviados a plantas de composta, plantas de selección y/o compactadoras por sus características con potencial de valorización. Estos se distribuyen de la siguiente manera: plantas de composta reciben 1,690 toneladas/día, las compactadoras 12 toneladas/día y las plantas de selección 1,666 toneladas/día (Inventario, 2014) (Figura, 3.6). Las plantas de selección se reciben residuos de diversas fuentes, y es aquí donde se lleva a cabo la selección y separación de materiales que conservan ciertas características ya sea químicas o físicas, que en general son las que permiten que dejen de ser residuos y se conviertan en materia prima para algún otro proceso. Estas plantas reciben un total de 3,758 toneladas de residuos sólidos al día, de los cuales $44 \%$ proviene de las estaciones de transferencia, $56 \%$ restante proviene de la recolección realizada por el servicio de limpia que tiene cada demarcación territorial, la Secretaría de Obras y Servicios, e incluso residuos provenientes del Estado de México. Las plantas de selección con las que cuenta la CDMX están ubicadas en San Juan de Aragón y Santa Catarina. Dentro de las plantas de selección se recuperan más de 20 materiales de características reciclables, tales como: aluminio, fierro, lámina metálica, cobre, alambre, botellas de refresco y cerveza, vidrio ámbar, transparente y verde, cartón, todo tipo de papel, periódico, PVC, PET, plástico rígido o nylon y vinil. Del total de los residuos sólidos que se reciben en las plantas de selección, se recuperan en su conjunto 191 toneladas de subproductos al día. De forma específica, en la Planta de Selección San Juan de Aragón existe infraestructura que permite compactar, que es una manera de procesar los residuos que ahí se encuentran, esto optimiza el espacio para almacenar para su posterior traslado. El porcentaje de recuperación es mínimo, es decir, los residuos que reciben San Juan de Aragón, Santa Catarina y las compactadoras son 3,758 toneladas por día, de las cuales sólo se aprovechan 191 toneladas y se manda el resto a disposición final (Secretaría de Obras y Servicio, 2014). Por otro lado, los RSU orgánicos se mandan a la cuarta fase: la transformación. Estos residuos se transforman en una planta de composta para obtener un producto completamente diferente y aprovechable. 


\subsubsection{Fase 4: Transformación}

El único esquema de transformación que actualmente existe en la CDMX es el de compostaje. Aunque existe un proyecto importante para echar a andar un biodigestor, con el cual se pretende generar energía verde, éste no ha podido concretarse. Así que, por el momento, la única alternativa en funcionamiento para el aprovechamiento de los residuos sólidos orgánicos es el compostaje; este proceso se lleva a cabo en ocho plantas de composta ubicadas en: Bordo Poniente IV Etapa, Bosque San Juan de Aragón, Álvaro Obregón, Cuajimalpa, Iztapalapa, Milpa Alta (2) y Xochimilco. Estas plantas reciben de manera conjunta 316,711 toneladas al año, provenientes de estaciones de transferencia, mercados, áreas verdes, podas y pastos. Con dicha cantidad de residuos, anualmente se produce un total de 121,657 toneladas de composta, de las cuales se destinan 8,640 toneladas para mejorar los suelos de camellones, áreas verdes de la red vial primaria, parques, jardines y en menor medida a la actividad agrícola y la producción agropecuaria (Inventario, 2104). La Tabla 3.2 enlista las plantas de composta, precisando el volumen de residuos sólidos recibidos y aquellos transformados a composta, teniendo como la planta de composta más eficiente la que se encuentra en Álvaro Obregón con un $79.7 \%$ de eficiencia y en segundo lugar la planta que se encuentra en Cuajimalpa con un 50\% de eficiencia. Entre las plantas que más baja eficiencia san Juan de Aragón e Iztapalapa ya que su eficiencia no sobrepasa el 10\%. Se sabe bien que el proceso de descomposición para generar composta implica la pérdida de materia orgánica, por lo que la cantidad de materia orgánica recibida casi se reduce a la mitad en cuanto a la composta que se produce. Por otro lado, se puede observar que la eficiencia total en cuanto a producción de composta es bastante baja, ya que no llega ni siquiera a un 50\%, lo que indica que es necesario mejorar la eficiencia de producción de composta, desde luego la clave se encuentra en la mejora de la eficiencia de recolección separada de RSU en la CDMX.

Tabla 3.2. Plantas de composta

\begin{tabular}{|c|c|c|c|c|}
\hline $\begin{array}{l}\text { Planta de } \\
\text { composta }\end{array}$ & $\begin{array}{l}\text { Residuos } \\
\text { orgánicos } \\
\text { recibidos }\end{array}$ & $\begin{array}{l}\text { Producción de } \\
\text { composta }\end{array}$ & $\begin{array}{l}\text { Composta } \\
\text { entregada }\end{array}$ & $\begin{array}{l}\text { Eficiencia en } \\
\text { la producción } \\
\text { de composta }\end{array}$ \\
\hline Bordo Poniente & 307,571 & 118,416 & 7,315 & $38.5 \%$ \\
\hline $\begin{array}{c}\text { San Juan de } \\
\text { Aragón }\end{array}$ & 422 & 42 & 5 & $10 \%$ \\
\hline Álvaro Obregón & 1,771 & 1,412 & N/D & $79.7 \%$ \\
\hline Cuajimalpa & 1,830 & 915 & 915 & $50 \%$ \\
\hline Iztapalapa & 1,789 & 186 & 186 & $10.4 \%$ \\
\hline Milpa Alta (2) & 1,600 & 314 & 219 & $19.6 \%$ \\
\hline Xochimilco & 1,728 & 372 & $\mathrm{~N} / \mathrm{D}$ & $21.5 \%$ \\
\hline TOTAL & $\begin{array}{c}316,711 \\
\text { Ton/año }\end{array}$ & $\begin{array}{l}\text { 121,657 } \\
\text { Ton/año }\end{array}$ & $\begin{array}{c}\mathbf{8 , 6 4 0} \\
\text { Ton/año }\end{array}$ & $38.5 \%$ \\
\hline
\end{tabular}

Fuente: Inventario, 2014.

En cuanto a la fase de la transformación, es una fase del manejo que necesita mucha atención en la CDMX, ya que no es muy común transformar los RSU en material aprovechable. Una de los factores que condicionan esta fase de manera determinante, es de igual manera, la recolección, dado que a la hora de recolectar no se hace de forma separada en al menos orgánica e inorgánica. Por ello, es muy complicado lograr una separación óptima en la fase tres. Aunque la mayoría de las demarcaciones territoriales tienen rutas que recolectan los residuos de forma separada, éstas no se cumplen en su totalidad. Lo anterior ocurre en parte, porque la población a pesar de saber que debe separar sus 
residuos, no lo hacen y los disponen de manera mezclada; asimismo, puede ser resultado de que la recolección se haga de manera mezclada porque el vehículo no tiene la opción para recibirlos de manera separada, esto no quiere decir que necesariamente los camiones deben tener doble compartimiento, ya que se sabe que los de carga trasera también pueden recolectar los residuos de manera separada. Para este punto del manejo, es de vital importancia saber que no se puede lograr un exitoso manejo de RSU si las primeras fases no se realizan adecuadamente, ya que éstas son la base para poder realizar un aprovechamiento óptimo. En general, la materia orgánica utilizable para composta que se recolecta en la CDMX se recolecta como se muestra en la Figura 3.7, según datos proporcionados por el Inventario de RSU para el 2014. La demarcación en donde mayor cantidad de RSU orgánicos se recolectan, es Iztapalapa, en gran parte se debe a la gran cantidad de RSU que en general se generan en esta demarcación. Caso contrario el de Milpa Alta, ya que con respecto a la cantidad de RSU generados en esa demarcación, la cantidad de RSU orgánicos recolectados son altos y esto también se confirma en la Figura 3.8, donde se observa una eficiencia de recolección separada de alrededor del $90 \%$ para la misma demarcación. Es decir, la cantidad de toneladas de residuos orgánicos recolectados, no tiene que ver con la eficiencia que cada demarcación muestra para separar los residuos, sino más bien con la cantidad de residuos que esta genera.

Figura 3.7. Recolección de RSU orgánicos por demarcación territorial en ton/día

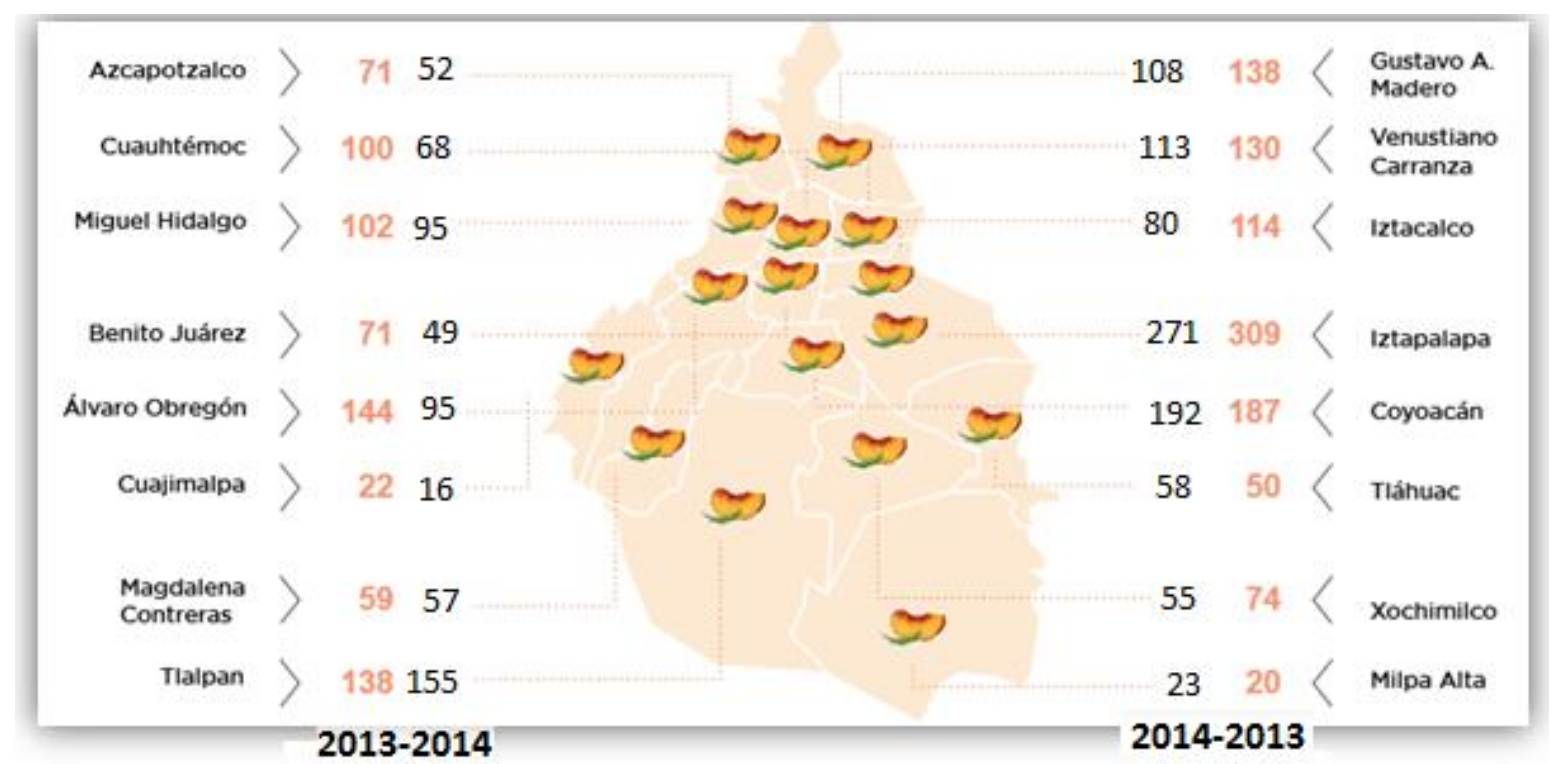

Fuente. Inventario 2013, SEDEMA, 2014

Por otro lado, la Secretaría de Obras y Servicios ha calculado la eficiencia en recolección de RSU de tipo orgánico, siendo entendido por eficiencia en la recolección de orgánicos la relación que hay entre la cantidad de RSU generados de origen orgánico y los recolectados que cada demarcación presenta. Estos residuos son pesados en las estaciones de transferencia y de manera general el porcentaje de eficiencia para la CDMX es de 58\% para el año 2013, también la gráfica muestra en contraste con el año 2014(IRSU, 2013; SEDEMA, 2014). Las demarcaciones territoriales que más producen residuos orgánicos son las que menor eficiencia de recolección separada tienen, esto pudiera deberse a diversos factores, como el número de rutas que recolectan los residuos separados o la cantidad de población en las colonias que cubren ciertas rutas, también puede deberse a que a mayor cantidad de RSU generados, existe menor control de los mismos y desde luego otro punto importante a considerar pudiera ser el factor cultural y social que en cada lugar se desempeña. Esto sin duda alguna, merma en el cumplimiento de objetivos de un manejo de RSU exitoso. Por ejemplo, en Iztapalapa se 
producen 309 ton al día, pero esta demarcación territorial sólo tiene un $49 \%$ de eficiencia en la recolección separada; por otro lado, la eficiencia de recolección separada para Milpa Alta es de 90\%, pero sólo se recolectan 20 ton/día de ésta demarcación. El caso de Coyoacán es diferente, ya que tiene una eficiencia alta del $80 \%$ y se recolectan cerca de 200 Ton/día de RSU orgánicos. Es importante no perder de vista que la recolección separada forma un papel trascendental en la transformación de RSU, ya que sin esta no existe materia prima que pueda ser transformada a componentes aprovechables. Esta es una causa en particular por la que la transformación de los RSU en la CDMX es exinanida. Como consecuencia de un una mala recolección y una transformación muy reducida, tenemos una disposición final de casi todos los RSU generados en la CDMX que asciende a 73.69\% del total de los RSU generados en dicha ciudad, se ha explicado de manera clara la cantidad de RSU que son llevados a sitios de disposición final; sin embargo, es importante mencionar que existe una cantidad estimada de RSU generados, ya que como se ha mencionado a lo largo de esta investigación, la generación de los residuos es una cifra estimada. Es decir, la cantidad que realmente se está recolectando, no es la que llega a las zonas de transferencia, en general pasa por una previa selección de los choferes de los camiones y esta asciende a 8,080 ton por día para el año 2013 y 10,146 ton/día, para el año 2014, lo que representa tan solo un 62\% en el 2013 y un $68 \%$ en el 2014 de los RSU generados. La fase de disposición final sólo se vuelve el reflejo de la calidad en la ejecución de las fases anteriores (IRS, 2013; 2014).

\section{Figura 3.8. Eficiencia de separación de RSU orgánicos por Demarcación Territorial}

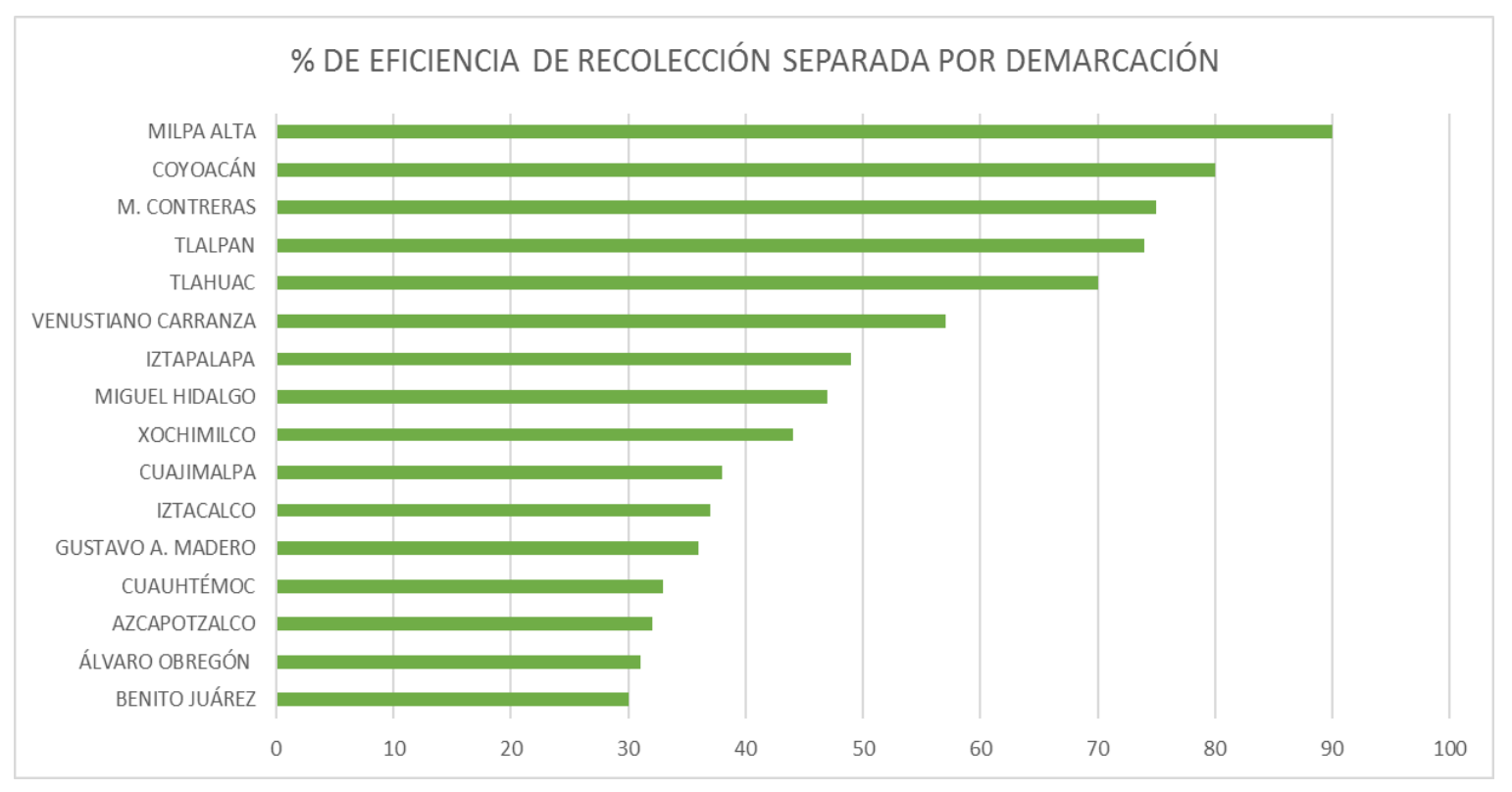

Fuente: Inventario 2014.

\subsubsection{Fase 5: Disposición Final}

La fase de disposición final, es una de las fases que más ha preocupado a los tomadores de decisiones, ya que no existen sitios de disposición final de RSU en la CDMX. Este factor sin duda deja a la ciudad a expensas de sitios de disposición final de otros lugares, como los sitios del Estado de México y el de Morelos. Diariamente estos sitios reciben 8,099 toneladas de residuos, considerando los residuos de manejo especial. Los sitios del Estado de México son La Cañada, Cuautitlán, Milagro y Tepotzotlán, y el sitio del estado de Morelos es Cuautla. 
De esta manera, la Dirección General de Servicios Urbanos de la Secretaría de Obras y Servicios es la responsable de la disposición final de los residuos sólidos generados en la CDMX, transportando 8,099 toneladas de residuos a diversos rellenos sanitarios, de los cuales se envía 97.5\% al Estado de México, esto evidentemente es una situación preocupante para el gobierno de la ciudad, ya que en años pasados el gobierno del Estado de México se ha negado por diversas cuestiones a recibir los RSU que normalmente recibe de la ciudad, lo que ha puesto en completo caos a la ciudad y a sus gobernantes . Como se puede ver en la Figura 3.9, sólo 2.5\% es enviado al Estado de Morelos. Esta situación pone en evidencia la complejidad de esta fase, dado que la CDMX está a expensas de otros estados. De hecho, la Procuraduría del Medio Ambiente del Estado de México (Propaem) colocó sellos de suspensión en los rellenos sanitarios en marzo de 2016 (La Jornada, 2016); aunque fue de manera temporal debido a una situación de contingencia ambiental en el Valle de México, la CDMX tuvo dificultades para disponer más de 8000 toneladas de RSU al día. Esta situación invita a reflexionar cómo poder gestionar los RSU de una forma sustentable y exitosa, tratando de generar tecnologías que ayuden a aprovechar la mayor parte de los RSU mediante la transformación y el reciclaje. Lo anterior, ayudaría a reducir en gran medida la cantidad de RSU que se llevarían a disposición final, lo cual orientaría la atención a invertir más recursos tanto de investigación como de tecnologías en las primeras fases, minimizando la disposición de RSU. El estudio realizado por el BM en el 2012 coincide con esta reflexión. De manera determinante se plasma en este estudio, que los países que más invierten en las primeras fases, son los que mayor éxito tienen con el manejo de sus RSU; este resultado pone en evidencia la urgencia de centrar la atención para una mejor gestión de RSU en las primeras fases y no sólo en la disposición final o en la recolección, sino en el problema de origen que es la elevada generación e incorrecta separación de dichos residuos.

\section{Figura 3.9. Distribución de la disposición de los RSU generados en la CDMX}

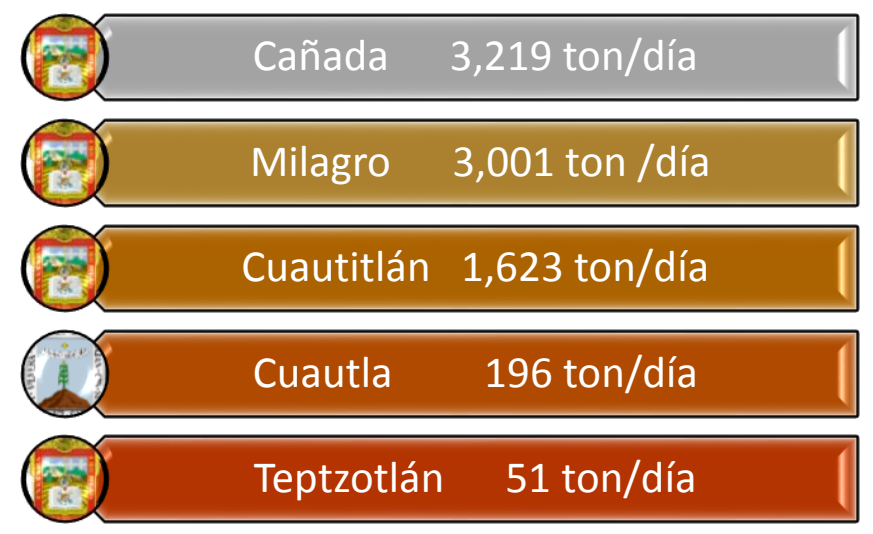

Fuente: Inventario, 2014.

De manera resumida, podemos ver el manejo de los RSU de la CDMX en la Figura 3.10, que es un diagrama de flujo que se presenta en el Inventario 2014, el cual de manera sintética ayuda a visualizar cómo se lleva a cabo el manejo de los RSU en la CDMX. Comenzando por el lado izquierdo, podemos observar la generación de RSU que pertenecen a la primera fase del manejo, las cuales se encuentran clasificadas por fuente: domiciliarios, comercios y mercados, entre otros. También se encuentra como fuente de generación la Central de Abasto, la recolección de empresas privadas y el barrido de cada demarcación territorial. Todas estas fuentes de generación son recolectadas como parte de la segunda fase. En la fase tres que consiste en manipular o procesar los RSU; éstos son enviados a las zonas de 
transferencia. La mayor parte del procesado se realiza en plantas de selección, en donde se compactan los materiales que pueden ser reciclados, o en el caso de los residuos orgánicos se llevan a las plantas de composta. Ahí se produce composta para mejorar la condición de las áreas verdes, lo que corresponde a la fase cuatro de transformación. Finalmente, todo lo que no se pudo transformar y lo que quedó de la manipulación y selección, se manda a la fase cinco que es la disposición final. Anteriormente se analizó un diagrama muy sencillo, únicamente con las cinco fases del manejo de los RSU que se contemplan en esta investigación; sin embargo, el flujo total de los RSU es mucho más complejo, ya que incluye también los residuos de manejo especial, que en realidad no son parte de esta investigación. Además, también se incluyen, por ejemplo, los RSU que son llevados por empresas privadas y que pagan derecho, esta cifra asciende a 45 ton/día, como se observa en la Figura 3.10. También se incluye lo que se genera en el barrido en cada demarcación.

Figura 3.10. Diagrama de flujo de RSU de la CDMX

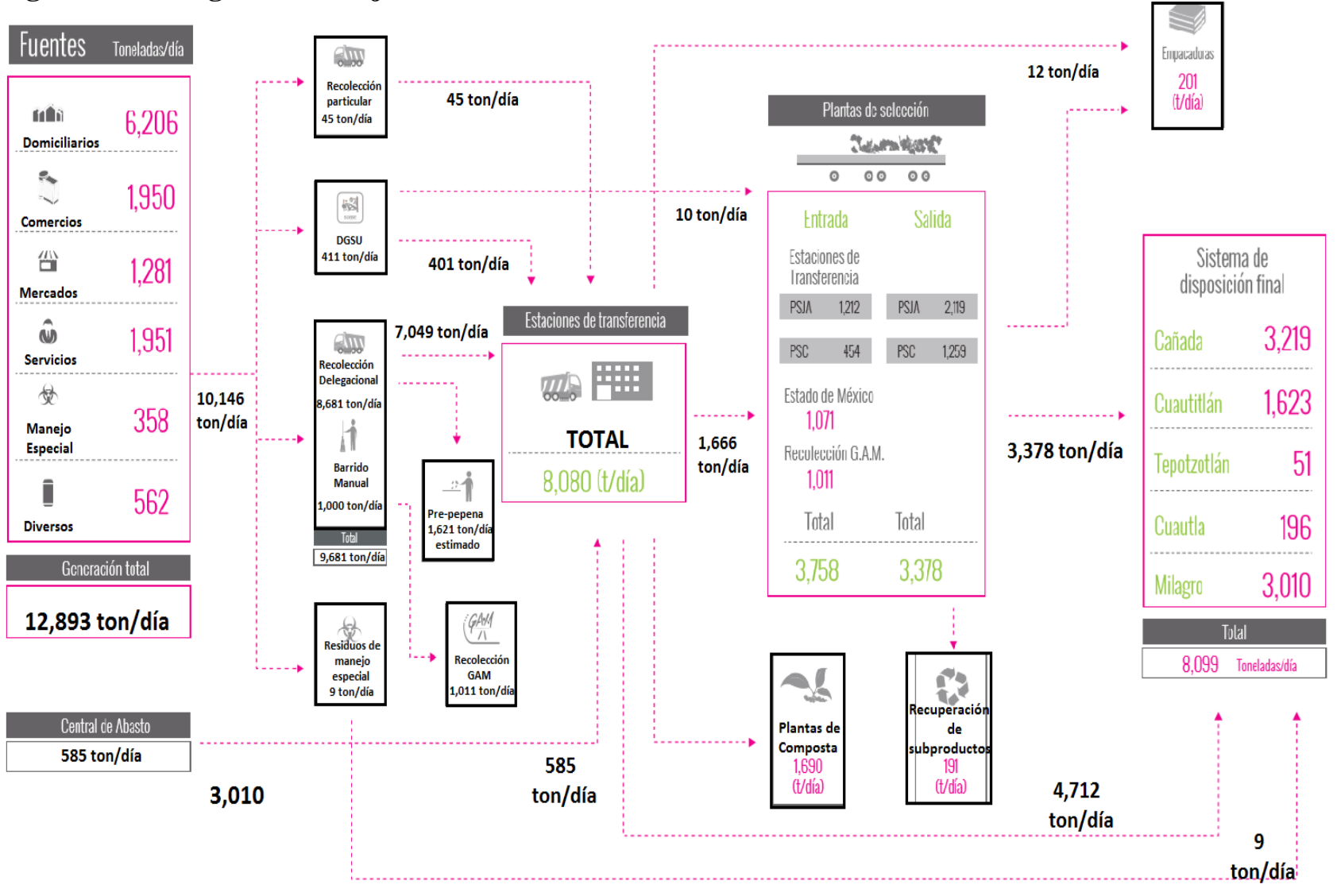

Fuente: Inventario, 2014.

Se han analizado cada una de las fases del manejo de los RSU en la CDMX, desde su generación hasta su disposición final y como es llevada a cabo en la ciudad, ya que es de suma importancia conocer lo que se realiza en cada fase, además de conocer el flujo de los residuos en la ciudad. Lo que entra y lo que sale, en toneladas por día. Sin embargo, para poder procesar los RSU es necesario tener conocimiento de la composición que estos tienen, por lo menos de una manera general o estimada. 


\subsection{Composición y propiedades de los RSU en la CDMX}

La Tabla 3.2, anteriormente mostró una composición detallada de los RSU, dicha composición referente al año 2016, estos datos fueron estimados y proporcionados por la Secretaría de Obras y Servicios con la finalidad de conocer a detalle la composición de los residuos de la ciudad; sin embargo, es importante tener también un estimado general. Por esta razón, un dato de suma importancia que siempre se debe considerar para un manejo exitoso de los RSU es la composición de los RSU que se generan. Sin embargo, a pesar de la gran importancia de este dato, uno de los grandes problemas u obstáculos con los que se encontró esta investigación, es la falta de información concreta sobre la caracterización física y química de los RSU generados, la información más detallada que pudo encontrarse fue la proporcionada por la Secretaría de Obras y Servicios. La composición de los RSU cambia con respecto al tiempo, ya que los patrones de consumo lo hacen también. Un ejemplo de esto, es cuando se reflexiona sobre el tipo de envase que tenía un refresco hace 20 años y el tipo de envase que hay en la actualidad; estas diferencias ponen en evidencia los cambios en la composición de los RSU que se generan, la cual se modifica a lo largo del tiempo. En el caso de los residuos orgánicos, de las 12,893 toneladas totales de RSU que se estima se generan en la CDMX, sólo 8,080 toneladas llegan a las zonas de transferencia, de las cuales 58\% es enviado a disposición final, ya que los esquemas vigentes de aprovechamiento no utilizan este tipo de residuos como materia prima, debido a que aún no tienen potencial económico en el mercado de reciclaje o se encuentran mezclados. Del 42\% restante, que equivale a 3,393 toneladas al día, se recuperan los orgánicos que se van a composta, estimándose aproximadamente 1,729 toneladas al día (Figura 3.11). Finalmente, restan 1,664 toneladas de residuos que contienen una serie de materiales como aluminio, fierro, lámina metálica, cobre, alambre, botellas de refresco y cerveza, vidrio ámbar, transparente y verde, cartón, todo tipo de papel, periódico, PVC, PET, plástico rígido o nylon y vinil, los cuales se recuperan en las plantas de selección, para el año 2013. Se puede observar en general, que mientras más RSU genera una demarcación, más RSU orgánicos se pueden recolectar, lo cual se observa bastante lógico, pues por lo regular los flujos van aumentando en la misma proporción. La Figura 3.12, nos muestra esta proporción, que a la hora de contrastar con los datos de la Tabla 3.1, se puede observar que la relación en proporciones se encuentra significativamente similar para el año 2013 que para el año 2016, que son los datos de la Tabla anteriormente mencionada.

Figura 3.11. Generación total de RSU generados y RSU orgánicos recolectados 


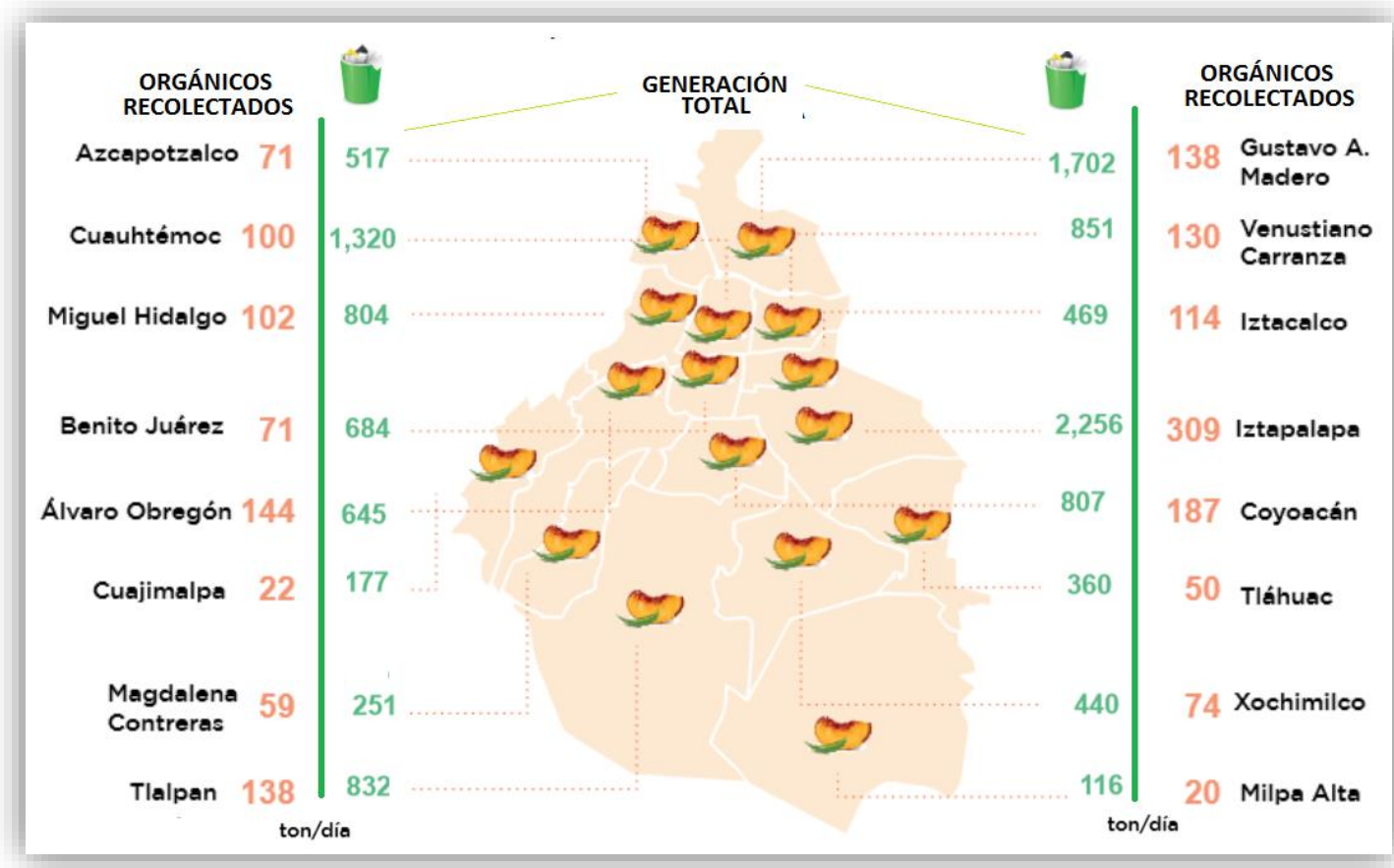

Fuente: Inventario, 2013

Como se puede observar, la cantidad que se recupera de RSU es muy poca; esto provoca que el manejo de RSU no sea eficaz. Este punto debe ser motivo, para que, como sociedad e individuos, nos cuestionemos sobre las necesidades que existen para poder lograr un manejo de RSU de manera exitosa. Al mismo tiempo, debe ser claro para cada uno de los habitantes de la CDMX, que un adecuado manejo de RSU es algo que beneficia a la población en general. Por ello, es pertinente considerar en esta investigación, además de los aspectos técnicos, el marco normativo que regula la gestión de los RSU. La revisión de dicho marco normativo permitirá tener una visión más completa y concreta que nos permitirá observar los puntos clave que fomentan un mal manejo o que no apoyan un buen manejo de los RSU. Esto es de gran importancia, ya que como se sabe, el marco normativo nos ayuda a regular cierto tipo de actividades en sociedad al mismo tiempo que instruyen del cómo deben hacerse ciertas actividades, especialmente la que impliquen riesgos para otros seres humanos y para el ambiente. Una de esas actividades es el manejo de los RSU. Otro aspecto que está muy relacionado con el marco normativo y que es muy importante de analizar es el marco de planeación, que está basado y fundamentado en el jurídico, pero que también da pauta a plantearse objetivos y metas que incluso conlleven a modificar el marco jurídico para lograr ser alcanzadas; esto evidentemente sólo para cuestiones de RSU, que es el tema central de esta investigación. 


\subsection{Marco jurídico normativo de México, respecto a el manejo de RSU}

Es importante no perder de vista los impactos ambientales ocasionados por un inadecuado manejo de los RSU, que se manifiestan principalmente en la contaminación del suelo, aire, aguas superficiales y subterráneas, e incluso en problemas que se generan a nivel de salud pública, desde luego como consecuencia del mal manejo de los RSU, ya sea en su disposición final o en su eliminación. A esto se suman, los impactos de orden estético y de incomodidad por malos olores y desorden ocupacional, e incluso las afectaciones psicológicas que los pobladores de lugares muy contaminados llegan a presentar, tal como se analizó en el primer capítulo de esta investigación. Es por eso, que existe la necesidad en cada nación del mundo de contar con un marco jurídico sólido y eficiente que ampare al medio ambiente y a los ciudadanos de cada nación.

Con este fin, en esta sección de la investigación, se analizarán las principales leyes y normas relacionadas de manera directa o indirecta con el manejo de RSU, que van desde la Constitución Política de los Estados Unidos Mexicanos, tratados internacionales cómo el Tratado Internacional ACCAN, leyes federales como LGEEPA y LGPGIR, códigos y leyes estatales, como el Código Penal, Normas oficiales y mexicanas, además de un amplio marco de planeación, como programas sectoriales, institucionales, de desarrollo, etc. Por otro lado, es importante recalcar que existe gran cantidad de normas, leyes, reglamentos, acuerdos internacionales, etc, dedicados a los residuos, pero de manejo especial o peligrosos, en donde se llega a mencionar también a los RSU; sin embargo, para esta investigación no son de interés los residuos peligrosos, por lo que sólo, si es necesario se mencionarán. Conocer el marco normativo es fundamental para el desarrollo de esta investigación, ya que para poder evaluar de cierta forma, el desempeño de las autoridades en términos del manejo de los RSU es indispensable conocer los objetivos que se han definido en esta materia tanto en el marco normativo como en los planes y programas existentes. Es pertinente aclarar, que se tratará de hacer un enfoque exclusivo de lo que es el manejo de RSU, pero en algunos casos, las disposiciones legales revisadas involucran norman el manejo adecuado de los RSU de manera indirecta. Como, por ejemplo, en el caso del artículo $4^{\circ}$ de la Constitución Política de los Estados Unidos Mexicanos, en el cual se hace referencia al derecho que tienen los ciudadanos a la salud. Como es sabido, la salud de un individuo se relaciona en gran parte con un ambiente sano, lo que recae directamente en un adecuado manejo de los RSU generados en cierta población, como es el caso de la CDMX. Otro punto a destacar, es la jerarquía que se considerará en esta investigación para poder llevar un orden al analizar el marco jurídico. Es de vital importancia saber, que no hay documento más importante que rija el comportamiento de los mexicanos y el actuar de sus instituciones, que la Constitución Política de los Estados Unidos Mexicanos. Este documento constituye la base para el desarrollo de tratados, leyes federales, códigos, leyes estatales, normas oficiales mexicanas y normas mexicanas. La Figura 3.12 muestra el orden jerárquico que hay en el marco normativo de la Ciudad de México respecto al manejo de los RSU en esta entidad. Cabe mencionar, que es a estas disposiciones normativas que se sujetan los programas asociados, entre los que destacan: el Programa Nacional para la GIRSU, el Programa General de Desarrollo de la CDMX, el Programa Institucional y los Programas Sectoriales.

Figura 3.12. Jerarquía de Legislación Mexicana para RSU 


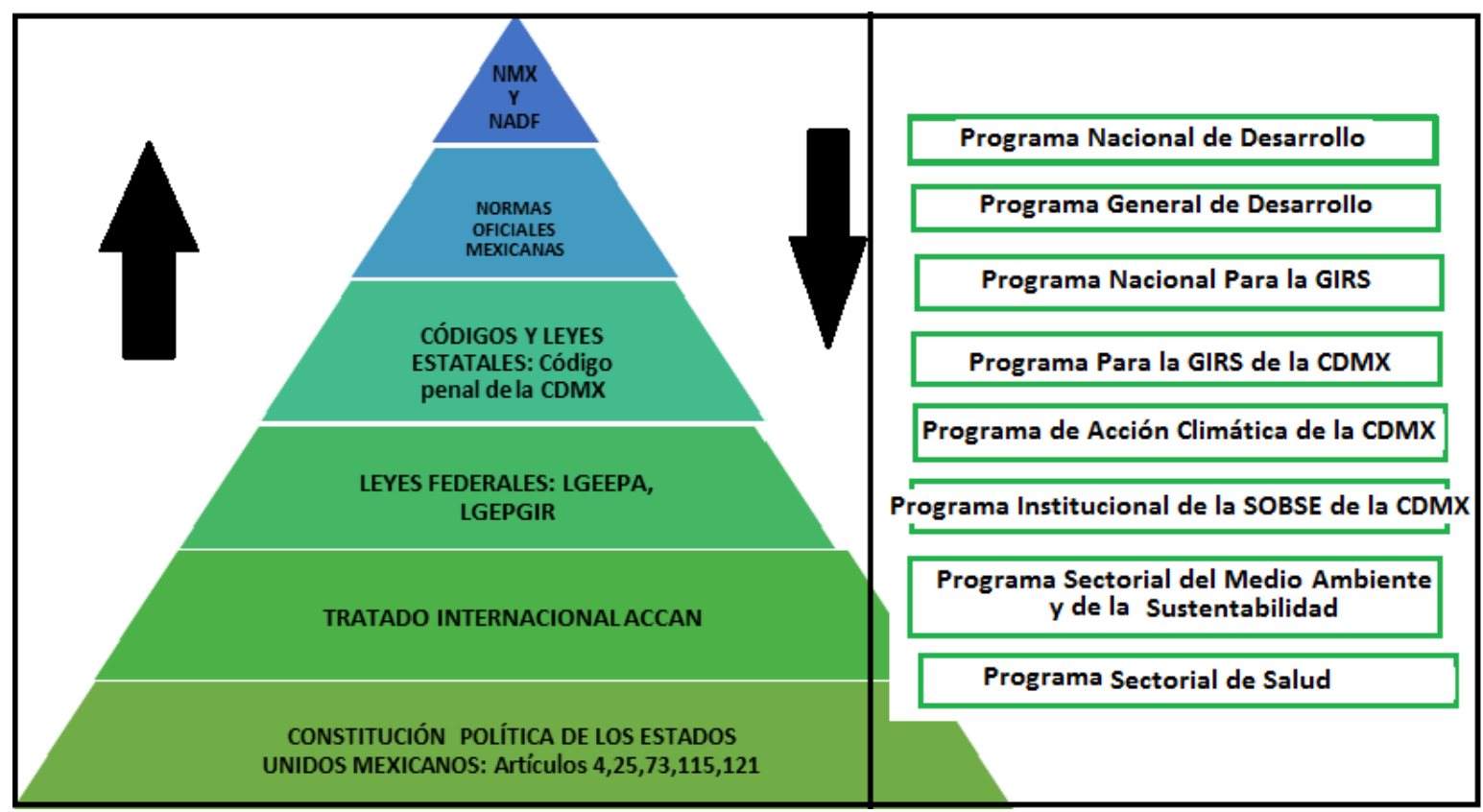

Fuente: Elaboración propia

\subsubsection{Constitución Política De Los Estados Unidos Mexicanos}

En la base de nuestro sistema jurídico se encuentra la Constitución Política de los Estados Unidos Mexicanos, al ser el ordenamiento supremo de todas las leyes, disposiciones reglamentarias y secundarias y decisiones políticas en el país. Desde 1917, es la norma fundamental o carta magna, establecida para regir jurídicamente México, fijando los límites y definiendo las relaciones entre los poderes de la Federación que comprenden el Poder Legislativo, Ejecutivo y Judicial, entre los tres niveles diferenciados del gobierno (el Federal, Estatal y Municipal), y entre todos aquellos y los ciudadanos. A su vez, establece las bases para el gobierno y para la organización de las instituciones en que el poder se asienta; y finalmente establece, los derechos y los deberes del pueblo. Es aquí, donde se sientan las bases que dan origen y se norma el adecuado manejo de los RSU en México. Por ejemplo, el artículo 4 de dicho documento menciona el derecho que todo ciudadano mexicano tiene a la protección de la salud, y es en este artículo donde se definen las bases y particularidades en cuanto al acceso a los servicios de salud, además de que detalla la participación de la Federación y sus entidades en materia de salubridad en general, conforme a lo que dispone la fracción XVI del artículo 73 de esta Constitución (Constitución Política de los Estados Unidos Mexicanos). Con base en este artículo, se retoma la relevancia de la GIRSU retoma su importancia, ya que como anteriormente se ha mencionado, una mala GIRSU propicia un ambiente insalubre, que finalmente repercutirá en la salud de los ciudadanos. Por otro lado, el artículo 25 de este mismo documento establece que es el Estado quien debe promover el desarrollo nacional propiciando que éste sea integral y sustentable (Constitución Política de los Estados Unidos Mexicanos). En este punto vale la pena aclarar que, el manejo de los RSU está considerado por los países de primer mundo como punto clave hacia la sustentabilidad ambiental, lo cual se analizó en el capítulo dos de esta investigación, en el que abordaron los casos de éxito de otros países con respecto al manejo de sus RSU. En lo que respecta al artículo 73, en una de sus fracciones se aclara que es el Congreso quien tiene la facultad de expedir leyes que establezcan la afluencia del Gobierno Federal, de los gobiernos de los Estados y de los 
municipios, en el ámbito de sus respectivas competencias en materia de protección al ambiente y de preservación y restauración del equilibrio ecológico, lo que en definitiva incluye la GIRSU. Sin embargo, es hasta el artículo 115 de la Carta Magna, en específico en el párrafo tercero del mismo, donde se refiere a que es el municipio específicamente quien tiene a su cargo diferentes servicios públicos, entre los que se encuentran el manejo de los RSU en cada una de sus fases, desde su recolección hasta su disposición final. Finalmente, el artículo 121, distribuye las competencias entre los Poderes de la Unión y las autoridades locales de la CDMX, esto para el caso especial de la Ciudad de México. Es aquí también, donde se sientan las bases para la protección al ambiente, y la preservación y restauración del equilibrio ecológico, que implica desde luego el manejo de RSU generados en dicha ciudad.

Este punto, resulta bastante controversial e interesante, la distribución de competencias ha sido un reto para los municipios, ya que estos presentan grandes dificultades para lograr el manejo exitoso de los RSU, entre las debilidades más comunes en los municipios se encuentran: (Zamora, 2011: Bernache, 2016)

1. Las limitaciones temporales bebido a los periodos de gobiernos.

2. Problemas ambientales que son de carácter regional y rebasan a los municipios.

3. Recursos económicos limitados en los presupuestos municipales.

4. Recursos humanos con poca preparación profesional especializada.

5. Estructura institucional y jurídica insuficiente.

6. No se cuenta con información pertinente para la toma de decisiones.

7. Discontinuidad de programas importantes en materia ambiental.

8. Baja participación ciudadana.

9. Falta de infraestructura física y vehicular.

10. Alta rotación de personal.

11. Ausencia de plataformas locales para la búsqueda de soluciones.

12. Carencia de esquemas de financiamiento requeridos para la gestión ambiental.

Estos puntos nos llevan a reflexionar de manera profunda sobre lo que la Constitución Política de los Estados Unidos Mexicanos refiere a la hora de asignar o distribuir competencias, pues se puede observar que la mayor parte del tiempo los municipios no están preparados para eso. Por esta razón, los municipios resumen el manejo de los RSU a sólo dos fases: recolección y disposición final, pues la mayor parte del tiempo es para lo único que les alcanza, en todos los aspectos, económicamente, profesionalmente y técnicamente.

Una de las lecciones que se vieron en el Capítulo II de esta investigación, fue referente a lo que el gobierno de la India intenta hacer con este tipo de problemas, ya que presentan cuestiones similares a lo que ocurre en México. Estas iniciativas intentan fomentar o implementar organizaciones internacionales sin fines de lucro, que apoyen el manejo de los RSU en países en vías de desarrollo ya sea con recurso humano o económico que ayuden a mejorar las prácticas para un manejo de RSU exitoso. 


\subsubsection{Acuerdos Internacionales}

\section{Acuerdo de Cooperación Ambiental para América del Norte (ACAAN)}

En general, los acuerdos son celebrados entre dos o más países, sujetos de Derecho Internacional Público, con objeto de crear, transferir, modificar o extinguir una relación jurídica entre ellos, estableciendo derechos y obligaciones por escrito en un instrumento único, a través de uno o más documentos relacionados entre sí (Trejo,2006); estos jurídicamente se encuentran por encima de las leyes federales, pero no por encima de la Constitución Política de los Estados Unidos Mexicanos, como podemos ver en la Figura 13.

En lo relativo a la cuestión ambiental, Canadá, EU y México, firmaron un acuerdo suplementario al Tratado de Libre Comercio de América del Norte TLCAN, denominado Acuerdo de Cooperación Ambiental para América del Norte ACAAN que entró en operación en 1994, el mismo año en que también entró en vigor el TLCAN. Este Acuerdo de Cooperación tiene como principal objetivo promover el desarrollo sustentable, por medio de la ayuda mutua para el desarrollo de políticas ambientales. Aunque ambos tratados se firmaron en el mismo año, en el acuerdo de cooperación se incluyeron distintas previsiones ambientales que no fueron incluidas en el TLCAN. El ACAAN, remota su origen al año de 1993, en donde México, Canadá y los Estados Unidos firmaron el Acuerdo de Cooperación Ambiental de América del Norte (ACAAN), el cual dio lugar a la creación de la Comisión para la Cooperación Ambiental (CCA) que se ha encargado de diseñar y aplicar planes regionales para la eliminación de sustancias tóxicas prioritarias, aunque en un comienzo aún no se incluían a los RSU como tal, sino más bien se enfocaban en los residuos peligrosos (Trejo, 2006). Esta Comisión entró en funcionamiento el 1 de enero de 1994, con el propósito de atender los asuntos ambientales de preocupación común, contribuir a prevenir posibles conflictos ambientales derivados de la relación comercial, y promover la aplicación efectiva de la legislación ambiental en los tres países. La CCA tiene como objetivos estratégicos la búsqueda de la sustentabilidad ambiental en mercados verdes y la protección regional del medio ambiente, y su principal función es la de facilitar por medio de la cooperación y la participación ciudadana, la conservación, protección y mejoramiento del medio ambiente de América del Norte para beneficio de las generaciones presentes y futuras (Álvarez, 2013). Es evidente que, entre estos aspectos podemos encontrar el manejo integral de los RSU que, si bien atañe más a los estados fronterizos, no debemos olvidar que lo que sucede en la CDMX no deja de afectar a toda la nación, debido a la gran cantidad de contaminantes que esta ciudad libera. Es aquí donde radica la importancia de los acuerdos a los que se compromete el gobierno de nuestro país, los cuales se encuentran justo arriba de la base de la pirámide que es la Constitución Política Mexicana. Por otro lado, se encuentran las leyes federales que están reglamentadas y básicamente fundamentadas en la Constitución Política de los Estados Unidos Mexicanos, y que a continuación se revisarán, ya que existen leyes federales de suma importancia en cuestión de RSU.

En general, se puede ver que los tratados internacionales están mayormente dirigidos a los residuos peligrosos o de manejo especial, ya que son considerados más nocivos para el ambiente y la salud que los RSU, pero es necesario considerar que la generación de RSU supera por mucho a la generación de residuos de manejo especial, por lo que es importante no menospreciar el manejo de los RSU desde la perspectiva internacional. Es decir, debe buscarse fomentar globalmente el 
adecuado manejo de los RSU con ayuda de países que tienen éxito en esta cuestión. Otros tratados o convenios como Convenio de los COPs, de Rotterdam, Convenio de Basilea, Protocolo de Montreal, entre otros son tratados exclusivos de los residuos peligrosos, que no incluyen los RSU.

\subsubsection{Leyes Federales y Generales}

Las leyes federales y generales son un conjunto de normas aplicadas en todo el territorio nacional, por lo cual toda persona que se encuentre en él, se ve obligado a cumplirlas. Estas leyes son creadas por el Congreso de la Unión y cada gobernador tiene la obligación de hacer que se cumplan en cada localidad; esta labor debe ser apoyada por el poder judicial. Las leyes federales y generales son reglamentarias de la Constitución, la cual se encuentra en la base de la pirámide jerárquica que se presenta en esta investigación en la Figura 12. En materia ambiental y específica para los RSU se encuentra la Ley General del Equilibrio Ecológico y la Protección al Ambiente (LGEEPA) y la Ley General para la Prevención y Gestión Integral de los Residuos (LGPGIR); estas dos leyes prevalecen a lo largo y ancho de la República Mexicana, incluyendo la CDMX, por lo que se vuelve relevante revisarlas.

\section{Ley General del Equilibrio Ecológico y la Protección al Ambiente (LGEEPA)}

En el periodo de gobierno 1982-1988 se realizaron importantes aportaciones al marco jurídicoecológico del país, debido a las reformas constitucionales y a la aparición de la Ley General de Equilibrio Ecológico (Carmona, 2013). Esta Ley se encuentra estructurada básicamente por seis títulos que contienen 25 capítulos, nueve secciones, 194 artículos y cuatro artículos transitorios y se puede decir que la ley se estructura bajo cuatro conceptos básicos:

- Política ecológica

- Manejo de recursos naturales

- Protección al ambiente

- Participación social

Estos conceptos, están fundamentados básicamente en el sistema de concurrencias, el sistema nacional de áreas naturales protegidas, y las medidas de control, seguridad y régimen de sanciones.

De una manera genérica podemos decir que el título primero, el de disposiciones generales, básicamente habla de la distribución de competencias. Este se vuelve un aspecto importante para el desarrollo de esta investigación, ya que aquí se describe detalladamente la competencia que tiene el estado y los municipios en el manejo de los RSU. Es por eso, que debemos tener claro que cada gobierno local debe hacerse cargo de sus residuos. Esto está especificado en el artículo 7, de dicha ley, en su fracción sexta, dónde se menciona claramente cada una de las fases, a excepción de la generación, que esta es la primera fase que esta investigación ha considerado dentro del manejo integral de los RSU, donde lo único que menciona es que cada una de las fases debe ser de acuerdo a lo mencionado en el artículo 137 de la misma Ley; al dirigirse al artículo citado lo único que muestra es distribución de competencias, es decir se refiere a que los municipios son los responsables de llevar a cabo cada fase: recolección, manipulación, transformación y disposición final.

Es hasta el artículo 8, en donde se hace mención de la primera fase del manejo, que es la generación de RSU, aunque de manera muy general, se establece claramente que es responsabilidad de los gobiernos locales o municipales la aplicación de las disposiciones jurídicas que estén relacionadas a 
la prevención y control de los efectos sobre el ambiente ocasionados por la generación, transporte, almacenamiento, manejo, tratamiento y disposición final de los residuos sólidos e industriales, que no estén considerados como peligrosos. Es hasta este punto, donde también se incluye la generación (primera fase del manejo de los RSU), como parte de las responsabilidades de los municipios o gobiernos locales para su buen manejo. En de los artículos, 135, 137, y 143 se hace mención respectivamente a la prevención y control de la contaminación que tengan su origen a través de los RSU, al servicio de limpia y sitios de disposición final, y por último, al funcionamiento de sistemas de recolección, transporte, tratamiento y disposición final. Básicamente, se refieren a la manera que deben tratarse y se enuncian las normas oficiales que detallan la manera como deben llevarse a cabo dichas fases, en el caso de que la haya, eso respecto a los artículos 135 y 137. Otra parte muy importante que considera la LGEEPA, son los acuerdos para mejorar e implantar sistemas de recolección, transporte, tratamiento y disposición final, contaminación por lixiviados y la biodegradación de RSU, en sus artículos 138,139 y 141, respectivamente. En lo que respecta a estos tres artículos mencionados es importante aclarar que no dice cómo debe hacerse, sino más bien sólo dice que debe hacerse, mencionan también a groso modo que deben generarse inventarios, por ejemplo, en el caso del artículo 138, en el caso de los lixiviados estos deben ser tratados de acuerdo a la Ley de Aguas Nacionales, disposiciones reglamentarias y normas oficiales. Es importante mencionar, que al revisar dichas leyes, éstas están básicamente enfocadas a los lixiviados de residuos de manejo especial o peligrosos y mencionando en algunos aspectos fundamentales a los RSU, como es el caso de su almacenamiento, ya que estos deben ser almacenados en bolsas o botes para evitar el contacto con el suelo.

De groso modo, esto es parte del fundamento con respecto a los RSU de lo que podemos llamar la legislación ambiental mexicana, que se integra por esta Ley, entre otras estatales y reglamentos y normas. Sin embargo, toda esta estructura no será eficaz sin la difusión y divulgación de sus principios, y sin la acción estatal y participación social para crear una conciencia ecológica que sea la que sustente la exigencia de su cumplimiento (Carmona, 2013).

Por otro lado, existe la Ley General para la Prevención y Gestión Integral de los Residuos (LGPGIR), que es la máxima ley en el territorio de México en materia de gestión de residuos; esta ley abarca la gestión tanto de residuos no peligrosos sólidos urbanos, como la gestión de los residuos peligrosos, y además considera una tercera clasificación de residuos denominados residuos de manejo especial. Esta Ley está basada en el artículo 4 de la Constitución Política de los Estados Unidos Mexicanos y en la Ley General del Equilibrio Ecológico y Protección al Ambiente (LGEEPA); fue promulgada el 8 de octubre de 2003, durante la presidencia de Vicente Fox Quezada.

\section{Ley General para la Prevención y Gestión Integral de los Residuos (LGEPGIR)}

Esta Ley, básicamente reglamenta las disposiciones de la Constitución Política de los Estados Unidos Mexicanos en lo que se refiere a la protección al ambiente, en materia de prevención y gestión de los residuos, y establece las bases para: (a) los principios de valorización, (b) responsabilidad compartida, (c) manejo integral, (d) criterios de gestión integral, (e) mecanismos de coordinación entre entidades, (f) mercado de subproductos, (g) participación de la sociedad, (h) creación de sistemas de información referentes a gestión de RSU (Residuos Sólidos Urbanos) y RME (Residuos de Manejo Especial), (i) prevención de la contaminación de sitios, (j) fortalecimiento de la innovación tecnológica, y (k) establecimiento de medidas de control y seguridad, entre otras (LGPGIR). 
Esta ley tiene una estructura basada en siete títulos y un apartado de artículos transitorios y decretos de reforma. En el título primero, se especifican los objetivos de su aplicación y el ámbito en el que ésta debe aplicarse; como continuación del título primero, el segundo especifica las competencias y responsabilidades de cada gobierno, además de su coordinación entre gobierno y dependencias. Para el título tercero, los contenidos empiezan a manejar especificaciones un tanto técnicas, ya que hace referencia a la clasificación de los RSU, donde se detallan los fines, criterios y bases generales. El título cuarto, se refiere a todo lo que tiene que ver con instrumentos de la política de prevención y gestión integral de los residuos como programas para la prevención y gestión integral de los residuos, planes de manejo, cuestiones referentes a participación social y el derecho a la información.

Aunado a esto, el título quinto es de suma importancia, ya que en él se fundamentan las bases para el manejo integral de residuos peligrosos, desde las disposiciones generales, generación de residuos peligrosos hasta las autorizaciones, además también el manejo integral de los residuos peligrosos y de la responsabilidad acerca de la contaminación y remediación de sitios. Finalmente, se trata también de la prestación de servicios en materia de residuos peligrosos, la importación y exportación de residuos peligrosos. Como últimos títulos están el sexto referente a la prevención y manejo integral de residuos sólidos urbanos y de manejo especial, y séptimo medidas de control y de seguridad, infracciones y sanciones. Estos últimos se enfocan en los residuos peligrosos, especialmente las sanciones, dejando a un lado las sanciones para los generadores de RSU.

En general, con relación a los puntos anteriores, es relevante destacar que, con respecto a la distribución de competencias, ésta, en su mayoría, ha surgido con base en criterios establecidos por el Gobierno Federal, el cual no siempre considera las circunstancias estructurales, sociales y económicas de los gobiernos locales, por lo que, en algunos casos, los limita para ejercer dicha competencia (Diagnóstico Básico para la GIRSU, 2006). En éste mismo contexto, podemos ver como otra debilidad que gran parte de los fundamentos de esta ley están enfocado a los residuos peligrosos. En la parte contraria a este contexto, se debe reconocer que se ha logrado un avance al incluirse ya la disposición de que el que contamina debe pagar y reparar el daño. Sin embargo, los RSU no se observan como un peligro para el ambiente por lo que los generadores de RSU no tienen ninguna restricción para limitar el volumen que se produce, ni la manera en que éstos los disponen.

Una vez conociendo la estructura básica de esta Ley, se puede reflexionar en diversos aspectos, comenzando por uno básico: la definición de residuos y RSU. Es decir, este punto es primordial y de vital importancia, pues ya que al tratarse de una Ley tan importante que rige totalmente lo que se debe hacer en cuestión de residuos, las definiciones deben ser claras.

Según la LGPGIR define "residuo" como un producto cuyo propietario o poseedor desecha y que se encuentra en estado sólido o semisólido, o es un líquido o gas contenido en recipientes o depósitos, y que puede ser susceptible de ser valorizado o requiere sujetarse a tratamiento o disposición final (Artículo $5^{\circ}$, fracción XXIX de la LGPGIR). Por otro lado, define RSU cómo los residuos generados en las casas habitación, que resultan de la eliminación de los materiales que utilizan en sus actividades domésticas, de los productos que consumen y de sus envases, embalajes y empaques; los residuos que provienen de cualquier otra actividad dentro de establecimientos o en la vía pública que genere (Artículo $5^{\circ}$, fracción XXXII de la LGPGIR). Sin embargo, estas definiciones deberían ser actualizadas, ya que, al buscar la sustentabilidad, es necesario cambiar la idea de que un residuo, específicamente RSU es un desecho y tratar de integrar al RSU como materia prima para otro tipo de procesos. Esto es importante destacar, ya que desde el momento en que los RSU se consideran inservibles por la misma Ley que rige lo que debe hacerse con ellos, existe una brecha conceptual que confunde y no es clara.

Un aspecto importante que también llama la atención es cómo la Ley, pareciera no poner suficiente énfasis en la generación de los RSU. Es decir, el artículo 44 de dicha Ley (LGPGIR) establece que los generadores de residuos peligrosos tendrán las categorías ahí citadas (ver Tabla 3.3), las 
definiciones que esta Ley marca para cada una de las categorías de generadores, en todo momento se refiere a residuos peligrosos por lo que el lector podría suponer que también las definiciones de pequeños y grandes generadores incluye residuos sólidos urbanos y residuos de manejo especial. En el caso de microgeneradores, específica que es únicamente aplicable para residuos peligrosos, tal y como lo señala la propia definición. Esto nos lleva a reflexionar sobre la especificidad de las leyes en cuestión ambiental. Como se observa, pareciera no tener la suficiente importancia, puesto que el control de la Generación de RSU como se ha visto a lo largo de esta investigación, es parte primordial para lograr un buen manejo de RSU. Esto queda completamente especificado cuando la Ley, en su artículo 23, dice que los microgeneradores de RSU no están sujetos a planes de manejo, pero es importante no olvidar que los microgeneradores de RSU, debido a la gran cantidad de personas que son, están generando casi el 50\% de los RSU totales que se generan en la CDMX.

Tabla 3.3. Clasificación de generadores de residuos, según el Artículo $5^{\circ}$ de la LGPGIR.

\begin{tabular}{|c|c|c|}
\hline $\begin{array}{c}\text { GRANDES } \\
\text { GENERADORES }\end{array}$ & $\begin{array}{c}\text { PEQUEÑOS } \\
\text { GENERADORES }\end{array}$ & MICROGENERADORES \\
\hline $\begin{array}{l}\text { Son aquellos que realizan una } \\
\text { actividad en la que generan una } \\
\text { cantidad igual o superior a diez } \\
\text { toneladas en peso bruto total de } \\
\text { residuos al año o su } \\
\text { equivalente en otra unidad de } \\
\text { medida }\end{array}$ & $\begin{array}{l}\text { Son aquellos que realizan una } \\
\text { actividad en la cual generan } \\
\text { una cantidad mayor a } 400 \\
\text { kilogramos y menor a } 10 \\
\text { toneladas en peso bruto total de } \\
\text { residuos al año o su } \\
\text { equivalente en otra unidad de } \\
\text { medid }\end{array}$ & $\begin{array}{l}\text { Son aquellos establecimientos } \\
\text { industriales, comerciales o de } \\
\text { servicios que generan una } \\
\text { cantidad hasta de } 400 \\
\text { kilogramos de residuos } \\
\text { peligrosos al año o su } \\
\text { equivalente en otra unidad de } \\
\text { medida }\end{array}$ \\
\hline
\end{tabular}

Fuente: LGPGIR

Otros aspectos relevantes que se pueden observar en la LGPGIR, se refieren a la distribución de competencias, en cuanto al manejo y cada una de sus fases, ya que, a lo largo del Título Sexto, de dicha Ley, aclara que son los gobiernos locales los que deben especificar cada una de las fases e informar de cómo debe ser el manejo mediante documentos específicos como reglamentos o planes de manejo. Es aquí, donde se vuelve a tocar un punto muy importante y controversial referente a la distribución de competencias, que anteriormente ya se ha mencionado, ya que los gobiernos locales no están preparados en ningún aspecto para llevar a cabo dicho manejo integral de los RSU. Esto en gran parte por sus presupuestos tan bajos destinados para ello o por los puntos anteriormente mencionados.

\section{Ley Ambiental de Protección a la Tierra en el Distrito Federal}

Es el instrumento legal que contiene aspectos relacionados con el manejo de los residuos, con el objetivo de conducir y evaluar la política ambiental en la CDMX, así como los instrumentos y procedimientos para su protección, vigilancia y aplicación, dentro de los que se considera la gestión integral de los residuos, a fin de conservar y restaurar el equilibrio ecológico, así como prevenir los daños al ambiente, de manera que la obtención de beneficios económicos y las actividades sociales se generen en un esquema de desarrollo sustentable, lo anterior a través de la participación de la sociedad en el desarrollo y la gestión ambiental.

Establece las facultades de la Secretaría del Medio Ambiente en materia de residuos sólidos, entre las que destacan, entre otras, la emisión de normas ambientales con el objeto de establecer los requisitos, condiciones o límites permisibles en la operación, recolección, transporte, almacenamiento, reciclaje, 
tratamiento, industrialización o disposición final de residuos sólidos, así como en el manejo de residuos sólidos que presenten riesgo para el ser humano, para el equilibrio ecológico o para el ambiente.

Por lo anterior, el Gobierno de la Ciudad publicó en la Gaceta Oficial la Norma Ambiental para el Distrito Federal NADF007-RNAT-2013, que establece la clasificación y especificaciones de manejo para residuos de la construcción y demolición, en el distrito federal, y la Norma Ambiental NADF024-AMBT-2013, que establece los criterios y especificaciones técnicas bajo los cuales se deberá realizar la separación, clasificación, recolección selectiva y almacenamiento de los residuos de la Ciudad de México; esta norma contempla en uno de sus apartados a "los residuos peligrosos provenientes de fuentes distintas a los establecimientos comerciales, industriales o de servicios"

Además, contempla diversos instrumentos administrativos para la presentación de planes de manejo por los sujetos generadores, ya sea a través de la Licencia Ambiental Única para el Distrito Federal "LAUDF" y el Registro y Autorización de Establecimientos Mercantiles y de Servicios Relacionados con la Recolección, Manejo, Transporte, Tratamiento, Reutilización, Reciclaje, y Disposición Final de los Residuos Sólidos de Competencia Local "RAMIR".

\subsubsection{Códigos}

\section{Código Penal Federal}

Los delitos contra el ambiente y la gestión ambiental, que serían interesantes para esta investigación se encuentran en el artículo 416 del Código Penal Federal, donde se mencionan las penas y multas que se impondrán, al que ilícitamente descargue, deposite, o infiltre, lo autorice u ordene, aguas residuales, líquidos químicos o bioquímicos, desechos o contaminantes en los suelos, subsuelos, aguas marinas, ríos, cuencas, vasos o demás depósitos o corrientes de agua de competencia federal, que cause un riesgo de daño o dañe a los recursos naturales, a la flora, a la fauna, a la calidad del agua, a los ecosistemas o al ambiente. Es importante mencionar que, existen huecos en la ley con respecto al manejo de los RSU, ya que, si bien se menciona sobre la contaminación a través de las sustancias o residuos mencionados anteriormente, no hay nada que especifique la contaminación de los RSU, aunque estos también pueden contaminar los mantos acuíferos, suelo y subsuelo mediante los lixiviados, lo cual no están especificados en código penal. Como anteriormente se vio, esto puede deberse a que el lector debe suponer que los RSU también están incluidos, lo que una vez más pone en evidencia la necesidad de especificar que los RSU están incluidos.

Por otro lado, en el artículo 414 y 415, se fundamentan las penas para quienes causen daños a la salud a través de la disposición o manejo inadecuado de los residuos peligrosos, pero no incluyen los RSU de manera explícita, aunque estos también causen daños a la salud tanto en el corto como en el largo plazo como infecciones estomacales, entre otros, por consumo de agua contaminada debido a los lixiviados o enfermedades respiratorias por la mala disposición de dichos residuos; estas afectaciones se vieron detalladamente en el capítulo uno de esta investigación. Es decir, algo ideal, sería poder implementar multas a quienes no separen adecuadamente sus residuos, a quienes no dispongan de ellos en lugares apropiados o mediante el servicio de recolección ya sea público o privado, a quienes de manera ventajosa se sorprenda arrojando RSU en vías públicas, puesto que esto debería considerarse como un delito ambiental, lo cual debería estar estipulado en el código penal. 
Es importante mencionar que en la CDMX existe la Ley de Cultura Cívica del Distrito Federal, que implementa multas entre 769 y 1,399 pesos, o arresto de 13 a 24 horas, por los siguientes motivos.

- No recoger las heces de los animales

- Defecar u orinar en la calle

- Tirar basura, animales muertos, muebles y otros desechos en la vía pública

- Dañar fachadas de inmuebles públicos o la infraestructura en vialidades.

Sanción de arresto entre 25 a 36 horas y multa de entre 21 a 40 Unidades de Cuenta de la CDMX, equivalente a entre 1,468.95 pesos a 2,798 pesos por desperdiciar el agua. Arresto de entre 25 a 36 horas y multa de entre 21 a 30 Unidades de Cuenta de la CDMX (1,468.95 pesos a 2,098.5 pesos) por:

- Obstruir la banqueta con enseres de un establecimiento mercantil sin autorización.

- Tirar desechos dañinos a la salud de la gente.

- Ingresar a zonas de acceso restringido.

- Dañar señalizaciones y letreros viales.

Es decir, el tirar RSU es más bien juzgado como un acto incívico que, como un delito ambiental, por lo que gran parte de la población no le da importancia suficiente. Con esto se puede reflexionar sobre la falta de rigor en el código penal para cuestiones ambientales, que como se ha visto a lo largo de esta investigación son de gran importancia pues va más allá de actos cívicos o incívicos, sino más bien implica cuestiones tan importantes como el calentamiento global y la sustentabilidad ambiental. Dichos temas son tendencia internacional debido a las implicaciones que ambos tiene para el medio ambiente y la humanidad en general.

\subsubsection{Reglamentos y Programas Federales y Locales}

En general, los programas nacionales son instrumentos normativos del sistema nacional de planeación, que tienen la finalidad de desagregar y detallar planteamientos y orientaciones generales del plan nacional, mediante la identificación de objetivo y metas. Dependiendo del nivel en que se elabore puede ser de carácter global, sectorial, institucional e incluso específico, y también de acuerdo con la temporalidad y el ámbito territorial puede ser nacional regional o acorto o largo plazo respectivamente (SEMARNAT, 2012). Un aspecto importante también es que en él se deben plasmar un conjunto homogéneo y organizado de actividades a realizar para alcanzar una o varias metas con recursos previamente determinados y a cargo de una unidad responsable. Como en el caso del Programa Nacional para la Prevención y Gestión Integral de Residuos Sólidos Urbanos, que está a cargo de la Secretaría del Medio Ambiente y Recursos Naturales (SEMARNAT).

\section{Programa Nacional para la Prevención y Gestión Integral de Residuos Sólidos (PNPGIRS) (Federal)}

Este programa, al igual que el resto de los programas que se elaboran a nivel nacional, se encuentran fundamentados en toda la normatividad mexicana, desde la Constitución Política hasta las leyes federales o generales, tal es el caso del Programa Nacional para la Prevención y Gestión Integral de Residuos Sólidos Urbanos (PNPGIRS), que en cumplimiento de los artículos 7 y 25 de la LGPGIR, la SEMARNAT en conjunto con otras dependencias y representantes de autoridades municipales, además de los sectores social, privado y académico, se dieron a la tarea de preparar dicho programa. 
Es este programa en donde se establece la política ambiental en materia de residuos y se plantean objetivos, lineamientos, acciones y metas en concreto respecto al tema de residuos.

De manera general, el programa tiene como objetivo consolidar el marco regulatorio y aplicar políticas para prevenir, reducir y controlar la contaminación, hacer una gestión integral de los residuos y remediar sitios contaminados para garantizar una adecuada calidad del aire, agua y suelo. Se apoyan proyectos para la gestión integral de residuos sólidos como: elaboración de programas y estudios, adquisición de vehículos y maquinaria, construcción de infraestructura y saneamiento de tiraderos a cielo abierto, entre otros, con el propósito de apoyar principalmente a los gobiernos y gente de los municipios y entidades federativas.

Por este motivo, este documento se encuentra entre los documentos más importantes en cuestión de RSU, especialmente porque es uno de los documentos que contempla la generación de RSU como uno de los puntos más importantes en el manejo de los RSU mediante la promoción de la educación de la población para orientar la preferencia del consumidor hacia los productos que generen la menor cantidad de residuos, bajo criterios de consumo racional, evitando el desperdicio y la generación innecesaria de residuos y que en su caso, los residuos puedan ser dispuestos con la menor carga posible hacia el medio ambiente (PNPGIRS).

Este programa en general está fundamentado bajo varios Principios Rectores de Política, que están cimentados principalmente con la necesidad de lograr el desarrollo sustentable de México, entre los principios más relevantes se tienen:

- El principio de autosuficiencia, que tiene que ver con que se cuente con la infraestructura necesaria para un adecuado manejo de los RSU, de manera sustentable principalmente.

- El principio de desarrollo sustentable que establece que cualquier estrategia debe guiada por un proceso evaluable mediante criterios e indicadores de carácter ambiental, económico y social.

- Principio de Prevención y minimización que básicamente está enfocada a la minimización de la generación de los RSU mediante estrategias y técnicas económicamente factibles y socialmente aceptables.

- Principio de manejo seguro y adecuado, estipulado básicamente para evitar la transferencia de contaminantes de un medio a otro.

- Principio de comunicación, educación y capacitación, que implica es desarrollo de acciones que fomenten el conocimiento, la sensibilización y la concientización en la sociedad y por otro lado también fomentar la investigación y la generación de especialistas que promuevan la GIRSU.

- Principio de la responsabilidad compartida, que intenta no delegar responsabilidades a una sola parte, sino más bien compartirla, es decir, ciudadanía, gobierno, sector privado, sector académico, etc.

Los anteriores principios, sólo son algunos de varios que el PNPGIR muestra para fundamentar la GIRSU en el país. Sin embargo, el programa mantiene también objetivos generales y específicos que fomenten la adecuada GIRSU y que son necesarios conocer.

El objetivo general del programa, que parece ser bastante acertado, está enfocado básicamente en las fases del manejo de los RSU, desde la generación hasta la disposición final. Es decir, está enfocado en prevenir y minimizar la generación de RSU desde la fuente de origen, la cual según el programa está en modificar los patrones de consumo para minimizar la generación, para que lo que se genere debe ser correctamente manipulado y separado, para posteriormente ser valorizado y utilizado como materia prima para otros procesos (como generación de energía verde) y así llevar la menor cantidad posible de RSU a disposición final. El programa muestra objetivos y estrategias específicos que se encuentran resumidos en la Tabla 3.4. con respecto a las fases del manejo que se han considerado en esta investigación. 
Tabla 3.4. Objetivos y estrategias específicos del PNPGIR.

\begin{tabular}{|c|c|c|}
\hline $\begin{array}{c}\text { FASES DEL } \\
\text { MANEJO DE LOS } \\
\text { RSU }\end{array}$ & OBJETIVOS & ESTRATEGIAS \\
\hline GENERACIÓN & $\begin{array}{l}\text { - Prevenir y minimizar la } \\
\text { generación de RSU, mediante } \\
\text { la implementación de normas } \\
\text { y programas } \\
\text { - Lograr participación activa de } \\
\text { todos los sectores de la } \\
\text { sociedad para la reducción de } \\
\text { la generación de RSU } \\
\text { - Prevenir y minimizar riesgos a } \\
\text { la salud de la población y } \\
\text { trabajadores que participan en } \\
\text { el manejo de los RSU }\end{array}$ & $\begin{array}{l}\text { - Fortalecer la capacidad } \\
\text { institucional técnica y financiera } \\
\text { de los tres órdenes de gobierno } \\
\text { para el cumplimiento de sus } \\
\text { responsabilidades en la GIRS } \\
\text { • Promover creación, } \\
\text { modificación y aplicación de } \\
\text { instrumentos jurídicos y } \\
\text { económicos que fortalezcan la } \\
\text { GIRS } \\
\text { Promover la comunicación entre } \\
\text { el gobierno federal y local para }\end{array}$ \\
\hline RECOLECCIÓN & $\begin{array}{l}\text { - Contar con infraestructura } \\
\text { ambiental adecuada. } \\
\text { - Lograr participación activa de } \\
\text { todos los sectores de la } \\
\text { sociedad para la separación de } \\
\text { los RSU desde su fuente de } \\
\text { origen en los hogares antes de } \\
\text { su recolección. }\end{array}$ & $\begin{array}{c}\text { - Aplicar el principio de las 3R's } \\
\text { en todas las fases del manejo de } \\
\text { los RSU y fortalecer } \\
\text { financiamiento que apoye este } \\
\text { principio. } \\
\text { - Construir infraestructura } \\
\text { necesaria para la disposición fina }\end{array}$ \\
\hline $\begin{array}{c}\text { MANIPULACIÓN } \\
\text { Y/O } \\
\text { PROCESAMIENTO }\end{array}$ & $\begin{array}{l}\text { - Lograr participación activa de } \\
\text { todos los sectores de la } \\
\text { sociedad para la separación de } \\
\text { los RSU desde su fuente de } \\
\text { origen en los hogares. } \\
\text { - Implementar el principio de las } \\
\text { 3R's (Reduce-Reúsa-Recicla) } \\
\text { - Contar con infraestructura } \\
\text { ambiental adecuada. } \\
\text { - Promover el desarrollo } \\
\text { científico y tecnológico para el } \\
\text { aprovechamiento de los } \\
\text { residuos }\end{array}$ & $\begin{array}{l}\text { de RSU que no puedan ser } \\
\text { aprovechados } \\
\text { - Promover sistemas de } \\
\text { financiamiento para implementar } \\
\text { tecnologías que ayuden a } \\
\text { provechar los RSU mediante la } \\
\text { generación energética, a través } \\
\text { de la iniciativa privada. } \\
\text { - Establecer un mecanismo } \\
\text { conjunto de financiamiento para } \\
\text { proyectos de gestión entre } \\
\text { instancias promotoras de } \\
\text { proyectos donde SEMARNAT }\end{array}$ \\
\hline TRANSFORMACIÓN & $\begin{array}{c}\text { - Implementar la recuperación } \\
\text { energética } \\
\text { - Contar con infraestructura } \\
\text { ambiental adecuada. } \\
\text { - Reducir y evitar la generación } \\
\text { de Gases Efecto Invernadero } \\
\text { para mitigar el cambio } \\
\text { climático, mediante la } \\
\text { transformación de los residuos }\end{array}$ & $\begin{array}{l}\text { tenga el control técnico. } \\
\text { - Implementar una estrategia } \\
\text { nacional para el control y } \\
\text { aprovechamiento de GEI } \\
\text { originados por RSU. } \\
\text { - Diseñar indicadores que } \\
\text { permitan la evaluación nacional } \\
\text { del desempeño ambiental en la } \\
\text { GIRS y que además apoyen en la }\end{array}$ \\
\hline
\end{tabular}




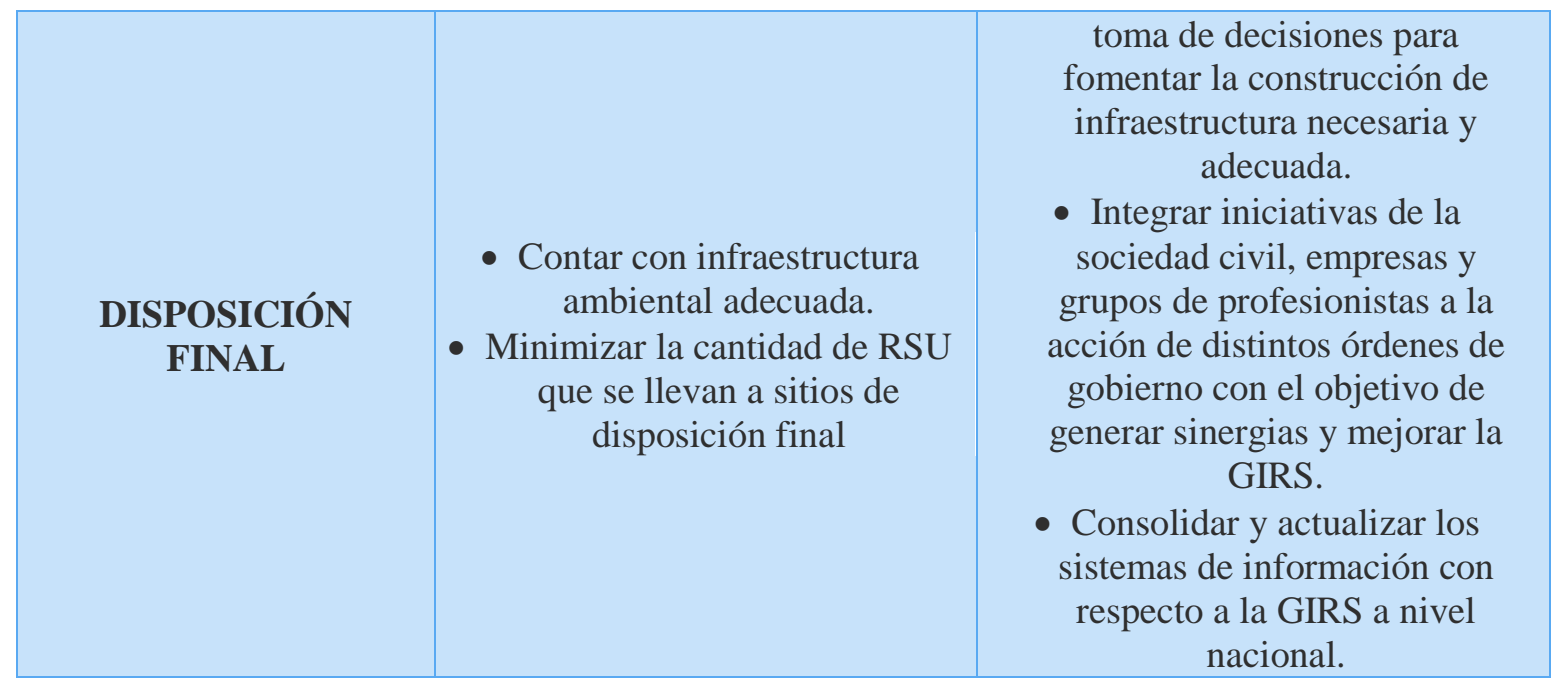

Fuente: Elaboración propia a partir de información del PNPGIR

A manera de resumen, se aprecia en la Tabla 3.4, los objetivos de acuerdo a cada una de las fases del manejo de los RSU y algunas de las estrategias más importantes para el manejo en general. Entre estas estrategias se pueden hallar, dos puntos de particular interés para esta investigación ya que le dan mayor sentido a la misma. Uno se observa cuando el PNPGIR toma como referencia el manejo de los RSU para la mejora de la GIRSU, pues los objetivos están claramente enfocados a cada una de las fases del manejo, desde su generación hasta su disposición final, por otro lado un punto que evidencia la necesidad de generar indicadores que evalúen el manejo de los RSU y que a su vez ayuden a los tomadores de decisiones a enfocar los recursos a donde mayormente se necesitan para que se pueda observar una clara mejoría en el manejo de los RSU y por lo tanto en la GIRSU.

Aunado a esto, se manejan cada una de las fases del manejo de RSU especificando líneas de acción para llegar a metas en concreto en cada una de estas fases mencionadas con anterioridad, partiendo también desde una promesa de apoyo para el fortalecimiento en el marco jurídico local. En el caso específico de la CDMX, se encuentra el Programa General de Desarrollo de la CDMX, que es un documento de suma importancia, en donde se encuentran los RSU involucrados de manera directa e indirecta, el cual se analizará brevemente a continuación.

En general, se puede observar que el PNPGIR se encuentra claramente fundamentado ya que se tiene una clara estructura de lo que se pretende hacer, basado en la parte central de la GIRSU que es el manejo de los mismos. Sin embargo, hay muchas estrategias que no se han logrado alcanzar, pues a pesar de que este programa se escribió en el año 2008, para un periodo 2009-2012, aún se encuentran inconclusas la mayoría de las estrategias que se pretendían alcanzar en ese periodo: como las de generar y actualizar información, generar la infraestructura necesaria para el tratamiento de los RSU que los transformen en energía, entre otras. Existe el mismo programa, pero a nivel local, en el caso de la CDMX, por lo que es importante que se analice de la misma manera.

\section{Programa de Gestión Integral de RSU de la CDMX 2016-2020. (Local)}

Este programa ha sido creado con la misma necesidad que el programa nacional. El de mejora de la GIRSU. El objetivo general de dicho programa es el de crear las pautas para mejorar el manejo de los RSU, que se generan en la CDMX, en cada una de las fases de dicho manejo, esto a través de líneas estratégicas y acciones aplicables, que además involucren diferentes sectores de la sociedad con una visión incluyente y perspectiva, teniendo en cuenta la filosofía de Basura Cero. Este programa fue creado bajo los mismos principios rectores que el PNPGIR, los cuales se pueden consultar en el 
apartado anterior, además de que se encuentra fundamentado por un marco normativo que incluye Ley General del Equilibrio Ecológico y la Protección al Ambiente, Ley General para la Prevención y Gestión Integral de Residuos y su Reglamento, Ley Ambiental de Protección a la Tierra en el Distrito Federal, Ley de Residuos Sólidos del Distrito Federal, Programa General de Desarrollo del Distrito Federal, Programa de Acción Climática de la Ciudad de México (PACCM) 2014-2020 y Programa Sectorial Ambiental y de Sustentabilidad 2013-2018 que se analizan en esta investigación. Al igual que el programa nacional, el programa de la CDMX mantiene sus objetivos alineados con cada una de las fases del manejo de los residuos y a diferencia del programa nacional este si tiene metas específicas y líneas de acción para cada una de las fases. A continuación, la Tabla 3.5, muestra una sistematización de los mismos, que incluyen los puntos más importantes.

Tabla 3.5. Objetivos, metas y acciones del PGRS de la CDMX

\begin{tabular}{|c|c|c|c|}
\hline FASES & OBJETIVOS & METAS & LÍNEAS DE ACCIÓN \\
\hline$\frac{\pi}{2}$ & $\begin{array}{l}\text { • Fomentar la } \\
\text { participación social } \\
\text { respecto a la reducción } \\
\text { de la generación de los } \\
\text { residuos y el consumo } \\
\text { sustentable en la } \\
\text { CDMX, a través del } \\
\text { desarrollo de un } \\
\text { instrumento de } \\
\text { consumo sustentable y } \\
\text { la aplicación de planes } \\
\text { de manejo; } \\
\text { involucrando así a los } \\
\text { distintos sectores de la } \\
\text { sociedad. }\end{array}$ & $\begin{array}{c}\text { • Prevención y } \\
\text { minimización: continuar } \\
\text { fomentando y promoviendo } \\
\text { los planes de manejo } \\
\text { • Sistema de administración } \\
\text { ambiental, que implica } \\
\text { potenciar el reciclaje y } \\
\text { reúso de al menos el 30\% } \\
\text { de los residuos sólidos } \\
\text { urbanos que se generan en } \\
\text { los inmuebles adscritos al } \\
\text { SAA, al 2020. } \\
\text { - Producción y consumo } \\
\text { sustentable que Para el } \\
\text { 2020, promover la } \\
\text { coordinación entre las } \\
\text { diferentes entidades, } \\
\text { órdenes del gobierno y } \\
\text { sociedad civil para el } \\
\text { establecimiento de } \\
\text { instrumentos que permitan } \\
\text { reducir la cantidad de } \\
\text { empaques y embalajes, } \\
\text { impulsando la valorización } \\
\text { a través del reciclaje y } \\
\text { reúso } \\
\text { Promover la separación de } \\
\text { residuos sólidos urbanos y } \\
\text { de manejo especial de } \\
\text { acuerdo a la normatividad } \\
\text { vigente desde la fuente de } \\
\text { generación para facilitar el } \\
\text { aprovechamiento de los } \\
\text { mismos con la visión de } \\
\text { "Basura Cero”. }\end{array}$ & $\begin{array}{l}\text { - Realizar programas de } \\
\text { capacitación acerca de los } \\
\text { planes de manejo } \\
\text { - Fortalecimiento y } \\
\text { coordinación } \\
\text { interinstitucional para } \\
\text { fomentar los planes de } \\
\text { manejo en mercados, } \\
\text { empresas, instituciones } \\
\text { educativas, edificios } \\
\text { públicos. } \\
\text { - Realizar capacitaciones de } \\
\text { servidores públicos. } \\
\text { - Revisar, monitorear y dar } \\
\text { seguimiento a inmuebles } \\
\text { donde ya se haya } \\
\text { implementado sistemas de } \\
\text { manejo ambiental } \\
\text { - Realizar campañas y } \\
\text { publicaciones que } \\
\text { fomenten el consumo } \\
\text { sustentable. } \\
\text { - Desarrollar una estrategia } \\
\text { que contemple aspectos de } \\
\text { producción y consumo } \\
\text { sustentable, considerando } \\
\text { la minimización de } \\
\text { residuos. } \\
\text { - Promover la coordinación } \\
\text { interinstitucional con } \\
\text { instancias federales y } \\
\text { megalopolitanas para } \\
\text { fomentar la reducción de } \\
\text { envases y embalajes a }\end{array}$ \\
\hline
\end{tabular}




\begin{tabular}{|c|c|c|c|}
\hline & & & $\begin{array}{c}\text { través del reciclaje y } \\
\text { reúso. }\end{array}$ \\
\hline 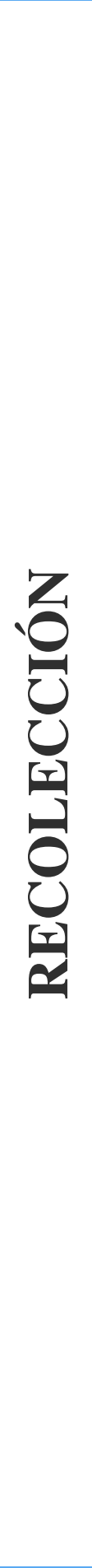 & $\begin{array}{l}\text { - Modernizar el sistema } \\
\text { de recolección } \\
\text { adaptándolo a los } \\
\text { requerimientos } \\
\text { normativos para la } \\
\text { separación de } \\
\text { residuos, promoviendo } \\
\text { la mejora en la } \\
\text { prestación del servicio, } \\
\text { a través de la } \\
\text { capacitación a mandos } \\
\text { medios y a los } \\
\text { trabajadores } \\
\text { operativos del sistema } \\
\text { de limpia de las } \\
\text { Demarcaciones } \\
\text { territoriales. }\end{array}$ & $\begin{array}{l}\text { - A partir del 2016, se deberá } \\
\text { recolectar en días } \\
\text { alternados o mediante } \\
\text { vehículos recolectores con } \\
\text { compartimientos, las } \\
\text { distintas fracciones de los } \\
\text { residuos separados en la } \\
\text { fuente, señalados en la } \\
\text { separación primaria } \\
\text { avanzada en la NADF-024- } \\
\text { AMBT-2013 } \\
\text { - Para 2016, establecer } \\
\text { calendarios anuales con las } \\
\text { 16 Demarcaciones } \\
\text { territoriales para llevar a } \\
\text { cabo jornadas de acopio, } \\
\text { recolección de residuos de } \\
\text { manejo especial y } \\
\text { voluminosos dirigidos a la } \\
\text { población en general, y } \\
\text { recibirlos en las } \\
\text { instalaciones de la DGSU } \\
\text { para envío a su destino. } \\
\text { - A partir de 2017, fortalecer } \\
\text { la regularización y } \\
\text { formalización de los } \\
\text { establecimientos de } \\
\text { compra-venta de residuos } \\
\text { reciclables }\end{array}$ & $\begin{array}{l}\text { - Elaborar y aplicar dos } \\
\text { programas anuales de } \\
\text { capacitación, para el } \\
\text { personal del servicio de } \\
\text { limpia, sobre la } \\
\text { clasificación de residuos } \\
\text { señalada en la NADF024- } \\
\text { AMBT-2013. } \\
\text { • Elaborar y aplicar } \\
\text { programas de difusión } \\
\text { dirigidos a los generadores } \\
\text { sobre la clasificación de } \\
\text { residuos señalada en la } \\
\text { NADF-024-AMBT-2013, } \\
\text { así como de la recolección } \\
\text { separada. } \\
\text { - Mantener la recolección } \\
\text { separada en días } \\
\text { alternados: lunes, } \\
\text { miércoles, viernes y } \\
\text { domingo: residuos } \\
\text { inorgánicos con potencial } \\
\text { de reciclaje y con } \\
\text { posibilidades de } \\
\text { aprovechamiento limitado. } \\
\text { martes, jueves y sábados: } \\
\text { residuos biodegradables. } \\
\text { • Realizar al menos una } \\
\text { jornada de acopio mensual } \\
\text { en cada Demarcación } \\
\text { territorial para la } \\
\text { recolección de residuos de } \\
\text { manejo especial y } \\
\text { voluminosos, así como } \\
\text { para residuos peligrosos de } \\
\text { fuentes distintas a } \\
\text { establecimientos } \\
\text { vehicular de recolección } \\
\text { con la adquisición de } \\
\text { vehículos de carga trasera }\end{array}$ \\
\hline
\end{tabular}




\begin{tabular}{|c|c|c|c|}
\hline & & & $\begin{array}{l}\text { con compartimentos y } \\
\text { retención de líquidos, para } \\
\text { la sustitución de vehículos } \\
\text { que han rebasado su vida } \\
\text { útil y tecnológica, o } \\
\text { aquellos que por su tipo o } \\
\text { diseño no facilitan la } \\
\text { recolección de residuos en } \\
\text { las condiciones de } \\
\text { recolección separada } \\
\text { prevista en la NADF-024- } \\
\text { AMBT-2013 }\end{array}$ \\
\hline$\underset{b}{2}$ & $\begin{array}{l}\text { Mejorar el proceso de } \\
\text { operación de } \\
\text { transferencia para la } \\
\text { recepción separada de } \\
\text { los residuos, de } \\
\text { acuerdo a las } \\
\text { fracciones señaladas } \\
\text { en la NADF- } \\
\text { 024AMBT-2013. } \\
\bullet\end{array}$ & $\begin{array}{l}\text { - A partir de } 2016 \text {, llevar a } \\
\text { cabo la recepción separada } \\
\text { de los residuos según las } \\
\text { fracciones señaladas en la } \\
\text { separación primaria } \\
\text { avanzada de la NADF-024- } \\
\text { AMBT2013 en las } \\
\text { estaciones de transferencia. } \\
\text { - A partir de 2016, asegurar } \\
\text { el envío de los residuos } \\
\text { recibidos, a los diferentes } \\
\text { destinos, dependiendo de } \\
\text { las fracciones recolectadas } \\
\text { separadamente y de los } \\
\text { requerimientos de las } \\
\text { diferentes instalaciones, } \\
\text { para el aprovechamiento o } \\
\text { disposición final de los } \\
\text { residuos. } \\
\text { Para el 2020, fortalecer los } \\
\text { esquemas de participación } \\
\text { público, privado y social } \\
\text { para incorporar residuos } \\
\text { reciclables a los procesos } \\
\text { productivos, con el fin de } \\
\text { consolidar a los centros de } \\
\text { acopio como opciones } \\
\text { económicamente favorables } \\
\text { de acuerdo a la NADF-024- } \\
\text { AMBT-2013. }\end{array}$ & $\begin{array}{c}\text { - Regularizar y formalizar la } \\
\text { operación de } 800 \\
\text { establecimientos de } \\
\text { compraventa de residuos } \\
\text { reciclables } \\
\text { - Consolidar tres nuevos } \\
\text { mercados ambientales para } \\
\text { fomentar el } \\
\text { aprovechamiento de los } \\
\text { residuos con potencial de } \\
\text { reciclaje } \\
\text { - Fortalecer los programas } \\
\text { de acopio de residuos } \\
\text { eléctricos y electrónicos. } \\
\text { Establecer mecanismos de } \\
\text { coordinación entre los } \\
\text { sistemas de limpia de las } \\
\text { Demarcaciones } \\
\text { territoriales, los } \\
\text { operadores y } \\
\text { administradores de las } \\
\text { estaciones de } \\
\text { transferencia, a fin de } \\
\text { garantizar que los residuos } \\
\text { recolectados, guarden la } \\
\text { calidad requerida por los } \\
\text { sistemas de tratamiento o } \\
\text { aprovechamiento en } \\
\text { operación. } \\
\text { - Construir y operar las } \\
\text { instalaciones y los } \\
\text { sistemas de tratamiento de } \\
\text { residuos biodegradables } \\
\text { seleccionados, de acuerdo } \\
\text { a los resultados de los } \\
\text { estudios y proyectos } \\
\text { realizados al efecto, tales } \\
\text { como plantas de }\end{array}$ \\
\hline
\end{tabular}




\begin{tabular}{|c|c|c|c|}
\hline & & & $\begin{array}{l}\text { compostaje aerobio } \\
\text { acelerado en instalaciones } \\
\text { cerradas y plantas de } \\
\text { biodigestión anaerobia con } \\
\text { recuperación de energía, } \\
\text { mediante concesión, } \\
\text { asociación pública privada } \\
\text { y/o prestación de servicios. }\end{array}$ \\
\hline 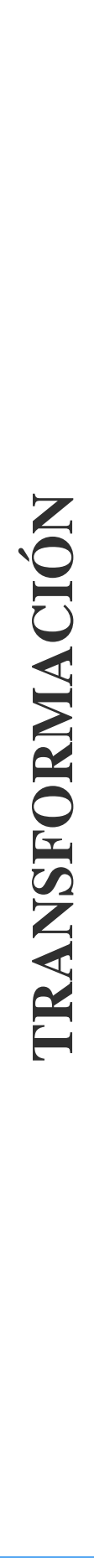 & $\begin{array}{c}\text { - Desarrollar e } \\
\text { implementar nuevas } \\
\text { tecnologías para tratar, } \\
\text { aprovechar y valorizar } \\
\text { los residuos sólidos } \\
\text { urbanos y de manejo } \\
\text { especial que se } \\
\text { generan en la CDMX; } \\
\text { promoviendo la } \\
\text { participación de } \\
\text { diversos sectores e } \\
\text { incentivando la } \\
\text { investigación en la } \\
\text { materia }\end{array}$ & $\begin{array}{l}\text { - A partir de } 2016 \text { y de } \\
\text { manera gradual, garantizar } \\
\text { el equipamiento y la } \\
\text { operación de instalaciones } \\
\text { para el procesamiento de } \\
\text { los residuos biodegradables } \\
\text { recolectados separadamente } \\
\text { por el servicio público de } \\
\text { limpia de las } \\
\text { Demarcaciones } \\
\text { territoriales. } \\
\text { - Para 2017, procesar en la } \\
\text { Planta de Composta de } \\
\text { Bordo Poniente los residuos } \\
\text { biodegradables } \\
\text { recolectados de manera } \\
\text { selectiva, en tanto no se } \\
\text { cuente con otras } \\
\text { instalaciones de } \\
\text { tratamiento. } \\
\text { - Para 2020, desarrollar las } \\
\text { condiciones mínimas para } \\
\text { el tratamiento de la fracción } \\
\text { orgánica de los residuos a } \\
\text { través del proceso } \\
\text { biodigestión anaerobia de } \\
\text { acuerdo a las acciones de } \\
\text { "Basura Cero". } \\
\text { • Para 2020, construir y } \\
\text { operar las instalaciones o } \\
\text { plantas para el } \\
\text { de construcción de } \\
\text { aprovechamiento } \\
\text { energético de residuos } \\
\text { inorgánicos con } \\
\text { aprovechamiento limitado, } \\
\text { recolectados y recibidos en } \\
\text { las estaciones de } \\
\text { transferencia en forma } \\
\text { sestar en proceso }\end{array}$ & $\begin{array}{l}\text { - Establecer mecanismos de } \\
\text { coordinación entre los } \\
\text { sistemas de limpia de las } \\
\text { Demarcaciones } \\
\text { territoriales, los } \\
\text { operadores y } \\
\text { administradores de las } \\
\text { estaciones de } \\
\text { transferencia, a fin de } \\
\text { garantizar que los residuos } \\
\text { recolectados, guarden la } \\
\text { calidad requerida por los } \\
\text { sistemas de tratamiento o } \\
\text { aprovechamiento en } \\
\text { operación. } \\
\text { - Recibir y procesar } 1,000 \\
\text { toneladas por día en } \\
\text { promedio de residuos } \\
\text { biodegradables } \\
\text { susceptibles de ser } \\
\text { aprovechados en la planta } \\
\text { de Composta en Bordo } \\
\text { Poniente. } \\
\text { • Construir y operar las } \\
\text { instalaciones y los } \\
\text { sistemas de tratamiento de } \\
\text { residuos biodegradables } \\
\text { seleccionados, de acuerdo } \\
\text { a los resultados de los } \\
\text { estudios y proyectos } \\
\text { realizados al efecto, tales } \\
\text { como plantas de } \\
\text { compostaje aerobio } \\
\text { proyectos sobre la } \\
\text { acelerado en instalaciones } \\
\text { cerradas y plantas de } \\
\text { biodigestión anaerobia con } \\
\text { recuperación de energía, } \\
\text { mediante concesión, } \\
\text { asociación pública privada } \\
\text { y/o prestación de servicios } \\
\text { Realizar estudios y }\end{array}$ \\
\hline
\end{tabular}




\begin{tabular}{|c|c|c|c|}
\hline & & $\begin{array}{c}\text { instalaciones de } \\
\text { valorización energética } \\
\text { para residuos inorgánicos } \\
\text { de aprovechamiento } \\
\text { limitado. } \\
\text { - Para 2016, incrementar con } \\
\text { el envío de Combustible } \\
\text { Derivado de Residuos a las } \\
\text { plantas de cemento. }\end{array}$ & $\begin{array}{l}\text { cantidad y características } \\
\text { de los residuos inorgánicos } \\
\text { de aprovechamiento } \\
\text { limitado y los residuos } \\
\text { mezclados, que estén } \\
\text { disponibles de la } \\
\text { recolección separada y su } \\
\text { depósito en las estaciones } \\
\text { de transferencia, para } \\
\text { determinar los posibles } \\
\text { procesos de tratamiento o } \\
\text { aprovechamiento mediante } \\
\text { sistemas de valorización } \\
\text { energética, CDR o } \\
\text { tratamiento térmico con } \\
\text { recuperación de energía. } \\
\text { - Realizar estudios y } \\
\text { proyectos, promoviendo la } \\
\text { cooperación internacional, } \\
\text { para determinar las } \\
\text { mejores opciones de } \\
\text { aprovechamiento de las } \\
\text { fracciones de los residuos } \\
\text { inorgánicos con } \\
\text { aprovechamiento limitado } \\
\text { y los residuos mezclados, } \\
\text { de acuerdo a los estudios y } \\
\text { proyectos realizados }\end{array}$ \\
\hline 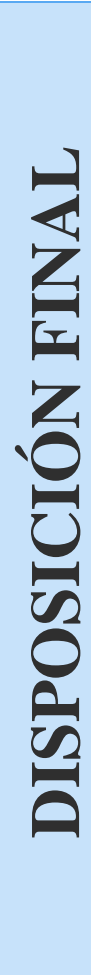 & $\begin{array}{l}\text { • Partiendo de las } \\
\text { estrategias planteadas } \\
\text { para todo el manejo de } \\
\text { residuos sólidos y } \\
\text { siguiendo las acciones } \\
\text { de "Basura Cero", esta } \\
\text { línea está enfocada en } \\
\text { acciones que } \\
\text { garanticen la } \\
\text { disposición final de los } \\
\text { residuos que no } \\
\text { pudieron ser tratados, } \\
\text { ello con la intención } \\
\text { de disminuir la } \\
\text { cantidad de residuos } \\
\text { enviados a estos sitios; } \\
\text { así como asegurar la } \\
\text { disposición de } \\
\text { residuos de } \\
\text { construcción y } \\
\text { demolición de una } \\
\text { manera }\end{array}$ & $\begin{array}{c}\text { - A partir de } 2016 \text { contar con } \\
\text { instalaciones } \\
\text { ambientalmente adecuadas } \\
\text { para la disposición final de } \\
\text { los residuos que no puedan } \\
\text { ser aprovechados o para los } \\
\text { residuos resultantes de los } \\
\text { procesos de } \\
\text { aprovechamiento mediante } \\
\text { cogeneración. } \\
\text { - A partir de 2016, contar } \\
\text { con un registro y control de } \\
\text { los planes de manejo de las } \\
\text { Manifestaciones de } \\
\text { Impacto Ambiental ante la } \\
\text { SEDEMA, así como contar } \\
\text { con sitios o instalaciones } \\
\text { ambientalmente adecuados } \\
\text { para tratamiento o } \\
\text { disposición de los residuos } \\
\text { de la construcción y } \\
\text { demolición generados en la }\end{array}$ & $\begin{array}{l}\text { - Continuar acuerdos y } \\
\text { convenios con los } \\
\text { gobiernos de la zona } \\
\text { megalopolitana para } \\
\text { garantizar sitios de } \\
\text { disposición final. } \\
\text { - Difundir la ubicación y } \\
\text { reglas de operación, de los } \\
\text { centros de acopio } \\
\text { temporal, para la recepción } \\
\text { de residuos de la } \\
\text { construcción y demolición } \\
\text { de pequeños generadores. } \\
\text { - Establecer los mecanismos } \\
\text { de coordinación para la } \\
\text { operación de centros de } \\
\text { acopio temporal de } \\
\text { residuos de la construcción } \\
\text { y demolición de pequeños } \\
\text { generadores. } \\
\text { - Establecer los mecanismos } \\
\text { de coordinación para la }\end{array}$ \\
\hline
\end{tabular}




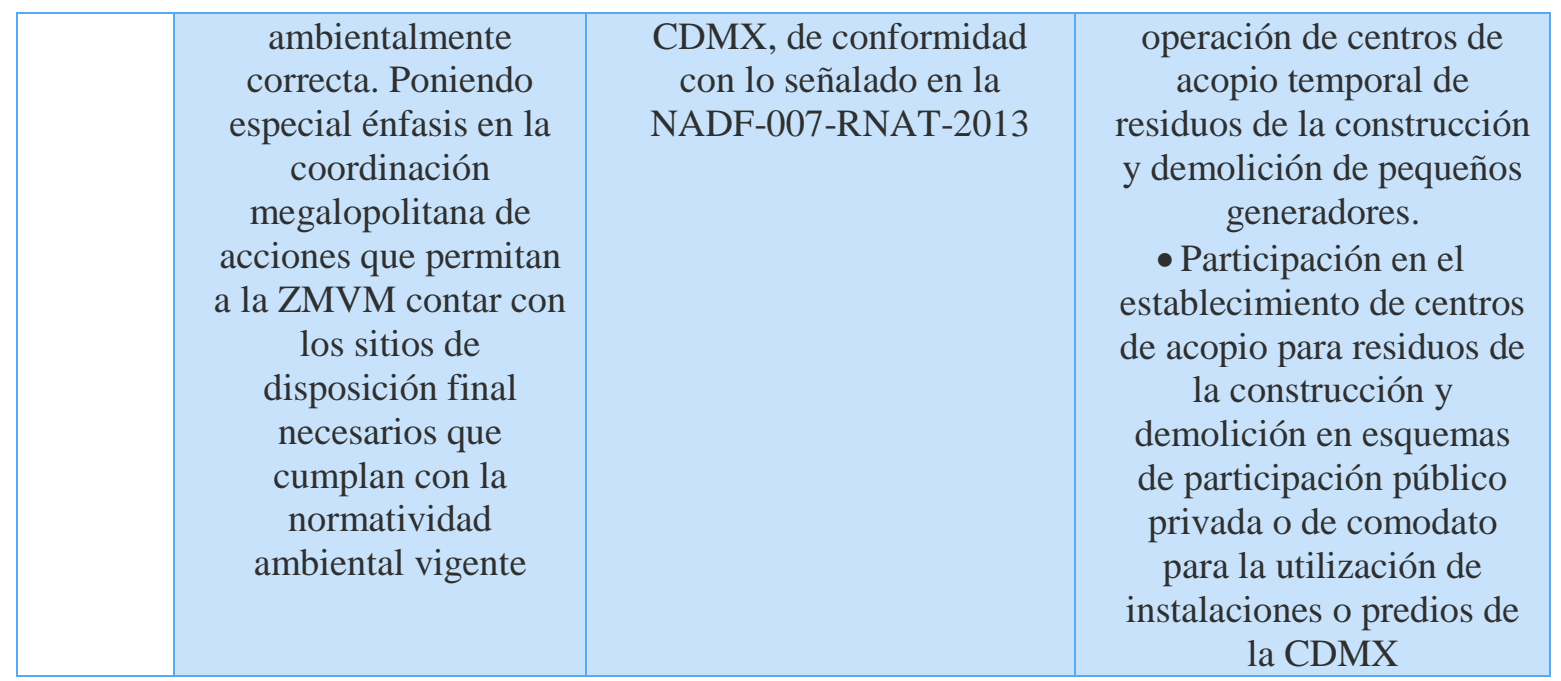

Fuente: Elaboración propia con información del PGIR de la CDMX

En la Tabla 3.5 se puede ver los objetivos, algunas de las metas y acciones más importantes del Programa para la GIR de la CDMX, se observa una similitud muy importante con los objetivos, metas $\mathrm{y}$ acciones que se han tomado a nivel nacional, sin embargo, a diferencia del programa nacional se puede observar mayor especificidad en las acciones, debido que se trata de acciones locales. Por otro lado, se pueden observar similitudes en acciones con países desarrollados que han logrado alcanzar el éxito en la gestión de sus residuos, por ejemplo, la filosofía de basura cero y la tendencia de generar instituciones híbridas, como en Suecia, estos puntos fueron detalladamente explicados en el capítulo dos de esta investigación.

\section{Programa General de Desarrollo de la CDMX (Local)}

El Programa General de Desarrollo es el documento rector que contiene las directrices generales del desarrollo social, del desarrollo económico, del desarrollo sustentable, protección civil y el ordenamiento territorial en la CDMX, así como de políticas en materia de desarrollo metropolitano, con proyecciones y previsiones para un plazo de 20 años. Éste está contemplado por ejes:

- Equidad e Inclusión Social para el Desarrollo Humano;

- Gobernabilidad, Seguridad y Protección Ciudadana;

- Desarrollo Económico Sustentable;

- Habitabilidad y Servicios, Espacio Público e Infraestructura;

- Efectividad, Rendición de Cuentas y Combate a la Corrupción.,

Éstos se encuentran ligados a ocho enfoques transversales que involucran a las diferentes entidades de Gobierno con criterios de orientación, los cuales son:

- Derechos Humanos,

- Igualdad de Género,

- Participación Ciudadana,

- Transparencia,

- Innovación, Ciencia y Tecnología,

- Sustentabilidad,

- Desarrollo Metropolitano y

- Acción Internacional.

El Programa General de Desarrollo del Distrito Federal 2013-2018 establece los objetivos, metas y líneas de acción que servirán de base para la definición e implementación de las políticas públicas de 
la Ciudad de México hasta el año 2018. A partir de este Programa, se elaborarán los programas sectoriales, institucionales, y especiales, y se desarrollará la programación, presupuestaria y evaluación de los mismos; deberá consultarse para la elaboración de los subsecuentes Programas Delegacionales y sus programas parciales respectivos para el periodo comprendido de 2015 a 2018 .

De manera general, se encuentran implícitas cuestiones con respecto a los RSU, en varios ejes. Pero de una manera algo más detallada se habla también de los RSU al contemplar un contexto regional, es decir, la interacción de otras partes del país y lo que esto implica, con la CDMX y la relevancia de ser consideradas en el Programa General de Desarrollo de la CDMX. Como es el Caso de la Zona Metropolitana del Valle de México ZMVM, esta zona presenta importantes desafíos tales como expansión territorial desmedida, periferias marginales y zonas dormitorio, problemas de tránsito, de convivencia y de seguridad, así como dificultades ambientales derivadas de la demanda de agua, la contaminación del aire y el manejo de los residuos sólidos.

El Programa de Desarrollo se conduce también con objetivos, metas, retos y líneas de acción para diferentes áreas a través de cada uno de los ejes, además de ser justificados con diagnósticos y en los cuales los RSU están involucrados de la siguiente forma: eje 2. gobernabilidad, seguridad y protección ciudadana, eje 3. desarrollo económico sustentable, eje 4 habitabilidad y servicios, espacio público e infraestructura. En estos ejes el manejo de RSU se encuentra involucrado de manera directa promoviendo desde políticas y estrategias que mejoren la calidad ambiental, hasta infraestructura que ayude al mejoramiento de áreas públicas y que mejoren el manejo de RSU. La visión que hace interesante este documento es que tampoco pretende sacrificar el desarrollo económico de la ciudad, sino más bien intenta que ambas partes, tanto el mejoramiento de la calidad ambiental como el crecimiento económico puedan mejorar de la mano sin sacrificar ni una ni la otra.

Finalmente, como uno de los objetivos en este documento también muestra el fuerte interés fomentar la educación y la concientización con e respecto a los RSU, qua al igual que el área de investigación es una de las áreas a la que menor apoyo presentan ya que, en términos generales, en México, durante el 2015 se invirtió sólo un 0.4\% del Producto Interno Bruto PIB en investigación y desarrollo (La jornada,2015). Sin embargo, éstos números se vuelven impactantes cuando se contrasta con los porcentajes que otros países invierten en el mismo rubro, como por ejemplo Suecia que invirtió alrededor del 3.8\% de su PIB en investigación y desarrollo para el mismo año (La Jornada, 2015). Desde luego es importante considerar que el PIB real per cápita en Suecia fue de 51,582.229 de miles de millones de dólares y en México fue de 1,894.552 de miles de millones de dólares (INEGI, 2014). Recordando el capítulo dos de esta investigación, Suecia es uno de los países que mejor GIRSU tiene en el mundo y además de los países que ha logrado reducir sus emisiones de Gases Efecto Invernadero (GEI) en los últimos años gracias a dicha gestión.

Es importante recordar que, los programas deben también ser apoyados de diferentes formas y por diversas instituciones, por lo que se encuentra el programa institucional, en general los programas institucionales definen la manera en que se aplicarán y operarán los instrumentos de política con que cuentan las entidades paraestatales, para coadyuvar al cumplimiento de los objetivos, prioridades, estrategias y políticas del Programa General de Desarrollo y de los programas que lo desagregan y detallan.

\section{Programa de Acción Climática de la Ciudad de México (PACCM) 2014-2020 (Local)}


Este programa resulta importante también analizarlo pues forma parte del marco de planeación que involucra a los RSU y es un instrumento de política ambiental local que integra, coordina e impulsa acciones para disminuir los riesgos ambientales, sociales y económicos derivados del cambio climático; cuenta con metas en materia de mitigación y adaptación al cambio climático. Entre los temas que destacan en este programa se encuentra el de RSU, al igual que la mayoría de los programas tiene una estructura basada en objetivos, estrategias y acciones a implementar. Con respecto a los RSU, su objetivo principal es reducir las emisiones de gases de efecto invernadero, ocasionadas por el tratamiento y la eliminación de los residuos sólidos en la Ciudad de México, proponiendo que haya procesamiento de residuos orgánicos, residuos inorgánicos y valorización energética, así como transformación, estimando una mitigación de 2.4 millones de toneladas equivalentes de dióxido de carbono acumuladas al año 2020. A diferencia del resto de los programas, el PACMM, les da particular importancia a las plantas de tratamiento de aguas residuales, que como anteriormente se ha observado en ningún programa de RSU se consideran las plantas de tratamiento de aguas, esto principalmente se debe a la cantidad de GEI que generan las plantas ya en conjunto con los RSU.

Los objetivos que básicamente están relacionados con los RSU, están enfocados principalmente en aprovechar los RSU a través de la generación de energía. Implementando distintas tecnologías, como la biodigestión, la valorización energética y otros procesos de transformación para el aprovechamiento de residuos dentro de la CDMX, con la finalidad de reducir emisiones de metano provenientes de su inadecuada disposición, ya que la eliminación de los residuos sólidos urbanos en la CDMX origina $12 \%$ de las emisiones del inventario de gases de efecto invernadero, mientras que el tratamiento biológico de residuos origina el $1 \%$.

Las metas en cuanto a residuos de este programa son congruentes con las cifras que maneja el Programa de GIR de la CDMX, entre las más importantes destacan las siguientes: Centros de Biodigestión que se construirán por fases, fase 1 (2015): Procesamiento de 500 t/día de materia orgánica Fase 2 (2018): Procesamiento de 2,500 t/día de materia orgánica que tengan una generación de 32 MWh. También, la construcción de Centros Regionales de Valorización Energética de los Residuos, donde en su fase 1 (2015), se pretende el procesamiento de 1,400 t/día de residuos inorgánicos y en su fase 2 (2018), se pretende el procesamiento de 4,100 t/día de residuos inorgánicos con una generación de 79 MWh. Además, se pretenden procesos de transformación de 2000 t/día y que el destino de residuos para el 2018 se distribuya de la siguiente forma: 1,000 t/día a planta de composta 3,000 t/día a recuperación 2,500 t/día a biodigestión 4,100t/día a valorización energética 2,000 t/día a transformación, para así poder lograr una mitigación potencial de 2.4 millones de t CO2eq acumuladas al año 2020.

Se puede observar, que las metas de este programa se encuentran claramente especificadas, sin embargo, aún sigue existiendo una brecha entre lo que se plasma en el papel y lo que realmente se logra hacer, especialmente porque la temporalidad de los gobiernos es muy corta para alcanzar dichos objetivos, quizá valdría la pena redactar metas más realistas y acorde con el periodo de gobierno.

\section{Programa Institucional de la Secretaría de Obras y Servicios (SOBSE) de la CDMX (Local)}

Anteriormente se mencionó que los programas institucionales son los documentos que desagregan a mediano y corto plazo los objetivos y metas de los programas sectoriales, que de igual forma regirán actividades en el ámbito de sus competencias y atribuciones respectivamente; conteniendo las 
políticas públicas necesarias para lograr lo dispuesto en el Programa General de Desarrollo de la CDMX para los años 2013-2018 y en los programas sectoriales.

Este programa se vuelve de importancia para el manejo de los RSU, ya que están directamente relacionados con la misión, visión y objetivo de este programa institucional. Por otro lado, se alinea con el Programa General de Desarrollo en el "Eje 4 Habitabilidad y Servicios, Espacio Público e Infraestructura" en el área de oportunidad 7 referente a los RSU, donde en el tema del manejo de los residuos sólidos se plantea llegar a tener en el 2018 una ciudad más limpia, más consciente y convencida de las ventajas que tiene el aprovechar, reciclar y valorizar los residuos sólidos urbanos. En síntesis, que los residuos sólidos dejen de ser basura para convertirse en una fuente de recursos, de materiales y de energía (Programa Institucional).

La meta sectorial de este apartado, se vuelve punto importante de análisis, ya que se pretendía que la SOBSE en una primera etapa pusiera en marcha 3 plantas de digestión anaerobia que en su conjunto procesarían 450 toneladas de residuos orgánicos por día; en una segunda etapa, hacia el cierre de la presente administración se supone debe escalarse este procesamiento hasta 2,500 toneladas por día con tecnología probada y respaldada internacionalmente. Adicionalmente, en una primera etapa se pensaba se procesarían 1,400 toneladas de residuos inorgánicos no recuperables o de rechazo, por medio de la valorización energética y posteriormente, en una segunda etapa se procesarían hasta 4,000 toneladas. Por otro lado, en coordinación con las delegaciones, se fortalecerían los mecanismos de acopio y reciclaje en los centros que se autoricen para ese propósito. Por último, en materia de la clausura, saneamiento, captura y aprovechamiento del biogás del relleno sanitario Bordo Poniente, se vigilará el proceso y cumplimiento de la concesión otorgada. A dos años del término de este mandato, no se ha podido echar andar ninguna planta, ya que son varias cuestiones técnicas que no lo han permitido; cómo, por ejemplo, la calidad del sustrato orgánico del que se piensa partir para la generación de biogás, ya que no se ha podido mantener estable debido a la gran variación en composición de materia orgánica que se recolecta en la CDMX. En principio, no existe la información necesaria por parte de los pobladores de cómo separar la basura, que como bien se ha visto, esa parte a la hora de la recolección se vuelve fundamental para posteriormente valorizarla.

Aprovechar al máximo posible las 12,740 toneladas de residuos sólidos que diariamente se generan en la metrópoli, a través de una estrategia integral para su manejo, la cual considera diversos procesos, también ha sido una meta planteada por éste programa que ha sido difícil de alcanzar, ya que con base en los datos reportados según el Inventario de RSU de la CDMX del 2014, se calcula que sólo se ha aprovechado $23.6 \%$ del total de RSU generados, por lo que según los indicadores propuestos en éste mismo programa, el restante $76.3 \%$ llega a sitios de disposición final en el mejor de los casos. Es decir, el total generado sólo es un estimado que calcula que se ha podido recolectar la cantidad de 8,080 toneladas (Inventario de RSU, 2014); eso nos hace pensar que las casi 3,000 toneladas faltantes se disponen en sitios clandestinos y/o además se hace una primera selección por parte de los choferes, de los camiones que recolectan la basura, donde se extrae el material de más valor.

Con visión metropolitana, avanzar en la instrumentación y operación de nuevas tecnologías que permitan la generación de energías alternativas como la generación de biogás, ha sido otro objetivo en este programa, que se ha intentado con la puesta en marcha y operación de la Planta de Composta ubicada en el Bordo Poniente. Esto también ha sido complicado de alcanzar, pues a dos años del término de este mandato no se ha podido generar biogás como se había planeado con anterioridad. 
Puede ser de gran importancia poder generar indicadores que evalúen cada una de las fases del manejo de los RSU, desde su generación hasta su disposición para que los tomadores de decisiones puedan modificar o proponer diferentes políticas públicas bajo una visión de GIRS.

\section{Programa Sectorial del Medio Ambiente y de Sustentabilidad 2013-2018 (Federal)}

Este programa contempla aspectos de gestión integral de residuos, muestra objetivos, metas y políticas públicas, para alcanzar: a) Una mayor educación ambiental sobre minimización, separación y aprovechamiento de residuos; b) Fortalecer las condiciones para la prestación del servicio público de limpia, su infraestructura y mobiliario; y c) Una visión megalopolitana avanzar en la instrumentación y operación de nuevas alternativas tecnológicas, encaminadas hacia el manejo, valorización y explotación de los residuos como fuente de generación de materiales complementarios, así como el uso de energía alterna

Los Programas Sectoriales son los documentos que desagregan en objetivos y metas de mediano plazo los lineamientos contenidos en el Programa General de Desarrollo para una materia específica de desarrollo y que regirá las actividades del sector administrativo que corresponda y se realizarán con base en las orientaciones generales establecidas en los componentes rectores de la planeación para las áreas que determine el Comité de Planeación en la instrumentación del Programa General.

En el caso del Programa Sectorial de Medio Ambiente mantiene entre sus objetivos los siguientes puntos:

- Objetivo 1 Promover y facilitar el crecimiento sostenido y sustentable de bajo carbono con equidad y socialmente incluyente

- Objetivo 2 Incrementar la resiliencia a efectos del cambio climático y disminuir las emisiones de compuestos y gases de efecto invernadero

- Objetivo 3 Fortalecer la gestión integrada y sustentable del agua, garantizando su acceso a la población y a los ecosistemas.

- Objetivo 4 Recuperar la funcionalidad de cuencas y paisajes a través de la conservación, restauración y aprovechamiento sustentablemente del patrimonio natural.

- Objetivo 5 Detener y revertir la pérdida de capital natural y la contaminación del agua, aire y suelo

- Objetivo 6 Desarrollar, promover y aplicar instrumentos de política, información investigación, educación, capacitación, participación y derechos humanos para fortalecer la gobernanza ambiental.

\subsubsection{Normas Oficiales Mexicanas}

Las Normas Oficiales Mexicanas (NOM) son regulaciones técnicas de observancia obligatoria expedidas por las Dependencias de la Administración Pública Federal, que establecen reglas, especificaciones, atributos, directrices, características o prescripciones aplicables a un producto, proceso, instalación, sistema, actividad, servicio o método de producción u operación, así como aquellas relativas a terminología, simbología, embalaje, marcado o etiquetado y las que se refieran a 
su cumplimiento o aplicación (SEMARNAT, 2015). En este particular caso, las normas que a continuación se especifican regulan el manejo de RSU.

NOM-083-SEMARNAT-2013: Especificaciones de protección ambiental para la selección del sitio, diseño, construcción, operación, monitoreo, clausura y obras complementarias de un sitio de disposición final de residuos sólidos urbanos y de manejo especial.

En general, esta norma proporciona especificaciones y criterios para seleccionar lugares adecuadamente para usarlos como sitios de disposición final de RSU, o en el caso de que ya se encuentre un sitio abierto, mantenerlo dentro de los parámetros adecuados, entre los criterios que esta norma presenta se encuentran, por ejemplo, su clasificación, que está basada en el tonelaje que reciba día a día. La clasificación es por tipo A, B, C Y D, donde A es mayor a 100 toneladas recibidas por día, B de 50 hasta $100, \mathrm{C}$ de 10 y menor a 50 y D menor a 10 ton por día. Otro ejemplo de especificación es la ubicación con respecto a la distancia a la que debe permanecer un sitio de disposición final, con respecto a la población, esto con la finalidad de evitar la contaminación del suelo, aire y agua provocada por la mala disposición de la basura, especialmente cundo son tiraderos a cielo abierto, también con el objetivo de mejorar las condiciones de salud de la población, al eliminar posibles fuentes de infección transmitidas por moscas, ratas u otros animales como insectos, además de disminuir los riesgos de incendio y explosiones en los tiraderos existentes y en general esta norma tiene el objetivo de inducir un mejor manejo integral de los residuos, desde la minimización de su generación, mejora de la eficiencia en la recolección, transporte, transferencia y disposición final. Desde luego el enfoque de esta norma está basado en la última fase del manejo; es importante no perder de vista que todas las fases se encuentran interrelacionadas. Finalmente, un aspecto importante también es el de mejorar las condiciones de la localidad (paisaje), lo que puede hacerla más atractiva para la inversión y para los turistas.

Otro aspecto importante es que esta norma debe cumplirse bajo la vigilancia de autoridades ambientales capacitadas para ello, estas autoridades pertenecen a las tres órdenes de gobierno y todos los sitios de disposición final deberán apegarse a la norma bajo los siguientes puntos principalmente:

- Es de vital importancia obtener toda la información relativa al servicio de disposición final con que en la actualidad cuente el municipio. Esto incluye las características del terreno, cantidad de RSU y de manejo especial que ingresan a él diariamente, infraestructura con que cuenta, forma de operación, vida útil, etc.

- Conocer las toneladas por día de RSU y de manejo especial que entran al sitio de disposición final actual, sólo así será posible establecer la categoría de relleno sanitario de acuerdo con la norma, y con ello poder conocer los requerimientos y criterios exigidos para cada modalidad.

- Comparar la información real con los criterios de la norma, a criterio de los encargados municipales, si el sitio de disposición final con que se cuenta actualmente cumple con todos los requisitos, entonces podrá solicitarse bajo la vigilancia de las autoridades ambientales federales y estatales en cualquier momento y saber que no existen anomalías en cuanto a ubicación del sitio, protección al suelo y acuíferos, forma de operación, monitoreos ambientales, etc. En el caso de que no se cumplan los criterios que marca la norma, el municipio deberá diseñar un plan para regularizar su sitio de disposición final y al mismo tiempo comenzar con el proceso para establecer un relleno sanitario de acuerdo con los criterios de la NOM.

En general, la norma da a detalle los criterios que deben tener los sitios de disposición final; sin embargo, es importante recordar que existen sitios de disposición final clandestinos, y obviamente no cumplen con el mínimo de requerimientos establecidos por esta norma, incluso existen diversos 
sitios que se encuentran es revisión continuamente por estar fuera de la norma, y que son sitios supuestamente establecidos, por lo que pudiera ser importante la actuación de la sociedad en el sentido de denunciar todos aquellos sitios que no cuenten con los requerimientos establecidos por la norma, por lo que por otra parte es importante que se informe a los ciudadanos de aquellos requerimientos básicos con los que debe contar un sitio de disposición final para que cualquier ciudadano común pueda exigir que estos se cumplan en el caso de que haya un sitio de disposición final cerca de su vecindario o en él.

NOM-098-SEMARNAT-2002: Protección ambiental-Incineración de residuos, especificaciones de operación y límites de emisión de contaminantes. Secretaría de Medio Ambiente y Recursos Naturales.

Esta norma, establece claramente que la incineración de residuos provenientes de cualquier actividad, incluyendo los residuos peligrosos, produce emisiones que provocan la contaminación al ambiente y con ello dañan a los ecosistemas y la salud humana; por este motivo esta norma demanda la adopción de acciones preventivas que proporcionen condiciones de operación adecuadas y valores límite de emisión aceptables, en particular en lo que se refiere a las dioxinas y furanos. Estas disposiciones aplican a los incineradores de todo tipo de residuos y están sujetos al cumplimiento de las obligaciones que derivan del Convenio de Estocolmo. En general, el objetivo de esta norma es establecer las especificaciones de operación, así como los límites máximos permisibles de emisión de contaminantes a la atmósfera para las instalaciones de incineración de residuos de todo tipo. A su vez, en ella se establece que es de observancia obligatoria aplicable en todo el territorio mexicano, con excepción de los mares territoriales en donde la nación ejerza su jurisdicción, para todas aquellas instalaciones destinadas a la incineración de residuos, excepto de hornos crematorios, industriales y calderas que utilicen residuos como combustible alterno, es importante aclarar que no aplica para la incineración de residuos radiactivos, para éstos se aplicarán las disposiciones que al respecto emita la Comisión Nacional de Seguridad Nuclear y Salvaguardias.

En general el convenio de Estocolmo, se refiere a los incineradores de desechos como una fuente contaminante (en el anexo de dicho convenio se presenta un listado de todo tipo de sustancias y productos químicos considerados como contaminantes), por lo que al considerar las propuestas de construcción de nuevos incineradores de desechos, debe ser objeto de atención prioritaria minimizar la generación de los desechos que piensan incinerarse, alternativas que incluyan: recuperación de recursos, reúso, reciclado, separación de los desechos y promoción de productos que generan menor cantidad de los mismos. Deben contemplarse prioritariamente, asimismo, los abordajes que previenen la formación y liberación de contaminantes orgánicos persistentes. La incineración se vuelve necesaria con los objetivos potenciales de: reducción de volumen, recuperación de energía, destrucción y minimización de constituyentes peligrosos, desinfección y reúso de algunos residuos. Por otro lado, la norma muestra especificaciones para cálculo de emisiones, especificaciones de mediciones, límites permisibles, procedimientos de muestreo, etc.

Es importante reflexionar, sobre la invitación que se hace en el convenio de Estocolmo, que corresponde a tratar de evitar en la medida de lo posible a llegar al punto de la incineración. Esta visión viene particularmente de una GIRS bien implementada, o mejor aún de una gestión sustentable de los RSU. 


\subsubsection{Normas Mexicanas}

Estas normas de carácter voluntario son documentos donde se especifican las características que los productos tienen en función de sus cualidades y los métodos de prueba que determinan esas características permitiendo definir diferentes grados de calidad. Por lo cual, permite que los productos se puedan diferenciar claramente en el mercado y permite la transparencia en las operaciones comerciales tanto a nivel nacional como internacional. Éstas deben ser tomadas como referencia por las autoridades judiciales o administrativas competentes en sus resoluciones en controversias de carácter civil, mercantil o administrativo. En el caso de RSU se contemplan las siguientes normas (Secretaría de Economía, 2015).

NMX-AA-015-1985 Protección al ambiente - Contaminación del suelo - Residuos sólidos municipales - Muestreo - Método de cuarteo. Como su nombre lo indica esta norma mexicana indica básicamente los procedimientos para determinar el método por cuarteo para residuos sólidos municipales y la obtención de muestras para los análisis en el laboratorio.

NMX-AA-016-1984 Protección al ambiente - Contaminación del suelo - Residuos sólidos municipales - Determinación de humedad: Esta Norma Mexicana establece el método llamado de Estufa que determina el porcentaje de la humedad, contenido en los residuos sólidos municipales; se basa en la pérdida de peso que sufre la muestra cuando se somete a las condiciones de tiempo y temperatura que se establecen en esta norma, considerando que dicha pérdida se origina por la eliminación de agua.

NMX-AA-018-1984 Protección al ambiente - Contaminación de suelo - Residuos sólidos municipales - Determinación de cenizas. Esta norma determina el procedimiento para determinar la cantidad de cenizas provenientes de los RSU

NMX-AA-019-1985 Protección al ambiente - Contaminación del suelo - Residuos sólidos municipales - Peso volumétrico "in situ": Esta Norma Mexicana, establece un método para determinar el peso volumétrico de los residuos sólidos municipales en el lugar donde se efectuó la operación de "cuarteo".

NMX-AA-021-1985 Protección al ambiente - Contaminación del suelo - Residuos sólidos municipales - Determinación de materia orgánica: La presente Norma Mexicana establece el método para la determinación de materia orgánica en los residuos sólidos municipales

NMX-AA-022-1985 Protección al ambiente - Contaminación del suelo - Residuos sólidos municipales - Selección y cuantificación de subproductos: Esta Norma Mexicana establece la selección y el método para la cuantificación de subproductos contenidos en los Residuos Sólidos Municipales.

NMX-AA-024-1984 Protección al ambiente - Contaminación del suelo - Residuos sólidos municipales - Determinación de nitrógeno total: Esta Norma Mexicana establece el método Kjeldabl para determinar la cantidad de nitrógeno total contenido en los Residuos Sólidos Municipales. Por este procedimiento se convierten todos los componentes del nitrógeno oxidados tales como nitrato a nitritos a nitrógeno reducido a sulfato de amonio. 
NMX-AA-025-1984 Protección al ambiente - Contaminación del suelo - Residuos sólidos Determinación del PH - Método potenciométrico: La presente norma establece el método potenciométrico para la determinación del valor del $\mathrm{pH}$ en los residuos sólidos. El cual se basa en la actividad de los iones hidrógeno presentes en una solución acuosa de residuos sólidos al 10\%.

NMX-AA-031-1976 Determinación de azufre en desechos sólidos: La presente Norma establece el método para la determinación de azufre transformado en ácido sulfúrico durante la combustión de desechos sólidos en el interior de una bomba calorimétrica, para fin de corrección.

NMX-AA-032-1976 Determinación de fosforo total en desechos sólidos (método del fosfavanadomolibdato): Esta Norma establece el método fotométrico para la determinación de fósforo total contenido en desechos sólidos.

NMX-AA-033-1985 Protección al ambiente - Contaminación del suelo - Residuos sólidos municipales - Determinación de poder calorífico superior: Esta Norma Mexicana especifica un método de prueba para determinar el poder calorífico superior de los residuos sólidos municipales, empleando una bomba calorimétrica de los diferentes tipos para planear y diseñar los sistemas adecuados de disposición final de los mismos.

NMX-AA-052-1985 Protección al ambiente - Contaminación del suelo - Residuos sólidos municipales - Preparación de muestras en el laboratorio para su análisis: Esta Norma Mexicana, establece el método de preparación de muestras en el laboratorio para su análisis.

NMX-AA-061-1985 Protección al ambiente - Contaminación del suelo - Residuos sólidos municipales - Determinación de la generación: Esta Norma Mexicana especifica un método para determinar la generación de residuos sólidos municipales a partir de un muestreo estadístico aleatorio. Para efectos de aplicación de esta norma los residuos sólidos municipales se subdividen en domésticos (que son los generados en casas habitación) y en no domésticos (generados fuera de las casas habitación). También en esta norma se especificael procedimienrto para determinar la generación per cápita de RSU.

NMX-AA-067-1985 Protección al ambiente - contaminación del suelo -Residuos sólidos municipales - Determinación de la relación carbono / nitrógeno: La presente Norma Mexicana especifica un método para la determinación de la relación Carbono/Nitrógeno de los Residuos Sólidos Municipales, para planear y diseñar los sistemas adecuados de disposición final de los mismos.

NMX-AA-068-1986 Protección al ambiente - Contaminación del suelo - Residuos sólidos municipales - Determinación de hidrogeno a partir de materia orgánica: Esta Norma Mexicana especifica un método para la determinación de Hidrógeno de los Residuos Sólidos Municipales, para planear y diseñar sus sistemas de disposición final.

NMX-AA-080-1986 Contaminación del suelo - Residuos sólidos municipales - Determinación del porcentaje de oxígeno en materia orgánica: La presente norma específica un método para la determinación del porcentaje de Oxígeno en Materia Orgánica presente en Residuos Sólidos Municipales, que se evalúa por la transformación a Monóxido de Carbono, que posteriormente reacciona con Pentóxido de Yodo, formando Yodo absorbido en solución alcalina para ser valorada con Tiosulfato de Sodio, con el objeto de diseñar sus sistemas de manejo y disposición final. 
NMX-AA-091-1987 Calidad del suelo - Terminología: La presente Norma Mexicana establece un marco de referencia en cuanto a los términos más empleados en el ámbito de la prevención y control de la contaminación del suelo, originada por residuos sólidos.

NMX-AA-092-1984 Protección al ambiente - Contaminación del suelo - Residuos sólidos municipales - Determinación de azufre: La presente norma establece el procedimiento para calcular la cantidad de azufre, transformándolo en sulfato de sodio, mediante el tostado de los residuos sólidos en presencia de la oxilíta

NMX-AA-094-1985 Protección al ambiente - Contaminación del suelo - Residuos sólidos municipales - Determinación de fosforo total: Esta Norma Mexicana especifica un método de prueba para determinar el fósforo total contenido en los Residuos Sólidos Municipales y no es aplicable a productos que generan soluciones coloridas como son las del tipo denominado escorias básicas.

\subsubsection{Normas Ambientales de la CDMX}

Existen también Normas Ambientales que deben ser cumplidas para la CDMX, entre las que destacan las siguientes, por su relación que tienen con los RSU. Es importante mencionar que estas normas son de carácter obligatorio para la CDMX. Estas nuevas normas son:

NADF-007-RNAT-2013 Clasificación y Especificaciones de Manejo para Residuos de la Construcción y Demolición, en el Distrito Federal: A través de la presente Norma Ambiental se establece la clasificación y especificaciones para el manejo de los residuos de la construcción y demolición enla CDMX; buscando fomentar el manejo adecuado de estos residuos, así como promover su reúso y reciclaje. El objetivo de esta norma es establecer la clasificación y especificaciones de manejo de los residuos de la construcción y demolición para optimizar y fomentar su aprovechamiento y minimizar su disposición final inadecuada. Es importante aclarar también que, La presente Norma Ambiental es de aplicación obligatoria en todo el territorio de la CDMX para los generadores de los residuos de la construcción y demolición, y prestadores de servicio que intervienen en su generación, recolección, transporte, aprovechamiento o disposición final.

NADF-020-AMBT-2011, que establece los requerimientos mínimos para la producción de composta a partir de la fracción orgánica de los residuos sólidos urbanos, agrícolas, pecuarios y forestales, así como las especificaciones mínimas de calidad de la composta producida y/o distribuida en la CDMX: Con la presente Norma Ambiental se busca establecer la gestión integral y valorización de la fracción orgánica de los residuos sólidos, esto en condiciones controladas de producción para fomentar un mercado de composta; contribuyendo con la práctica de la agricultura ecológica y desincentivar la extracción de tierra en Suelo de Conservación. Además, el objetivo de esta norma es establecer los requisitos mínimos para la producción de composta a partir de la fracción orgánica de los RSU, así como la generada por las actividades agrícolas, forestales y pecuarias, siempre que estos últimos sean de carácter biodegradable, que no afecten la calidad del producto final ni representen riesgo para la salud humana y el ambiente. La presente Norma es de observancia obligatoria para las personas físicas, morales y Dependencias Gubernamentales que produzcan composta proveniente de la fracción orgánica de los RSU y otros señalados en esta Norma. Asimismo, aplica para la composta que se produzca, se aplique y/o se comercialice en la CDMX. Quedaran exentos del cumplimiento de esta Norma quienes produzcan composta para autoconsumo a partir de 
los residuos orgánicos que ellos mismos generan, siempre que dichos residuos no rebasen la cantidad de $500 \mathrm{~kg} /$ día o un volumen de $1 \mathrm{~m} 3 /$ día, de lo contrario debe ajustarse a los criterios de la presente Norma.

NADF-024-AMBT-2013 Que establece los criterios y especificaciones técnicas bajo los cuales se deberá realizar la separación, clasificación, recolección selectiva y almacenamiento de los residuos de la CDMX: En los residuos sólidos urbanos y de manejo especial se aplicará el principio de "Basura Cero", el cual consiste en disminuir, aprovechar y valorizar al máximo la cantidad de residuos que actualmente llegan a sitios de disposición final, a través de la reutilización, reciclaje y aprovechamiento energético; en su mayoría éstos están constituidos por materiales que pueden ser seleccionados con facilidad para usarse como materias primas recuperables tales como: orgánicos biodegradables, papel, cartón, vidrio, plásticos, metales, textiles, entre otros. Para el procesamiento de dichos materiales es necesario un paso previo; la separación de los mismos, la cual debe hacerse en condiciones específicas que permitan una adecuada selección de ellos a través de una separación primaria, primaria avanzada y secundaria. Con la finalidad de fomentar en la sociedad la participación y encauzarla en el cumplimiento de las distintas disposiciones en materia de manejo de residuos sólidos de manera responsable, y como parte de la política ambiental que promueve el Gobierno de la CDMX, se pretende a través de la presente Norma Ambiental, establecer los criterios y especificaciones técnicas bajo las cuales se deberá realizar la separación, clasificación, recolección selectiva y valorización de los residuos sólidos, para que se lleve a cabo de acuerdo a lineamientos técnicos que garanticen una adecuada separación primaria, primaria avanzada y secundaria de los materiales, de tal forma que puedan ser valorizados para su reincorporación nuevamente a procesos de producción, reduciendo la cantidad que llega a sitios de disposición final. El objetivo primordial de esta norma es establecer los criterios y especificaciones técnicas bajo las cuales se deberá realizar la separación, clasificación, recolección selectiva y almacenamiento para el aprovechamiento y valorización de los residuos generados en la CDMX. La presente Norma Ambiental es de observancia obligatoria para generadores de residuos, personas físicas o morales, de carácter público o privado, dependencias, entidades, órganos políticos administrativos desconcentrados y en general para toda la Administración Pública de la CDMX, así como asociaciones o gremios que participen en cualquier momento, forma o proceso de la gestión integral de los residuos de competencia local, ubicados en la CDMX.

Es importante no sólo conocer el marco jurídico de nuestro país, sino poder observarlo en orden de entender o percibir las fortalezas y debilidades del mismo con respecto a cada una de las fases que contempla el manejo de RSU de la CDMX. La Figura 13 muestra una relación de cada una de las leyes, códigos, reglamentos y normas que regulan los RSU, ya sea de manera explícita o implícita. Como ejemplo, en el caso de la Constitución Política de los Estados Unidos Mexicanos en sus artículos 4, 25, 73, y 121 la inclusión del manejo de RSU no viene especificado de manera explícita, sino se encuentra de manera implícita al referirse a que todos los ciudadanos del país tienen derecho a la protección de la salud, a que el estado propicie un desarrollo sustentable y a la protección del ambiente. En el caso del Artículo 115, la inclusión del manejo de RSU viene de manera explícita, ya que habla de la obligación de los gobiernos locales de llevar a cabo las cinco fases del manejo de los residuos. Es así como se recorre el marco jurídico, pudiendo observar de qué manera se incluyen el manejo de los RSU en el marco jurídico mexicano.

Figura 3.13. Inclusión del manejo de RSU en el marco jurídico mexicano 


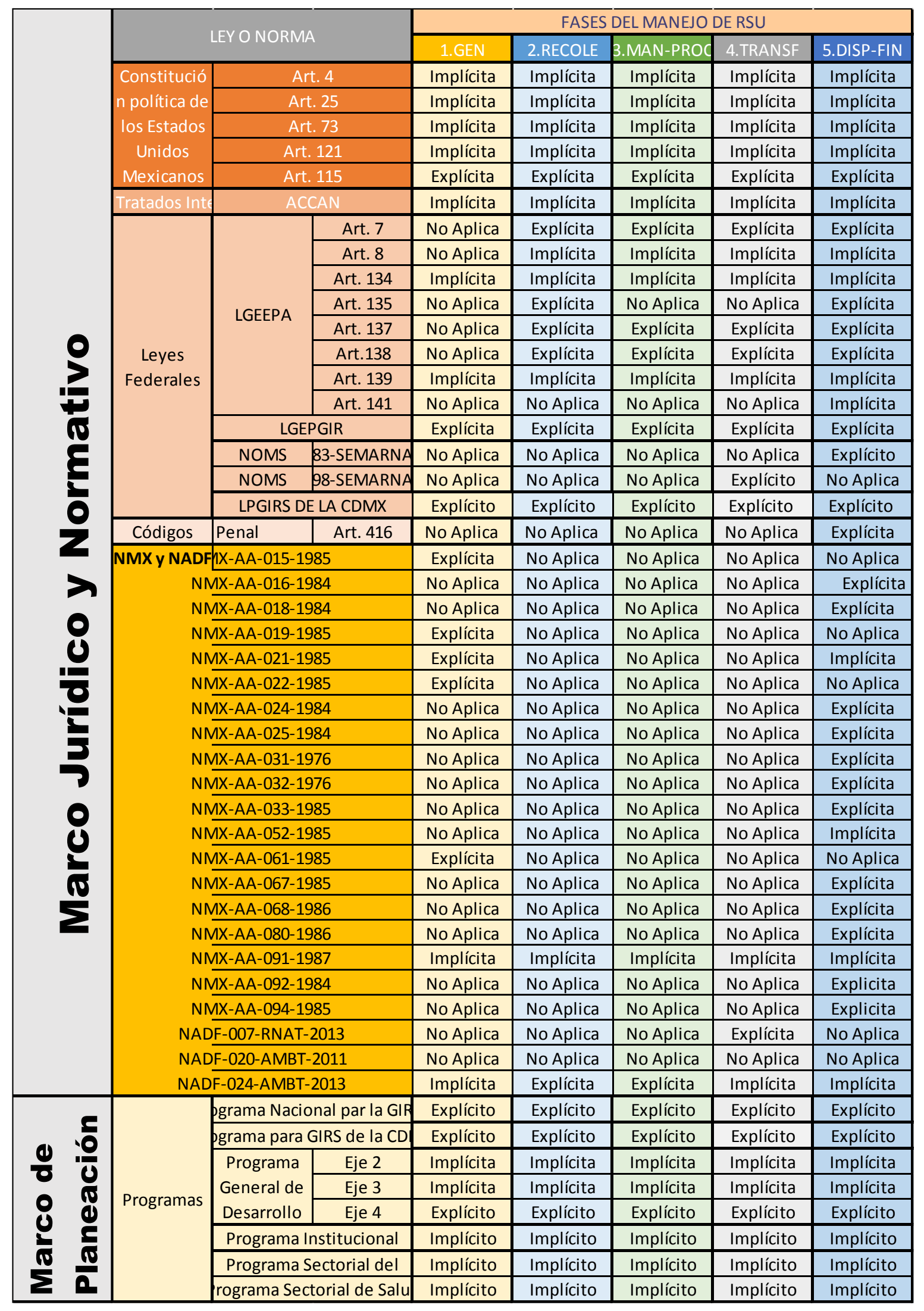


En general, se observa que la gran mayoría de las normas mexicanas, que son de opcional aplicación, están enfocadas solamente a cómo los procedimientos deben realizarse para determinar ciertas características en lo RSU ya generados y que se encuentran en sitios de disposición final, incluso el procedimiento de cómo se debe estimarse la generación de RSU en cierta población se encuentra descrito en estas normas. (ver Figura 3.13) Por otro lado, las normas ambientales para la CDMX NADF, ahora la Ciudad de México, describen técnicas y procedimientos que en el caso de la CDMX si son de aplicación obligatoria, según lo escrito en las mismas. Se puede observar que en el caso de la CDMX, se cuenta con un norma que regula la transformación de los RSU de origen orgánico, como es el caso de la composta y además en el caso de la NADF-024 se describe la manera en que estos deben ser separados desde su origen (que simplemente es en orgánico e inorgánico), además que dice que todas las personas están obligadas a llevarlo a cabo; sin embargo la realidad es muy diferente, como en los anteriores capítulos se ha descrito, la separación desde la fuente de origen, en el caso de los RSU de origen doméstico, aun es un caos; sin perder de vista que alrededor de $50 \%$ de los RSU generados en la CDMX proviene de esta fuente de origen. Esto nos lleva a reflexionar sobre un punto muy importante: ¿Es el marco jurídico y normativo, ambientalmente hablando, realmente sólido en México? Si bien, el análisis meticuloso de la normatividad ambiental mexicana se sale de los objetivos de esta investigación, es importante poder al menos observar que es lo que está ocurriendo, ya que no solo se trata de cuestiones de RSU, sino en general la legislación ambiental en México no ha sido lo suficientemente sólida para poder proteger y gestionar el medio ambiente en general, pues tan solo basta ver el deterioro y escases de recursos con los que actualmente se vive.

Por esta razón es importante considerar un fortalecimiento en la gestión ambiental y como consecuencia contantes actualizaciones en su marco jurídico ambiental en México. Es decir, la revisión y análisis de las acciones que se llevan a cabo para promover y vigilar la aplicación y el cumplimiento de la normatividad ambiental en México, debe ubicarse dentro de dos procesos que actualmente se presentan en el país: el fortalecimiento de la gestión ambiental y la consecuente actualización de la legislación en la materia. No se puede negar que ha habido progreso y modificaciones en el marco normativo, especialmente en las últimas tres décadas (Brañes 2000), sin embargo estas no han sido suficientes, la sociedad en general constantemente muestra interés en los temas ambientales, especialmente ha mostrado preocupación por detener y revertir fenómenos y situaciones que propician el deterioro del ambiente, el agotamiento de los recursos naturales y por lo tanto afectaciones a las personas y sus bienes, lo que es prueba infalible de que el marco normativo requiere de constante evolución. Uno de los retos más importantes que se pueden observar, en el caso de los RSU es la regulación de acciones que permitan la participación del poder judicial en la solución de conflictos ambientales. Es decir, no se aprecia nada en el código civil o penal que pueda tener consecuencias para los ciudadanos comunes que no puedan gestionar adecuadamente sus residuos generados, ni tampoco hay penalización por producir mayor cantidad de residuos, ambos casos podrían considerarse como un delito en contra del medio ambiente; sin embargo, pasas desapercibidos.

Esta observación del marco jurídico mexicano con respecto al manejo de los RSU, nos ayudará a analizar las fortalezas y debilidades del mismo para posteriormente poder hacer un análisis de resultados. Sin embargo, es pertinente aclarar que hay una brecha importante entre lo que se dice que debe hacerse, según el marco jurídico-normativo, y lo que realmente se hace en nuestro país, en particular en el caso de la CDMX. 
Es muy importante no perder de vista las ideas que se han generado a través de los primeros capítulos de esta investigación. Estos nos ayudan a adquirir bases sólidas para alcanzar el objetivo general de esta investigación: el cual consiste en evaluar la eficacia del manejo de los residuos sólidos en la CDMX desde su generación hasta su disposición final para el año 2015, determinando en qué medida cumplen con los objetivos propuestos por el modelo de gestión integral, así como con base en aquellos objetivos planteados en el marco normativo y de planeación de la CDMX para el manejo de los residuos sólidos en sus fases de generación, recolección, manipulación-procesamiento, transformación y disposición final. Así que una vez teniendo un panorama más amplio es preciso comenzar con el desarrollo de la metodología para dicha evaluación. 


\section{CAPÍTULO IV}

\section{Modelo de evaluación de la eficacia del manejo de RSU}

En el capítulo III se hizo un análisis del marco normativo y de planeación, se identificaron objetivos, metas y estrategias de ambos marcos, además de que identificaron les leyes, acuerdos internacionales, normas, etc., pero todos bajo el enfoque que contempla las cinco fases del manejo de RSU; Generación, recolección, manipulación y procesamiento, transformación y disposición final. Esto se llevó a cabo con el fin de obtener las herramientas necesarias para poder generar el modelo de evaluación de la eficacia del manejo de lo RSU y desarrollar la metodología que a continuación se describirá. Por otro lado, también se hace un análisis de los indicadores, para poder entender los resultados finales, ya que como anteriormente se ha mencionado, el modelo construido para la evaluación de la eficacia del manejo de los RSU en la CDMX, arrojará indicadores en una escala del 1 al 10, como lo marca el sistema educativo en México, para mayor compresión de los lectores.

\subsection{Componentes para medir la eficacia en el manejo de los RSU}

Es necesario, primeramente, identificar los componentes que nos permitirán medir la eficacia en el manejo de los RSU de la CDMX, los cuales incluyen las partes más importantes del marco normativo y de planeación, con un contraste de lo que la GIRS plantea, para poder identificar que tanto se cumples los objetivos que esta última parte plantea, con respecto al marco jurídico de la CDMX.

\subsubsection{La GIRS, el marco normativo y de planeación de la CDMX}

El modelo económico global actual ha promovido un acelerado desarrollo industrial, acompañado de un incremento de la población urbana; ambos han aumentado el deterioro ambiental que enfrentan los países. La creciente preocupación a nivel mundial sobre los problemas ambientales actuales se ha convertido en un tema prioritario en las reuniones internacionales convocadas por la Organización de las Naciones Unidas (ONU); resultado de estas reuniones se han realizado tratados internacionales que establecen objetivos y metas hacia un desarrollo sustentable. Uno de los sectores más importantes en el desarrollo sostenible es el de los RSU; estos suelen ser un problema para la mayoría de los países en el mundo, aunque en algunos casos, gracias a la valorización de dichos recursos, se han aprovechado para la generación de energía e ingresos económicos, reduciendo el deterioro ambiental al que están expuestos. Bajo este contexto, vale la pena reflexionar sobre lo que estos países han realizado en materia de RSU a partir de constantes evaluaciones y monitoreo de sus procesos y mecanismos, a fin de optimizar el manejo de sus residuos.

Figura 4.1. Evaluación del manejo de los RSU 


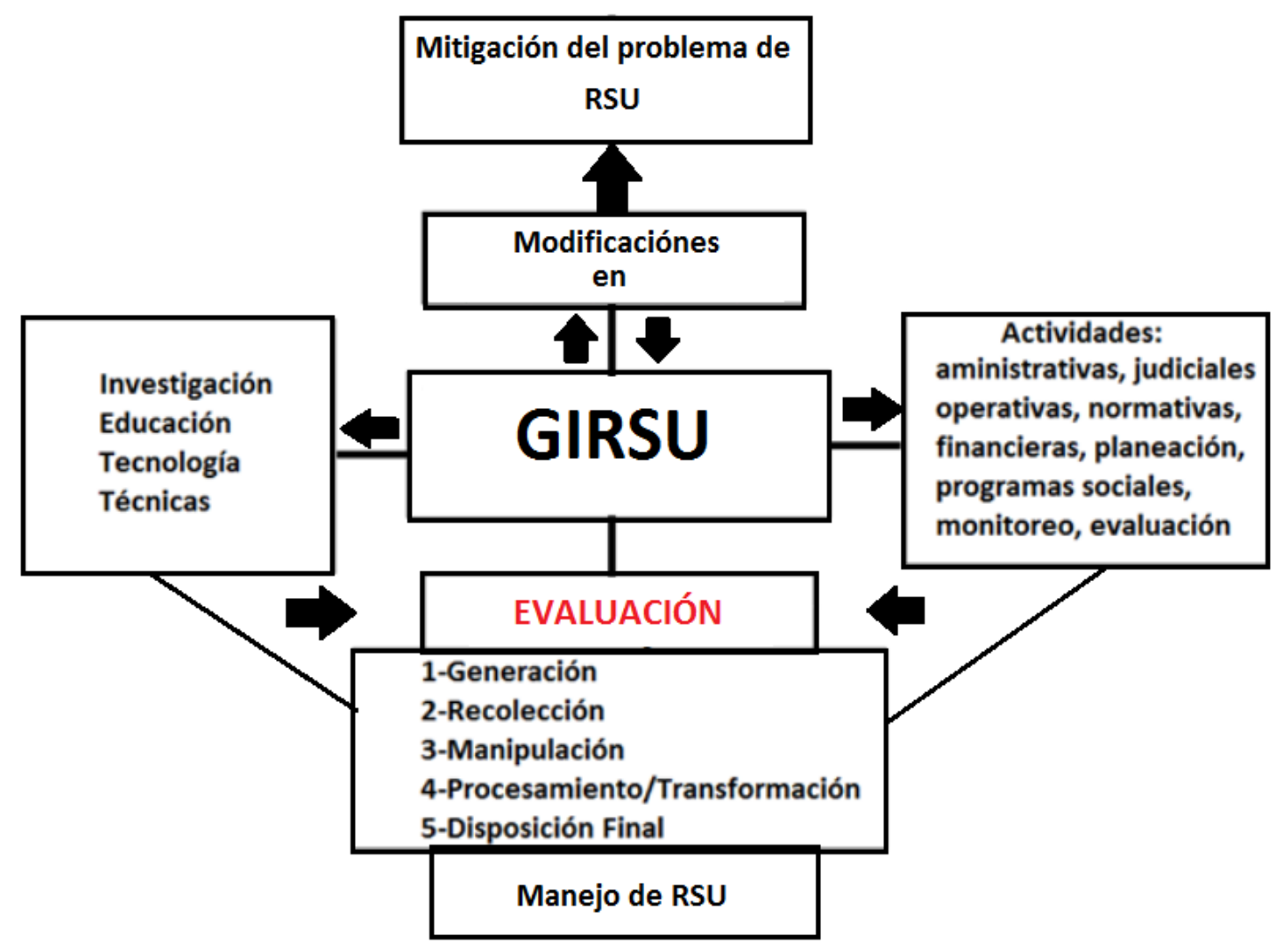

Fuente: Elaboración propia.

Uno de los pasos más importantes para que un determinado proceso mejore, parte de una evaluación constante del mismo. En el caso de los RSU, su manejo puede ser considerado como un proceso conformado por cinco fases, como lo muestra la Figura 4.1; que implican el manejo de los residuos desde que se originan hasta que se disponen finalmente. El manejo, como en anteriores capítulos se ha mencionado, es la parte medular de la GIRS, de esta forma, si una evaluación arroja que la generación de los RSU se ha incrementado desmedidamente, y que además no ha cumplido con las metas y objetivos esperados con respectos a esa primera fase del manejo, entonces las tecnologías, la investigación, el marco jurídico y de planeación, y todos los demás atributos que la GIRS comprende deben modificarse con relación a la "generación"; lo anterior, con el fin de mejor la eficacia de la GIRS, y por ende, alcanzar los objetivos planteados.

En esta investigación, se realizó una evaluación del manejo de los RSU en todas sus fases y en el periodo de 2015; esta evaluación tiene la finalidad de aportar nuevas ideas a los tomadores de decisiones, mediante una serie de indicadores para cada fase y para el manejo en sus cinco fases. Dichos indicadores permiten conocer y comprender en qué situación se encuentra cada fase en términos de su nivel de cumplimiento de los objetivos definidos tanto por la GIRS y del marco normativo de la CDMX, por ende,

Bajo este contexto es pertinente preguntarse qué es evaluar. Según la Real Academia Española, evaluar tiene que ver con señalar, estimar, apreciar, o calcular el valor de algo como, por ejemplo, valorar conocimientos, aptitudes o rendimientos. Por lo que en general, en el ámbito de la gestión, una evaluación corresponde a estudios o revisiones técnicas que, haciendo uso de un conjunto de información ordenada y relacionada según un marco metodológico, tienen por finalidad construir 
valoraciones de aspectos concretos de la gestión para poder hacer recomendaciones respecto a hallazgos significativos. La evaluación apunta directamente a la mejora, ya sea en el diseño o implementación de lo que se está evaluando, por ejemplo, en el caso de evaluar programas públicos (PP), la evaluación básicamente tiene dos objetivos de retroalimentación permanente: (1) en fases de diseño o de ejecución del programa, aporta al proceso de aprendizaje institucional y de (mejoramiento del desempeño del PP, y (2) también tiene como objetivo informar, a partir de criterios técnicos, el proceso de toma de decisión sobre la asignación de recursos públicos (Winchester, 2010).

En el caso de esta investigación, lo que se pretende es evaluar la eficacia en el manejo de los RSU en cada una de sus fases. En el caso de la eficacia, es importante tener este concepto claro, ya que a menudo existe confusión con el termino eficiencia. La eficacia tiene que ver con la capacidad de cumplir con los objetivos a los que se desea llegar; mientras que la eficiencia tiene que ver con la capacidad de lograr un objetivo en cuestión, con el mínimo de recursos posibles o en el menor tiempo posible. Es importante tener clara la diferencia, ya que, en el caso particular de esta investigación, se evaluará la eficacia con la que se han cumplido los objetivos en cada una de las fases del manejo de los RSU, desde su generación hasta su disposición final. Estos objetivos están fundamentados básicamente por el marco teórico y jurídico mexicano, ambos se detallaron en el capítulo dos y tres respectivamente.

A manera de resumen se generó la siguiente tabla, en la que se pueden observar los componentes para medir la eficacia en el manejo de los RSU respecto a su marco normativo y de planeación versus el enfoque de GIRS. Ambos aspectos se analizaron detalladamente en el capítulo dos y tres; sin embargo, resulta importante poder extraer aspectos claves para realizar la evaluación considerando tanto el enfoque general de la GIRS, así como el marco normativo y de planeación resumidos en la Tabla 4.1

Tabla 4.1 Resumen de metas y objetivos planteados en el marco normativo y de planeación en la CDMX.

\begin{tabular}{|c|c|c|}
\hline $\begin{array}{c}\text { FASES DEL } \\
\text { MANEJO }\end{array}$ & $\begin{array}{c}\text { ENFOQUE GENERAL DE } \\
\text { LA GIRS }\end{array}$ & $\begin{array}{l}\text { MARCO NORMATIVO Y DE } \\
\text { PLANEACIÓN }\end{array}$ \\
\hline GENERACIÓN & $\begin{array}{l}\text { La generación de RSU debe } \\
\text { ser reducida al máximo } \\
\text { posible, evitando así que } \\
\text { incrementen los kilogramos } \\
\text { de RSU que cada habitante } \\
\text { genera diariamente. }\end{array}$ & $\begin{array}{l}\text { Generar estrategias y programas que } \\
\text { ayuden a fomentar el consumo } \\
\text { sustentable y consciente, para as } \\
\text { reducir la cantidad total de RSU que se } \\
\text { generan anualmente. }\end{array}$ \\
\hline RECOLECCIÓN & $\begin{array}{l}\text { Se debe recolectar de manera } \\
\text { separada y organizada, el } \\
100 \% \text { de los RSU generados. } \\
\text { Esto debe hacerse con rutas } \\
\text { establecidas y bien diseñadas } \\
\text { para aumentar la eficiencia en } \\
\text { la recolección. }\end{array}$ & $\begin{array}{l}\text { Compra de camiones para modernizar } \\
\text { el sistema de recolección en la ciudad } \\
\text { establecer horarios de recolección } \\
\text { selectiva, realizar recolección } \\
\text { separada, establecer programas para } \\
\text { enseñar a los ciudadanos a separar } \\
\text { residuos, y se prohíbe que cualquier } \\
\text { persona tenga accesos a los RSU } \\
\text { recolectados. }\end{array}$ \\
\hline
\end{tabular}




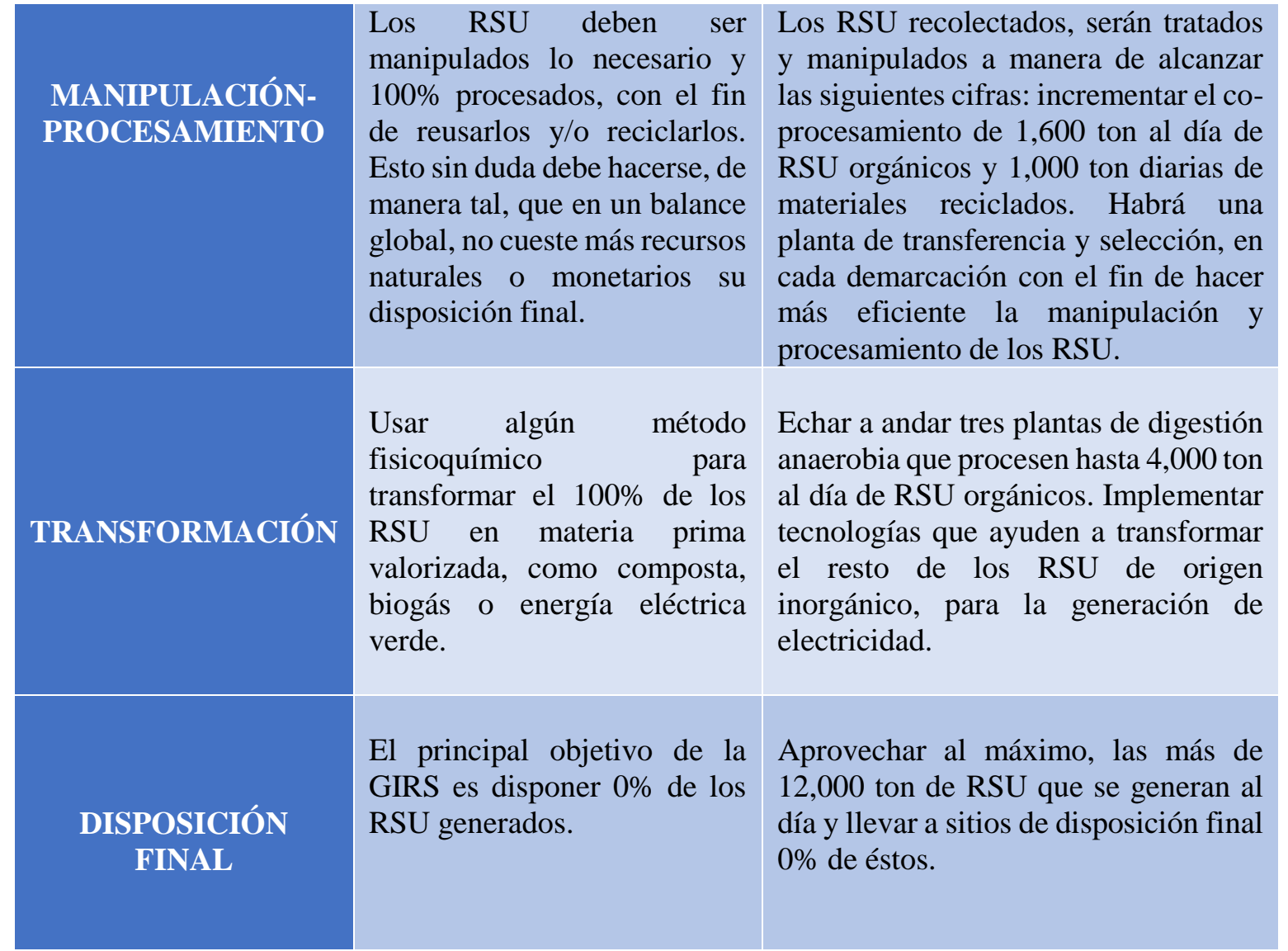

Fuente: Elaboración propia con base en: Tchobanouglus et al. (1994); GTZ-COMIA (2003); Ley General para la Prevención y Gestión Integral de los Residuos (2014); Cortinas Nava., C, (2004); Reglamento de la Ley General para la Prevención y Gestión Integral de los Residuos. (2014); Ley de Residuos Sólidos del Distrito Federal, (2003); Programa Institucional de la Secretaría de Obras y Servicios (SOBSE) de la CDMX (2013-2018).

A partir de estos objetivos, se diseñaron indicadores de desempeño que, justamente sirvieron para analizar qué tanto se cumplen las metas u objetivos planteados tanto por el enfoque de la GIRS como por el marco normativo y planeación específicamente en la CDMX para el 2015. Para ello, es un requisito entender qué es un indicador y para qué sirve, así como las características que deben tener, dado que en esta investigación se utilizaron un conjunto de indicadores que fueron estimados con información proveniente de las bases de datos proporcionadas por la Secretaría de Obras y Servicios (SOS) del Gobierno de la CDMX. Estos indicadores como se explicará en otras secciones de este capítulo fueron estimados por medio de un modelo de componentes principales utilizando el programa SPSS, cuyos resultados permitieron evaluar la eficacia en el manejo de los RSU en el año 2015.

\subsection{Indicadores de desempeño para la evaluación de la eficacia en el manejo de los} RSU. 
México en diferentes aspectos ambientales ha aprovechado experiencias de otros países con respecto a su organización y políticas públicas realizadas, ya que éstas frecuentemente dan solución a problemas en común de forma práctica y coordinada (OCDE, 2008). En cuestión de RSU, la CDMX ha estado trabajando intensamente en generar indicadores, ya que esto se ha vuelto una tendencia a nivel internacional debido a que son una herramienta de gran utilidad para la evaluación en la gestión ambiental. Una de las partes medulares de esta investigación, es generar y utilizar indicadores que sirvan como herramienta para evaluar el manejo de los RSU en cada una de sus fases (generación, recolección, manipulación-procesamiento, transformación y disposición final), ya que de esta manera se puede orientar a los tomadores de decisiones para la mejorar el manejo de los RSU bajo un enfoque de Gestión Integral.

En general, un indicador es la combinación de una o más variables que adquieren distintos valores en determinados espacios y tiempos, los cuales tienen la estricta función de entregar señales al público y a los tomadores de decisiones sobre aspectos fundamentales, trascendentales o prioritarios, en el proceso de cualquier tipo de desarrollo (CEPAL, 2009). Para ello, es de vital importancia conocer qué es un indicador y sus características.

Los indicadores se generan a través de estadísticas seleccionadas por su capacidad de revelar un fenómeno importante, frecuentemente son el resultado de procesar series estadísticas en formas de agregación, proporción y tasas de crecimiento para mostrar el estado, la evolución y las tendencias de un fenómeno que es relevante monitorear. Los indicadores se diseñan con el propósito de monitorear algunos fenómenos o conjuntos de dinámicas que requieren algún tipo de intervención o programa (Gobierno del Estado de Veracruz, 2014). Por esta razón, los indicadores desde su origen, requieren de un cuidadoso proceso de diseño en el que se calibran varios criterios como la disponibilidad y calidad de información, la relevancia del indicador y el aporte del indicador, entre otros aspectos. Es importante presentar dichos indicadores a los ciudadanos, autoridades y tomadores de decisiones de forma contextualizada, precisando sus implicaciones e importancia. De la misma forma que con las estadísticas, los indicadores deben ser respaldados por metadatos, que se conocen habitualmente como hojas metodológicas o fichas técnicas (CEPAL, 2009) para validar que los indicadores fueron generados o construidos con una base sólida.

Un indicador, es también una observación empírica o estimación estadística que sintetiza aspectos importantes de uno o más fenómenos que resultan importantes para uno o más propósitos analíticos y de monitoreo en el tiempo. Si bien el término indicador puede aludir a cualquier característica observable de un fenómeno suele aplicarse a aquellas que son susceptibles de expresión numérica y que son pertinentes o de máxima importancia para el interés público (Quintero, 2016). Por lo regular, los principales usuarios de los indicadores son los tomadores de decisiones, autoridades, ciudadanos y líderes de opinión, quienes por lo general no tienen el tiempo ni el conocimiento especializado profundo para utilizar directamente las series estadísticas y para los cuales se producen los conjuntos de indicadores (Gobierno del Estado de Veracruz, 2014). Como ya se mencionó, un indicador es un tipo particular de estadística, es decir, es un variable que en función del valor que asume en determinado momento y en determinado territorio, despliega significados que no son aparentes inmediatamente, y que los usuarios decodificarán más allá de lo que muestran directamente, porque existe un constructo cultural y de significado social que se asocia al mismo. Un indicador despliega más significados de los que son inmediata o directamente aparentes, siempre que se presenten adecuadamente contextualizados y descritos (CEPAL, 2009). 
De ahí, que no todas las estadísticas puedan ser consideradas indicadores, pues para entrar en esta última categoría, el indicador debe comunicar claramente una historia pertinente, debe ser una señal que alerta sobre lo que ocurre respecto de un fenómeno, problema, desafío o meta acordada, y debe decirlo en forma robusta, clara y contextualizada, sin lugar a dudas o interpretaciones encontradas (Gobierno del Estado de Veracruz, 2014).

Los indicadores varían su valor o nivel en el tiempo y en el espacio, y son estas variaciones las que también entregan información importante sobre un determinado fenómeno o problema. De ahí, que los indicadores requieran de más de un punto de observación en el tiempo o en el espacio para que puedan entregar su potencia como señal. Por lo mismo, si sólo se tiene un indicador con un sólo valor para un determinado año o sólo para un punto del territorio, no será de tanta utilidad como si se pudiera contar con su trayectoria en el tiempo o su variación entre distintos lugares (Gobver, 2011).

Como los indicadores pueden adoptar distintos valores o estados, se puede conferir a ciertos estados una significación especial a partir de ciertos juicios de valor: estos estados específicos se convierten así en umbrales, estándares, normas, metas o valores de referencia, es decir, las empresas tienen indicadores financieros y de productividad que les permiten evaluar su desempeño; los gobiernos cuentan con un notable conjunto de indicadores económicos que permiten evaluar la marcha de la economía y ejercer en forma calibrada la política monetaria, fiscal y/o cambiaria; los ministerios de salud cuentan con indicadores sanitarios; y las autoridades sociales tienen indicadores de pobreza, educación y distribución de la renta (Gobierno del Estado de Veracruz, 2014). De esta misma forma, la GIRS tiene su conjunto de indicadores que ayudan a saber el estado de la misma, como indicadores que hablan de la generación, recolección y transformación. Estas herramientas son de gran utilidad en la actualidad, e incluso podrían considerarse indispensables, para los tomadores de decisiones que pretendan realizar un buen trabajo, y que además que las decisiones que tome estén fundamentadas. Una vez, entendiendo la importancia que tienen los indicadores, y que con base en ellos se toman decisiones de gran relevancia, es necesario que éstos cumplan con ciertas características o condiciones, para que puedan ser considerados como una verdadera herramienta.

\subsubsection{Características básicas de un indicador y sus tipos}

En primer lugar, un indicador debe ser relevante y aplicable para la gestión, es decir, que aporte información imprescindible para informar, controlar, evaluar y tomar decisiones, y que los recursos que se utilicen para realizar la observación y recoger la información sean posibles y coherentes con la situación observada. A su vez, el cálculo que se realice a partir de las magnitudes observadas no puede dar lugar a ambigüedades (CEPAL, 2009). Esta cualidad permite que los indicadores puedan ser auditables y se evalúe de forma externa su fiabilidad siempre que sea preciso, es decir que sea verificable en cuanto a permitir comprobar su verdad y examinar el método por el que se ha alcanzado. A esta cualidad debe añadírsele, que un indicador debe ser inequívoco, es decir, que no permita interpretaciones contrapuestas. El concepto que expresa el indicador es claro y se mantiene en el tiempo. El indicador es adecuado a lo que se pretende medir (pertinencia) (Guía Práctica para la Construcción de Indicadores, 2011; CEPAL, 2009). La información debe estar disponible en el momento en que se deben tomar las decisiones.

Otra característica deseable es la objetividad. Los indicadores deben evitar estar condicionados por factores externos, tales como la situación del país o accionar a terceros, ya sean del ámbito público o 
privado. También, en este caso deben ser susceptibles de evaluación por un externo. La medida del indicador tiene que ser lo suficientemente eficaz para identificar variaciones pequeñas. Es la característica de la sensibilidad de un indicador, que debe construirse con una calidad tal, que permita automáticamente identificar cambios en la bondad de los datos. A su vez, el indicador debe ser preciso, su margen de error debe ser aceptable (Guía Práctica para la Construcción de Indicadores, 2011).

A estas cualidades debe añadirse la accesibilidad; su obtención tiene un costo aceptable (que el costo de la obtención sea superado por los beneficios que reporta la información extraída) y es fácil de calcular e interpretar. El indicador debe proporcionar una calidad y una cantidad razonables de información (relevancia) para no distorsionar las conclusiones que de él se puedan extraer (inequívoco), a la vez que debe estar disponible en el momento adecuado para la toma de decisiones (pertinencia, oportunidad), y todo ello, siempre que los costos de obtención no superen los beneficios potenciales de la información extraíble (CEPAL, 2009).

Se habla de manera general de indicadores de desempeño cuando con el uso de esta herramienta se pretende evaluar el cumplimiento de lo cometido, es decir, que tanto se cumplieron los objetivos propuestos. En México, a nivel federal el indicador de desempeño se utiliza como sinónimo de indicador de resultado, definido en la Ley General de Contabilidad Gubernamental. Se entiende que los indicadores tienen al menos, tres funciones básicas: descriptiva, valorativa y causal (Guía Práctica para la Construcción de Indicadores, 2011). La función descriptiva se refiere a la aportación de información sobre el estado real de un programa o proyecto; la valorativa consiste en añadir a esa información, un juicio de valor lo más objetivo posible sobre si el resultado es adecuado o no; y finalmente, la causal está relacionada con identificar las causas del menor, mayor o igual resultado esperado, respecto a la meta.

Los indicadores utilizados por la administración pública para evaluar el desempeño de la misma, por lo general deben permitir la medición de los objetivos en las dimensiones de eficacia, eficiencia, economía y calidad. Cada una de estas dimensiones se detallan a continuación (Hernández et al., 2010):

- Eficacia: miden el grado de cumplimiento de los objetivos y pueden subclasificarse en indicadores de:

$>$ Cobertura: se expresa en términos geográficos, en términos de universo o de una demanda a cubrir.

$>$ Focalización: se puede expresar en la cantidad de beneficiarios/usuarios elegibles y en el porcentaje de esa población objetivo que está recibiendo beneficios.

$>$ Capacidad para cubrir la demanda actual: este indicador determina qué parte de la demanda real es posible satisfacerse con las condiciones actuales. Resultado final: mide la contribución del conjunto de la intervención de la entidad pública, además de estar relacionada con el proceso de rendición de cuentas.

- Eficiencia: que mide la relación entre la cantidad de los bienes y servicios generados y los insumos o recursos utilizados para su producción, entre las cuales destacan:

$>$ Relación entre la productividad física y el costo de los factores e insumos utilizados en la generación de un bien o servicio.

$>$ Cuántas unidades de producto se obtienen en promedio por cada unidad de factor.

$>$ Costo de un servicio en relación al número de usuario 
- Economía: mide la capacidad para generar y movilizar adecuadamente los recursos financieros, los indicadores en esta dimensión suelen subclasificarse de la siguiente manera:

$>$ Capacidad de autofinanciamiento, que son los que se utilizan para medir cuando las dependencias o entidades tienen capacidad para generar ingresos propios.

$>$ Capacidad de ejecución, que puede medir la capacidad que una institución tiene para ejecutar el presupuesto de acuerdo con lo programado.

$>$ Capacidad de recuperación, que mide la capacidad de una institución para pagar deudas, originadas por préstamos, financiamientos u otros pasivos.

$>$ Nivel de recursos utilizados, es la relación entre el nivel de recursos financieros utilizados con los gastos que realizó una institución.

- Calidad: en esta dimensión, los indicadores miden en general, los atributos, propiedades o características que deben tener los bienes y servicios públicos generados en la atención de la población objetivo, vinculados con la satisfacción del usuario o beneficiario. Estos pueden clasificarse en indicadores de:

$>$ Oportunidad, mide el tiempo promedio de respuesta a las demandas de un determinado servicio público.

$>$ Accesibilidad, que miden la facilidad con la que un usuario tiene acceso a un servicio.

$>$ Precisión y continuidad en la entrega de servicios, son utilizados para conocer qué tan adecuados a las necesidades de la población son los bienes y servicios que generan los tomadores de decisiones o el gobierno en general, al mismo tiempo que permite determinar si cumplen con el tiempo establecido para cubrir la necesidad sin ser interrumpido antes del cumplimiento del objetivo.

Con base en lo anterior, existe una amplia gama de indicadores que miden todo tipo de fenómenos. Para el caso de esta investigación, se tomarán en cuenta los indicadores que se encuentren relacionados con el manejo de los RSU y cada una de sus fases en la CDMX. No se debe perder de vista que algunos indicadores se tomaron de informes, generados por el mismo gobierno, y algunos otros se generaron como parte de la metodología en esta investigación; esto con la finalidad de emplearlos en un modelo estadístico y así poder realizar la evaluación del manejo en su totalidad, tomando en cuenta todas las fases que éste implica.

Los indicadores para la GIRS pueden abarcar aspectos sociales, culturales y económicos; caso contrario a los indicadores que tienen que ver sólo con el manejo de los RSU, comprenden información relacionada con cada una de sus fases referentes a la generación, de recolección, manipulación, transformación y disposición final. Es importante destacar, que en el caso de esta investigación se utilizaron indicadores de GIRS que incluyen también los indicadores del manejo.

De manera general, se puede decir que los indicadores de GIRS surgen de combinar parámetros simples, y pretenden analizar aspectos básicos tales como calidad del servicio prestado para el manejo de los RSU, aspectos de generación de RSU de manera total y per cápita, tipos de residuos que se generan, eficiencias relativas en el proceso de recolección, e información sobre infraestructura. Estos indicadores se realizan con el objetivo de poder visualizar el estado real en cuanto a los RSU y su gestión, además de que son utilizados como una herramienta para solucionar problemas dentro de la misma que afecten particularmente a una localidad (Sinia, 2001). 
En esta investigación se utilizaron una gran variedad de indicadores, que más adelante se especificarán, algunos ejemplos se detallan en la Tabla 4.2. Cabe destacar, que los indicadores comprenden un grupo de indicadores por cada fase.

Tabla 4.2. Ejemplos de indicadores para la GIRS en México

\begin{tabular}{|c|c|}
\hline INDICADOR & UNIDADES \\
\hline Generación Total de RSU por día (GenT/día) & Ton/día \\
\hline Generación de RSU por habitante por día (GenPCap/día) & KG/habDía \\
\hline Peso volumétrico de RSU por tamaño del municipio la localidad $\left(\mathbf{P v}\left[\mathbf{k g} / \mathbf{m}^{3}\right]\right)$ & $\mathbf{m}^{3}\left(\mathrm{~kg} / \mathrm{m}^{3}\right)$ \\
\hline Recolección Selectiva (RecS) & Ton/día \\
\hline Recolección Mixta (RecM) & Ton/día \\
\hline Estaciones de transferencia (EstTr) & Ton/día \\
\hline Reciclaje (Rec) & Ton/día \\
\hline Plantas de Selección (PlanS) & Unidades \\
\hline Plantas de Composta (PlanC) & Unidades \\
\hline Disposición Final (DF) & Ton/día \\
\hline Camiones de recolección (CamRec) & Unidades \\
\hline Número de barredoras (NoBarr) & Unidades \\
\hline
\end{tabular}

En la Tabla 4.2 se enlistaron algunos de los indicadores más comunes en México; sin embargo, es muy importante tener noción del proceso para su construcción, pues existen algunos que podrían resultar simples relaciones y otros que requieren de cierta metodología y se vuelven más complejos, por lo es importante conocer el proceso general de la construcción de un indicador.

\subsubsection{Proceso para la construcción de un indicador}

Cómo se mencionó anteriormente, existen indicadores simples y compuestos. Por lo que es importante, conocer primero la diferencia entre cada uno de ellos para así poder entender el proceso que los construye. Un indicador simple es aquel que se define como la relación de por lo menos dos variables en una fórmula matemática simple (Secretaría de Desarrollo Económico de Bogotá, 2007). Esto para analizar las causas del cambio de una respecto de la otra, ya que una sola variable no "indica" cómo se está comportando frente a otra. Por ejemplo, el número de diabéticos en una comunidad x, no podría significar o representar algo importante si no se contrasta con el número de pobladores de la misma comunidad, es decir, una relación entre dos variables. En cambio, los indicadores compuestos incluyen un gran conocimiento de temas específicos y además no se calculan con simples relaciones, sino requieren procedimientos matemáticos y conceptuales complejos. Aunado a esto, este tipo de indicadores pueden ser distinguidos por su grado de complejidad: ya sea en su lado teórico y/o practico o en su lado referente a su cálculo usando procedimientos matemáticos en software especializado (Secretaría de Desarrollo Económico de Bogotá, 2007). Por ejemplo, este tipo de indicadores son frecuentemente usados en la evaluación del desarrollo sostenible, como la huella ecológica, índice de calidad de aire, huella de carbón y la huella hídrica (Schuschny, 2009). 
En el caso de los indicadores de desempeño, los cuales pueden ser simples o compuestos, existen pasos mínimos a considerar; de manera general, para construir los indicadores que permiten realizar la evaluación del desempeño de un programa en cualquier ámbito se requiere (Metodología para la formulación de Indicadores, 2007):

- Identificar las variables que se encuentran en los objetivos del programa o proyecto, en sus metas y en sus resultados, seleccionando los "conceptos claves" del programa o proyecto.

- Construir un significado colectivo de la variable (acuerdo sobre lo que se entiende por cada variable).

- Combinar las variables en fórmulas matemáticas que resulten en indicadores que representan ámbitos específicos de las variables.

- Diseñar todos los indicadores que sean necesarios para expresar cada significado, cobertura o alcance de las variables.

- Priorizar y seleccionar los indicadores. Se requiere que el equipo identifique un conjunto de criterios de ponderación y selección de indicadores de acuerdo con las características específicas del programa.

De acuerdo con el programa, proyecto o plan específico que se evalúa, los objetivos de los mismos y la disponibilidad de la información, se seleccionan los indicadores. Una vez que se cuente con la información de fuentes directas o indirectas se efectúa el respectivo cálculo, el que se realiza dependiendo de la unidad de medida seleccionada (e.g., cifra absoluta, tasa o promedio). En el caso particular de esta investigación, el análisis de los indicadores seleccionados, se hizo bajo en enfoque de la GIRS, y bajo el marco jurídico y de planeación de la CDMX, estos últimos en el rubro de RSU únicamente, y específicamente en cada una de las fases de su manejo, desde su generación, hasta su disposición final. Cabe mencionar que algunos indicadores se tomaron de la bibliografía revisada y otros fueron construidos.

Recientemente, los indicadores compuestos o sintéticos que resumen la información contenida en los sistemas de indicadores, han logrado incrementar el interés como una herramienta eficaz que favorece y contribuye a la formulación y el análisis de políticas públicas, así como a su evaluación y comunicación. Esto, especialmente por su capacidad de síntesis, los indicadores compuestos permiten atraer la atención de la comunidad en general, dando lugar a la creación de narrativas convincentes y ayudar a enfocar los debates de las políticas integradas que promuevan el desarrollo de una nación, desde luego en todos los ámbitos, económico social y ambiental (CEPAL, 2009). Por esta razón, el principal interés de esta investigación es poder sintetizar una gran cantidad de indicadores que tienen que ver con los RSU, para así poder generar otros que a su vez evaluarán el desempeño del manejo de los RSU bajo un enfoque de gestión integral en la CDMX, con el fin de contribuir a la mejora del mismo. Estos nuevos indicadores, se dan en un formato simple, para que todos los lectores puedan entenderlo. Con el fin de analizar y evaluar el desempeño de los países, la construcción de este tipo de indicadores compuestos, suele realizarse en múltiples áreas de la gestión pública tales como la Economía y sus diversos sectores. Estos indicadores compuestos también suelen aplicarse en la formulación de políticas de promoción de la innovación y la investigación científica. La Unión Europea y la Organización para la Cooperación y el Desarrollo Económicos (OCDE) han sido pioneras en el desarrollo de iniciativas relacionadas con estos conceptos, generando un acervo de documentación que puede servir de punto de partida para su estudio (CEPAL, 2009; Quiroga, 2007). 
En general a nivel global, podemos encontrar diversos indicadores que son empleados en una vasta gama de sectores, en particular, esta investigación se enfoca en usar la mayor cantidad posible de indicadores que tengan que ver con el manejo de RSU a nivel local como una herramienta para la generación de un modelo que nos ayude a evaluar el manejo de los residuos en la CDMX. Sin embargo, es importante mantener una visión amplia y sobre todo apoyarse de los indicadores que se usan en otras partes para aprender de otras experiencias y mejorar el manejo de los RSU a nivel local. La Tabla 4.3 resume de manera breve, algunos de los indicadores más comunes e importantes utilizados en la evaluación de los RSU en diferentes países del mundo. Estos indicadores se clasificaron por cada fase del manejo de la siguiente manera: a la fase de generación se le asignó el número 1, a la de recolección el 2, la de manipulación o procesamiento 3 , a la de transformación 4 , y a la de disposición final 5. En el caso de México, aunque se consideran las cinco fases de manejo entre sus objetivos, se le ha dado una menor importancia a la fase 3 y 4 que corresponden a la manipulación o procesamiento y a la transformación.

\section{Tabla 4.3 Indicadores para el manejo de RSU a nivel global}




\begin{tabular}{|c|c|c|c|c|}
\hline AUTOR & PAÍs & $\begin{array}{l}\mathrm{N}^{\circ} \mathrm{DE} \\
\text { IND }\end{array}$ & INDICADORES & $\begin{array}{l}\text { FASE DEL } \\
\text { MANEJO }\end{array}$ \\
\hline \multirow{10}{*}{$\begin{array}{c}\text { ARENDSE, L \& GODFREY, } \\
\text { L, } 2010\end{array}$} & \multirow{10}{*}{ Sudáfrica } & \multirow{10}{*}{10} & Los residuos totales generados por grupo de ingresos anuales & 1 \\
\hline & & & Los residuos totales generados per cápita al año & 1 \\
\hline & & & Los residuos peligrosos producidos por sector y por año & 1 \\
\hline & & & Reciclado de residuos & 3 \\
\hline & & & Valor del residuo reciclado & 3 \\
\hline & & & RSU dispuestos correctamente en sitios de disposición final & 5 \\
\hline & & & Residuos peligrosos dispuesto correctamente & 5 \\
\hline & & & Sitios de disposición final con vida útil & 5 \\
\hline & & & \begin{tabular}{|ll} 
Gasto municipal en la GIRSU & presupuesto anual gastado/gr per cápita \\
\end{tabular} & NA \\
\hline & & & Capacidad municipal para la recolección de RSU & 2 \\
\hline \multirow{11}{*}{$\begin{array}{l}\text { Armijo, C, Puma, A \& } \\
\text { Ojeda, S; } 2011\end{array}$} & \multirow{11}{*}{ México } & \multirow{11}{*}{11} & Costo de operación por tonelada de RSU & NA \\
\hline & & & Porcentaje de Personas que no estan satisfechas con el manejo de RSU & NA \\
\hline & & & Porcentaje de material recolectado recuperable & 3 \\
\hline & & & Residuos recolectados comparado con residuos generados $\%$ & $1 \mathrm{y} 2$ \\
\hline & & & Calificación promedio del sistema de manejo de residuos y de su recolección & 2 \\
\hline & & & Cumplimiento de la normatividad mexicana para la disposición final & 5 \\
\hline & & & Covertura del servicio de recolección & 2 \\
\hline & & & Porcentaje de comentarios a favor del reciclaje & 2 \\
\hline & & & Porcentaje de material recuperable del total recuperado & $2 \mathrm{y} 3$ \\
\hline & & & Toneladas totales del material recuperado con respecto al generado & $1 \mathrm{y} 3$ \\
\hline & & & Composición de los RSU recolectados & 2 \\
\hline \multirow{7}{*}{$\begin{array}{l}\text { Gobierno de Chile, } \\
\text { Comisión Nacional del } \\
\text { Medio Ambiente, } 2001\end{array}$} & \multirow{7}{*}{ Chile } & \multirow{7}{*}{7} & Producción per cápita de RSU & 1 \\
\hline & & & \begin{tabular}{|l|} 
Cobertura de recolección \\
\end{tabular} & 2 \\
\hline & & & Eficiencia de camiones recolectores & 2 \\
\hline & & & Reclamos de la comunidad & NA \\
\hline & & & \begin{tabular}{|l|} 
Costo total de recolección por tonelada \\
\end{tabular} & 2 \\
\hline & & & Costo total de disposición final por tonelada & 5 \\
\hline & & & Retorno de ingresos-reciclado & 3 \\
\hline \multirow{2}{*}{ Castellón, 2008} & \multirow{2}{*}{ Venezuela } & \multirow{2}{*}{2} & Efectividad de operación en barrido y limpieza de las calles & 2 \\
\hline & & & Generación de RSU por habitante & 1 \\
\hline \multirow{15}{*}{$\begin{array}{c}\text { Diagnóstico Básico para } \\
\text { la GIRSU en México, } 2012\end{array}$} & \multirow{15}{*}{ México } & \multirow{15}{*}{15} & Generación de RSU per cápita & 1 \\
\hline & & & Peso volumétrico promedio ponderado de la generación de RSU & 1 \\
\hline & & & Composición de los RSU generados & 2 \\
\hline & & & Recolección mixta & 2 \\
\hline & & & \begin{tabular}{|l|l|l} 
Recolección selectiva \\
\end{tabular} & 2 \\
\hline & & & Estaciones de transferencia & 3 \\
\hline & & & plantas de composta & 4 \\
\hline & & & Pepena en recolección & 2 \\
\hline & & & Pepena de tiradero a cielo abierto & 2 \\
\hline & & & Acopio industrial & 3 \\
\hline & & & Plantas de selección & 3 \\
\hline & & & Dispocición en relleno sanitario y sitio controlado & 5 \\
\hline & & & Disposición desconocida & 5 \\
\hline & & & Disposición a cielo abierto & 5 \\
\hline & & & Camiones recolectores & 2 \\
\hline Zaman \& Lehmann, 2013 & Australia & 1 & Basura cero & $1-2-3-4-5$ \\
\hline
\end{tabular}

Fuente: Elaboración propia.

Haciendo referencia a la mayoría de los indicadores expuestos en la Tabla 4.3, se puede observar que son indicadores simples, donde se relacionan dos o más variables. Por ejemplo, el más común es el de generación de RSU, el cual la mayoría de los países lo manejan, de forma total y per cápita. Otros países como Sudáfrica, cuentan con indicadores desagregados por grupo de ingresos anuales. Este indicador no es más que una relación de la cantidad de RSU que estiman generan, entre el número de pobladores, en el caso de generación per cápita. El caso de Sudáfrica resulta interesante, pues agrega una variable más que está dada por el nivel de ingresos de cada habitante de manera anual, es decir, clasifica la generación de RSU por habitantes de ingresos altos, medios y bajos. En el caso de México (Chávez et al, 2011), se generaron un par de indicadores complejos como la calificación promedio del sistema de manejo de RSU y de su recolección y el cumplimiento de la normatividad mexicana para la disposición final. Cabe mencionar que en Ojeda et. al (2006), se utilizaron una serie de indicadores, los cuales fueron integrados a un modelo Fuerza Motriz-Presión-Estado-Impacto- 
Respuesta (FPEIR). Basados en el modelo FPEIR, se construyó un esquema del Sistema de Manejo de Residuos, en el que se integró la lista de factores externos en el sistema de manejo de residuos, así como los indicadores. El modelo cuenta con indicadores de Causa, Presión, Estado, Impacto y Respuesta en el que se evaluó el estado de cada criterio mediante la siguiente fórmula:

$$
\begin{gathered}
\text { Estado }=F(x)=[(- \text { causa })+(- \text { presión })]=(\text { respuesta }) \\
\downarrow \text { Eimpacto } \rightarrow \uparrow \text { Eideal }=f(\text { presión, respuesta })
\end{gathered}
$$

Se identificaron y eligieron los indicadores de mayor relevancia, mediante un proceso de selección hecho a través del análisis de opiniones de un grupo de expertos en residuos, revisión bibliográfica de indicadores, así como análisis de los indicadores propuestos por el Programa de Manejo de Residuos en México, por lo que el resultado fueron los dos indicadores antes mencionados, que desde luego son indicadores complejos. El resto de los indicadores en los otros países siguen siendo simples, ya que sólo es la relación entre dos variables o incluso tres, como cobertura de recolección en el caso de Sudáfrica, y eficiencia de barrido y limpieza en las calles en el caso de Venezuela.

Chile, por otro lado, generó indicadores que tienen que ver con el servicio de recolección de desechos y la opinión de inconformidad de los usuarios de dicho servicio. Este tipo de indicador refleja la percepción que tiene la comunidad respecto del servicio de recolección. Puede emplearse para evaluar tanto el servicio de recolección como el de disposición final. En general, debe ser calculado cuidando que los reclamos sean contabilizados por sector atendido, por lo que al momento de calcularlo hacerse considerando la población atendida por ese sector respectivo. En caso contrario, deben contabilizarse unitariamente y presentarse cono aparece en los valores de referencia. Este indicador no requiere formula como tal sino más bien se obtiene a partir de información generada en encuestas según el Gobierno de Chile (Comisión Nacional del Medio Ambiente, 2011).

Uno de los casos más sobresalientes es el caso de Australia con el índice de basura cero, este es un gran ejemplo de indicador complejo, que además incluye todas las fases del manejo de los RSU. Este indicador fue desarrollado en dicho país, ya que las ciudades australianas tienen como objetivo llevar a sitios de disposición final el 0\% de los RSU generados. Cabe mencionar, que la CDMX tiene la intención, en el actual periodo de gobierno, de poner en marcha un programa de "Basura Cero" con el mismo propósito, y con el fin de no depender más de otras ciudades o estados para tratar sus residuos o para disponer los mismos. Por lo que resultaría interesante poder profundizar un poco más en lo que la construcción de un indicador de esta magnitud implica (Estrada, 2016).

Uno de los primeros pasos sería entender lo que implica el concepto de "basura cero". Esta filosofía nace de la idea de perseguir una vida sustentable y tiene como principio básico el reducir los residuos a cero, ya sea valorizándolos o reincorporándolos al sistema de producción, partiendo desde la fabricación de los productos, ya que estos deberían tener una larga vida útil y además estar diseñados para poder ser reciclados o recuperados fácilmente. Su premisa básica es la separación en origen que consiste en que cada ciudadano separe los residuos reciclables de los que no lo son y que pueda desecharlos de manera diferenciada y fácilmente (Panarisi, 2015). Este movimiento que ha tomado gran fuerza a lo largo y ancho del globo, pone énfasis en que el diseño de los productos debe ser óptimo para ser aprovechado al cien por ciento. Es decir, el alcance de Basura Cero, comprende varios conceptos que se han desarrollado para lograr una gestión sustentable de los RSU, estos conceptos incluyen evitar, reducir, reusar, rediseñar, regenerar, revender, redistribuir, todos los RSU (Zaman \& Lehmann, 2013). La mayoría de las ciudades han trabajado en realizar una gestión integral de los RSU, la cual implica reciclar y recuperar de alguna manera el $100 \%$ de los RSU generados; sin embargo, el concepto de Basura Cero, va un paso hacia adelante y no está limitado a recuperar y 
reciclar solamente, sino que está enfocado más ampliamente en la eliminación de la generación de los residuos innecesarios desde la primera etapa de su existencia, la cual parte desde su diseño (Zaman \& Lehmann, 2013). Como se puede ver, tan sólo el concepto de Basura Cero es bastante amplio y complejo, entonces generar un indicador que pueda arrojar información de las ciudades para saber qué tan comprometidas realmente están con la implementación de esta filosofía, no es tarea fácil. Adelaida, Australia, es una ciudad que lleva varios años trabajando en ello, al igual que San Francisco, E.U y Estocolmo, Suecia.

El índice de Basura Cero es un indicador que sirve como una herramienta para medir la potencialidad que tiene la materia prima virgen de ser introducida al sistema de tratamiento de basura cero. En otras palabras, la meta de este concepto radica en evitar a toda costa el agotamiento de los recursos naturales. Por lo que finalmente poder medir el desempeño de Basura Cero en una ciudad, es midiendo la cantidad de recursos naturales que son extraídos, para ser recuperados, consumidos, desechados, reciclados, y finalmente sustituidos por materia prima virgen nuevamente, las cuales nuevamente vuelven a ser compensadas en el sistema del manejo de los RSU. Es decir, el índice de Basura Cero es una herramienta de vanguardia que mide la cantidad de materia prima virgen que puede ser remplazada por material proveniente del sistema de manejo de los residuos (Zaman \& Lehmann, 2013).

De manera general, el Índice de Basura Cero IBC, está conformado por la siguiente ecuación:

$$
I B C=\frac{\sum_{1}^{n} R M S i * F S i}{\sum_{1}^{n} R G T}
$$

RMS $=$ Cantidad de residuos manejados por el sistema $\mathrm{i}(\mathrm{i}=1,2,3, \ldots)$

$\mathrm{n}=$ cantidad de residuos que se trataron, reciclaron y redujeron.

FSi $=$ Factor de sustitución para diferentes sistemas de manejo de residuos basados en su eficiencia de reemplazo de materia prima virgen.

Este ejemplo de indicador, resulta tan complejo, pero tan completo al mismo tiempo, que incluso considera la sustitución no sólo de materia prima virgen, sino también de los recursos que se emplean para extraerla, como agua, energía y emisiones de gases efecto invernadero, además puede ser utilizado para diferentes ciudades con el fin de medir su capacidad de manejo sustentable de los RSU. En conclusión, se puede observar que los indicadores pueden ser simples relaciones o complejas fórmulas matemáticas que conlleven no solo un amplio conocimiento estadístico sino todo un bagaje en diferentes temas, como en este caso en el tema de los RSU y ambientales. Este índice contempla las cinco fases que se han manejado a lo largo de esta investigación más una amplia gama de índices ambientales, como los que se mencionaron anteriormente; con el fin de poder interpretar o visualizar un escenario completo que deben considerar los tomadores de decisiones y que son una herramienta de suma utilidad para evaluar el desempeño de los países mediante los ejercicios de comparación. Sin embargo, el descuido metodológico durante su diseño, la falta de información y el uso de datos inconsistentes pueden dar lugar a conclusiones, si no erróneas, demasiado simplificadas (CEPAL, 2009). 
La CDMX ha mostrado gran interés en la implementación de la filosofía Basura Cero. Sin embargo, es importante considerar que apenas se está explorando sobre el tema y analizando diversas estrategias para la valoración de los residuos sólidos y su transformación en energía u otros subproductos. En general, las ciudades que más éxito tienen como ciudades de Suecia, Estados Unidos, entre otras que se vieron en el capítulo 2 de esta investigación, ya han dominado las cinco fases del manejo de los RSU con un enfoque de GIRS, por lo que el siguiente paso es la gestión sustentable de residuos sólidos urbanos (GSRSU), lo que implica la filosofía de Basura Cero.

En general, para la construcción de indicadores complejos se requiere determinar el procedimiento que se seguirá. En esta investigación, la metodología seguida consistió en la construcción de indicadores simples para cada una de las fases del manejo de RSU, los cuales alimentaron el modelo de componentes principales; modelo enfocado a evaluar los niveles de eficacia tanto de la GRSU total como de cada una de sus fases, utilizando información proporcionada por la SOS del Gobierno de la CDMX y de los Inventarios de Residuos Sólidos de la CDMX publicados con una periodicidad anual. Uno de los primeros pasos para la construcción de la metodología fue desarrollar un marco teóricoconceptual que sustente en qué consiste el indicador, qué aspecto en particular del manejo de los RSU va a medir y qué variables lo conforman. Es a partir de ese marco, que se justifica la construcción del indicador, dando pertinencia y razón de ser a los valores que posteriormente serán analizados. Una vez definido el marco conceptual, se evalúan los indicadores que se desea sintetizar. Esta etapa debe remitirse a un proceso previo de generación de indicadores, que es básico para la construcción de indicadores compuestos (CEPAL, 2009). Este proceso previo consiste en una búsqueda de los indicadores que, dentro del marco conceptual definido, puedan ser construidos o utilizados si es que ya existen, para posteriormente ser incorporados en un indicador compuesto. En este caso, se utilizaron los indicadores mostrados en la Tabla 4.4, precisándose si el indicador propuesto fue generado o si proviene de otra fuente como inventarios, reportes o artículos de investigación.

La selección de los indicadores y las variables que conformarán el indicador compuesto se debe realizar respetando no sólo los criterios conceptuales basados en el marco mencionado, sino también los estadísticos. Para ello, se debe considerar la naturaleza subyacente de los datos y la relación que pudiera haber entre ellos, ya que éstos deben ser cuidadosamente analizados antes de proceder a integrar toda la información en un sólo indicador o en un grupo indicadores (CEPAL, 2009). Con este fin, se puede recurrir a diversos métodos de síntesis estadística. El análisis combinado de la información puede realizarse sobre la base de dos criterios (Quiroga, 2007):

$>\mathrm{El}$ análisis de relaciones entre variables: el cual consiste en agrupar las variables en subindicadores, definiendo una estructura anidada y determinando si la selección de éstas, resulta apropiada para describir el fenómeno en cuestión; para lo cual se requiere recurrir a técnicas estadísticas como el análisis de componentes principales (ACP) que se presenta a continuación y que permite estudiar cómo se interrelacionan estadísticamente las dimensiones del fenómeno estadístico que se considerarán en indicador compuesto.

$>$ El estudio de relaciones entre unidades de análisis: que se refiere a establecer grupos de unidades de análisis vinculadas por su similitud. En este caso, se puede recurrir al análisis de conglomerados (o cluster analysis).

Esta investigación utilizó un análisis de relación entre variables, seleccionado el método de Análisis de Componentes Principales, utilizando como software el SPSS. Las características, ventajas y limitaciones de este tipo de método se desarrollan en el siguiente apartado. 


\subsection{Modelo de análisis de componentes principales para evaluar la eficacia en el manejo de los RSU en la CDMX}

\subsubsection{Planteamiento del modelo de Análisis de Componentes Principales (ACP)}

El Análisis de Componentes Principales (ACP) se suele aplicar cuando se tiene por objetivo agrupar las variables estudiadas en subindicadores. Se trata de un método creado por Pearson (1901) desde un enfoque geométrico, que posteriormente fue planteado de manera algebraica por Hotelling (1933), popularizándose a partir del uso frecuente de la computadora. Actualmente, es uno de los métodos más utilizados, ya que permite reducir la dimensionalidad de un conjunto de datos (CEPAL, 2009).

El objetivo del ACP es explicar la mayor parte de la variabilidad total observada en un conjunto de variables, con el menor número de componentes posibles (Uriel, 1985). Esto se logra transformando el conjunto de variables originales que generalmente tienen correlación entre sí, en otro conjunto de variables no correlacionadas, denominadas factores o componentes principales, relacionadas con las primeras por medio de una transformación lineal, estando ordenadas de acuerdo con el porcentaje de variabilidad total que explican. Se selecciona de entre las componentes principales, a aquellos que explican la mayor variabilidad acumulada en la muestra, reduciendo así la dimensión total del conjunto de información (CEPAL, 2009).

Los componentes obtenidos de la transformación lineal, no necesariamente son directamente interpretables empíricamente, en el sentido de que no constituyen un indicador o índice per se, pues quedan definidas a partir de la combinación lineal de variables que pueden aparentar no estar vinculadas por una interpretación afín. Existen por ello, herramientas que posibilitan la interpretación de los componentes principales, como el análisis de las correlaciones entre los componentes identificados con respecto a las variables originales, los gráficos de saturación o los métodos de rotación para la conformación de dichos componentes (Jolliffe, 2002).

En un breve resumen, las fases de un análisis de componentes principales comprenden los siguientes aspectos (Terradez, 2007):

\section{a. Análisis de la matriz de correlaciones}

Un análisis de componentes principales tiene sentido si existen altas correlaciones entre las variables, ya que esto es indicativo de que existe información redundante y, por tanto, pocos factores explicarán gran parte de la variabilidad total.

\section{b. Selección de los componentes}

La selección de los componentes se realiza de tal forma que, el primero comprende la mayor proporción posible de la variabilidad original; el segundo factor o componente debe recoger la máxima variabilidad posible no considerada por el primero, y así sucesivamente. Del total de factores se elegirán aquéllos que comprendan el porcentaje de variabilidad que se considere suficiente.

\section{c. Análisis de la matriz de componentes}

Una vez seleccionados los componentes principales, se representan en forma de matriz. Cada elemento de ésta, representa los coeficientes factoriales de las variables (las correlaciones entre las 
variables y los componentes principales). La matriz tendrá tantas columnas como componentes principales y tantas filas como variables.

\section{d. Interpretación de los componentes}

Para que un componente sea fácilmente interpretable debe tener las siguientes características:

- Los coeficientes factoriales deben ser próximos a 1.

- Una variable debe tener coeficientes elevados sólo con un factor.

- No deben existir factores con coeficientes similares.

e. Cálculo de las puntuaciones factoriales

Son las puntuaciones que tienen los componentes principales para cada caso, que nos permitirán su representación gráfica.

Se calculan mediante la expresión: $\quad X_{i j}=a_{i 1} \cdot Z_{1 j}+\ldots+a_{i k} \cdot Z_{k j}=\sum_{s=1}^{k} a_{i s} \cdot Z_{s k}$

donde a son los coeficientes y $\mathrm{Z}$ son los valores estandarizados que tienen las variables en cada uno de los sujetos de la muestra.

Po otro lado, al realizar una reducción de la dimensionalidad del sistema de indicadores, se pierde cierta cantidad de información. Sin embargo, tal pérdida se puede compensar con la simplificación realizada, ya que algunas de las correlaciones entre las variables pueden resultar redundantes en el análisis global.

\section{f. Supuestos del ACP}

Para aplicar el ACP se deben considerar los siguientes supuestos (Nardo et. al, 2005): a. Poseer un número de casos suficientemente grande, lo que supondrá la adopción de alguna de las siguientes reglas empíricas planteadas por varios autores:

a.1 Regla del 10: disponer de al menos 10 casos por cada variable.

a.2 El 3 a 1: que el número de casos sea el triple que el de variables.

a.3 El 5 a 1: otros autores plantean respetar una relación 5 a 1 entre casos y variables.

a.4 Regla del 100: el número de casos debería ser 5 veces el número de variables y superiores a 100.

a.5 Regla del 150: disponer de más de 150 cuando hay muy pocas variables correlacionadas.

a.6 Regla del 200: tener más de 200 casos, sin importar el número de variables.

a.7 Regla de la significancia: tener 51 casos más que el número de variables, con el fin de poder realizar la prueba chi-cuadrada.

Nótese la dispersión que poseen estas reglas empíricas, por ende, la elección de aquellas a aplicar dependerá de la relación que se establezca entre la disponibilidad de información y el número de variables involucradas, así como del nivel de robustez pretendido.

\section{g. Otras consideraciones}


Otras consideraciones en la realización del ACP incluyen los siguientes aspectos:

a. Que no haya sesgos en la selección de las variables. Esto se refiere a que la exclusión de variables relevantes junto con la inclusión de otras irrelevantes, afectará ciertamente a la matriz de covarianza, y por lo tanto, a la representatividad del resultado que se obtenga.

b. Que no haya datos atípicos (conocidos también como outliers). Como en el caso de otras técnicas estadísticas, la presencia de datos atípicos puede afectar las interpretaciones que devienen de un análisis de componentes principales.

c. Linealidad: El análisis de componentes principales es una técnica basada en el uso del álgebra lineal y por eso es claramente conveniente que la relación entre las variables sea lineal. Cuando no se cumple este supuesto, se pueden optar por otros métodos estadísticos que incluyen los componentes principales no lineales.

d. Normalidad multivariada: este supuesto es conveniente de validar si se busca realizar pruebas de contraste estadístico. Si se supone que las variables están distribuidas a partir de funciones de distribución diferentes, será más complicado hacer dichas pruebas pues generalmente las herramientas de software sólo contemplan las basadas en el supuesto de normalidad (CEPAL,2009).

En la Figura 4.2 se establecen los trece pasos básicos que sigue el ACP propuestos por Uriel (1995) para la estimación de los componentes principales de una muestra dada y de las matrices de covarianza y correlación.

\section{Figura 4.2 Pasos para realizar un Análisis de Componentes Principales}

Con base en Uriel (1995), los Componentes Principales son combinaciones lineales de las variables originales que pueden ser ordenadas en forma decreciente de acuerdo a la "cantidad de varianza" que ellas contribuyen a estimar a partir de los datos originales. Por lo general, la mayor parte de la variabilidad de los datos originales queda condensada en las primeras componentes (las principales).

Formalmente, se parte de $p$ variables, muestreadas sobre $n$ (unidades de análisis) casos, esto es: $x_{11}, \cdots, x_{p 1}, \cdots, x_{1 n}, \cdots, x_{p n}$.

Esta información puede expresarse matricialmente como (ecuación 1):

$$
\mathbf{X}=\left(\begin{array}{ccc}
x_{11} & \cdots & x_{1 p} \\
\vdots & \vdots & \vdots \\
x_{n 1} & \cdots & x_{n p}
\end{array}\right) \in \Re^{n \times p}
$$

La matriz de covarianza muestral queda definida por (ecuación 2)

$$
\Sigma=\mathrm{E}\left[(\mathbf{X}-\mathrm{E}[\mathbf{X}])(\mathbf{X}-\mathrm{E}[\mathbf{X}])^{\top}\right]=\left(\begin{array}{ccc}
\sigma_{1}^{2} & \cdots & \sigma_{1 n} \\
\vdots & \vdots & \vdots \\
\sigma_{n 1} & \cdots & \sigma_{n}^{2}
\end{array}\right) \in \Re^{n \times n}
$$

Por otro lado, partiendo de $X$ se puede calcular la matriz muestral de correlaciones $R$. Los componentes principales pueden ser estimados tanto a partir de la matriz de covarianza como de la matriz de correlación. Estas matrices proporcionan información acerca de la concomitancia en la 
variabilidad observada en las variables. Las variables que muestran una baja correlación serán candidatas a ser eliminadas del análisis (ecuación 3).

$$
\mathbf{R}=\left(\begin{array}{cccc}
1 & r_{12} & \cdots & r_{1 p} \\
\vdots & \vdots & \vdots & \vdots \\
r_{p 1} & r_{p 2} & \cdots & 1
\end{array}\right) \in \Re^{p \times p} \operatorname{con} r_{i j}=\frac{\operatorname{cov}\left(x_{i}, x_{j}\right)}{\sqrt{\operatorname{var}\left(x_{i}\right) \operatorname{var}\left(x_{j}\right)}}, \quad 1 \leq i, j \leq p
$$

Los componentes principales son un conjunto de variables ortogonales entre sí (no correlacionadas), que surgen de una transformación lineal de las variables originales y que tienen la propiedad de contener en conjunto la misma varianza total que el conjunto original. El primer componente se construye de modo que contenga la máxima proporción posible de la varianza de los x's; la segunda, la máxima de la varianza restante; y así sucesivamente. Esto significa que los componentes quedan ordenados con base en la información estadísticamente relevante que contienen, expresada por el porcentaje de la varianza total explicada por cada una.

El primer componente principal se expresará como la combinación lineal (ecuación 4):

$$
\left(\begin{array}{c}
Z_{11} \\
\vdots \\
Z_{1 n}
\end{array}\right)=\left(\begin{array}{ccc}
x_{11} & \cdots & x_{p 1} \\
\vdots & \vdots & \vdots \\
x_{1 n} & \cdots & x_{p n}
\end{array}\right)\left(\begin{array}{c}
u_{11} \\
\vdots \\
u_{1 p}
\end{array}\right) \text { б } \mathbf{Z}_{1}=\mathbf{X} \cdot \mathbf{u}_{1}
$$

Resta conocer el vector $\mathrm{u}_{1}$, que se obtiene maximizando la varianza $\operatorname{Var}\left(\mathrm{Z}_{1}\right)$ (ecuación 5):

$$
\begin{aligned}
\operatorname{Var}\left(\mathbf{Z}_{1}\right) & =\frac{\sum_{i=1}^{n} Z_{1 i}^{2}}{n}=\frac{1}{n} \mathbf{Z}_{1}^{\top} \mathbf{Z}_{1}=\frac{1}{n} \mathbf{u}_{1}^{\top} \mathbf{X}^{\top} \mathbf{X} \mathbf{u}_{1} \\
& =\mathbf{u}_{1}^{\top}\left[\frac{1}{n} \mathbf{X}^{\top} \mathbf{X}\right] \mathbf{u}_{1}
\end{aligned}
$$

sujeta a la restricción de que la suma de los ponderadores al cuadrado sea igual a uno (condición de ortogonalidad) (ecuación 6):

$$
\sum_{j=1}^{p} \mathbf{u}_{1}^{2} \equiv \mathbf{u}_{1}^{\top} \cdot \mathbf{u}_{1}=1
$$

Si las variables están normalizadas, la expresión entre corchetes de (5) es la matriz de correlaciones. Si las variables están sólo expresadas como desviaciones alrededor de la media, de acuerdo a (2), tenemos que tal expresión es la matriz de covarianza. Sin pérdida de generalidad, supongamos esta última situación, entonces (ecuación 7):

$$
\operatorname{Var}\left(\mathbf{Z}_{1}\right)=\mathbf{u}_{1}^{\top} \cdot \mathbf{\Sigma} \cdot \mathbf{u}_{1}
$$

Para maximizar (7) sujeta a la restricción (6), se procede usualmente construyendo el lagrangiano (ecuación 8):

$$
\mathcal{L}=\mathbf{u}_{1}^{\top} \cdot \mathbf{\Sigma} \cdot \mathbf{u}_{1}-\lambda\left(\mathbf{u}_{1}^{\top} \cdot \mathbf{u}_{1}-1\right)
$$


Cuya condición de primer orden es (ecuación 9):

$$
\frac{\partial \mathcal{L}}{\partial \mathrm{u}_{1}}=2 \Sigma \cdot \mathrm{u}_{1}-2 \lambda \mathrm{u}_{1}=0, \quad(\Sigma-\lambda \mathrm{I}) \cdot \mathrm{u}_{1}=0
$$

dado que $\mathrm{u}_{1}$ es un vector no nulo, tenemos que $\Lambda$ es el autovalor de la matriz de covarianzas $\Sigma$ y $\mathrm{u}_{1}$ su autovector $\left(\Sigma \cdot \mathrm{u}_{1}=\lambda \mathrm{u}_{1}\right)$.

El resto de las componentes se obtienen de la misma manera, pero hay que introducir una restricción de ortogonalidad (no correlatividad) respecto de la primera: $\mathrm{u}_{2} \mathrm{u}_{1}=0$, y así se sigue sucesivamente; de manera tal que, la j-ésima componente $Z_{j}$ deberá restringirse a satisfacer la maximización de la ortogonalidad respecto a todos los componentes anteriores (ecuación 10):

$$
\mathbf{u}_{j}^{\top} \mathbf{u}_{1}=0, \cdots, \mathbf{u}_{j}^{\top} \mathbf{u}_{j-1}=0, \mathbf{u}_{j}^{\top} \mathbf{u}_{j}=1
$$

Es posible ordenar los componentes de mayor a menor variabilidad explicada, la cual queda expresada en la magnitud de cada autovalor puesto que como $\mathbf{u}_{j}^{\top} \mathbf{u}_{j}=1 \quad \forall 1 \leq j \leq p^{-}$, la varianza de $Z_{\mathrm{j}}$ es precisamente $\kappa_{\mathrm{j}}$ (ecuación 11):

$$
\operatorname{Var}\left(\mathbf{Z}_{j}\right)=\mathbf{u}_{j}^{\top} \Sigma \mathbf{u}_{j}=\lambda_{j}
$$

El autovector de ponderación $\mathrm{u}_{\mathrm{j}}$ de la componente $\mathrm{Z}_{\mathrm{j}}$ está asociado al autovalor de $\Lambda_{\mathrm{j}}$.

Asimismo, puesto que se obtuvo una base ortogonal, la variabilidad total observada en las variables originales puede definirse como la suma de sus varianzas, es decir la traza de la matriz, o equivalentemente (ecuación 12):

$$
\operatorname{Traza}(\Sigma)=\sum_{j=1}^{p} \lambda_{j}
$$

Por consiguiente, el componente $Z_{\mathrm{j}}$ cuyo autovalor correspondiente es $\kappa_{\mathrm{j}}$ explica una fracción $\mathrm{F}_{\mathrm{j}}$ de la variabilidad total (ecuación 13):

$$
F_{j}=\frac{\lambda_{j}}{\sum_{i=1}^{p} \lambda_{\mathbf{i}}}
$$

Fuente: Uriel (1995)

La Figura 4.2 extraída directamente de Uriel (1995), sintetiza de manera breve las bases con las que el ACP se estima. Sin embargo, este método como cualquier otro, también presenta ventajas y desventajas que se desarrollan a continuación.

\subsubsection{Ventajas y Desventajas del ACP}

Entre las ventajas del ACP destacan: 1) que sistematiza información eliminando el problema de las unidades, y 2) evita algunos problemas en la especificación de los modelos como la multicolinealidad 
y heterocedasticidad. La multicolinealidad es resultado de la estrecha relación entre las variables, lo cual provoca un problema de identificación del efecto individual de cada variable, además de hacer que los estimadores sean sesgados. La heterocedasticidad se atribuye a las variaciones no constantes de los residuos por deficiencias en la información o porque el modelo está mal especificado, incrementando la varianza de los estimadores y haciéndolos sesgados (Green, 2000).

Además, el ACP tiene dos propiedades muy importantes que hacen de este método de reducción de la dimesionalidad uno de los más usados (Sánchez, 2012):

1. Los componentes principales obtienen secuencialmente la máxima variabilidad o varianza de $\mathrm{X}$, por lo que se garantiza la mínima pérdida de información (en el sentido de error de reconstrucción).

2. Los componentes principales obtenidos son ortogonales entre sí, facilitando su posterior procesado y análisis, ya que pueden tratarse independientemente.

Por otro lado, una de las principales desventajas del ACP es que las correlaciones que son la base de su cálculo pueden no necesariamente representar la "influencia real" de los componentes sobre el fenómeno que quiere medirse, sino un efecto estadístico espurio. Asimismo, los resultados obtenidos del ACP pueden ser sensibles a la modificación de la muestra de datos o, como ya se dijo, a la presencia de datos atípicos (también conocidos como outliers). Sobre la base de la información obtenida de los $p$ autovalores calculados según las indicaciones del recuadro, se plantean diversos criterios para decidir el número razonable de componentes que permita condensar de mejor manera la estructura de los datos y posibilite su posterior interpretación. Los criterios más relevantes son (CEPAL,2009):

a. Criterio de Kaiser (Kaiser, 1958). Consiste en eliminar todas las componentes cuyos autovalores sean inferiores a la unidad. La justificación de este criterio es que no tiene sentido agregar una componente que explique menos varianza que la contenida en una variable. El criterio de Jolliffe toma como límite inferior el valor 0.7; otra posibilidad es seleccionar el número de factores explicativos cuya raíz característica supere el valor medio de todas las raíces características.

b. Contraste de caída (Cattell, 1965). Este criterio parte de graficar los autovalores de manera decreciente (gráfico de sedimentación), escogiéndose aquellas componentes hasta el punto en que la curva decreciente converge a una línea horizontal, lo que indica que a partir de allí la varianza explicada adicional no aporta mucho más.

c. Porcentaje de la varianza explicada. Consiste en acumular con los autovalores de mayor valor un porcentaje de la varianza explicada hasta alcanzar un nivel mínimo aceptable (por ejemplo, entre 70 y $80 \%)$.

d. Criterios de comprensibilidad. Cuando la construcción de las componentes da lugar a algún tipo de interpretación que sea entendible en términos de las clases que se constituyen.

Una vez determinadas las componentes principales más significativas se puede crear con éstas una medida compuesta como la media aritmética simple, es decir, una suma usualmente ponderada con el mismo peso a cada una de ellas. Otra alternativa puede ser la agregación directa de las primeras componentes ponderadas, por ejemplo, por la desviación estándar de cada una (Peters y Butler, 1970). Cualquier procedimiento elegido de los mencionados anteriormente, será conveniente realizar un análisis posterior de la correlación entre las variables originales y las componentes seleccionadas para validar la bondad de los resultados. El paso final es la valoración de la necesidad de cambios en el 
análisis realizado; ello puede llevar a la eliminación de variables o el empleo de otros métodos de selección de componentes, lo que se conoce como la fase de calibración del modelo.

Uriel (1995) recomienda el uso de variables expresadas en forma de razones (ratios) puesto que eliminan el problema de magnitud o escala que puede enmascarar otras características relevantes de la información disponible. No obstante, esta práctica acarrea otro tipo de problemática, ya que se modifica la forma de la distribución y atribuyéndoles demasiada importancia a los casos que, en términos absolutos, estarían localizados en las colas de la distribución de cada variable.

\subsubsection{Análisis de datos con el Statistical Package for Social Sciences (SPSS)}

Para poder analizar todos los indicadores para cada una de las demarcaciones territoriales de la CDMX se utilizó el software SPSS, el cual es un sistema para el análisis de datos. Este software proporciona herramientas que permiten a los usuarios consultar datos y formular hipótesis de pruebas adicionales de forma rápida, así como ejecutar procedimientos para ayudar a aclarar las relaciones entre variables, crear clústeres, identificar tendencias y realizar predicciones (Pérez, 2014). Entre los análisis que realiza encontramos el Análisis de Componentes Principales (ACP). Este software es una potente aplicación de análisis estadísticos de datos, dotada de una intuitiva interfaz gráfica que resulta muy fácil de manejar. Respecto a su capacidad de procesamiento de datos, puede manejar bases de datos con más de 30,000 variables y cualquier tamaño de casos.

Aunque actualmente SPSS pertenece a IBM, originalmente la empresa fue creada por Norman $\mathrm{H}$. Nie, C. Hadlai (Tex) Hull y Dale H. Bent, quienes desarrollaron un software basado en la idea de convertir los datos estadísticos en información esencial para la toma de decisiones (Méndez y Cuevas, 2015). Este sistema de software estadístico tiene como fin analizar rápidamente grandes volúmenes de datos obtenidos a partir de distintos métodos de investigación. Estos atributos fueron de las principales razones por las que se eligió este software para realizar el análisis de los datos generados en esta investigación.

\subsection{Metodología para la evaluación de la eficacia en el manejo de RSU en la CDMX}

Esta investigación trata de resolver la necesidad de contar con indicadores en materia de RSU en la CDMX para la toma de decisiones, ya que el incremento de la generación de RSU se ha convertido en una severa problemática para las ciudades del mundo, especialmente las más pobladas y que aún no cuentan con adecuadas estrategias para mitigarlos. Un resultado de esto se ve reflejado claramente en dos indicadores básicos que la mayoría de las ciudades y países tienen a su alcance: Generación de RSU y Disposición Final de RSU generados. Mientras menos RSU se dispongan con respecto a la cantidad total que se genera, mejor puede considerarse su manejo. En el caso particular de la CDMX, se está disponiendo más del 80\% de los RSU generados, con base en el Inventario de RSU de 2014. Bajo este contexto, es pertinente preguntarnos en qué medida el manejo de residuos sólidos urbanos en la CDMX, desde su generación hasta su disposición final, ha sido eficaz para cumplir los objetivos propuestos por el modelo de gestión integral y por el marco jurídico y de planeación de esta entidad. 
Se piensa que el manejo de los RSU en la CDMX no es eficaz, porque está centrado en la fase de recolección y disposición final, sin prestar atención a la adecuada separación que permita un procesamiento eficiente de los residuos para su valoración y aprovechamiento en otras fases productivas, para la generación de energía y la producción de composta.

Dada la compleja problemática que presenta todas las fases del manejo de los RSU en la Ciudad de México, es de gran importancia realizar una evaluación de la eficacia, con el fin de contar con insumos que apoyen una mejor toma de decisiones y permitan dar seguimiento a la efectividad de los programas implementados en la materia para reducir la generación, mejorar la recolección y separación, incrementar el procesamiento, y minimizar la disposición final. En este sentido, esta evaluación ayudará a los tomadores de decisiones a determinar qué partes del manejo de los RSU en la CDMX requiere de la implementación o ajuste de las medidas utilizadas. La evaluación utilizará el modelo de ACP para la generación de indicadores compuestos, los cuales son alimentados por indicadores simples para cada una de las fases del manejo de los RSU. Los resultados obtenidos fueron normalizados y transformados en una escala del 1 al 10, haciendo referencia al modo de evaluar del sistema escolar mexicano, para facilitar la comprensión de los resultados por parte de los tomadores de decisiones y de la población en general.

Es de vital importancia realizar varias aclaraciones con respecto a las bases de datos utilizadas para la estimación de los indicadores simples que alimentaron el modelo de componentes principales. La primera y más importante, es reconocer que la información y datos disponibles son estimados por la Secretaría de Obras y Servicios (SOS) de la CDMX. Esta situación se debe a varias cuestiones políticas entre el gobierno de la CDMX y el sindicato de los empleados encargados de la recolección de los RSU en la ciudad. Los datos disponibles que se tienen con respecto a la generación están estimados por medio de los datos que se emiten en las plantas de transferencia. Los camiones recolectores de basura recorren ciertas rutas que abarcan varias colonias, de incluso diferentes demarcaciones territoriales, y en el momento en que los ciudadanos entregan sus residuos sólidos a los camiones recolectores, éstos se vuelven los nuevos dueños. Las personas encargadas de recolectar dichos residuos seleccionan el material reusable o reciclable para venderlo en mercados formales o informales, antes de llegar a su destino final que son las estaciones de transferencia. Por consiguiente, el volumen total de residuos sólidos generados está subestimados, y en particular, de aquellos residuos que pueden ser valorados y comercializados. En este sentido, es las estaciones de transferencia en donde se puede obtener el primer dato real, ya que los camiones son pesados hasta entonces. Si bien lo deseables es pesar el camión justo cuando termina la recolecta, esto es prácticamente imposible, ya que el sindicato de los trabajadores de la basura y los mismos trabajadores argumentan sentirse vigilados y asegura que con los bajos salarios que perciben no pueden cubrir sus gastos, así que se ven en la necesidad de vender en la medida de lo posible los residuos que va saliendo de cada domicilio que sean reusables o reciclables. Con base en esta información y conociendo las condiciones en que se pesan los camiones, se calcula un promedio de RSU generados por demarcación territorial, y posteriormente, una generación total por año y per cápita. Teniendo conocimiento de esta situación entendemos que la mayoría de los datos disponibles en la CDMX son cálculos que parten de estimaciones, incluyendo lo relativo a los volúmenes recolectados, los volúmenes separados de residuos orgánicos e inorgánicos, y los volúmenes de residuos que pueden reciclarse o reutilizarse.

La segunda aclaración se refiere a la periodicidad de la evaluación de esta investigación. Se seleccionó el periodo 2014-2015, ya que son los datos más recientes y disponibles por parte de la Secretaría de Obras y Servicios (SOS) de la CDMX. Es importante recalcar, que la disponibilidad de datos sólo está desagregada por demarcación territorial y no por colonia o ruta, que hubiera sido lo 
deseable. Por este motivo, la investigación utilizó como unidad de análisis las demarcaciones territoriales, reconociendo que los siguientes pasos para investigaciones futuras, será trabajar con un mayor nivel de desagregación espacial, situación que estará sujeta a la disponibilidad de información que se cuente en el sector. El tener los datos desagregados por colonia podría dar mejores resultados.

\subsubsection{Generación y tratamiento de la base de datos}

El primer paso fue generar una base de datos que tuviera la mayor cantidad de indicadores posibles, que pudieran tener relación con los RSU; esta base fue procesada de diversas maneras, ya que se encontraron varias inconsistencias a la hora de extraer los datos de las fuentes de información originales, que en este caso fueron la Secretaría de Obras y Servicios (SOS) en el año 2015, de los Inventarios de Residuos Sólidos Urbanos para el año 2014 y 2015 y del INEGI para el mismo periodo mencionado.

La Secretaría de Obras, tuvo a bien proporcionar diversos datos para esta investigación, que son los datos que en algún momento se ocuparán para generar el Inventario de RSU de la CDMX del año 2015. Es importante mencionar, que a lo largo de diversas entrevistas que se hicieron tanto en la Secretaría de Obras como en la Secretaría del Medio Ambiente, se advirtió de la complejidad política y social en la CDMX relacionada con el manejo de los RSU y sus implicaciones para la disposición de información real y fidedigna tanto del manejo de los RSU como de cada una de sus fases. La base de datos que se utilizó para generar el modelo de evaluación, está constituida en su mayoría por indicadores simples; algunos fueron extraídos directamente de informes, inventarios y otras bases de datos, y otros fueron estimados o calculados a partir de los datos con los que ya se contaba. En primer lugar, es importante conocer cuáles fueron los indicadores empleados en la base de datos, precisando los criterios utilizados para generarlos (Tabla 4.4). En la Tabla 4.4 se precisan los criterios que se utilizaron para la generación de indicadores simples y los indicadores que fueron seleccionados para cada fase y que alimentaron el modelo de componentes principales.

Tabla 4.4. Criterios para la generación de indicadores simples

\begin{tabular}{|c|c|}
\hline $\begin{array}{l}\text { EXT. TERR KM2 } \\
\text { Extensión territorial en } \\
\text { kilómetros cuadrados }\end{array}$ & $\begin{array}{l}\text { La extensión territorial de cada demarcación territorial fue extraída de la } \\
\text { base de datos del INEGI, } 2010 .\end{array}$ \\
\hline $\begin{array}{c}\text { POBLACIÓN } \\
\text { Población dada por } \\
\text { número de habitantes }\end{array}$ & $\begin{array}{l}\text { La población se encuentra representada por el número de habitantes de } \\
\text { cada una de las demarcaciones territoriales y fue extraída del inventario de } \\
\text { RSU de la CDMX del año } 2014 \text {. }\end{array}$ \\
\hline $\begin{array}{c}\text { PIB MMP } \\
\text { Producto Interno Bruto en } \\
\text { millones de pesos }\end{array}$ & $\begin{array}{l}\text { El PIB representa el nivel de producción generado en una determinada } \\
\text { demarcación territorial a lo largo de un año. Se utiliza a menudo para } \\
\text { comparar el desempeño económico de los países con el fin de contar con } \\
\text { una medida de sus ingresos totales. Esta variable fue consultada en el } \\
\text { Censo económico realizado por el INEGI en } 2014\end{array}$ \\
\hline $\begin{array}{c}\text { PIB PER CAP } \\
\text { Producto Interno Bruto } \\
\text { per cápita }\end{array}$ & $\begin{array}{l}\text { Es la relación del PIB entre el número de habitantes de cada demarcación } \\
\text { territorial }\end{array}$ \\
\hline $\begin{array}{l}\text { PIB/HAB/DIA } \\
\text { Producto Interno Bruto } \\
\text { por persona por día }\end{array}$ & $\begin{array}{l}\text { Es la relación del PIB entre el número de habitantes de cada demarcación } \\
\text { territorial por día del año. }\end{array}$ \\
\hline
\end{tabular}


PER OCUP

Personal ocupado

REMUN TOT

Remuneración total

\section{REM/TRABA/ANUAL}

Remuneración por

trabajador al año

REM/TRABAJ/DÍA

Remuneración por

trabajador al día

\% PO. FEMENINA

Porcentaje de población

femenina

\section{NIVEL DE ESCOL}

Nivel de escolaridad máximo

18> UNIVER

Personas mayores de 18 años con estudios

universitarios

$\mathrm{P}<5$ AÑOS

Personas menores de cinco años

P\% < 4 AÑOS

Porcentaje de personas

menores de cinco años

P-15 Y 60

Personas entre 15 y 60

años

P\% 15Y60

Porcentaje de personas entre 15 y 60 años

PCATOLICA

Población católica

\%P católica

Porcentaje de población católica

PNCATOLICA

Población Nacional Católica

$\%$ PNCATOLICA

Porcentaje de Población

nacional católica

POTRAS_REL

Personas con otras

religiones

\% POTRAS_REL

Porcentaje de personas con otras religiones
Comprende a la población que laboró por unidad económica, y que cubrió como mínimo una tercera parte de la jornada laboral. Puede ser personal de planta, eventual o no remunerado.

Se entiende por remuneración las contraprestaciones en dinero y las adicionales en especie evaluables en dinero que debe percibir el trabajador del empleador por causa del contrato de trabajo. Este indicador fue extraído directamente del Censo económico elaborado por el INEGI en 2014.

Se calculó con base en la remuneración total dividida entre el número de trabajadores en un año

Se calculó con base en la remuneración total dividida entre el número de trabajadores por día a lo largo de un año.

Dato extraído de las bases del INEGI 2014

Extraído directamente de las bases del INEGI 2014. Considera los años de estudio globales que ha cursado cada persona

Extraído directamente de las bases del INEGI 2014. Se refiere a las personas que son mayores de 18 años y que se encuentran cursando estudios universitarios o ya los concluyeron.

Extraído directamente de las bases del INEGI 2014. Se refiere a las personas que son menores de 5 años.

Calculado en relación al número de menores de 5 años y la población total de cada demarcación territorial.

Extraído directamente de las bases del INEGI 2014. Se refiere a las personas que se encuentran entre 15 y 65 años de edad.

Calculado en relación al número de adultos entre 15 y 65 años de edad y la población total de cada demarcación territorial.

Población católica en cada una de las demarcaciones territoriales y extraída de la base de datos del INEGI 2014.

Calculado en relación al número de personas católicas y la población total de cada demarcación territorial.

Población no católica en cada una de las demarcaciones territoriales y extraído de la base de datos del INEGI 2014.

Calculado en relación al número de personas no católicas y la población total de cada demarcación territorial

Personas de otras religiones diferentes a la religión católica en cada una de las demarcaciones territoriales y extraída de la base de datos del INEGI 2014.

Calculado en relación al número de personas de diferente religión a la católica y la población total de cada demarcación territorial. 
PSIN_RELIG

Personas si religión

$\%$ PSIN_RELIG

Porcentaje de Personas sin religión

VIVPAR_HAB

Viviendas particulares

habitadas

VPH PISODT

Viviendas particulares

habitadas con piso de

tierra

\% VPH_PISODT

Porcentaje de viviendas

particulares habitadas con piso de tierra

VPH_C_ELEC

Viviendas particulares

habitadas con electricidad

VPH_S_ELEC

Viviendas particulares

habitadas sin electricidad

VPH_AGUADV

Viviendas particulares

habitadas con suministro

de agua

\% VPH_AGUADV

Porcentaje de viviendas

particulares habitadas con suministro de agua

VPH_DRENAJ

Viviendas particulares

habitadas con drenaje

\% VPH_DRENAJ

Porcentaje de viviendas

particulares habitadas con drenaje

VPH_C_SERV

Viviendas particulares habitadas

$\%$ VPH_C_SERV

Porcentaje de viviendas

particulares habitadas con todos los servicios

VPH_RADIO

Viviendas particulares

habitadas con radio

$\%$ VPH_RADIO

Porcentaje de viviendas

particulares habitadas con radio

VPH_TV
Personas sin religión en cada una de las demarcaciones territoriales y extraída de la base de datos del INEGI 2014.

Calculado en relación al número de personas sin religión y la población total de cada demarcación territorial.

Número de viviendas particulares habitadas en cada demarcación territorial. Extraído del Censo de población y vivienda del INEGI 2010 y del Conteo de Población 2014

Número de viviendas particulares habitadas con piso de tierra en cada demarcación territorial. Extraído del Censo de población y vivienda del INEGI 2010 y del Conteo de Población 2014

Porcentaje de viviendas particulares habitadas con piso de tierra en cada demarcación territorial. Calculado a partir de la relación con el total de viviendas particulares habitadas en cada una de las demarcaciones territoriales.

Número de viviendas particulares habitadas con electricidad. Extraído de la base de datos del INEGI 2014.

Número de viviendas particulares habitadas sin electricidad. Extraído de la base de datos del INEGI 2014.

Número de viviendas particulares habitadas con suministro de agua. Extraído de la base de datos del INEGI 2014.

Porcentaje de viviendas particulares habitadas con suministro de agua, calculado a partir de la relación con el total de viviendas particulares habitadas en cada una de las demarcaciones territoriales.

Número de viviendas particulares habitadas que cuentan con servicio de drenaje. Extraído de la base de datos del INEGI 2014.

Porcentaje de viviendas particulares habitadas que cuentan con servicio de drenaje, calculado a partir de la relación con el total de viviendas particulares habitadas en cada una de las demarcaciones territoriales.

Número de viviendas particulares habitadas que cuenta con todos los servicios. Extraído de la base de datos del INEGI 2014.

Porcentaje de viviendas particulares habitadas que cuentan con todos los servicios, calculado a partir de la relación con el total de viviendas particulares habitadas en cada una de las demarcaciones territoriales.

Número de viviendas particulares habitadas que cuenta con radio. Extraído de la base de datos del INEGI 2014.

Porcentaje de viviendas particulares habitadas que cuentan con radio, calculado a partir de la relación con el total de viviendas particulares habitadas en cada una de las demarcaciones territoriales.

Número de viviendas particulares habitadas que cuenta con televisión. Extraído de la base de datos del INEGI 2014. 
Viviendas particulares

habitadas con televisión

\%VPH_RADIO

Porcentaje de viviendas

particulares habitadas

$\%$ MARGIN

Porcentaje de marginación

GEN PER CÁPITA

KG/HAB/DÍA

KG de RSU generados

habitadas por día

GEN TOTAL TON

Generación total de RSU

en toneladas

$\mathrm{N}^{\circ}$ DE COLONIAS

Número de colonias

RECOL POR COL. RUTAS

Número de rutas de

recolección por colonia

RUT/COL

Ruta por colonia

VEHÍCULOS RECOL

Número de vehículos

recolectores

CHOFERES

Número de choferes con

los que dispone cada colonia

VEHI/COL

Número de vehículos por colonia

$\mathrm{CHOF} / \mathrm{COL}$

Número de choferes por colonia

RECOL SEP x COL

Rutas que recolectan RSU

separados por colonia

EFICIENCIA DE SEP \%

Porcentaje de eficiencia de separación en cada

demarcación territorial

ORGA. RECO TON

RSU totales recolectados de origen orgánico

PLANTA DE SELECCIÓN
Porcentaje de viviendas particulares habitadas que cuentan con radio, calculado a partir de la relación con el total de viviendas particulares habitadas en cada una de las demarcaciones territoriales.

El porcentaje de marginación fue calculado en relación al total de pobladores de cada una de las demarcaciones territoriales y el índice de marginación, éste último da cuenta de las carencias de la población asociadas a la escolaridad, la vivienda, los ingresos y otros aspectos sociodemográficos. El índice para el cálculo de este indicador fue extraído de la base de datos deCONAPO2014.

Calculado a partir de la relación de número de pobladores de cada demarcación territorial y el total de los residuos generados por día. Este dato fue ajustado como parte del tratamiento que se le dio a la base de datos.

La generación total de RSU en cada una de las demarcaciones territoriales, extraída del Inventario de RSU de 2014.

Número de colonias con las que cuenta cada una de las demarcaciones territoriales y extraído directamente del Inventario de RSU 2014.

Número de rutas con las que cuenta cada colonia por demarcación territorial, extraído del Inventario de RSU 2014.

Calculado a partir de la relación del número de colonias entre el número de rutas que cada colonia por demarcación territorial.

Número de vehículos recolectores con los que cuenta cada colonia por demarcación territorial. Extraído del Inventario de RSU 2014.

Número de choferes disponibles con las que cuenta cada colonia por demarcación territorial. Extraído del Inventario 2014.

Calculado con base en la relación de número de vehículos recolectores por demarcación territorial y el número de colonias.

Calculado con base en la relación del número de choferes con las que cuenta cada demarcación territorial con el número de colonias.

Número de rutas que recolectan la basura separada por colonia en cada demarcación territorial. Extraído del Inventario de RSU 2014.

Extraído del Inventario de RSU 2014. Se refiere a la eficiencia que tiene cada demarcación territorial para recolectar sus RSU de manera separada.

Referente a los RSU orgánicos totales, recolectados en cada demarcación territorial.

Es el total de toneladas de RSU que egresan por estación de transferencia y tienen como destino la planta de selección. Extraído del Inventario de RSU 2013.

Este indicador fue ajustado por otros indicadores que se generaron en el tratamiento de la información. 
PLANTA DE COMPOSTA

DISPOSICIÓN FINAL

PLANT SEL/GEN TOT

COMPOSTA/ GEN TOT

DISP FIN/ GEN TOT

\# PLANTAS COMPOSTA

EST DE TRANFERENCIA

\#SITIOS DE DISP FINAL

\% DE EFICIENCIA EN LA RECOLECCIÓN
Es el total de toneladas de RSU que egresan de cada una de las estaciones de transferencia y que tienen como destino la planta de composta. Extraído del Inventario de RSU en 2013.

Este indicador fue ajustado en la fase de tratamiento de la información. Es el total de toneladas de RSU que egresan por estaciones de transferencia y tienen como destino algún sitio de disposición final. Indicador extraído del Inventario de RSU 2013. Este indicador fue ajustado en la fase de tratamiento de la información.

Calculado a partir de la relación del total de RSU que se va a las plantas de selección con respecto al total de RSU generados por demarcación territorial.

Calculado a partir de la relación del total de RSU que se va a las plantas de composta con respecto al total de RSU generados por demarcación territorial.

Calculado a partir de la relación del total de RSU que se va a los sitios de disposición final con respecto al total de RSU generados por demarcación territorial.

Número de plantas de composta por demarcación territorial. Extraído de la Secretaría de Obras y Servicios.

Número de estaciones de transferencia por demarcación territorial. Extraído de la Secretaría de Obras y Servicios.

Números de sitios de disposición final por demarcación territorial.

Calculado con base en diversos indicadores proporcionados por el Inventario de RSU 2014. Los indicadores que formaron parte de dicho cálculo están relacionados con la infraestructura para la recolección, por ejemplo, el número de vehículos recolectores, el número de choferes y el número de rutas por colonia.

Fuente: Elaboración propia.

El análisis de los indicadores simples y compuestos asociados a las fases de manejo de RSU fue complementó con información socioeconómica que permitiera identificar posibles relaciones en el manejo de los RSU, por ejemplo, aspectos relacionados al género, ingresos, nivel educativo y condiciones de marginación.

Uno de los hallazgos más importantes, fueron ciertas inconsistencias en los indicadores que se generaron en los Inventarios de RSU de la CDMX para los años 2013 y 2014, para lo cual ciertos indicadores se tuvieron que estandarizar a la hora de ser procesados. Por ejemplo, se sabe que existen doce estaciones de transferencia distribuidas a lo largo de la CDMX, en doce de sus demarcaciones territoriales, ubicadas en once demarcaciones. Cada una de estas estaciones, tiene a bien atender a las delegaciones aledañas que no cuentan con estación de transferencia, y se distribuyen de la manera que lo indica la Tabla 4.5; cada estación atiende a las demarcaciones territoriales en la siguiente forma.

\section{Tabla 4.5. Distribución de RSU por estación de transferencia}

ESTACIONES DE

TRANSFERENECIA

1 ÁLVARO OBREGÓN
DEMARCACIONES QUE ATIENDE

Álvaro Obregón, Cuajimalpa y Miguel Hidalgo y Magdalena Contreras 


\begin{tabular}{|l|l|l|}
\hline $\mathbf{2}$ & AZCAPOTZALCO & Azcapotzalco y Miguel Hidalgo \\
\hline $\mathbf{3}$ & BENITO JUÁREZ & Benito Juárez \\
$\mathbf{4}$ & COYOACÁN & Coyoacán y Xochimilco \\
$\mathbf{5}$ & CUAUHTÉMOC & Cuauhtémoc \\
\hline $\mathbf{6}$ & $\begin{array}{l}\text { GUSTAVO A. } \\
\text { MADERO }\end{array}$ & Gustavo A. Madero \\
\hline $\mathbf{7}$ & IZTAPALAPA & Iztapalapa \\
\hline $\mathbf{8}$ & $\begin{array}{l}\text { CENTRAL DE } \\
\text { ABASTO }\end{array}$ & Central de Abasto e Iztacalco \\
\hline $\mathbf{9}$ & MILPA ALTA & Milpa Alta \\
\hline $\mathbf{1 0}$ & TLALPAN & Tlalpan y Magdalena Contreras \\
\hline $\mathbf{1 1}$ & VENUSTIANO & Venustiano Carranza \\
\hline $\mathbf{1 2}$ & XOCHIMILCO & Xochimilco y Tláhuac \\
\hline Fuente: Secretá́a de Obras y Servicios & 2015 \\
\hline
\end{tabular}

Fuente: Secretaría de Obras y Servicios, 2015.

Así bien, podemos decir que la estación de transferencia de la Álvaro Obregón, atiende a cuatro demarcaciones territoriales que incluyen: Cuajimalpa, Miguel Hidalgo y Magdalena Contreras y Álvaro Obregón. La estación de transferencia ubicada en Azcapotzalco atiende, además de a ella misma, a la demarcación de Miguel Hidalgo, que ésta última también es atendida por Álvaro Obregón. Así, la Tabla 4.5, explica a qué demarcaciones territoriales atiende cada una de las estaciones de transferencia; teniendo claro este dato se deduce que todos los RSU generados en cada una de las demarcaciones territoriales llegan a las estaciones de transferencia que les corresponde, y de ahí, los residuos parten a tres diferentes destinos: (1) a plantas de selección, (2) a plantas de composta, y (3) a sitios de disposición final. Sin embargo, es importante recordar que no todos los RSU generados son recolectados y además que pasan por una previa selección de los recolectores, por lo que se asume que lo que los recolectores aprovechan más lo que no se recolecta, es la diferencia de lo que se estima que se genera menos el total de lo que llega a las plantas de selección, plantas de composta, y sitios de disposición final. Siendo así, se reporta que, para el año 2013, llegaron a sitios de disposición final 4,309 ton/día recolectados, a las plantas de composta 1,942 ton/día, a las plantas de selección 1,506 ton/día, y de la industria cementera 0.1 ton/día; esto suma un total de 7757.1 ton/día (Inventario de RSU del DF, 2013). Aunado a esto, para el mismo año 2013, se reporta en el mismo inventario la siguiente información, correspondiente al destino que tienen los RSU de cada una de las estaciones de transferencia explicada en la Figura 4.3. Es muy importante mencionar que se tomó para este cálculo los datos del año 2013, ya que el Inventario 2014, no se dispone y el Inventario 2015 aún no está disponible al público.

Figura 4.3. Destino de los residuos sólidos de cada una de las estaciones de transferencia 


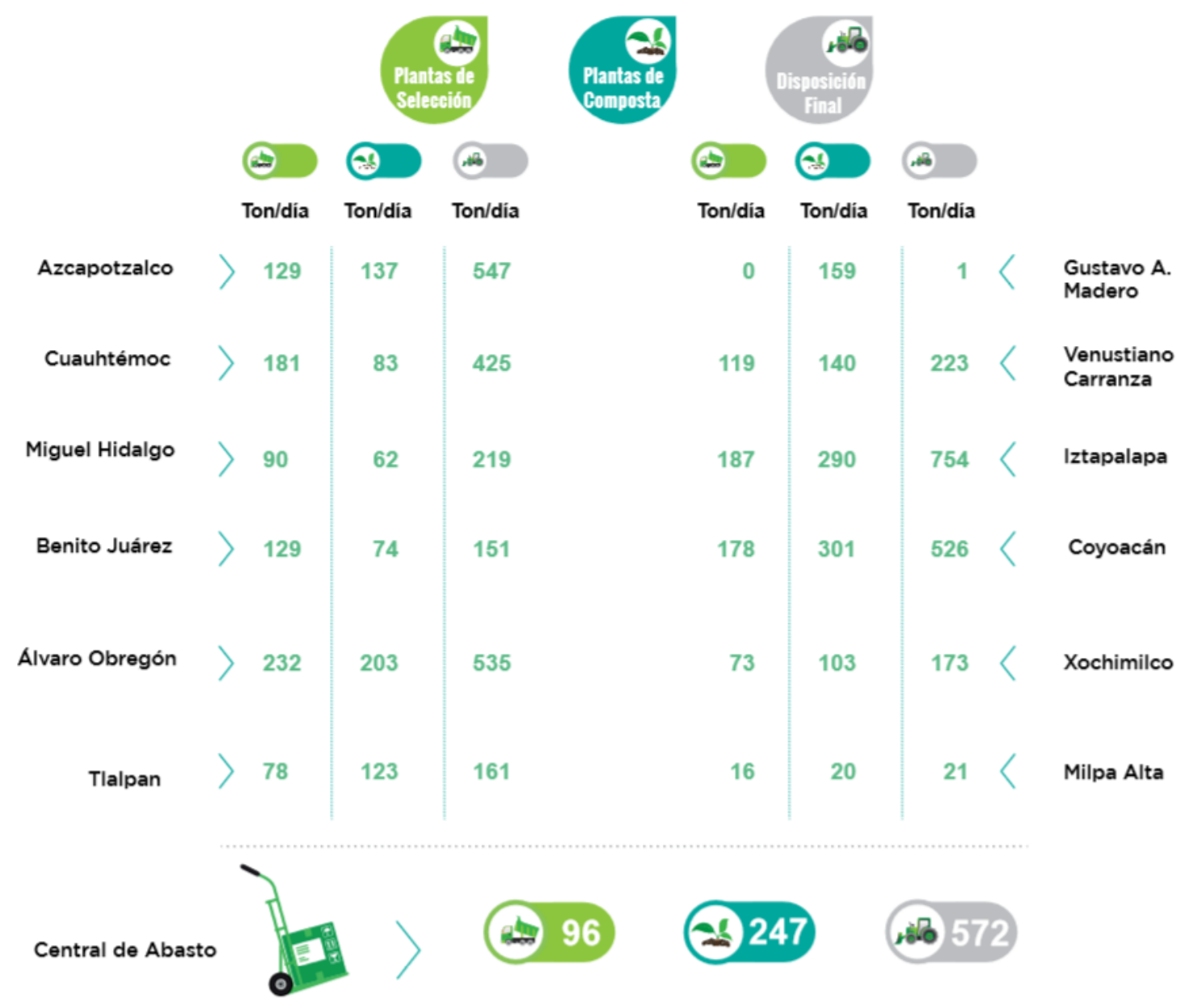

Fuente: Inventario de RSU, 2013

Se asume que el volumen de residuos que salen de las estaciones de transferencia es lo que llega a cada uno de sus destinos. Sin embargo, no es lo que parece estar ocurriendo, ya que al momento de sumar cada una de las columnas, los datos no corresponden a lo que egresa de las estaciones de transferencia. Por ejemplo, se tiene registrado que de las estaciones de transferencia sale un total de 1,631 ton/día con destino a las plantas de selección, un total de 1,934 ton/día con destino a las plantas de composta y un total de 4,308 ton /día con destino a los sitios de disposición final, lo que da un total de 7,873 ton/día. Esta cifra es inconsistente con lo reportado en los inventarios para otras variables reportadas, por lo que se estimó la disposición final con base en la información reportada para cada una de las fases, dado que hay una diferencia de casi120 ton/día. Esta diferencia radica en lo que llega a las plantas de selección y de composta. Aunado a esto, para el año 2014, según las estimaciones de generación de RSU realizadas por la Secretaría de Obras y Servicios (SOS) se calculó una generación de 12,893 ton/día de residuos, de lo cual sumando lo que llega a plantas de composta, de selección y sitios de disposición final se trata de un total de 8,080 ton/día para el mismo año, por lo que hay una diferencia de 4,813 ton/día, cifra que se presume que son las toneladas de RSU que se recolectan de manera informal y son valorizadas, a pesar de que no formen parte del inventario por los problemas de contabilización antes mencionado. . 
Por otro lado, para el año 2014 parece ocurrir lo mismo en cuanto a las inconsistencias del destino de los RSU en cada una de las estaciones de transferencia, siendo necesario recalcular varios datos y generar nuevos indicadores que permitieran construir una base de datos consistente. La base de datos y el tratamiento que se le dio a la información se encuentra en el anexo de esta investigación para su consulta. Algunos de los indicadores simples que fueron calculados fue el \% de eficiencia en la recolección, en el cual se considera la infraestructura para la recolección de los RSU generados. Se asume que mientras mayor infraestructura tenga cada demarcación territorial, mejor será su nivel de recolección.

La SOS estimó una generación total de RSU para la CDMX de 12,816 ton/día y 12,893 ton/día para los años 2013 y 2014, respectivamente (Inventario de RSU del DF 2013, 2014) y para el año 2015 hasta el mes de agosto, se había generado un promedio de 12,843 ton/día (SOS, 2015). Con base en esta estimación para la generación de RSU en la CDMX, del 2013 al 2014 hubo un incremento en la misma de $0.6 \%$ y para el año 2014 y lo registrado hasta el mes de agosto del 2015, este incremento asciende a $0.38 \%$. Debido a la disponibilidad de información del sector, indispensable para construir las bases de datos que alimentaron el modelo de componentes principales, diseñado para ser un modelo de evaluación del manejo de los RSU en la CDMX, se utilizó la información de los años 2014 y 2015, con el fin de contar con el mayor número posible de indicadores simples que incluyen: la recolección separada por colonias, las rutas de recolección separada, y los residuos orgánicos recolectados, la eficiencia de la separación de los residuos orgánicos y los vehículos recolectores por demarcación territorial, entre otros. Otro aspecto a destacar en el tratamiento de la base de datos consiste en explicar por qué en algunas demarcaciones territoriales los indicadores presentados en el inventario como plantas de selección, plantas de composta y sitios de disposición final aparecen en cero. Esto no implica que se destinen cero ton/día de RSU, sino más bien tiene que ver que en dichas demarcaciones territoriales no se cuentan con estaciones de transferencia, por lo que sus RSU generados se suman con los de otras demarcaciones, para ser transportadas a los sitios en donde se ubican este tipo de infraestructura. Lo anterior se explica en la Tabla 4.5. En cuanto a los sitios de disposición final que tiene cada demarcación territorial, en el inventario se reporta como cero, lo cual no implica que no se dispongan RSU; esta cifra refleja una de las problemáticas más severa en materia de disposición de RSU en la CDMX, ya que ésta no cuenta con sitios de disposición final, viéndose obligada a trasportar aquellos RSU que no pudieron ser valorizados a otras entidades. Por esta razón, este indicador se decidió descartarlo del modelo de Evaluación, ya que no contribuía a mejorar la explicación de la variabilidad de la muestra y evitaba que la matriz se pudiera invertir para la estimación de los parámetros. Este es otro de los puntos que dan relevancia a esta investigación, ya que sin sitios de disposición final es urgente implementar mejoras en la GIRS de la CDMX, para mejorar el aprovechamiento de los residuos, y a su vez aminorar el problema de la disposición de los mismos, Esta problemática fundamenta la urgencia de implementar un programa Basura Cero para la ciudad, cuyo cumplimiento está planeado para el actual periodo de gobierno, es decir antes del año 2018. Por lo pronto, alcanzar el objetivo de Basura Cero, se sigue viendo lejano para la CDMX.

También, se hicieron otros ajustes con los datos de generación per cápita de RSU por demarcación territorial, obteniéndose el ratio de la generación de RSU entre el número de habitantes para cada demarcación territorial con base en el inventario 2014, para evitar inconsistencias con el inventario 2014. La Tabla 4.4 detalla los criterios que se siguieron para la generación de indicadores, explicando de manera detallada cómo fue que se calculó cada uno de los indicadores presentados en la base de datos, o en su defecto de dónde se extrajeron para conformar esta base de datos. 
En el Anexo se puede encontrar la base de datos completa, con todos los indicadores mencionados en la Tabla 4.4 para cada demarcación territorial de la CDMX en el periodo 2014-2015.

\subsubsection{Procedimiento para la estimación del modelo de Evaluación}

Una vez estandarizada la base de datos, se eligió la opción de Análisis de Componentes Principales en el programa SPSS; asimismo, se examinaron los resultados de la Matriz de Correlaciones. La presencia de correlaciones altas en las variables es un indicativo de que existe información redundante y por lo tanto, pocos serán los factores que expliquen la mayoría de la variabilidad total de la muestra. En el análisis de la Matriz de correlaciones se van seleccionando aquellas variables que pueden contribuir al modelo de Evaluación de RSU en la CDMX en el periodo 2014-2015. Dicha selección de variables se complementará con el análisis de los componentes obtenidos, eliminando aquellas variables que no contribuyan a la explicación del modelo o se trate de una variable redundante.

Posteriormente, se estimó el modelo de componentes principales con una rotación varimax, para facilitar la interpretación de los resultados. Se realizaron varias corridas para calibrar el modelo y elegir las variables que mejor explicaran la variabilidad de la muestra. Una vez calibrado el modelo se procedió a la Selección de los Componentes, identificándose la contribución que cada componente tiene para explicar los resultados del desempeño del manejo de los RSU en la CDMX, como lo muestra la Figura 4.4.

Figura 4.4 Selección de los componentes

\begin{tabular}{|c|c|c|c|c|c|c|c|c|c|}
\hline \multicolumn{10}{|c|}{ Varianza total explicada } \\
\hline & \multicolumn{3}{|c|}{ Autovalores iniciales } & \multicolumn{3}{|c|}{ de la extracción } & \multicolumn{3}{|c|}{ la rotación } \\
\hline Componente & Total & $\begin{array}{c}\% \text { de la } \\
\text { varianza }\end{array}$ & $\begin{array}{c}\% \\
\text { acumulado }\end{array}$ & Total & \begin{tabular}{c|}
$\%$ de la \\
varianza
\end{tabular} & $\begin{array}{c}\% \\
\text { acumulado }\end{array}$ & Total & $\begin{array}{c}\% \text { de la } \\
\text { varianza }\end{array}$ & $\begin{array}{c}\% \\
\text { acumulado }\end{array}$ \\
\hline 1 & 3.222 & 53.696 & 53.696 & 3.222 & 53.696 & 53.696 & 2.377 & 39.613 & 39.613 \\
\hline 2 & 1.380 & 22.994 & 76.689 & 1.380 & 22.994 & 76.689 & 1.198 & 19.960 & 59.574 \\
\hline 3 & .725 & 12.076 & 88.765 & .725 & 12.076 & 88.765 & 1.113 & 18.550 & 78.124 \\
\hline 4 & .577 & 9.616 & 98.381 & .577 & 9.616 & 98.381 & 1.032 & 17.199 & 95.323 \\
\hline 5 & .097 & 1.619 & 100.000 & .097 & 1.619 & 100.000 & .281 & 4.677 & 100.000 \\
\hline 6 & $6.961 \mathrm{E}-16$ & $1.160 \mathrm{E}-14$ & 100.000 & & & & & & \\
\hline
\end{tabular}

Fuente: Impresión de pantalla del programa SPSS.

Con base en el porcentaje de la varianza total explicada por cada componente, se determina la forma funcional de la ecuación que representa el índice de desempeño del manejo de los RSU en la CDMX (ID), la se precisa a continuación (ecuación 1):

$$
I D=0.39613 C 1+0.19960 C 2+0.18550 C 3+0.17199 C 4+0.04677 C 5 . .(1)
$$

Para determinar las variables que conforman cada uno de los componentes seleccionados, se evalúan los resultados de la Matriz de Componentes y de la Matriz de Puntuación de los Componentes (Figura 4.5). A partir de esta información se pueden generar las ecuaciones que conforman cada uno de los componentes, los cuales están asociados a la evaluación de las fases del manejo de los RSU en la CDMX. 
Figura 4.5 Cálculo de la puntuación de los componentes

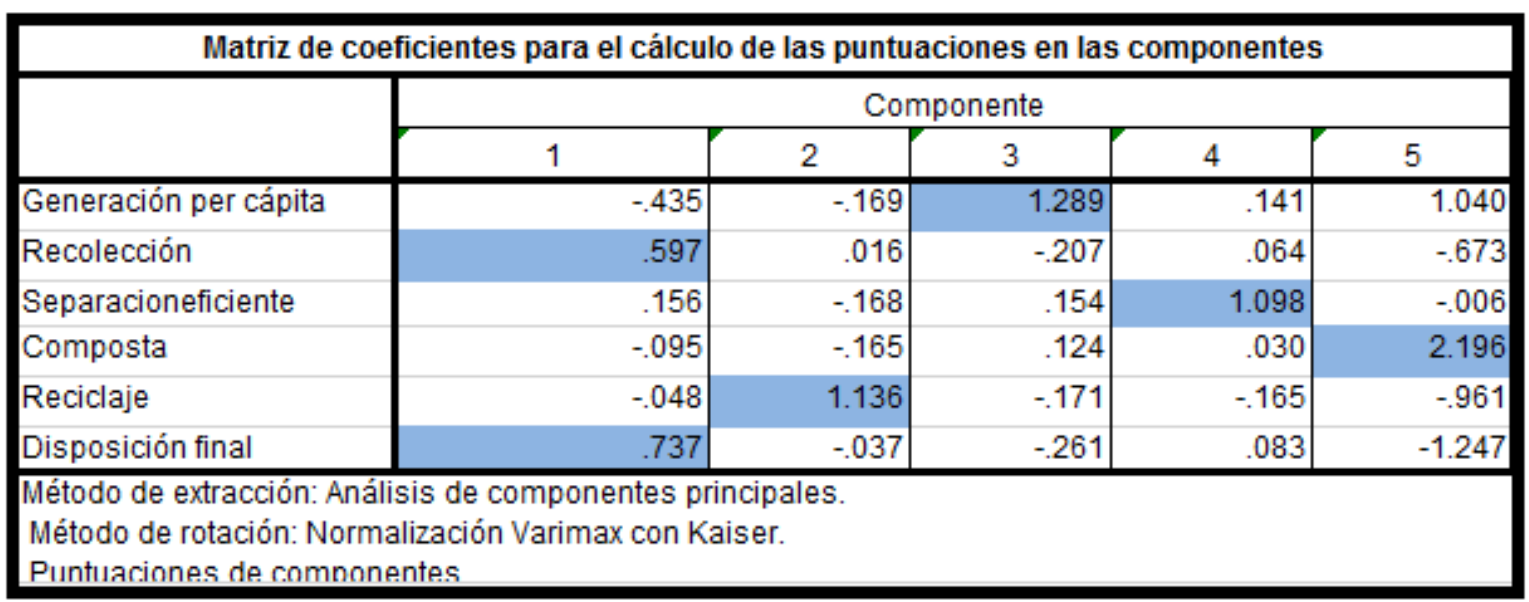

Fuente: Impresión de pantalla del programa SPSS.

Posteriormente, se le dio nombre a cada componente considerando las variables que los conforman, obteniéndose como resultado, indicadores compuestos para la evaluación de diferentes fases del manejo de los RSU. A partir de la Figura 4.6, se obtuvieron las siguientes ecuaciones:

C1=0.597 Recolección + 0.737 Disposición Final

C2=1.136 Reciclaje.

C3=1.289 Generación per cápita

C4=1.098 Separación Eficiente.

C5=2.196 Composta.

Los nombres otorgados a cada componente, considerando las variables que lo conformaron se detallan en la Tabla 4.6.

Tabla 4.6 Nombres de los indicadores compuestos del modelo de evaluación del desempeño

\begin{tabular}{|c|c|}
\hline Componente & Indicador compuesto \\
\hline C1 & Índice de Eficiencia en la Recolección y Disposición \\
\hline Ecuación 2 & \\
\hline C2 & Índice de Eficiencia en el Procesamiento \\
Ecuación 3 &
\end{tabular}




\begin{tabular}{|c|c|}
\hline $\begin{array}{c}\text { C3 } \\
\text { Ecuación } 4\end{array}$ & Índice de Eficiencia para la Reducción de la Generación \\
\hline C4 & Índice de Eficiencia en la Manipulación \\
\hline Ecuación 5 & Índice de Eficiencia en la Transformación \\
\hline C5 & Índice de Desempeño en el Manejo de los RSU \\
\hline Ecuación 6 & \\
\hline DD & \\
\hline Ecuación 1 &
\end{tabular}

Fuente: Elaboración propia

Definidos los indicadores compuestos para las fases mencionadas en la Tabla 4.6, éstos fueron estimados y estandarizados de manera que se obtuvieran valores entre 1 y 10 , para facilitar su interpretación, tomando como base el sistema de evaluación escolar de México; de esta forma, los tomadores de decisiones y el público en general podrán relacionar el desempeño de cada una de las fases con una calificación aprobatoria o reprobatoria. La estandarización de los resultados se basó en la selección de parámetros base atribuidos a un muy buena o muy malo manejo de los RSU, siguiendo el enfoque de la GIRS y considerando el marco de planeación de la CDMX, en particular el Plan Institucional de la Secretaría de Obras y Servicios 2013-2018 y el Programa de Gestión Integral de RSU de la CDMX 2016-2018. De acuerdo con este enfoque, la GIRS plantea que los países deben reducir la generación de RSU al mínimo, ya que de esta manera será menos costoso llevar a cabo el resto de las fases del manejo. Con respecto a las siguientes fases, propone una recolección del 100\% de los RSU generados para que posteriormente se lleve a cabo la manipulación, el procesamiento y la transformación del $100 \%$ de estos residuos, así como una valoración eficiente de los mismos, de manera que se alcance una disposición final del 0\% de los RSU generados.

Cabe mencionar, que la CDMX, en el plan y programa previamente mencionados, se compromete a llevar a cabo, o por lo menos intentar llevar a cabo, una GIRS; esto implica que se tratará de aprovechar al máximo posible los RSU generados en la CDMX, para así ya no depender de otras localidades para la disposición final. Por esta razón se tomaron casos de excelencia en el manejo delos RSU, cuyo desempeño en las diferentes fases fue evaluado con una calificación de 10; de manera contraria aquellos casos que representaban un muy mal manejo de los RSU, su desempeño fue evaluado con una calificación de cero.

Para la generación de RSU se ocupó el ejemplo de Uruguay, ya que es el país que menos genera RSU en el mundo con base en el informe del Hoornweg y Bhada (2012), registrando una generación per cápita de $0.325 \mathrm{Kg}$ /día; este país obtuvo una calificación de 10; de manera contraria, China es el país que más RSU genera en el mundo con $4.2 \mathrm{~kg}$ /día per cápita, por lo que la calificación de su desempeño en la fase de generación fue de cero. Con base en lo anterior, a partir de estos criterios se estandarizaron las calificaciones de las demarcaciones territoriales de la CDMX por su desempeño en la fase de generación de RSU.

En el caso de las fases de recolección, procesamiento, transformación y disposición final se utilizó el ejemplo de Suecia; país considerado como uno de los que mejor manejan sus RSU: Suecia, recolecta $90 \%$ de los RSU generados, ya que el restante $10 \%$ es procesado por los mismos ciudadanos en forma de composta; además, los RSU que son recolectados, $100 \%$ es transformado en energía verde. En este sentido, Suecia por su desempeño en las fases de recolección, procesamiento, transformación y disposición final obtuvo una calificación de 10. En el caso contrario, se utilizó el ejemplo de la India, 
ya que este país dispone $90 \%$ de los RSU generados en sitios de disposición final, y es el país según el Hoornweg y Bhada (2012) que peor gestiona sus RSU, ya que además de que casi todo lo que generan de RSU sus habitantes lo dispone, tiene problemas muy parecidos a México con respecto al servicio de recolección, ya que se puede recolectar el 100\% de RSU debido a que existe un aprovechamiento informal que comercializa aquellos residuos que pueden ser sujetos de una valoración económica. Este país como resultado se le asignó una calificación por su desempeño en las fases del manejo de los RSU mencionadas de cero.

Una vez definidos los parámetros de estandarización, se procedió a obtener los indicadores en forma de calificación para cada demarcación territorial de la CDMX. Los resultados obtenidos se analizan en la siguiente sección.

\subsection{Análisis de resultados}

Como primera fase de la generación del modelo se calculó una matriz capaz de expresar la variabilidad conjunta de todas las variables, esta matriz es llamada la matriz de correlación, la cual se sistematiza en las Tablas 4.8, 4.9 y 4.10. En el anexo de esta investigación se puede consultar dicha matriz completa, con todas las variables analizadas. Una vez estandarizada la base de datos, se introdujo la información al software SPSS, realizándose varias corridas hasta calibrar el modelo para que sus resultados fueran más robustos con respecto a la generación de un modelo de evaluación del manejo de RSU. En el análisis de la matriz de correlación, se consideraron aquellas variables de mayor relevancia en aras de identificar las relaciones más importantes entre las variables y cuáles pudieran ser descartadas para incrementar la capacidad del modelo de explicar una mayor variabilidad de la muestra. Si las variables presentan una correlación superior a \pm 0.7 , ésta se considera significativa. Asimismo, pueden existir variables en las que los resultados sean cercanos a \pm 1.0 , lo cual implica que se encuentren altamente relacionados entre sí. Sin embargo, además de analizar la relación matemática que presentan las variables, es necesario verificar la cumplen con el criterio de significancia unilateral, cuyos valores deben ser menores a 0.05 para que la relación identificada sea estadísticamente significativa. En caso de ser mayor a 0.05 , dicha relación no es estadísticamente significativa, por lo que si la relación matemática fuera superior a \pm 0.7 se trataría de una relación espuria. Una relación espuria se presenta cuando se piensa que dos o más variables están estadísticamente relacionadas, pero no tienen relación de causalidad entre ellas en realidad. En otras palabras, es simplemente una relación matemática entre acontecimientos que no tienen ninguna conexión (Uriel, 1985). Por esta razón, estos datos son importantes de analizar y reportar para evitar caer en errores o falsas interpretaciones a la hora de identificar los componentes que explican el manejo de los RSU y construir el modelo de evaluación del manejo de los RSU.

En la Tablas 4.8, se pone en evidencia que la variable Generación Total está estrechamente relacionada con las variables Recolección, Composta, Disposición Final, PIB/hab/día y Estaciones de transferencia; relación que es estadísticamente significativa. Este resultado verifica lo que se ha planteado en los capítulos anteriores: la generación de RSU se ha incrementado en gran medida porque la población urbana se ha incrementado también y sus estilos de vida se han modificado, especialmente por el consumismo que caracteriza la modernidad, esto también como consecuencia del modelo económico que en la actualidad nos rige. Esta última parte también lo demuestra, ya que la variable relacionada con el PIB presenta una fuerte relación con la generación de RSU con el resto 
de las variables que conforman el manejo de los RSU. Asimismo, la variable Generación per cápita tiene una relación relevante con la Recolección, lo cual pone en evidencia la estrecha relación que se esperaría que tuviera la Generación de RSU con la Recolección de los mismos; situación que refleja la eficiencia en materia de recolección y a la gran cantidad de recursos que se invierten en la infraestructura para la recolección, especialmente en las demarcaciones que más residuos per cápita generan. A lo largo de esta investigación se ha mencionado que, la generación de RSU está relacionada directamente con la intensidad de las actividades económicas en general, por lo que también podríamos asumir que las demarcaciones que más RSU generan por habitante, son las que destinan bastos ingresos a la infraestructura para la recolección de los mismos.

En el caso de la Recolección, esta variable presenta la relación más fuente con la variable Disposición Final, después con Composta, y por último, con Generación per cápita con valores de 0.979, 0.770 y 0.580 , respectivamente. La relación presentada en estas variables puede deberse en gran medida a que los tomadores de decisiones asignan gran parte del presupuesto para recolectar y disponer la basura, y en menor medida para promover el aprovechamiento y valoración de los RSU, ya sea en composta o en la generación de energía. Estos resultados coinciden con lo identificado por el Hoornweg y Bhada (2012), en un estudio realizado en materia de RSU en el cual se identificó que los países en vías de desarrollo invierten la mayor parte de su presupuesto destinado al manejo de los RSU, sólo a la recolección y a la disposición final, dejando de lado al resto de las fases del manejo que tienen gran importancia. Esta fuerte relación también puede deberse a que en general lo que se recolecta es lo que se dispone, ya que como se mencionó en esta investigación sólo $23 \%$ de los RSU son aprovechados, mientras que el procesamiento y transformación relacionada con la generación de composta y el reciclaje son mínimos, en comparación con el $77 \%$ restante que se va directamente a la disposición final. Mientras tanto, la variable de recolección asociada con la composta, esta relación parece bastante clara pues la cantidad de composta generada va a depender directamente de lo que se recolecte, dado que la posibilidad de generar más composta aumenta cuando se recolectan más residuos, especialmente si estos se encuentran bien separados.

En el caso de la variable Composta, ésta está fuertemente relacionada con variables como la Recolección, como anteriormente se analizó, Reciclaje y Disposición final también tiene valores que indican esta relación de 0.630 y 0.555 respectivamente y con una significancia 0.004 y 0.013 , respectivamente. Esto sugiere que a mayor cantidad de composta que se lograra generar, menor sería la cantidad de RSU de origen orgánico que se dispondrían. Recordando que casi la mitad de los RSU generados en la CDMX son de origen orgánico, se estaría hablando de un promedio de $42 \%$ según los datos de los inventarios de RSU para la ciudad en los años 2014-2015.

Finalmente, la variable Disposición final está relacionada con la Recolección y la Generación per cápita de manera muy estrecha, y esta relación parece obvia si partimos desde una perspectiva con base en todo lo estudiado a lo largo de la investigación. En otras palabras, se sabe que la disposición final es la parte más problemática del manejo de los RSU en la CDMX, ya que no existen sitios de disposición final, por lo que se destina gran cantidad de recursos para recolectar los residuos y además transportarlos a lo largo y ancho de toda la ciudad para llevarlos al Estado de México y disponerlos finalmente. Una vez más se puede corroborar y reafirmar lo propuesto por el Hoornweg y Bhada (2012) en materia de los recursos que los países en desarrollo destinan a la recolección y disposición final de RSU.

Algo muy interesante que se identificó es que desafortunadamente la relación que tiene el nivel de escolaridad y el de estudios universitarios, no tiene nada que ver con la manera en la que se manejan 
los RSU. Por ende, se podría suponer que una persona mientras mayor grado de educación tenga e incluso asista a la universidad, podría tener mayor grado de conciencia ambiental y generar menos residuos, o ya en el último de los casos disponer de sus residuos de manera responsable, lo cual no es así. Pareciera que fuera de manera contraria, ya que como personas con altos grados de estudio perciben mejores salarios, estos presentan mayores niveles de consumo, generando como resultado grandes cantidades de RSU por día.

En la Tabla 4.9, que muestra el segmento dos, de la matriz de correlaciones, se puede confirmar lo que anteriormente se menciona, que de igual forma se observa la fuerte relación que existe entre el PIB y las fases del manejo, especialmente con la Generación Total y Generación por cápita, aunque se demuestran otro tipo de relaciones a lo largo de la matriz, no pertenecen al objetivo de esta investigación. Por lo que la variable más relevante a analizar es la de PIB/hab/día.

Finalmente, la Tabla 4.10 detalla relaciones muy interesantes, dado que el índice de marginación tiene una fuerte relación negativa con la Generación per cápita de RSU, lo cual implica que una persona con un mayor grado de marginación genera una menor cantidad de RSU. En realidad, esto tiene mucho sentido ya que se piensa que una persona que tiene buen estatus social, mejor trabajo, mejores ingresos, mejor vivienda, genera más RSU. En el caso de la vivienda también pude pensarse que, si su vivienda es de mejor calidad, necesitará mayor cantidad de insumos, como, por ejemplo, muebles, accesorios y televisores; por lo tanto, mayor será su generación de RSU. Por otro lado, otra variable interesante de analizar son las Estaciones de Transferencia, aunque esta variable parece no estar muy relacionada con otras variables, esto puede deberse a que la gran cantidad de movimientos que se hace con los RSU se hace en las estaciones de transferencia.

Con este análisis queda demostrado que el nivel de escolaridad no tiene nada que ver con la conciencia ambiental, se pensaba que las personas que asisten a la universidad tienen mayor información sobre la necesidad de aprender a manejar los RSU de forman adecuada; sin embargo, eso no es garantía que tengan una disposición de los RSU más sustentable. Esta situación obliga a reflexionar qué estrategias pueden favorecer un enfoque diferente al manejo de los RSU y guiar a los tomadores de decisiones, para que se aprecien los residuos como una materia prima que genera dinero. Quizá cambiando la perspectiva, las personas puedan ver que, al gestionar mal los residuos, están perdiendo la oportunidad de recibir ingresos. 
Tabla 4. 8. Segmento 1 de la matriz de correlaciones.

\begin{tabular}{|c|c|c|c|c|c|c|c|c|c|c|c|c|c|c|}
\hline \multirow[b]{2}{*}{ VARIABLE } & \multicolumn{2}{|c|}{ GENERACIÓN TOTAL } & \multicolumn{2}{|c|}{ GEN-PER CÁPITA } & \multicolumn{2}{|c|}{ RECOLECCIÓN } & \multicolumn{2}{|c|}{ SEPARACIÓN EFICIENTE } & \multicolumn{2}{|c|}{ COMPOSTA } & \multicolumn{2}{|c|}{ RECICLEJE } & \multicolumn{2}{|c|}{ DISPOSICIÓN FINAL } \\
\hline & CORRELACÓN & \begin{tabular}{|l} 
Significancia \\
Unilateral
\end{tabular} & CORRELACÓN & $\begin{array}{l}\text { Significancia } \\
\text { Unilateral }\end{array}$ & CORRELACÓN & \begin{tabular}{|l|} 
Significancia \\
Unilateral
\end{tabular} & CORRELACÓN & \begin{tabular}{|l} 
Significancia \\
Unilateral
\end{tabular} & CORRELACÓN & $\begin{array}{l}\text { Significancia } \\
\text { Unilateral }\end{array}$ & CORRELACÓN & $\begin{array}{l}\text { Significancia } \\
\text { Unilateral }\end{array}$ & CORRELACÓN & \begin{tabular}{|l} 
Significancia \\
Unilateral
\end{tabular} \\
\hline Generación total & 1.000 & & .402 & .061 & .967 & .000 & -322 & .112 & .835 & .000 & .305 & 5.126 & .305 & .000 \\
\hline Generación per cápita & .402 & .061 & 1.000 & & .580 & .009 & -324 & 110 & .150 & 289 & .229 & 9.197 & .229 & .004 \\
\hline Recolección & .967 & .000 & .580 & .009 & 1.000 & & -310 & .121 & .770 & .000 & .323 & 3.111 & .323 & 3.000 \\
\hline Separacioneficient & -.322 & .112 & -.324 & 1.110 & -.310 & .121 & 1.000 & & $\begin{array}{l}.071 \\
\end{array}$ & .397 & .178 & 255 & .178 & 3.081 \\
\hline Composta & .835 & .000 & .150 & .289 & .770 & .000 & -.071 & .397 & 1.000 & & .555 & 5.013 & .555 & 5.004 \\
\hline Reciclaje & .305 & .126 & .229 & .197 & .323 & .111 & .178 & 255 & .555 & .013 & 1.000 & & 1.000 & .268 \\
\hline Disposición final & .925 & .000 & .635 & 5004 & .979 & .000 & -367 & .081 & .630 & .004 & .167 & .268 & .167 & \\
\hline Extension & -.026 & .462 & -.410 & .057 & -.070 & .399 & .433 & .047 & .027 & .461 & -.009 & 9.486 & -.009 & .372 \\
\hline Poblacion & .922 & .000 & .038 & .445 & .812 & .000 & -248 & .177 & .891 & .000 & .291 & .137 & .291 & .001 \\
\hline PIB/HAB/DIA & -.719 & .001 & -.328 & .107 & -.691 & .002 & $\begin{array}{l}.478 \\
\end{array}$ & .030 & -.738 & .001 & -.664 & .003 & -.664 & .008 \\
\hline REM/TRABAJ/DÍA & .079 & .386 & .633 & 3.004 & .213 & .214 & -.439 & .044 & -.010 & .486 & -.011 & 4.484 & -.011 & .168 \\
\hline \%PO. FEMENINA & .028 & 460 & .590 & .008 & .170 & .264 & -406 & .059 & .012 & 482 & .040 & .442 & .040 & .233 \\
\hline NIVEL DE ESCOL & .062 & .410 & .628 & .005 & .190 & .240 & $\begin{array}{l}-423 \\
\end{array}$ & .051 & .015 & .478 & .168 & 3.267 & .168 & .219 \\
\hline 18\&gt; UNIVER & .038 & .444 & .593 & .008 & .158 & .279 & -429 & .049 & -.017 & .474 & .098 & 358 & .098 & .247 \\
\hline P\%\&lt;5AÑOS & -.133 & .312 & .393 & .066 & -.025 & .464 & $\begin{array}{l}.067 \\
\end{array}$ & 402 & -.210 & 218 & -.123 & 325 & -.123 & .454 \\
\hline P\%15Y60 & .089 & .371 & -.394 & .066 & -.066 & .404 & -200 & .229 & .051 & .425 & -.051 & 4.425 & -.051 & .374 \\
\hline \%P catolica & -.245 & .181 & -.773 & .000 & -.374 & .077 & .311 & .121 & -.114 & .338 & -.251 & .175 & -.251 & .064 \\
\hline \%VPH_PISODT & .391 & .067 & .186 & .245 & .415 & .055 & -279 & .148 & .493 & .026 & .518 & 3.020 & .518 & .104 \\
\hline \%VPH_C_ELEC & -.021 & .470 & -.697 & .001 & -.174 & 260 & .327 & .108 & .037 & .446 & -.150 & .290 & -.150 & .225 \\
\hline \%VPH_AGUADV & .381 & .073 & .214 & .213 & .366 & .081 & $\begin{array}{l}-464 \\
\end{array}$ & .035 & .359 & .086 & .144 & .298 & .144 & .100 \\
\hline \%VPH_DRENAJ & .118 & .331 & -.608 & .006 & -.028 & .460 & .203 & 225 & .182 & 250 & -.066 & \begin{tabular}{|l|l}
5.404 \\
\end{tabular} & -.066 & .397 \\
\hline \%VPH_C_SERV & .394 & .065 & .237 & .189 & .385 & .071 & -.478 & .030 & .375 & .076 & .160 & 277 & .160 & .089 \\
\hline \%VPH_RADIO & -.312 & 120 & -.725 & 5001 & -.433 & .047 & .127 & .320 & -.044 & 436 & -.003 & 4.496 & -.003 & .023 \\
\hline$\%$ VPH_TV & .030 & .456 & -.674 & .002 & -.120 & .330 & .180 & 253 & .134 & .310 & -.025 & 4.464 & -.025 & .262 \\
\hline$\%$ MARGIN & $\begin{array}{ll}-468 \\
\end{array}$ & .034 & -.672 & .002 & -.552 & .013 & .483 & .029 & $\begin{array}{ll}.357 \\
\end{array}$ & .087 & -.165 & 271 & -.165 & .012 \\
\hline RUT/COL & .386 & .070 & -.087 & .375 & .360 & .085 & .029 & .458 & .562 & .012 & .614 & .006 & .614 & .183 \\
\hline VEHI/COL & .185 & 247 & .738 & .001 & .335 & .103 & -233 & 193 & -.017 & .475 & -.040 & .441 & -.040 & .059 \\
\hline CHOF/COL & .065 & 405 & .629 & .004 & .185 & 247 & -365 & .082 & -.156 & .282 & -.108 & 346 & -.108 & .159 \\
\hline \# PLANTAS COMPOSTA & -.204 & .225 & -.556 & .013 & -.314 & .118 & .197 & .232 & -.080 & .384 & -.481 & .030 & -.481 & .118 \\
\hline EST DE TRANFERENCIA & .708 & .001 & .300 & .130 & .650 & .003 & \begin{tabular}{|c|}
-153 \\
\end{tabular} & 286 & .672 & .002 & .235 & \begin{tabular}{|l}
5.191 \\
\end{tabular} & .235 & .008 \\
\hline
\end{tabular}

Fuente: Elaboración propia con SPSS 
Tabla 4.9. Segmento 2 de la matriz de correlaciones.

\begin{tabular}{|c|c|c|c|c|c|c|c|c|c|c|c|c|c|c|}
\hline \multirow[b]{2}{*}{ VARIABLE } & \multicolumn{2}{|c|}{ EXTENCIÓN } & \multicolumn{2}{|c|}{ POBLACIÓN } & \multicolumn{2}{|c|}{ PIB/HAB/DÍA } & \multicolumn{2}{|c|}{ REM/TRAB/DÍA } & \multicolumn{2}{|c|}{ \%PO. FEMENINA } & \multicolumn{2}{|c|}{ NIVEL DE ESCOL } & \multicolumn{2}{|c|}{ 18\&gt; UNIVER } \\
\hline & CORRELACÓN & \begin{tabular}{|l|} 
Significancia \\
Unilateral \\
\end{tabular} & CORRELACÓN & \begin{tabular}{|l|} 
Significancia \\
Unilateral \\
\end{tabular} & CORRELACÓN & $\begin{array}{l}\text { Significancia } \\
\text { Unilateral } \\
\end{array}$ & CORRELACÓN & \begin{tabular}{|l|} 
Significancia \\
Unilateral
\end{tabular} & CORRELACÓN & \begin{tabular}{|l} 
Significancia \\
Unilateral
\end{tabular} & CORRELACÓN & \begin{tabular}{|l|} 
Significancia \\
Unilateral \\
\end{tabular} & CORRELACÓN & \begin{tabular}{|l} 
Significancia \\
Unilateral
\end{tabular} \\
\hline Generación total & $\begin{array}{ll}.026 \\
\end{array}$ & 462 & .922 & .000 & -.719 & .001 & .079 & .386 & .028 & .460 & .062 & 410 & .038 & .444 \\
\hline Generación per cápita & -.410 & .057 & .038 & .445 & -.328 & .107 & .633 & .004 & .590 & .008 & .628 & .005 & .593 & .008 \\
\hline Recolección & -.070 & .399 & \begin{tabular}{l|l}
.812 \\
\end{tabular} & .000 & -691 & .002 & .213 & 214 & .170 & .264 & .190 & 240 & .158 & 279 \\
\hline Separacioneficient & .433 & .047 & -.248 . & .177 & .478 & .030 & -.439 & .044 & $\begin{array}{ll}.406 \\
\end{array}$ & .059 & -.423 & .051 & $\begin{array}{ll}-.429 \\
\end{array}$ & .049 \\
\hline Composta & .027 & .461 & .891 . & .000 & -.738 & .001 & -.010 & 486 & .012 & 482 & .015 & 478 & \begin{tabular}{l|l|}
-017 \\
\end{tabular} & 474 \\
\hline Reciclaje & -.009 & .486 & .291. & .137 & -.664 & .003 & -.011 & .484 & .040 & 4.442 & .168 & 267 & .098 & 358 \\
\hline Disposición final & -.088 & .372 & .728 . & .001 & -.589 & .008 & .257 & .168 & .197 & .233 & .209 & 219 & .184 & 247 \\
\hline Extension & 1.000 & & .117 . & .333 & .185 & .246 & \begin{tabular}{ll|}
-303 \\
\end{tabular} & .127 & -.556 & .013 & -.468 & .034 & \begin{tabular}{ll|}
-.488 \\
\end{tabular} & .027 \\
\hline Poblacion & .117 & .333 & 1.000 & & -.701 & .001 & -.128 & 318 & -.161 & .275 & \begin{tabular}{|l|l|}
-146 \\
\end{tabular} & 295 & \begin{tabular}{ll|}
.159 \\
\end{tabular} & .279 \\
\hline PIB/HAB/DIA & .185 & .246 & \begin{tabular}{l|}
.701 \\
\end{tabular} & .001 & 1.000 & & -200 & .229 & -209 & 218 & -282 & 145 & -239 & .187 \\
\hline REM/TRABAJ/DÍA & -.303 & .127 & -.128 & .318 & -200 & .229 & 1.000 & & .572 & .010 & .590 & .008 & .583 & .009 \\
\hline \%PO. FEMENINA & -.556 & .013 & -.161 . & .275 & -209 & .218 & .572 & .010 & 1.000 & & .907 & .000 & .905 & .000 \\
\hline NIVEL DE ESCOL & -.468 & .034 & -.146 & .295 & -282 & .145 & .590 & .008 & .907 & .000 & 1.000 & & .994 & .000 \\
\hline 18\&gt; UNIVER & -.488 & .027 & -.159 & .279 & -239 & .187 & .583 & .009 & .905 & .000 & .994 & .000 & 1.000 & \\
\hline P\%\&lt;5AÑOS & \begin{tabular}{l|l|}
.023 \\
\end{tabular} & .466 & -.279 & .148 & .265 & .161 & .406 & .059 & .510 & .022 & .614 & .006 & .623 & .005 \\
\hline P\%15Y60 & .123 & .325 & .246 . & .179 & -269 & .157 & -.048 & 430 & -.452 & .039 & -359 & .086 & -345 & .095 \\
\hline \%P catolica & .313 & .119 & .024 . & .465 & .261 & .165 & -.504 & .023 & -.721 & .001 & -860 & .000 & -831 & .000 \\
\hline \%VPH_PISODT & -.373 & .077 & .398. & .063 & \begin{tabular}{c|c|}
-687 \\
\end{tabular} & .002 & .127 & .319 & .347 & .094 & .244 & .182 & .206 & .222 \\
\hline \%VPH_C_ELEC & .336 & .102 & .216 . & .211 & .149 & .291 & -611 & .006 & -845 & .000 & -.948 & .000 & $\begin{array}{l}.937 \\
\end{array}$ & .000 \\
\hline \%VPH_AGUADV & -.788 & .000 & .349 . & .093 & -.506 & .023 & .168 & 267 & .370 & .079 & .188 & 243 & .191 & .239 \\
\hline \%VPH_DRENAJ & .172 & .262 & .344 . & .096 & \begin{tabular}{|c|}
.047 \\
\end{tabular} & .432 & -.539 & .016 & \begin{tabular}{|c|}
-697 \\
\end{tabular} & .001 & -.851 & .000 & -.845 & .000 \\
\hline \%VPH_C_SERV & -.786 & .000 & .357 . & .087 & -.533 & .017 & .191 & .239 & .404 & .060 & .223 & 203 & .225 & 202 \\
\hline \%VPH_RADIO & .097 & .360 & -.025 . & .464 & -.053 & .423 & -293 & .135 & -.326 & .109 & -.433 & .047 & -.413 & .056 \\
\hline$\%$ \%PH_TV & .166 & .269 & .283. & .144 & \begin{tabular}{ll|}
.056 \\
\end{tabular} & .418 & \begin{tabular}{ll|}
-557 \\
\end{tabular} & .012 & -685 & .002 & -.830 & .000 & -.825 & .000 \\
\hline \%MARGIN & .696 & .001 & -.250 . & .176 & .407 & .059 & -.332 & .105 & -.700 & .001 & -.641 & .004 & -.628 & .005 \\
\hline RUT/COL & .199 & .230 & .496 & .025 & \begin{tabular}{l|l|}
-653 \\
\end{tabular} & .003 & -.063 & 409 & .115 & .335 & .116 & .335 & .071 & .397 \\
\hline VEHI/COL & -.469 & .033 & -.125 . & .322 & -.078 & .387 & .517 & .020 & .435 & .046 & .439 & .044 & .410 & .058 \\
\hline CHOF/COL & -369 & .080 & -203 . & .225 & -.091 & .369 & .491 & .027 & .489 & .027 & .541 & .015 & .516 & .020 \\
\hline \# PLANTAS COMPOSTA & .343 & .097 & -.011 . & .484 & .514 & .021 & -293 & .135 & -.543 & .015 & -.524 & .019 & -486 & .028 \\
\hline EST DE TRANFERENCIA & 207 & .221 & .675 . & .002 & -.447 & .041 & .049 & 428 & \begin{tabular}{l|l|}
-014 \\
\end{tabular} & .479 & .068 & 401 & .065 & 406 \\
\hline
\end{tabular}

Fuente: Elaboración propia con SPSS 
Tabla 4.10. Segmento 3 de la matriz de correlaciones.

\begin{tabular}{|c|c|c|c|c|c|c|c|c|c|c|c|c|}
\hline \multirow[b]{2}{*}{ VARIABLE } & \multicolumn{2}{|c|}{ \% MARGIN } & \multicolumn{2}{|c|}{ RUT/COL } & \multicolumn{2}{|c|}{ VEHI/COL } & \multicolumn{2}{|c|}{ CHOF/COL } & \multicolumn{2}{|c|}{ \# PLANTAS COMPOSTA } & \multicolumn{2}{|c|}{ EST DE TRANFERENCIA } \\
\hline & CORRELACÓN & \begin{tabular}{|l|} 
Significancia \\
Unilateral
\end{tabular} & CORRELACÓN & $\begin{array}{l}\text { Significancia } \\
\text { Unilateral }\end{array}$ & CORRELACÓN & \begin{tabular}{|l} 
Significancia \\
Unilateral
\end{tabular} & CORRELACÓN & \begin{tabular}{|l|} 
Significancia \\
Unilateral
\end{tabular} & CORRELACÓN & $\begin{array}{l}\text { Significancia } \\
\text { Unilateral }\end{array}$ & CORRELACÓN & $\begin{array}{l}\text { Significancia } \\
\text { Unilateral }\end{array}$ \\
\hline Generación total & -.468 & .034 & .386 & .070 & .185 & 247 & .065 & .405 & -.204 & .225 & .708 & .001 \\
\hline Generación per cápita & -.672 & .002 & $\begin{array}{ll}.087 \\
\end{array}$ & .375 & .738 & .001 & .629 & .004 & -.556 & .013 & .300 & .130 \\
\hline Recolección & -.552 & .013 & .360 & .085 & .335 & .103 & .185 & .247 & -.314 & .118 & .650 & .003 \\
\hline Separacioneficient & .483 & .029 & .029 & .458 & -.233 & .193 & -.365 & .082 & .197 & .232 & -.153 & .286 \\
\hline Composta & -.357 & .087 & .562 & .012 & \begin{tabular}{l|l|}
-.017 \\
\end{tabular} & .475 & -.156 & .282 & -.080 & .384 & .672 & .002 \\
\hline Reciclaje & -.165 & .271 & .614 & .006 & -.040 & .441 & -.108 & .346 & -.481 & .030 & .235 & .191 \\
\hline Disposición final & -.558 & .012 & .242 & .183 & .406 & .059 & .266 & .159 & -.315 & .118 & .593 & .008 \\
\hline Extension & .696 & .001 & .199 & .230 & -.469 & .033 & -.369 & .080 & .343 & .097 & .207 & .221 \\
\hline \begin{tabular}{|l|} 
Poblacion \\
\end{tabular} & -.250 & .176 & .496 & .025 & -.125 & .322 & -.203 & .225 & -.011 & .484 & .675 & .002 \\
\hline PIB/HAB/DIA & .407 & .059 & -.653 & .003 & \begin{tabular}{l|}
-.078 \\
\end{tabular} & .387 & \begin{tabular}{l|l|}
-.091 \\
\end{tabular} & .369 & .514 & .021 & \begin{tabular}{l|}
-.447 \\
\end{tabular} & .041 \\
\hline REM/TRABAJ/DÍA & -.332 & .105 & -.063 & .409 & .517 & .020 & .491 & .027 & -.293 & .135 & .049 & .428 \\
\hline \%PO. FEMENINA & -.700 & .001 & .115 & .335 & .435 & .046 & .489 & .027 & -.543 & .015 & $\begin{array}{l}.014 \\
\end{array}$ & .479 \\
\hline NIVEL DE ESCOL & -.641 & .004 & .116 & .335 & .439 & .044 & .541 & .015 & -.524 & .019 & .068 & .401 \\
\hline 18\&gt; UNIVER & -.628 & .005 & .071 & .397 & .410 & .058 & .516 & .020 & -.486 & .028 & .065 & .406 \\
\hline P\%\&lt;5AÑOS & \begin{tabular}{l|}
-195 \\
\end{tabular} & .234 & -.139 & .304 & .109 & .343 & .184 & .247 & -.071 & .397 & .063 & .409 \\
\hline P\%15Y60 & .469 & .034 & 200 & .229 & -.139 & .303 & .039 & .443 & .083 & .379 & -.102 & .354 \\
\hline \%P catolica & .625 & .005 & -.021 & .469 & -.566 & .011 & -.637 & .004 & .443 & .043 & -.240 & .185 \\
\hline$\%$ VPH_PISODT & -.390 & .068 & .752 & .000 & -.031 & .455 & -.119 & .331 & -.635 & .004 & -.036 & .447 \\
\hline$\%$ VPH_C_ELEC & .574 & .010 & .005 & .493 & -.413 & .056 & -.488 & .028 & .431 & .048 & -.157 & .281 \\
\hline$\%$ VPH_AGUADV & -.620 & .005 & .221 & .205 & .266 & .160 & .142 & .300 & -.384 & .071 & \begin{tabular}{l|l|}
-.088 \\
\end{tabular} & .373 \\
\hline$\%$ VPH_DRENAJ & .416 & .055 & .170 & .265 & -.344 & .096 & -.439 & .045 & .258 & .168 & -.158 & .279 \\
\hline \%VPH_C_SERV & -.636 & .004 & .250 & .175 & .275 & .151 & .157 & .281 & -.411 & .057 & -.074 & .392 \\
\hline$\%$ VPH_RADIO & .495 & .026 & .335 & .103 & -.505 & .023 & -.437 & .045 & .086 & .376 & \begin{tabular}{l|}
-.372 \\
\end{tabular} & .078 \\
\hline$\%$ YPH_TV & .444 & .042 & .213 & .214 & -.433 & .047 & -.502 & .024 & .238 & .188 & -.219 & .207 \\
\hline$\%$ MARGIN & 1.000 & & .016 & .476 & -.536 & .016 & -.396 & .064 & .395 & .065 & \begin{tabular}{l|l|}
-.302 \\
\end{tabular} & .128 \\
\hline RUT/COL & .016 & .476 & 1.000 & & -.305 & .125 & -.250 & .175 & -.533 & .017 & .083 & .380 \\
\hline VEHI/COL & -.536 & .016 & -.305 & .125 & 1.000 & & .904 & .000 & -.226 & .201 & -.079 & .385 \\
\hline CHOF/COL & -.396 & .064 & -.250 & .175 & .904 & .000 & 1.000 & & -.256 & .170 & -.129 & .317 \\
\hline \# PLANTAS COMPOSTA & .395 & .065 & -.533 & .017 & -.226 & 201 & -.256 & .170 & 1.000 & & .061 & .411 \\
\hline EST DE TRANFERENCIA & -.302 & .128 & .083 & .380 & -.079 & .385 & -.129 & .317 & .061 & .411 & 1.000 & \\
\hline
\end{tabular}

Fuente: Elaboración propia con SPSS 
Tabla 4.11. Varianza total explicada

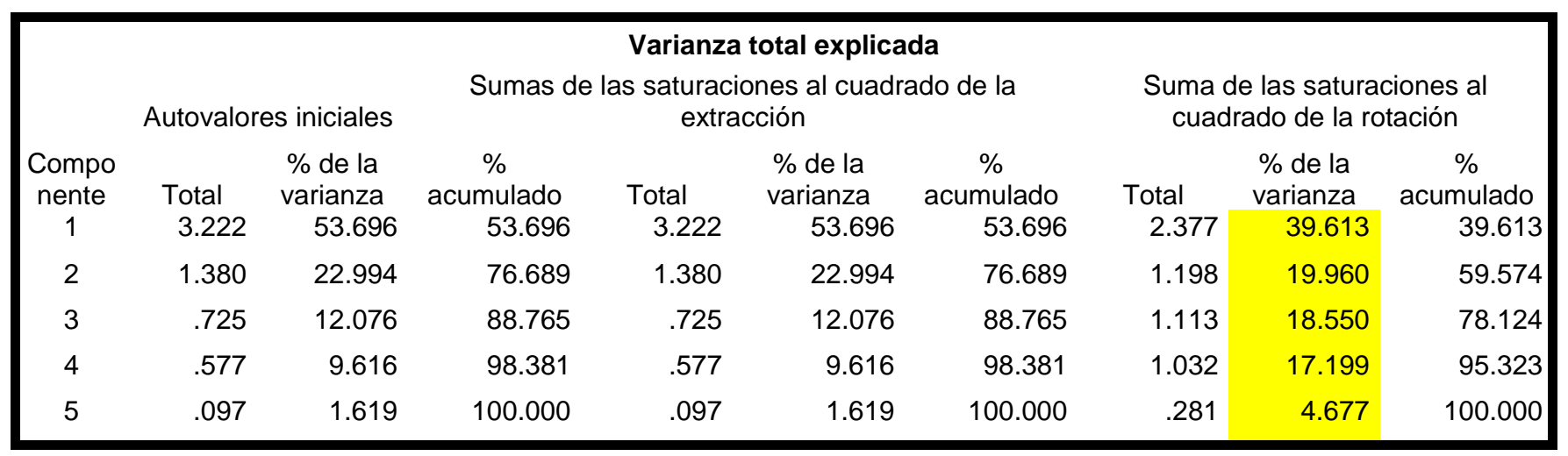

Fuente: Elaboración propia

La Tabla 4.11 permite analizar la varianza total explicada por cada componente. Esta matriz se generó en el software SPSS con base en una solución rotada de tipo VARIMAX, que es una rotación ortogonal que minimiza el número de variables que tienen saturaciones altas en cada factor o componente, simplificando así la interpretación de los componentes optimizando la solución por columna. En el caso del modelo de evaluación de la GIRS, se encontró que el componente C1 explica $39.613 \%$ de la muestra, el componente C2 19.96\%, el componente C3 18.55\%, el componente C4 $17.199 \%$ y el componente C5 4.68\%. De acuerdo con la varianza total explicada de cada componente, se determinó la ponderación que le corresponde a cada componente para la estimación del índice del desempeño del manejo de los residuos (IDMRSU), considerando que se trata de un modelo lineal. La ecuación que explica dicho componente es la siguiente:

$$
\mathrm{ID}=0.39613 \mathrm{C} 1+0.19960 \mathrm{C} 2+0.18550 \mathrm{C} 3+0.17199 \mathrm{C} 4+0.04677
$$

Otro método alternativo para la selección de factores o componentes es el gráfico de sedimentación, en el que se representan gráficamente los autovalores (eje de ordenadas) para cada factor o componente (eje de abscisas). El análisis visual de este gráfico se centra básicamente en la búsqueda de un punto de inflexión, que habitualmente se produce con los puntos que se encuentran por debajo del uno. Tal como lo muestra el gráfico 4.1. 


\section{Gráfico 4.1 Gráfico de sedimentación}

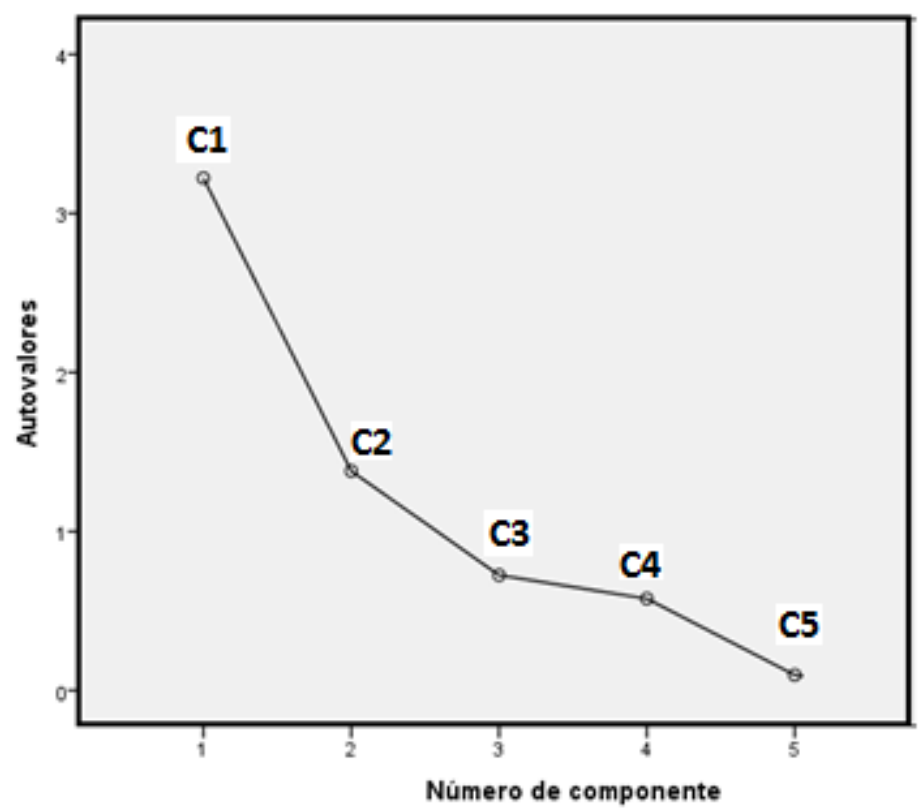

Fuente: Extraido del software SPSS.

En este gráfico podemos observar como el C1 explica la mayor parte de la variabilidad de la muestra, dejando por debajo del uno el componente tres, cuatro y cinco. Lo que significa que el componente uno y dos están explicando alrededor de 50\%, mientras que el otro 50\% lo está explicando el componente tres, cuatro y cinco en diferentes proporciones.

Por otro lado, también se obtuvo la matriz de componentes rotados como podemos ver en la siguiente tabla.

\section{Tabla 4.12 Matriz de componentes rotados}

Matriz de componentes rotadosa

\begin{tabular}{|l|r|r|r|r|r|}
\hline \multirow{2}{*}{} & \multicolumn{5}{|c|}{ Componente } \\
\cline { 2 - 6 } & \multicolumn{1}{|c|}{1} & \multicolumn{1}{c|}{2} & \multicolumn{1}{c|}{3} & \multicolumn{1}{c|}{4} & \multicolumn{1}{c|}{5} \\
\hline Generación per cápita & .304 & .106 & .933 & -.158 & -.029 \\
Recolección & .929 & .174 & .277 & -.144 & .092 \\
Separacioneficiente & -.161 & .109 & -.143 & .970 & -.004 \\
Composta & .526 & .441 & -.112 & -.017 & .576 \\
Reciclaje & .144 & .975 & .109 & .114 & .068 \\
Disposición final & .920 & .019 & .348 & -.177 & -.020 \\
\hline
\end{tabular}

Método de extracción: Análisis de componentes principales.

Método de rotación: Normalización Varimax con Kaiser.

a. La rotación ha convergido en 8 iteraciones. 
En general, el proceso de rotación lo que busca es generar una estructura más simple: variables que saturen, de ser posible en un único componente y componentes que contengan un número reducido de variables que saturen inequívoca y exclusivamente el ellos (Tabla 4.12).

En el caso del componente $\mathrm{C} 1$, las variables que se saturan en el mismo incluyen la Recolección y Disposición final; para el componente C2 son el Reciclaje; para el componente C3 la Generación per cápita, para el componente C4 la Separación Eficiente; y finalmente, para el componente C5, la variable Composta. Con ayuda de la Tabla 5.6, se identifica que las variables Recolección y Disposición Final están sumamente relacionadas explicando un $39.61 \%$ de la variabilidad de la muestra, lo cual pone en evidencia que las autoridades y tomadores de decisiones están completamente enfocados en las dos fases del manejo que la mayoría de los países en desarrollo como lo identifico el Hoornweg y Bhada (2012). Esto pone en evidencia la falta de atención que existe por parte del gobierno en fomentar un buen plan para el manejo de los RSU, o que incluso, aunque exista el plan o la intención de realizar un buen manejo que contemple las cinco fases, en especial la de transformación, como lo hacen los países desarrollados, no se lleva a cabo, sino simplemente se está dejando en la intención de querer hacer las cosas bien, pero no se logran concretar.

$\mathrm{Al}$ igual que el gráfico de sedimentación, existe un gráfico de componentes rotados mostrado en la Gráfico 4.2, que muestra la saturación de las variables.

\section{Gráfico 4.2 Gráfico de componentes rotados}

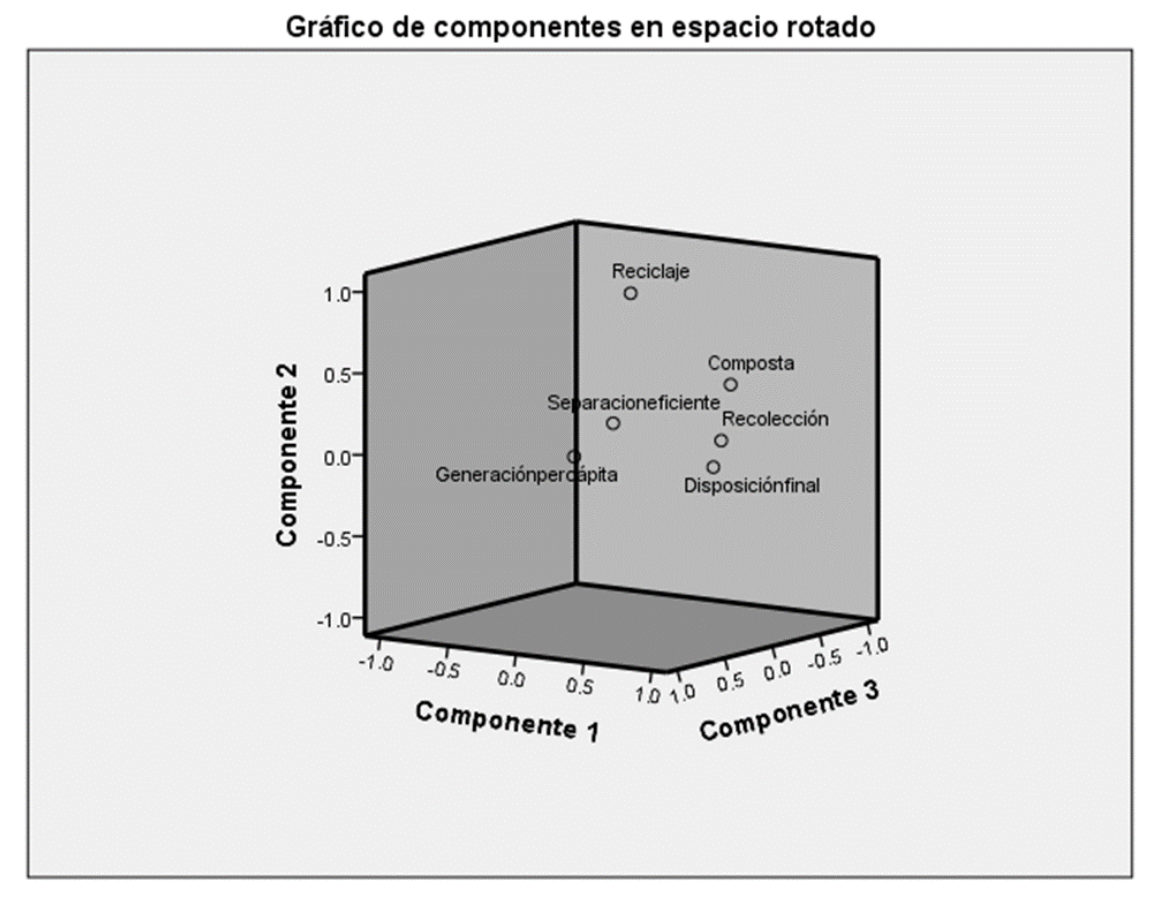

Fuente: Extraído del software SPSS.

Este gráfico muestra sólo tres componentes en tres dimensiones ya que sería imposible mostrar cinco dimensiones donde se pudieran representar los cinco componentes y sus respectivas variables de 
saturación. En general, este gráfico es una representación visual de la saturación de las variables en los componentes en un espacio rotado.

En adición a esto, también se genera la matriz de coeficientes para el cálculo de las puntuaciones en las componentes, representada por la Tabla 4.13, con la cual se generan los valores de cada componente para finalmente calcular el Índice de Desempeño del Manejo de los RSU IDMRSU, dada por la siguiente ecuación $\mathrm{ID}=0.39613 \mathrm{C} 1+0.19960 \mathrm{C} 2+0.18550 \mathrm{C} 3+0.17199 \mathrm{C} 4+0.04677 \mathrm{C} 5$, que se obtuvo de la Tabla 3; con base en esta ecuación se puede calcular el índice de desempeño del manejo para cualquier año, sin olvidar que: C1 está relacionado con Recolección y Disposición Final, C2 con Reciclaje, C3 con Generación per cápita, C4 Eficiencia en la separación y C5 Composta.

Tabla 4.13. Matriz de coeficientes para el cálculo de las puntuaciones en las componentes Matriz de coeficientes para el cálculo de las puntuaciones en las componentes

\begin{tabular}{|l|r|r|r|r|r|}
\hline & \multicolumn{5}{|c|}{ Componente } \\
\cline { 2 - 6 } & \multicolumn{1}{|c|}{1} & \multicolumn{1}{c|}{2} & \multicolumn{1}{c|}{3} & \multicolumn{1}{c|}{4} \\
\hline Generación per cápita & -.435 & -.169 & 1.289 & .141 & 1.040 \\
Recolección & .597 & .016 & -.207 & .064 & -.673 \\
Separacioneficiente & .156 & -.168 & .154 & 1.098 & -.006 \\
Composta & -.095 & -.165 & .124 & .030 & 2.196 \\
Reciclaje & -.048 & 1.136 & -.171 & -.165 & -.961 \\
Disposición final & .737 & -.037 & -.261 & .083 & -1.247 \\
\hline
\end{tabular}

Fuente: Elaboración propia

C1=0.597Recolección + 0.737Disposición Final

C2=1.136Reciclaje

C3=1.289Generación per cápita

C4=1.098Separación Eficiente

C5=2.196Composta

Una vez teniendo estos datos, se procedió a calcular cada uno de los índices para cada una de las demarcaciones territoriales. Es de vital importancia mencionar que, los valores que se originaron con el uso de estas fórmulas van del rango de -2 a 2, como lo muestra la Tabla 4.14; así que tuvieron que someterse a una estandarización usando valores máximos y mínimos, y también para transformarlos a una calificación similar al que se usa en el sistema escolar mexicano, el cual va del 1 al 10. Esto con el fin de que fuera de fácil interpretación para los tomadores de decisiones de la CDMX. Los datos así por si solos serían difíciles de interpretar, por lo que carecerían de valor informativo.

Tabla 4.14. Componentes para cada una de las Demarcaciones Territoriales 


\begin{tabular}{|l|r|r|r|r|c|}
\hline \multicolumn{1}{|c|}{ Delegación } & \multicolumn{1}{c|}{ C1 } & \multicolumn{1}{c|}{ C2 } & \multicolumn{1}{c|}{ C3 } & \multicolumn{1}{c|}{ C4 } & C5 \\
\hline Val max & -1.6095 & -0.27099 & -1.74414 & -0.59065 & -1.16018 \\
\hline Val min & 2.7799 & -1.21116 & -1.37429 & -1.37195 & -0.78943 \\
\hline Azcapotzalco & -0.86122 & -0.28425 & -0.10809 & -1.35173 & 0.37223 \\
\hline Coyoacán & -0.15428 & 1.83336 & -0.00895 & 1.39386 & 0.85535 \\
\hline Cuajimalpa & -0.62432 & -1.50475 & -0.66991 & -0.28387 & -0.34776 \\
\hline GAM & 2.1794 & -0.35833 & -0.63139 & -0.68121 & -2.09867 \\
\hline Iztacalco & -0.54339 & 0.25366 & -0.2799 & -0.65083 & 0.62835 \\
\hline Iztapalapa & 2.38868 & 0.01779 & -0.97634 & 0.09119 & 1.91743 \\
\hline MContreras & -0.45668 & -0.81764 & -0.17934 & 1.61283 & 0.01038 \\
\hline Milpa Alta & -0.46917 & -1.97029 & -1.03801 & 1.94597 & -0.10084 \\
\hline Álvaro Obregón & -0.42567 & -0.11184 & -1.05826 & -1.18985 & 1.40978 \\
\hline Tláhuac & -0.84734 & 1.11391 & -0.79721 & -0.14998 & -1.52738 \\
\hline Tlalpan & 0.41922 & 1.12632 & -0.42742 & 0.52328 & -0.80793 \\
\hline Xochimilco & -0.95779 & 0.89396 & -0.54398 & -0.26496 & -0.47578 \\
\hline Benito Juárez & -0.41622 & -0.4406 & 0.68286 & -1.14538 & 0.05844 \\
\hline Cuauhtémoc & 0.69835 & -0.46458 & 2.14323 & -0.33769 & -0.35128 \\
\hline Miguel Hidalgo & -0.03378 & -0.1747 & 1.93827 & -0.27445 & 0.44309 \\
\hline VCarranza & 0.10421 & 0.88797 & 1.35444 & 0.76282 & 0.01459 \\
\hline Val min & -1.6095 & 1.83336 & & & \\
\hline
\end{tabular}

Fuente: Elaboración propia.

Los valores máximos y mínimos que se utilizaron para la estandarización de estos índices, se basan principalmente en los objetivos propuestos en el marco normativo y de planeación. Es decir, en la ley mexicana como en los planes de desarrollo y sectoriales, existen los ideales a alcanzar para cada una de las fases del manejo. Esto se analizó detalladamente en el capítulo cuatro, donde se explica a detalle la metodología que se desarrolló para la elaboración de este modelo de evaluación. Sin embargo, es impórtate recordar los siguientes puntos, con el fin de entender cómo se establecieron los valores máximos y mínimos que ayudaron a dar origen a los índices de desempeño del manejo de los RSU para el periodo 2014-2015 en esta investigación. Una vez estandarizados los valores se obtuvieron las siguientes calificaciones, expresadas en la Tabla 4.15. 
Tabla 4.15. Calificación para el manejo de RSU por Demarcación Territorial

\begin{tabular}{|c|c|c|c|c|c|c|}
\hline Delegación & $\begin{array}{c}\text { Índice de Eficiencia } \\
\text { en la Recolección y } \\
\text { Disposición }\end{array}$ & $\begin{array}{l}\text { Índice de Eficiencia } \\
\text { en el Procesamiento }\end{array}$ & $\begin{array}{c}\text { Índice de Eficiencia } \\
\text { para la Reducción de } \\
\text { la Generación }\end{array}$ & $\begin{array}{l}\text { Índice de Eficiencia en } \\
\text { la Manipulación }\end{array}$ & $\begin{array}{l}\text { Índice de Eficiencia } \\
\text { en la Transformación }\end{array}$ & $\begin{array}{c}\text { Índice de Desempeño } \\
\text { en el Manejo de los } \\
\text { RSU }\end{array}$ \\
\hline Azcapotzalco & 8.30 & 3.98 & 6.00 & 1.33 & 6.20 & 5.71 \\
\hline Coyoacán & 6.68 & 8.60 & 5.75 & 7.45 & 7.12 & 7.05 \\
\hline Cuajimalpa & 7.76 & 1.31 & 7.37 & 3.71 & 4.83 & 5.56 \\
\hline GAM & 1.37 & 3.81 & 7.28 & 2.82 & 1.50 & 3.21 \\
\hline Iztacalco & 7.57 & 5.15 & 6.42 & 2.89 & 6.69 & 6.03 \\
\hline Iztapalapa & 0.89 & 4.64 & 8.12 & 4.54 & 9.15 & 3.99 \\
\hline MContreras & 7.37 & 2.81 & 6.17 & 7.94 & 5.52 & 6.25 \\
\hline Milpa Alta & 7.40 & 0.29 & 8.27 & 8.68 & 5.30 & 6.27 \\
\hline Álvaro Obregón & 7.30 & 4.35 & 8.32 & 1.69 & 8.18 & 5.98 \\
\hline Tláhuac & 8.26 & 7.03 & 7.68 & 4.01 & 2.59 & 6.91 \\
\hline Tlalpan & 5.38 & 7.06 & 6.78 & 5.51 & 3.96 & 5.93 \\
\hline Xochimilco & 8.52 & 6.55 & 7.06 & 3.75 & 4.59 & 6.85 \\
\hline Benito Juárez & 7.28 & 3.63 & 1.67 & 1.79 & 5.61 & 4.49 \\
\hline Cuauhtémoc & 4.74 & 3.58 & 5.24 & 3.59 & 4.83 & 4.41 \\
\hline Miguel Hidalgo & 6.41 & 4.22 & 4.74 & 3.73 & 6.34 & 5.20 \\
\hline VCarranza & 6.10 & 6.54 & 3.31 & 6.04 & 5.52 & 5.63 \\
\hline
\end{tabular}

Fuente: Elaboración propia.

En la Tabla 4.15, también se muestra el Índice de desempeño global para cada una de las demarcaciones territoriales de la CDMX. En general, podemos observar que las calificaciones en la mayoría de las demarcaciones territoriales son reprobatorias, aún y a pesar de que los marcos normativos y de planeación, promueven la idealidad. Es importante identificar, las debilidades del manejo de los RSU en la CDMX, que al parecer van muy de acuerdo con los estudios realizados por el Banco Mundial en el año 2012. Este estudio hace hincapié, básicamente en la mala administración que los países en vías de desarrollo con respecto a sus presupuestos destinados al manejo de RSU. Esto está ocurriendo en la CDMX, ya que el promedio en el Índice de Recolección y Disposición es el que más alta calificación tiene con respecto al global del resto de las calificaciones, con un promedio de 7.05. Esto tiene bastante lógica para la CDMX, tan sólo considerando que no existen sitios de disposición final en la ciudad, lo que encarece de manera excesiva el proceso de traslado de los RSU a los sitios de disposición final, que principalmente se encuentran en el estado vecino a esta ciudad: el Estado de México. No sólo es un problema trasladarlos, sino que también se genera gran cantidad de emisiones contaminantes como bióxido de carbono que los camiones emiten día con día al transportar alrededor de 9,000 ton de RSU al vecino estado. Mientras tanto, la calificación más baja en promedio se encuentra en el Índice de la eficiencia en la manipulación, es decir en la CDMX, los ciudadanos no saben separa la basura, por lo que la transformación ya sea para generar energías verdes, o aprovechar en reciclaje, se vuelve casi imposible, pues los RSU que no son adecuadamente separados no pueden ser aprovechados. Por mencionar un ejemplo, si se piensa aprovechar el cartón o papel y este se mezcla con RSU de origen orgánico, este papel se humedece perdiendo su valor, lo mismo sucede con el resto de los materiales reciclables como plásticos y metales que al ser ensuciados por los RSU orgánicos, se encarece su procesamiento para ser reciclados y se complica aprovecharlos. Por el contrario, si se piensa generar biogás con los desechos orgánicos generados en la CDMX y estos están contaminados con otro tipo de residuos no degradables o peligrosos, el proceso de metabolización de las bacterias para genera biogás se termina, pues las características físico-químicas del sustrato (en este caso los desechos orgánicos) cambian abruptamente y terminan con las bacterias metanogénicas dando fin por consiguiente al proceso de metanogénesis que las bacterias realizan. En general, el saber separar la basura y no separarla desde donde se origina, es el mayor reto que 
actualmente está viviendo la CDMX, ya que como vivos como una especie de efecto dominó el resto de las fases se entorpece.

Por otro lado, a manera de visualizar mejor los índices obtenidos en esta investigación, se generaron mapas de la CDMX, con cada una de sus demarcaciones territoriales, para poder analizar mejor los resultados obtenidos. En la Figura 4.8, se puede apreciar las demarcaciones territoriales que generan mayor cantidad de RSU por habitante. Es importante mencionar que la generación de RSU por habitante nos da una mejor noción de la cantidad de RSU que en realidad se están generando, ya que, si se tomara en cuenta sólo la generación total de RSU por demarcación territorial, no se sabría en realidad lo que las personas están generando, ya que la cantidad de RSU es directamente proporcional a la población, motivo por el cual es muy importante conocer el patrón de generación de los habitantes de cada demarcación territorial. Es importante recordar que en el Capítulo I de esta investigación se mencionó que otro factor que influye en la generación de RSU de una población en específico es el Producto Interno Bruto por habitante (PBI per cápita), que también está directamente relacionada con otros indicadores cómo el Gasto del Consumo Final Privado. En el caso específico de la CDMX, tenemos las demarcaciones territoriales con los habitantes que más RSU generan sombreados en rojo, las cuales corresponden a Cuauhtémoc y Miguel Hidalgo con casi de $2.5 \mathrm{~kg} / \mathrm{hab} /$ día de RSU. En seguida, encontramos a las demarcaciones sombreadas en naranja y amarillo que van de 1.5 a poco más de $2 \mathrm{~kg} / \mathrm{hab} /$ día. Finalmente, las que menos generan sombreadas en tonos verdes que van de menos de un kilogramo a un poco más del kg/hab/día.

En el caso de la recolección de RSU que cada demarcación territorial presenta, se esperaría una fuerte relación con los datos antes mencionados de generación de RSU por habitante al día, ya que se puede intuir que las demarcaciones que más RSU generan, van a requerir de un servicio de recolección más intenso, en comparación con las demarcaciones territoriales que menos generan RSU (ver Figura 4.9). Sin embargo, los más generados en esta investigación, nos demuestran que no es así. Es decir, en el caso de Miguel Hidalgo y Cuauhtémoc, que son las demarcaciones que más RSU generan por habitante, presentan una recolección de RSU no muy altas. En el caso de las demarcaciones en tonalidades verdes, se observa que su servicio de recolección no es tan intenso, esto también se debe a que en general, son demarcaciones en donde sus pobladores están generando alrededor de $1 \mathrm{~kg} / \mathrm{hab} /$ día. (ver Figura 4.8-4.9).

A continuación, la Figura 4.10, nos muestra una de las fases más importantes para poder aprovechar los RSU, a esta fase pertenecen la manipulación y procesamiento. Aquí varios datos que se conjuntan y arrojan información importante, pues las demarcaciones que más RSU generan por habitante, son las que no presentan una recolección intensa y peor aún, una separación escuálida de los RSU o presentan una menor eficiencia en la separación de los mismos (manipulación). Lo contrario sucede en el caso de las demarcaciones que menos RSU generan ya que son las demarcaciones que mayor eficiencia en su recolección separada de RSU presentan, tal es el caso de Milpa Alta, Coyoacán y Magdalena Contreras. A esto se le suma que estas demarcaciones no recolectan gran cantidad de RSU pues en realidad no los generan. Aunado a esto, la Figura 4.12, que sigue representando la fase 3 del manejo delos RSU, en la parte de procesamiento y que se refiere al reciclaje, tenemos a Coyoacán cómo la demarcación que más RSU recicla, además de es de las que no genera tantos RSU y que tiene una buena recolección separada. Aquí nuevamente se demuestra, que mientras mayor eficiencia en la recolección de RSU separados, mayores probabilidades hay de reciclar y transformar los RSU para su aprovechamiento. Es por eso la importancia de implementar programas sociales para enseñar a la población a separar los RSU y por otro lado informar a los tomadores de decisiones que es conveniente invertir en la mejora de la recolección, para lograr una mayor eficiencia de separación 
de RSU que a su vez faciliten la fase 3 y 4 del manejo de los RSU y así llevar la menor cantidad de RSU a sitios de disposición final.

En la Figura 4.12, se observa la fase 4 del manejo de los RSU, la transformación y en general depende también de la cantidad de RSU que produzcan sus habitantes. Este caso resulta especial pues el caso de Milpa Alta en realidad, está produciendo pocos RSU por lo que la cantidad de transformación que tiene es muy poca, sin embargo, en comparación con los grandes generadores de RSU Milpa Alta está transformando gran parte de sus RSU, el mismo caso aplica para Coyoacán, por lo que es importante poder relacionar los datos que hay en cada caso de manera adecuada y así poder interpretar los resultados.

La disposición final es la quinta fase del manejo de los RSU, y está directamente relacionada con la generación que cada demarcación territorial tiene, es decir en el caso de Cuauhtémoc, Iztapalapa y Gustavo A. Madero, son las demarcaciones que llevan gran parte de sus RSU que generan a disposición final. Es importante recordar que la CDMX no tiene sitios de disposición final, por lo que resulta crítico generar formas de aprovechamiento de los residuos. En la Actualidad el Estado de México es el que recibe la gran mayoría de los RSU, hablamos de alrededor del $90 \%$ del total de los residuos recolectados en la CDMX. En esta investigación se genera una evaluación del manejo para poder identificar los puntos críticos y que más ayuda necesitan para mejorar el manejo de los RSU a través de un enfoque de GIRS y así poder llevar la menor cantidad posible de RSU a sitios de disposición final. En las siguientes figuras se observan los índices generados para cada una de las fases del manejo.

De acuerdo con los datos obtenidos y observados a través del desarrollo del modelo a inicios de este capítulo, es importante recordar que, para la generación de este índice, se contemplaron valores máximos y mínimos. Es decir, se usó cómo valor mínimo el del país que menos RSU genera en promedio por habitante por día y el valor máximo la del país que más RSU genera por habitante por día. Esto con la finalidad de tener un referente a nivel mundial de cómo es la generación de los RSU de los habitantes de la CDMX. En este caso la Figura 4.14, muestra los resultados indicando que el que menos RSU genera, es el que mayor calificación tiene y el que más genera RSU es la que más baja calificación tiene. La figura 4.15, muestra un comportamiento interesante y muy similar a lo que el Banco Mundial publicó en el año 2012: En general, en los países en vías de desarrollo, se muestra una relación muy íntima entre la segunda y última fase, ya que por lo general se dispone finalmente casi todo lo que de recolecta, aunado a esto los gobiernos locales gastan la mayor parte de sus presupuestos destinados al manejo delos RSU, sólo en la recolección y la disposición final. Lo mismo ocurre en la CDMX, por lo que estas dos fases están relacionadas en el índice de recolección y disposición final. Aquí podemos ver que las demarcaciones territoriales con mayor calificación, son las que llevan una cantidad menor de RSU a disposición final de su total recolectado; por el contrario, las demarcaciones que tienen el índice menor o la calificación más baja, son las que llevan casi todo los RSU recolectados a sitios de disposición final. Al igual que el resto de los índices, el índice de la Figura 4.16, se calcula en comparación con valores máximo y mínimos, en este caso las mejores calificaciones son para quien separa la mayor parte de RSU que genera y por lo tanto recolecta. En el caso contrario las calificaciones más bajas son para que menos separa los RSU que genera. En este caso Milpa alta, Coyoacán y Magdalena Contreras, podría decirse que tienen competitividad a nivel mundial en cuestión del manejo de RSU. El índice de Eficacia en el Procesamiento y el Índice de la eficacia en la transformación, se muestra en la Figura 4.17 y 4.18, los cuales están basados básicamente en la cantidad de RSU aprovechados a través del reciclaje y la transformación de los RSU que se recolectan. 
Finalmente, se tiene el Índice del desempeño en el manejo de los RSU de la CDMX, el cual está representado en la Figura 4.19; éste contempla el resto de los índices con la finalidad de obtener una visión completa del desempeño del manejo de los residuos. Aunque no hubo calificaciones perfectas, pudiera ser alentador el poder tener calificaciones al menos aprobatorias en varias de las demarcaciones territoriales, esto al ser comparados con las más altas élites en cuestión del manejo de los RSU a nivel mundial. Es decir, a pesar de que la CDMX pertenece a un país en vías de desarrollo, el desempeño que tiene específicamente la CDMX y en particular algunas de sus demarcaciones territoriales, alienta a pensar que se pueden lograr grandes cosas si se ponen en marcha los planes adecuados en los puntos estratégicos. Es aquí donde radica la importancia de esta investigación ya que ayuda a enfocarse en los puntos que mayor atención requieren y que además parten de un punto real. Algunas demarcaciones tuvieron un desempeño pobre, pero es importante mencionar que se propone avanzar hacia la idealidad con programas como basura cero. Po otro lado, la constante evaluación es necesaria, para identificar las debilidades de la GIRS que ayuden a mejorar el manejo de los RSU en general. Ampliar la visión y dejar de ver los RSU como un problema y verlos como un negocio es otro punto que resulta interesante comprender y sobre todo Invertir más en el tratamiento y procesamiento que en la recolección y la disposición final, empezando con tecnologías económicamente factibles y socialmente aceptadas. 


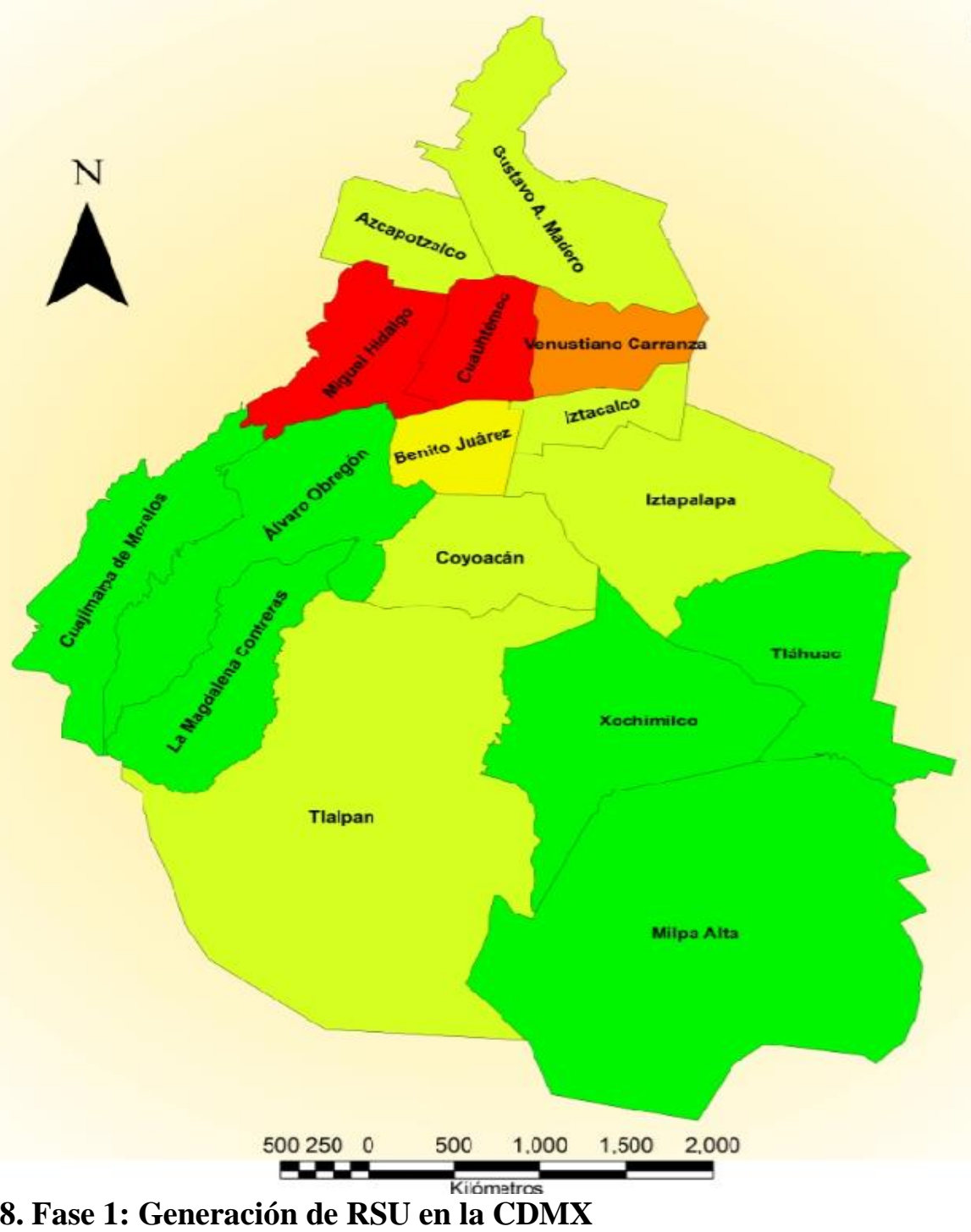

\section{GENERACIÓN PER CÁPITA DE RSU} KG/hab/día

\begin{tabular}{|c|c|}
\hline Muy bajo & $0.85-1.17$ \\
\hline Bajo & $1.18-1.48$ \\
\hline Medio & $1.49-1.80$ \\
\hline Alto & $1.81-2$ \\
\hline Muy alto & $2.12-2.43$ \\
\hline
\end{tabular}

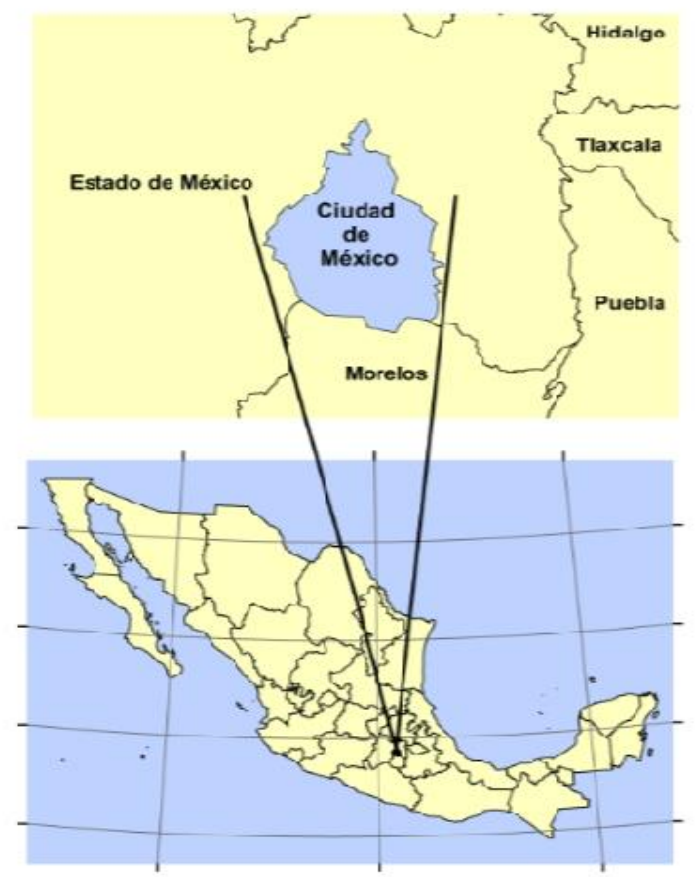

Figura 4.8. Fase 1: Generación de RSU en la CDMX 


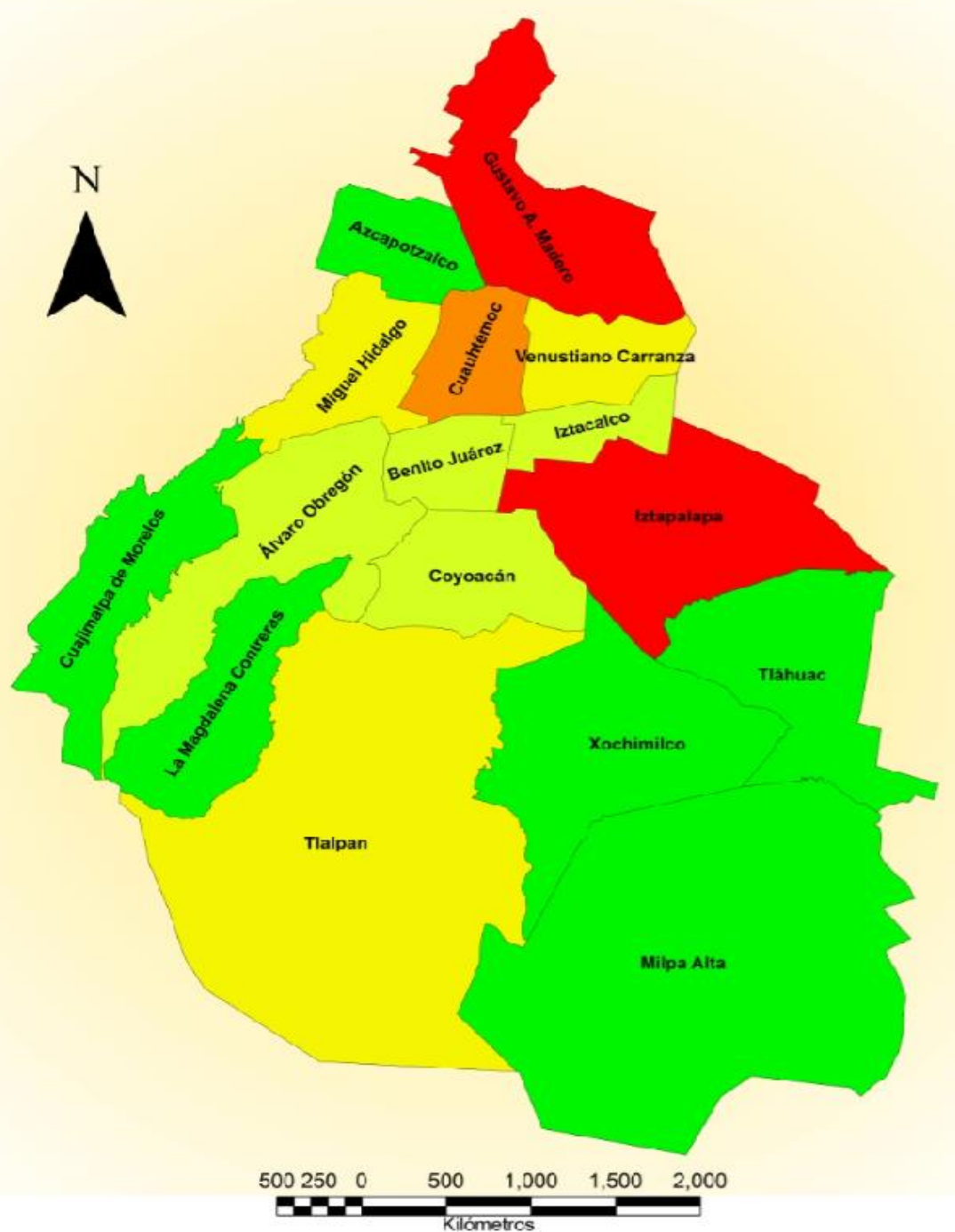

\section{RECOLECCIÓN TOTAL DE RSU}

TONELADAS

\begin{tabular}{|c|c|}
\hline Muy bajo & $87.12-319.48$ \\
\hline Bajo & $319.49-551.84$ \\
\hline Medio & $551.85-784.20$ \\
\hline Alto & $784.21-1016.56$ \\
\hline Muy alto & $1016.57-1248.92$ \\
\hline
\end{tabular}

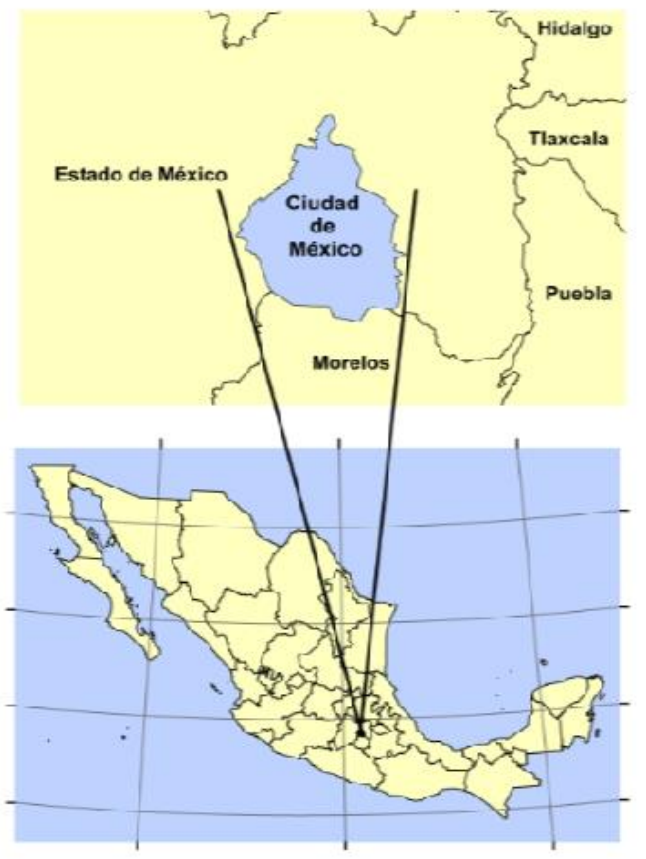

Figura 4.9. Fase 2: Recolección de RSU en la CDMX 


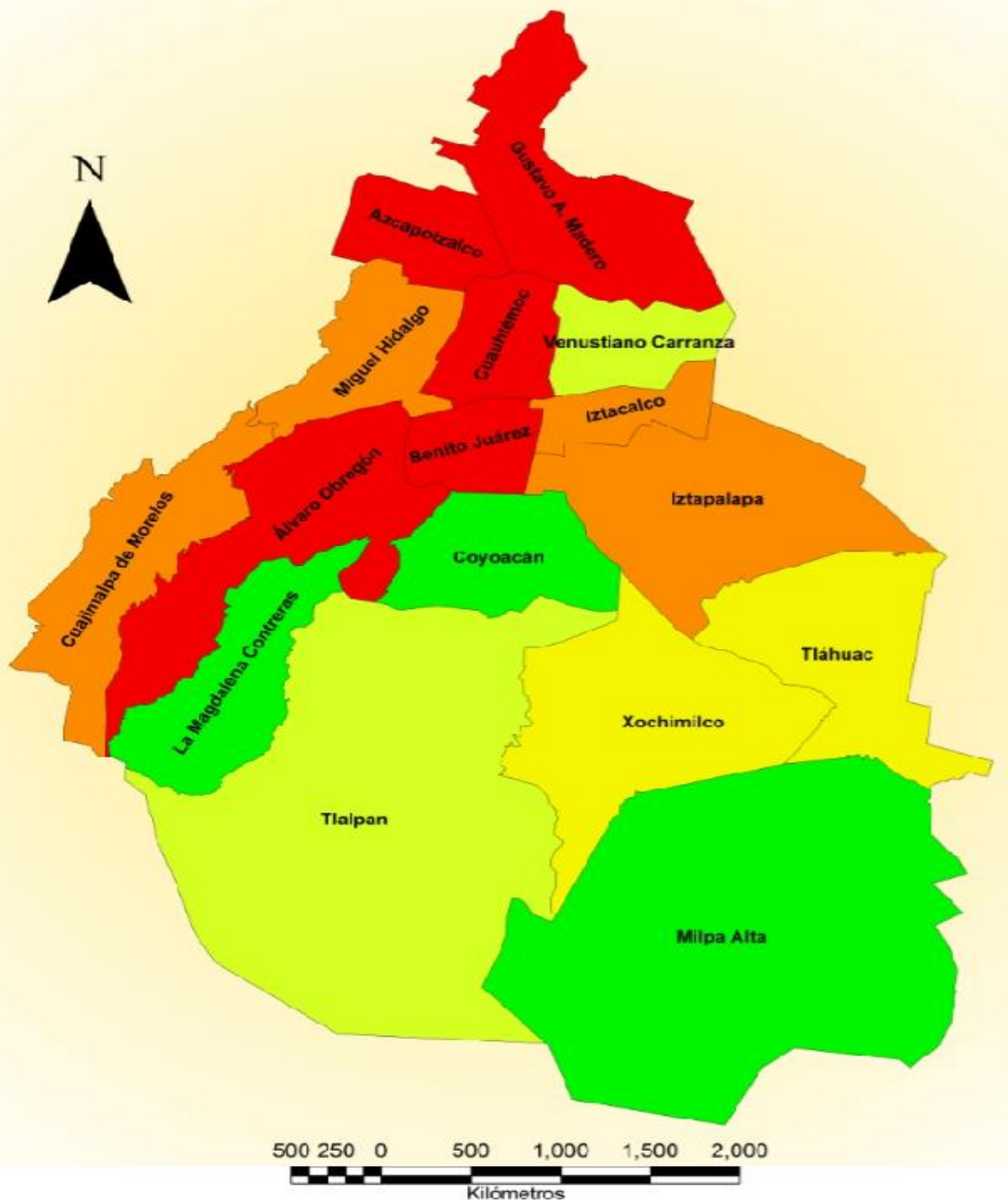

Figura 4.10. Fase 3: Manipulación y/o Procesamiento de RSU en la CDMX

\section{EFICIENCIA EN LA SEPARACIÓN} PORCENTAJE

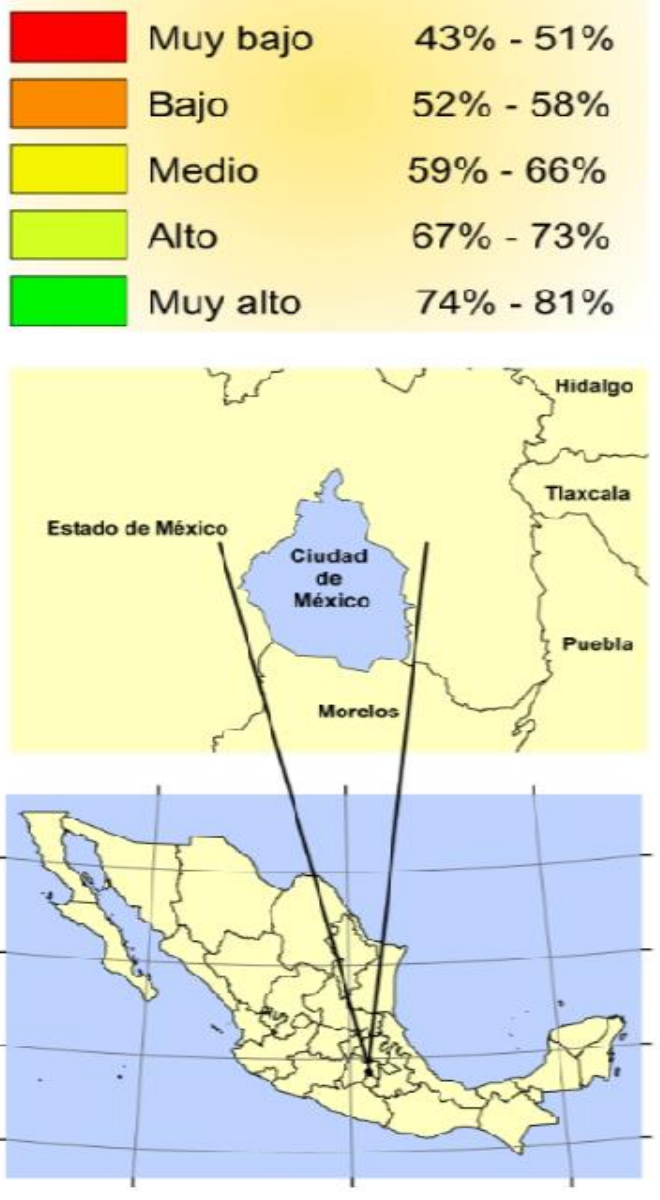

Fuente: Elaboración propia. 


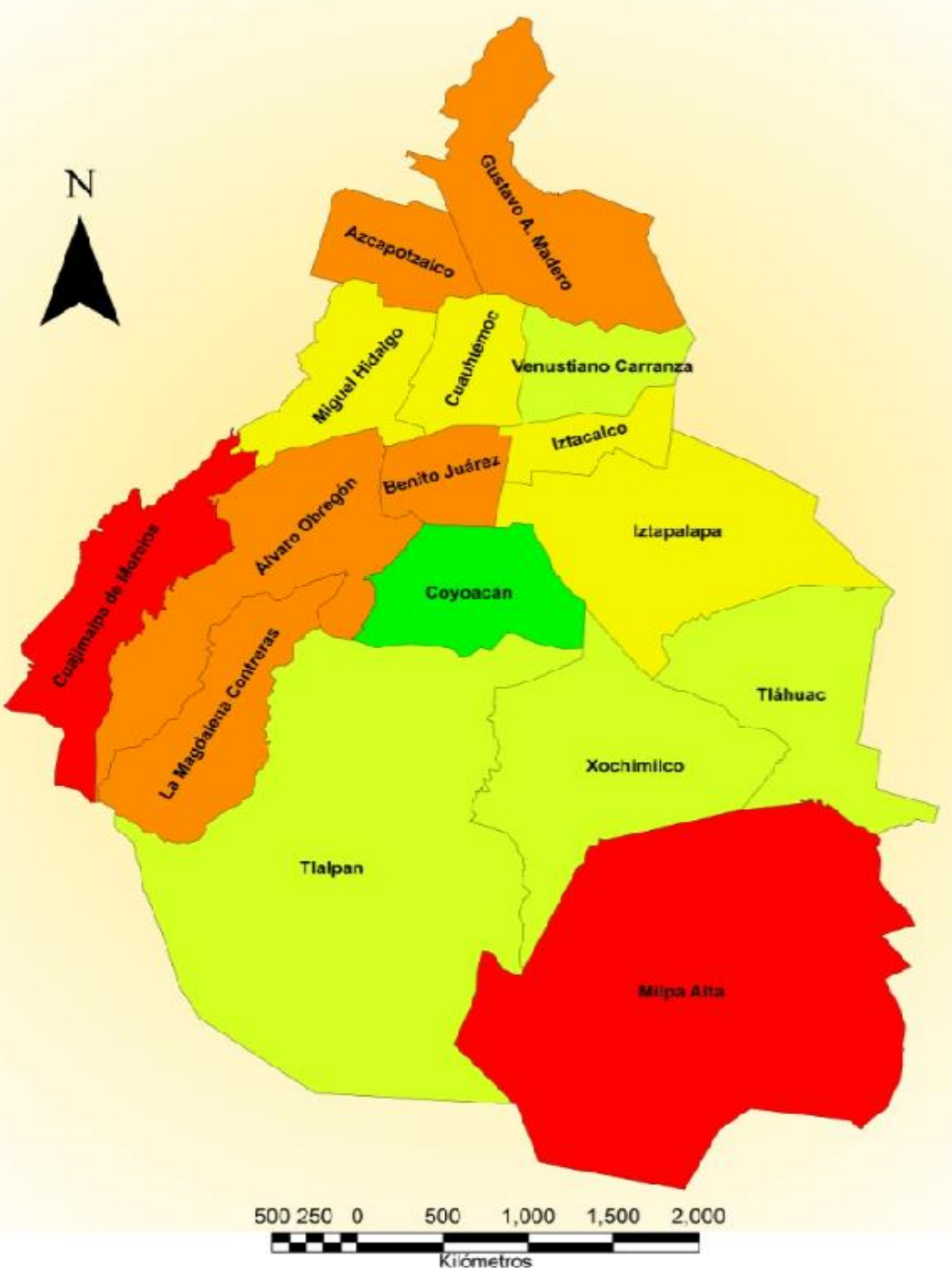

Figura 4.11. Fase 3: Manipulación y/o Procesamiento de RSU en la CDMX.

\section{RECICLAJE}

TONELADAS

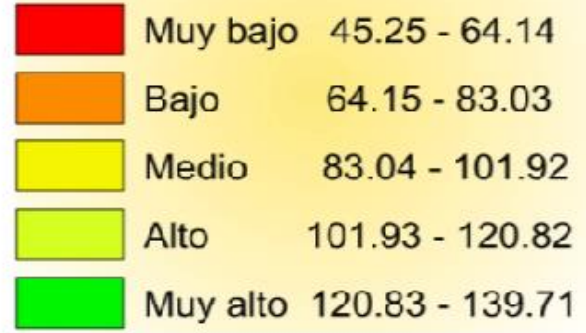

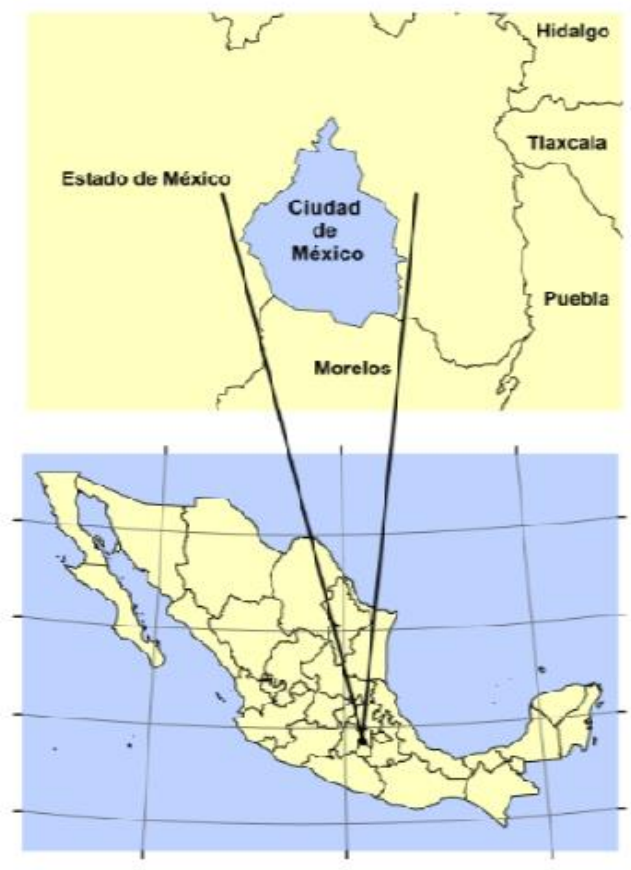

Fuente: Elaboración propia 


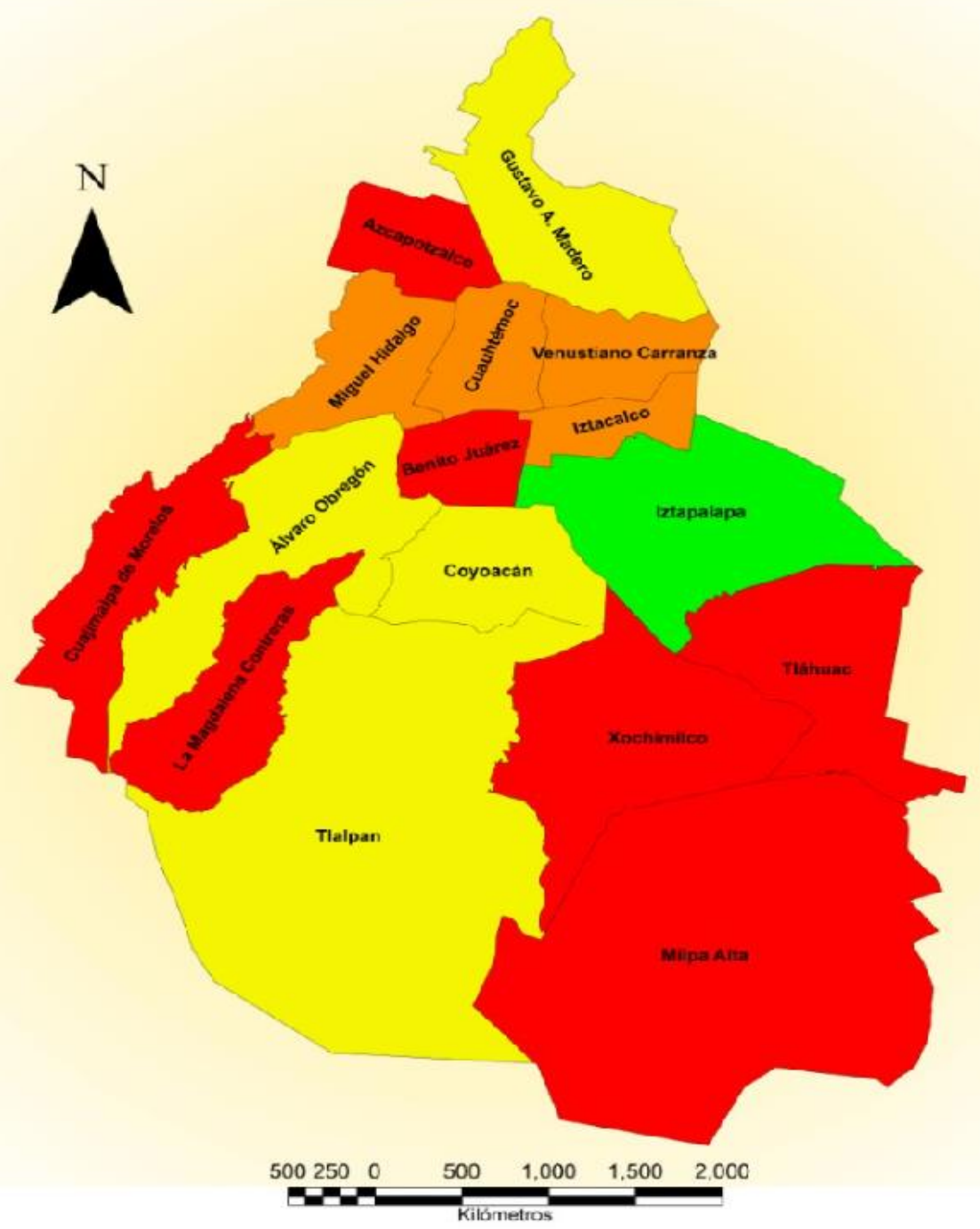

\section{GENERACIÓN DE COMPOSTA} TONELADAS

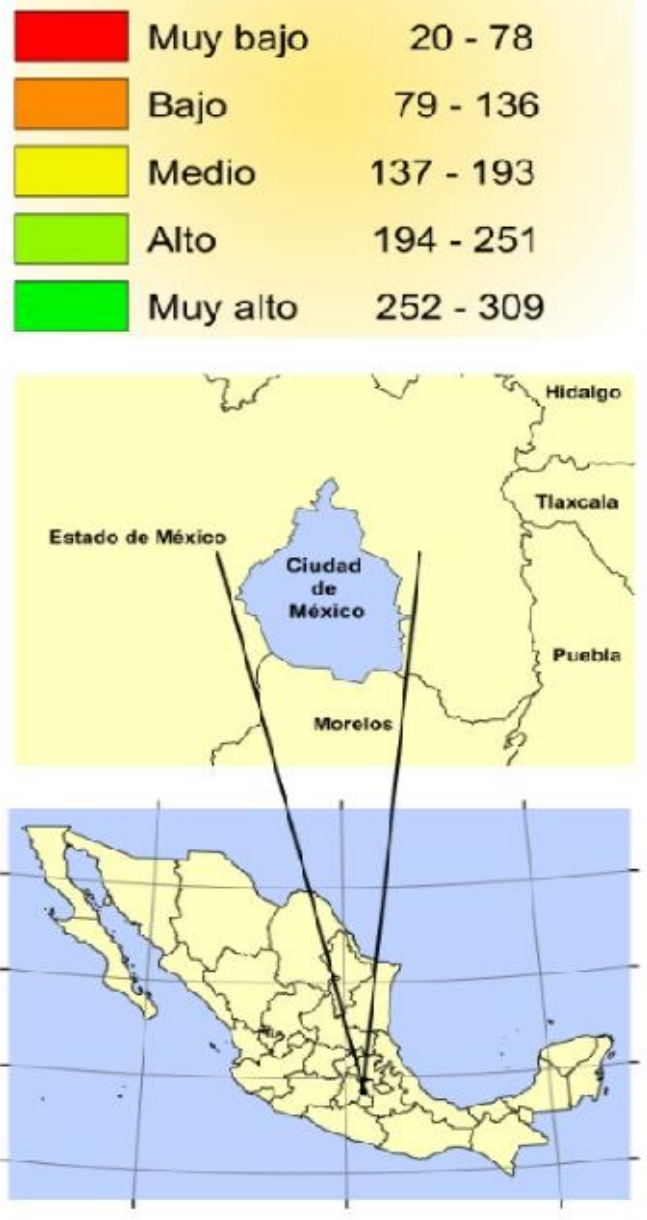

Figura 4.12. Fase 4. Transformación de RSU en la CDMX

Fuente: Elaboración propia. 


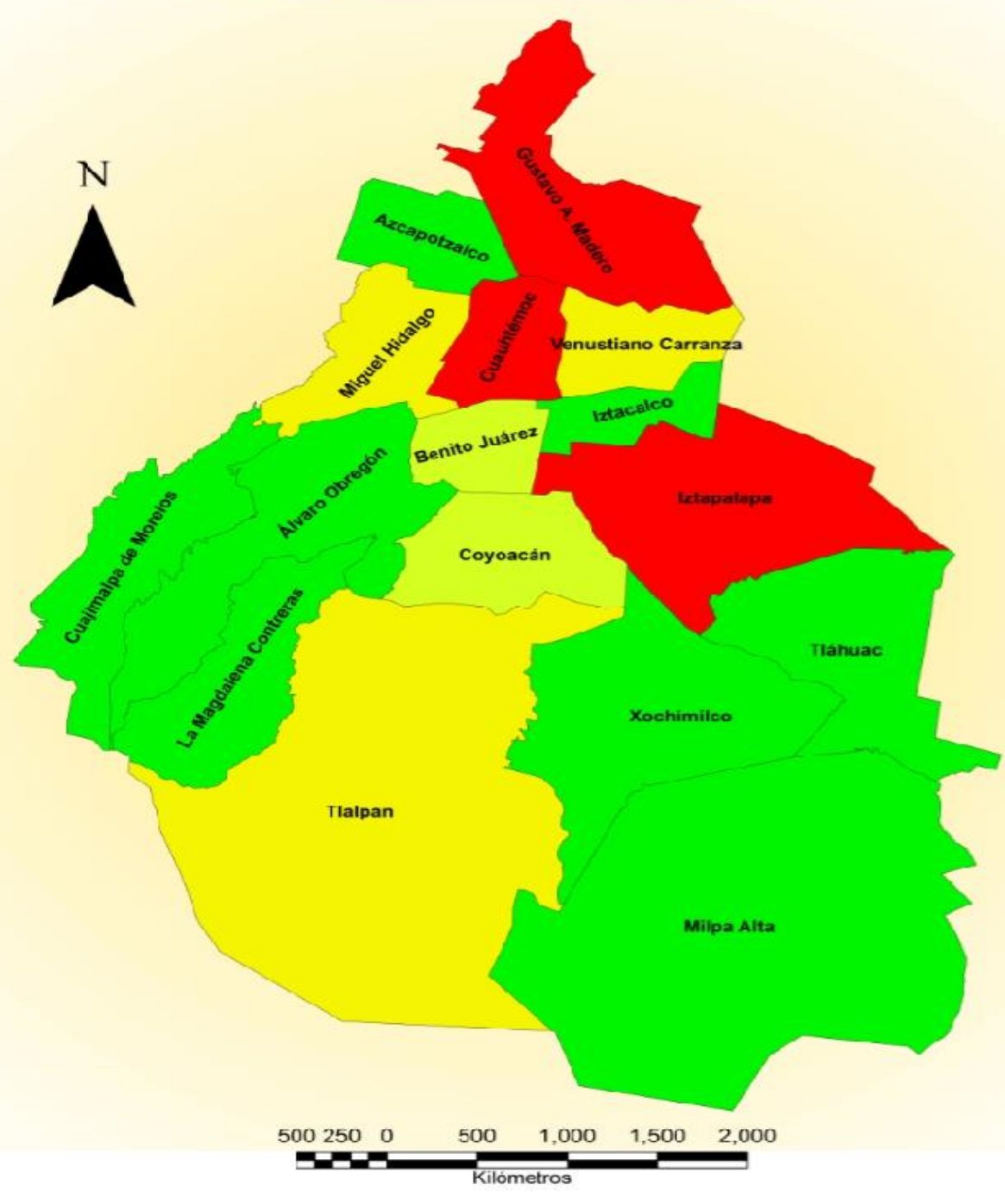

Figura 4.13. Fase 5: Disposición final de RSU en la CDMX

\section{DISPOSICIÓN FINAL}

\section{TONELADAS}

\begin{tabular}{|c|c|}
\hline Muy bajo & $11.83-185.44$ \\
\hline Bajo & $185.45-359.05$ \\
\hline Medio & $359.06-532.66$ \\
\hline Alto & $532.67-706.26$ \\
\hline Muy alto & $706.27-879.87$ \\
\hline
\end{tabular}

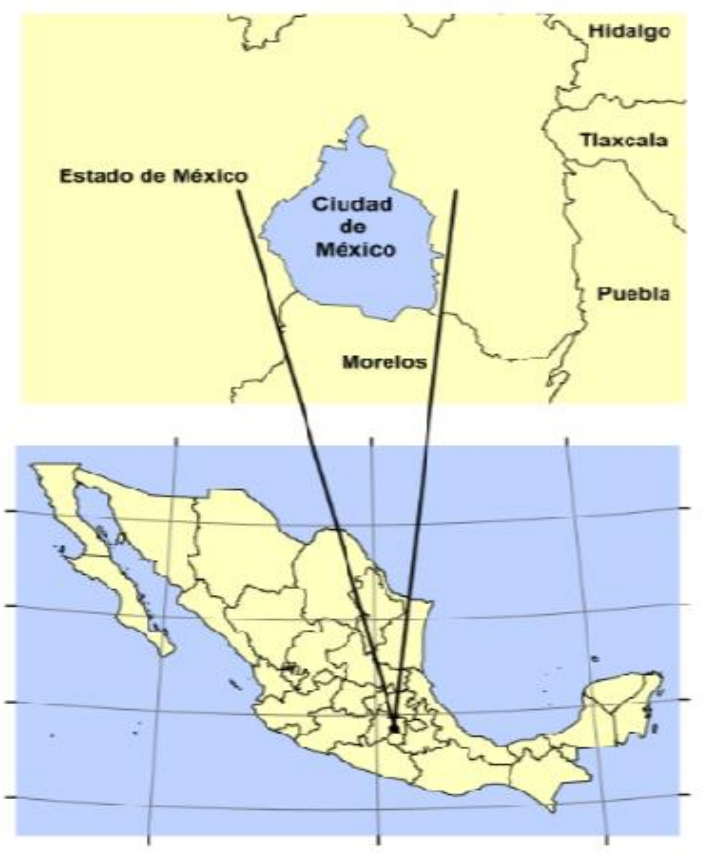

Fuente: Elaboración propia. 


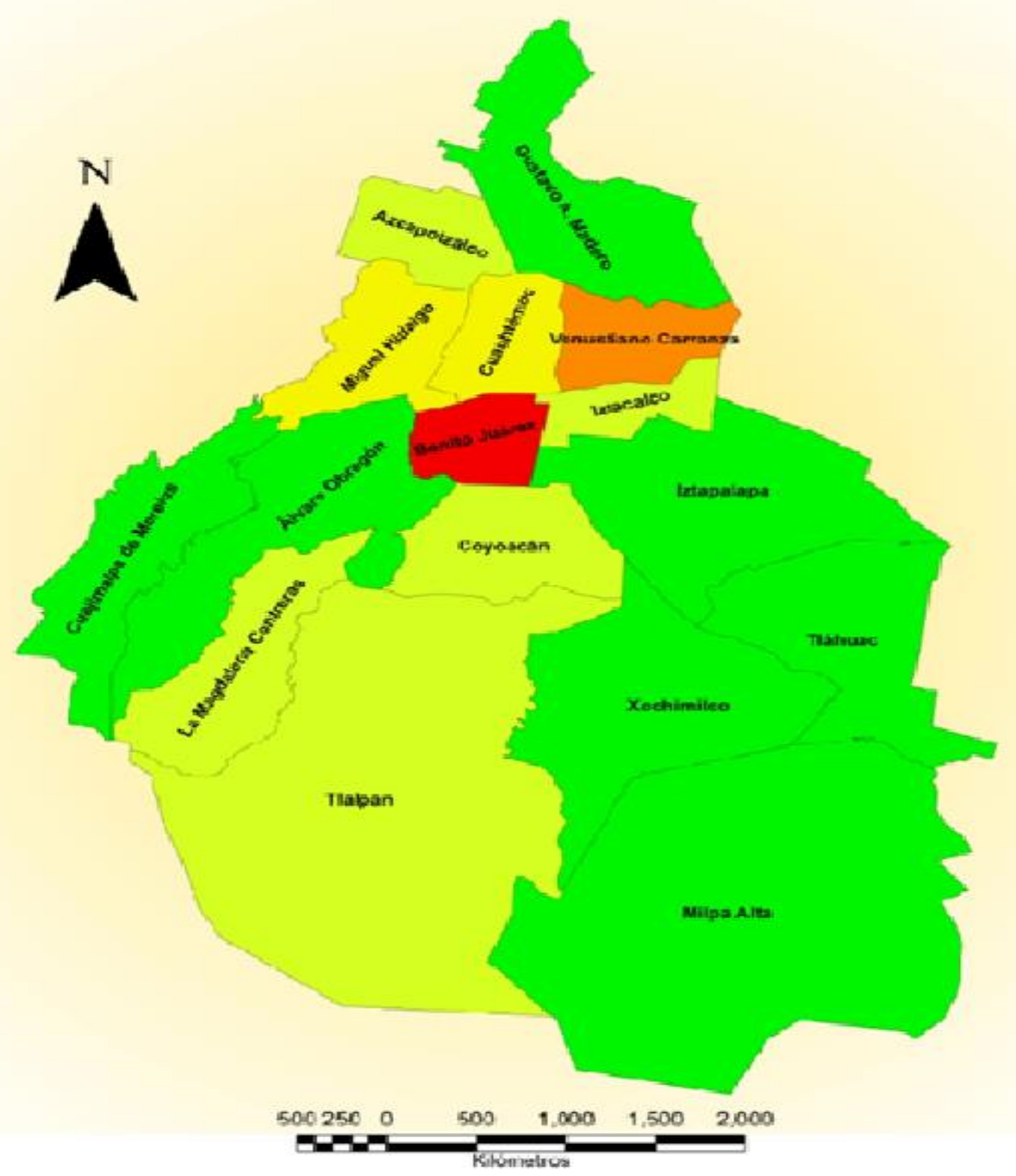

Figura 4.14. Índice de eficacia para la fase 1 del manejo de los RSU en la CDMX

\section{ÍNDICE DE LA EFICACIA PARA LA REDUCCIÓN DE LA GENERACIÓN DE RSU} CALIFICACIÓN DE 0 A 10

\begin{tabular}{|c|c|}
\hline Muy bajo & $0.89-2.42$ \\
\hline Bajo & $2.43-3.94$ \\
\hline Medio & $3.95-5.47$ \\
\hline Alto & $5.48-6.99$ \\
\hline Muy alto & $7.00-8.52$ \\
\hline
\end{tabular}

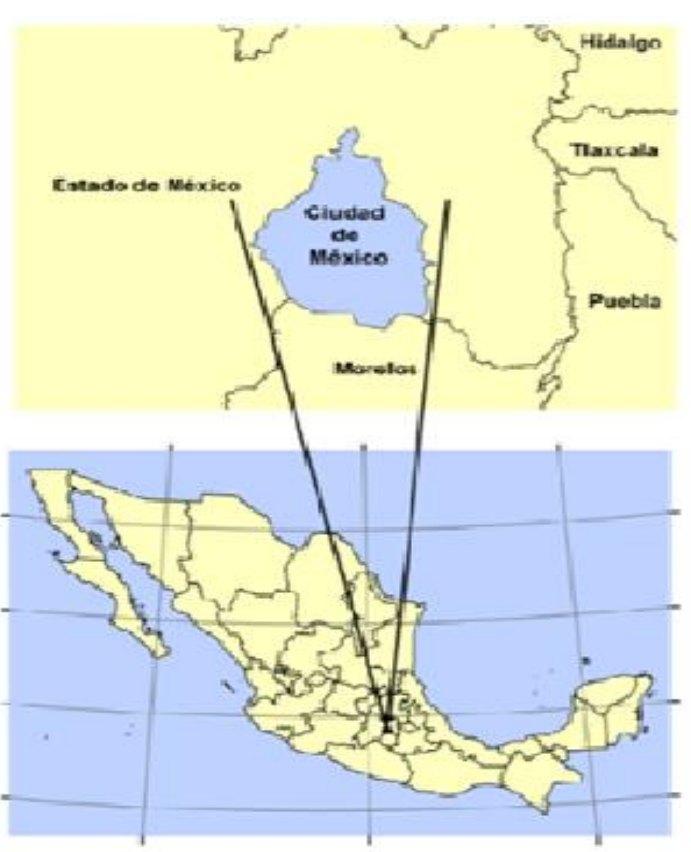

Fuente: Elaboración propia. 


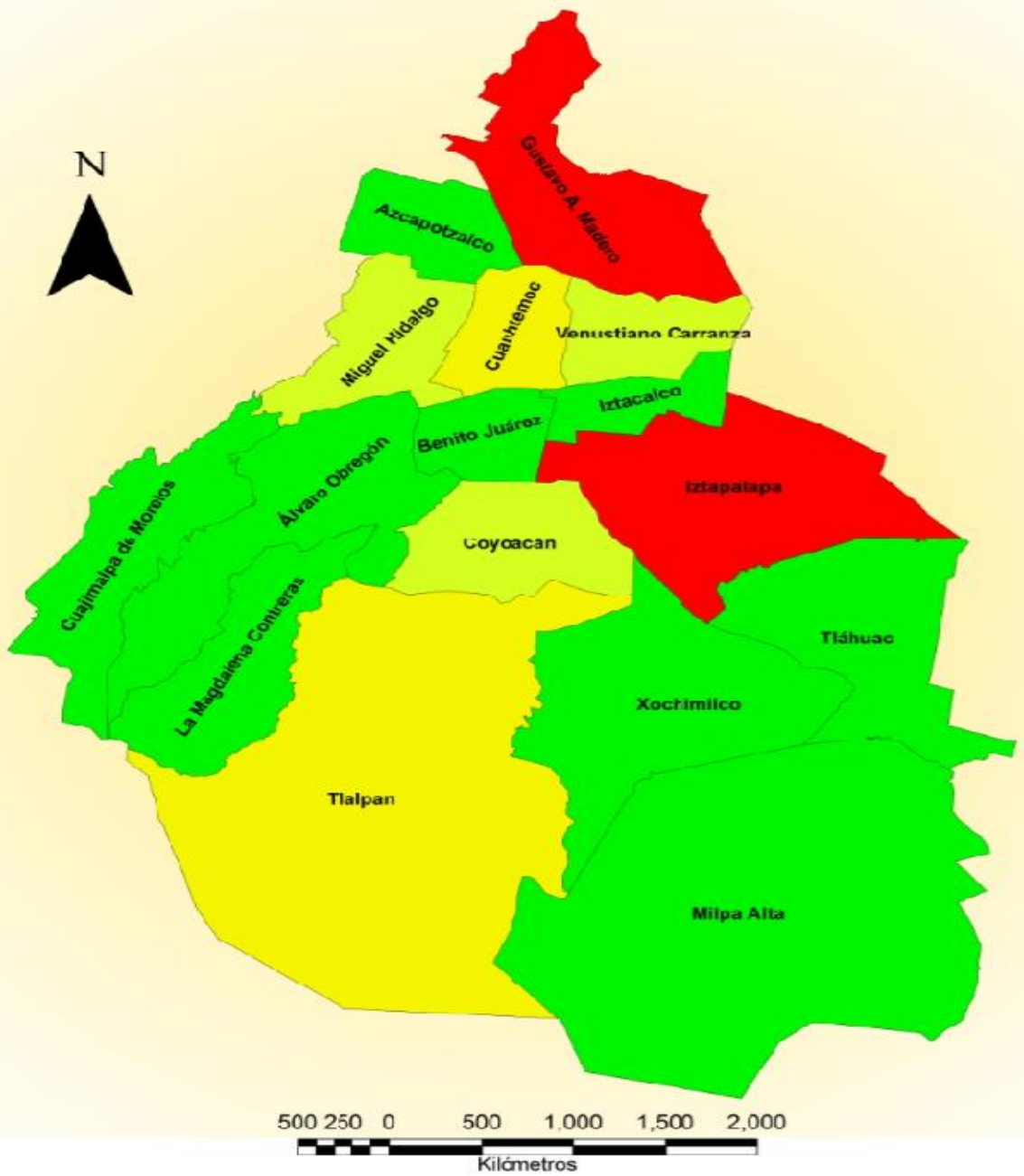

Figura 4.15. Índice de eficacia en la fase 2 y 5 del manejo de los RSU en la CDMX

\section{ÍNDICE EN LA RECOLECCIÓN Y LA DISPOSICIÓN}

\section{CALIFICACIÓN de 0 a 10}

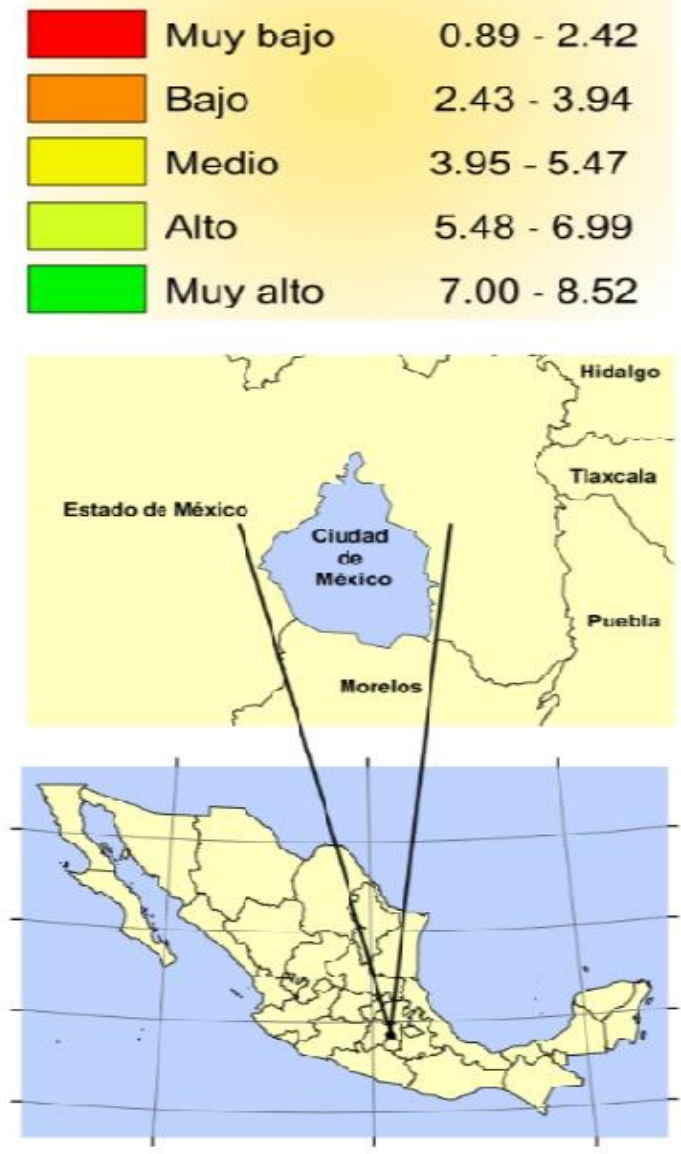

Fuente: Elaboración propia. 


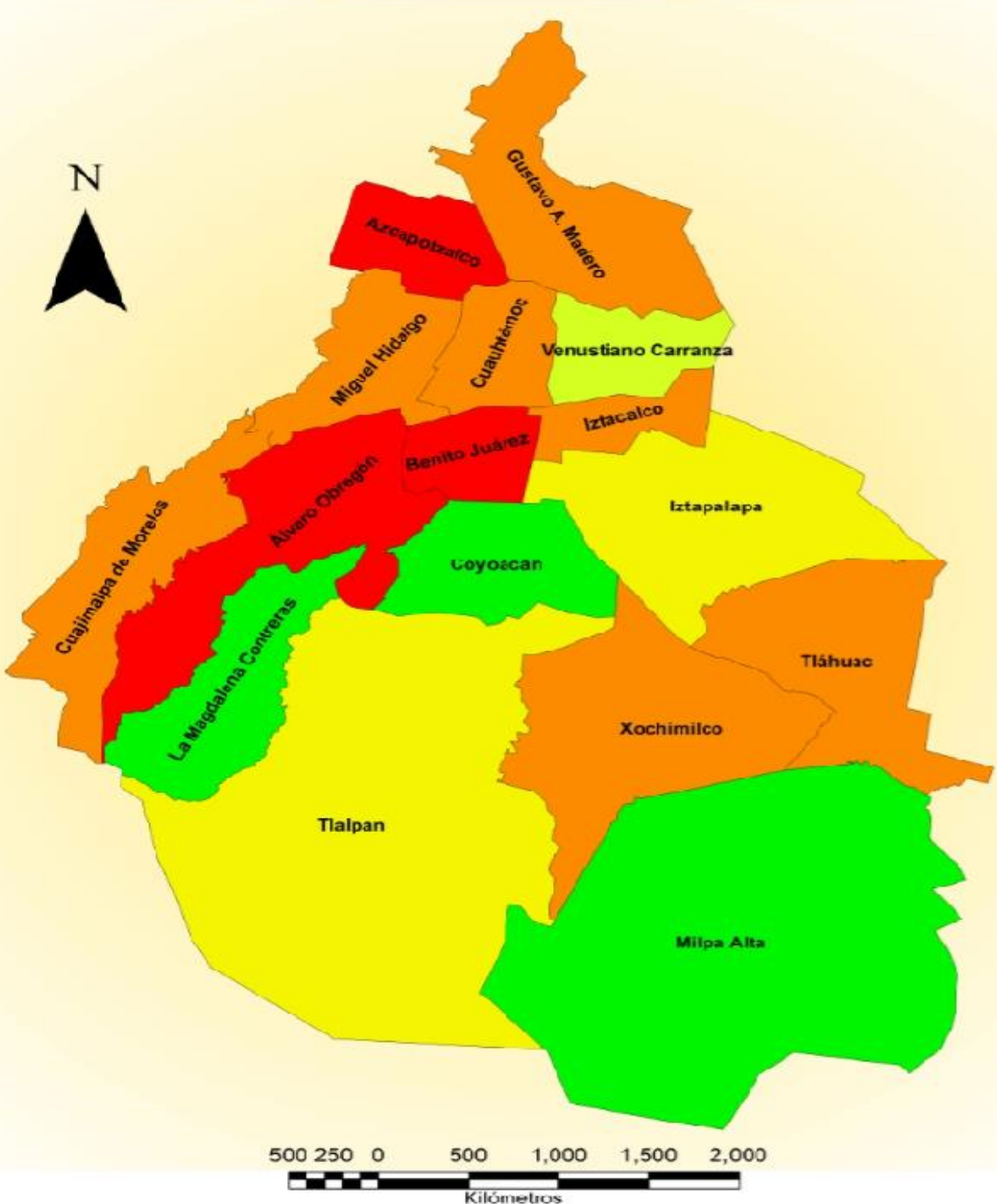

Figura 4.16. Índice de eficacia en la fase 3 del manejo de los RSU de la CDMX

\section{ÍNDICE DE EFICACIA EN LA MANIPULACIÓN CALIFICACION DE OA 10}

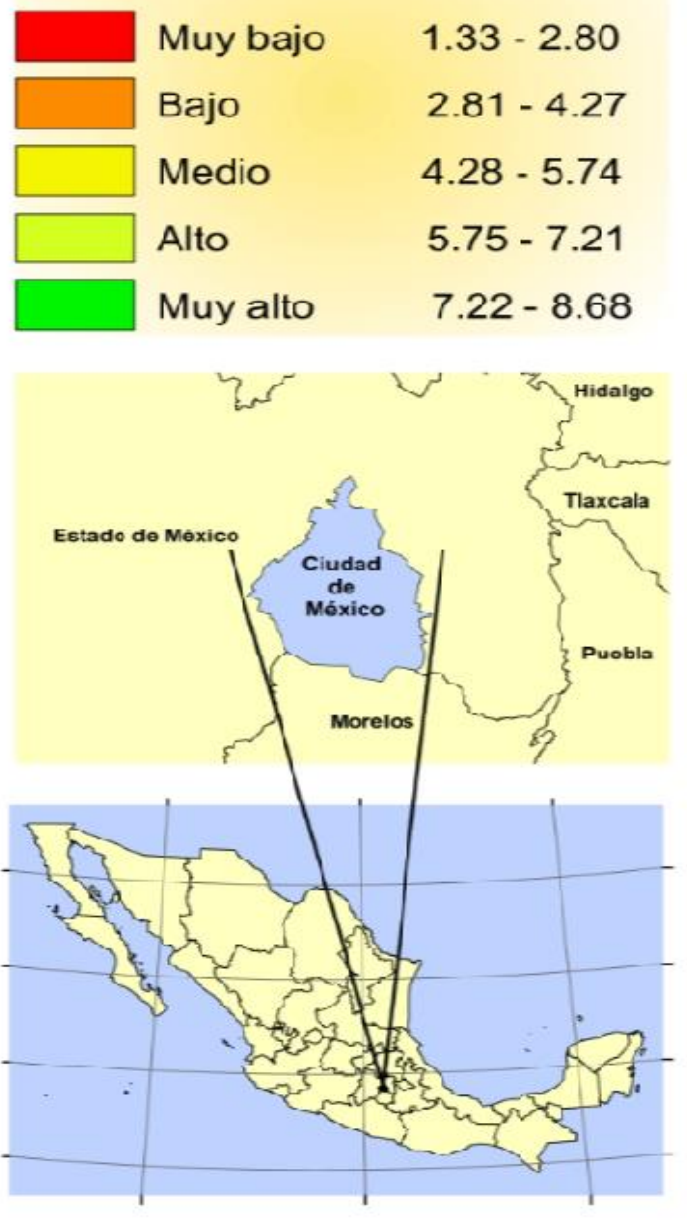

Fuente: Elaboración propia. 


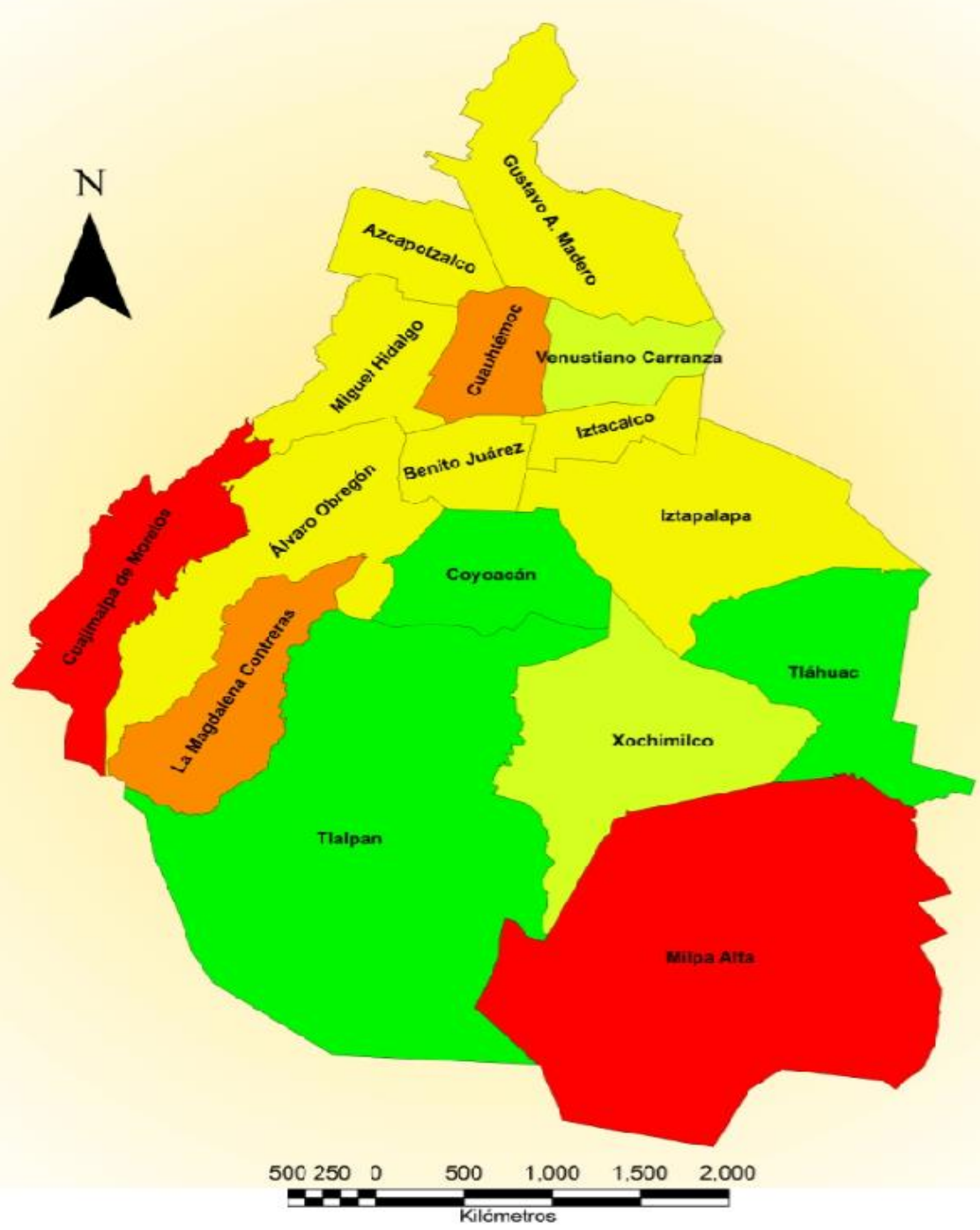

Figura 4.17. Índice de eficacia en la fase 3 del manejo de los RSU de la CDMX.

\section{ÍNDICE DE EFICACIA EN}

EL PROCESAMIENTO CALIFICACIÓN DE O A 10

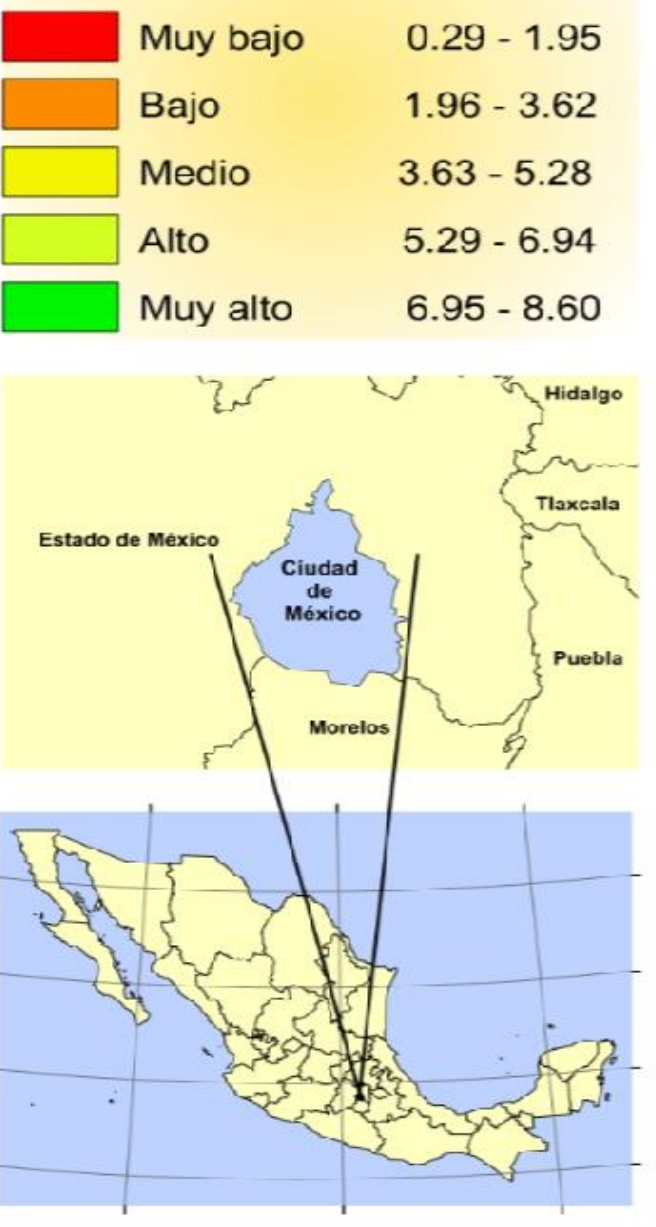

Fuente: Elaboración propia. 


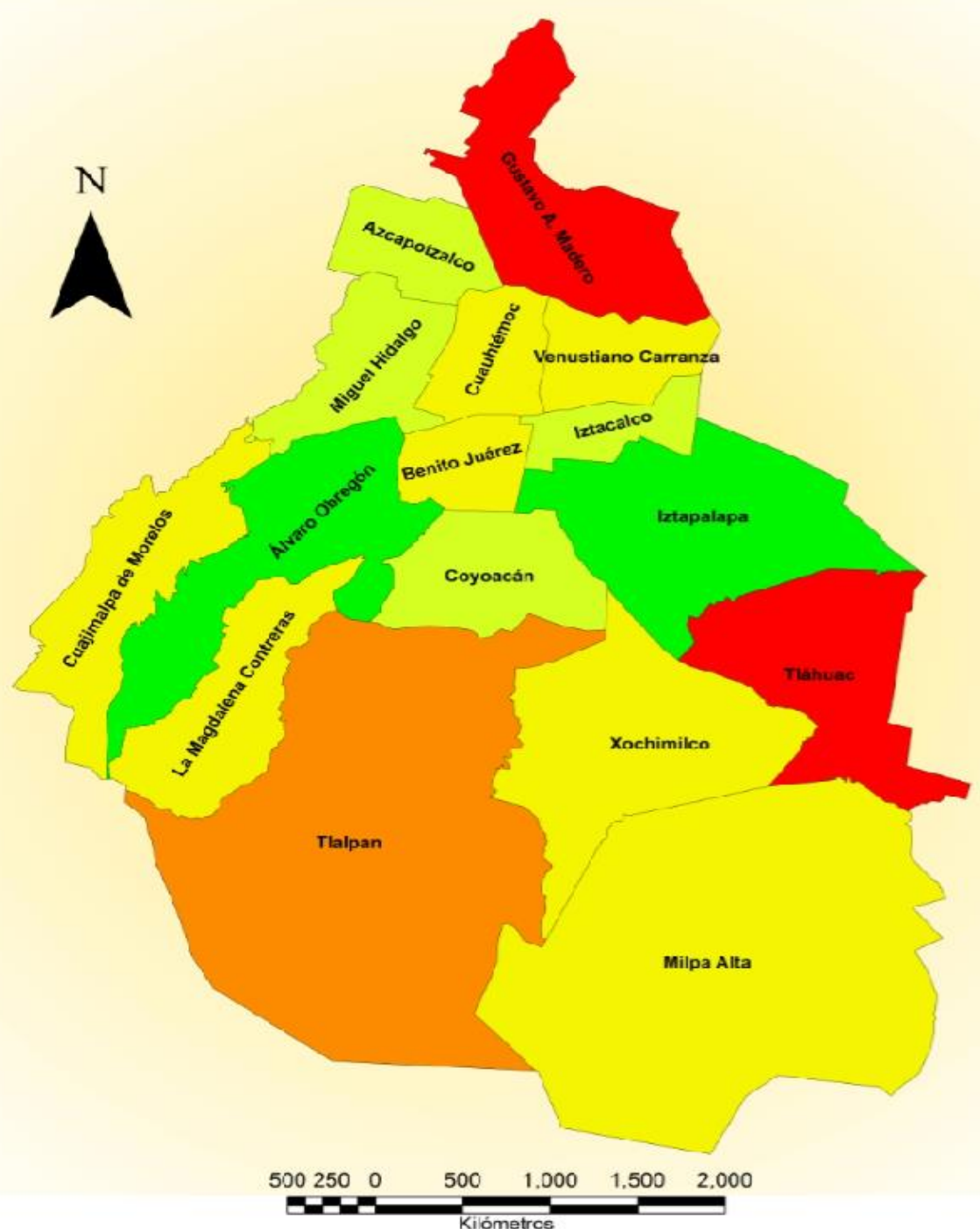

Figura 4.18. Índice de eficacia en la fase 4 del manejo de los RSU de la CDMX.
ÍNDICE DE $\mid$ EFICACIA EN LA TRANSFORMACION CALIFICACIÓN DE O A 10

\begin{tabular}{|c|c|}
\hline Muy bajo & $1.50-3.03$ \\
\hline Bajo & $3.04-4.56$ \\
\hline Medio & $4.57-6.09$ \\
\hline Alto & $6.10-7.62$ \\
\hline Muy alto & $7.63-9.15$ \\
\hline
\end{tabular}

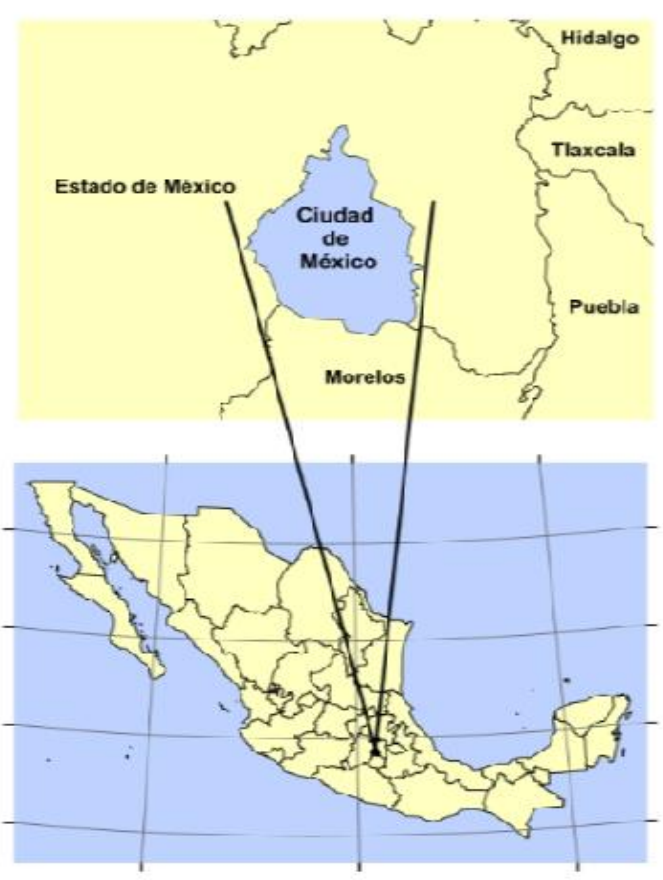

Fuente: Elaboración propia. 


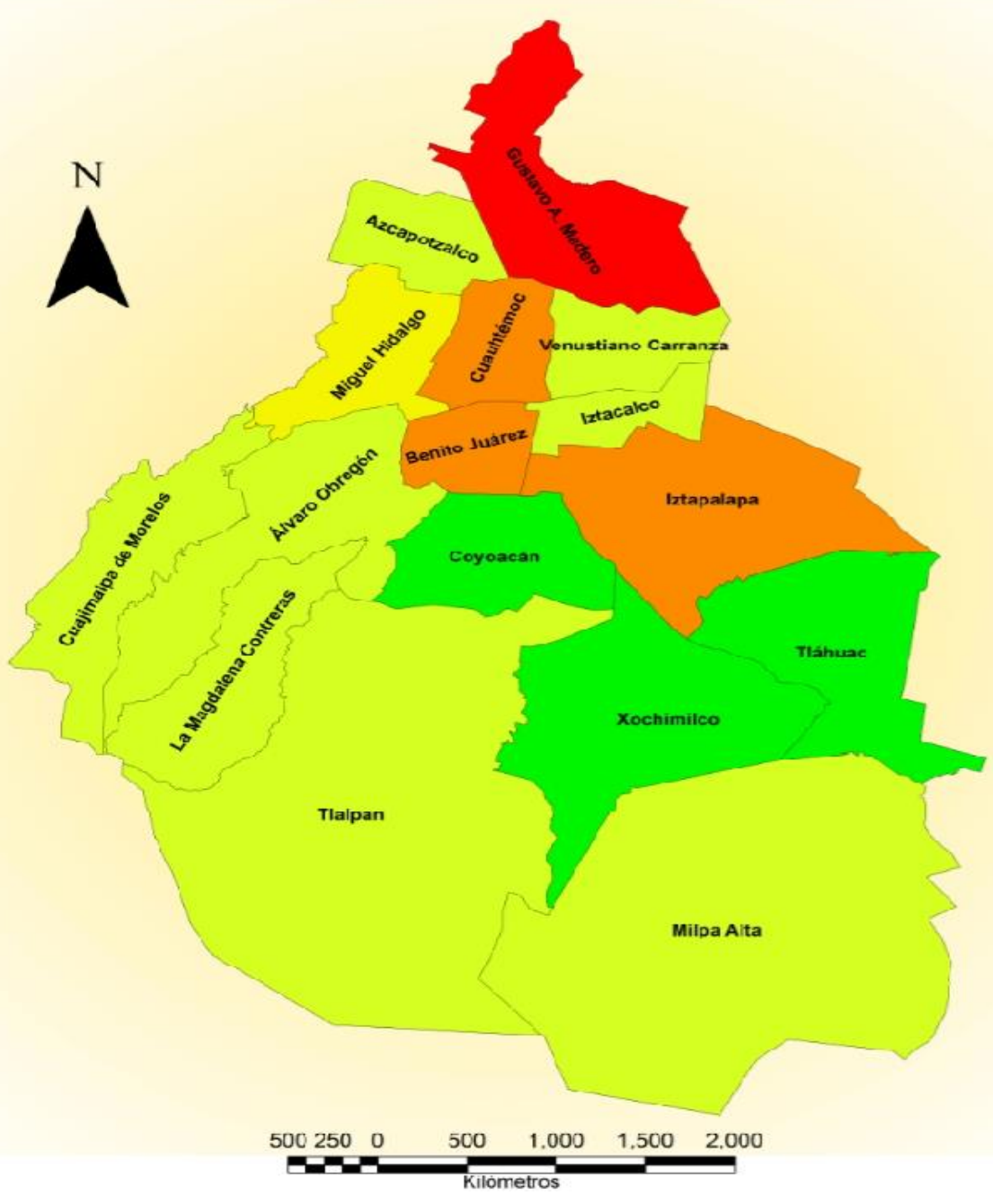

Figura 4.19. Índice de desempeño en el manejo de los RSU de la CDMX

\section{ÍNDICE DE DESEMPEÑO EN EL MANEJO DE LOS RSU} CALIFICACIÓN DE 0 A 10

\begin{tabular}{|c|c|}
\hline Muy bajo & $3.21-3.98$ \\
\hline Bajo & $3.99-4.74$ \\
\hline Medio & $4.75-5.51$ \\
\hline Alto & $5.52-6.28$ \\
\hline Muy alto & $6.29-7.05$ \\
\hline
\end{tabular}

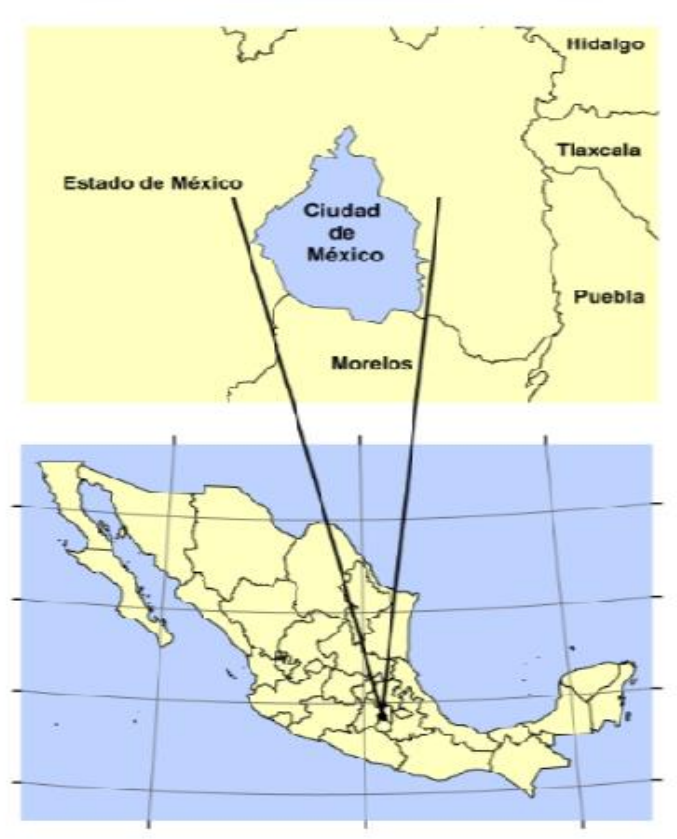

Fuente: Elaboración propia. 


\section{Conclusiones Generales y Perspectivas}

Como se ha demostrado a lo largo de esta investigación, los residuos sólidos son un problema global, que necesitan urgentemente se abordados de forma sustentable y holística, ya que estos representan un problema ambiental y de salud severo; sin embargo, lo más importante debe ser el comprender que se trata más de un problema vinculado directamente con el incremento de población urbana y con el modelo económico que existe en el mundo, es decir, la forma de producir y consumir que tiene el planeta debe ser cambiada. Lo más alarmante es que a pesar de esta urgencia ambiental, la gestión integral de los residuos, respecto a la gestión pública de otro tipo de servicios, suele ser de menor importancia. Desafortunadamente, las consecuencias de hacer poco o nada para abordar la gestión de residuos puede ser muy costosa para la sociedad, para la economía en general y para el ambiente. Una de las causas: debilidad en el marco normativo respecto a residuos y su aplicación rigurosa, ya que en general, un generador de desechos tiende a optar por el recurso de acción disponible más barato sin vivir una mala consecuencia por ello. Esto es reflejado en el aumento de las cantidades de RSU generados a lo largo del globo, como los países que más generan residuos como China y Estados unidos, que su generación alcanza alrededor de los $4 \mathrm{Kg}$ de RS por habitante por día, sin tener sanción alguna. México no rebasa esas cifras, sin embargo, es de considerar que de lo que genera, alrededor del $90 \%$ se va directamente a disposición final, lo cual obliga a los tomadores de decisiones a hacer grandes cambios en las políticas públicas para la mejora del manejo de los RSU. El caso de Suecia, sin duda alguna, es ideal a alcanzar y el ejemplo a seguir por cualquier país, ya que está aprovechando, mediante la trasformación en energía más del 90\% de los RSU que genera, que, aunque es un país desarrollado, puede aportar diversas lecciones a los países que están en vías de desarrollo principalmente a través de la implementación de instrumentos económicos, que ayuden a gestionar mejor los RSU. Aunado a esto, una mejor administración de los recursos que no sólo se enfoque en recolección y disposición final, también puede ayudar a mejorar en gran parte el manejo de los RSU.

La mala distribución del presupuesto público destinado a la GIRS, no es el único obstáculo que impide la mejora del manejo de los RSU, sino que también intereses políticos, frustran gran parte del tiempo el intento de la mejora en el manejo de los RSU, tal es el caso específico de la CDMX, donde sindicatos que protegen a choferes de camiones recolectores de RSU y a pepenadores, generalmente encuentran su ingreso económico en el mercado informal de los RSU valorizados.

Por otro lado, el estudio del manejo de los residuos sólidos urbanos en la CDMX enfrenta diversos retos, aunque uno de los más importantes está relacionado con la falta de información con la que se dispone a nivel de mayor detalle por demarcación territorial y por colonia. Esta falta de información en parte se explica a los insuficientes recursos que se le asigna a esta labor, lo cual es un reflejo de la falta de presupuesto que recibe la Secretaria de Obras y Servicios de la CDMX para realizar la recolección, separación, tratamiento y disposición de los residuos sólidos. Mientras éstos no sean percibidos como sujetos de valor económica, los tomadores de decisiones poca relevancia les prestarán. Con relación a la información, muchos de los datos que se encontraron no están actualizados, y los que son más recientes no están disponibles en el mismo año en que se generan, estando su publicación desfasada por menos uno o dos años. Asimismo, se encontraron ciertas inconsistencias en los indicadores que se generaron en los Inventarios de RSU de la CDMX para los 
años 2013 y 2014, (complementa con varios de los retos de información que detallan en la metodología brevemente) Sin embargo, es importante mencionar que, para esta investigación se contó con la colaboración de la SOS, para poder hacer algunas estimaciones y llegar a la conclusión de que no hay gran diferencia entre los años 2014-2015, que fueron los años en los que esta investigación se desarrolló. Aunado a esto, la mayoría de los datos no se encuentran segregados por colonias, sino más bien por demarcaciones territoriales, lo cual definitivamente representó un obstáculo a la hora de realizar la evaluación del manejo de los RSU en la CDMX. Por esta razón, es importante recomendar a los tomadores de decisiones, que son los que manejan información de primera mano, generar bases de datos más detallada del manejo de los residuos sólidos no sólo en la CDMX sino en todo el país, con el fin de que la investigación que se realice sea más oportuna para guiar las decisiones de política y sus estrategias. En la revisión del estado del arte sobre las características con las que debe cumplir una GIRSU, fue evidente las diferencias que existen entre la gestión integrada y el manejo integrado: el primero se refiere a toda una serie de atributos, como actividades administrativas, financieras, operativas, normativas judiciales, de planeación, supervisión, evaluación y monitoreos, además de todo el aspecto técnico científico y el segundo, a un proceso de cinco fases que van desde la generación del RSU hasta su disposición final. Esta investigación por razones de tiempo y recursos se centró en la evaluación del manejo de los RSU y no en la gestión en sí; es deseable continuar analizando los diversos componentes de la gestión integral para tener una idea más completa de la complejidad presente en la misma. Sin embargo, el manejo de los residuos sólidos en las cinco fases mencionadas es una parte central de la gestión, por lo que mejoras en alguna de estas fases puede tener importantes mejoras en la GIRSU. Bajo este contexto, se estudió también la problemática global, nacional y local, identificándose que tanto la gestión como el manejo de los residuos sólidos urbanos constituyen una problemática relevante para muchos de los países en desarrollo, así como para la mayoría de los países desarrollados, como resultado de los elevados volúmenes que se generan diariamente como por la limitada valoración que se está haciendo de los mismos, lo cual repercute en la enorme cantidad de residuos que se disponen finalmente. A pesar de ello, existen casos de éxito que valen la pena estudiarlos a mayor profundidad, con el fin de determinar en qué ha consistido el éxito de los mismos, como lo es Suecia, un país que ha alcanzado la sustentabilidad, mediante la implementación de políticas públicas, basadas principalmente en la gobernanza híbrida adempas de una estructura normativa muy sólida y de rigurosa aplicación, que desde luego va de la mano de sus instrumentos económicos. Es importante también hacer mención que en el caso del mencionado país, los ciudadanos juegan un papel importante, pues pareciera que la participación ciudadana es una de las características más importantes y con mayor éxito a la hora de manejar los RSU

A través de este ejercicio, se pudo encontrar que una de las maneras más eficaces que los países desarrollados tienen de abordar la temática de RSU, es destinando gran parte del presupuesto que está consignado al manejo de los residuos, a las fases tres y cuatro del manejo, es decir a la reducción en la generación, el procesamiento y la transformación de los RSU para su aprovechamiento. Estas fases tienen que ver básicamente con el aprovechamiento de los residuos, las cuales se realizan básicamente a través de la transformación de los residuos mediante tratamientos térmicos y que además permiten generar ingresos económicos pues generan energía que abastece a las mismas comunidades. Por el contrario, los países en vías de desarrollo gastan el poco presupuesto que se les asigna para el manejo de los RSU en las fases dos y cinco, las cuales se refieren a la recolección y disposición final, es decir, los países en desarrollo están gastándola mayor parte de su presupuesto sólo en recolectar los residuos y trasladarlos a los sitios de disposición final. Tal es el caso de la CDMX, la cual no cuenta con un sitio de disposición final por lo que tienen que trasladarlos hacia otro estado; esta práctica no sólo no resuelve la problemática de los RSU, sino que además contribuye al deterioro del ambiente, ya que 
el proceso de recolectar y disponer no es para nada sustentable, pues sólo se mueven los contaminantes de un medio a otro.

Es importante reconocer, que los países en vías de desarrollo tienen que vencer una gran cantidad de obstáculos, con respecto a los países de primer mundo; entre los más importantes está el reconocer que los RSU podrían dejar de ser un problema y podrían comenzar a ser un ingreso económico y energético extra, pero esto desde luego implica un costo, una inversión y un riesgo, esto para poder llegar a gozar del beneficio de los RSU. Aunado a esto la población de los países en desarrollo, en el caso particular de los pobladores de la CDMX, podrían estar desinteresados en la temática de los RSU, ya que cuestiones de desempleo, inseguridad, pobreza y transporte público, ocupan su total atención.

Por lo que informar a la población y hacerla entender sobre los beneficios que implicarían manejar los RSU de manera sustentables, se vuelve otro reto más. En el caso de los pobladores de las ciudades del primer mundo, esto no representa ningún inconveniente, ya que los temas que preocupan a los ciudadanos en vías de desarrollo, los ciudadanos del primer mundo ya los han superado y tienen gran interés y obsesión por mantener un ambiente sano, por lo que son población de participación activa a la hora de manejar los RSU. Por ejemplo, los residuos orgánicos de origen doméstico son tratados por los mismos ciudadanos, generando de manera responsable y adecuada composta para sus jardines, otro ejemplo más puede ser observado a la hora que separan los residuos, ya que se analizó en el capítulo dos, que llegan a separar su basura hasta en ocho diferentes contenedores, mientras que en algunas partes de la CDMX, a los pobladores les es difícil reconocer entre tan sólo dos contenedores, el de residuos orgánicos e inorgánicos. Por esta razón, se sugiere implementar instrumentos económicos como sanciones e incentivos a quienes disponga o no adecuadamente sus RSU. En el caso de Suecia, por ejemplo, se cobra por la cantidad de 1euro por kg de residuos que se generan, ya que estos son pesados al ser recolectados, pero también se proporcionan incentivos a quienes los separan adecuadamente, y estos se ven reflejados en su recibo de consumo energético.

Otra diferencia relevante que se encontró al realizar el ejercicio de comparación en el manejo de los RSU entre países desarrollado y en vías de desarrollo, fue la gran cantidad de investigadores y profesionistas que se tienen tan sólo para la GIRSU, es decir, ciudades de países como Suecia, tienen grandes consultoras específicamente desarrolladas en el ámbito de los RSU, ya que países vecinos se interesan por el gran éxito que el país nórdico ha tenido con el manejo de los RSU, por lo que son contratados para asesoramientos en el tema. Contrariamente a lo que sucede en países en vías de desarrollo, ya que el tema de los residuos no es de gran importancia, en muchos casos, ni siquiera para los tomadores de decisiones.

Esto llevó a otra conclusión más, que puede existir cierta debilidad en el marco normativo y el de planeación, por lo que ambos marcos fueron analizados en la tercera parte de esta investigación. El análisis se hizo enfocado básicamente en las cinco fases del manejo de los RSU: generación, recolección, manipulación y/o procesamiento, transformación y disposición final, y se encontró que en algunos casos ni siquiera se encuentran explícitas las cinco fases, especialmente en la fase de generación, pues no hay límite en la cantidad de RSU que se puedan, especialmente en los de origen doméstico, los cuales constituyen alrededor del 50\% de los RSU generados totalmente, para la CDMX. El no tener límites en la generación, no obliga al ciudadano a emplear las estrategias como la de las 3R's, por ejemplo, sin límites en la generación no hay necesidad de reducir, reusar ni reciclar. Por otro lado, se pudo observar, que el marco de planeación tiende demasiado a la idealidad, lo cual sería bastante bueno como metas a largo plazo, pero en el caso de periodos de gobierno de seis o tres 
años, esto se vuelve problemático, pues cuando apenas se están obteniendo resultados hay cambio de gobierno y con ello cambio de metas. Al final de cuentas, los programas del gobierno anterior quedan ene le olvido. Con respecto a la generación de RSU en los domicilios, no hay un límite, es decir un ciudadano puede generar tantos residuos como quiera.

Al desarrollar la metodología que conduciría a la evaluación del manejo de los RSU en la CDMX, se llegó a varias conclusiones importantes: una de las más interesantes fue entender la gran importancia que los indicadores tienen en la gestión, ya que gracias a ellos las autoridades fundamentan y justifican las decisiones que toman, lo que le da un valor importante a esta investigación, ya que se generaron varios indicadores que arrojan información importante. Entre esta información destaca la posición que tienen las demarcaciones territoriales y la CDMX en general con respecto al manejo de los RSU a nivel mundial; esto da un panorama real de las debilidades y fortalezas del manejo de los RSU bajo en enfoque de gestión integral, encontrando como una debilidad, el hecho de destinar todo o la mayor parte del presupuesto sólo a la recolección y disposición final de los RSU, de manera contraria, se puede observar como una fortaleza la gran cantidad de intentos por recolectar de manera separada los RSU. Para hacer esta evaluación se escogieron valores máximos y mínimos a nivel internacional, partiendo de las siguientes premisas: los valores que representan la idealidad, son los países que menos RSU generan el mundo, los que recolectan la totalidad de los RSU que generan, y que además la recolectan de manera completamente separada, para que posteriormente los residuos sean totalmente aprovechados ya sea mediante el reciclaje o la transformación y así se lleve la mínima cantidad de RSU a sitios de disposición final, estos países son; Suecia y Estados Unidos. El caso contrario, los valores mínimos se les asignaron a países que más RSU generan en el mundo, además de que recolectan sólo una mínima parte de los mismos y lo hacen de manera mezclada, por lo que les es prácticamente imposible aprovechar los RSU y se van completamente de recolección a disposición final, entre los cuales se encuentran: India y China. No debemos olvidar que, aunque se usaron datos a nivel país estos tienen gran cantidad de población urbana, por lo que la tendencia en sus ciudades es prácticamente la misma, de manera tal que, fue posible compararlos con la CDMX.

A partir de estos valores máximo y mínimos que se establecieron, se ubicó a la CDMX y se pudo verificar la hipótesis que se planteó al inicio de esta investigación: el manejo de los RSU en la CDMX no es eficaz, porque está centrado en la fase de recolección y disposición final, sin prestar atención a la adecuada separación que permita un procesamiento eficiente de los residuos para su valoración y aprovechamiento en otras fases productivas, para la generación de energía y la producción de composta. Esto definitivamente no se cumple para algunas demarcaciones territoriales que tienen un buen manejo de sus RSU, tal es el caso de Coyoacán, por ejemplo, esta demarcación logró una de las calificaciones más altas en la evaluación que se desarrolló. Esto se vuelve bastante alentador, pues las autoridades con esta información podrían rastrear las fortalezas que Coyoacán está teniendo y así implementarlas en el resto de las demarcaciones territoriales, caso contrario, hubo demarcaciones que no tienen un buen manejo de sus RSU, como por ejemplo Iztapalapa, donde casi no se separan los residuos, por lo que el aprovechamiento es mínimo y es prácticamente sólo a través del reciclaje ya que la transformación es casi nula, llevando así el total de RSU recolectados a sitios de disposición final. Al final la calificación del desempeño corresponde a 5.6, aunque pareciera desalentador, no se debe perder de vista que la comparación se hizo en contra de los países que mejores prácticas tiene en el mundo, por lo que resultaría muy interesante hacerlo con respecto a otras ciudades que también están en vías de desarrollo, probablemente el promedio sería mucho mayor.

En este mismo tenor, se pudo identificar también algo interesante: desafortunadamente la relación que tiene el nivel de escolaridad y el de estudios universitarios, no tiene nada que ver con la manera 
en la que se manejan los RSU; por ende, se podría suponer que una persona mientras mayor grado de educación tenga e incluso asista a la universidad, podría tener mayor grado de conciencia ambiental y generar menos residuos, o ya en el último de los casos disponer de sus residuos de manera responsable, lo cual no es así. Pareciera que fuera de manera contraria, ya que como personas con altos grados de estudio perciben mejores salarios, estos presentan mayores niveles de consumo, generando como resultado grandes cantidades de RSU por día. El caso contrario a este, se concluyó también que la marginación tiene una fuerte relación con la generación de residuos de manera inversamente proporcional, es decir, una persona con un mayor grado de marginación genera una menor cantidad de RSU; en realidad, esto tiene sentido ya que se piensa que una persona que tiene buen estatus social, mejor trabajo, mejores ingresos, mejor vivienda, genera más RSU. En el caso de la vivienda también pude pensarse que, si su vivienda es de mejor calidad, necesitará mayor cantidad de insumos, como, por ejemplo, muebles, accesorios y televisores; por lo tanto, mayor será su generación de RSU.

Finalmente, se llevó a cabo el objetivo primordial de esta investigación, el cual fue evaluar el manejo de los RSU en la CDMX para un periodo de tiempo determinado, en este caso el año 2014-2015 y así poder proporcionar a las autoridades una herramienta más para fundamentar y justificar la toma de decisiones. Es importante mencionar que este modelo es reproducible, para cualquier entidad y en cualquier periodo de tiempo, lo que podría ser de mucha ayuda. Por ejemplo, si fuera necesario saber si el manejo de los RSU ha mejorado con el paso del tiempo y si ha mejorado, saber en qué medida lo ha hecho, sólo se toman datos disponibles de RSU para diferentes años y se hace la comparación. Esto ayudaría a saber cómo ha ido mejorando y en que partes del manejo se ha dado la mejora, lo que le da una ventaja a esta investigación. Retomando la calificación promedio del desempeño, esta tiene varias implicaciones para los tomadores de decisiones, las cuales están enfocadas al fortalecimiento del marco normativo que orienten a mejoras en la forma de consumo, producción y reducción en la generación de residuos, además de implementación de instrumentos económicos que promuevan controlen la generación de los residuos y que obliguen a implementar prácticas como las de las 3R's. Finalmente a que se orienten sus políticas públicas basadas en la gobernanza y participación social, sin olvidar el administrar mejor el presupuesto público, que no sólo se enfoque en recolectar y disponer, sino que se le dé énfasis a la investigación en pro de la generación de nuevas tecnologías para el máximo aprovechamiento del o RSU. 


\section{Bibliografía}

- ABORGARSE- EDIFESA. (2001). Manual para la GIRS. febrero 16, 2015, de EDIFESA Sitio web: http://www.edifesa.galeon.com/EDIFESA.htm

- Acuerdo de Cooperación Ambiental para América del Norte (ACAAN)

- Agencia Sueca de Protección Ambiental (Naturvårdsverket) (2006). «Sweden's Environmental Objectives - Buying into a better future». Reporte del Consejo Sueco del Medio Ambiente

- Álvarez. A. (2013). ENSAYO SOBRE EL ACUERDO DE COOPERACIÓN AMBIENTAL DE AMÉRICA DEL NORTE (ACAAN): DE ACUERDO A SU FUNCIÓN Y ESTRUCTURACIÓN. Desarrollo local sostenible, (16).

- Antoni, D., Zverlov, V. \& Schwarz, W. (2007). Biofuels from microbes. Applied Microbiology and Biotechnology. 77, 23

- BALLESTER, Ferran. Contaminación atmosférica, cambio climático y salud. Rev. Esp. Salud Publica [online]. 2005, vol.79, n.2, pp. 159-175. ISSN 1135-5727.

- Banco Mundial. (2015). Desarrollo Urbano. Julio 2017, de Banco Mundial Sitio web: http://www.bancomundial.org/es/topic/urbandevelopment/overview

- BBC. (2012). China reports weaker than expected trade data. Agosto 2016, de BBC NEWS Sitio web: http://www.bbc.com/news/business-23251089

- Bernache, G. \& Gran, A. (2016, febrero 16). Gestión de residuos sólidos urbanos, capacidades del gobierno municipal y derechos ambientales. Sociedad y Ambiente, 1, 73-101. 2016, marzo18, De Sociedad y Ambiente Base de datos

- Bertolino R., Fogwill, E., Chidiak, M., Cinquangelis, s., \& Forgione, N.. (2008). Experiencias urbanas de gestión integral de residuos en 10 municipios de Argentina.. noviembre 30, 2015, de UNICEF Sitio web: https://www.unicef.org/argentina/spanish/EcoclubesbajaWEB.pdf

- Bloomberg, M., Xi, B., Wang, Y., Jia, L., Li, G., \& Di, N. (2013). Characteristics of fine root system and water uptake in a triploid Populus tomentosa plantation in the North China Plain: implications for irrigation water management. Agricultural water management, 117, 83-92.

- Bogner, J. and Pipatti, R. et al. (2008). Mitigation of Global Greenhouse Gas Emissions from Waste: Conclusions and Strategies from the Intergovernmental Panel on Climate Change (IPCC) Fourth Assessment Report. Working Group III (Mitigation). Waste Management \& Research, 26 (1), 11-32.

- Bogner, J., Pipatti, R., Hashimoto, S., Diaz, C., Mareckova, K., Diaz, L., ... \& Zhang, T. (2008). Mitigation of global greenhouse gas emissions from waste: conclusions and strategies from the Intergovernmental Panel on Climate Change (IPCC) Fourth Assessment Report. Working Group III (Mitigation). Waste Management \& Research, 26(1), 11-32.

- Bono, E. and Tomás, J. Estrategias y elementos para un desarrollo sostenible, 1.

- Brañes Ballesteros, R., \& Ballesteros, R. B. (2000). Manual de derecho ambiental mexicano (No. 346.044072 B7/2000).

- Brenner, L. \& Vargas del Río, D.. (2010). Gobernabilidad y gobernanza ambiental en México. La experiencia de la Reserva de la Biosfera Sian Ka'an. 05-diciembre-2015, de POLISUniversidad Autónoma Metropolitana Sitio web: http://www.redalyc.org/src/inicio/ArtPdfRed.jsp?iCve=72618890005 
- Callaghan, H. (2010). Beyond methodological nationalism: how multilevel governance affects the clash of capitalisms. Journal of European Public Policy, 17(4), 564-580.

- Callejo, J. (1994). Modelos de comportamiento del consumidor: apropósito de la motivación. Política y sociedad, 16, 93.

- Calvo, J., Pratt Fairchild, H., Nuñoz, J., \& Medina Echaverría, J. (1997). Diccionario de sociología. Fondo de Cultura Económica.

- Carmona L. (2010). "Derechos humanos y medio ambiente", en Carmona Tinoco y Hori Fojaco, Jorge M. (coords.). Derechos humanos y medio ambiente. México: UNAM, pp. 1-34

- Carreras, A. (1992). La producción industrial en el muy largo plazo: una comparación entre España e Italia de 1861 a 1980. España: Alianza Editorial 173-210.

- Cattell, R. B., \& Cattell, A. K. S. (1955). Factor rotation for proportional profiles: analytical solution and an example. British Journal of Mathematical and Statistical Psychology, 8(2), 8392.

- Central Intelligence Agency. (2011). SWEDEN. octubre 25, 2015, de CIA Sitio web: https://www.cia.gov/library/publications/the-world-factbook/

- CES (2008) Profiling of recyclables in the municipal solid waste of Chennai. Report of the study done for Neel metal Fanalca by Centre for Environmental Studies, Anna University, Chennai, India

- Chang, M., Memon, M. A., \& Imura, H. (2003). International experience of public-private partnerships for urban environmental infrastructure, and its application to China. International Review for Environmental Strategies, 4(2), 223-248.

- Chávez, P., Armijo-De Vega, C., Calderón-De La Barca, N., Leyva-Aguilera, C., \& OjedaBenítez, S. (2011). Diseño de un instrumento de evaluación para los programas de manejo de residuos domiciliarios. Investigación ambiental Ciencia y política pública, 3(1).

- Chávez, S. (2016). Edomex: clausuran 4 rellenos sanitarios usados por la CDMX. Agosto 2016, de La Jornada Sitio web: http://www.jornada.unam.mx/ultimas/2016/03/15/edomex-clausuran-4rellenos-sanitarios-usados-por-la-cdmx-5834.html

- Chen, X., Geng, Y., \& Fujita, T. (2010). An overview of municipal solid waste management in China. Waste management, 30(4), 716-724.

- Chinarro, E., Jurado, J. R., \& Colomer, M. T. (2007). Synthesis of ceria-based electrolyte nanometric powders by urea-combustion technique. Journal of the European Ceramic Society, 27(13), 3619-3623.

- Cisneros, A. (2008). Propuesta para el aprovechamiento de desechos porcino y avícolas generados en la Granja Villavicencio, ubicada en Amecameca, San Pedro, mediante la implementación de un biorreactor. Tesis de Licenciatura. Universidad Nacional Autónoma de México.

- Código Penal Federal

- Colomer, F., Mendoza, J. \& Gallardo, A. (2007). Tratamiento y gestión de residuos sólidos. Valencia, España: Universidad Politécnica de Valencia.

- Composición de los RSU en México, 2011. SEDESOL-Dirección General de Equipamiento e Infraestructura en Zonas Urbano-Marginadas, México.

- CONAPO. (2012). Proyeccipnes de la Población 2010-2050. 20-mayo.2015, de SEMARNAT Sitio web: http://www.conapo.gob.mx/es/CONAPO/Proyecciones

- Constitución política de los Estados Unidos Mexicanos 
- Coordinación General para la Gestión Integral de Residuos Sólidos Urbanos. (2009). Gestión de Residuos. 10-05-2015, de Coordinación General para la Gestión Integral de Residuos Sólidos Urbanos Sitio web: http://www.ambiente.gob.ar/observatoriorsu/grupo.asp?Grupo=8074\&Subgrupo=8225

- Coordinación General para la Gestión Integral de Residuos Sólidos Urbanos. (2009). Gestión de Residuos. 10-05-2015, de Coordinación General para la Gestión Integral de Residuos Sólidos Urbanos Sitio web: http://www.ambiente.gob.ar/observatoriorsu/grupo.asp?Grupo=8074\&Subgrupo=8225

- Cortinas, C. (2004). Valorización de residuos. México, DF: Cámara de Diputados

- Couto, I., \& Hernández, A. (2012). Participación y rendimiento de la iniciativa privada en la gestión integral de los residuos sólidos urbanos en la frontera México-Estados Unidos. Gestión y política pública, 21(1), 215-261.

- CPCB, "Status report on solid waste management" 2012

- CPHEEO (2000) Manual on municipal solid waste management, Central Public Health and Environmental Engineering Organization, Ministry of Urban Development, New Delhi

- CSY: China Statistical Yearbook, (2011); National Bureau of Statistics of China, China Statistics Press: Beijing (2011).

- Cuevas, A. (2014). Introducción a SPSS. Manuscrito no publicado, Centro de Investigación de la Universidad de Celaya en Guanajuato, México.

- De Geer, H., Borglund, T. \& Frostenson, M. (2003). An Anglo-Swedish affair . diciembre 20, 2017, de Stockholm School of Economics Sitio web: http://web.archive.org/web/20080527220016/http://www.nff2003.hi.is/Apps/WebObjects/HI.wo a/swdocument/1003350/An\%20Anglo-Swedish\%20affair\%20\%20$\% 20 \% 20$ Changing\%20relations\%20in\%20an\%20international\%20acquisiton\%20\%20Hans\%20De\%20Geer,\%20Tommy\%20.pdf

- Deffis, A. (1994). La basura es la solución. México DF: Árbol Editorial.

- Diagnóstico Básico de Residuos Sólidos Urbanos y de Manejo especial, 2006

- Diagnóstico Básico de Residuos Sólidos Urbanos y de Manejo especial, 2012

- Dirección Provincial De Servicios Comunales De La Ciudad de La Habana Laboratorio de Análisis de Residuos. (2007). Guía para la gestión integral de los residuos sólidos urbanos. octubre 28, 2015, de Organización de las Naciones Unidas para el Desarrollo Industrial Sitio web: https://www.unido.org/fileadmin/import/72852_Gua_Gestin_Integral_de_RSU.pdf

- EBC Enviro. (2008). BIOGASANLAGE PASTITZ. Enero, 2007, de ECB - ENVIRO Berlin AG Sitio web: http://www.biogasanlage-ruegen.de/aep/partner.htm

- ECOINVENTOS, GREEN TECHNOLOGY. (2016). Suecia recicla un asombroso $99 \%$ de su basura.. 03-MARZO-2016, de ECOINVENTOS, GREEN TECHNOLOGY Sitio web: http://ecoinventos.com/suecia-recicla-un-asombroso-99-de-su-basura

- Ecomaine. (2014). Waste-To-Energy Plant . febrero, 2016, de Ecomaine Sitio web: http://www.ecomaine.org/our-facility/waste-to-energy-plant/

- Environmental Protection Agency . (2012). Municipal Solid Waste Generation, Recycling, and Disposal in the United States: Facts and Figures for 2012. octubre 8, 2015, de EPA Sitio web: https://www.epa.gov/sites/production/files/2015-09/documents/2012_msw_fs.pdf

- Environmental Protection Agency . (2014). What Is Integrated Solid Waste Management? 
- EPB. (2010). Dalian Environmental Protection Bureau. Dalian Environment Report. Dalian: Dalian Press.

- Estrada, R. (febrero 2016). Comunicación Personal (A. Cisneros, entrevistador)

- Evans, G. W. (2003). The built environment and mental health. Journal of urban health, 80(4), 536-555.

- Evans, G. W., Colome, S. D., \& Shearer, D. F. (1988). Psychological reactions to air pollution. Environmental Research, 45(1), 1-15.

- Facts and Figures for 2012. octubre 8, 2015, de EPA Sitio web: https://www.epa.gov/sites/production/files/2015-09/documents/2012_msw_fs.pdf

- FAO. (2011). Manual de Biogás. 03-marzo-2016, de FAO Sitio web: http://www.fao.org/3/aas400s.pdf

- Friedman, D., Jiang, Y., S., He, M., Huang, S., Kong, X., \& Foster, P. J. (2010). Design and methodology of a randomized controlled trial of laser iridotomy for the prevention of angle closure in southern China: the Zhongshan Angle Closure Prevention trial. Ophthalmic epidemiology, 17(5), 321-332.

- Gaggero, E.\& Ordoñez, M.. (2014). Gestión inte G ral de residuos sólidos urbanos. noviembre 30, 3015, de Organismo Provincial para el Desarrollo Sostenible Sitio web: http://www.opds.gba.gov.ar/uploaded/File/residuos_03_10.pdf

- Gaggero, E., \& Ordoñez, M. . (2002). Gestión Integral de Residuos Sólidos Urbanos. 30Noviembre-2014, de Organismo Provincial de Desarrollo Sostenible OPDS Sitio web: http://www.opds.gba.gov.ar/uploaded/File/residuos_03_10.pdf

- Gobierno del Estado de Veracruz, "Guía Práctica para la Construcción de Indicadores de Desempeño", Publicado en la Gaceta Oficial Número 237 de fecha 27 de noviembre de 2014

- Gran, J.A. \& Bernach, G.. (2015). Gestión de residuos sólidos urbanos, capacidades del gobierno municipal y derechos ambientales. 05-04-2016, de Colegio de la Frontera Sur. Sociedad y Ambiente. Sitio web: http://revistas.ecosur.mx/sociedadyambiente/index.php/sya/article/view/1634

- GREEN TECHNOLOGY. (2016). Suecia recicla un asombroso $99 \%$ de su basura. 03-MARZO2016, de ECOINVENTOS, GREEN TECHNOLOGY Sitio web: http://ecoinventos.com/sueciarecicla-un-asombroso-99-de-su-basura

- GTZ-COMIA. (2003). La basura en el limbo: desempeño de gobiernos locales y participación privada. 09-febrero-2015, de Comisión Méxicana de Infraestructura Ambiental Sitio web: http://www2.gtz.de/dokumente/bib/07-0126.pdf

- Guillén, R \& Rivas, O. (2011). Producción de metano a partir de desechos orgánicos generados en el Tecnológico de Costa Rica. 15-marzo-2016, de Tecnológico de Costa Rica. Tecnología en Marcha. Sitio web: https://dialnet.unirioja.es. desgargaarticulo.2316546.pdf

- Guillén, R \& Rivas, O. (2011). Producción de metano a partir de desechos orgánicos generados en el Tecnológico de Costa Rica. 15-marzo-2016, de Tecnológico de Costa Rica. Tecnología en Marcha. Sitio web: https://dialnet.unirioja.es. desgargaarticulo.2316546.pdf

- Gupta, R.\& Kumar.M. (2013, noviembre 29). Cross Fuctional Team for Integrated Solid Waste Management (ISWM) Practices: An Approach Suitable for indian and other developing Countries. Advances in Energy Engineering, 2, 458-462. 2015, octubre 16, De seipub Base de dato 
- Hernández, E, \& Bermúdez, B. (2010) “Indicadores de Desempeño: Nociones Básicas para su Construcción”, Presupuesto, Gasto y Contabilidad, INDETEC, No. 6. Pág. 54-62

- Hernández, S. (2016). Renovación, Zona de Pepenadores. Abril 2016, de El Universal Sitio web: http://archivo.eluniversal.com.mx/ciudad-metropoli/2014/renovacion-zona-de-pepenadores1029489.html

- Hilbert, J. (1998). Manual para la producción de biogás. Instituto de Ingeniería Rural I.N.T.A. Castelar. 57 pp.

- Holloway, Joseph E (2005). Africanisms in American Culture (en inglés) (2a edición). Bloomington, Indiana: Indiana University Press

- Hoornweg, D., \& Bhada-Tata, P. (2012). What a waste: a global review of solid waste management. Urban development series knowledge papers,

- Hoornweg, D., Lam, P., Chaudhry, M. (2005). Waste management in China: issues and recommendations. Abril, 2015, de World Bank Sitio web:

http://documents.worldbank.org/curated/en/237151468025135801/Waste-management-inChina-issues-and-recommendations

- Hotelling, H. (1933). Analysis of a complex of statistical variables into principal components. Journal of educational psychology, 24(6), 417.

- INARE. (2016). Congreso Nacional de Reciclaje. Marzo 2016, de InstitutoNacional del Reciclaje Sitio web: http://www.inare.mx/

- INECC-SEMARNAT (Instituto Nacional de Ecología y Cambio Climático, Secretaría de Medio Ambiente y Recursos Naturales) (2012). —Diagnóstico básico para la gestión integral de los residuosll, Disponible en: http://biblioteca.semarnat.gob.mx/Documentos/Ciga/libros2009/CD001408.pdf

- INEGI (2012). SEDESOL, C. (2010). Delimitación de las zonas metropolitanas de México.

- INEGI. (2010). Censo de Población. Febrero 2015, de Instituto Nacional de Estadística y Geografía Sitio web: http://www.beta.inegi.org.mx/proyectos/ccpv/2010/

- INEGI. (2012). Estadísticas Ambientales. 20-mayo.2015, de INEGI Sitio web: http://mapserver.inegi.org.mx/ambiental/map/indexV3FF.html

- INEGI. Sistema de Cuentas Nacionales de México. México. 2013. Disponible en: http://dgcnesyp.inegi.org.mx/cgi-win/bdieintsi. exe/ y Dirección General de Equipamiento e Infraestructura en Zonas Urbano-Marginadas, SEDESOL. México. 2012

- INEGI. Sistema de Cuentas Nacionales de México. México. 2013. Disponible en: http://dgcnesyp.inegi.org.mx/cgi-win/bdieintsi. exe/ y Dirección General de Equipamiento e Infraestructura en Zonas Urbano-Marginadas, SEDESOL. México. 2012.

- INNEC. (2013). Evaluación del Desempeño y

Sustentabilidad ambiental en ciudades intermedias de México. La zona metropolitana de Queréta ro. noviembre 25, 2015, de Instituto nacional de ecología y cambio climático Sitio web: https://www.gob.mx/cms/uploads/attachment/file/191432/2013_Evaluaci_n_del_desempe_o.pdf

- Inventario de Residuos Sólidos Urbanos de la Ciudad de México, 2006 a 2014

- IPCC (2006). 2006 IPCC Guidelines for National Greenhouse Gas Inventories. Waste Generation, Composition, and Management Data. Ch. 2.

- Jiménez, N. (2015). La gestión integral de residuos sólidos urbanos en México: entre la intención y la realidad. Letras Verdes. Revista Latinoamericana de Estudios Socioambientales, (17), 29-56. 
- Johnson, Fern L (1999). Speaking Culturally: Language Diversity in the United States (en inglés). Thousand Oaks, California:

- Jolliffe, T.. (2002). Principal Component Analysis . En Principal Component Analysis (10-27). UK: Springe

- Kaiser, H. F. (1958). The varimax criterion for analytic rotation in factor analysis. Psychometrika, 23(3), 187-200.

- Karak, Tanmoy, R. M. Bhagat y Pradip Bhattacharyya (2012). -Municipal solid waste generation, composition, and management: The World Scenarioll en Critical Reviews in Environmental Science and Technology,

- Katj, L. (2013). Hybrid Governance: The Caseof Household SolidWaste Management in Sweden. Springer Science+Business Media, 13, 146-157. 2015, septiembre 9, De Springer Base de datos.

- Kaushal, K., Varghese, K., Chabukdhara, M., "Municipal solid waste management in India c urrent state and future challenges - a review" International Journal of Engineering Science a nd Technology, 4 (2012), 1473- 1489

- Kumar S, Gaikwad SA (2004) Municipal solid waste management in Indian urban centres: an approach for betterment. In: Gupta KR (ed) Urban development debates in the new millennium, Atlantic Publishers \& Distributors, New Delhi, pp. 100-111

- Kurian J, Nagendran R, Thanasekaran K (2007) In: Proceedings of international conference on sustainable solid waste management, Anna University, Chennai, 5-7 September 2007

- Kurian, J. (2014, november). Municipal Solid Waste Management in India. Environmental Science and Engineering, 15, 4451-73. 2016, September 16, De Springer Base de datos.

- Lemus, M.. (2000). Residuos Sólidos Urbanos. 24.enero-2015, de Universidad de Pinar del Rio Sitio web: http://coodes.upr.edu.cu/index.php/coodes/search/search

- Liopis, J. (2011). Tipología de sistemas de recogida de residuos sólidos municipales en Europa según niveles de desarrollo. España: UPC.

- Lipovetsky, G. (2007). La felicidad paradójica. Ensayo sobre la sociedad del hiperconsumo. Barcelona: Anagrama.ONU (2014). Perspectivas de urbanización en el mundo, 2014. UN Press, Washington.

- Lucero, L. C., González, E. M., Velázquez, E. C., González, R. C., \& Felix, R. ¿Qué características tienen los consumidores verdes en México? Un enfoque sobre segmentación demográfica fundamentada en las 3R'sy la compra de productos ecológicos.

- Ma, L. J. (2000). Urban transformation in China, 1949-2000: a review and research agenda. Environment and planning A, 34(9), 1545-1569.

- Mandujano, M. (1998). Biogás: Energía y Fertilizantes a partir de Desechos Orgánicos. Cuernavaca, Morelos, México: Organización Latinoamericana de Energía

- Marshall, S. (2013). Commercial Application of Pyrolysis Technology in Agriculture. Noviembre 2015, de AGROWASTE Sitio web: https://ofa.on.ca/uploads/userfiles/files/pyrolysis\%20report\%20final.pdf

- Masera, O., Ghilardi, R., Drigo, R., y Trossero, M. (2005). Wisdom: A gis-based supply demand mapping tool for woodfuel management. Biomass \& Bioenergy. México: Mundi-Prensa.

- Masera, O.R., A. Ghilardi, R. Drigo y M. Trossero. (2005). La bioenergía en México: un catalizador del desarrollo sustentable. México: Publicación de la Red Mexicana de Bioenergía y la Comisión Nacional Forestal, Mundi-Prensa 
- Mayorga, F. \& Córdova, E., 2007, “Gobernanza y Gobernanza en América latina”, Working Paper NCCR Norte-Sur IP8, Ginebra.

- Mazzeo, N.. (2012). Manual para la sensibilización comunitaria y educación ambiental. Noviembre 30, 2015, de INTI - Gerencia de Asistencia Tecnológica para la Demanda Social Sitio web: http://www.inti.gob.ar/GIRS/pdf/Manual_EA_GIRS.pdf

- Medina, M. (1992). Recovery of Recyclables in Mexico City. Urban Issues. New Haven: Urban Resources Institute, 17-18.

- Méndez, s. \& Cuevas, A. (2014). Manual introductorio al SPSS Statistics Standard Edition 22. Diciembre 2015, de Universidad de Celaya e Instituto Politécnico Nacional Sitio web: http://www.fibao.es/media/uploads/manual_de_spss_universidad_de_celaya.pdf

- Merino, J.. (2012). Bienestar y Consumo, El consumidor mexicano del siglo XXI.. 01Diciembre-2015, de PROFECO Sitio web: http://www.consumidor.gob.mx/wordpress/wpcontent/uploads/2012/11/Resumen-Ejecutivo.pdf

- Montin, S. (2007). Municipios y el clima de políticas un ejemplo de las políticas de tercera generación. Estado Diario Scientific, 109 (1).

- Morrison, A. (1999). Slavery and the American West: The Eclipse of Manifest Destiny and the Coming of the Civil War . Chapel Hill: University of North Carolina Press

- Nardo, M., Munda, G., \& Saltelli, A. (2006). From Complexity to Multidimensionality: the Role of Composite Indicators for Advocacy of EU Reform. EU: Tijdschrift voor Economie en Management.

- Navarro, P., Moral, H., Gómez, L. \& Mataix, B.. (1995). Residuos orgánicos. En Residuos Orgánicos y la Agricultura(pp. 6-18). España: Espagrafic.

- ODCE

- Ojeda, S. (2006). Gestión de residuos sólidos municipales. en M. Quintero, Una visión de la problemática ambiental de Mexicali y su valle. Mexicali. Universidad Autónoma de Baja California. pp. 137-168.

- ONU. (2014). ONU-Hábitat - Por un mejor futuro urbano. octubre 28, 2015, de United Nations Human Settlements Programme Sitio web: www.unhabitat.org

- Opubor, T. (2004). Gestión de Residuos en los Municipios Suecos: Tecnología Medioambiental e Iniciativas Locales. abril 2016, de BBC TV Sitio web: www.subdere.cl/sites/default/noticiasold/articles-69522_recurso_2.doc

- Organización Mundial de la Salud. (2012). Gestión Ambiental. Diciembre 2015, de OMS Sitio web: http://www.who.int/denguecontrol/control_strategies/environmental_management/es/

- Panarisi, E. A. (2015). Basura Cero, una política pública para el siglo XXI: el caso de la ciudad de Rosario (Bachelor's thesis, Facultad de Ciencia Política y Relaciones Internacionales).

- Pearson, K. (1901). Principal components analysis. The London, Edinburgh and Dublin Philosophical Magazine and Journal, 6(2), 566.

- Pérez, M. (2014). Estadística aplicada a las cien cias sociales. Manual para el alumno. Definiciones, ejercicios e instrucciones básicas con SPSS.

- Peters, W. S., \& Butler, J. Q. (1970). The construction of regional economic indicators by principal components. The Annals of Regional Science, 4(1), 1-14.

- PNUMA \& ISWA. (2015). Global Waste Management Outlook. noviembre 4, 2015, de United Nations Environment Programme Sitio web: 
https://www.iswa.org/fileadmin/galleries/Publications/ISWA_Reports/GWMO_summary_web.p df

- Porras, F. (2012). Gobernanza y redes de política pública en espacios locales de México. México, Instituto Mora.

- Psicología Social (1999) J.F.Morales., C.Huici., M.Moya., E.Gaviria., M. López- Sáez. Mc GRAW-HILL.

- Quintero, A. (2008). Guía para Diseño, Construcción e Interpretación de Indicadores. Departamento Administrativo Nacional de Estadística (DANE) Colombia.

- Quiroga Martínez, R. (2007). Indicadores ambientales y de desarrollo sostenible: avances y perspectivas para América Latina y el Caribe. CEPAL.

- Quiroga, R.. (2009). Guía metodológica para desarrollar indicadores ambientales y de desarrollo sostenible en países de América Latina y el Caribe . Noviembre, 2015, de Guía metodológica para desarrollar indicadores ambientales y de desarrollo sostenible en países de América Latina y el Caribe Sitio web: http://estadisticas.cepal.org/cepalstat/WEB_CEPALSTAT/estadisticasIndicadores.asp

- Requena, C. (2015). Ciudades producen hasta 10,000 millones de toneladas de basura. Septiembre 7, 2015, de El economista Sitio web: http://eleconomista.com.mx/internacional/2015/09/07/ciudadesproducenhasta10000millonestoneladasbasura

- Reunión de la CEA-Cepal, Q. (2009). Diagnóstico sobre temas metodológicos y nuevos indicadores TICs para América Latina y el Caribe.

- Rodríguez, E. (2007). Situación Actual de China. 05-febrero-2016, de Biblioteca de Economía y Enciclopedia Multimedia Interactiva de Economía Sitio web: http://www.eumed.net/rev/china/02/era-02c.htm

- Salas, N.. (2014). Los secretos del éxito de la gestión de basura en Suecia.. 03-febrero-2016, de ECOSIGLOS Sitio web: http://www.ecosiglos.com/2014/02/gestion-de-basuras-en-suecia.html

- Sánchez, A. (2012). Análisis de componentes principales: versiones dispersas y robustas al ruido impulsivo (Master's thesis).

- Schejtman, L., \& Cellucci, M. (2014). Gestión Integral de residuos sólidos. Políticas municipales que promueven la sustentabilidad. Serie Buenas Prácticas Municipales.

- Schlesinger, R. B., Kunzli, N., Hidy, G. M., Gotschi, T., \& Jerrett, M. (2006). The health relevance of ambient particulate matter characteristics: coherence of toxicological and epidemiological inferences. Inhalation toxicology, 18(2), 95-125.

- Schwans, E. (2014 enero-abril). La basura: un reto y una oportunidad para la Zona Metropolitana de la Ciudad de México. Interdisciplina, 2, 14. 2015, octubre 28, De DOSSIER Base de datos

- Schwanse, E., y Schmidt, W. (2013). Revitalización de sitios contaminados y tierras baldías en las ciudades mexicanas. Basura y desechos (Revitalización de zonas industriales abandonadas y vertederos en metrópolis mexicana)

- Secretaría de Desarrollo económico de Bogotá. (2007). Metodología para la formulación de Indicadores para el Seguimiento y la Evaluación. Mayo 2016, de Observatorio de Desarrollo Económico de Bogotá Sitio web: http://observatorio.desarrolloeconomico.gov.co/base/lectorpublic.php?id=721\#sthash.AvrkMFof .dpbs 
- Secretaría de Hacienda y Crédito Público. (2011). Indicadores. 14-julio-2015, de SHCP Sitio web:

http://www.shcp.gob.mx/EGRESOS/sitio_pbr/progra_presupuestacion/Paginas/indicadores_des. aspx

- Secretaría del Medio Ambiente. (2013). Inventario de Residuos Sólidos de la Ciudad de México. 10-abril-2015, de SEDEMA Sitio web: http://www.sedema.df.gob.mx/sedema/index.php/temasambientales/programas-generales/residuos-solidos

- SEDESOL, 1998. El Manejo de los Residuos Sólidos Municipales en México. Sancho y Cervera, J. - Rosiles, G.

- SEDESOL, 1999. Situación Actual del Manejo Integral de los Residuos Sólidos en México. Sancho y Cervera, J. - Rosiles, G.

- SEDESOL, 2005. El Manejo de los Residuos Sólidos Urbanos y de Manejo Especial en México. Sancho y Cervera, J. - Rosiles, G.

- SEDESOL. (2009). MANUAL PARA LA OPERACIÓN DE RELLENOS SANITARIOS. 05abril-2016, de SEDESOL Sitio web: http://www.sustenta.org.mx/3/wpcontent/files/MT_OperacionRellenoSanitario.pdf

- SEDESOL. (2011). MANUAL TÉCNICO SOBRE GENERACIÓN, RECOLECCIÓN Y TRANSFERENCIA DE RESIDUOS SÓLIDOS MUNICIPALES. Enero 2016, de SEDESOL Sitio web: http://www.sustenta.org.mx/3/wpcontent/files/MT_ManualTecnicosobreGeneracionRecoleccion.pdf

- SEDESOL. (2011). Urbanización. 8-junio-2015, de Secretaría de Desarrollo Social Sitio web: http://www.sedesol.gob.mx/es/SEDESOL/Subsecretaria_de_Desarrollo_Social_y_Humano

- SEMARNAT (Secretaría de Medio Ambiente y Recursos Naturales) (2007), -Política y Estrategias para la Prevención y Gestión Integral de Residuos Sólidos en Méxicoll. 28 junio, 2015. Disponible en: http://siscop.inecc.gob.mx/novedades/politica_y_estrategias_gir.pdf

- Siemens AG. (2007). Desafíos de las Megaciudades. diciembre 20, 2015, de GlobeScan y MRC McLean Hazel Sitio web: http://www.aan.siemens.com/chile/ebrochures/Documents/Desaf\%C3\%ADo\%20sde\%201as\%20Megaciudades\%20-\%20Siemens.pdf

- Singhal S, Pandey S (2001) Solid waste management in India—status and future directions. TERI Inf Monit Environ Sci 6(1):1-4

- SINIA. (2001). Indicadores para Gestión Municipal de Residuos Sólidos. Febrero 2016, de Sistema Nacional deinformación Ambiental, Gobierno de Chile Sitio web: http://www.sinia.cl/1292/articles-31698_recurso_11.pdf

- Sitio web: http://documents.worldbank.org/curated/en/694561468770664233/pdf/multi-page.pdf

- Steiner, A. (2013). PNUMA prevé repercusiones crecientes del cambio climático en las empresas. CENTRO DE NOTICIAS ONU, 2-4.

- Stoll-Kleemann, S., Welp, M., de la Vega-Leinert, A., \& Jaeger, C. C. (2006). Science-based stakeholder dialogues: Theories and tools. Global Environmental Change, 16(2), 170-181.

- Sullivan, H. (2015). Democracy and Hybrid Governance in Australia. 26-marzo-2016, de DEMOCRACY RENEWAL Sitio web: http://democracyrenewal.edu.au/democracy-and-hybridgovernance-australia

- Sysav AB. (2013). Waste-to-Energy Plant Sysav Malmö, enhancing the overall Energy Efficiency with 2 Unitop 28C heat pump units. febrero 8, 2016, de Friotherm AG Sitio web: http://www.friotherm.com/webautor-data/41/sysave006_uk.pdf 
- Tapia, A. (2014). En 2030, el mundo tendrá 41 ciudades con más de 10 millones de habitantes. junio 15, 2015, de La Tercera Sitio web: http://www.latercera.com/noticia/mundo/2014/07/6785875849en2030elmundotendra41ciudadesconmasde10millonesdehabitantes.shtml

- Tchobanoglous George, Hilary Theisen y Samuel Vigil (1994). Gestión Integral de Desechos Sólidos. Madrid: Editorial McGraw Hill. Torey, S (1996)

- Teorema Ambiental. (2015). Ciudad de México: los retos para la nueva administración Parte II. octubre 25, 2015, de Revista Ambiental Sitio web: http://www.teorema.com.mx/residuos/ciudaddemexicolosretosparalanuevaadministracionparteii/

- Terrádez, M. (2007). Análisis de componentes principales, 2002.

- Torey, S. (1996). El impacto ambiental del consumo en Chile. Ambiente y desarrolloXII (2), 714.

- Torres, L., \& Pina, V. (2002). Changes in public service delivery in the EU countries. Public Money and Management, 22(4), 41-48.

- Trejo, C. (2006). Los tratados internacionales como fuente de derecho nacional. Servicio de Investigación y análisis, Subdirección de política exterior.

- UNEP (2010). Waste and Climate Change: Global Trends and Strategy Framework. http://www.unep.or.jp/ietc/Publications/spc/ Waste\&ClimateChange/Waste\&ClimateChange.pdf

- UNEP. (2013). Programa de las Naciones Unidas para el Medio Ambiente. Julio 2016, de UN Sitio web: http://research.un.org/es/docs/environment/unep

- United Nations. (2014). World Urbanization Prospects. octubre 28, 2015, de United Nations Sitio web: https://esa.un.org/unpd/wup/publications/files/wup2014-highlights.Pdf

- URIEL, E. (1985): “Análisis de datos: Series temporales y análisis multivariante”.Editorial AC, Colección plan nuevo, Madrid

- US EPA (2006). Solid Waste Management and Greenhouse Gases: A Life-Cycle Assessment of Emissions and Sinks., 3rd Edition.

- Wang, X.\&Geng, Y. (2011, February 1). Municipal solid waste management in Dalian: practices and challenges. Higher Education Press and Springer-Verlag Berlin Heidelberg, 6(4), 540-548. 2015, noviembre 6, De Springer Base de datos.

- Weiss, A; Jérôme, V.; Burghardt, D; Likke, L.; Peiffer, S.; Hoffstetter, E.; Gabler, R. \& Freitag, R. (2009). Investigation of Factors Influencing Biogas Production in A LargeScale Thermophilic Municipal Biogás Plant. Applied Microbiology and Biotechnology. 84(5), 987-1001.

- White, R., Franke, M., \& Hindle P. (1992). Integrated Solid Waste Management: A Lifecycle Inventory. New York, USA: Blackie Academic \& Professional.

- Winchester, L. (2016). Evaluación de Programas de Programas: Eficacia - Eficiencia. Diciembre 2016, de CEPAL-ILPES Sitio web: http://www.cepal.org/ilpes/noticias/paginas/7/41647/EvaluacionEE.pdf

- World Bank. (2012). WHAT A WASTE A Global Review of Solid Waste Management. 28 junio, 2015, de World Bank Sitio web: https://siteresources.worldbank.org/INTURBANDEVELOPMENT/Resources/3363871334852610766/What_a_Waste2012_Final.pdf

- Yang, L., Chen, Z., Liu, T., Wan, R., Wang, J., \& Xi, W.. (2013, February). Research output analysis of municipal solid waste: a case study of China. Scientometrics, 96, 641-650. 2016, octubre 4, De Springer Base de datos 
- Zaman, A. \& Lehmann, S. (2013 Junuary). The Zero Waste Index: A performance Measurement Tool for Waste Management in a Zero Waste City. ELSEVIER, 36, 682-693. 2016 june, De CrossMark Base de datos.

- Zaman, A. \& Lehmann, S. (2013 September). Identification of key assessment indicators of zero waste management system. ELSEVIER, 36, 682-693. 2016 june, De CrossMark Base de datos.

- Zamora, A. (2011). La cooperación entre municipios, una alternativa para el desarrollo rural sustentable. Foro de Cooperación Intermunicipal para el Desarrollo Sustentable.

\section{Leyes y Programas}

- Constitución Política de los Estados Unidos Mexicanos. México: Cámara de diputados (2012).

- Ley Ambiental de Protección a la Tierra en el Distrito Federal

- Ley General del Equilibrio Ecológico y la Protección al Ambiente (LGEEPA)

- Ley General para la Prevención y Gestión Integral de los Residuos (LGEPGIR)

- NADF-007-RNAT-2013 Clasificación y Especificaciones de Manejo para Residuos de la Construcción y Demolición, en la CDMX:

- NADF-020-AMBT-2011, que establece los requerimientos mínimos para la producción de composta a partir de la fracción orgánica de los residuos sólidos urbanos, agrícolas, pecuarios y forestales, así como las especificaciones mínimas de calidad de la composta producida y/o distribuida en la CDMX

- NADF-024-AMBT-2013 Que establece los criterios y especificaciones técnicas bajo los cuales se deberá realizar la separación, clasificación, recolección selectiva y almacenamiento de los residuos de la CDMX

- NMX-AA-015-1985 Protección al ambiente - Contaminación del suelo - Residuos sólidos municipales Muestreo - Método de cuarteo.

- NMX-AA-016-1984 Protección al ambiente - Contaminación del suelo - Residuos sólidos municipales Determinación de humedad:

- NMX-AA-018-1984 Protección al ambiente - Contaminación de suelo - Residuos sólidos municipales Determinación de cenizas.

- NMX-AA-019-1985 Protección al ambiente - Contaminación del suelo - Residuos sólidos municipales Peso volumétrico "in situ"

- NMX-AA-021-1985 Protección al ambiente - Contaminación del suelo - Residuos sólidos municipales Determinación de materia orgánica

- NMX-AA-022-1985 Protección al ambiente - Contaminación del suelo - Residuos sólidos municipales Selección y cuantificación de subproductos

- NMX-AA-024-1984 Protección al ambiente - Contaminación del suelo - Residuos sólidos municipales Determinación de nitrógeno total

- NMX-AA-025-1984 Protección al ambiente - Contaminación del suelo - Residuos sólidos Determinación del PH - Método potenciométrico:

- NMX-AA-031-1976 Determinación de azufre en desechos sólidos

- NMX-AA-032-1976 Determinación de fosforo total en desechos sólidos (método del fosfavanadomolibdato)

- NMX-AA-033-1985 Protección al ambiente - Contaminación del suelo - Residuos sólidos municipales Determinación de poder calorífico superior 
- NMX-AA-052-1985 Protección al ambiente - Contaminación del suelo - Residuos sólidos municipales Preparación de muestras en el laboratorio para su análisis

- NMX-AA-061-1985 Protección al ambiente - Contaminación del suelo - Residuos sólidos municipales Determinación de la generación.

- NMX-AA-067-1985 Protección al ambiente - contaminación del suelo -Residuos sólidos municipales Determinación de la relación carbono / nitrógeno

- NMX-AA-068-1986 Protección al ambiente - Contaminación del suelo - Residuos sólidos municipales Determinación de hidrogeno a partir de materia orgánica

- NMX-AA-080-1986 Contaminación del suelo - Residuos sólidos municipales - Determinación del porcentaje de oxígeno en materia orgánica:

- NMX-AA-091-1987 Calidad del suelo - Terminología

- NMX-AA-092-1984 Protección al ambiente - Contaminación del suelo - Residuos sólidos municipales Determinación de azufre

- NMX-AA-094-1985 Protección al ambiente - Contaminación del suelo - Residuos sólidos municipales Determinación de fosforo total

- NOM-083-SEMARNAT-2003: Especificaciones de protección ambiental para la selección del sitio, diseño, construcción, operación, monitoreo, clausura y obras complementarias de un sitio de disposición final de residuos sólidos urbanos y de manejo especial.

- NOM-098-SEMARNAT-2002: Protección ambiental-Incineración de residuos, especificaciones de operación y límites de emisión de contaminantes. Secretaría de Medio Ambiente y Recursos Naturales.

- NOM-098-SEMARNAT-2002: Protección ambiental-Incineración de residuos, especificaciones de operación y límites de emisión de contaminantes. Secretaría de Medio Ambiente y Recursos Naturales.

- Programa de Acción Climática de la Ciudad de México (PACCM) 2014-2020

- Programa de Gestión Integral de RSU de la CDMX 2016-2020.

- Programa General de Desarrollo de la CDMX

- Programa Institucional de la Secretaría de Obras y Servicios (SOBSE) de la CDMX

- Programa Nacional para la Prevención y Gestión Integral de Residuos Sólidos (PNPGIRS)

- Programa Sectorial de Salud 2013-2018

- Programa Sectorial del Medio Ambiente y de Sustentabilidad 2013-2018 


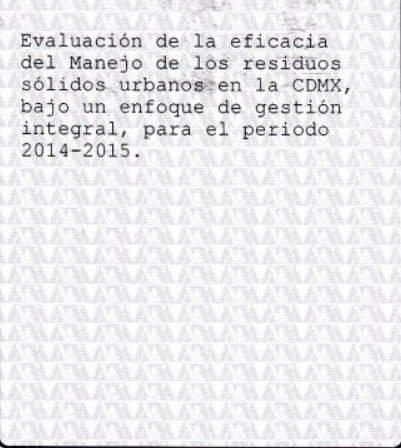

En la Ciudad de México, se presentaron a las 16:00 horas del día 17 del mes de julio del año 2017 en la Unidad Iztapalapa de la Universidad Autónoma Metropolitana, los suscritos miembros del jurado:

M. EN I. GUILLERMO ENCARNACION AGUILAR

M. EN C. CRISTAL BERENICE AYALA HERNANDE

M. EN B.E. ENRIQUE MENDIETA MARQUEZ

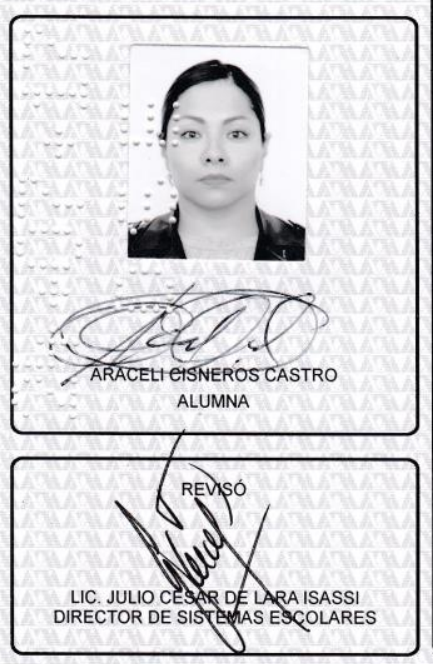

Bajo la Presidencia del primero y con carácter de Secretario el último, se reunieron para proceder al Examen de Grado cuya denominación aparece al margen, para la obtención del grado de:

MAESTRA EN CIENCIAS (ENERGIA Y MEDIO AMBIENTE)

DE: ARACELI CISNEROS CASTRO

$y$ de acuerdo con el artículo 78 fracción III del Reglamento de Estudios Superiores de la Universidad Autónoma Metropolitana, los miembros del jurado resolvieron:

\section{APROBAR}

Acto continuo, el presidente del jurado comunicó a la interesada el resultado de la evaluación $y$, en caso aprobatorio, le fue tomada la protesta.
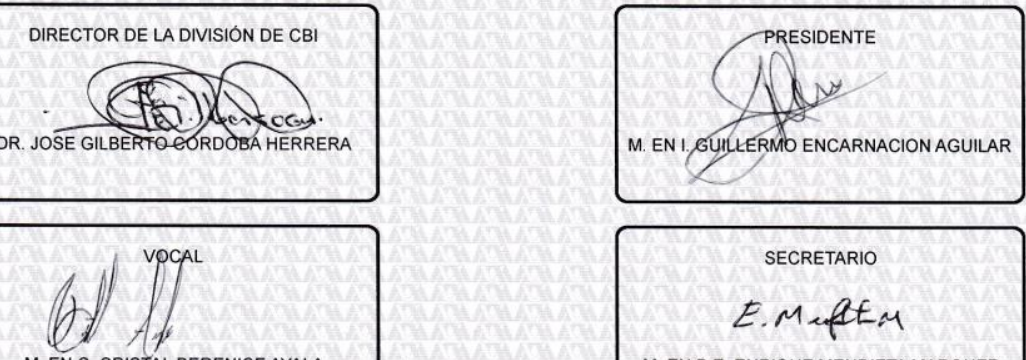

M. EN C. CRISTAL BERENICE AYALA HERNANDEZ

$$
\begin{aligned}
& \text { SECRETARIO } \\
& \text { E.MefLEM }
\end{aligned}
$$

M. EN B.E. ENRIQUE MENDIETAMARQUEZ 